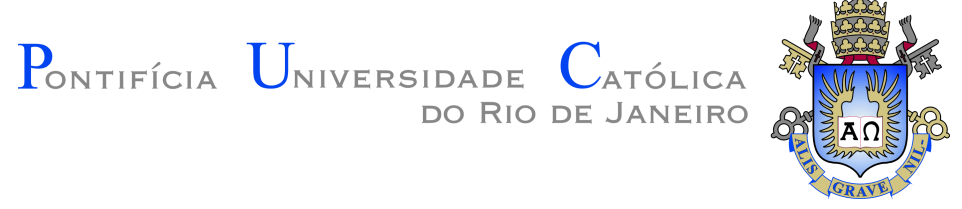

William Alfonso Piñerez Bettin

Comportamento de Treliças de Aço em Forma de Arco Utilizadas no Projeto e Construção de Estruturas Protendidas de Coberturas

Tese de Doutorado

Tese apresentada como requisito parcial para obtenção do grau de Doutor pelo Programa de Pós-Graduação em Engenharia Civil da PUC-Rio.

Orientador : Prof. Sebastião Arthur Lopes de Andrade

Co-orientador : Prof. José Guilherme Santos da Silva 

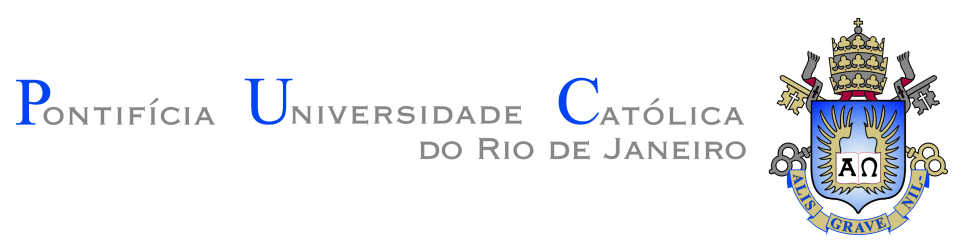

William Alfonso Piñerez Bettin

\section{Comportamento de Treliças de Aço em Forma de Arco Utilizadas no Projeto e Construção de Estruturas Protendidas de Coberturas}

Tese apresentada como requisito parcial para obtenção do grau de Doutor pelo Programa de Pós-Graduação em Engenharia Civil da PUC-Rio. Aprovada pela Comissão Examinadora abaixo assinada.

Prof. Sebastião Arthur Lopes de Andrade Orientador Departamento de Engenharia Civil e Ambiental - PUC-Rio

Prof. José Guilherme Santos da Silva Co-orientador Universidade do Estado do Rio de Janeiro

Prof. Raul Rosas e Silva Departamento de Engenharia Civil e Ambiental - PUC-Rio

Prof. Emil de Souza Sánchez Filho Universidade Federal Fluminense

Prof. Ricardo Rodrigues de Araujo Centro Federal de Educação Tecnológica Celso Suckow da Fonseca / RJ

Prof. Pedro Colmar Gonçalves da Silva Vellasco Universidade do Estado do Rio de Janeiro

Prof. Márcio da Silveira Carvalho

Coordenador Setorial do

Centro Técnico Científico - PUC-Rio

Rio de Janeiro, 3 de Agosto de 2018 
Todos os direitos reservados. É proibida a reprodução total ou parcial do trabalho sem autorização da universidade, do autor e do orientador.

\section{William Alfonso Piñerez Bettin}

Graduou-se em Engenharia Civil com ênfase em Estruturas pela Universidade Nacional de Colômbia em 2006, especialista em estruturas pela Universidade Nacional de Colômbia em 2009, mestrado em estruturas e materiais pela Universidade Federal do Rio de Janeiro/COPPE, Brasil em 2013. Participou nos CILAMCE 2015 e 2016. Tem experiência na área de Engenharia Civil, com ênfase em projeto de estruturas e construção de edifícios.

Ficha Catalográfica

Piñerez Bettin, William Alfonso

Comportamento de Treliças de Aço em Forma de Arco Utilizadas no Projeto e Construção de Estruturas Protendidas de Coberturas / William Alfonso Piñerez Bettin; orientador: Sebastião Arthur Lopes de Andrade; co-orientador: José GuiIherme Santos da Silva. - Rio de janeiro: PUC-Rio, Departamento de Engenharia Civil e Ambiental , 2018.

v., 261 f: il. color. ; $30 \mathrm{~cm}$

Tese (doutorado) - Pontifícia Universidade Católica do Rio de Janeiro, Departamento de Engenharia Civil e Ambiental.

Inclui bibliografia

1. Engenharia Civil - Teses. 2. Engenharia Civil - Teses. 3. Treliças de aço protendidas;. 4. Modelagem computacional;. 5. Efeito da protensão;. 6. Comportamento estrutural.. I. Andrade, Sebastião Arthur Lopes de. II. Silva, José Guilherme Santos da. III. Pontifícia Universidade Católica do Rio de Janeiro. Departamento de Engenharia Civil e Ambiental . IV. Título. 
Dedico esta tese com amor e carinho a minha mãe e meu pai(in memoriam). 


\section{Agradecimentos}

Principalmente agradeço a Jeová Deus, por me ajudar a terminar este projeto superando os obstáculos e as dificuldades encontradas ao longo do doutorado. Obrigado por me dar a força e a coragem para fazer deste sonho uma realidade.

A minha mãe Maria Auxiliadora Bettin Diaz, pelo carinho, educação e condições de estudo que me fizeram alcançar essa meta. Minha gratidão eterna por tudo que fez por mim.

Aos meus orientadores Prof. Sebastião Arthur Lopes de Andrade e Prof. José Guilherme Santos da Silva por todo o conhecimento e apoio transmitidos ao longo do meu doutorado.

A todos os professores da pós-graduação de Engenharia Civil da área de Estruturas e Materiais da PUC-Rio pela transmissão de conhecimentos e incentivos dados durante todo o curso.

A minhas professoras de português da Faculdade de Letras da PUC-Rio, principalmente Maria Cecilia G. Carvalho e Mônica Fuks Maron pela transmissão de conhecimentos, incentivos dados durante os cursos de português e por sua ajuda neste trabalho de doutorado.

Aos técnicos do laboratório de Estruturas e Materiais da PUC-Rio, pelo auxílio e colaboração. À secretaria Rita de Cassia N. Leite pelo apoio administrativo.

A CAPES e CNPq pelo apoio financeiro em todo o meu doutorado.

Aos meus amigos e companheiros da Sala 617 (Estruturas de Aço) da PUC-Rio, agradeço por sua ajuda e motivação durante a minha trajetória neste trabalho.

A todos que estiveram comigo nessa marcha, meus sinceros agradecimento. 


\section{Resumo}

Piñerez Bettin, William Alfonso; Andrade, Sebastião Arthur Lopes de (Orientador); Silva, José Guilherme Santos da (Co-Orientador). Comportamento de Treliças de Aço em Forma de Arco Utilizadas no Projeto e Construção de Estruturas Protendidas de Coberturas. Rio de Janeiro, 2018. 261p. Tese de Doutorado - Departamento de Engenharia Civil e Ambiental , Pontifícia Universidade Católica do Rio de Janeiro.

O efeito da protensão pode ser introduzido sobre estruturas de aço em forma de arco, de tal modo que é adicionado um estado de tensões oposto ao estado proveniente da ação de sucção do vento. Dentro deste escopo, o presente trabalho de pesquisa visa apresentar os resultados obtidos com a modelagem numérica, através do Método dos Elementos Finitos (MEF), sobre o comportamento estrutural de treliças de aço utilizadas no projeto de coberturas protendidas. Para tal, a modelagem numérica é realizada com base em formulações não lineares, com o uso do programa computacional ANSYS, avaliando-se o comportamento estrutural de modelos de treliças de aço em forma de arco até o regime de ruptura. Considerando-se a complexidade do comportamento das treliças em estudo, foram feitas análises com inclusão do efeito da não linearidade física. Com base nos resultados obtidos por meio de uma análise paramétrica, no que tange a comparações entre os valores de resistência das treliças protendidas investigadas, são estabelecidas conclusões e recomendações de projeto. Cabe ressaltar que a economia de material obtida na solução estrutural com base no uso da protensão é resultante do aumento dos níveis de forças de tração nas barras da estrutura, diminuindo-se os de compressão que são menos eficientes. Assim, as soluções estruturais com protensão apresentam diversas vantagens que compensam o seu custo adicional.

\section{Palavras-chave}

Treliças de aço protendidas; Modelagem computacional; Efeito da protensão; Comportamento estrutural. 


\section{Abstract}

Piñerez Bettin, William Alfonso; Andrade, Sebastião Arthur Lopes de (Advisor); Silva, José Guilherme Santos da (Co-Advisor). Behavior of Arched Steel Trusses Used in the Design and Construction of Prestressed Structures for Roofs. Rio de Janeiro, 2018. 261p. Tese de doutorado - Departamento de Engenharia Civil e Ambiental, Pontifícia Universidade Católica do Rio de Janeiro.

Prestressing forces can be introduced on arched steel structures in such a way that a state of tensile stresses is added which to the existing state counteract the state introduced by the wind negative pressures. Within this scope, the present research aims to present the results obtained with the numerical modeling through the Finite Element Method (FEM) on the structural behavior of steel trusses used in the design of prestressed roof structures. For this purpose, the numerical modeling is performed based on non-linear formulations using the ANSYS software in order to evaluate the structural behavior of arched steel trusses modelled up to failure. Considering the complexity of the behavior of the trusses studied, some structural analysis were carried out including the effects of physical nonlinearities. Based on the results obtained through an extensive parametric analysis, with respect to comparisons between the resistance values of the investigated prestressed trusses, conclusions and design recommendations are established. It should be noted that the material savings achieved by the use of prestressing is the resultant from the increase of tensile state of stresses in the bars of the structure, thus reducing the compression stresses, which are less efficient. In this sense, the structural solutions with prestressed trusses have several advantages that compensate for the additional cost of prestressing.

\section{Keywords}

Prestressed steel trusses; Computational modeling; Prestressing effect; Structural behavior. 


\section{Sumário}

1 Introdução 28

1.1. Motivação

1.2. Objetivo 37

1.3. Escopo

2 Revisão bibliográfica $\quad 40$

2.1. Considerações gerais 40

2.2. Desempenho dos elementos de aço protendido 44

2.2.1. Barra axialmente protendida 45

2.3. Cabos de aço de protensão 49

2.4. Protensão externa 52

2.5. Economia de estruturas protendidas 53

2.6. Treliça de aço protendida

2.7. Treliça de aço em forma de arco protendida

3 Ação do vento em coberturas curvas $\quad 69$

3.1. Introdução

3.2. Considerações sobre a ação do vento em coberturas curvas segundo

Eurocode 1:1991 70

3.2.1. Coeficiente de pressão externa $\mathrm{C}_{\mathrm{pe}}$ segundo Eurocode1: 1991

3.3. Considerações sobre a ação do vento em coberturas curvas segundo AS/NZS

1170.2:2002 (Australian/New Zealand Standard) 73

3.3.1. Coeficiente de pressão externa $\mathrm{C}_{\mathrm{pe}}$ segundo AS/NZS 1170.2:2002 73

3.4. Considerações sobre a ação do vento em coberturas curvas segundo

ABNT NBR 6123:1988 75

3.4.1. Pressão dinâmica devida ao vento 76

3.4.2. Coeficientes aerodinâmicos para coberturas curvas $\quad 80$

3.4.2.1. Coeficiente de pressão externa $\mathrm{C}_{\mathrm{pe}}$ segundo NBR 6123:1988 80

3.4.2.2. Coeficiente de pressão interna Cpi NBR 6123:1988 83

3.5. Aplicação das normas citadas para coeficientes de pressão externos 85 
4 Descrição dos modelos estruturais $\quad 88$

4.1. Modelos estruturais investigados $\quad 88$

4.2. Características físicas e geométricas das seções 95

4.2.1. Características físicas dos materiais usados 95

4.2.2. Características geométricas das seções. 96

4.3. Cargas atuantes sobre os modelos estruturais. 99

4.3.1. Calculo da ação do vento.

4.3.2. Cálculo das ações permanentes 104

4.3.3. Cálculo da força de protensão nas treliças protendidas 104

4.4. Combinação de ações 106

5 Modelagem por elementos finitos 108

5.1. Introdução 108

5.2. Elementos finitos empregados na modelagem numérica 108

5.2.1. Solid185 109

5.2.2. Link10 110

5.3. Testes de convergência das malhas 111

5.4. Técnica MPC: Multi Point Constraint 114

5.5. Análises numéricas realizadas 116

5.5.1. Análise Estática Linear 116

5.5.2. Análise estática não linear física 117

$\begin{array}{ll}\text { 5.6. Modelos numéricos das treliças } & 118\end{array}$

5.6.1. Modelo de treliça com 10 m de Vão (Modelo $\mathrm{A}_{10}$ ) 118

5.6.2. Modelo de treliça com $20 \mathrm{~m}$ de vão (Modelo B20) 120

5.6.3. Modelo de treliça com $40 \mathrm{~m}$ de vão (Modelo $\mathrm{C}_{40}$ ) 122

5.6.4. Modelo de treliça com 80 m de vão (Modelo $\mathrm{D}_{80}$ ) 124

5.6.5. Modelo de treliça com 120 m de vão (Modelo $\mathrm{E}_{120}$ ) 126

6 Análise estática linear elástica das treliças $\quad 129$

6.1. Análise da treliça de $10 \mathrm{~m}$ de vão 129

6.1.1. Treliça de $10 \mathrm{~m}$ sem protensão $\left(\mathrm{A}_{10}\right) \quad 129$

6.1.2. Treliça de $10 \mathrm{~m}$ protendida $\left(\mathrm{A}_{\mathrm{P} 10}\right) \quad 131$

6.1.2.1. Evento 2: Para combinação da fase de construção $\left(\mathrm{A}_{\mathrm{P} 10}\right)$ 
6.1.2.2. Evento 3 : Para combinação última normal $\left(\mathrm{A}_{\mathrm{p} 10}\right)$

6.2. Análise da treliça de $20 \mathrm{~m}$ de vão

6.2.1. Treliça de $20 \mathrm{~m}$ sem protensão $\left(\mathrm{B}_{20}\right)$

6.2.2. Treliça de $20 \mathrm{~m}$ protendida $\left(\mathrm{B}_{\mathrm{P} 20}\right)$

6.2.2.1. Evento 2: Para combinação da fase de construção ( $\left.\mathrm{B}_{\mathrm{P} 20}\right) \quad 139$

6.2.2.2. Evento 3: Para combinação última normal ( $\left.\mathrm{B}_{\mathrm{P} 20}\right)$

6.3. Análise da treliça de $40 \mathrm{~m}$ de vão 143

6.3.1. Treliça de $40 \mathrm{~m}$ sem protensão $\left(\mathrm{C}_{40}\right)$

6.3.2. Treliça de $40 \mathrm{~m}$ protendida $\left(\mathrm{C}_{\mathrm{P} 40}\right) \quad 145$

6.3.2.1. Evento 2: Para combinação da fase de construção $\left(\mathrm{C}_{\mathrm{P} 40}\right) \quad 145$

6.3.2.2. Evento 3: Carga combinação última normal $\left(\mathrm{C}_{\mathrm{P} 40}\right) \quad 147$

6.4. Análise da treliça de $80 \mathrm{~m}$ de vão 149

6.4.1. Treliça de $80 \mathrm{~m}$ sem protensão $\left(\mathrm{D}_{80}\right) \quad 149$

6.4.2. Treliça de $80 \mathrm{~m}$ protendida $\left(\mathrm{D}_{\mathrm{P} 80}\right) \quad 151$

6.4.2.1. Evento 2: Para combinação da fase de construção ( $\left(\mathrm{D}_{\mathrm{P} 80}\right)$

6.4.2.2. Evento 3: Carga combinação última normal $\left(\mathrm{D}_{\mathrm{P} 80}\right) \quad 153$

6.5. Análise da treliça de $120 \mathrm{~m}$ de vão 155

6.5.1. Treliça de $120 \mathrm{~m}$ sem protensão $\left(\mathrm{E}_{120}\right) \quad 155$

6.5.2. Treliça de $120 \mathrm{~m}$ protendida $\left(\mathrm{E}_{\mathrm{P} 120}\right)$

6.5.2.1. Evento 2: Para combinação da fase de construção $\left(\mathrm{E}_{\mathrm{P} 120}\right) \quad 157$

6.5.2.2. Evento 3: Carga combinação última normal $\left(\mathrm{E}_{\mathrm{P} 120}\right)$

6.6. Avalição das forças nas cordas superior e inferior ao longo do vão obtidos na análise estática linear das treliças

6.7. Análise dos resultados das solicitações máximas obtidos na análise linear das treliças investigada

6.7.1. Análise dos valores das forças $\quad 169$

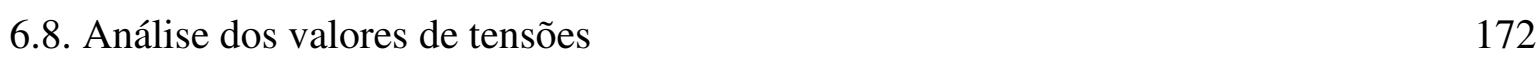

7 Análise estática não linear das treliças 174

7.1. Análise não linear da treliça de $10 \mathrm{~m}$ de vão 175

7.1.1. Treliça de $10 \mathrm{~m}$ sem protensão $\left(\mathrm{A}_{10}\right) \quad 176$

7.1.2. Treliça de $10 \mathrm{~m}$ protendida $\left(\mathrm{A}_{\mathrm{P} 10}\right) \quad 181$

7.1.2.1. Análise dos níveis de força de protensão para o modelo AP10 181 
7.2. Análise não linear da treliça de $20 \mathrm{~m}$ de vão

7.2.1. Treliça de $20 \mathrm{~m}$ sem protensão $\left(\mathrm{B}_{20}\right)$

7.2.2. Treliça de $20 \mathrm{~m}$ protendida $\left(\mathrm{B}_{\mathrm{P} 20}\right)$

7.2.2.1. Analise dos níveis de força de protensão para de $\mathrm{B}_{\mathrm{P} 20}$

7.2.2.2. Treliça de $20 \mathrm{~m}$ com protensão ótima ( $\left.\mathrm{B}_{\mathrm{P} 20}\right) \quad 198$

7.3. Análise não linear da treliça de $40 \mathrm{~m}$ de vão 204

7.3.1. Treliça de $40 \mathrm{~m}$ sem protensão $\left(\mathrm{C}_{40}\right)$

7.3.2. Treliça de $40 \mathrm{~m}$ protendida $\left(\mathrm{C}_{\mathrm{P} 40}\right) \quad 210$

7.3.2.1. Analise dos níveis de força de protensão para de $\mathrm{C}_{\mathrm{P} 40}$

7.3.2.2. Treliça de $40 \mathrm{~m}$ com protensão ótima $\left(\mathrm{C}_{\mathrm{P} 40}\right) \quad 211$

7.4. Análise não linear da treliça de $80 \mathrm{~m}$ de vão 217

7.4.1. Treliça de $80 \mathrm{~m}$ sem protensão $\left(\mathrm{D}_{80}\right) \quad 218$

7.4.2. Treliça de $80 \mathrm{~m}$ protendida $\left(\mathrm{D}_{\mathrm{P} 80}\right)$

7.4.2.1. Analise dos níveis de força de protensão para de $\mathrm{D}_{\mathrm{P} 80}$

7.4.2.2. Treliça de $80 \mathrm{~m}$ com protensão ótima $\left(\mathrm{D}_{\mathrm{P} 80}\right)$

7.5. Análise não linear da treliça de 120 m de vão 230

7.5.1. Treliça de $120 \mathrm{~m}$ sem protensão $\left(\mathrm{E}_{120}\right) \quad 231$

7.5.2. Treliça de $120 \mathrm{~m}$ protendida $\left(\mathrm{E}_{\mathrm{P} 120}\right)$

7.5.2.1. Analise dos níveis de força de protensão para de $\mathrm{E}_{\mathrm{P} 120}$

7.5.3. Treliça de 120 com Protensão Ótima $\left(\mathrm{E}_{\mathrm{P} 120}\right)$

8 Considerações finais 243

8.1. Conclusões 243

8.2. Principais contribuições 249

$\begin{array}{ll}\text { 8.3. Sugestões para trabalhos futuros } & 250\end{array}$

9 Referências bibliográficas $\quad 251$

10 Apêndice A 256 


\section{Lista de figuras}

Figura 1.1 Etapas construtivas das treliças protendida em arco (Ellen, 1987). 29

Figura 1.2 Montagem e etapa da protensão na Treliça Hyde Park,

London (Gkantou et al., 2015).

Figura 1.3 Treliça de arco protendida Hyde Park (Gkantou et al., 2015).

Figura 1.4 Coluna protendida do Edifício do Chiswick Park,

(Osofero et al., 2012).

Figura 1.5 Coluna estaiada de cobertura do prédio do Frick Chemistry

Laboratory.

na Universidade de Princeton, Nova Jersey, EUA (Seward, 2012).

Figura 1.6 Palco principal do Rock in Rio III (2011) durante a

montagem (Andrade, et al., 2003).

Figura 1.7 Ponte de 33,8 m de vão de ferro fundido e forjado em

New York (Darnell, 1991).

Figura 1.8 Treliça de aço em forma de arco protendida (PTIA, 2007).

(Fonte:<www.s-squared.com.au>. Acesso em: 20 de jul.2014).

(b) Cabos ancorados na treliça.

Figura 1.9 Reconstrução Estádio Olímpico de Sydney (PTIA, 2007). 35

Figura 1.10 Cabos ancorados na estrutura (PTIA, 2007). 35

Figura 1.11 Hangar de aeronave (PTIA, 2007). 36

Figura 1.12 Cabos de protensão na estrutura (PTIA, 2007). 36

Figura 2.1 Squire Whipple Bridge at UnionCollege.

(Fonte:<http://www.hmdb.org>.Acesso em: 28 de jul.2014). 41

Figura 2.2 Vigas metálicas protendidas (Nunziata, 1999). 42

Figura 2.3 Ponte de Condet, Indonésia (Daly e WitarnAwan,2000). 43

Figura 2.4 Ponte de Condet, Indonésia: a) cabos de protensão da

ponte e b) detalhes de ancoragem (Daly e WitarnAwan, 2000). 43

Figura 2.5 Viga de concreto protendido com distribuição de tensões.

Figura 2.6 Esquema do processo de protensão em perfil de aço durante a protensão. 
Figura 2.7 Deslocamento em cada estágio em relação à deformação do tubo para caso 1 .

Figura 2.8 Deslocamento em cada estágio em relação à deformação do tubo para caso 2 .

Figura 2.9 Cordoalhas em forma de espiral: (a) grupo de fios para formar uma cordoalha $\quad 50$

de 7 fios; (b) fios para formar cordoalhas em forma de hélice. 50

Figura 2.10 componentes para ancoragem. 51

(Fonte: http://impactoprotensao.com.br> acesso em 4 de jul.2014). 51

Figura 2.11 Barra de aço de alta resistência.

(Fonte: http://awacomercial.com.br/> Acesso em: 22 de jul.2014). 51

Figura 2.12 Detalhe de desviador (Nunziata, 1999). 52

Figura 2.13 Ancoragens de uma viga metálica protendida (Nunziata, 1999) 53

Figura 2.14 Configuração experimental treliça protendida na corda inferior (Magnel, 1950).

Figura 2.15 Treliça com carregamento e sem protensão. 56

Figura 2.16 Treliça protendida ao longo da corda inferior. 56

Figura 2.17 Sistema de treliça $\mathrm{N}$ e as diferentes técnicas de traçado dos

cabos de protensão. $\quad 58$

Figura 2.2.18 Aplicação da protensão induz força de compressão na corda inferior protendida.

Figura 2.19 Carregamento vertical induz uma força de tração induzida na corda inferior.

Figura 2.20 Carregamento do vento induz uma força de compressão induzida na corda inferior.

Figura 2.21 Treliça (HSS) testada no Imperial College (Gkantou et al., 2015). 61

Figura 2.22 Carga normalizada versus Deslocamento, para as classes de aço 62

(Gkantou et al., 2015). 62

Figura 2.24 Esquemas de traçados dos cabos na estrutura de arco tridimensional (Yongjun et al., 2018).

Figura 2.25 Configuração da estrutura em 3D completa (Yongjun et al., 2018). 64 Figura 2.26 Secção transversal dos arcos tridimensionais e das treliças longitudinais. 
Figura 2.27 Os esquemas de carregamento do arco tridimensional (Yongjun et al., 2018).

Figura 2.28 Apoio na extremidade do cabo da treliça arco

(Yongjun et al., 2018).

Figura 2.29 Diferentes esquemas traçados de cabos sob carga total e carga meia-extensão ( $\mathrm{F}=0,25)$ (Yongjun et al., 2018).

Figura 2.30 Novo sistema de arco vagonado.

Figura 3.1 Hangar de avião de 25 m x 25 m (PTIA, 2007).

Figura 3.2 Coeficientes de pressão externo, $\mathrm{CPe}, 10$ para coberturas abobadados com base retangular (Eurocode 1:1991).

Figura 3.3 Coeficientes externos de pressão,Cpe,10, para cúpulas com base circular (Eurocode 1: 1991).

Figura 3.4 Coeficientes de pressão externa $\mathrm{Cp}$,e para coberturas curvas segundo AS/NZS 1170.2.

Figura 3.5 Fator topográfico S1(z)para morros e taludes (NBR 6123:1988).

Figura 3.6 Abóbadas cilíndricas de seção circular com vento perpendicular à geratriz da cobertura com 0,5 12<11 < 312 da NBR 6123:1988.

Figura 3.7 Vento paralelo à geratriz da cobertura de acordo do anexo $\mathrm{E}$ da NBR 6123:1988.

Figura 3.8 Esquema da região onde sopra o vento na estrutura.

Figura 3.9 Coeficientes de pressão externo, CPe,10, uma cobertura de $\mathrm{d}=80 \mathrm{~m}$ vão, altura h= $6 \mathrm{~m}$ e flecha de $\mathrm{f}=11 \mathrm{~m}$, segundo Eurocode 1 (1991)

Figura 3.10 Forças atuantes nas cordas da treliça de $80 \mathrm{~m}$ de vão, para ação externa do vento, segundo critérios das normas (Eurocode 1, AS/NZS

1170.2 e NBR 6123)

Figura 4.1 Vista lateral da treliça parametrizada.

Figura 4.2 Perspectiva da simetria da treliça parametrizada.

Figura 4.3 Identificação das posições dos nós do modelo de treliça de 10 m de vão.

Figura 4.4 Identificações dos nós da simetria do modelo de treliça de 10 m de vão.

Figura 4.5 Identificações dos nós da simetria do modelo de treliça de 20 m de vão. 
Figura 4.6 Identificações dos nós da simetria do modelo de treliça de 40 m de vão.

Figura 4.7 Identificações dos nós da simetria do modelo de treliça de 80 m de vão.

Figura 4.8 Identificações dos nós da simetria do modelo de treliça de 120 m de vão.

Figura 4.9 Perfis de aço utilizados.

Figura 4.10 Detalhe da ligação da corda superior. $\quad 97$

Figura 4.11. Detalhe da ligação da corda inferior no centro da treliça. 97

$\begin{array}{ll}\text { Figura 4.12 Perfis detalhe da chapa de ancoragem. } & 98\end{array}$

Figura 4.13 Esquema de desviador e cabo. 98

Figura 4.14 Representação da atuação dos coeficientes de pressão externa do vento perpendicular à geratriz da cobertura (vento $90^{\circ}$ ). 100

Figura 4.15 Representação paramétrica da atuação da carga distribuída $\begin{array}{ll}\text { do vento a sucção. } & 102\end{array}$

Figura 4.16 Fluxograma para o cálculo da ação do vento para cobertura curva.

Figura 5.1 Geometria do elemento finito SOLID185 implementado no programa ANSYS 15.0.

Figura 5.2 Elemento estrutural SOLID185: são indicadas as tensões para as direções globais ANSYS 15.0.

Figura 5.4 Detalhes dos níveis de discretização em função do número de elementos.

Figura 5.5 Gráfico de convergência entre os níveis de refinamento de malhas. 114 Figura 5.6 Técnica MPC aplicada ao perfil na região do modelo.

Figura 5.7 Tensão versus deformação específica da elástica do perfil e do cabo de protensão.

Figura 5.8 Tensão versus deformação bi-linear isotrópico com endurecimento linear.

Figura 5.9 Perspectiva e simetria: criação dos elementos SOLID185 ( $\left.\mathrm{A}_{10}\right) . \quad 118$

Figura 5.10 Perspectiva e simetria: criação da malha triangular $\left(\mathrm{A}_{10}\right)$.

Figura 5.11 Perspectiva e simetria: elementos dos cabos de protensão $\left(\mathrm{A}_{10}\right)$.

Figura 5.12 Perspectiva treliça protendida: sucção do vento e carga 
permanente $\left(\mathrm{A}_{10}\right)$

Figura 5.13 Perspectiva e simetria: criação dos elementos SOLID185 (B $\left.{ }_{20}\right) . \quad 120$

Figura 5.14 Perspectiva e simetria: criação da malha triangular $\left(\mathrm{B}_{20}\right) . \quad 121$

Figura 5.15 Perspectiva e simetria: elementos dos cabos de protensão $\left(\mathrm{B}_{20}\right)$.

Figura 5.16 Perspectiva treliça protendida:sucção do vento e permanente $\left(\mathrm{B}_{20}\right) .121$

Figura 5.17 Perspectiva e simetria: criação dos elementos SOLID185 (C $\left.\mathrm{C}_{40}\right) . \quad 122$

$\begin{array}{ll}\text { Figura 5.18 Perspectiva e simetria: criação da malha triangular }\left(\mathrm{C}_{40}\right) . & 123\end{array}$

Figura 5.19 Perspectiva e simetria: elementos dos cabos de protensão $\left(\mathrm{C}_{40}\right) . \quad 123$

Figura 5.20 Perspectiva treliça protendida: sucção do vento e permanente

$\left(\mathrm{C}_{40}\right)$.

Figura 5.21 Perspectiva e simetria: criação dos elementos SOLID185 (D $\left.\mathrm{D}_{80}\right) . \quad 124$

Figura 5.22 Perspectiva e simetria: criação da malha triangular $\left(\mathrm{D}_{80}\right) . \quad 125$

Figura 5.23 Perspectiva e simetria: elementos dos cabos de protensão $\left(\mathrm{D}_{80}\right) . \quad 125$

Figura 5.24 Perspectiva treliça protendida: sucção do vento e permanente

$\left(\mathrm{D}_{80}\right)$.

Figura 5.25 Perspectiva e simetria: criação dos elementos SOLID185 (E $\left.\mathrm{E}_{120}\right) .126$

Figura 5.26 Perspectiva e simetria: criação da malha triangular $\left(\mathrm{E}_{120}\right)$.

Figura 5.27 Perspectiva e simetria: elementos dos cabos de protensão $\left(\mathrm{E}_{120}\right)$.

Figura 5.28 Perspectiva treliça protendida: sucção do vento e permanente

$\left(\mathrm{E}_{120}\right)$.

Figura 6.1 Distribuição das tensões de von Mises (em MPa) para o evento 1 $\left(\mathrm{A}_{10}\right)$

Figura 6.2 Vista lateral e perspectiva com plano de simetria X-Z:

deslocamento Uy para o evento $1\left(\mathrm{~A}_{10}\right)$.

Figura 6.3 Distribuição das tensões de von Mises (em MPa) correspondente na chapa com espessura de 2,45 mm para o evento 2 ( $\left.A_{P 10}\right)$.

Figura 6.4 Distribuição das tensões de von Mises (em MPa) correspondente na chapa com espessura de $6,3 \mathrm{~mm}$ para o evento $2\left(\mathrm{~A}_{\mathrm{P} 10}\right)$.

Figura 6.5 Distribuição das tensões de von Mises (em MPa) correspondente na chapa com espessura de 9,3 $\mathrm{mm}$ para o evento $2\left(\mathrm{~A}_{\mathrm{P} 10}\right)$.

Figura 6.6 Vista lateral e perspectiva com plano de simetria $\mathrm{X}-\mathrm{Y}$ :

deslocamento Uy para o evento $2\left(\mathrm{~A}_{\mathrm{P} 10}\right)$.

Figura 6.7 Distribuição das tensões de von Mises (em MPa) para o 
evento $3\left(\mathrm{~A}_{\mathrm{P} 10}\right)$

Figura 6.8 Vista lateral e perspectiva com plano de simetria X-Z:

deslocamento Uy para o evento $3\left(\mathrm{~A}_{\mathrm{P} 10}\right)$.

Figura 6.9 Distribuição das tensões de von Mises (em MPa) para o

evento $1\left(\mathrm{~B}_{20}\right)$

Figura 6.10 Vista lateral e perspectiva com plano de simetria X-Y:

deslocamento Uy para o evento $1\left(\mathrm{~B}_{20}\right)$.

Figura 6.11 Distribuição das tensões de von Mises (em MPa) máxima

para o evento $2\left(\mathrm{~B}_{\mathrm{P} 20}\right)$

Figura 6.12 Vista lateral e perspectiva com plano de simetria X-Y:

deslocamento Uy para o evento $2\left(\mathrm{~B}_{\mathrm{P} 20}\right)$.

Figura 6.13 Distribuição das tensões de von Mises (em MPa) para o

evento $3\left(\mathrm{~B}_{\mathrm{P} 20}\right)$.

Figura 6.14 Vista lateral e perspectiva com plano de simetria X-Y:

deslocamento Uy para o evento $3\left(\mathrm{~B}_{\mathrm{P} 20}\right)$.

Figura 6.15 Distribuição das tensões de von Mises (em MPa) para o

evento $1\left(\mathrm{C}_{40}\right)$.

Figura 6.16 Vista lateral e perspectiva com plano de simetria X-Z:

deslocamento Uy para o evento $1\left(\mathrm{C}_{40}\right)$.

Figura 6.17 Distribuição das tensões de von Mises (em MPa) máxima para o evento $2\left(\mathrm{C}_{\mathrm{P} 40}\right)$.

Figura 6.18 Vista lateral e perspectiva com plano de simetria X-Y:

deslocamento Uy para o evento $2\left(\mathrm{C}_{\mathrm{P} 40}\right)$.

Figura 6.19 Distribuição das tensões de von Mises (em MPa) para o

evento $3\left(\mathrm{C}_{\mathrm{P} 40}\right)$

Figura 6.20 Vista lateral e perspectiva com plano de simetria X-Z:

deslocamento Uy para o evento $3\left(\mathrm{C}_{\mathrm{P} 40}\right)$.

Figura 6.21 Distribuição das tensões de von Mises (em MPa) para o

evento $1\left(\mathrm{D}_{80}\right)$.

Figura 6.22 Vista lateral e perspectiva com plano de simetria X-Y:

deslocamento Uy para o evento $1\left(\mathrm{D}_{80}\right)$.

Figura 6.23 Distribuição das tensões de von Mises (em MPa) máxima para o evento $2\left(\mathrm{D}_{\mathrm{P} 80}\right)$. 
Figura 6.24 Vista lateral e perspectiva com plano de simetria $\mathrm{X}-\mathrm{Y}$ :

deslocamento Uy para o evento $2\left(\mathrm{C}_{\mathrm{P} 80}\right)$.

Figura 6.25 Distribuição das tensões de von Mises (em MPa) para o

evento $3\left(\mathrm{C}_{\mathrm{P} 80}\right)$.

Figura 6.26 Vista lateral e perspectiva com plano de simetria X-Y:

Deslocamento Uy para o evento $3\left(\mathrm{C}_{\mathrm{P} 80}\right)$.

Figura 6.27 Distribuição das tensões de von Mises (em MPa) para o

evento $1\left(\mathrm{E}_{120}\right)$.

Figura 6.28 Vista lateral e perspectiva com plano de simetria X-Z:

deslocamento Uy para o evento $1\left(\mathrm{D}_{120}\right)$.

Figura 6.29 Distribuição das tensões de von Mises (em MPa) máxima para o evento $2\left(\mathrm{E}_{\mathrm{p} 120}\right)$.

Figura 6.30 Vista lateral e perspectiva com plano de simetria X-Y:

deslocamento Uy para o evento $2\left(\mathrm{C}_{\mathrm{P} 120}\right)$.

Figura 6.31 Distribuição das tensões de von Mises (em MPa) para o

evento $3\left(\mathrm{E}_{\mathrm{P} 120}\right)$

Figura 6.32 Vista lateral e perspectiva com plano de simetria X-Y:

deslocamento Uy para o evento 3 ( $\mathrm{C}_{\mathrm{P} 120}$ ).

Figura 6.33 Corte da seção dos trechos das cordas superior e inferior para visualização dos resultados.

Figura 6.34 Forças fatoradas normalizadas atuantes nas cordas da treliça de $10 \mathrm{~m}$ de vão para as combinações de ações dos eventos 1 e 3 .

Figura 6.35 Forças fatoradas normalizadas atuantes nas cordas da treliça de 20 m de vão para as combinações de ações dos eventos 1 e 3.

Figura 6.36 Forças fatoradas normalizadas atuantes nas cordas da treliça de 40 m de vão para as combinações de ações dos eventos 1 e 3.

Figura 6.37 Forças fatoradas normalizadas atuantes nas cordas da treliça de 80 m de vão para as combinações de ações dos eventos 1 e 3 .

Figura 6.38 Forças fatoradas normalizadas atuantes nas cordas da treliça de 120 m de vão para as combinações de ações dos eventos 1 e 3 .

Figura 6.39 Forças de tração máximas solicitantes da corda superior para diferentes modelos.

Figura 6.40 Forças de compressão máximas solicitantes da corda inferior 
para diferentes modelos.

$\begin{array}{ll}\text { Figura 7.1 Esquema de controles de deslocamento vertical (Fida, 2015). } & 174\end{array}$

Figura 7.2 Deslocamento vertical aplicado no centro da treliça $\mathrm{A}_{10}$.

Figura 7.3 Força versus deslocamento vertical do meio do vão de $\mathrm{A}_{10}$ sem e com protensão.

Figura 7.4 Distribuição de tensões de von Mises (MPa) correspondente ao ponto $\mathrm{A}\left(\mathrm{A}_{10}\right)$.

Figura 7.5 Distribuição de tensões de von Mises (MPa) correspondente ao ponto $\mathrm{B}\left(\mathrm{A}_{10}\right)$.

Figura 7.6 Distribuição de tensões de von Mises (MPa) correspondente ao ponto $\mathrm{C}\left(\mathrm{A}_{10}\right)$.

Figura 7.7 Distribuição de tensões de von Mises (MPa) correspondente ao ponto $\mathrm{D}\left(\mathrm{A}_{10}\right)$.

Figura 7.8 Força versus deslocamento vertical do meio do vão da $A_{P 10}$ para vários níveis de protensão.

Figura 7.9 Distribuição de tensões de von Mises (MPa) correspondente ao ponto $\mathrm{A}\left(\mathrm{A}_{\mathrm{P} 10}\right)$.

Figura 7.10 Distribuição de tensões de von Mises (MPa) correspondente ao ponto $\mathrm{B}\left(\mathrm{A}_{\mathrm{P} 10}\right)$.

Figura 7.11 Distribuição de tensões de von Mises (MPa) correspondente ao ponto $\mathrm{C}\left(\mathrm{A}_{\mathrm{P} 10}\right)$.

Figura 7.12 Distribuição de tensões de von Mises (MPa) correspondente ao ponto $\mathrm{D}\left(\mathrm{A}_{\mathrm{P} 10}\right)$.

Figura 7.13 Deslocamento vertical aplicado no centro da treliça $\mathrm{B}_{20}$.

Figura 7.14 Força versus deslocamento vertical do meio do vão de $\mathrm{B}_{20}$ sem e com protensão.

Figura 7.15 Distribuição de tensões de von Mises (MPa) correspondente ao ponto $\mathrm{A}\left(\mathrm{B}_{20}\right)$.

Figura 7.16 Distribuição de tensões de von Mises (MPa) correspondente ao ponto $\mathrm{B}\left(\mathrm{B}_{20}\right)$.

Figura 7.17 Distribuição de tensões de von Mises (MPa) correspondente ao ponto $\mathrm{C}\left(\mathrm{B}_{20}\right)$.

Figura 7.18 Distribuição de tensões de von Mises (MPa) correspondente 
ao ponto $\mathrm{D}\left(\mathrm{B}_{20}\right)$.

Figura 7.19 Distribuição de tensões de von Mises (MPa) correspondente ao ponto $\mathrm{A}\left(\mathrm{B}_{\mathrm{P} 20}\right)$.

Figura 7.20 Distribuição de tensões de von Mises (MPa) correspondente ao ponto $\mathrm{B}\left(\mathrm{B}_{\mathrm{P} 20}\right)$.

Figura 7.21 Distribuição de tensões de von Mises (MPa) correspondente ao ponto $\mathrm{C}\left(\mathrm{B}_{\mathrm{P} 20}\right)$.

Figura 7.22 Distribuição de tensões de von Mises (MPa) correspondente ao ponto $\mathrm{D}\left(\mathrm{B}_{\mathrm{P} 20}\right)$.

Figura 7.23 Deslocamento vertical aplicado no centro da treliça C40.

Figura 7.24 Força versus deslocamento vertical do meio do vão de $\mathrm{C}_{40}$ sem e com protensão.

Figura 7.25 Distribuição de tensões de von Mises (MPa) correspondente ao ponto $\mathrm{A}\left(\mathrm{C}_{40}\right)$.

Figura 7.26 Distribuição de tensões de von Mises (MPa) correspondente ponto $\mathrm{B}\left(\mathrm{C}_{40}\right)$.

Figura 7.27 Distribuição de tensões de von Mises (MPa) correspondente ao ponto $\mathrm{C}\left(\mathrm{C}_{40}\right)$.

Figura 7.28 Distribuição de tensões de von Mises (MPa) correspondente ao ponto $\mathrm{D}\left(\mathrm{C}_{40}\right)$.

Figura 7.29. Distribuição de tensões de von Mises (MPa) correspondente ao ponto $\mathrm{A}\left(\mathrm{C}_{\mathrm{P} 40}\right)$.

Figura 7.30 Distribuição de tensões de von Mises (MPa) correspondente ao ponto $\mathrm{B}\left(\mathrm{C}_{\mathrm{P} 40}\right)$.

Figura 7.31 Distribuição de tensões de von Mises (MPa) correspondente ponto $\mathrm{C}\left(\mathrm{C}_{\mathrm{P} 40}\right)$.

Figura 7.32 Distribuição de tensões de von Mises (MPa) correspondente ao ponto $\mathrm{D}\left(\mathrm{C}_{\mathrm{P} 40}\right)$.

Figura 7.33 Deslocamento vertical aplicado no centro da treliça $\mathrm{D}_{80}$.

Figura 7.34 Força versus deslocamento vertical do meio do vão de $\mathrm{D}_{80}$ sem e com protensão.

Figura 7.35 Distribuição de tensões de von Mises (MPa) correspondente ao ponto $A\left(D_{80}\right)$ 
Figura 7.36 Distribuição de tensões de von Mises (MPa) correspondente ao ponto $\mathrm{B}\left(\mathrm{D}_{80}\right)$.

Figura 7.37 Distribuição de tensões de von Mises (MPa) correspondente ponto $\mathrm{C}\left(\mathrm{D}_{80}\right)$.

Figura 7.38 Distribuição de tensões de von Mises (MPa) correspondente ao ponto $\mathrm{D}\left(\mathrm{D}_{80}\right)$.

Figura 7.39. Distribuição de tensões de von Mises (MPa) correspondente ao ponto $\mathrm{A}\left(\mathrm{D}_{\mathrm{P} 80}\right)$.

Figura 7.40 Distribuição de tensões de von Mises (MPa) correspondente ao ponto $\mathrm{B}\left(\mathrm{D}_{\mathrm{P} 80}\right)$.

Figura 7.41 Distribuição de tensões de von Mises (MPa) correspondente ponto $\mathrm{C}\left(\mathrm{D}_{\mathrm{P} 80}\right)$.

Figura 7.42. Distribuição de tensões de von Mises (MPa) correspondente ao ponto $\mathrm{D}\left(\mathrm{D}_{80}\right)$

Figura 7.43 Deslocamento vertical aplicado no centro da treliça $\mathrm{E}_{120}$.

Figura 7.44 Força versus deslocamento vertical do meio do vão de $\mathrm{E}_{120}$ sem cabo e com protensão.

Figura 7.45 Distribuição de tensões de von Mises (MPa) correspondente ao ponto $\mathrm{A}\left(\mathrm{D}_{120}\right)$.

Figura 7.46. Distribuição de tensões de von Mises (MPa) correspondente ao ponto $\mathrm{B}\left(\mathrm{E}_{120}\right)$.

Figura 7.47. Distribuição de tensões de von Mises (MPa) correspondente ao ponto $\mathrm{C}\left(\mathrm{E}_{120}\right)$.

Figura 7.48. Distribuição de tensões de von Mises (MPa) correspondente ponto $\mathrm{D}\left(\mathrm{E}_{120}\right)$.

Figura 7.49. Distribuição de tensões de von Mises (MPa) correspondente ao ponto $\mathrm{A}\left(\mathrm{E}_{\mathrm{P} 120}\right)$.

Figura 7.50 Distribuição de tensões de von Mises (MPa) correspondente ao ponto $\mathrm{B}\left(\mathrm{E}_{\mathrm{P} 120}\right)$.

Figura 7.51 Distribuição de tensões de von Mises (MPa) correspondente ponto $\mathrm{C}\left(\mathrm{E}_{\mathrm{P} 120}\right)$.

Figura 7.52. Distribuição de tensões de von Mises (MPa) correspondente ao ponto $\mathrm{D}\left(\mathrm{E}_{\mathrm{P} 120}\right)$ 


\section{Lista de tabelas}

Tabela 2.1 Vantagens econômicas das estruturas protendidas (Troitsky, 1990). 54

Tabela 2.2 Percentagem de reduções nas forças internas dos elementos da treliça após o uso de diferentes técnicas de protensão. 58

Tabela 2.3 Propriedades dos elementos da estrutura.

Tabela 2.4 Seções transversais de vários elementos das estruturas com diferentes extensões $(\mathrm{mm})$.

Tabela 2.5 Cargas máxima dos esquemas de traçados dos arcos sob carga total $(\mathrm{F}=0,25)$.

Tabela 2.6 Cargas máxima dos esquemas de traçados dos arcos sob carga de meia extensão $(\mathrm{F}=0,25)$.

Tabela 3.1 Coeficientes de pressão externa, Cpe, para coberturas curvas com h / $\mathrm{r} \leq 2$, segundo AS/NZS 1170.2:2002.

Tabela 3.2 Parâmetros meteorológicos da NBR 6123:1988.

Tabela 3.3 Valores mínimos do fator estatístico S3 de acordo com NBR 6123:1988.

Tabela 3.4 Coeficientes de pressão externa, Cpe, para vento soprando perpendicularmente à geratriz da cobertura de acordo do anexo E da NBR 6123:1988.

Tabela 3.5 Coeficientes de pressão externa, Cpe, para vento atuando paralelamente à geratriz da cobertura de acordo do anexo E da NBR 6123:1988.

Tabela 3.6 Coeficientes de pressão externa, Cpe, para vento atuando obliquamente à geratriz da cobertura de acordo do anexo $\mathrm{E}$ da NBR 6123:1988.

Tabela 3.7 Avalição dos resultados dos esforços na estrutura de vão $80 \mathrm{~m} . \quad 87$

Tabela 4.1 Os modelos das treliças estudadas.

Tabela 4.2 Coordenadas nós da simetria do modelo de treliças de $10 \mathrm{~m}$ de vão. 90 Tabela 4.3 Coordenadas nós da simetria do modelo de treliças de $20 \mathrm{~m}$ de vão. 91 Tabela 4.4 Coordenadas nós da simetria do modelo de treliças de $40 \mathrm{~m}$ de vão. 92 Tabela 4.5 Coordenadas nós da simetria do modelo de treliças de $80 \mathrm{~m}$ 
de vão.

Tabela 4.6 Coordenadas nós da simetria do modelo de treliças de $120 \mathrm{~m}$ de vão.

Tabela 4.7 Propriedades físicas dos perfiles e cabos utilizados na modelagem. 96

Tabela 4.8 Coeficiente de pressão externa do vento a sucção para seção

circular.

Tabela 4.9 Composição dos valores das forças do vento mais desfavorável.

101

Tabela 4.10 Ação permanente (G) nos modelos.

Tabela 4.11 Especificações dos perfis das treliças em cada modelo.

Tabela 4.12 Especificações dos cabos de protensão em cada modelo.

Tabela 5.1 Resumo do estudo de tamanho de malhas.

Tabela 5.2 Porcentual da diferença de tamanho de malhas.

Tabela 5.3 Resumos de números de elementos finitos para os diferentes modelos numéricos

Tabela 6.1 Força máxima normalizada atuante na corda superior.

Tabela 6.2 Força máxima normalizada atuante na corda inferior.

Tabela 6.3 Força máxima atuante na corda superior.

Tabela 6.4 Força máxima e deslocamento atuante na corda inferior.

Tabela 6.5 Tensão máxima de von Mises.

Tabela 7.1 Níveis de força de protensão da treliça $\mathrm{A}_{10}$.

Tabela 7.2 Resumo dos resultados das forças e deslocamentos da treliça

10 m sem e com protensão nos pontos das curvas (Figura 7.3).

Tabela 7.4 Resumo dos resultados das forças e deslocamentos da treliça

$20 \mathrm{~m}$ sem e com protensão nos pontos das curvas (Figura 7.14).

Tabela 7.5 Níveis de força de protensão da treliça $\mathrm{C}_{40}$

Tabela 7.6 Resumo dos resultados das forças e deslocamentos da treliça

$40 \mathrm{~m}$ sem e com protensão nos pontos das curvas (Figura 7.24).

Tabela 7.7 Níveis de força de protensão da treliça $\mathrm{D}_{80}$.

Tabela 7.9 Níveis de força de protensão da treliça $\mathrm{E}_{120}$

Tabela 7.10 Resumo dos resultados das forças e deslocamentos da treliça 120 m sem e com protensão nos pontos das curvas (Figura 7.44). 


\section{Lista de Símbolo}

\section{Letras romanas maiúsculas}

A Região da parte da cobertura

$\mathrm{A}_{1} \quad$ Região da parte da cobertura

$\mathrm{A}_{2} \quad$ Região da parte da cobertura

$\mathrm{A}_{10} \quad$ Modelo de treliças de $10 \mathrm{~m}$ de vão

$\mathrm{A}_{\mathrm{c}} \quad$ Áreas de seção transversal do cabo

$\mathrm{A}_{\mathrm{t}} \quad$ Áreas de seção transversal do perfil

B Região B da parte da cobertura

$\mathrm{B}_{20} \quad$ Modelo de treliças de $20 \mathrm{~m}$ de vão

C Região $\mathrm{C}$ da parte da cobertura

$\mathrm{C}_{\mathrm{pe}} \quad$ Coeficiente externo de pressão

$\mathrm{C}_{\mathrm{pi}} \quad$ Coeficiente interno de pressão

$\mathrm{C}_{40} \quad$ Modelo de treliças de $40 \mathrm{~m}$ de vão

D Um quarto da região das partes da cobertura

$\mathrm{D}_{1} \quad$ Região da parte da cobertura

$\mathrm{D}_{2} \quad$ Região da parte da cobertura

$\mathrm{D}_{80} \quad$ Modelo de treliças de $80 \mathrm{~m}$ de vão

$\mathrm{E}_{\mathrm{c}} \quad$ Módulo de elasticidade do cabo de aço

$\mathrm{E}_{\mathrm{t}} \quad$ Módulo de elasticidade do perfil de aço

$\mathrm{E}_{120} \quad$ Modelo de treliças de $120 \mathrm{~m}$ de vão

$\mathrm{F}_{\max }^{\mathrm{cs}} \quad$ Força interna máxima na corda superior

$\mathrm{F}_{\text {meio }}^{\mathrm{cs}} \quad$ Força interna no meio da corda superior

$\mathrm{F}_{\max }^{\mathrm{ci}} \quad$ Força interna máxima na corda inferior

$\mathrm{F}_{\text {meio }}^{\mathrm{ci}} \quad$ Força interna no meio da corda inferior

$\mathrm{F}_{\max }^{\mathrm{cd}} \quad$ Força interna máxima na diagonal

$\mathrm{F}_{\max }^{\mathrm{cm}} \quad$ Força interna máxima no montante

$\mathrm{F}_{\mathrm{d}} \quad$ Força longo do vão para carga de serviço Forças fatoradas atuantes nas cordas da treliça

$\mathrm{F}_{\mathrm{d}} / \mathrm{P}_{\mathrm{opt}, \mathrm{c}}$ Forças normalizadas solicitantes Forças fatoradas normalizadas atuantes nas cordas da treliça

$\mathrm{F}_{\mathrm{d}} / \mathrm{P}_{\mathrm{opt}, \mathrm{c}}$ Forças normalizadas solicitantes Forças fatoradas normalizadas atuantes nas cordas da treliça

$\mathrm{G}$ Ação permanente

$\mathrm{K}_{\mathrm{c}} \quad$ Rigidez axial do cabo

$\mathrm{K}_{\mathrm{t}} \quad$ Rigidez axial do perfil

$\mathrm{L}_{0} \quad$ Comprimento inicial do cabo e do tubo

M Ponto do centro da corda superior da treliça

MPC Multi Point Constraint 


$\begin{array}{cl}\mathrm{P} & \text { Força de protensão } \\ \mathrm{P}_{\text {cabo }} & \text { Força no cabo } \\ \mathrm{P}_{\text {perfil }} & \text { Força no perfil } \\ \mathrm{P}_{\text {equi }} & \text { Força de protensão equivalente } \\ \mathrm{P}_{\mathrm{opt}, \mathrm{c}} & \text { Força de protensão ótima } \\ \mathrm{R}_{\text {apoio }}^{\mathrm{y}} & \text { Reação de apoio na direção y } \\ \mathrm{S}_{1} & \text { Fator topográfico } \\ \mathrm{S}_{2} & \text { Rugosidade do terreno } \\ \mathrm{S}_{3} & \text { Baseado em conceitos probabilístico } \\ \mathrm{T} & \text { Metade da região da parte da cobertura } \\ \mathrm{U} & \text { Um quarto da região da parte da cobertura } \\ \mathrm{V}_{0} & \text { Velocidade básica } \\ \mathrm{V}_{\mathrm{k}} & \text { Velocidade característica do vento } \\ \mathrm{W} & \text { Força do vento } \\ \mathrm{X}_{\mathrm{c}} & \text { Alargamento do cabo } \\ \mathrm{X}_{\mathrm{t}} & \text { Encurtamento do tubo } \\ \mathrm{Z}_{\mathrm{e}} & \text { Altura de referência (Eurocode1) }\end{array}$

\section{Letras romanas minúsculas}

$\begin{array}{ll}\mathrm{d} & \text { Vão segundo Eurocode } \\ \mathrm{f} & \text { Flecha da cobertura } \\ \mathrm{f}_{\mathrm{ty}} & \text { Tensão limite de escoamento do perfil de aço } \\ f_{p c k} & \text { Valor característico da resistência à tração do cabo de aço } \\ f_{c y} & \text { Tensão limite de escoamento do cabo de aço } \\ \mathrm{h} & \text { Altura da coluna da cobertura (Eurocode) } \\ \mathrm{h} & \text { Altura da cobertura (AS/NZS) } \\ \mathrm{l}_{1} & \text { Largura da abobada cilíndrica medida na direção } \\ & \text { perpendicular ao vento } \\ \mathrm{l}_{2} & \text { Largura da abóbada cilíndrica medida na direção paralela ao } \\ & \text { vento } \\ \mathrm{q} & \text { Pressão dinâmica pico } \\ \mathrm{r} & \text { Flecha da cobertura (AS/NZS) }\end{array}$




\section{Letras gregas}

$\begin{array}{cl}\sigma_{\text {cantoneira }}^{V} & \text { Tensão de von Mises na cantoneira } \\ \sigma_{\max }^{V} & \text { Tensão máxima de von Mises } \\ \sigma_{\mathrm{M}}^{\mathrm{V}} & \text { Tensão de von Mises em meio da treliça } \\ \mathrm{v} & \text { Coeficiente de Poisson do aço } \\ \Delta_{c} & \text { Variação deformação nos cabos } \\ \delta_{\mathrm{M}} & \text { Incremento de deslocamento } \\ \delta_{\max }^{Y} & \text { Deslocamento máximo no eixo y } \\ \mathrm{U}_{\mathrm{y}} & \text { Deslocamento no eixo y } \\ \sigma_{c} & \text { Tensão no cabo de protensão }\end{array}$

\section{Lista de Abreviaturas}

AASHO American Association of State Highway and Transportation Officials

ABNT Associação Brasileira de Normas Técnicas

$\mathrm{ACI}$

American Concrete Institute

ASCE

American Society Of Civil Engineers

AS

Standards Australia

ASTM

American Society for Testing and Materials

APDL

Ansys Parametric Design Language

EUROCODE

Normas Européias - Basis of Structural Design

MEF

Método dos Elementos Finitos

NBR

Norma Brasileira

NZS

Standards New Zealand

PTIA

Post-Tensioning Institute of Australia Limited

$\mathrm{RB}$

Relaxação Baixa

$\mathrm{RN}$

Relaxação Normal

SAP

Structural Analysis and Design Program

W

Valor da ação do vento 
"A ciência é feita de suor como dizemos, temos sobre salto de lógica, temos anos de indagações não respondidas, temos frustações, temos horas de arrancar os cabelos, mas o verdadeiro poder do gênio é a força de vontade para fazer todos os erros necessários para chegar à resposta".

Michio Kaku. 


\section{Introdução}

Estruturas com uma geometria em arco têm a capacidade de suportar carregamentos gravitacionais através do arqueamento clássico, ação que os torna uma solução econômica e esteticamente apropriada para grandes vãos em estruturas de aço. Em particular, as estruturas de treliças em arco alcançam grande eficiência estrutural para resistir ao carregamento aplicado por meio da atuação arqueada das cordas, bem como utilizando a rigidez a flexão e rigidez axial, dos membros das cordas superior e inferior.

Nas estruturas protendidas observa-se o princípio básico da protensão, que consiste na criação, em determinadas regiões da estrutura, de tensões de sinais opostos às produzidas pelas cargas externas. Esse efeito é obtido a partir do emprego de cordoalhas de aço de alta resistência que são ancorados na estrutura, de modo que esta possa ser protendida. Dessa maneira ocorre um aumento da capacidade resistente da peça, possibilitando a redução das dimensões dos perfis de aço e, como consequência, a redução dos custos de construção.

Na Austrália a empresa $S^{2}$ Space Solutions, Sydney, Austrália (Ellen, 1987) desenvolveu treliças protendidas com cordas tubulares e com protensão com cabos localizados na corda inferior que introduz solicitação contrária aos efeitos provenientes de cargas gravitacionais e do vento. A seguir são descritas as etapas construtivas das treliças em arco mencionadas.

Inicialmente as treliças são montadas ao nível do solo, como apresentado na Figura 1.1 (a), com a coluna rotulada na parte da treliça. Em seguida vê-se a protensão dos cabos inseridos dentro da corda inferior do trecho do vão principal (Figura 1.1 b). O comprimento segmentado da corda inferior determina a curvatura da parte superior e da corda inferior de modo que o comprimento segmentado pode ser variado na fase de projeto para obter-se a forma desejada da treliça. Na Figura 1.1 (c) mostra-se a montagem do conjunto das colunas que após receber protensão formam uma estrutura completa. 


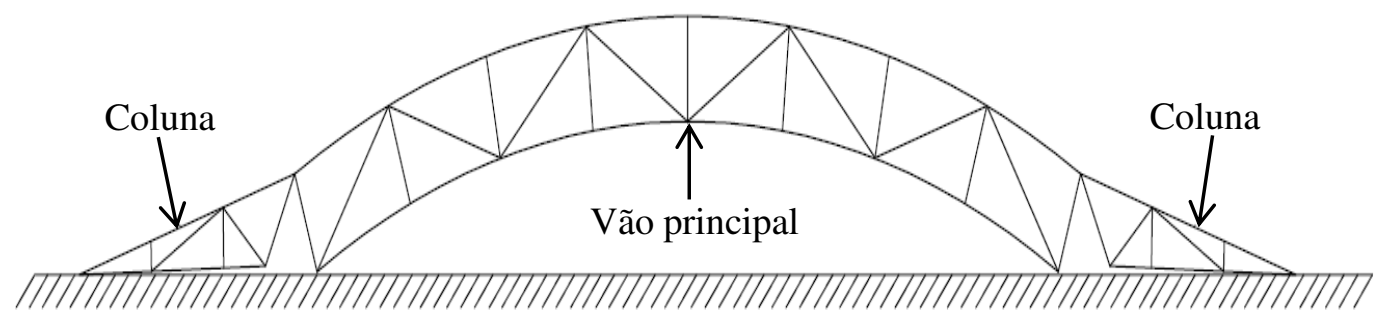

(a) Construção das componentes da treliça tubular.

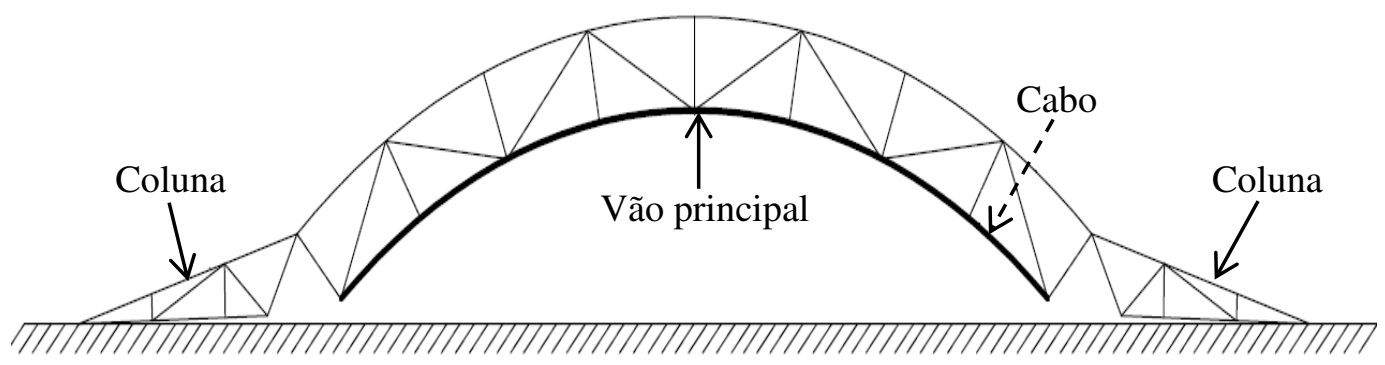

(b) Cabos de protensão encaixados na corda tubular inferior.

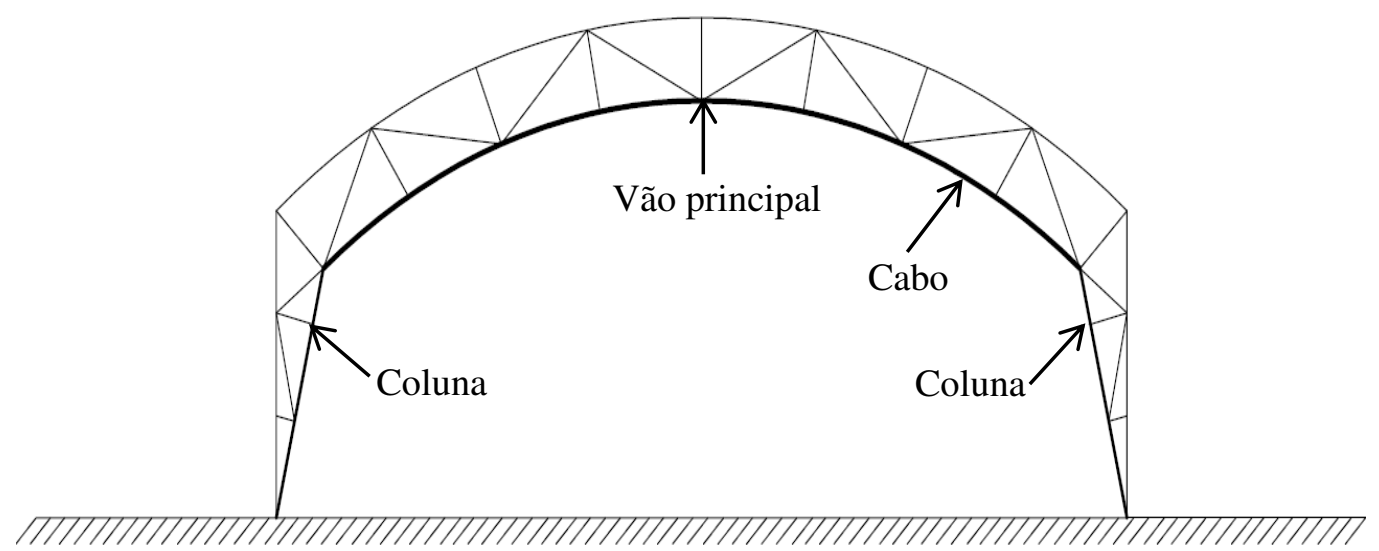

(c) Conexão da estrutura da coluna e a estrutura principal.

Figura 1.1 Etapas construtivas das treliças protendida em arco (Ellen, 1987).

Nas treliças de aço arqueadas, protendidas com articulação deslizante, a protensão tem sido utilizada como processo de montagem de estruturas em forma de arco (técnica com juntas deslizantes por meio do tensionamento de um cabo na corda inferior). Foi recentemente aplicada para a construção de cobertura temporária em estrutura de aço em Londres no Hyde Park, como pode ser visto nas Figuras 1.2 e 1.3 . 

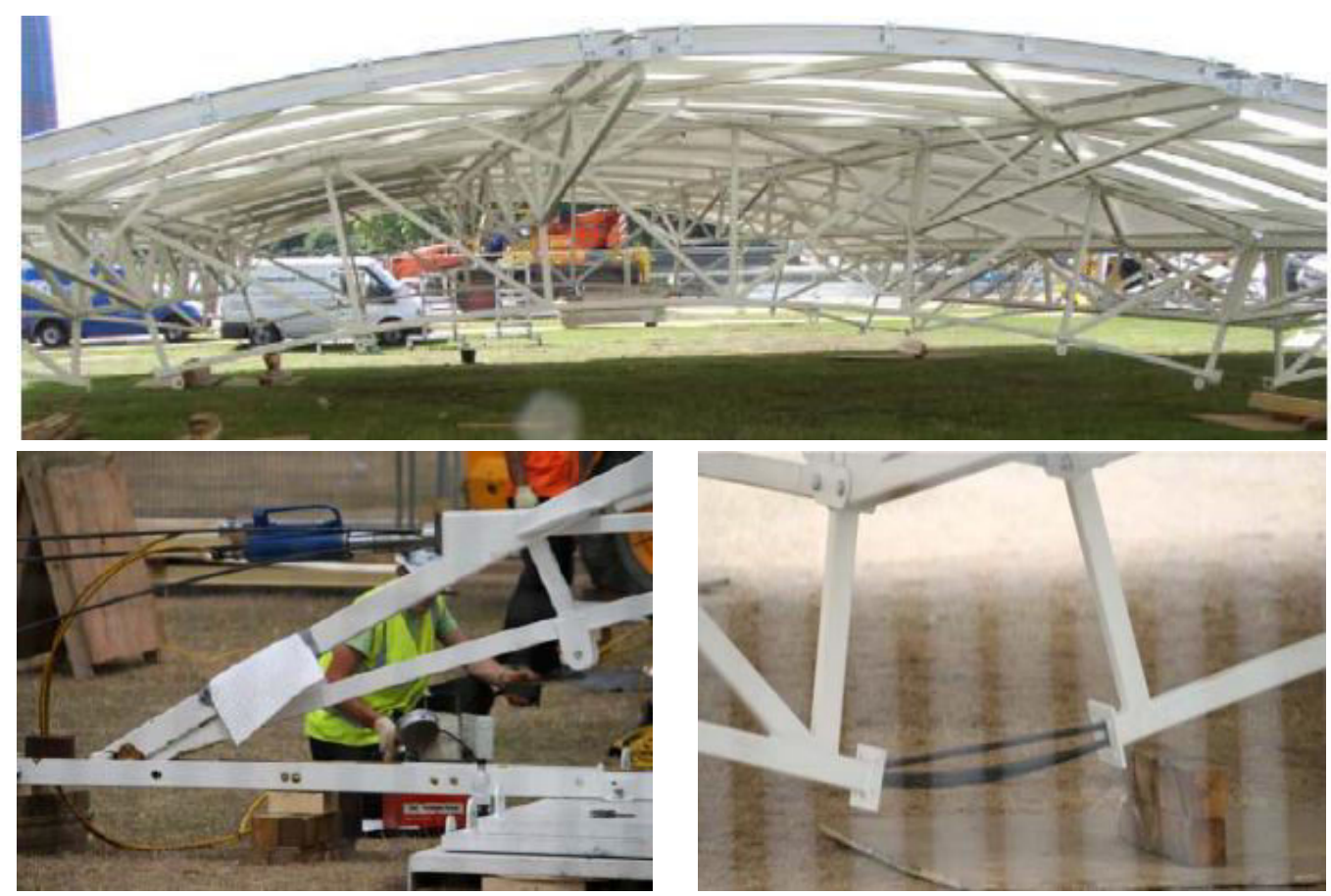

Figura 1.2 Montagem e etapa da protensão na Treliça Hyde Park, London (Gkantou et al., 2015).

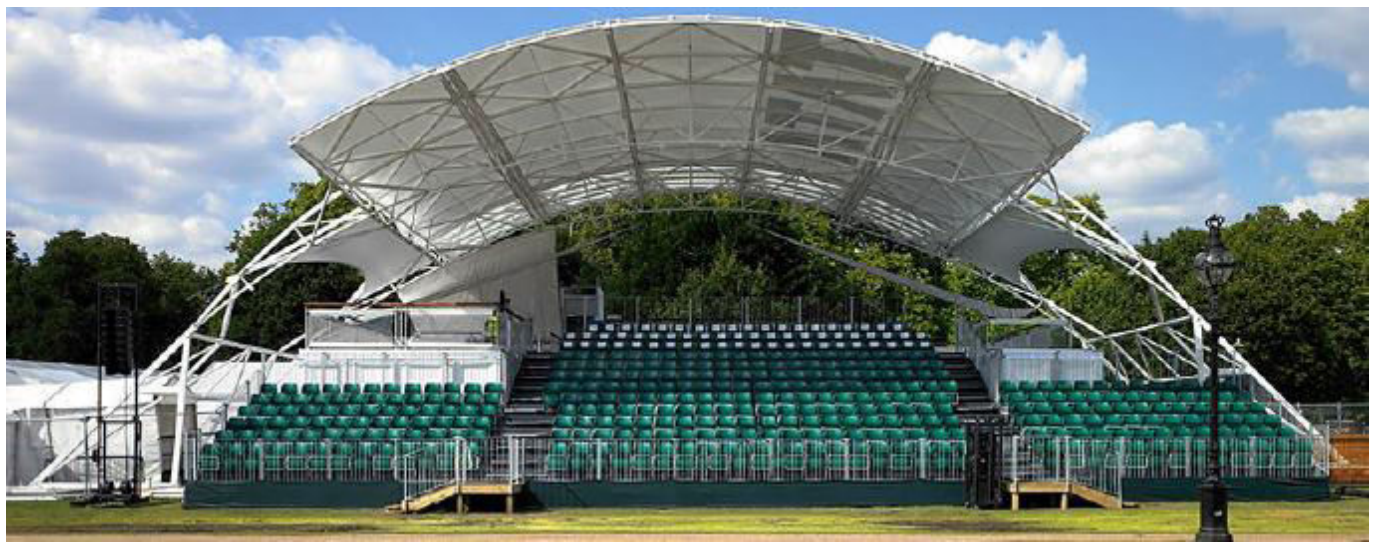

Figura 1.3 Treliça de arco protendida Hyde Park (Gkantou et al., 2015).

$\mathrm{Na}$ literatura técnica o tema específico do estudo e do comportamento estrutural de treliças de aço em forma de arco protendidas com diferentes tipos de perfis tem sido pouco abordado, havendo poucas publicações. Esta tese apresenta um estudo do comportamento estrutural de treliças de aço em forma de arco utilizadas no projeto de coberturas protendidas, considerando uma extensiva análise para diferentes variações de geometria e de vão nos modelos de treliça.

Apresenta um estudo da geração de arquivos de entrada de dados, usando-se o recurso $A P D L$ do programa ANSYS de modo a possibilitar a análise paramétrica das estruturas e definições das ações, segundo os critérios das normas. 
Uma das aplicações de estruturas com protensão é a coluna permanente protendida, que foi utilizada em 2012 no Chiswick Park em Londres, cujo sistema de fachada é mostrado na Figura 1.4. Compreende uma coluna central de 23,5 m, empregada para suportar uma estrutura suporte de fachada e de cobertura, com um sistema de membros transversais ao longo do comprimento da coluna (cruzetas triplas) e cabos de protensão que atuam para impedir os deslocamentos e melhorar a resistência à flambagem da coluna.

Esse sistema de reforço adicional pode aumentar consideravelmente a capacidade de carga da coluna, resultando em uma solução estrutural eficiente. A Figura 1.5 mostra outro exemplo de coluna estaiada no telhado da cobertura do prédio do Frick Chemistry Laboratory na Universidade de Princeton, Nova Jersey, EUA (Seward, 2012).

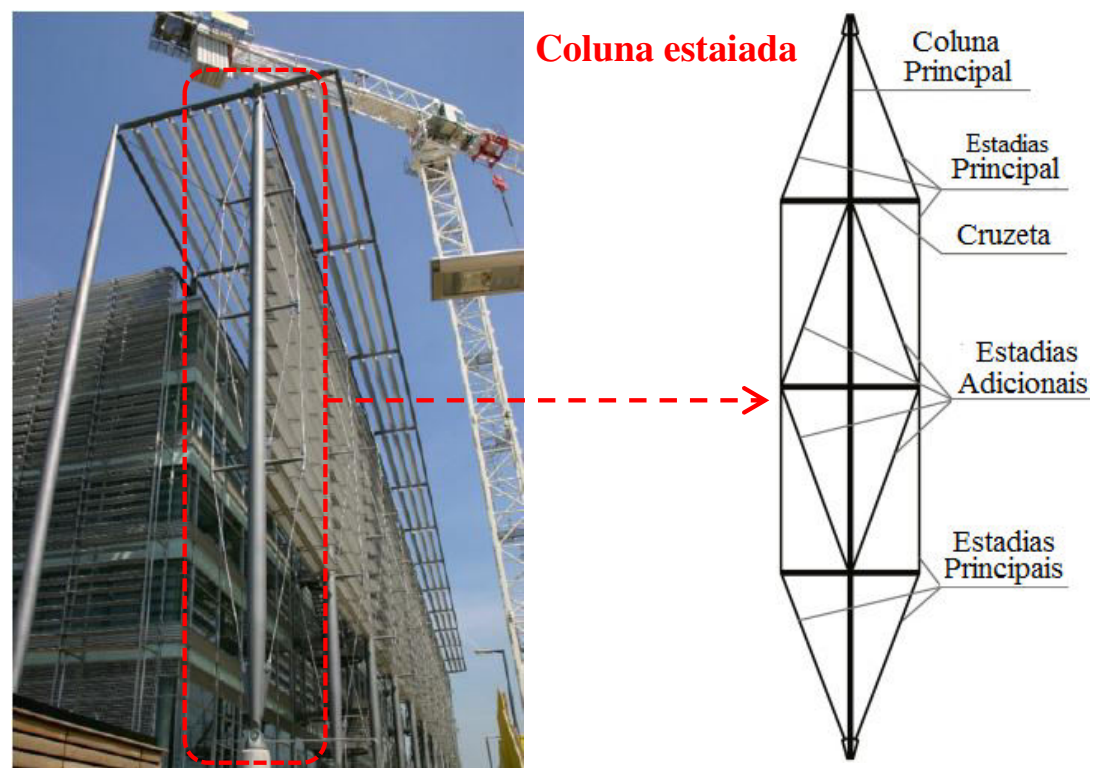

Figura 1.4 Coluna protendida do Edifício do Chiswick Park, (Osofero et al., 2012).

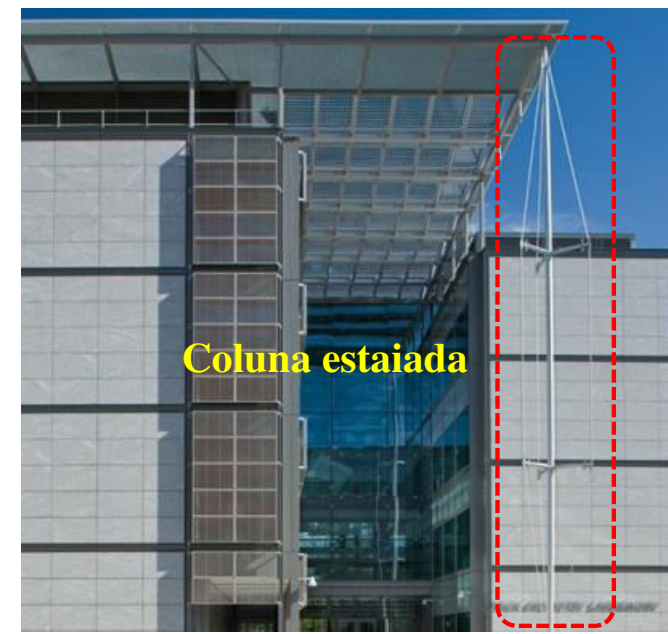

Figura 1.5 Coluna estaiada de cobertura do prédio do Frick Chemistry Laboratory na Universidade de Princeton, Nova Jersey, EUA (Seward, 2012). 
Outra aplicação de estruturas de aço protendidas foi o uso de colunas de aço esbeltas e estaiadas com utilização de protensão que ocorreu durante a fase de construção do palco principal do "Rock in Rio III(2003)", realizado na cidade de Rio de Janeiro para suporte temporário da estrutura espacial da cobertura.

Nesse projeto houve necessidade de se apoiar parte da estrutura de cobertura, cuja altura de montagem foi de $36 \mathrm{~m}$ acima do nível do chão. Utilizando-se um sistema de barras perpendiculares ao tubo principal e em forma de cruz, essa solução estrutural proporcionou redução do comprimento efetivo de flambagem da coluna.

Pelos métodos convencionais de construção uma estrutura de cobertura com essa altura teria exigido um sistema denso e complicado de andaimes estaiados, com grande perda de tempo de execução. Para prevenir esse problema os engenheiros decidiram adotar esse tipo de sistema. Devido à sua simplicidade estrutural e superioridade em resistir a cargas axiais, tal opção permitiu a redução de tempo de construção.

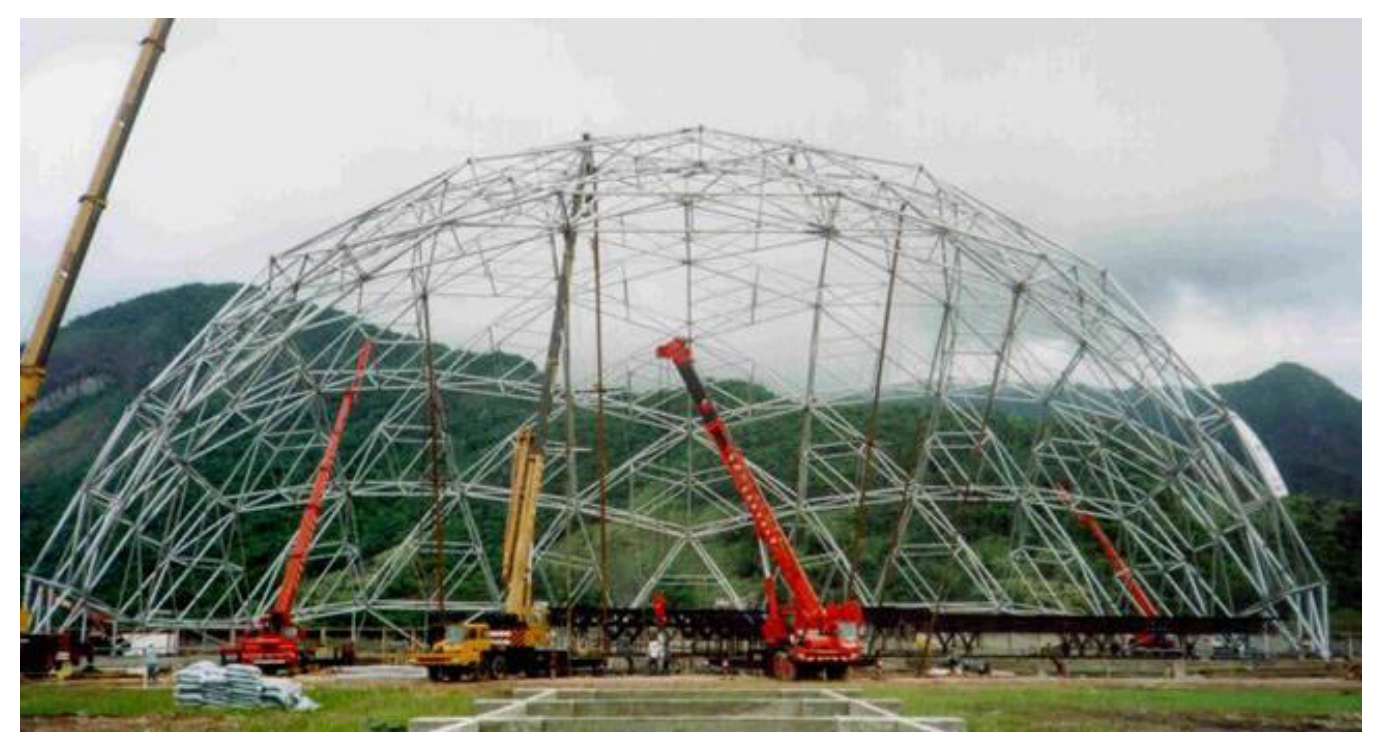

Figura 1.6 Palco principal do Rock in Rio III (2011) durante a montagem (Andrade, et al., 2003).

Em treliças o uso da protensão foi inicialmente estudado e aplicado em treliças de ferro fundido, por Rider, Nathaniel, que, em 1847, projetou um ponte com tabuleiro de madeira com treliças protendidas (Figura 1.7), cuja corda superior, os montantes de apoio e diagonais são de ferro fundido. A protensão foi aplicada nas diagonais, onde as conexões da estrutura foram simplificadas e a rigidez de ponte foi aumentada. 


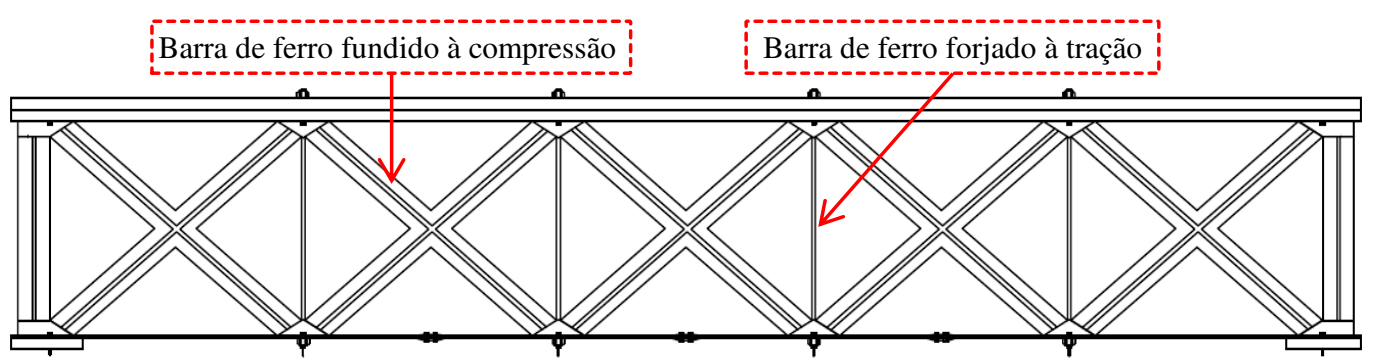

Figura 1.7 Ponte de 33,8 m de vão de ferro fundido e forjado em New York (Darnell, 1991).

Outra construção importante foi a grande ponte ferroviária tubular de Britania, de autoria de Robert Stephenson, sobre o Estreito de Menai, na Inglaterra, concluída em 1850. Cada via férrea foi colocada sobre uma viga contínua de ferro forjado de $140 \mathrm{~m}$ do vão e dois vãos laterais de $70 \mathrm{~m}$. Uma ponte com esse vão, quando sujeita ao seu próprio peso, apresenta um grande momento fletor, e quando aplicada a força de protensão cria-se um sistema de forças internas na estrutura que atua em oposição ao efeito das cargas gravitacionais, particularmente seu próprio peso, dai se tem economia de material e redução de custos.

Ayyub et al. (1990) examinaram as componentes confiabilidade e redundância de treliças protendidas. Afirmam que uma abordagem estatística é apropriada devido à incerteza envolvida em resistência estrutural e condições futuras de carga. Os resultados mostraram maior confiabilidade e redundância quando as treliças foram protendidas.

No entanto, esses autores apenas compararam treliças com e sem cabos e, portanto, a melhoria na confiabilidade e redundância pode ser atribuída, em grande parte, ao fato de ter sido acrescentada uma componente estrutural do cabo à estrutura. Han e Park (2005), realizaram um estudo paramétrico do comportamento e capacidade de suporte de carga de treliças protendidas.

Bhargavi e Rama (2015) apresentaram uma comparação de resultados entre o projeto de treliças protendidas com cabos de alta resistência e o projeto com o uso de treliças convencionais. A partir dessa comparação, esses autores mostraram que há uma considerável economia para os membros de treliças individuais, e melhoria notável no comportamento da estrutura. O uso da protensão em estruturas de aço tem por finalidade a obtenção de economia de material, ou, em certos casos, atender às imposições arquitetônicas ou construtivas. 


\section{1.}

\section{Motivação}

De acordo com Post-Tensioning Institute of Australia Limited (PTIA, 2007), a grande vantagem da utilização de treliças protendidas se deve à redução do peso do aço em até $60 \%$. Além disso, por serem protendidos, esses elementos conseguem vencer grandes vãos com economia, controlando a flecha e aumentando a resistência estrutural. Pós-tensionamento dos cabos de aço dentro da estrutura proporciona o mecanismo de armazenamento de energia, quanto maior as cargas impostas associadas ao fenômeno natural tais como terremotos, tornados e carregamento de neve, com os benefícios de redução de custos e aumento de rigidez.

A Figura 1.8 apresenta uma cobertura protendida para hangares de aviões, também para instalações industriais e complexos desportivos desenvolvidos por Post-Tensioning Institute of Australia Limited, líder mundial no fornecimento de soluções em estruturas de aço em coberturas em grande extensão pós-tensionada.

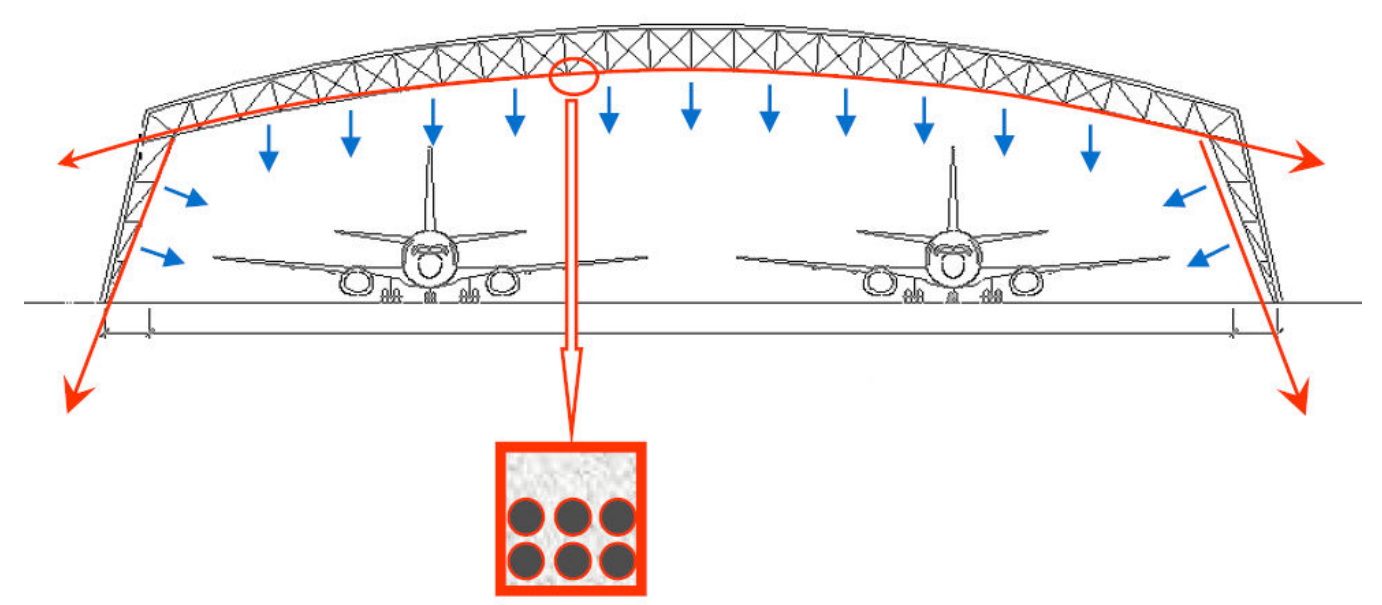

Figura 1.8 Treliça de aço em forma de arco protendida (PTIA, 2007).

(Fonte:<www.s-squared.com.au>. Acesso em: 20 de jul.2014).

Um caso de estudo recente de estruturas de aço protendidas de alta resistência e de grande importância é o caso da reconfiguração do estádio “Olympic Sydney”, em 2003, localizado em Homebush, New South Wales, com vão livre de $114 \mathrm{~m}$ de seções de norte e sul do telhado e área total de cobertura de $7.000 \mathrm{~m}^{2}$ (Figura 1.9). A treliça protendida forneceu uma solução de alto grau de sustentação de carga, com redução de $40 \%$ de peso de aço. 


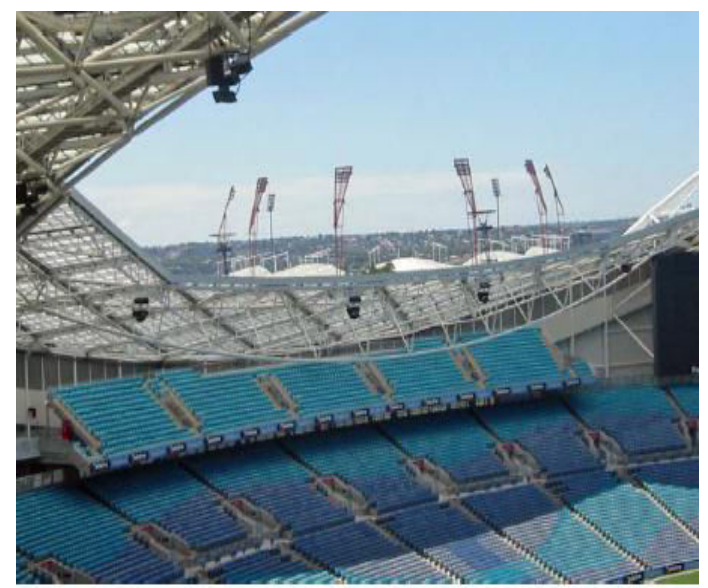

(a) Estruturas da treliça protendida.

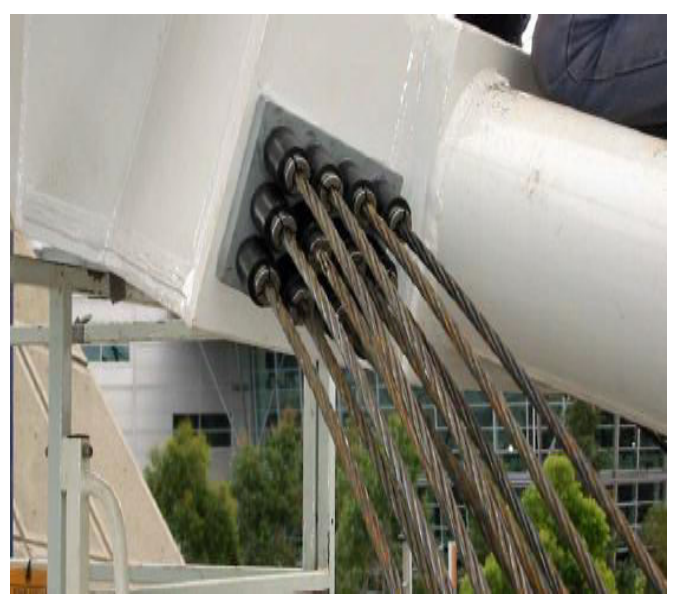

(b) Cabos ancorados na treliça.

Figura 1.9 Reconstrução Estádio Olímpico de Sydney (PTIA, 2007).

O uso da protensão em estruturas de aço tem por finalidade a obtenção de economia de material, ou, em certos casos, atender às imposições arquitetônicas ou construtivas. O seu princípio consiste em criar, em determinadas regiões da estrutura, tensões de sinais opostos às produzidas pelas cargas externas. Isso é obtido pelo emprego de fios de aço de alta resistência que são ancorados na estrutura, de modo que possam ser protendidos e gerassem solicitações em sentidos opostos aos causados pelas cargas externas, em trechos previamente estruturados.

Com isso há um aumento da capacidade resistente da peça, possibilitando a redução das dimensões dos perfis e, como consequência, a redução dos custos das construções. A Figura 1.10 mostra os cabos de aço ancorados em elementos metálicos da estrutura, e a Figura 1.11 a construção do hangar de aeronave de grande vão livre.

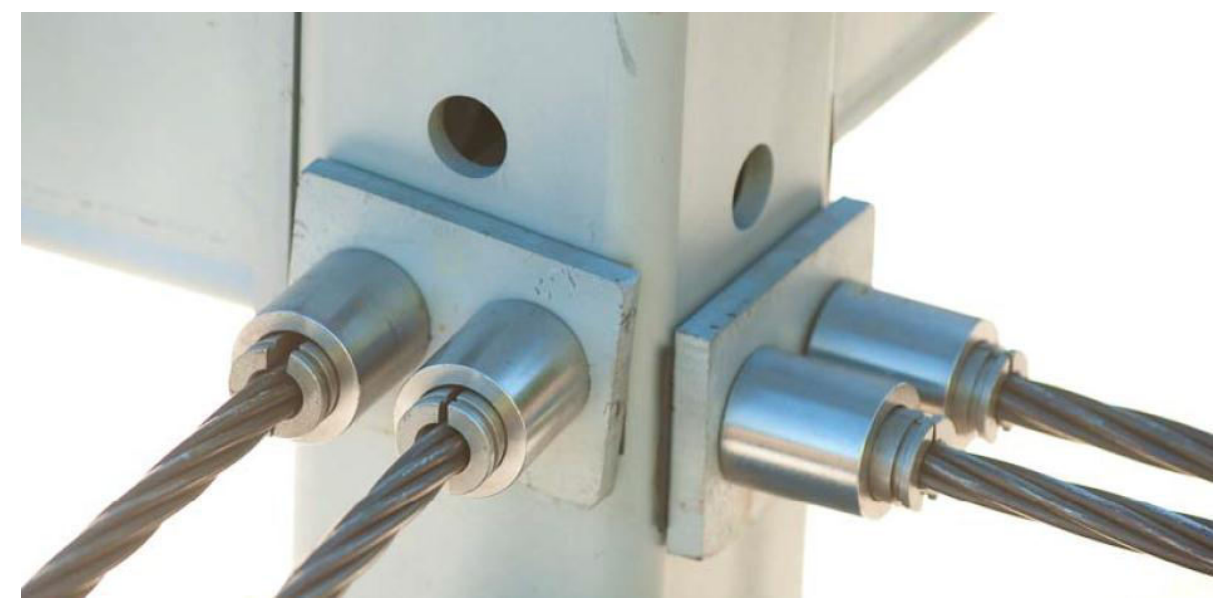

Figura 1.10 Cabos ancorados na estrutura (PTIA, 2007). 


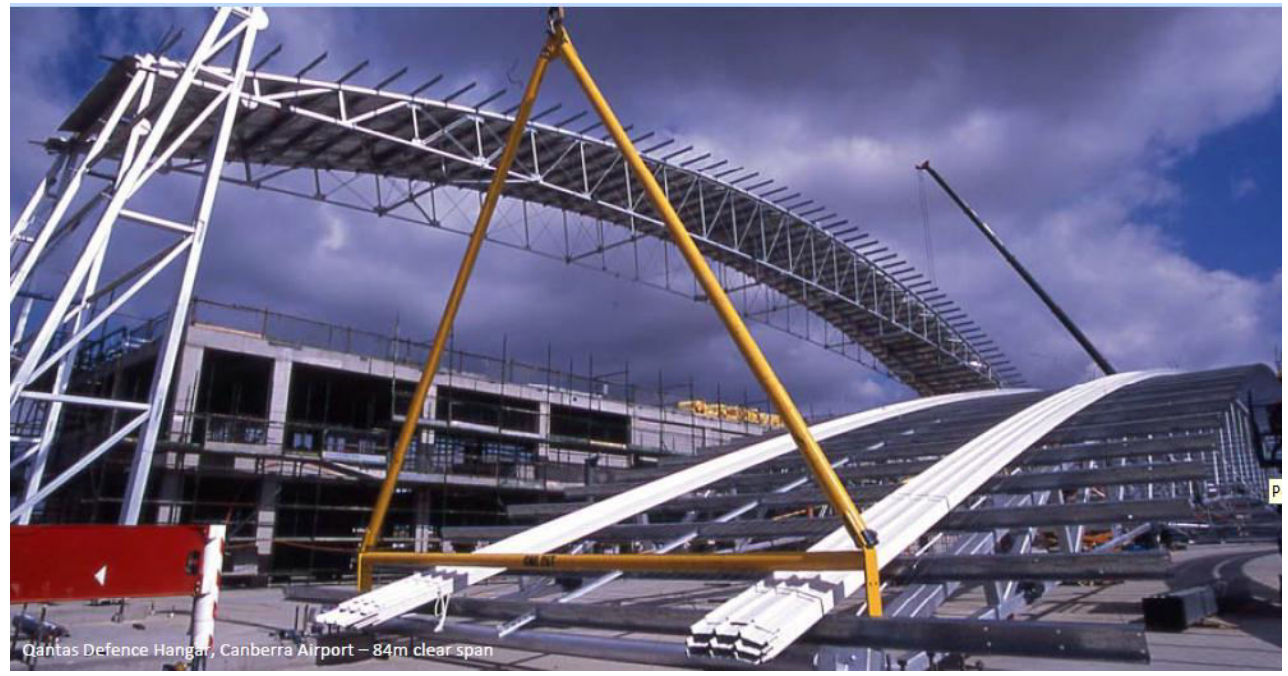

Figura 1.11 Hangar de aeronave (PTIA, 2007).

Entre as vantagens da protensão tem-se a facilidade de inspeção e a manutenção durante e após a protensão. Os cabos são dispostos fora da área física ocupada pela seção transversal da estrutura, o que facilita uma possível substituição quando necessário e previsto em projeto. Entretanto, algumas desvantagens estão relacionadas à exposição dos cabos às influências ambientais e às possíveis vibrações, o que pode ser solucionado com a proteção e a redução do comprimento livre do cabo, respectivamente. As fotos da Figura 1.12 mostram o processo de colocação dos cabos em elementos metálicos da estrutura e cabo tensionado na ancoragem.

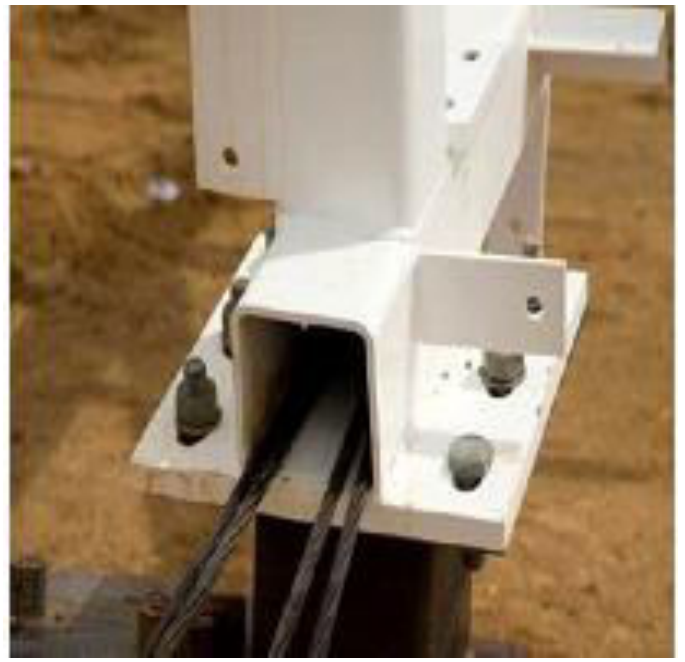

(a) Colocação dos cabos

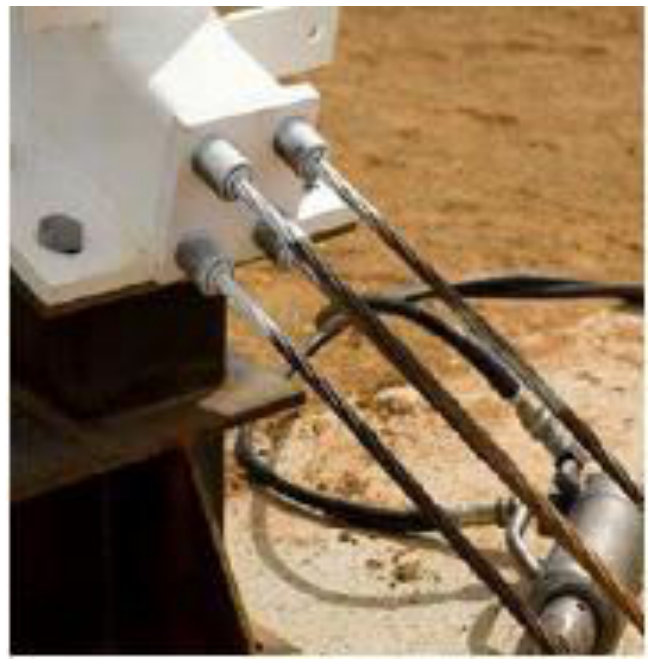

(b) Cabos ancorados

Figura 1.12 Cabos de protensão na estrutura (PTIA, 2007). 
1.2.

\section{Objetivo}

Esta tese tem como objetivo principal desenvolver um estudo acerca da modelagem do comportamento estrutural das treliças de aço em forma de arco, utilizadas no projeto de coberturas protendidas, com base no método dos elementos finitos (MEF), utilizando linguagem APDL do programa ANSYS. O propósito é avaliar o comportamento estrutural dos modelos, através da análise estática linear e não linear física, considerando as treliças até a ruptura.

Como objetivos decorrentes almeja-se determinar o aumento da rigidez e da eficiência do referido sistema estrutural com protensão, comparando-se os resultados dos modelos estruturais para os diferentes vãos desenvolvidos na modelagem.

\section{Como objetivos específicos, pretende-se:}

Desenvolver um estudo sobre as considerações da ação do vento em coberturas curvas, segundo critérios das normas. Posteriormente, efetuar uma análise estática linear com aplicação dos carregamentos de vento ao longo do vão de uma estrutura de $80 \mathrm{~m}$, segundo critério das normas citadas no capítulo 3.

Realizar uma calibração do modelo computacional da treliça de $10 \mathrm{~m}$ de vão, por meio de um estudo de sensibilidade de convergência das malhas empregadas para obter o tamanho ideal do elemento, para apresentar resultados precisos, por meio da avaliação das tensões obtidas com o critério de von Mises e das reações de apoios para os diferentes níveis de discretização.

Avaliar a calibração do nível de força de protensão ideal que foi aplicado nas estruturas, definido como aquele em que tanto os elementos da treliça como o cabo de protensão permanecem no regime elástico. Para simular a aplicação da força de protensão nas estruturas, admite-se uma variação de deformação nos cabos, de modo que esses elementos se deformem, e como consequência é gerada uma força próxima ao valor da força de protensão calculada para cada modelo. 
Realizar, para a fase de construção, um estudo de sensibilidade das espessuras de chapas de ancoragem adequadas para os diferentes modelos das treliças protendidas, com a finalidade de analisar a interface entre a chapa e o cabo nas extremidades com força de protensão.

Efetuar uma análise computacional dos níveis das forças de protensão aplicadas na treliça, com a finalidade de analisar o comportamento da estrutura à medida que a magnitude das tensões na estrutura aumenta.

Realizar uma análise estática linear e não linear com a utilização de perfil tipo W, com o objetivo de investigar a influência das estruturas com a variação para grandes vãos, obtendo as solicitações, tensões e deslocamentos no estado de serviço, e considerando-se as estruturas até a ruptura.

Ressalte-se que durante a fase de pesquisa foi encontrada pouca informação sobre atividade de modelagem numérica da implementação paramétrica e experimental para treliças de coberturas curvas protendidas, verificando-se, entretanto, mais estudos ao se abordar a utilização com perfis tipo W. 


\section{3. \\ Escopo}

A tese é apresentada na sequência dos capítulos a seguir descritos:

Capítulo 1: introdução ao projeto de estruturas de coberturas protendidas. Mostra a relevância e a motivação do presente estudo. São apresentados, também, os objetivos, organização do trabalho e divisões em capítulos.

Capítulo 2: apresenta uma revisão bibliográfica do estudo do comportamento estrutural de treliças de aço em forma de arco, utilizadas no projeto de coberturas protendidas, como: conceitos gerais, o desempenho de aço de protensão, as características dos cabos de aço, a protensão externa, economia em estruturas protendidas, efeitos da protensão sobre o comportamento estrutural de treliças e diversas pesquisas que podem ser encontradas na literatura.

Capítulo 3: nesse item, é apresentada uma revisão sobre a ação do vento em estruturas em coberturas curvas, segundo os critérios das normas Eurocode 1, AS/NZS 1170 e NBR 6123.

Capítulo 4: nesse capitulo é apresentado o modelo estrutural da treliça de aço em forma de arco, sem e com protensão, incluindo-se as características dos materiais, as dimensões, especificações dos perfis, os cabos de protensão, os modelos de carregamentos aplicados e as condições de contorno adotadas.

Capítulo 5: descreve as considerações gerais sobre a modelagem numérica do código comercial ANSYS.R15, utilizando-se linguagem de programação APDL, para os modelos estruturais utilizados.

Capítulo 6: nesse item são apresentados os resultados da análise linear elástica dos modelos numérico-computacionais desenvolvidos empregando-se o programa ANSYS para avaliar o comportamento estrutural com as cargas de serviço.

Capítulo 7: nessa seção apresentam-se os resultados obtidos na análise não linear elástica das treliças, sem e com protensão, que tem como objetivo avaliar o comportamento estrutural dos modelos até a ruptura.

Capítulo 8: trata das considerações finais, conclusões, principais contribuições e sugestões para trabalhos futuros.

\section{Referências bibliográficas.}

Apêndice A. 


\section{2 \\ Revisão bibliográfica}

Neste capítulo apresenta-se uma revisão bibliográfica geral das principais contribuições teóricas e experimentais sobre o desempenho de aço de protensão e os efeitos da protensão em estruturas. São relatadas as características dos cabos de aço, a protensão externa, os desviadores e traçados em treliça, economia em estruturas protendidas, os tipos de cabos, o processo construtivo da protensão. A seguir tem-se as considerações mais significativas sobre o efeito da protensão e sua importância atual.

\section{1 .}

\section{Considerações gerais}

A tecnologia para a aplicação da protensão em estruturas metálicas, de forma que se possa obter ganho econômico, sendo capaz de vencer grandes vãos, resistindo a carregamentos elevados com peso reduzido, menores dimensões de seções transversais e facilidade construtiva, começou a se desenvolver na Europa, mas ainda é considerada uma técnica nova para a maioria dos países. A aplicação da tecnologia da protensão pode ser usada com a finalidade de reforçar e recuperar estruturas metálicas já existentes, como passarelas e, principalmente, pontes metálicas.

Um sistema de protensão em estruturas metálicas, segundo Troitsky (1990), foi utilizado inicialmente em 1837 por Squire Whipple, que aplicou a protensão aos elementos tracionados de treliças em ferro fundido, que formavam o tabuleiro de uma ponte de ferro em forma de arco, com o objetivo de tornar a estrutura mais dúctil. Na cidade de Johnstown, em Nova Iorque, uma réplica dessa ponte foi construída no ano de 1980 pelos estudantes de Engenharia Civil do "Union College Campus", como apresenta a Figura 2.1, em comemoração à contribuição de Whipple para a construção de pontes. 


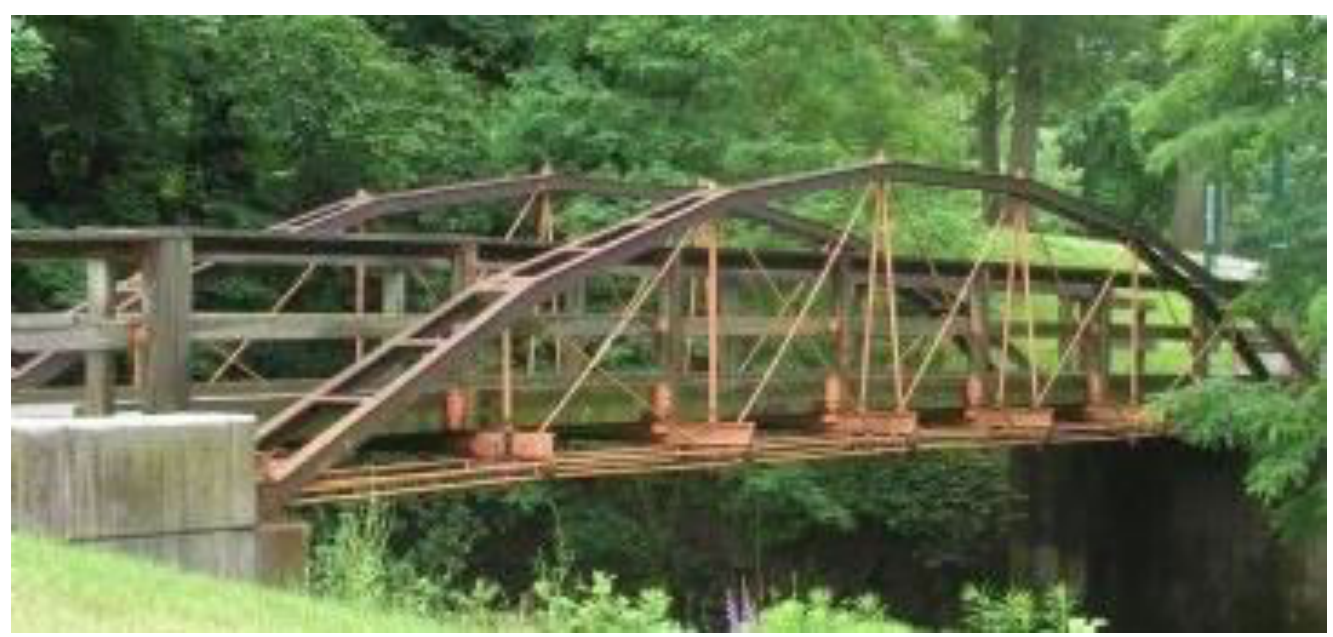

Figura 2.1 Squire Whipple Bridge at UnionCollege.

(Fonte:〈http://www.hmdb.org >.Acesso em: 28 de jul.2014).

Porém, apenas em meados da década de 1930, F. Dischinger na Alemanha e Gustave Magnel na Bélgica, dentre outros na Europa, deram início aos estudos com análises teóricas, ensaios experimentais e construções, utilizando-se a protensão e voltados, principalmente, para a construção de pontes. Somente a partir da década de 1950 surgiram as publicações de artigos técnico-científicos mais expressivos sobre esse tema.

Os primeiros trabalhos técnicos que apresentaram procedimentos para o projeto e o dimensionamento de estruturas metálicas protendidas foram publicados em Moscou, no ano de 1963, e em Praga, no ano de 1969. Na mesma época, em 1968, foi criado pelo ASCE-AASHO um comitê para estudos sobre protensão em estrutura metálica e mista para construções e recuperação de pontes. Com isso o interesse por esse sistema construtivo foi sendo incrementado, dando origem a pesquisas teóricas e experimentais para entender o comportamento estrutural do aço com protensão.

Com o desenvolvimento da construção mista aço-concreto houve uma tendência de estudos sobre a aplicação da protensão em vigas mistas. Os primeiros estudos foram apresentados inicialmente por Dischinger em 1979, originando uma série de trabalhos propondo essa técnica de protensão em pontes formadas por estrutura mista e utilizando-se cabos de alta resistência. 
Logo em seguida Coff, em 1950, e Naillon, em 1961, patentearam separadamente a invenção do método de protensão em sistemas mistos e metálicos, respectivamente. Szilard, em 1959, sugeriu métodos para dimensionamento e análise de protensão em estrutura mista. Reagan, em 1967, analisou os efeitos da variação da espessura da laje, da força de protensão e do tipo de carregamento no comportamento de vigas mistas biapoiadas.

Dentre as pesquisas mais recentes acerca do comportamento de estruturas de aço protendidas (Figura 2.2), destacam-se os seguintes autores, no tema de "vigas metálicas protendidas e aspectos aplicados relacionados à inspeção e recuperação de ponte de aço": Belenya (1977); Troitsky (1990); Brandford (1991); Nunziata (1999); Nunziata (2003); Nunziata (2004); Ronghe e Gupta (2002); e Belletti e Gasperi (2010). No Brasil pode-se citar: Sampaio Júnior (1976); Gonçalves (1992); Ferreira (2007); Rezende (2007).

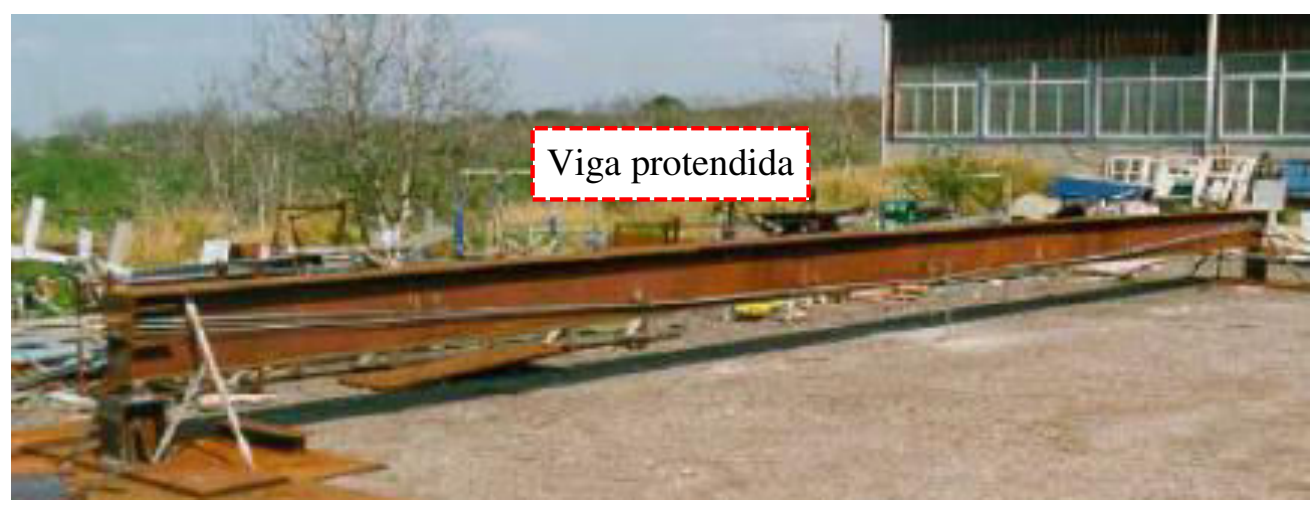

Figura 2.2 Vigas metálicas protendidas (Nunziata, 1999).

O uso de protensão externa como meio de reforçar ou reabilitar pontes existentes e estruturas metálicas tem sido utilizado em muitos países desde a década de 1950, proporcionando uma solução eficiente e econômica para uma vasta gama de tipos e condições de ponte. O uso dessa técnica cresceu por causa da velocidade de instalação e do mínimo de interrupção para o fluxo de tráfego.

As Figuras 2.3 e 2.4 apresentam a Ponte de Condet, na Indonésia. Em 1994 foi necessário reforçar sua estrutura e optou-se por aplicar a protensão externa para reabilitar essa ponte. 


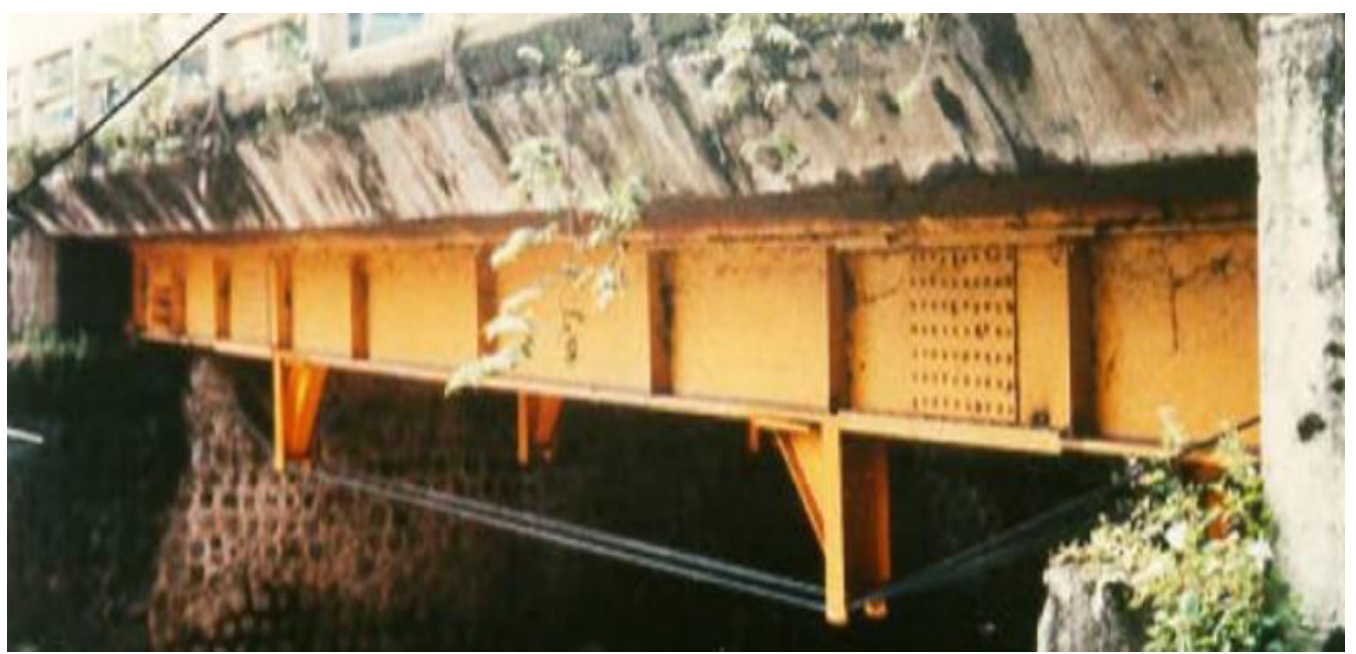

Figura 2.3 Ponte de Condet, Indonésia (Daly e WitarnAwan,2000).

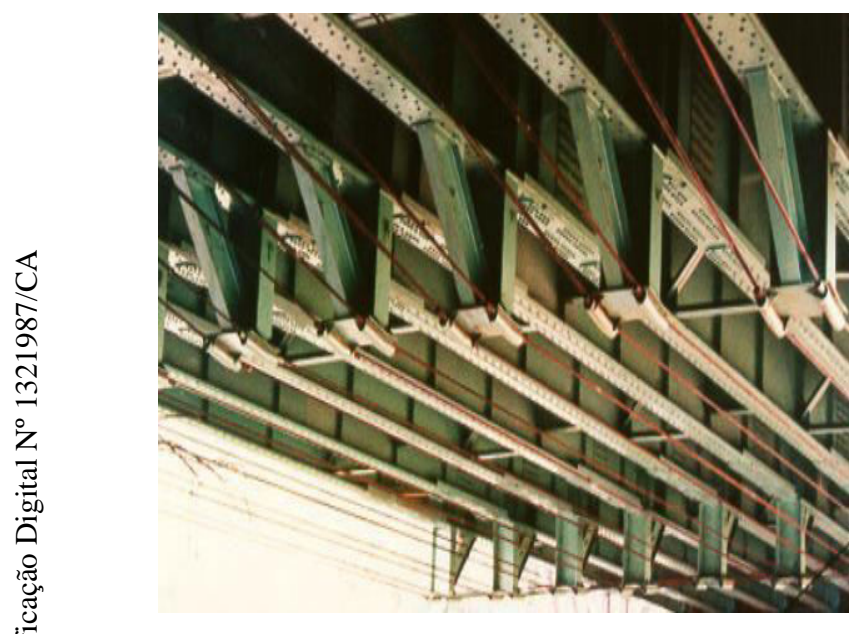

(a)

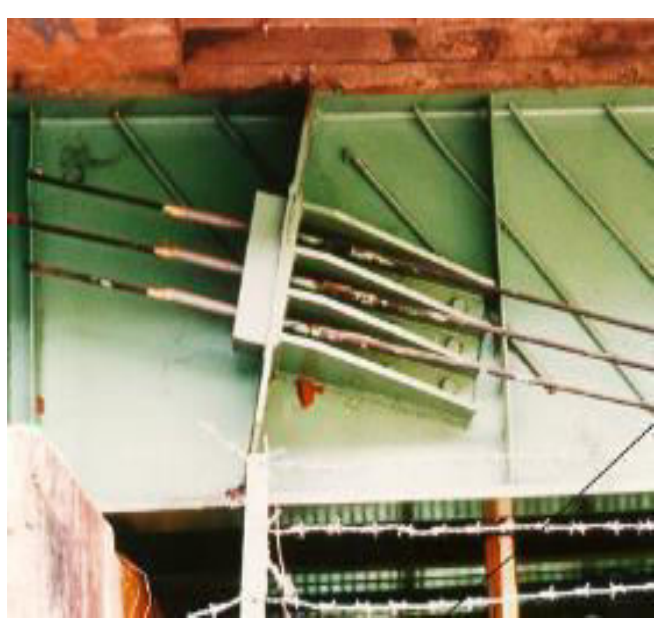

(b)

Figura 2.4 Ponte de Condet, Indonésia: a) cabos de protensão da ponte e b) detalhes de ancoragem (Dalye WitarnAwan, 2000). 


\section{2.}

\section{Desempenho dos elementos de aço protendido}

Historicamente o princípio da protensão foi empregado muito antes da invenção desse termo, e é usado hoje em alguns objetos do cotidiano. As estruturas protendidas mais antigas eram navios de vela egípcios, construídos em 2700 a.C, que foram solicitados por um sistema de cabos de arame e uma corda principal ao longo do navio e um número de cordas na direção transversal. Os barris e as rodas de madeira são ambos protendidos por anéis de ferro. Materiais como o ferro fundido, que têm resistência à compressão, mas baixa resistência à tração, requerem compressão prévia para torná-los mais efetivos.

Para sistemas estruturais com grandes vão, na quais cargas externas e o próprio peso se tornam uma componente cada vez mais dominante do carregamento, economias significativas de material podem ser alcançadas com o uso de cabos de aço de alta resistência em conjunto com aço convencional. Benefícios adicionais podem ser obtidos por protensão dos cabos, induzindo forças internas na estrutura que podem contrariar as aplicadas por cargas externas e controlar as flechas devidas ao peso próprio.

$\mathrm{Na}$ engenharia estrutural a técnica de protensão é comumente aplicada em estruturas de concreto, devido à fraqueza inerente do material sob tensão de tração. A baixa resistência à tração de concreto gera acréscimo de fissuras nos primeiros estágios de carregamento. Na Figura 2.5 observa-se uma viga simplesmente apoiada de concreto protendido.

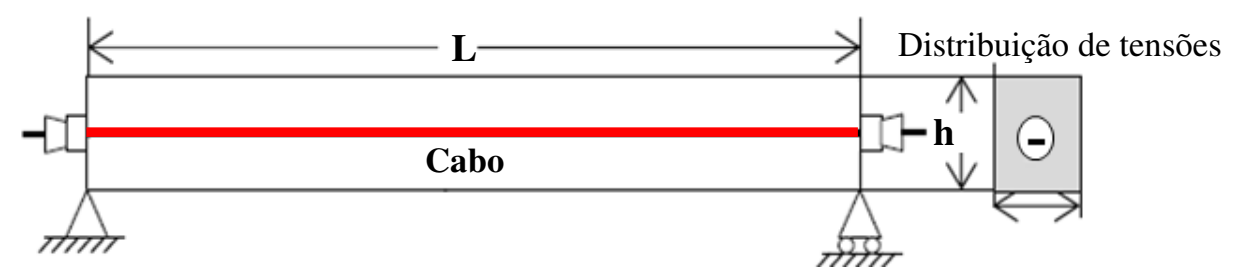

(a) Aplicação de força de protensão inicial.
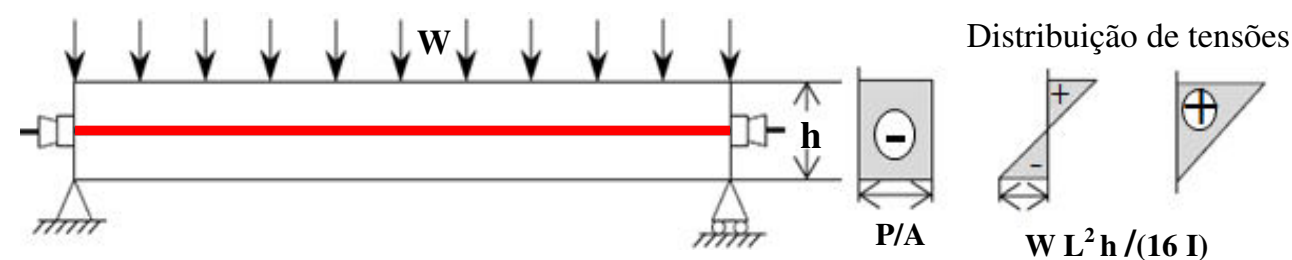

(b) Aplicações da carga uniformemente distribuída e a força protensão

Figura 2.5 Viga de concreto protendido com distribuição de tensões. 


\subsection{1.}

\section{Barra axialmente protendida}

Neste item são apresentados os principais aspectos comportamentais do elemento de aço protendido, incluindo-se sua resposta a protensão e sob a aplicação subsequente da força de tração e o nível de protensão.

A protensão é a introdução de tensões, exatamente definidas nas seções transversais dos membros para aumentar a resistência da estrutura, que são opostas às cargas externas aplicadas. Esse método pode usar o material de forma mais econômica. Além disso, a força de protensão em elementos de aço na tensão resulta em compressão, o que fornece a estrutura maior capacidade resistente.

Em estruturas de aço protendido ou seus elementos estruturais, o efeito da protensão induz um estado de tensões que, em geral, é de sinal oposto às tensões devido as ações aplicadas. Exemplos isolados da aplicação de estruturas de aço protendido foram encontrados no século passado, mas apenas durante a última década esse método de aumentar a efetividade das estruturas teve ampla aplicação.

Durante a fase de protensão do sistema de um cabo de aço em perfil tubular de aço aplica-se uma força de tração $P$ no cabo e uma força de compressão de igual magnitude é induzida na barra de aço, como apresenta a Figura 2.6. Quando o processo de protensão é concluído o cabo e o perfil são bloqueados na posição em que ambos terminam, de modo que não há movimento relativo entre os dois componentes, como mostrado na Figura 2.6.c., onde:

$\mathbf{L}_{\mathbf{0}}$ : comprimento inicial do cabo e do tubo;

$\mathbf{X}_{\mathbf{c}}$ : alargamento do cabo;

$\mathbf{X}_{\mathbf{t}}$ : encurtamento do tubo. 


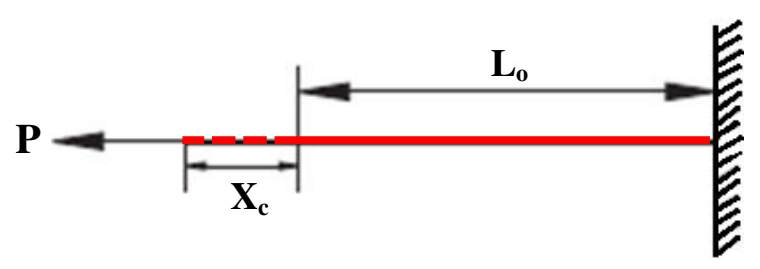

(a) Força do cabo durante a protensão.

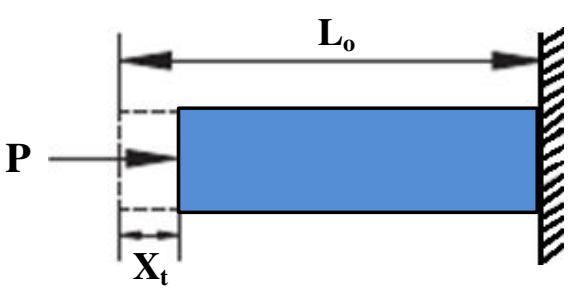

(b) Diagrama de força do tubo durante a protensão.

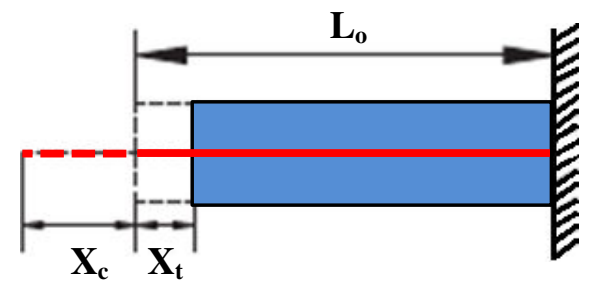

(c) Tubo e cabo travados em posição após a protensão.

Figura 2.6 Esquema do processo de protensão em perfil de aço durante a protensão.

Uma vez que a força de protensão $P$, da mesma magnitude, mas de sentido oposto, é aplicada para o cabo e o perfil, o elemento protendido é autoequilibrado. Portanto, desde que não haja deslocamentos fora do plano (isto é, nenhuma flambagem) as forças são induzidas durante a condição de equilíbrio para o sistema, assim:

$$
\mathrm{P}_{\text {cabo }}-\mathrm{P}_{\text {perfil }}=\mathrm{K}_{\mathrm{c}} \mathrm{X}_{\mathrm{c}}-\mathrm{K}_{\mathrm{t}} \mathrm{X}_{\mathrm{t}}
$$

onde

$\mathbf{K}_{\mathbf{c}}, \mathbf{K}_{\mathbf{t}}$ : representam a rigidez axial do cabo e de perfil, respectivamente, que são dadas pelas seguintes expressões

$$
\mathrm{K}_{\mathrm{c}}=\frac{\mathrm{E}_{\mathrm{c}} \times \mathrm{A}_{\mathrm{c}}}{\mathrm{L}_{0}} \quad \text { e } \quad \mathrm{K}_{\mathrm{t}}=\frac{\mathrm{E}_{\mathrm{t}} \times \mathrm{A}_{\mathrm{t}}}{\mathrm{L}_{0}} ;
$$

onde

$\mathbf{E}_{\mathbf{c}}, \mathbf{E}_{\mathbf{t}}$ : são os módulos de elasticidade do cabo e do perfil, com $\mathrm{A}_{\mathrm{c}}$ e $\mathrm{A}_{\mathrm{t}}$ sendo as áreas de seção transversal do cabo e do perfil, respectivamente. 
No comportamento do sistema protendido do perfil tem-se três casos: (1) O tubo plastifica antes do cabo; (2) O cabo plastifica antes do tubo; (3) Plastificação simultânea dos dois elementos. A seguir são exemplificados os três casos:

\section{Caso 1: Plastificação do tubo antes do cabo}

Para o caso 1 ocorrem três etapas do comportamento da plastificação do sistema, ilustradas na Figura 2.7. O nível de protensão aplicado determina se o tubo plastifica antes do cabo ou ao contrário. Se a barra plastifica antes do cabo, tem-se:

$$
\frac{f_{c y}}{E_{c}}-\frac{P}{A_{C} E_{c}}>\frac{f_{t y}}{E_{t}}+\frac{P}{A_{t} E_{t}}
$$

onde $\mathbf{f}_{\text {cy }}$ e $\mathbf{f}_{\text {ty }}$ são as tensões de escoamentos do cabo e do tubo, respectivamente.

Etapa: 1

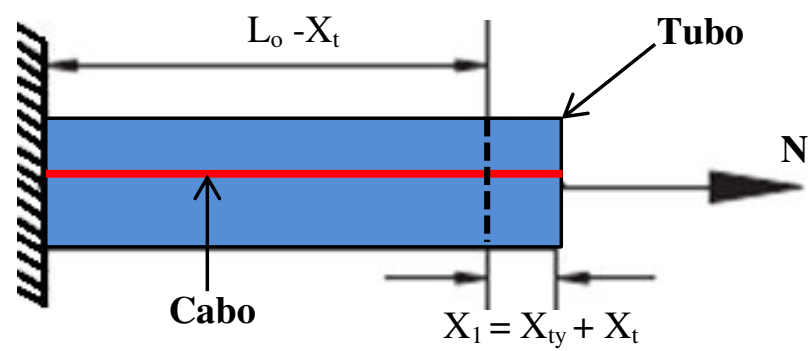

(a) Início de carregamento até a plastificação do tubo inicialmente em compressão e o cabo em tensão, ambos de magnitude $\mathrm{P}$, é submetido a um carregamento $\mathrm{N}$.

Etapa: 2

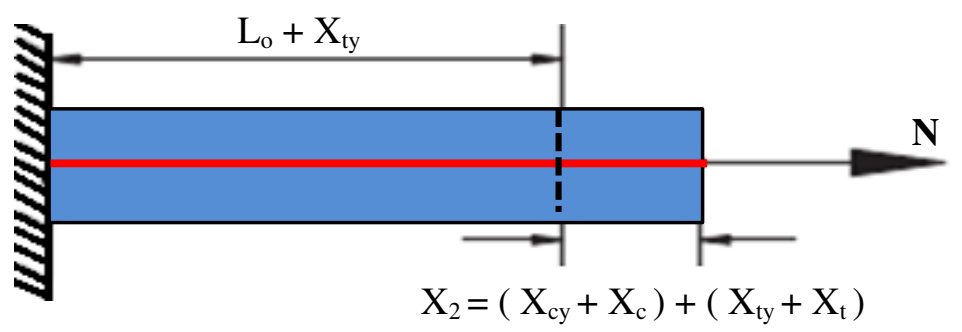

(b) O tubo plastifica e o cabo continua armazenando energia de deformação elástica à tração.

Etapa: 3

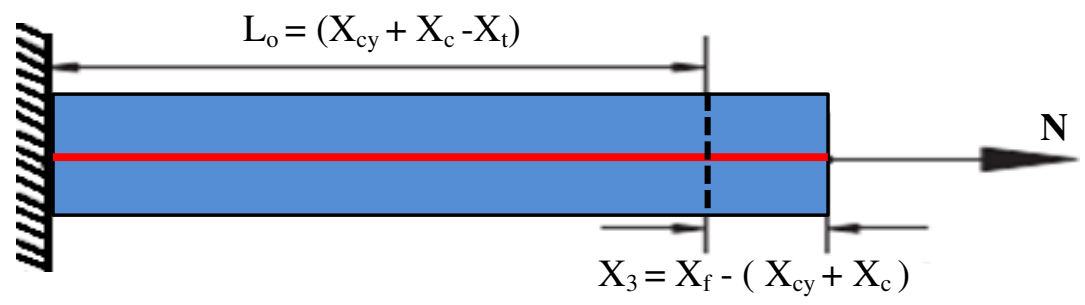

(c) Continua até a fratura do tubo ou, mais provavelmente, fratura do cabo em um deslocamento relativo ao estado do sistema no final do protendido.

Figura 2.7 Deslocamento em cada estágio em relação à deformação do tubo para caso 1. 


\section{Caso 2: Plastificação do cabo antes do tubo}

Para este caso ocorrem três fases de plastificação do sistema ilustrado na Figura 2.8. As expressões da fase (a) são as mesmas do caso 1, pois o tubo e o cabo são elásticos (Fase a) ou plásticos (Fase c), assim:

$$
\frac{f_{c y}}{E_{c}}-\frac{P}{A_{C} E_{c}}<\frac{f_{t y}}{E_{t}}+\frac{P}{A_{t} E_{t}}
$$

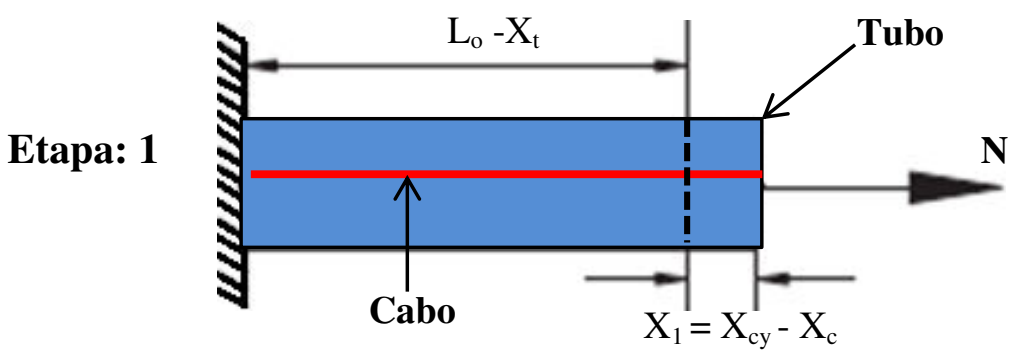

(a) Início de carregamento até a plastificação do cabo inicialmente em tensão e tubo a compressão, ambos de magnitude $\mathrm{P}$, é submetido a um carregamento $\mathrm{N}$.

(b)

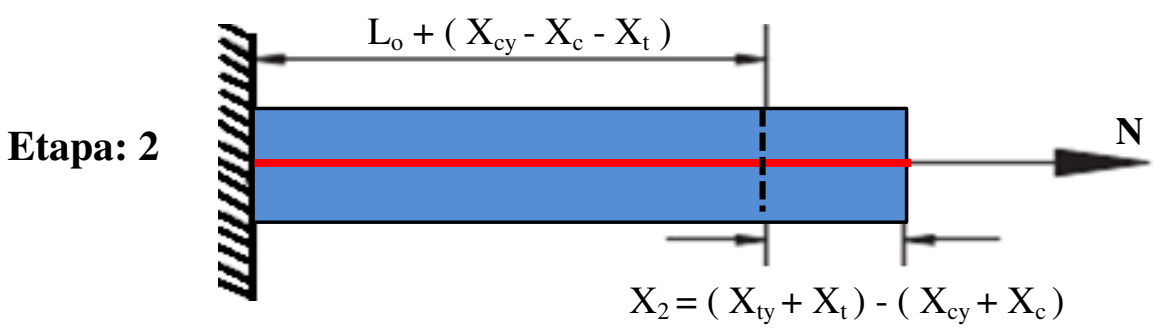

(b) O cabo cedeu e o tubo continua armazenando energia de deformação elástica.

Etapa: 3

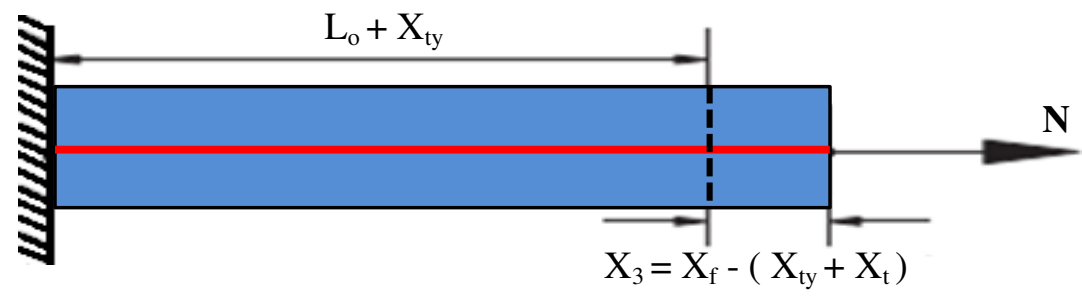

c) Continua até a fratura do cabo ou, mais provavelmente, fratura do tubo em um deslocamento relativo ao estado do sistema no final do protendido.

Figura 2.8 Deslocamento em cada estágio em relação à deformação do tubo para caso 2. 


\section{Caso 3: Plastificando-se simultaneamente ambos os elementos}

Para o caso 3 o nível de protensão ideal, $\mathrm{P}_{\mathrm{opt}, \mathrm{c}}$, sob carga de tração pode ser definido como aquele nível que causa a plastificação simultânea do cabo e do perfil, uma vez que isso proporciona a resposta mais rígida. O nível de protensão ideal sob a carga de tração aplicada, $\mathrm{P}_{\text {opt,c }}$ pode ser calculado ao igualar-se as expressões para a tensão necessária para produzir a plastificação tanto do cabo como para o perfil, como mostrado abaixo:

$$
\frac{f_{c y}}{E_{c}}-\frac{P_{o p t, c}}{A_{C} E_{c}}=\frac{f_{t y}}{E_{t}}+\frac{P_{o p t, c}}{A_{t} E_{t}}
$$

Isolando-se o termo $\mathrm{P}_{\text {opt,c }}$ :

$$
P_{o p t, c}=\frac{A_{c} A_{t}}{A_{t} E_{t}+A_{c} E_{c}}\left(f_{c y} E_{t}-f_{t y} E_{c}\right)
$$

Sistemas de cabo em tubo, no qual os cabos estão colocados dentro de seções estruturais (cavidades), oferecendo vantagens, como garantindo a estabilidade do tubo sob as forças de protensão devido à ação estabilizadora do cabo tensionado. Exemplos de aplicações recentes de sistemas de cabo em tubo protendido incluem a reconfiguração do estádio olímpico de Sydney e do hangar Five Star Aviation em Brisbane Airport, ambos na Austrália (Ellen et al., 2012).

\section{3.}

\section{Cabos de aço de protensão}

$\mathrm{Na}$ literatura os elementos usados para protensão geralmente são cordoalhas e barras de aço (Troitsky, 1990; Belenya, 1977). Podem ser colocados internos ou externos em sistema da treliça (Ayyub et al, 1990).

Para os cabos de protensão das estruturas protendidas, utilizam-se usualmente cordoalhas de 3 a 15,3 mm de diâmetro que são fios trefilados de mesmo diâmetro nominal agrupados em espiral para formar uma corda (fios trefilados, enrolado em forma de hélice, de dois, três ou sete fios). 
A corda em espiral tem um fio de núcleo redondo central, e seis fios são enrolados helicoidalmente com passo e direção idênticos (Figura 2.9). Quando são tensionados os fios na corda se apoiam um no outro causando compressão lateral, e consequentemente a inclinação dos fios constituintes com o eixo da corda reduz a resistência à tração da corda em 15-25\% em comparação com fios simples.

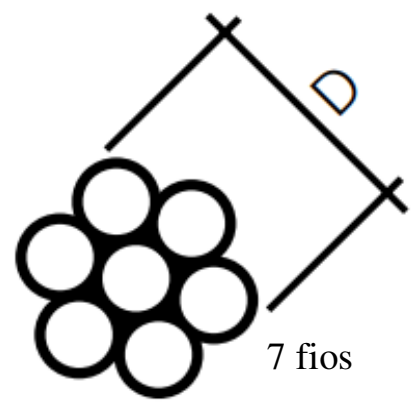

(a)

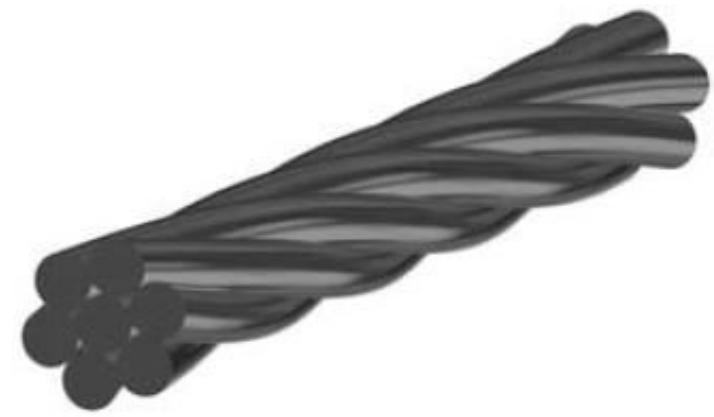

(b)

Figura 2.9 Cordoalhas em forma de espiral: (a) grupo de fios para formar uma cordoalha de 7 fios; (b) fios para formar cordoalhas em forma de hélice.

Ressalta-se que a composição química máxima dos principais componentes dos cabos de aço para protensão é de 0,70 a 1,20 \% de carbono, maior do que perfil de aço A572 de grau 50 (0,23\% de carbono), portanto, os cabos têm uma tensão limite de escoamento maior.

Os cabos de aço na estrutura protendida caracterizam-se por sua alta resistência e são classificados em aços de relaxação normal, denominados por $\mathbf{R N}$, e aços de relaxação baixa, denominados por RB. Os RN consistem em aços retificados por um tratamento térmico que melhora as tensões internas de trefilação e permite uma menor perda devido à relaxação; os RB recebem um tratamento termomecânico que reduz a perda por relaxação e que consiste em aquecimento a $400^{\circ} \mathrm{C}$ e tração até a deformação unitária de $1 \%$. As cordoalhas devem receber a designação conforme NBR 7482 [4].

As tensões nas armaduras de protensão são limitadas a certos valores máximos, a fim de se reduzir o risco de ruptura dos cabos e também de evitar perdas exageradas por relaxação do aço. De acordo com o item 9.6.1.2.1 da NBR 6118 [1], são especificados os seguintes valores-limites de tensão inicial para armadura protendida. 


$$
\mathrm{RN} \leq\left[\begin{array}{c}
0,77 \mathrm{f}_{\mathrm{ptk}} \\
\text { ou } \\
0,90 \mathrm{f}_{\mathrm{pyk}}
\end{array}\right] \quad \text { e } \quad \mathrm{RB} \leq\left[\begin{array}{c}
0,77 \mathrm{f}_{\mathrm{ptk}} \\
\text { ou } \\
0,85 \mathrm{f}_{\mathrm{pyk}}
\end{array}\right]
$$

onde

$\mathrm{f}_{\mathrm{ptk}}$ : resistência à tração do aço de armadura ativa;

$\mathrm{f}_{\mathrm{pyk}}$ : resistência ao escoamento do aço de armadura ativa.

Também utiliza-se para protensão as barras de aços-liga, de alta resistência, com diâmetro superior a $12 \mathrm{~mm}$. As Figuras 2.10 e 2.11 mostram esquemas do cabo de aço e barra de aço com os componentes de ancoragem para a protensão.

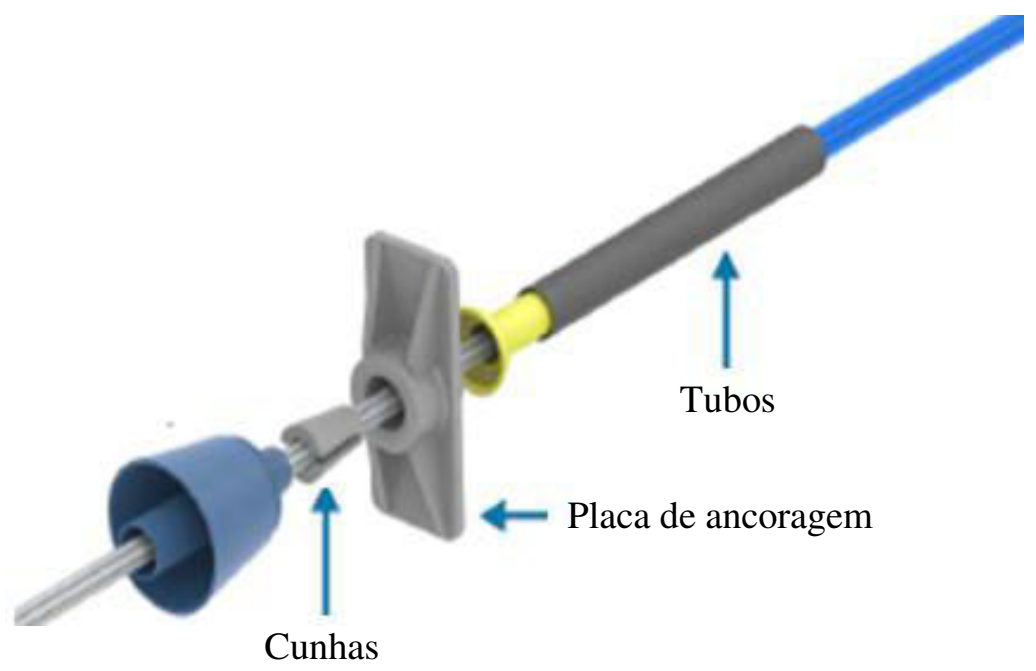

Figura 2.10 componentes para ancoragem.

(Fonte: http://impactoprotensao.com.br> acesso em 4 de jul.2014).

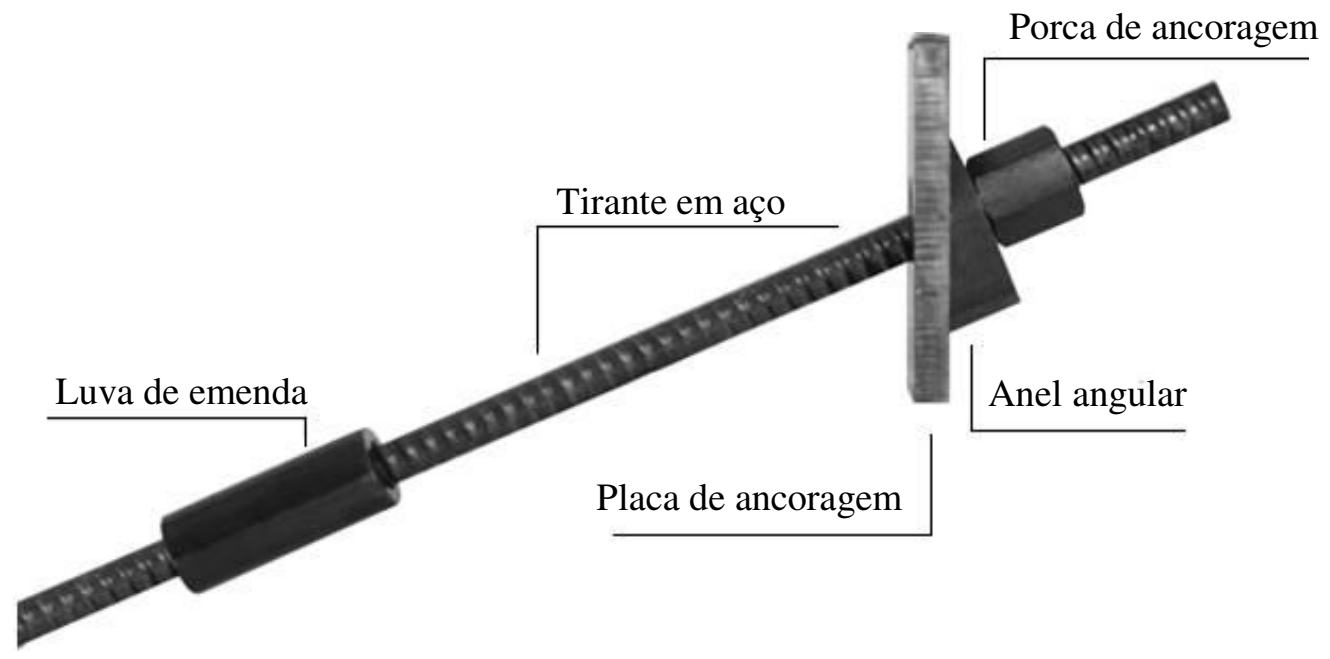

Figura 2.11 Barra de aço de alta resistência.

(Fonte: http://awacomercial.com.br/> Acesso em: 22 de jul.2014). 


\section{4 .}

\section{Protensão externa}

A protensão externa pode ser utilizada para diversos tipos de materiais, como concreto, aço ou estruturas mistas. No caso de estruturas metálicas protendidas é importante o domínio dessa técnica de protensão para que se possa projetar as peças e entender o seu comportamento estrutural. De acordo com REIS (2003) alguns aspectos técnicos caracterizam a protensão externa em viga protendidas:

(a) os cabos de protensão são colocados fora da área física ocupada pela seção transversal da estrutura;

(b) a força de protensão é transmitida à estrutura apenas pelos pontos de ancoragem e pelos desviadores (Figura 2.12). Dessa forma, esses dispositivos ficam solicitados por forças bastante elevadas, e precisam ser projetados, detalhados e executados de forma adequada para evitar danos na estrutura. Os desviadores são utilizados para manter o traçado desejado do cabo, podendo ser constituídos por chapas ou pinos soldados no perfil metálico;

(c) aderência entre o cabo de protensão e a estrutura dá-se apenas nos pontos de ancoragem (Figura 2.13) e de desvio dos cabos, onde ocorre o atrito criado pela necessidade de fixação do cabo ou devido ao contato do cabo com o desviador;

(d) os desviadores devem ser posicionados com alto grau de precisão para reduzir o atrito e evitar danos ao aço de protensão.

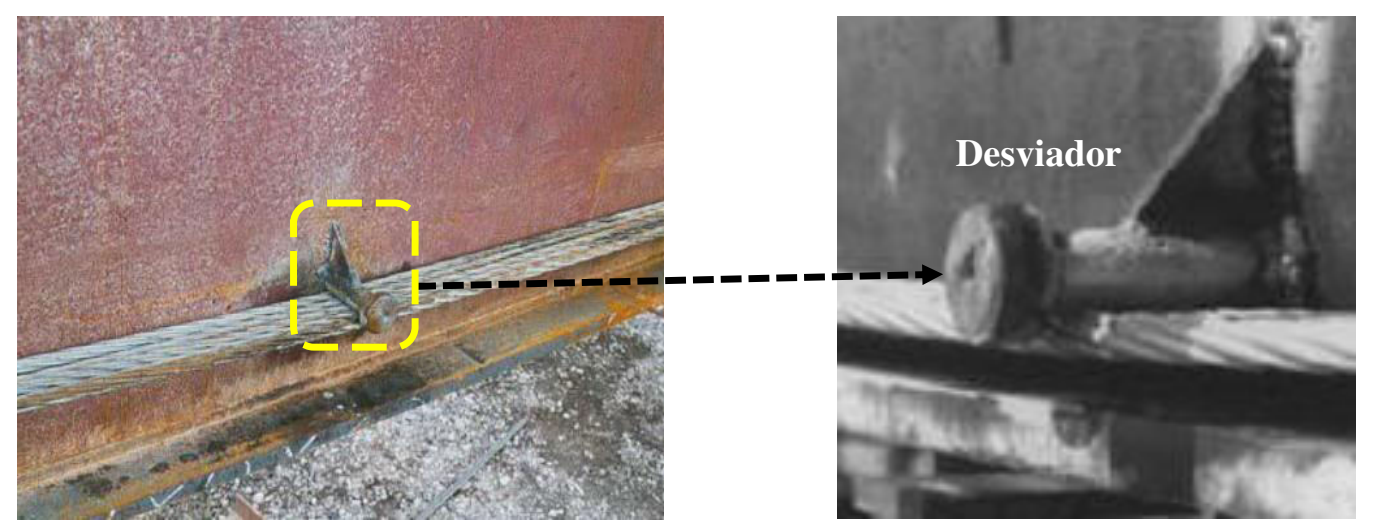

Figura 2.12 Detalhe de desviador (Nunziata, 1999). 


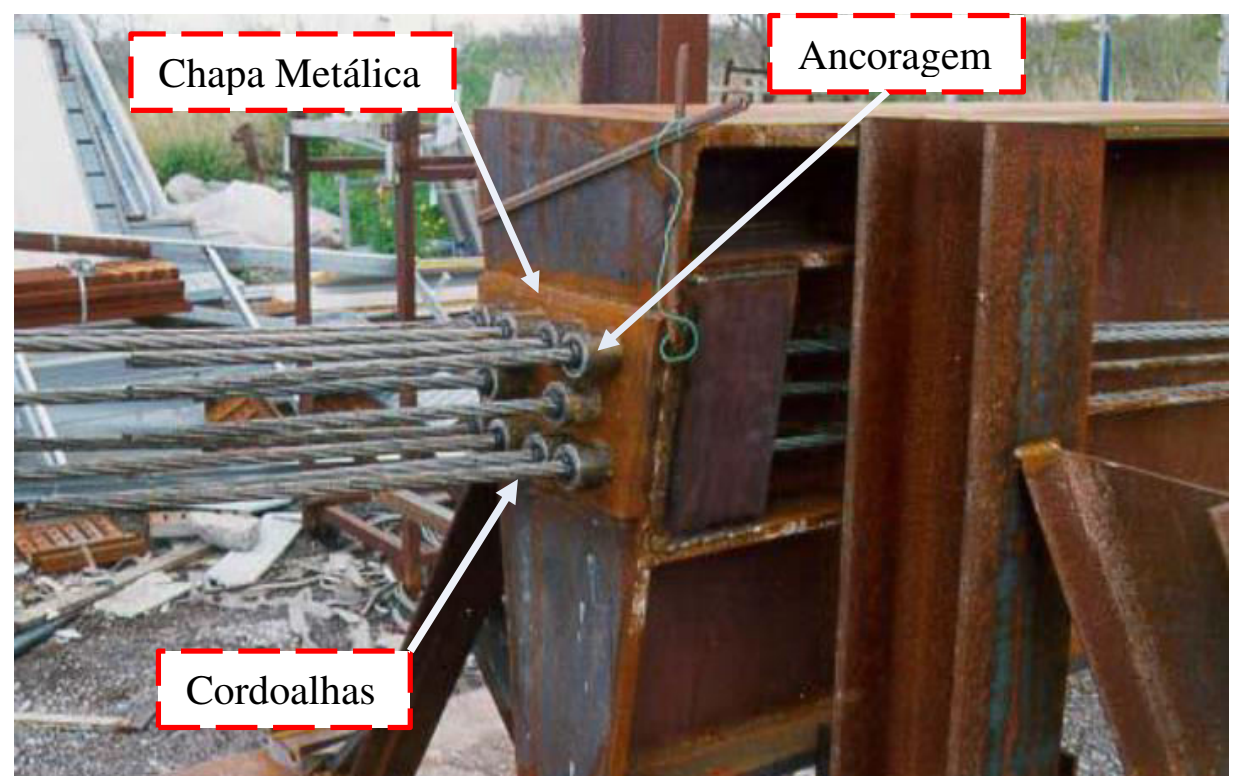

Figura 2.13 Ancoragens de uma viga metálica protendida (Nunziata, 1999)

\section{5.}

\section{Economia de estruturas protendidas}

A aplicação da protensão às estruturas de aço permite reduzir a quantidade de aço e o custo. Ao usar cabos de aço de alta resistência, podemos obter os seguintes benefícios: a utilização de aço convencional para os membros estruturais aumenta os limites da deformação elástica sob cargas maiores, de modo que a quantidade de aço é reduzida e os cabos participam no carregamento. Para simplificar a análise técnico-econômica de estruturas de aço protendida, tem-se:

$$
\mathrm{Q}=\gamma 1 \frac{\mathrm{P}_{\mathrm{x}}}{\sigma_{\text {all }}}
$$

onde

Q: massa do aço em kg;

$\gamma$ : peso específico do aço em $\mathrm{kg} / \mathrm{cm}^{3}$;

l: comprimento do membro protendido em $\mathrm{cm}$;

$\mathbf{P}_{\mathbf{x}}$ : força de protensão em kgf;

$\boldsymbol{\sigma}_{\text {all: }}$ tensão admissível em $\mathrm{kgf} / \mathrm{cm}^{2}$. 
Sob a suposição de que a quantidade de aço está na proporção inversa das tensões admissíveis, esta expressão é válida somente quando o membro está sendo protendido. Portanto, a equação sob essa forma não pode ser aplicada a toda a estrutura. Os seguintes fatores influenciam o custo final de uma estrutura de aço protendida:

(a) o peso da estrutura, macaco, ancoragem e cabos;

(b) custo de fabricação da estrutura na fábrica;

(c) transporte e custo de carregamento;

(d) custo de montagem, incluindo a protensão;

(e) custo da proteção contra corrosão.

A economia de aço aumenta à medida que aumenta a diferença entre as tensões admissíveis do aço utilizado para as estruturas e o aço de alta resistência para os cabos. Quando os elementos são protendidos a capacidade de carga se torna duas vezes maior para eles.

Se a estrutura for protendida em várias fases, sob as cargas correspondentes, ela deve aumentar a capacidade de carga dos membros tensionados de três a cinco vezes, e as forças das seções transversais principais serão transferidas para os cabos. (Troitsky,1990). As estruturas protendidas foram provadas ser mais econômicas que as estruturas não protendidas em termos de economia de aço, de uso e tempo, conforme dados da Tabela 2.1.

Tabela 2.1 Vantagens econômicas das estruturas protendidas (Troitsky, 1990).

\begin{tabular}{lcc}
\hline \multicolumn{1}{c}{ Estruturas } & $\begin{array}{c}\text { Economia em } \\
\text { aço \% }\end{array}$ & $\begin{array}{c}\text { Economia em } \\
\text { custo \% }\end{array}$ \\
\hline Vigas de alma cheia & $10-12$ & $8-12$ \\
Treliça de 30 m de vãos & $5-10$ & $2-5$ \\
Treliça de coberturas de 30-40 m de vãos & $10-20$ & $5-10$ \\
Treliça de coberturas de 40-60 m de vãos & $10-45$ & $7-20$ \\
Estruturas em arcos de 30-40 m & $20-50$ & $10-30$ \\
\hline
\end{tabular}




\section{6.}

\section{Treliça de aço protendida}

Considerando-se as diversas pesquisas que podem ser encontradas na literatura sobre treliças de aço protendidas, são descritos a seguir alguns trabalhos mais significativos sobre o efeito da protensão.

Magnel (1954) conduziu o primeiro estudo experimental em vigas treliçadas de aço protendido. A treliça foi executada em aço com seções tubulares circulares para os elementos verticais que conectam as cordas superior e inferior, enquanto perfis de chapa dobrada foram usadas para os outros elementos estruturais. Toda a estrutura é aparafusada. A Figura 2.14 mostra o sistema de aplicação da carga e a protensão na treliça.

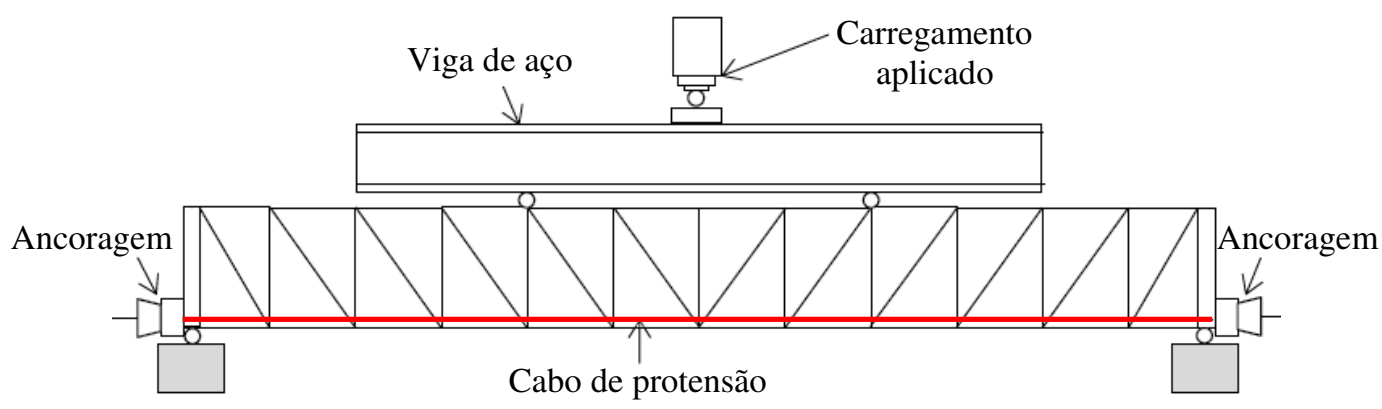

Figura 2.14 Configuração experimental treliça protendida na corda inferior (Magnel, 1950).

Os resultados mostraram que após aplicação da protensão foi gerada uma tensão insignificante em elementos que não são da corda inferior. No entanto, a falha prematura ocorreu devido à flambagem do elemento de corda superior entre a conexão dos membros verticais perto da região central devido ao uso de perfis de chapa dobrada para todos os elementos das cordas.

O uso de aço de alta resistência para protensão é eficaz e econômico, já que a força dos cabos de aço é de quatro a seis vezes maior do que o aço comum, embora o custo seja apenas duas a três vezes maior (Troitsky, 1990). Venkateswara e Prabhakar (1990) apresentaram uma comparação do projeto de treliça protendida com uma treliça convencional. A partir de seu projeto mostraram que a economia é considerável pela protensão aplicada nos membros da treliça. 
O trabalho de Ravindra e Nagaraja (2013), tinha como objetivo principal conhecer o efeito da protensão da corda inferior de uma treliça do tipo Pratt. Os detalhes geométricos e da carga aplicada a treliça são mostrados na Figura 2.15 e a Figura 2.16 mostra a treliça protendida com o desenho do cabo localizado na corda inferior entre $\mathrm{L}_{0}$ e $\mathrm{L}_{8}$.

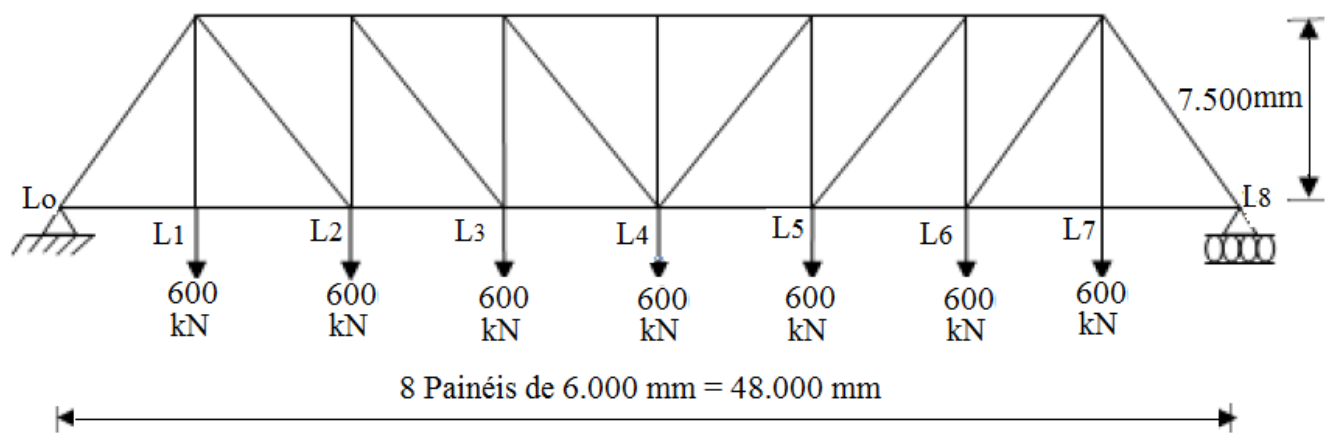

Figura 2.15 Treliça com carregamento e sem protensão.

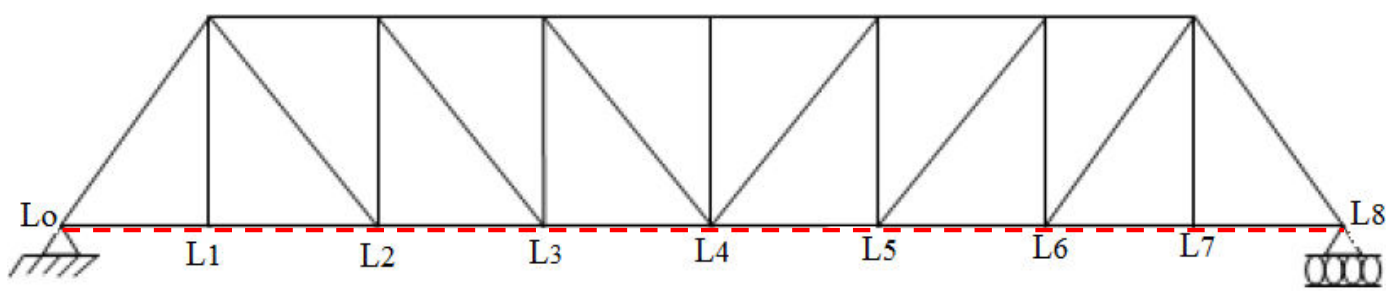

Figura 2.16 Treliça protendida ao longo da corda inferior.

A seção transversal do cabo é de $600 \mathrm{~mm}^{2}$ com tensão de protensão inicial 1.120 MPa e com força de protensão de $672 \mathrm{kN}$, os módulos de elasticidade para os membros de cabo e treliça são de $160.000 \mathrm{MPa}$ e $200.000 \mathrm{MPa}$ respectivamente. Os resultados das forças em todos os membros da corda inferior foram significativamente reduzidos após a protensão.

Nas cordas $\mathrm{L}_{\mathrm{O}}-\mathrm{L}_{1} ; \mathrm{L}_{1}-\mathrm{L}_{2}$ passou de $1.680 \mathrm{KN}$ para $802,7 \mathrm{kN}$, uma diferença de $52,2 \%$. Na corda $\mathrm{L}_{2}-\mathrm{L}_{3}$ apresenta-se uma redução de $2.880 \mathrm{kN}$ para $2.002,7 \mathrm{kN}$, uma diferença de $30,46 \%$. Para $\mathrm{L}_{3}-\mathrm{L}_{4}$ foi de $3.600 \mathrm{kN}$ reduzido para $2.722,7 \mathrm{kN}$, uma redução porcentual de $24,37 \%$. Conclui-se também que as forças nos membros que estão mais próximos das extremidades dos cabos sofreram maior redução que aqueles que estão distantes das extremidades do cabo. 
Mohamed et al.,(2017), apresentaram artigo que estuda o efeito dos cabos de protensão no reforço de diferentes sistemas de aplicação de treliças de aço para determinar a técnica de localização adequada de cabos de protensão para cada sistema de treliça. A análise e os resultados são obtidos usando-se o programa ANSYS. Foi utilizado o elemento Link (8) para os membros de treliça e o elemento tipo Beam (4) para modelar o cabo protensão. Observa-se que os elementos são usados para rigidez axial, ignorando a rigidez a flexão.

As dimensões da treliça são de $11.582,4 \mathrm{~mm}$ de altura e oito painéis de 8.229,6 mm de comprimento cada um. Foi aplicado o carregamento em três pontos com valor da carga permanente de $450 \mathrm{kN}$ e carga variável de $900 \mathrm{kN}$, como mostra a Figura 2.17 (a).

Nas primeiras três técnicas de posicionamento do cabo a seção transversal do cabo é de $548 \mathrm{~mm}^{2}$ com tensão inicial $1.674 \mathrm{MPa}$ e com força de protensão de $927 \mathrm{kN}$, e na quarta técnica, a área da seção transversal é de $361 \mathrm{~mm}^{2}$ com tensão inicial de 1.266,4 MPa, com força de $457 \mathrm{KN}$. Os detalhes dos traçados dos cabos de protensão na treliça que foram usados na análise são mostrados da Figura 2.17 (b) até a Figura 2.17 (e).

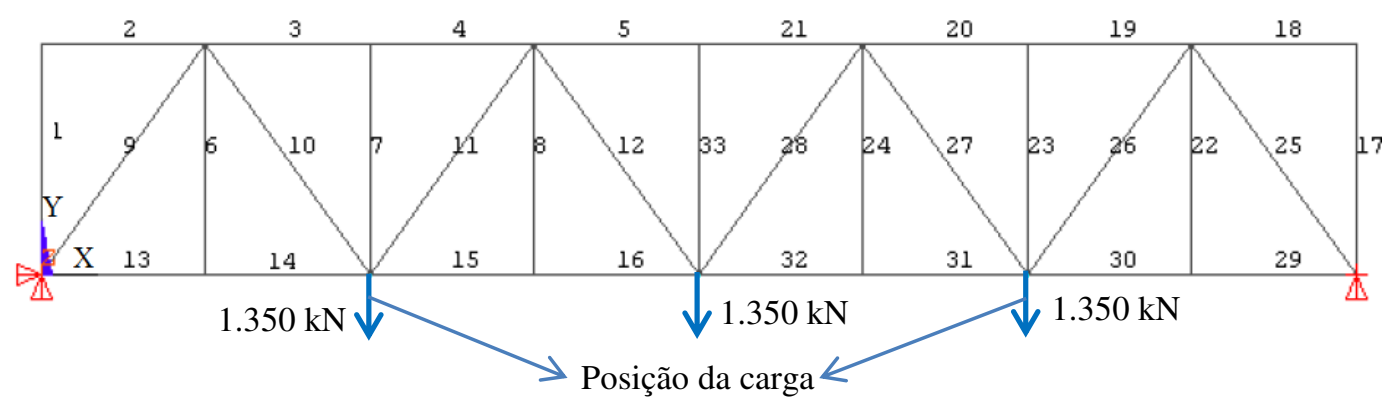

(a) Treliça principal com carregamento.

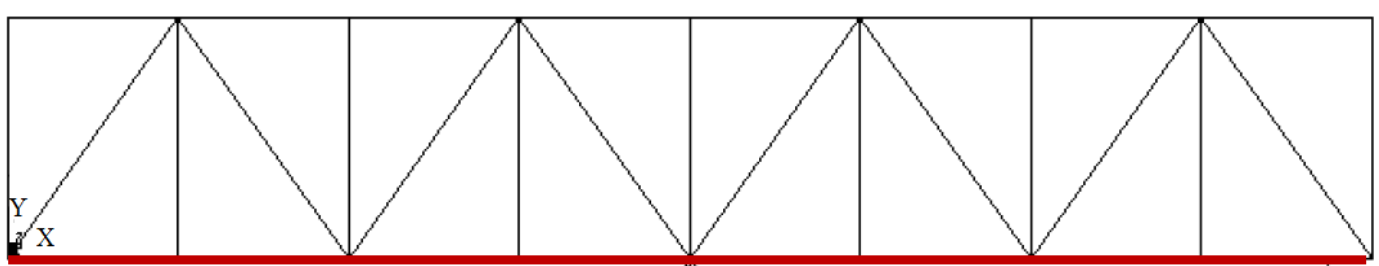

(b) Primeira técnica: Traçado retilíneo na corda inferior ao longo de todo o comprimento.

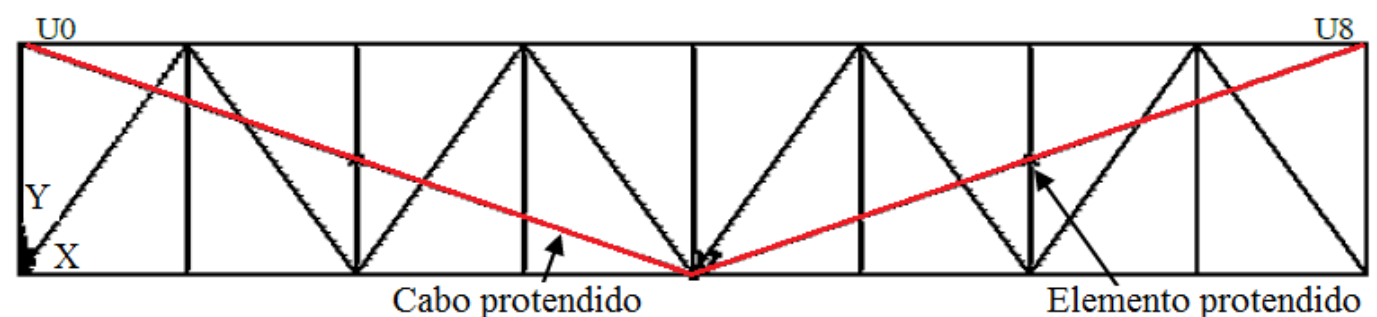

(c) Segunda técnica: traçado poligonal posicionado em três pontos. 


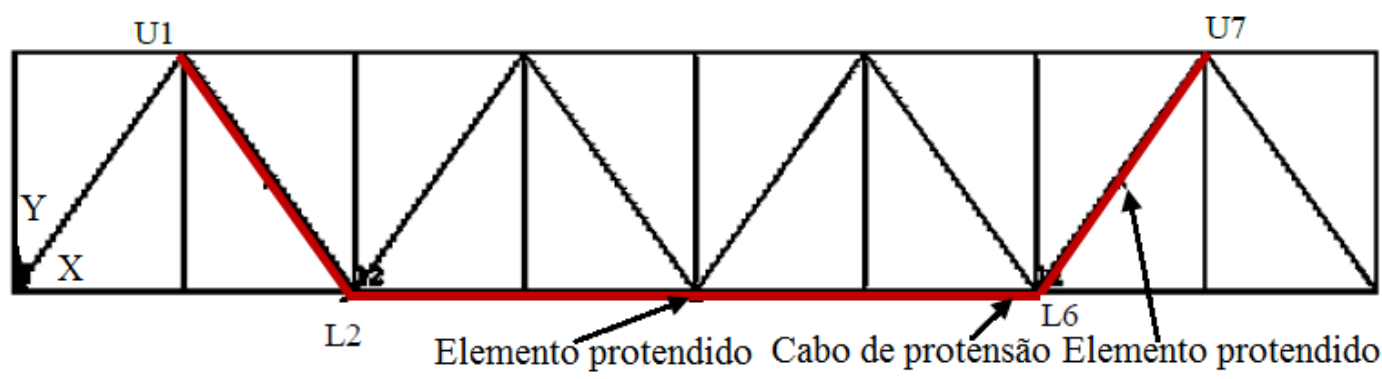

(d) Terceira técnica: traçado poligonal posicionado em quatro pontos.

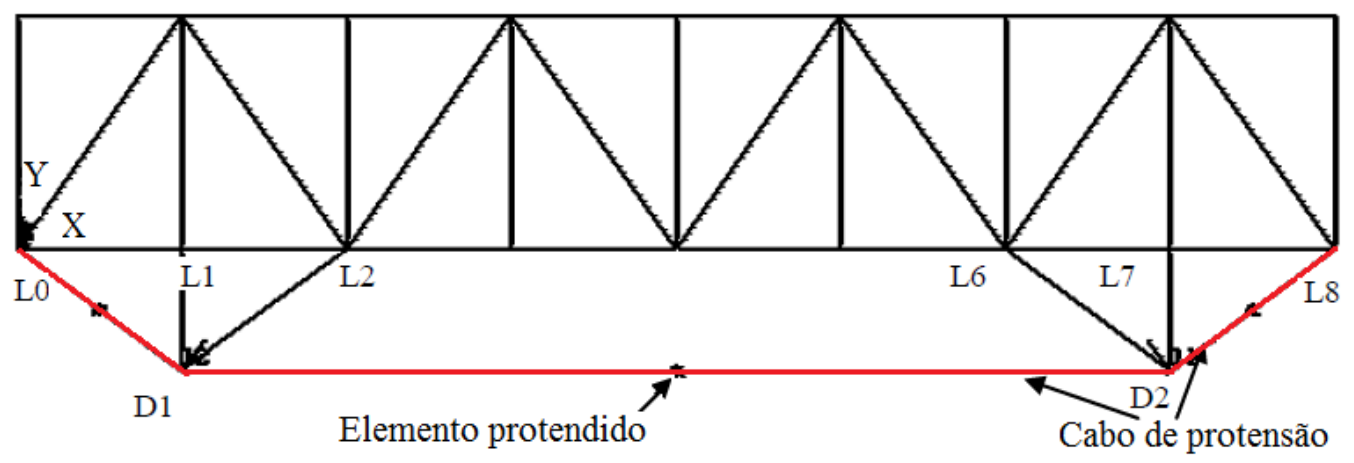

(e) Quarta técnica: traçado poligonal fora da seção.

Figura 2.17 Sistema de treliça $\mathrm{N}$ e as diferentes técnicas de traçado dos cabos de protensão.

A Tabela 2.2 mostra a porcentagem de reduções de forças internas de tração e compressão dos elementos da treliça devida ao uso de diferentes técnicas de protensão.

A melhor técnica para fortalecer o sistema $\mathrm{N}$ de treliça é a técnica quatro, que dá uma redução de $9,5 \%$ do total de forças internas do elemento a tração e uma redução de 1,66 \% do total de forças de compressão interna. Embora a primeira técnica proporcione uma redução de $9,05 \%$ do total da força de tração, essas técnicas causam um aumento das forças totais do elemento de compressão em $0,65 \%$.

Tabela 2.2 Percentagem de reduções nas forças internas dos elementos da treliça após o uso de diferentes técnicas de protensão.

\begin{tabular}{|c|c|c|c|c|c|c|}
\hline \multirow{3}{*}{$\begin{array}{c}\text { Sistema } \\
\text { de } \\
\text { Treliça }\end{array}$} & \multicolumn{6}{|c|}{ Relação de forças internas das treliças protendidas (\%) } \\
\hline & Técnica $\mathrm{N}^{\circ} 1$ & Técnica $\mathrm{N}^{\circ} 2$ & \multicolumn{2}{|c|}{ Técnica $\mathrm{N}^{\circ} 3$} & \multicolumn{2}{|c|}{ Técnica $\mathrm{N}^{\circ} 4$} \\
\hline & Tração. Comp. & Tração. Comp. & Tração. & Comp. & Tração. & Comp. \\
\hline $\begin{array}{c}\text { Sistema } \\
\text { N }\end{array}$ & $-0,65$ & 0,14 & 7,63 & 0,98 & 9,5 & 1,66 \\
\hline
\end{tabular}




\section{7.}

\section{Treliça de aço em forma de arco protendida}

Como mencionado anteriormente as estruturas treliçadas protendidas em forma de arco são o foco principal do presente estudo e, portanto, a literatura sobre esse tema será revisada nesta seção.

Comportamento à força de tração do elemento protendida de treliça em forma de arco: Os elementos protendidos são os componentes críticos que regem o comportamento da estrutura de aço protendida, e o benefício de adicionar o protensão inicial é maximizado quando esses componentes são sujeitos a forças de tração. A aplicação da protensão gera uma força de compressão no elemento, conforme mostrado na Figura 2.18.

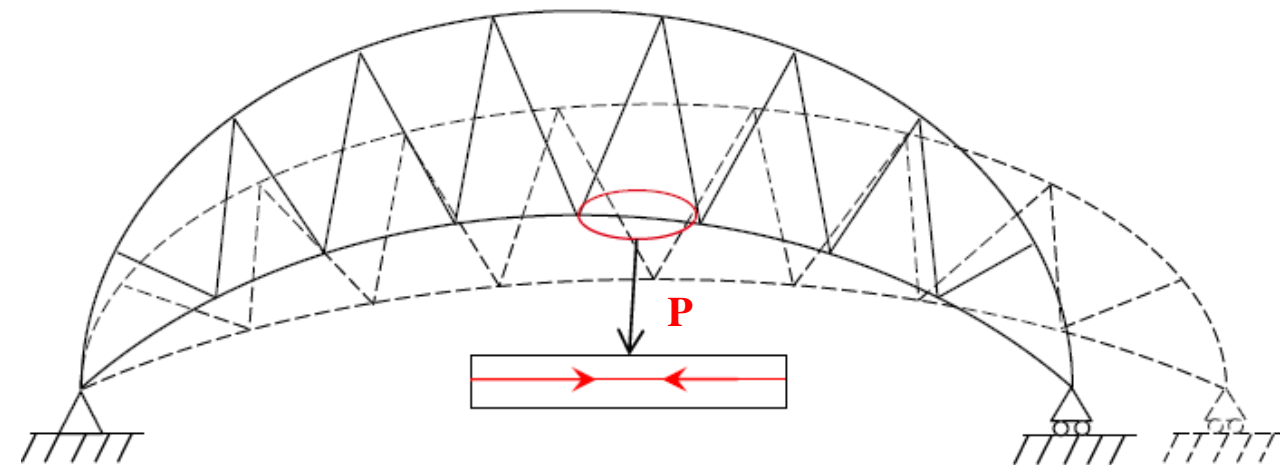

Figura 2.2.18 Aplicação da protensão induz força de compressão na corda inferior protendida.

O carregamento subsequente para baixo na estrutura protendida resultará forças de tração nos elementos da corda inferiores, como apresenta a Figura 2.19.

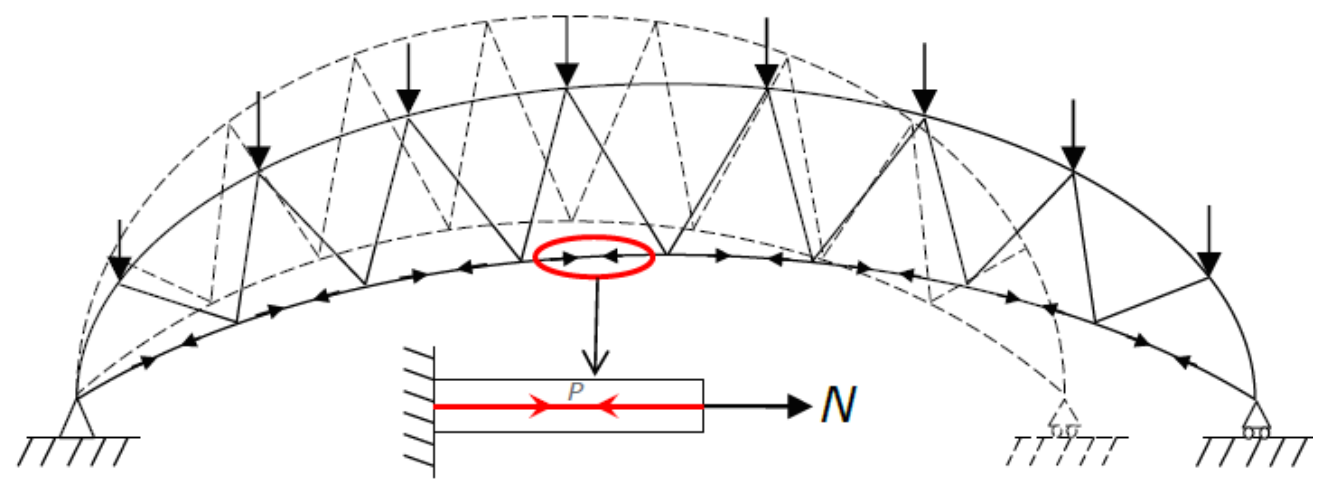

Figura 2.19 Carregamento vertical induz uma força de tração induzida na corda inferior. 
$\mathrm{Na}$ estrutura protendida podem surgir forças de compressão nos membros protendidos devido à inversão de carga, como no caso da força do vento, conforme mostrado na Figura 2.20. Portanto, o desempenho desse elemento sob carga do vento é estudado nesta tese por meio de modelagem numérica.

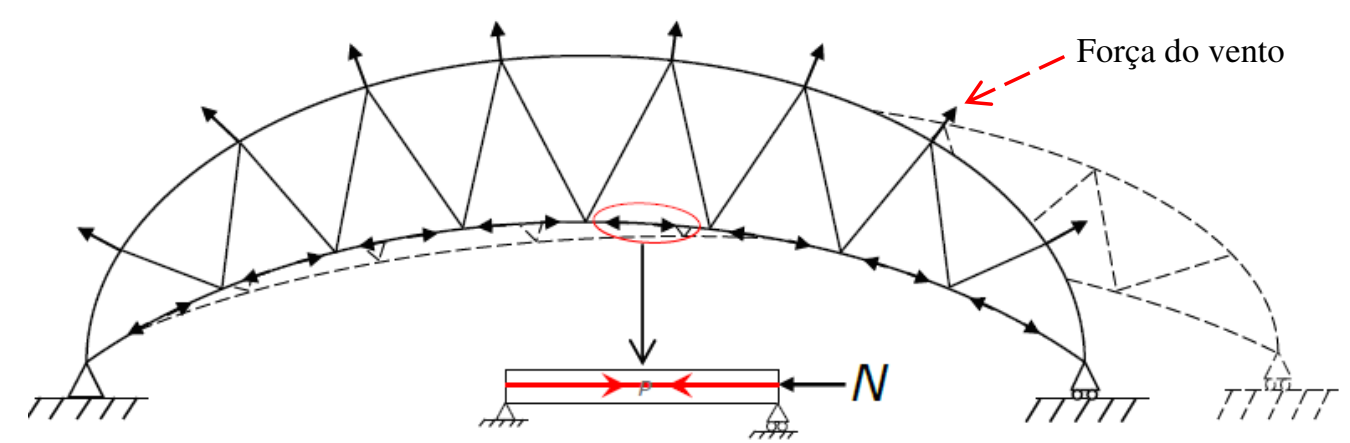

Figura 2.20 Carregamento do vento induz uma força de compressão induzida na corda inferior.

Dentre as diversas pesquisas que podem ser encontradas na literatura sobre treliças de aço em forma de arco protendidas são descritas a seguir aquelas que são as mais significativas com base no efeito de protensão.

A pesquisa de Gkanto et al., (2015) visa a avaliação da configuração estrutural ótima para treliças de aço de alta resistência (HSS) em forma de arco de perfil tubular e o efeito da aplicação da protensão através de cabos incorporados na corda inferior da treliça para submeter à análise estática não linear geométrica.

Os resultados da resposta estrutural são apresentados em gráficos normalizados de deslocamento e carga considerando-se o efeito de variação do grau de aço e magnitude da protensão. Foi testado no Imperial College, Londres, no Projeto HILONG, como mostrado na Figura 2.21. As treliças são estaticamente testadas sob uma carga vertical e uma seção tubular quadrada para todas as cordas. As especificações das seções dos perfis das cordas e o aço estrutural empregado são mostrados na Tabela 2.3. 


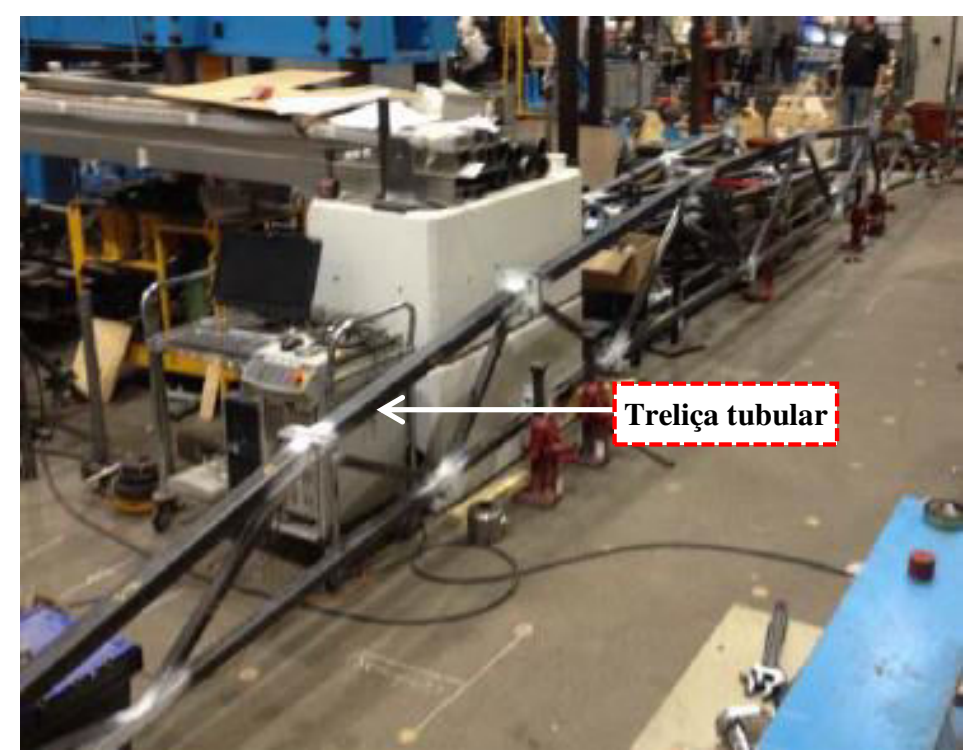

Figura 2.21 Treliça (HSS) testada no Imperial College (Gkantou et al., 2015).

Tabela 2.3 Propriedades dos elementos da estrutura.

\begin{tabular}{lccc}
\hline \multicolumn{1}{c}{ Desenho dos Perfis } & $\begin{array}{c}\text { Área } \\
\left(\mathrm{mm}^{2}\right)\end{array}$ & $\begin{array}{c}\text { Momento de inercia } \\
\left(\mathrm{mm}^{4}\right)\end{array}$ & Classe de Aço \\
\hline Corda Inferior 60x60x7 & $1.399,9$ & $639.330,12$ & $\mathrm{~S} 235$ \\
Corda Superior 80x80x7 & $1.679,9$ & $1.087 .804,52$ & $\mathrm{~S} 235$ \\
Diagonais 40x40x7 & 548,5 & $115.984,16$ & $\mathrm{~S} 235$ \\
\hline
\end{tabular}

A fim de avaliar o benefício fornecido para treliças de aço pela incorporação de cabos de protensão, para os cinco tipos de aço empregados (S235, S275, S355, S460 e S690) para os elementos da treliça, é considerada a área da seção do cabo de $150 \mathrm{~mm}^{2}$ e a tensão limite de escoamento de $1.860 \mathrm{MPa}$ (força ótima de $279 \mathrm{kN})$.

Ressalta-se que foram analisados três magnitudes de força de protensão para as diferentes treliças, para análise não linear, correspondendo aos seguintes critérios: (a) sem cabo; (b) cabo incorporado sem força aplicada; (c) cabo incorporado com protensão ótima $\left(\mathrm{P}_{\mathrm{opt}, \mathrm{c}}\right)$, para o qual tanto os elementos da treliça como o cabo de protensão atingem a plastificação simultânea.

As Figuras 2.22 e 2.23 apresentam as cargas normalizadas pela carga de plastificação $\left(\mathrm{Af}_{\mathrm{y}}\right.$ ) versus deslocamentos no meio do vão, obtidas na análise não linear das treliças, sem cabos, sem e com protensão ótima, considerando as diferentes classes de aço. Nessa análise observa-se que as treliças de aço, sem 
cabos e com cabo na corda inferior com força de protensão ótima, a carga máxima aumenta significativamente, com um valor médio de 35\% para as diferentes treliças com diferentes classes de aço, como pode ser visto na Figura 2.22.

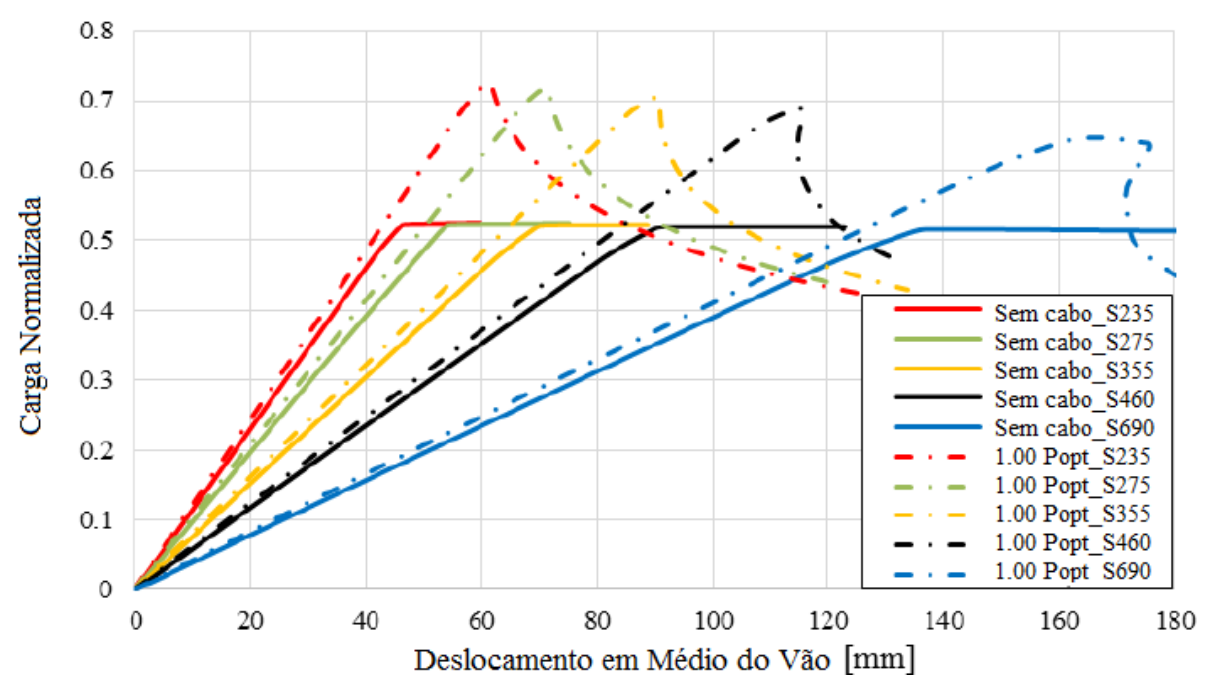

Figura 2.22 Carga normalizada versus Deslocamento, para as classes de aço (Gkantou et al., 2015).

A Figura 2.23 apresenta os resultados para nível zero de força de protensão e protensão ótima para todos os casos. Tem-se que para todos os casos o deslocamento no meio do vão das treliças para a carga final diminui significativamente quando a protensão é empregada. Verificou-se redução do deslocamento com um valor médio de $28,5 \%$ para as diferentes classes de aço.

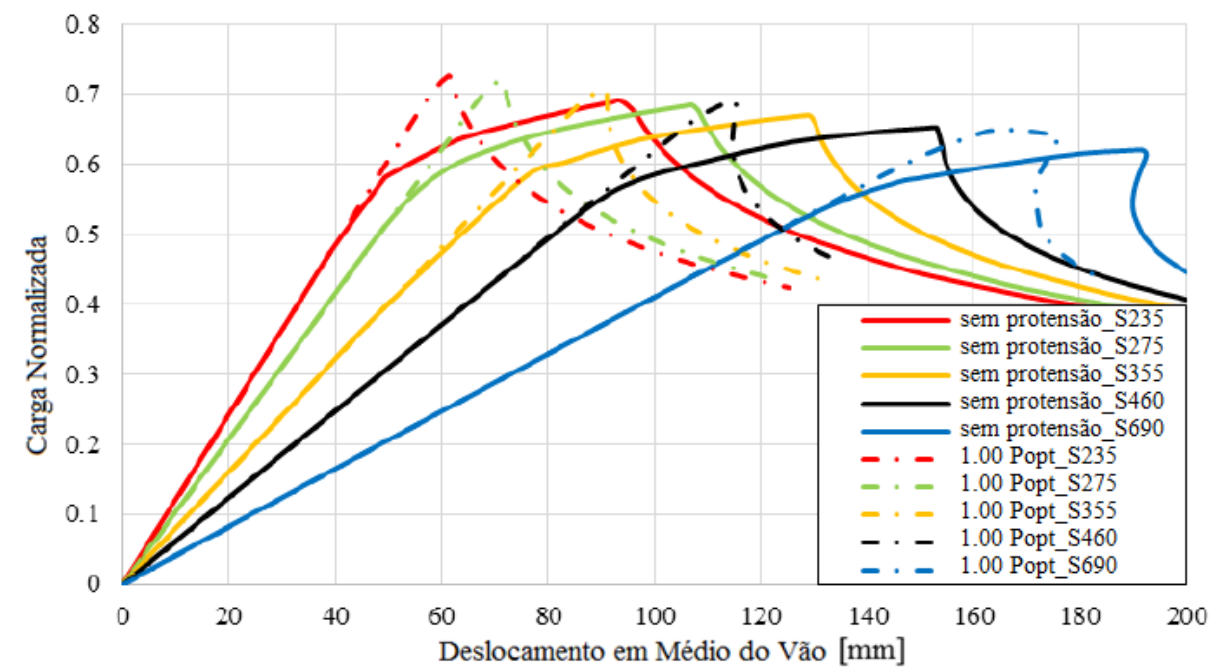

Figura 2.23 Carga normalizada versus deslocamento, para força de protensão zero e $\mathrm{P}_{\mathrm{opt}}$ (Gkantou et al., 2015).

Conclui-se que a incorporação de um cabo protendido na corda inferior contribui positivamente para um aumento significativo da rigidez e capacidade da estrutura. Também a força de protensão aumenta na carga máxima. 
Na pesquisa de Yongjun et al., (2018) é apresentada uma inovadora estrutura de arco tridimensional protendida com diferentes traçados de cabos, ver Figura 2.24. É analisada a influência da posição de ancoragem do cabo na estabilidade da estrutura em três diferentes esquemas, conforme abaixo mostrado:

Esquema 1: dois cabos são simetricamente traçados na treliça e cruzados no ponto C. Uma extremidade de um cabo é ancorada na extremidade do arco no ponto $\mathbf{E}$, enquanto a outra extremidade está ancorada em uma junta de corda inferior A. Simetricamente outro cabo é ancorado em outra extremidade no ponto D e a articulação da corda inferior no ponto B (Figura 2.24. b), sendo a posição de ancoragem nos pontos A e B. Os suportes dos cabos são distribuídos uniformemente entre a corda inferior do arco e os cabos, e na extremidade de dois suportes no topo do arco ambos são ancorados no ponto $\mathbf{C}$, formando um suporte em forma de $\mathbf{V}$, como ilustra a Figura 2.24. c.

Esquema 2: com base no esquema 1 os suportes são todos removidos, exceto o em forma de V no ponto C, como mostrado na Figura 2.24.d.

Esquema 3, com base no esquema 2 os segmentos de cabo entre o ponto de intersecção C e as duas extremidades do arco são eliminados, conforme Figura 2.24.e.

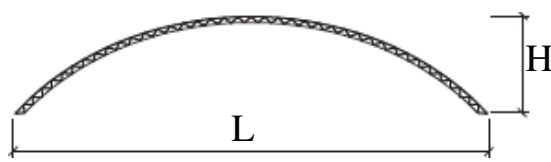

(a) Arco sem sistema de cabo e suporte.

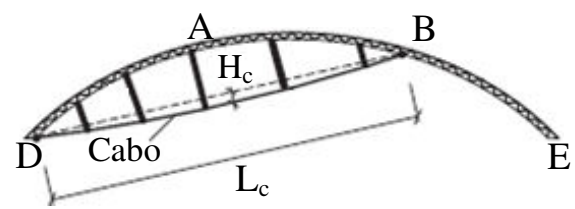

(b) Sistema de cabo de suporte um lado.

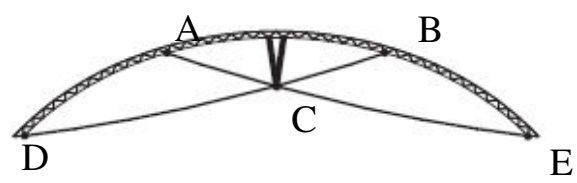

(d) Esquema 2.

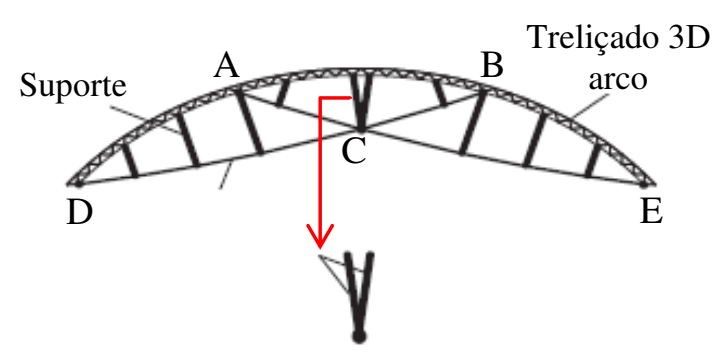

(c) Esquema 1 e suporte em forma de V.

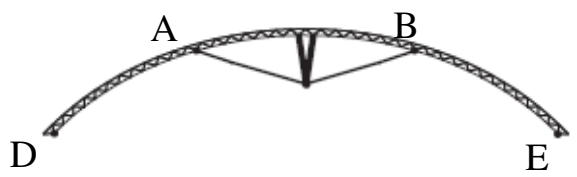

(e) Esquema 3.

Figura 2.24 Esquemas de traçados dos cabos na estrutura de arco tridimensional (Yongjun et al., 2018). 
$\mathrm{Na}$ estrutura 3D os componentes longitudinais de travamento são treliças e se cruzam perpendicularmente com vários arcos paralelos. Um conjunto de travamento em "X" é colocado no meio da estrutura entre dois arcos trançados adjacentes, como mostrado na Figura 2.25, em que $\mathrm{S}_{1}$ e $\mathrm{L}_{1}$ denotam o comprimento entre dois pontos de travamento e o espaçamento entre treliças, respectivamente. A seção transversal das treliças em forma de arco e as treliças longitudinais são triangulares, como mostrado na Figura 2.26.

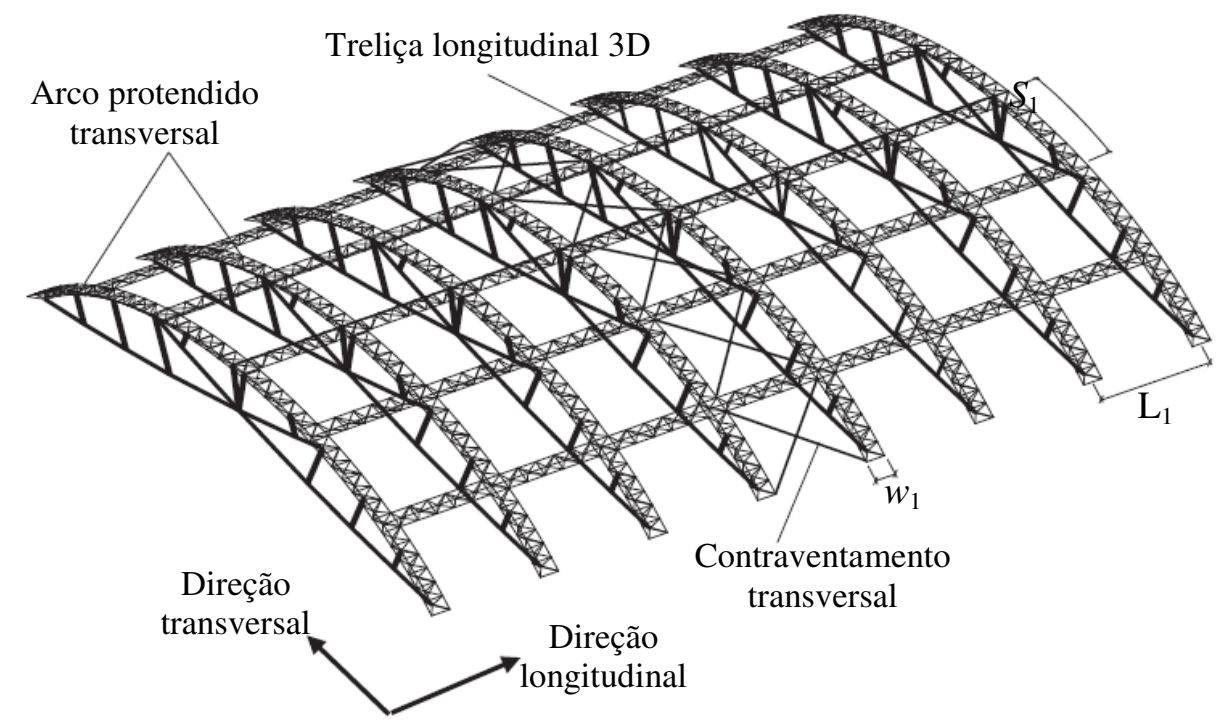

Figura 2.25 Configuração da estrutura em 3D completa (Yongjun et al., 2018).

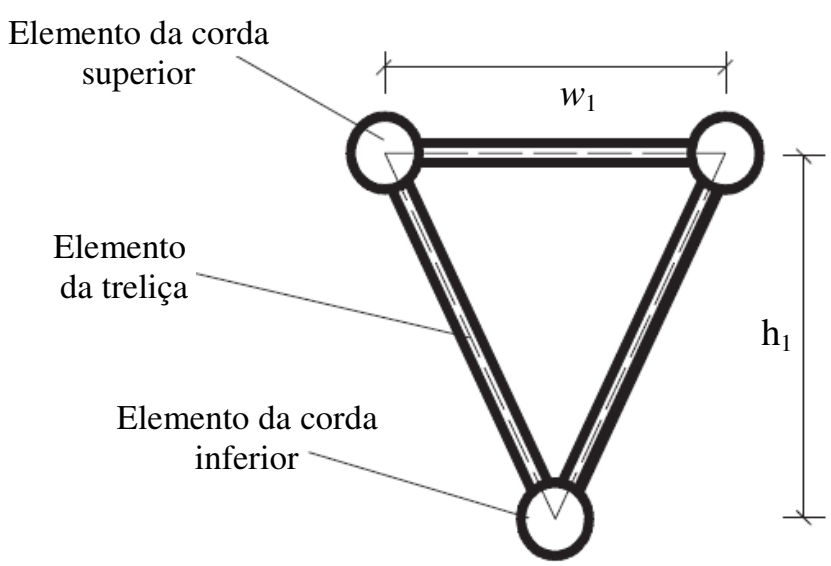

Figura 2.26 Secção transversal dos arcos tridimensionais e das treliças longitudinais.

O comportamento estrutural é investigado por aplicação do método dos elementos finitos, baseado no software ANSYS V14.5, realizando-se análise não linear geométrica. Para as barras da treliça e para os cabos, foram empregados os seguintes tipos de elementos: BEAM188 (para as treliças) e LINK180 (para os cabos). As informações sobre a seção transversal de vários componentes das estruturas com diferentes vãos estão listadas na Tabela 2.4. 
Tabela 2.4 Seções transversais de vários elementos das estruturas com diferentes extensões (mm).

\begin{tabular}{ccccc}
\hline $\begin{array}{c}\text { Vão da Estrutura } \\
(\mathrm{m})\end{array}$ & $\begin{array}{c}\text { Elementos da corda } \\
\text { superior e inferior }\end{array}$ & $\begin{array}{c}\text { Elementos } \\
\text { de treliça }\end{array}$ & Suporte & Cabos \\
\hline 100 & $\phi 232 \times 12,5$ & $\phi 133 \times 5$ & $\phi 377 \times 12,5$ & $54 \times \phi 7$ \\
120 & $\phi 273 \times 15$ & $\phi 142 \times 5,5$ & $\phi 426 \times 13$ & $65 \times \phi 7$ \\
150 & $\phi 356 \times 18$ & $\phi 159 \times 6$ & $\phi 450 \times 16$ & $81 \times \phi 7$ \\
180 & $\phi 377 \times 19$ & $\phi 168 \times 6$ & $\phi 480 \times 16$ & $86 \times \phi 7$ \\
\hline
\end{tabular}

O módulo de elasticidade das barras das treliças e os suportes é $E_{t}=$ 210.000 $\mathrm{MPa}$ e para os cabos é $E_{t}=180.000 \mathrm{MPa}$. A força de protensão $\mathrm{N}$ dos cabos é realizada pelo método de deformação, é calculado por $\mathrm{N}=\varepsilon \mathrm{E} \mathrm{A}$, onde $\mathrm{E}$ e A são o módulo de elasticidade e a área transversal do cabo, respectivamente.

Para a treliça de $100 \mathrm{~m}$ de vão analisada foram considerados diferentes valores da razão de vão/flecha $F(F=H / L)$, como 0,$1 ; 0,15 ; 0,2 ; 0,25 ; 0,3 ; 0,35$ e 0,4. A seção transversal do arco tridimensional apresenta altura $\mathrm{h}_{1}$, de $1,5 \mathrm{~m}$, e largura $\mathrm{w}_{1}$, de $3 \mathrm{~m}$.

As cargas são aplicadas em várias articulações das cordas superiores dos arcos, considerando o caso da carga total e carga de meia extensão, como mostrado na Figura 2.27. Além disso a tensão da protensão é de $100 \mathrm{MPa}$ nos cabos, e os apoios são definidos nas articulações das cordas superior e inferior das duas extremidades dos arcos, como mostrado na Fig. 2.28.

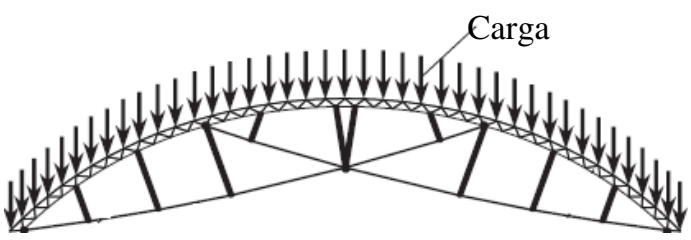

(a) Carregamento o longo do vão completa.

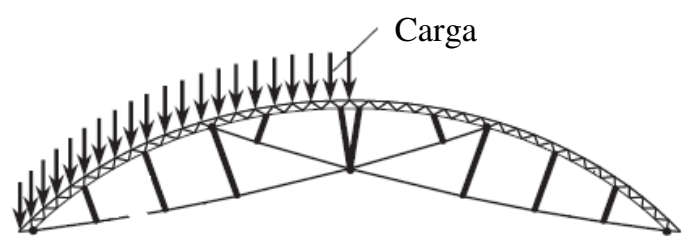

(b) Carregamento o longo metade do vão.

Figura 2.27 Os esquemas de carregamento do arco tridimensional (Yongjun et al., 2018).

A Tabela 2.5 mostra as cargas finais das treliças com diferentes esquemas de traçados de cabos, todas melhoradas significativamente em comparação com a carga final dos arcos sem cabo. Além disso, por comparação, pode-se observar que os últimos graus de melhoria de carga e os vários esquemas de traçado de 
cabo são quase idênticos no caso de carga total. Isso se dá, principalmente, porque os cabos e suportes no topo do arco desempenham um papel importante e podem efetivamente melhorar a rigidez do arco no meio da extensão.

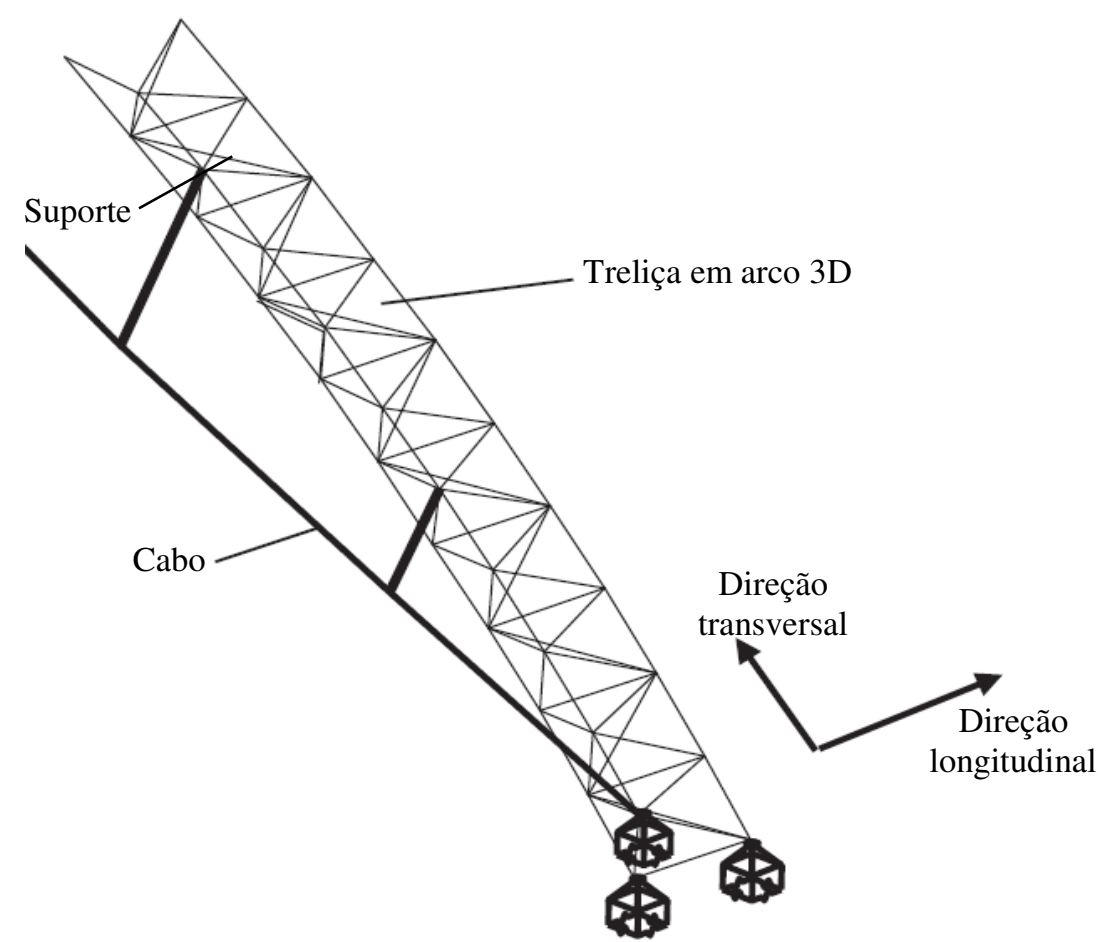

Figura 2.28 Apoio na extremidade do cabo da treliça arco (Yongjun et al., 2018).

Tabela 2.5 Cargas máxima dos esquemas de traçados dos arcos sob carga total $(\mathrm{F}=0,25)$.

\begin{tabular}{ccccc}
\hline \multirow{2}{*}{ Rezão de flecha } & \multicolumn{4}{c}{ Carga máxima / kN } \\
\cline { 2 - 5 } & Sem cabo & Esquema 1 & Esquema 2 & Esquema 3 \\
\hline 0,1 & 192,4 & $279,0(45,0 \%)$ & $271,7(41,2 \%)$ & $271,7(40,9 \%)$ \\
0,15 & 309,8 & $512,6(65,5 \%)$ & $498,7(61,0 \%)$ & $497,5(60,6 \%)$ \\
0,2 & 388,6 & $690,8(77,8 \%)$ & $676,0(74,0 \%)$ & $674,6(73,6 \%)$ \\
\hdashline 0,25 & 432,7 & $804,2(85,9 \%)$ & $784,8(84,1 \%)$ & $783,3(81,0 \%)$ \\
0,3 & 450,8 & $854,1(89,5 \%)$ & $835,5(85,3 \%)$ & $834,1(85,0 \%)$ \\
0,35 & 450,5 & $859,3(90,7 \%)$ & $842,6(87,0 \%)$ & $841,2(86,7 \%)$ \\
0,4 & 437,8 & $834,6(90,6 \%)$ & $818,7(87,0 \%)$ & $817,1(86,6 \%)$ \\
\hline
\end{tabular}

A partir dos resultados da Tabela 2.6 observa-se que as cargas finais de três tipos de arcos de cabos no caso de carregamento de meia-extensão também são melhoradas em diferentes graus em comparação com os dos arcos sem cabo. As taxas finais de aumento de carga dos arcos com traçados de cabo do esquema 1 são todos acima de $110 \%$. 
Tabela 2.6 Cargas máxima dos esquemas de traçados dos arcos sob carga de meia extensão $(\mathrm{F}=0,25)$.

\begin{tabular}{ccccc}
\hline \multirow{2}{*}{ Razão de flecha } & \multicolumn{4}{c}{ Carga máxima / kN } \\
\cline { 2 - 5 } & Sem cabo & Esquema 1 & Esquema 2 & Esquema 3 \\
\hline 0,1 & 213,2 & $573,8(169,1 \%)$ & $429,9(101,6 \%)$ & $379,0(77,8 \%)$ \\
0,15 & 304,3 & $643,5(111,5 \%)$ & $407,2(33,8 \%)$ & $467,6(53,7 \%)$ \\
0,2 & 373,7 & $880,6(135,6 \%)$ & $513,9(37,5 \%)$ & $484,3(29,6 \%)$ \\
\hdashline 0,25 & 421,1 & $1.074,5(155,2 \%)$ & $593,1(40,8 \%)$ & $511,0(21,3 \%)$ \\
$-0,25$ & 448,6 & $1.213,1(170,4 \%)$ & $672,1(49,8 \%)$ & $522,1(16,4 \%)$ \\
0,35 & 448,6 & $1.289,9(187,5 \%)$ & $745,5(66,2 \%)$ & $519,3(15,8 \%)$ \\
0,4 & 457,1 & $1.312,7(187,2 \%)$ & $841,6(84,1 \%)$ & $506,2(10,7 \%)$ \\
\hline
\end{tabular}

A Figura 2.29.a mostra as curvas de cargas finais das treliças versus deslocamento. Comparando-se as cargas finais dos arcos com e sem cabo, constata-se uma grande diferença, sendo notavelmente maiores as primeiras, o que implica que a rigidez estrutural pode ser efetivamente melhorada pela adoção dos cabos no sistema. Além disso, as curvas dos três esquemas de traçados de cabos, vistos anteriormente, são quase idênticas.

Na Figura. 2.29.b disposição do cabo dos esquemas 1 e 2 pode obviamente melhorar a rigidez estrutural e a capacidade de carga. Assim, o efeito do esquema 1 é mais notável. Também pode ser visto que o incremento na capacidade última de carga e rigidez do arco com traçado de cabo do esquema 3 não é notável em comparação com as do arco sem cabo.

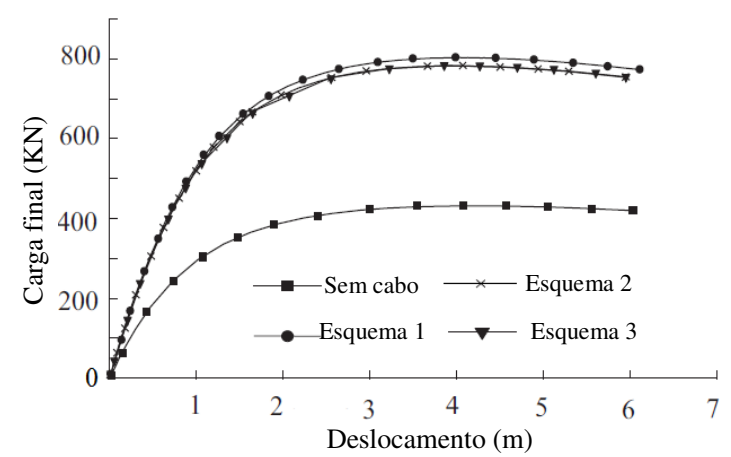

(a) Esquemas dos arcos sob carga total

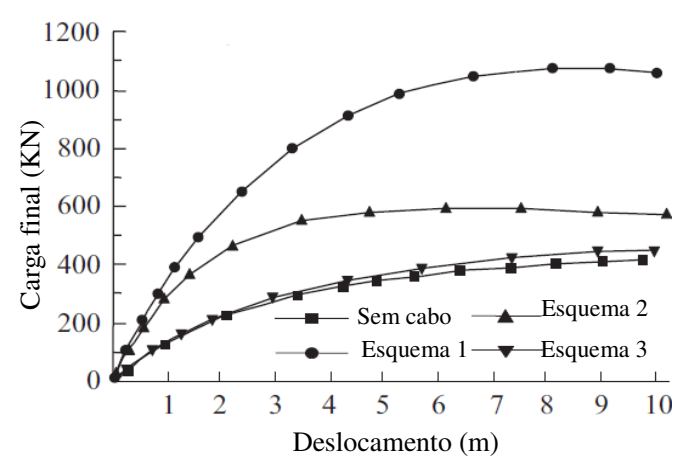

(b) Esquemas dos arcos carga meia-extensão

Figura 2.29 Diferentes esquemas traçados de cabos sob carga total e carga meia-extensão $(\mathrm{F}=0,25)$ (Yongjun et al., 2018). 
Ressalta-se que esta pesquisa sobre a estrutura tridimensional não apresenta os detalhes das ligações e dos apoios dos cabos de protensão, que podem resultar de difícil fabricação e execução. Esse novo sistema poderia resolver a questão, conforme mostrado na Figura 2.30.

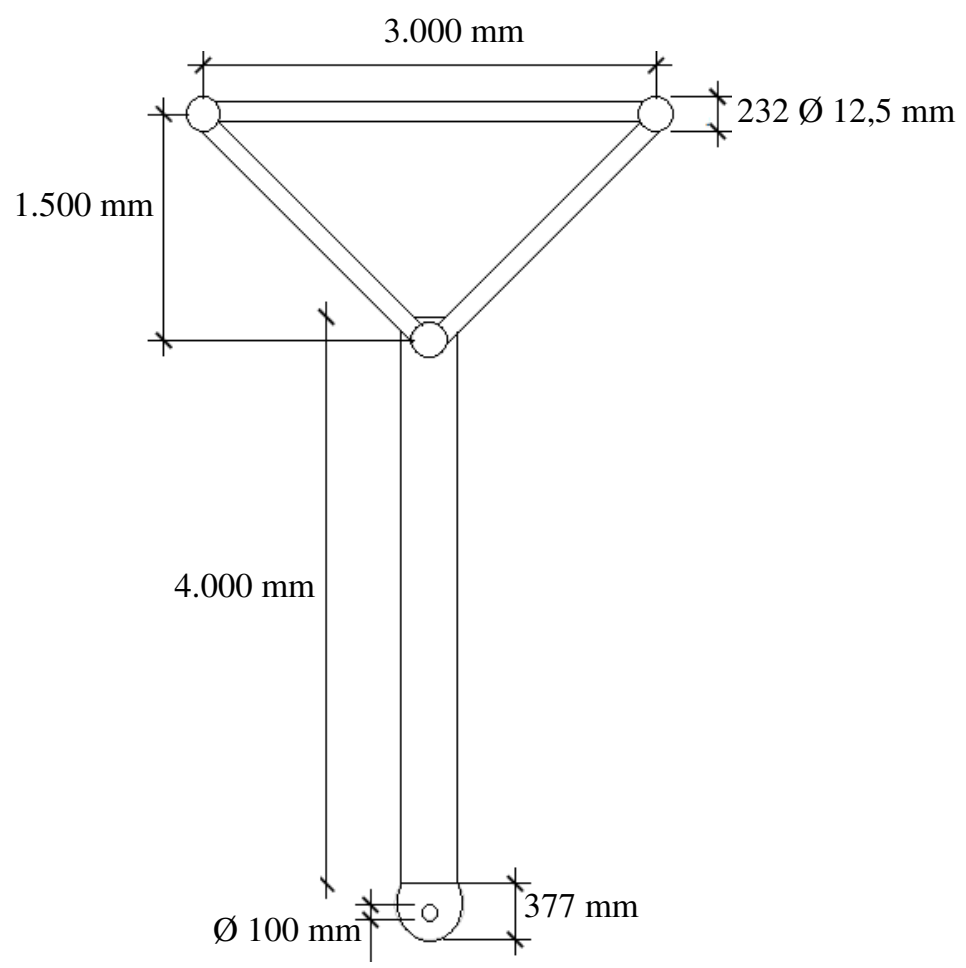

Figura 2.30 Novo sistema de arco vagonado. 


\section{Ação do vento em coberturas curvas}

\section{1.}

\section{Introdução}

A maioria das coberturas metálicas é utilizada para fins comerciais e industriais, por exemplo, hangares de aviões (Figura 3.1), complexos desportivos, centros de distribuições, depósitos e fabricas, sendo este tipo de estrutura projetada para vencer grandes vãos. Para suprir a necessidade de vencer esses vãos a maioria dessas estruturas é projetada com perfis de aço e tubos de paredes finas, considerados como estruturas metálicas leves, geralmente localizadas em zonas industriais, de baixo fator de ocupação. Esses fatores fazem com que muitas vezes a ação do vento seja um fator determinante no dimensionamento.

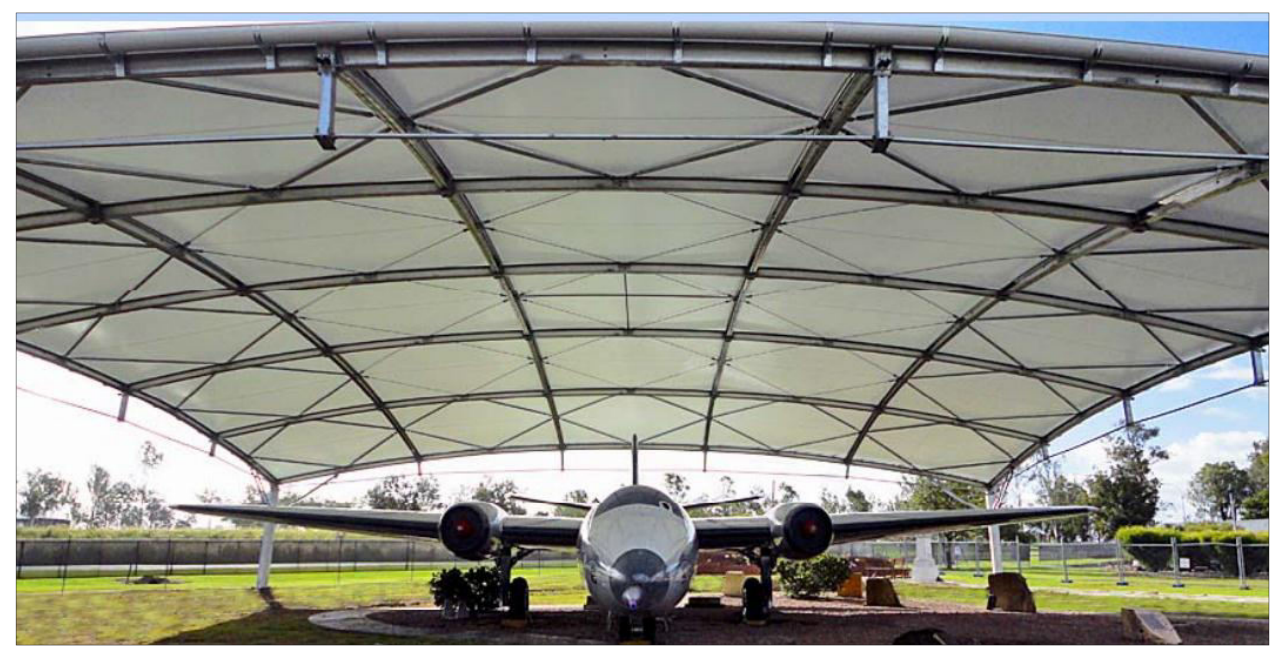

Figura 3.1 Hangar de avião de 25 m x 25 m (PTIA, 2007).

Sendo o vento na estrutura uma ação variável no tempo, ou seja, atua em forma de rajadas, pode produzir pressões nas superfícies externas das estruturas e também devido à existência de aberturas na edificação podem produzir pressões internas nos elementos de vedação. As pressões atuam nas áreas da superfície resultando em forças normais à superfície da estrutura ou de componentes 
individuais do revestimento. Além disso, quando grandes áreas de estruturas são varridas pelo vento, as forças de atrito atuam tangencialmente à superfície com intensidades que podem ser significativas para o dimensionamento.

Visando-se explorar a eficiência estrutural das coberturas de forma de arco de grandes vãos, que se caracterizam por apresentar baixo peso próprio, deve-se levar em conta que esse tipo de estrutura é propenso ao problema de instabilidade estrutural, devido ao carregamento do vento. Então, visando-se a segurança estrutural, neste capítulo é apresentada uma revisão as considerações da ação do vento em coberturas curvas, segundo os critérios das normas (Eurocode1: 1991; AS/NZS 1170:2002 e NBR6123:1988).

\section{2.}

\section{Considerações sobre a ação do vento em coberturas curvas segundo Eurocode 1:1991}

Segundo Eurocode 1:1991 o efeito do vento sobre a estrutura, depende do tamanho, forma e propriedades dinâmicas da estrutura. A resposta da estrutura deve ser calculada a partir da pressão de pico, $\mathrm{q}_{\mathrm{p}}$, na altura de referencia no campo de vento não perturbado. A pressão $\mathrm{q}_{\mathrm{p}}$ depende das condições atmosféricas, da rugosidade do terreno, topografia, etc. Cabe ressaltar que pressão pico, $\mathrm{q}_{\mathrm{p}}$, é igual á pressão media do vento mais a contribuição das flutuações de pressão de curta duração.

\subsection{1.}

\section{Coeficiente de pressão externa $\mathrm{C}_{\mathrm{pe}}$ segundo Eurocode1: 1991}

Na secção 7.2.8 do Eurocode 1:1991 são apresentados os cálculos dos coeficientes aerodinâmicos apropriados para coberturas cilíndricas circulares e cúpulas. De acordo com as Figura 3.2 e 3.3 os coeficientes externos de pressão $\mathrm{C}_{\mathrm{pe}, 10}$ (onde 10 representa área carregada de $10 \mathrm{~m}^{2}$ ) para coberturas abóbadas cilíndricas de seção circular com base retangular e para cúpulas com base circular. 
A seção da cobertura é dividida em quatro partes iguais, sendo o coeficiente de pressão externo considerado constante em cada uma das três regiões partes da cobertura (A, B e C da Figura 3.2). A altura de referência deve ser tomada como $\mathrm{Z}_{\mathrm{e}}=\mathrm{h}+\mathrm{f}$, os coeficientes são determinados de acordo com a razão $\mathrm{h} / \mathrm{c}$. Para Figura 3.2, a utilização do gráfico considera-se os seguintes intervalos:

para $0<\mathrm{h} / \mathrm{d}<0,5$ é obtido por interpolação linear;

para $0,2<\mathrm{f} / \mathrm{d}<0,3 \mathrm{e} \mathrm{h}>0,5$ devem ser considerados os dois valores.

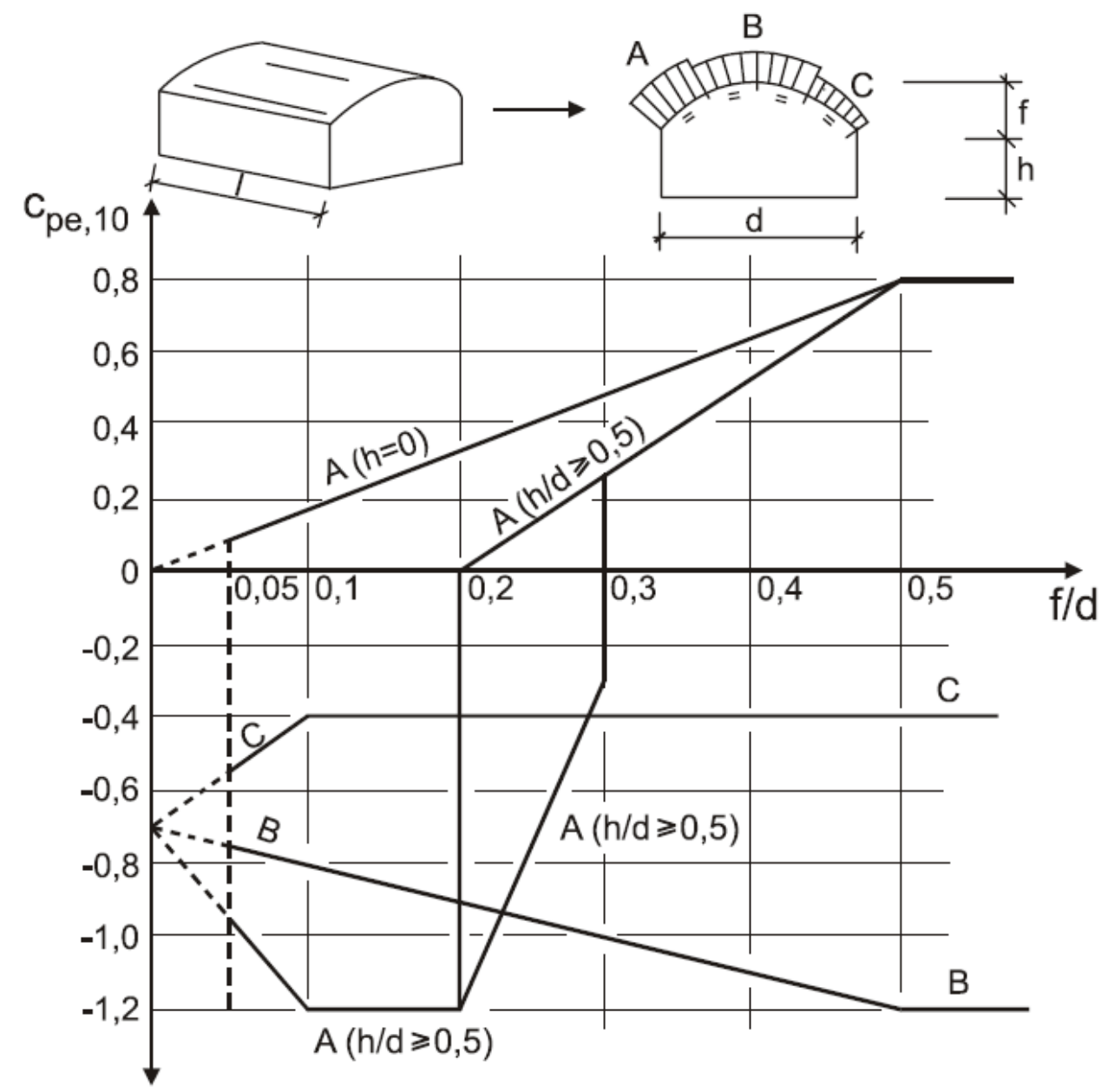

Figura 3.2 Coeficientes de pressão externo, CPe,10 para coberturas abobadados com base retangular (Eurocode 1:1991). 
Para Cúpulas, na figura 3.3 pode-se obter tais coeficientes com a utilização do gráfico, onde considera-se: $\mathrm{C}_{\mathrm{pe}, 10}$ é constante ao longo de arcos de círculos, intersecções da esfera e de planos perpendiculares a direção do vento. Cpe pode ser determinado como uma primeira aproximação por interpolação linear entre os valores em $\mathrm{A}, \mathrm{B}$ e $\mathrm{C}$ ao longo dos arcos de círculos paralelos ao vento.

Da mesma forma os valores de $\mathrm{C}_{\mathrm{pe}, 10}$ em $\mathbf{A}$ : $0<\mathrm{h} / \mathrm{d}<1$ e em $\mathbf{B}$ ou C: $0<\mathrm{h} / \mathrm{d}<0,5$ podem ser obtidos por interpolação linear em gráfico da parte inferior.

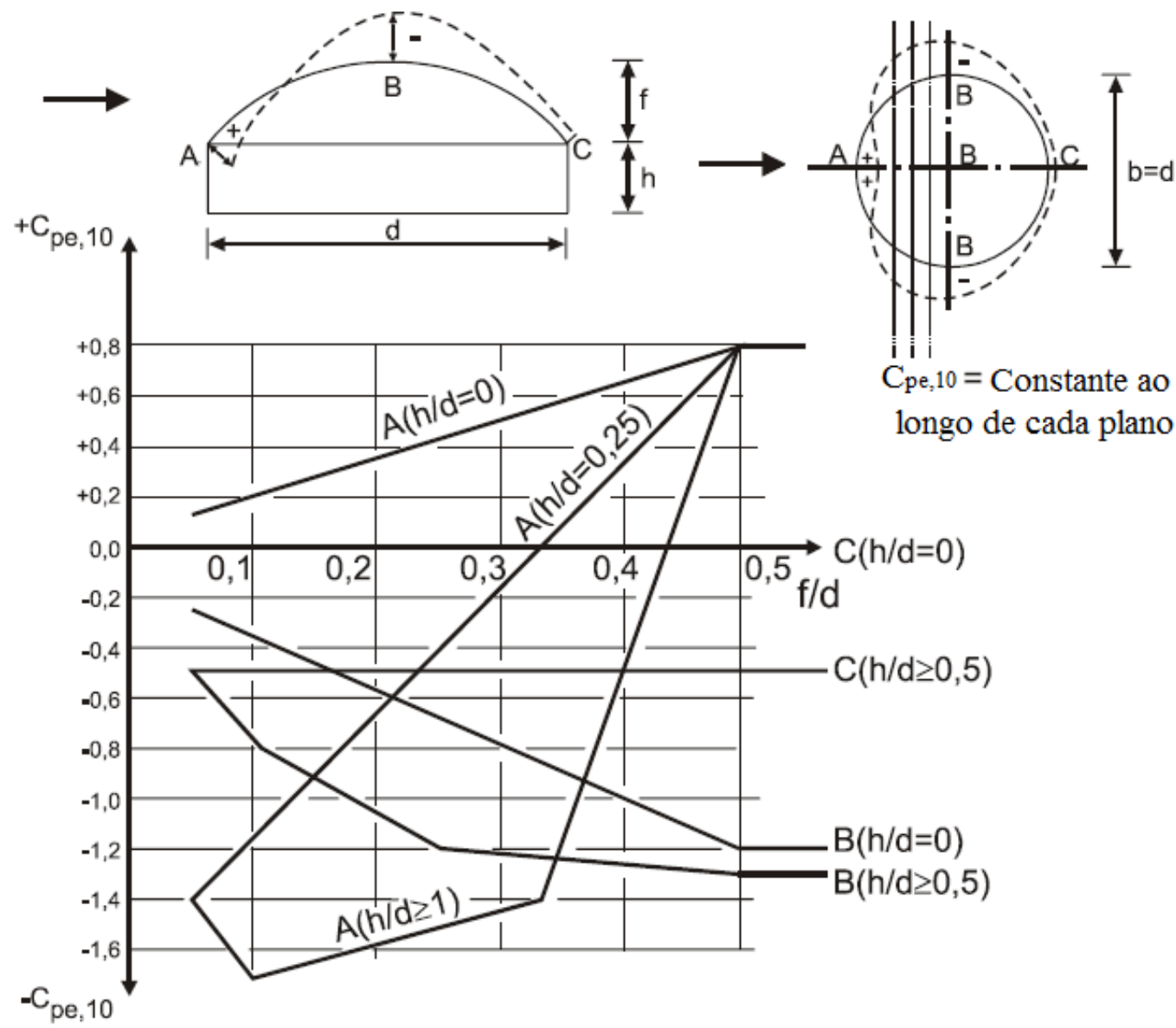

Figura 3.3 Coeficientes externos de pressão,Cpe,10, para cúpulas com base circular (Eurocode 1: 1991). 


\section{3.}

Considerações sobre a ação do vento em coberturas curvas segundo AS/NZS 1170.2:2002 (Australian/New Zealand Standard)

\subsection{1.}

\section{Coeficiente de pressão externa $C_{p e}$ segundo AS/NZS 1170.2:2002}

A determinação dos coeficientes de pressão externa, $C_{p, e}$, para coberturas curvas, arqueadas ou cúpulas com perfis aproximando um arco circular, para as direções de vento normais ao eixo de curvatura e onde $\mathrm{h} / \mathrm{r}<2$, ( $\mathrm{r}$ é a altura do arco) podem ser determinados na Tabela 3.1, do anexo C da AS/NZS 1170.2:2002.

Quando dois valores são listados, a cobertura deve ser projetada para ambos os valores. Nesses casos as superfícies da cobertura podem ser submetidas a valores positivos ou negativos devido à turbulência. Alternativas das combinações de pressões externas e internas devem ser consideradas, para obter as condições mais severas da estrutura.

Todos os coeficientes de pressão devem ser usados com o valor da velocidade do vento aplicado na altura média da cobertura h. Os coeficientes de pressão externos, $\mathrm{C}_{\mathrm{p}, \mathrm{e}}$, para direções do vento paralelas ao eixo da cobertura deve ser obtido a partir da Tabela 3.1. Para valores intermediários deve-se utilizar interpolação linear.

O efeito da razão entre $\mathbf{d}$ e $\mathbf{r}$ deve ser considerado multiplicando-se todos os coeficientes da Tabela 3.1, por um fator de $(\mathrm{b} / \mathrm{d})^{0,25}$, onde b é a largura na direção normal ao vento e d é o vão (Figura 3.4). Se (b/d) $)^{0,25}$ resultar menor que 1,0, deve ser adotado o valor de (1.0).

A Tabela 3.1 fornece coeficientes de pressão externos para estrutura de arco circular sem interferência significativa no fluxo de ar sobre a cobertura. Quando existir cobertura um lanternim com altura de pelo menos $5 \% \mathrm{~h}$, o coeficiente de pressão externa na metade central da cobertura $\mathrm{T}$ será modificado pela soma de $+0,3$, ou seja, o valor de um coeficiente negativo (sucção) é reduzido em 0,3. 
Tais reduções não devem ser realizadas para a direção do vento ao longo do eixo da cobertura, para o qual a ventilação de lanternins tem pouco efeito sobre o fluxo de ar e pressões externas resultantes.

Tabela 3.1 Coeficientes de pressão externa, Cpe, para coberturas curvas com $\mathrm{h} / \mathrm{r} \leq 2$, segundo AS/NZS 1170.2:2002.

\begin{tabular}{cccc}
\hline $\begin{array}{c}\text { Proporção } \\
(\mathrm{r} / \mathrm{d})\end{array}$ & $\begin{array}{c}\text { Quarto de barlavento } \\
(\mathrm{U})\end{array}$ & $\begin{array}{c}\text { Metade central } \\
(\mathrm{T})\end{array}$ & $\begin{array}{c}\text { Quarto de sotavento } \\
\text { (D) }\end{array}$ \\
\hline 0,05 & $-(0,2+0,4 \mathrm{~h} / \mathrm{r})$ ou 0,0 & & $-(0,4+0,2 \mathrm{~h} / \mathrm{r})$ ou 0,0 \\
0,2 & $(0,3-0,4 \mathrm{~h} / \mathrm{r})$ ou 0,0 & $-(0,55+0,2 \mathrm{~h} / \mathrm{r})$ ou 0,0 & $-(0,25+0,2 \mathrm{~h} / \mathrm{r})$ ou 0,0 \\
& & & $-(0,1+0,2 \mathrm{~h} / \mathrm{r})$ ou 0,0 \\
\hline
\end{tabular}

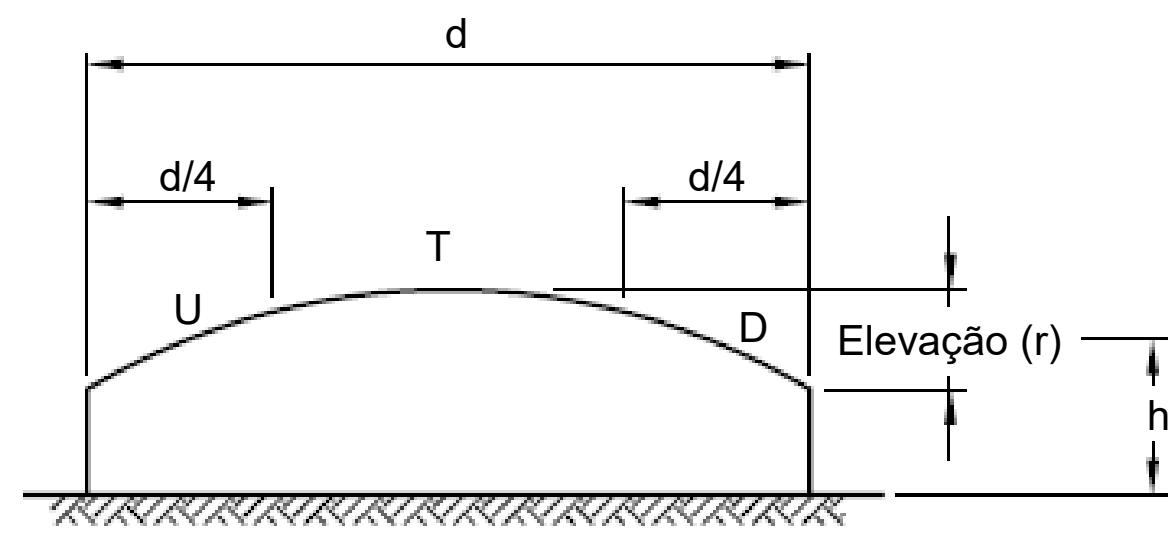

Figura 3.4 Coeficientes de pressão externa Cp,e para coberturas curvas segundo AS/NZS 1170.2. 


\section{4 . \\ Considerações sobre a ação do vento em coberturas curvas segundo ABNT NBR 6123:1988}

NBR 6123:1988 estabelece os critérios para determinação da ação do vento em edificações. Tais critérios são estabelecidos de acordo com o tipo de estrutura a ser analisada, em particular, como sua forma geométrica, localização, aberturas e dimensões da estrutura. Um dos principais fatores para a determinação da ação do vento é a localização da estrutura, tanto para determinar a velocidade básica a que a estrutura estará exposta como para estabelecer os critérios de rugosidade do terreno, em função da presença de obstáculos.

A ação do vento é o fator mais relevante para dimensionamento em projetos de cobertura. As principais influências do vento ocorrem sobre as construções leves, principalmente de grandes vãos livres, tais como hangares, pavilhões de feira, galpões, etc. As estatísticas mostram que nestas estruturas é onde ocorre a maior quantidade de acidentes devidos ao vento.

A ação do vento em coberturas curvas deve ser avaliada em função de: velocidade característica do vento, pressão dinâmica e coeficientes aerodinâmicos para coberturas em forma de abóbadas cilíndricas de seção circular, de acordo com as recomendações do anexo E da NBR 6123:1988.

Embora a ação do vento na estrutura seja uma ação dinâmica, ela é considerada como uma ação estática equivalente na estrutura, determinada em função de coeficientes aerodinâmicos para estruturas de formas geométricas variadas, como galpões, primas retangulares, cúpulas, etc. 


\subsection{1.}

\section{Pressão dinâmica devida ao vento}

A NBR 6123:1988 define a pressão do vento em função da velocidade característica do vento. Essa velocidade, em função da altura em relação a superfície do terreno, aumentando de valor conforme se aproxima do topo da estrutura, sendo definida por

$\mathrm{V}_{\mathrm{k}}=\mathrm{V}_{0} \mathrm{~S}_{1} \mathrm{~S}_{2} \mathrm{~S}_{3}$

(3.1) onde

$\mathbf{V}_{\mathbf{0}}$ : velocidade básica máxima velocidade média de uma rajada de $3 \mathrm{~s}$, a $10 \mathrm{~m}$ acima do terreno, em campo aberto e plano de categoria II, com um período médio de recorrência de 50 anos. Pode ser determinada pelas isopletas (curvas de igual velocidade) pela Figura 1 do item 5.1 da NBR 6123, para várias regiões do Brasil, variando de 30 a $50 \mathrm{~m} / \mathrm{s}$.

$\mathbf{S}_{\mathbf{1}}$ : fator topográfico, que considera a influência da topografia nas vizinhanças da construção. Três situações são contempladas

a) para terreno plano ou pouco ondulado $\left(\mathrm{S}_{1}=1,0\right)$;

b) para taludes e morros alongados nos quais pode ser admitido um fluxo de ar bidimensional soprando no sentido indicado na Figura 3.4 (Ver item 5.2 da NBR 6123[3]) Se edificação estiver localizado no ponto A (morros) e nos ponto A e C (taludes) o valor de $S_{1}=1,0$ e estiver nos pontos B é uma função de $S_{1}(z)$, será de determinado por meio das seguintes equações:

$$
\begin{array}{ll}
S_{1}=1,0 & \text { Para } \theta \leq 3^{\circ} \\
S_{1}=1,0+\left(2,5-\frac{z}{d}\right) \operatorname{tg}\left(\theta-3^{\circ}\right) \geq 1 & \text { Para } 6^{\circ} \leq \theta \geq 17^{\circ} \\
S_{1}=1,0+\left(2,5-\frac{z}{d}\right) 0,31 \geq 1 & \text { Para } \theta \geq 45^{\circ}
\end{array}
$$


onde

z: altura medida a partir da superfície do terreno no ponto considerado;

d: diferença do nível entre a base e o topo do talude ou morro;

ө: inclinação média do talude ou encosta do morro.

Para edificações posicionadas entre os pontos A e B ou entre os pontos B e $\mathrm{C}$, o fator $\mathrm{S}_{1}$ deve ser igualmente obtido através de interpolação linear.

c) Vales profundos protegidos de ventos em qualquer direção $\left(S_{1}=0,9\right)$.

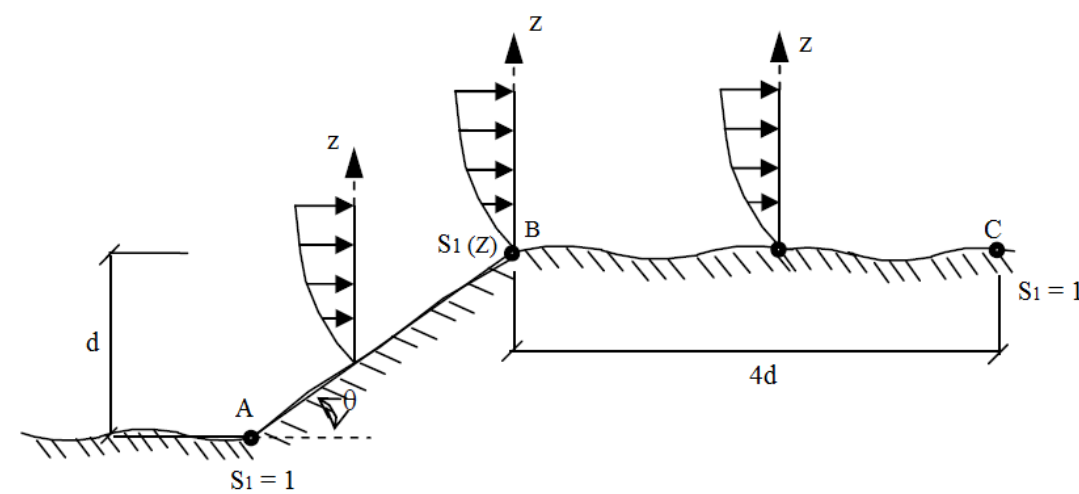

(a) Talude

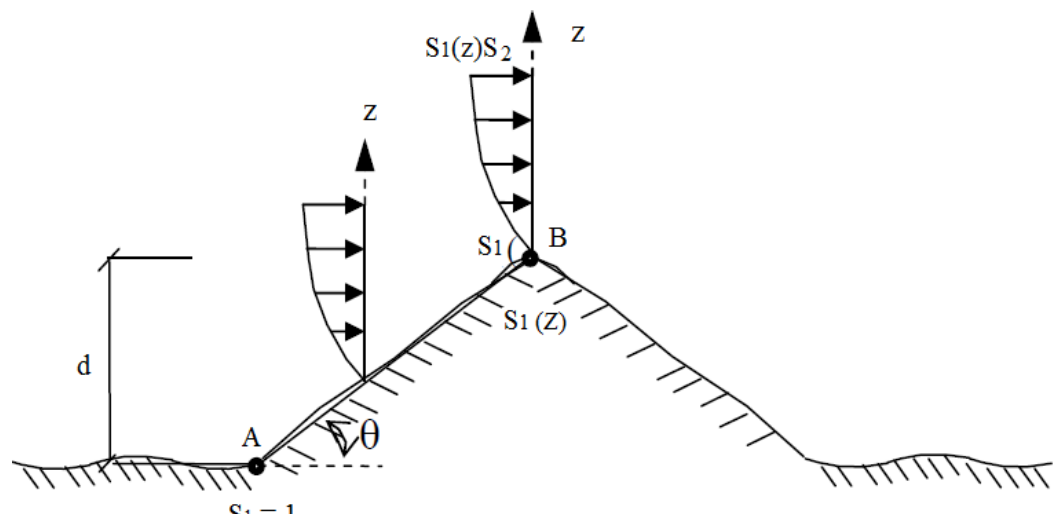

(b) Morro

Figura 3.5 Fator topográfico S1(z)para morros e taludes (NBR 6123:1988).

$\mathbf{S}_{2}$ : fator que considera o efeito combinado da rugosidade do terreno, da variação da velocidade do vento com a altura acima do terreno e das dimensões da edificação ou parte da edificação em consideração. $\mathrm{O}$ fator $\mathrm{S}_{2}$ é uma função de $\mathrm{z}$, avaliada pela seguinte:

$$
\mathrm{S}_{2}=\mathrm{bF} \mathrm{F}_{\mathrm{r}}\left(\frac{\mathrm{z}}{10}\right)^{\mathrm{p}}
$$


Onde:

b: parâmetro meteorológico;

Fr: fator de rajada;

p: expoente da lei potencial de variação de $S_{2}$.

A rugosidade do terreno é classificada por categorias I, II, III, IV e V, de acordo com as suas superfícies com as seguintes características: lisas, de grandes dimensões, poucos espaçados, abertos, cobertos, planos, ondulados, altos, com e sem obstáculos. As edificações são definidas por classes A, B e C, que dependem da dimensão horizontal e vertical da edificação acima do nível geral do terreno. O fator de rajada $\mathrm{F}_{\mathrm{r}}$ é sempre o correspondente à categoria II.

Essa expressão é aplicável até a altura $\mathrm{z}_{\mathrm{g}}$, que define o contorno superior da camada atmosférica. Os parâmetros que permitem determinar $S_{2}$ para as cinco categorias desta norma são apresentados na Tabela 3.1.

Tabela 3.2 Parâmetros meteorológicos da NBR 6123:1988.

\begin{tabular}{cccccc}
\hline \multirow{2}{*}{ Categoria } & \multirow{2}{*}{$\mathrm{Z}_{\mathrm{g}}(\mathrm{m})$} & \multirow{2}{*}{ Parâmetro } & \multicolumn{3}{c}{ Classes } \\
\cline { 4 - 6 } I & \multirow{2}{*}{250} & $\mathrm{~b}$ & 1,10 & 1,11 & 1,12 \\
& & $\mathrm{P}$ & 0,06 & 0,065 & 0,07 \\
\hline \multirow{2}{*}{$\mathrm{II}$} & \multirow{2}{*}{300} & $\mathrm{~b}$ & 1,00 & 1,00 & 1,00 \\
& & $\mathrm{~F}_{\mathrm{r}}$ & 1,00 & 0,98 & 0,95 \\
& & $\mathrm{p}$ & 0,085 & 0,09 & 0,10 \\
\hline \multirow{2}{*}{$\mathrm{III}$} & \multirow{2}{*}{350} & $\mathrm{~b}$ & 0,94 & 0,94 & 0,93 \\
& & $\mathrm{p}$ & 0,10 & 0,105 & 0,115 \\
\hline \multirow{2}{*}{$\mathrm{IV}$} & \multirow{2}{*}{420} & $\mathrm{~b}$ & 0,86 & 0,85 & 0,84 \\
& & $\mathrm{p}$ & 0,12 & 0,125 & 0,135 \\
\hline \multirow{2}{*}{$\mathrm{V}$} & \multirow{2}{*}{500} & $\mathrm{~b}$ & 0,74 & 0,73 & 0,71 \\
& & $\mathrm{p}$ & 0,15 & 0,16 & 0,175 \\
\hline
\end{tabular}


$\mathbf{S}_{\mathbf{3}}$ : este fator é baseado em conceitos probabilístico que consideram o grau de segurança requerido e a vida útil da construção. A NBR 6123-1988 adota um período de recorrência de 50 anos, que fornece uma probabilidade de $63 \%$ de que a velocidade básica seja igualada ou superada neste período. Esse nível de probabilidade, com esse período de recorrência, é considerado adequado para a segurança das edificações normais. Na Tabela 3.2 mostram valores mínimos do fator estadístico $S_{3}$, que são classificados por cinco grupos, de acordo tipo de edificação e ocupação.

Tabela 3.3 Valores mínimos do fator estatístico S3 de acordo com NBR 6123:1988.

\begin{tabular}{c|l|c}
\hline Grupo & \multicolumn{1}{|c|}{ Descrição } & $\mathrm{S}_{3}$ \\
\hline 1 & $\begin{array}{l}\text { Edificações cuja ruína total ou parcial pode afetar a } \\
\text { segurança ou possibilidade de socorro a pessoas após } \\
\text { uma tempestade destrutiva (hospitais, quartéis de } \\
\text { bombeiros e de forças de segurança, centrais de } \\
\text { comunicação, etc.). }\end{array}$ & 1,10 \\
\hline 2 & $\begin{array}{l}\text { Edificações para hotéis e residências. Edificações para } \\
\text { comércio e indústria com alto fator de ocupação. }\end{array}$ & 1,00 \\
\hline 3 & $\begin{array}{l}\text { Edificações e instalações industriais com baixo fator de } \\
\text { ocupação (depósitos, silos, construções rurais, etc.). }\end{array}$ & 0,95 \\
\hline 5 & $\begin{array}{l}\text { Vedações (telhas, vidros, painéis de vedação, etc.). } \\
\text { Edificações temporárias. Estruturas dos grupos 1 a 3 }\end{array}$ & 0,88 \\
\hline
\end{tabular}

Pelo item 4.2 da NBR 6123 a pressão dinâmica ou obstrução do vento $\left(\mathrm{q}_{\mathrm{w}}\right)$ pode ser obtida pelo Teorema de Bernoulli, conservação de energia para fluidos perfeitos (incompreensíveis e não viscosos) em regime permanente, em função da velocidade característica, e é definida pela seguinte expressão:

$$
\mathrm{q}_{\mathrm{w}}=0,613 \mathrm{~V}_{\mathrm{k}}^{2} \quad \text { sendo (unidade SI): } \quad \mathrm{q}_{\mathrm{w}}\left(\mathrm{N} / \mathrm{m}^{2}\right) \text { e } \mathrm{V}_{\mathrm{k}}(\mathrm{m} / \mathrm{s})
$$




\subsection{2.}

\section{Coeficientes aerodinâmicos para coberturas curvas}

De acordo com a NBR 6123:1988 os coeficientes aerodinâmicos são definidos como coeficientes de pressão externo e interno, são adimensionais, e são calculados em função de: dimensões da edificação, da forma geométrica da estrutura, permeabilidade das paredes e cobertura. Vale notar que esses coeficientes são multiplicados pela pressão dinâmica do vento para obter o carregamento do vento na estrutura. A seguir são apresentados os coeficientes aerodinâmicos de pressões para coberturas curvas segundo recomendações das normas vigentes.

\subsubsection{1.}

\section{Coeficiente de pressão externa $C_{p e}$ segundo NBR 6123:1988}

As pressões externas em superfícies abóbadas cilíndricas de seção circular dependem da localização dos pontos de separação do fluxo, os quais variam com a velocidade do vento, características de sua turbulência, relação entre as dimensões da estrutura, curvatura da superfície externa e sua rugosidade.

As Tabelas 24 a 26 do anexo E.1 da NBR 6123 apresentam os coeficientes de pressão externa $\mathrm{C}_{\mathrm{pe}}$ para coberturas curvas de seção circular com evento perpendicular à geratriz da cobertura, para vento paralelo à geratriz da cobertura $\mathrm{e}$ para vento oblíquo à geratriz da cobertura, para cálculo das pressões estáticas que atuam sobre a cobertura. A referida norma fornece resultados baseados em ensaios realizados em fluxo aproximadamente uniforme.

A Figura 3.6 mostra a região da abóbada cilíndrica de seção circular para vento perpendicular à geratriz da cobertura $\left(90^{\circ}\right)$, onde o arco está dividido em seis partes iguais, sendo o coeficiente de pressão considerado constante em cada uma das seis partes. Dessa forma os valores normativos dos coeficientes são apresentados na Tabela 3.4 de acordo com as indicações da Figura 3.6. 


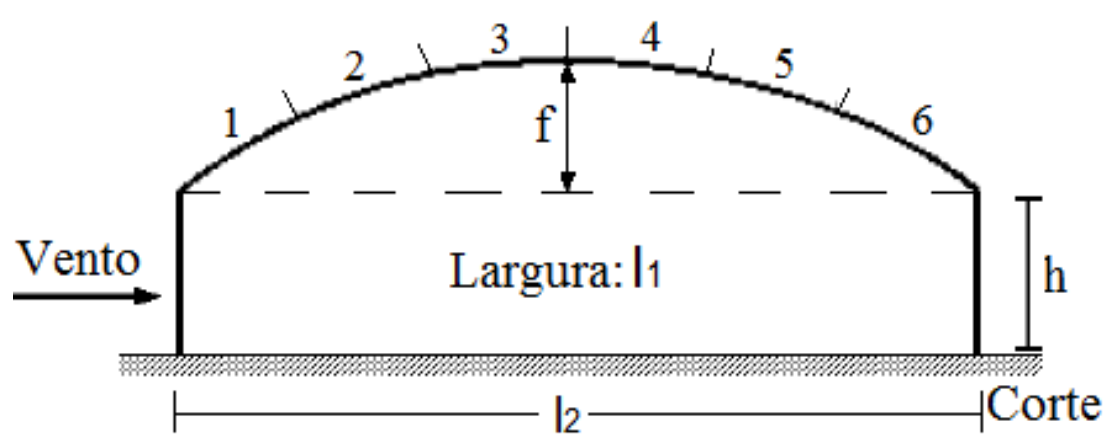

Figura 3.6 Abóbadas cilíndricas de seção circular com vento perpendicular à geratriz da cobertura com $0,512<11<312$ da NBR 6123:1988.

Tabela 3.4 Coeficientes de pressão externa, Cpe, para vento soprando perpendicularmente à geratriz da cobertura de acordo do anexo E da NBR 6123:1988.

\begin{tabular}{|c|c|c|c|c|c|c|c|}
\hline \multirow{2}{*}{$\mathrm{f} / \mathrm{l}_{1}$} & \multirow{2}{*}{$\mathrm{h} / \mathrm{l}_{2}$} & \multicolumn{6}{|c|}{ Cpe para a parte } \\
\hline & & 1 & 2 & 3 & 4 & 5 & 6 \\
\hline \multirow{6}{*}{$1 / 5$} & 0 & $+0,3$ & $-0,3$ & $-0,6$ & $-0,7$ & $-0,6$ & $-0,2$ \\
\hline & $1 / 8$ & $-0,5$ & $-0,5$ & $-0,7$ & $-0,7$ & $-0,5$ & $-0,2$ \\
\hline & $1 / 4$ & $-0,9$ & $-0,6$ & $-0,8$ & $-0,8$ & $-0,4$ & $-0,2$ \\
\hline & $1 / 2$ & $-1,2$ & $-0,7$ & $-0,9$ & $-0,8$ & $-0,3$ & $-0,2$ \\
\hline & 1 & $-1,4$ & $-0,8$ & $-0,9$ & $-0,9$ & $-0,4$ & $-0,4$ \\
\hline & 5 & $-1,8$ & $-1,0$ & $-1,1$ & $-1,2$ & $-0,8$ & $-0,7$ \\
\hline \multirow{4}{*}{$1 / 2$} & $1 / 8$ & $-1,0$ & $-0,4$ & $-0,4$ & $-0,4$ & $-0,4$ & $-0,3$ \\
\hline & $1 / 4$ & $-1,2$ & $-0,5$ & $-0,4$ & $-0,4$ & $-0,4$ & $-0,3$ \\
\hline & $1 / 2$ & $-1,5$ & $-1,0$ & $-0,7$ & $-0,5$ & $-0,4$ & $-0,3$ \\
\hline & 1 & $-1,6$ & $-1,0$ & $-0,8$ & $-0,6$ & $-0,4$ & $-0,3$ \\
\hline
\end{tabular}

De acordo com os valores normativos dos coeficientes na Figura 3.7, mostra-se ocorrência de vento mais significativo com direção preferencial soprando paralelo à geratriz da cobertura $\left(0^{\circ}\right)$. A cobertura está dividida, na direção do vento, em quatro partes iguais, sendo o coeficiente de pressão considerado constante em cada uma das quatro partes, ou seja, a região de $A_{1}$ e $A_{2}$ é avaliada como uma parte, o mesmo ocorrendo com $\mathrm{D}_{1}$ e $\mathrm{D}_{2}$. A Tabela 3.4 apresenta os coeficientes da parte cobertura para vento atuando a $0^{\circ}$. 


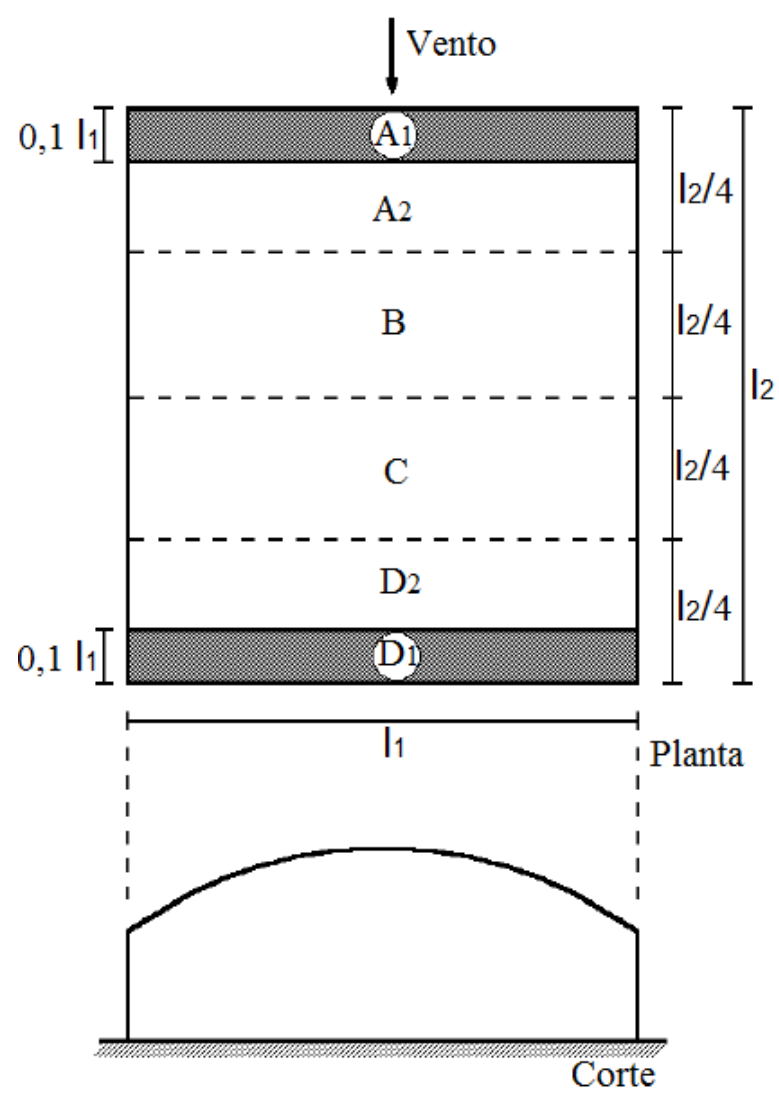

Figura 3.7 Vento paralelo à geratriz da cobertura de acordo do anexo E da NBR 6123:1988.

Tabela 3.5 Coeficientes de pressão externa, Cpe, para vento atuando paralelamente à geratriz da cobertura de acordo do anexo E da NBR 6123:1988.

\begin{tabular}{ccccc}
\hline Parte da cobertura & $\mathrm{A}_{1}+\mathrm{A}_{2}$ & $\mathrm{~B}$ & $\mathrm{C}$ & $\mathrm{D}_{1}+\mathrm{D}_{2}$ \\
\hline Cpe & $-0,8$ & $-0,6$ & $-0,3$ & $-0,2$ \\
\hline
\end{tabular}

Os valores normativos dos coeficientes de pressão externa quando o vento atua obliquamente em relação à geratriz da cobertura, onde rajadas oblíquas podem provocar sucções muito elevadas, principalmente em regiões periféricas da cobertura, encontram-se dispostos na Tabela 3.6, de acordo com as indicações da Figura 3.7. Ressalta-se que são consideradas constantes as duas partes, $\mathrm{A}_{1}$ e $\mathrm{D}_{1}$ $\left(0,11_{1}\right)$.

Tabela 3.6 Coeficientes de pressão externa, Cpe, para vento atuando obliquamente à geratriz da cobertura de acordo do anexo E da NBR 6123:1988.

\begin{tabular}{ccc}
\hline Parte da cobertura & $\mathrm{A}_{1}$ & $\mathrm{D}_{1}$ \\
\hline Cpe & $-1,8$ & $-1,8$ \\
\hline
\end{tabular}




\subsubsection{2.}

\section{Coeficiente de pressão interna Cpi NBR 6123:1988}

Os coeficientes de pressão interna recomendados pela NBR 6123:1988 apresentam os detalhes necessários para determinação dos coeficientes, que dependem da permeabilidade da estrutura, ou seja, a relação entre as áreas das aberturas e a área total da estrutura. É considerada permeável a presença de aberturas, tais como portas, janelas, ventilação em telhados, pavilhões e hangares abertos, etc. Também são considerados impermeáveis os seguintes elementos construtivos e vedações: lajes e cortinas de concreto armado ou protendido, paredes de alvenaria, de pedra, tijolos e afins.

A Figura 3.8 mostra a região onde atua o vento (Barlavento) e a região oposta em relação à estrutura (Sotavento). São considerados valores positivos dos coeficientes correspondentes à sobrepressão quando a região a barlavento é permeável e valores negativos (sucção) quando a região a sotavento é permeável.
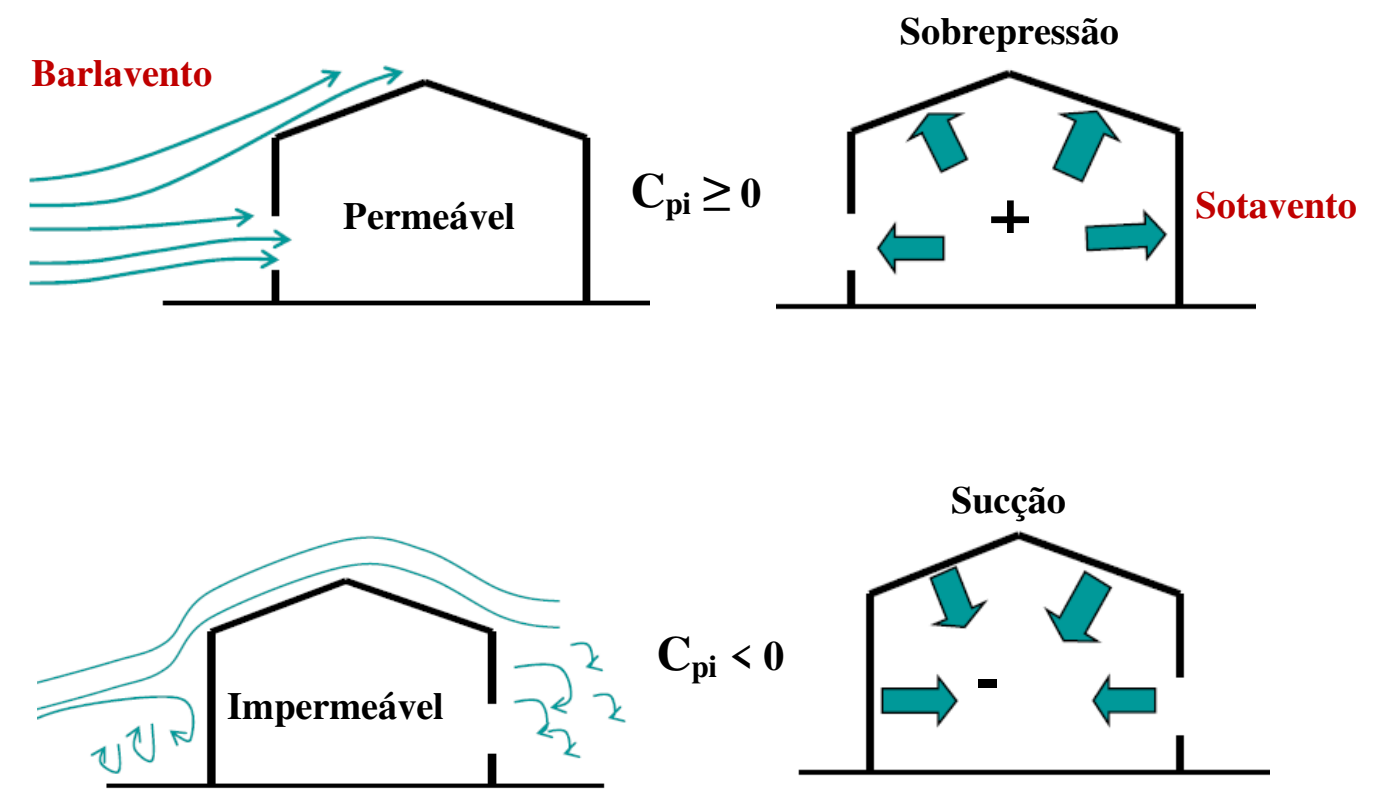

Figura 3.8 Esquema da região onde sopra o vento na estrutura.

Para edificações com paredes internas permeáveis a pressão interna é considerada uniforme. De acordo com item 6.2 da NBR 6123 (1988) verificam-se os seguintes valores para coeficientes de pressão interna: 
a) duas faces opostas igualmente permeáveis e a demais impermeáveis: Vento perpendicular a face permeável o coeficiente é $\mathrm{C}_{\mathrm{pi}}=+0,2$ e para a face impermeável é $\mathrm{C}_{\mathrm{pi}}=-0,3$;

b) quatro faces igualmente permeáveis: os valores para $\mathrm{C}_{\mathrm{pi}}=-0,3$ ou $\mathrm{C}_{\mathrm{pi}}=0$, considerar o valor mais nocivo.

c) Para edificações efetivamente estanques e com janelas fixas que tenham uma probabilidade desprezível de serem rompidas por acidente: $\mathrm{C}_{\mathrm{pi}}=0,2$ ou 0 , considerar o mais nocivo dos valores.

e) quando não for considerado necessário ou quando não for possível determinar com precisão razoável a relação de permeabilidade do item c, deve ser adotado para valor de Cpi o mesmo valor do coeficiente de forma externo (para incidências do vento de $0^{\circ}$ e de $90^{\circ}$ ) para a zona em que se situa a abertura dominante, tanto em paredes como em coberturas.

De acordo com o anexo D da NBR 6123 (1988) os valores dos coeficientes de pressão interna para pavilhões de planta retangular, como em cúpulas ou hangares permeáveis com a existência de um lanternim aberto, causam diminuição do coeficiente de pressão interna, o qual se situa entre $+0,2$ e $+0,3$. 


\section{5 .}

\section{Aplicação das normas citadas para coeficientes de pressão externos}

Aplicação para cobertura curva com base retangular com vão $\mathrm{d}=80 \mathrm{~m}$, altura de $\mathrm{h}=10 \mathrm{~m}$ e uma flecha de $\mathrm{f}=11 \mathrm{~m}$. A seguir apresentam-se os cálculos dos coeficientes de pressão externas das normas citadas.

O código Eurocode 1 (1991) mostra os resultados obtidos para dimensões especificadas para três regiões $\operatorname{com} \mathrm{h} / \mathrm{r} \leq 2$ : $(\mathrm{A})=-0,01 ;(\mathrm{B})=-0,81$; e $(\mathrm{C})=-0,4$, de acordo a Figura 3.9, ressaltando-se que para a região (A) foi efetuada uma interpolação linear. O código Australian AS/NZS 1170.2 (2002) especifica valores (ver Tabela 3.1) de $(U)=-0,32 ;(T)=-0,76$ e $(D)=-0,52$, com interpolação linear. A NBR 6123 (1988) apresenta os seguintes coeficientes: $\left(C_{1}\right)=-0,5$; $\left(\mathrm{C}_{2}\right)=-0,5 ;\left(\mathrm{C}_{3}\right)=-0,7 ;\left(\mathrm{C}_{4}\right)=-0,7 ;\left(\mathrm{C}_{5}\right)=-0,5 ;\left(\mathrm{C}_{6}\right)=-0,2$ (ver Tabela 3.4)

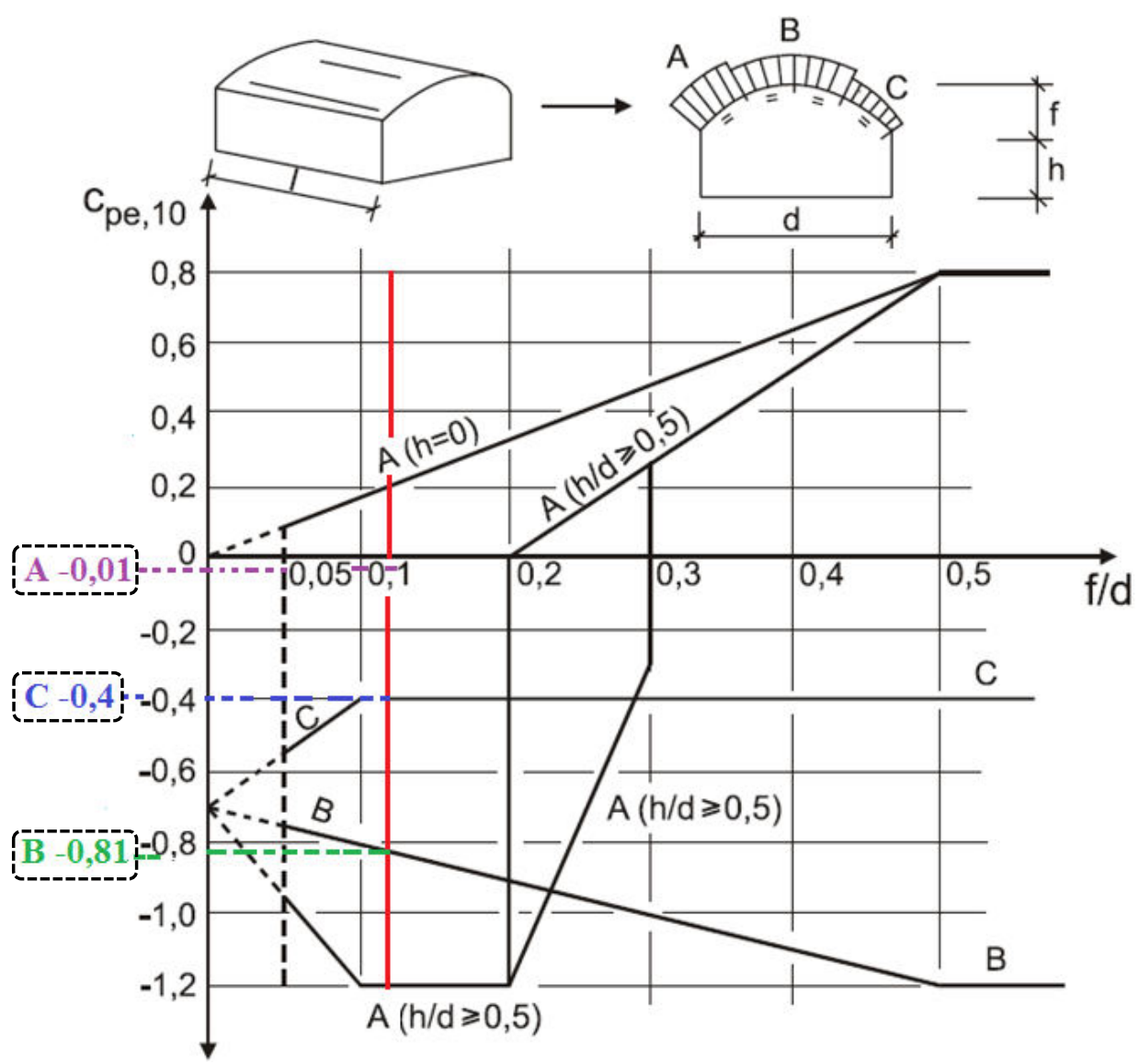

Figura 3.9 Coeficientes de pressão externo, $\mathrm{CPe}, 10$, uma cobertura de $\mathrm{d}=80 \mathrm{~m}$ vão, altura $\mathrm{h}=6 \mathrm{~m}$ e flecha de f= 11 m, segundo Eurocode 1 (1991) 
Com a utilização dos coeficientes externos obtidos pelas recomendações das normas citadas anteriormente, avalia-se o efeito do vento na cobertura de $80 \mathrm{~m}$ de vão, ver Figura 4.7, para espaçamentos entre treliças de $10.0 \mathrm{~m} \mathrm{e} \mathrm{q}_{\mathrm{w}}=1.00 \mathrm{kPa}$. Foi empregado o programa SAP2000. V17 (2014) para a análise estrutural de treliça de cobertura, e são apresentados na Figura 3.10 as solicitações atuantes nas cordas da treliça, tanto na corda superior (tração) como na corda inferior (compressão).

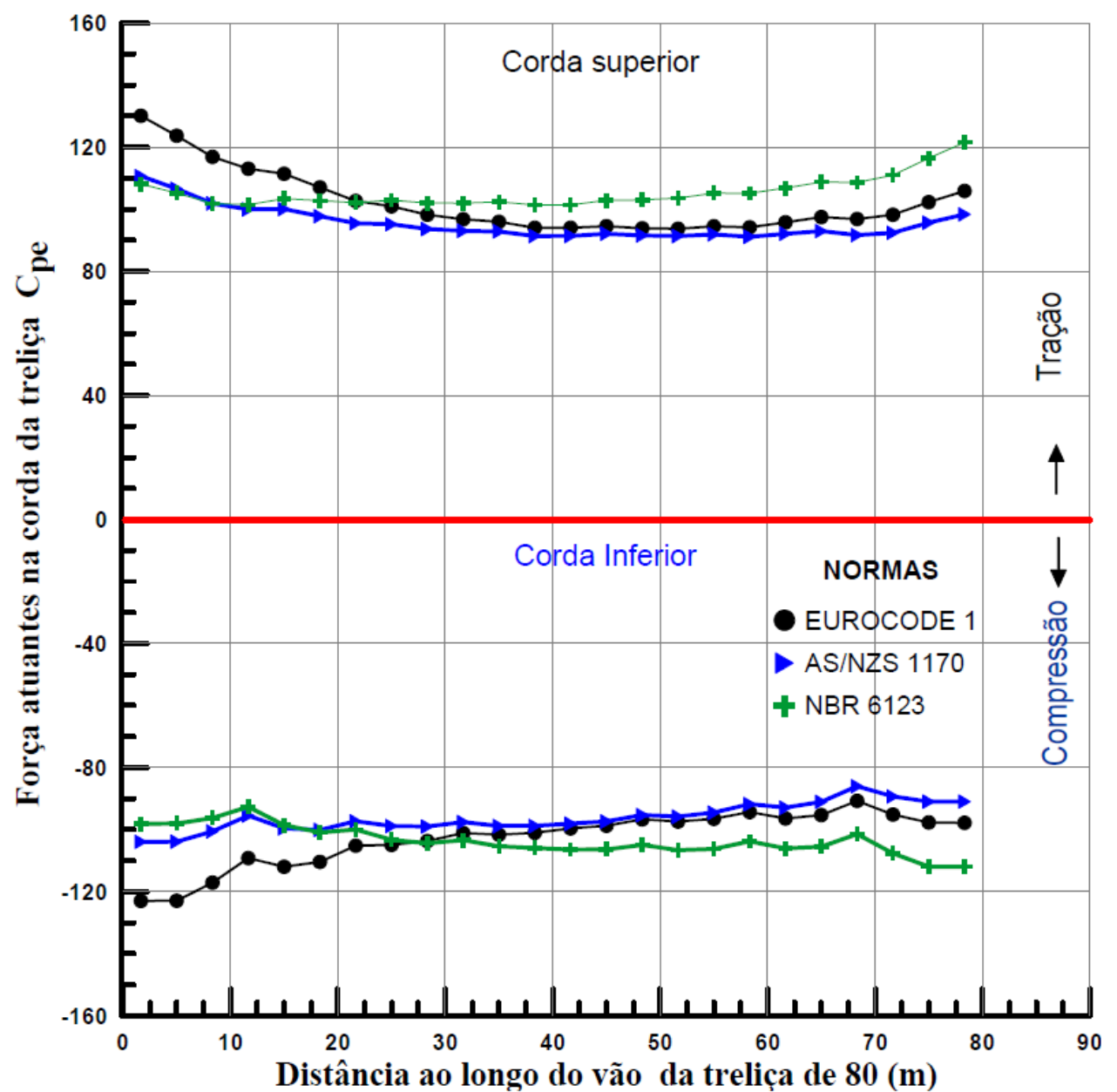

Figura 3.10 Forças atuantes nas cordas da treliça de $80 \mathrm{~m}$ de vão, para ação externa do vento, segundo critérios das normas (Eurocode 1, AS/NZS 1170.2 e NBR 6123)

Os resultados da AS/NZS 1170 apresentam esforços de valores inferiores em comparação com resultados das outras normas citadas. As solicitações obtidas segundo critérios da NBR 6123 são superiores em grande parte da estrutura, exceto nas regiões um e dois, conforme Figura 3.6. 
A Tabela 3.7 mostra os resultados das forças axiais máximas atuantes nas barras, das reações de apoio e do deslocamento vertical da estrutura no centro do vão devidos à ação do vento externo, para as diferentes normas citadas.

Tabela 3.7 Avalição dos resultados dos esforços na estrutura de vão 80 m.

\begin{tabular}{cccccc}
\hline Avaliação & NBR 6123 & \multicolumn{4}{c}{ Resultados das diferentes normas } \\
\cline { 3 - 6 } & & Eurocode 1 & vs NBR6123 & AS/NZS 1170 vs NBR6123 \\
\hline $\begin{array}{c}\text { Forças } \\
\text { tração }\end{array}$ & 121,5 & 130,12 & $+7,09 \%$ & 110,69 & $-8,90 \%$ \\
$\begin{array}{c}\text { Forças } \\
\text { compressão }\end{array}$ & 111,97 & 122,98 & $+9,83 \%$ & 103,93 & $-7,18 \%$ \\
$\begin{array}{c}\sum \text { Reações } \\
\text { Verticais }\end{array}$ & 54,85 & 55,58 & $+1,33 \%$ & 48,98 & $-10,70 \%$ \\
$\begin{array}{c}\text { Deslocamento } \\
\text { vertical }\end{array}$ & 47 & 45,46 & $-3,28 \%$ & 43,03 & $-8,45 \%$ \\
\hline
\end{tabular}




\section{4}

\section{Descrição dos modelos estruturais}

Neste item são apresentados os modelos estruturais das treliças de aço em forma de arco protendidas, incluindo-se as dimensões, características dos materiais, especificações dos perfis, os cabos de protensão, os modelos de carregamentos aplicados e as combinações de ações.

\section{1. \\ Modelos estruturais investigados}

Os modelos estruturais investigados neste trabalho de pesquisa consistem em treliças de aço em forma de arco, protendidas com cabos não aderentes. Foram também estudados diversos níveis de protensão, o caso de protensão nula (sem folga) e o caso de treliça sem cabos. As treliças têm diferentes concepções geométricas de comprimento do vão, a flecha do arco, compreendendo cinco modelos estruturais. A geometria do sistema estrutural estudado é formada por perfis soldados.

Inicialmente foi executado um estudo para obtenção da flecha do arco que representa a solução estrutural mais eficiente. Conclui-se que a flecha próxima de um sétimo da metade do vão da treliça é o valor desejado. Na Tabela 4.1 são apresentados os valores de cinco vãos estudados e as respectivas flechas adotadas para os arcos treliçados. Foi mantido constante em todos os modelos estudados o espaçamento entre treliças de $10 \mathrm{~m}$.

Nas Figuras 4.1 e 4.2 são apresentadas a vista lateral e a vista em perspectiva. Convém notar que as cordas são todas em perfil laminado com o eixo forte contido no plano da treliça, e que os montantes têm as mesmas dimensões das cordas. A ligação entre os montantes e as cordas é sempre do tipo contínua, executada por soldagem das mesas. 
Tabela 4.1 Os modelos das treliças estudadas.

Modelos de Treliças Flecha (m) Vão (m)

\begin{tabular}{lcc}
\hline Modelo $\mathrm{A}_{10}$ & 0,7 & 10 \\
${\text { Modelo } \mathrm{B}_{20}}$ & 1,5 & 20 \\
${\text { Modelo } \mathrm{C}_{40}}$ & 3,0 & 40 \\
${\text { Modelo } \mathrm{D}_{80}}$ & 5,5 & 80 \\
${\text { Modelo } \mathrm{E}_{120}}$ & 7,5 & 120 \\
\hline
\end{tabular}

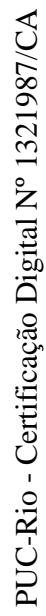

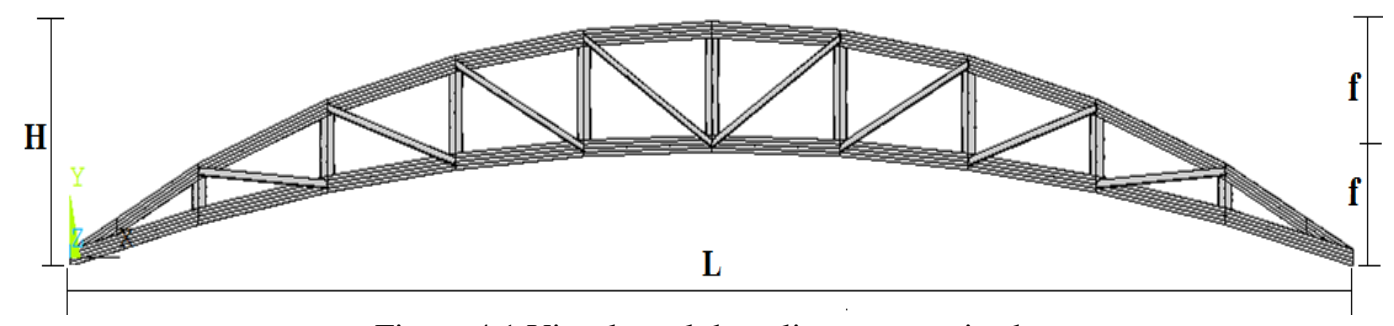

Figura 4.1 Vista lateral da treliça parametrizada.

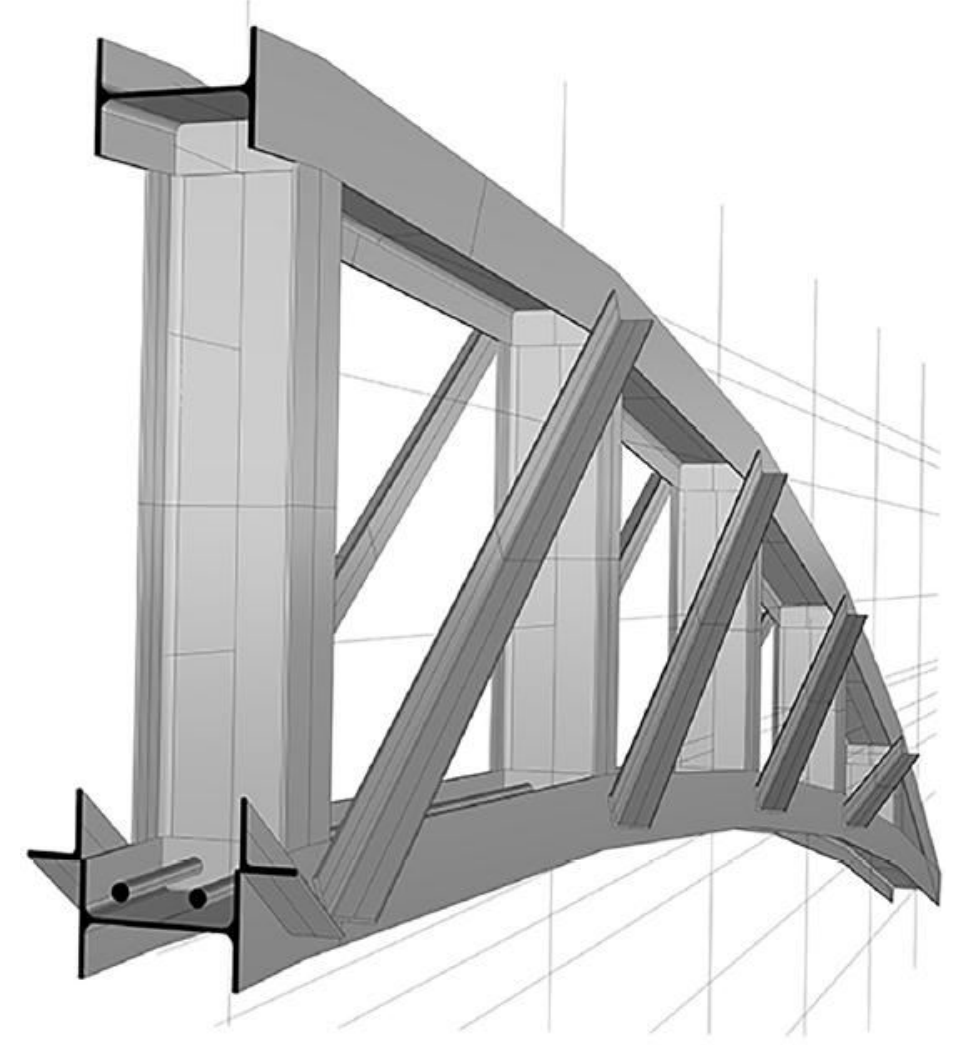

Figura 4.2 Perspectiva da simetria da treliça parametrizada. 
Na Figura 4.3 é apresentado o modelo estrutural completo da treliça de $10 \mathrm{~m}$ de vão. Para melhor identificação da geometria dos modelos são apresentadas as Tabelas 4.2 até 4.6, e nas Figuras 4.4 até 4.8 com as coordenadas nodais de meia treliça, devido à simetria existente.
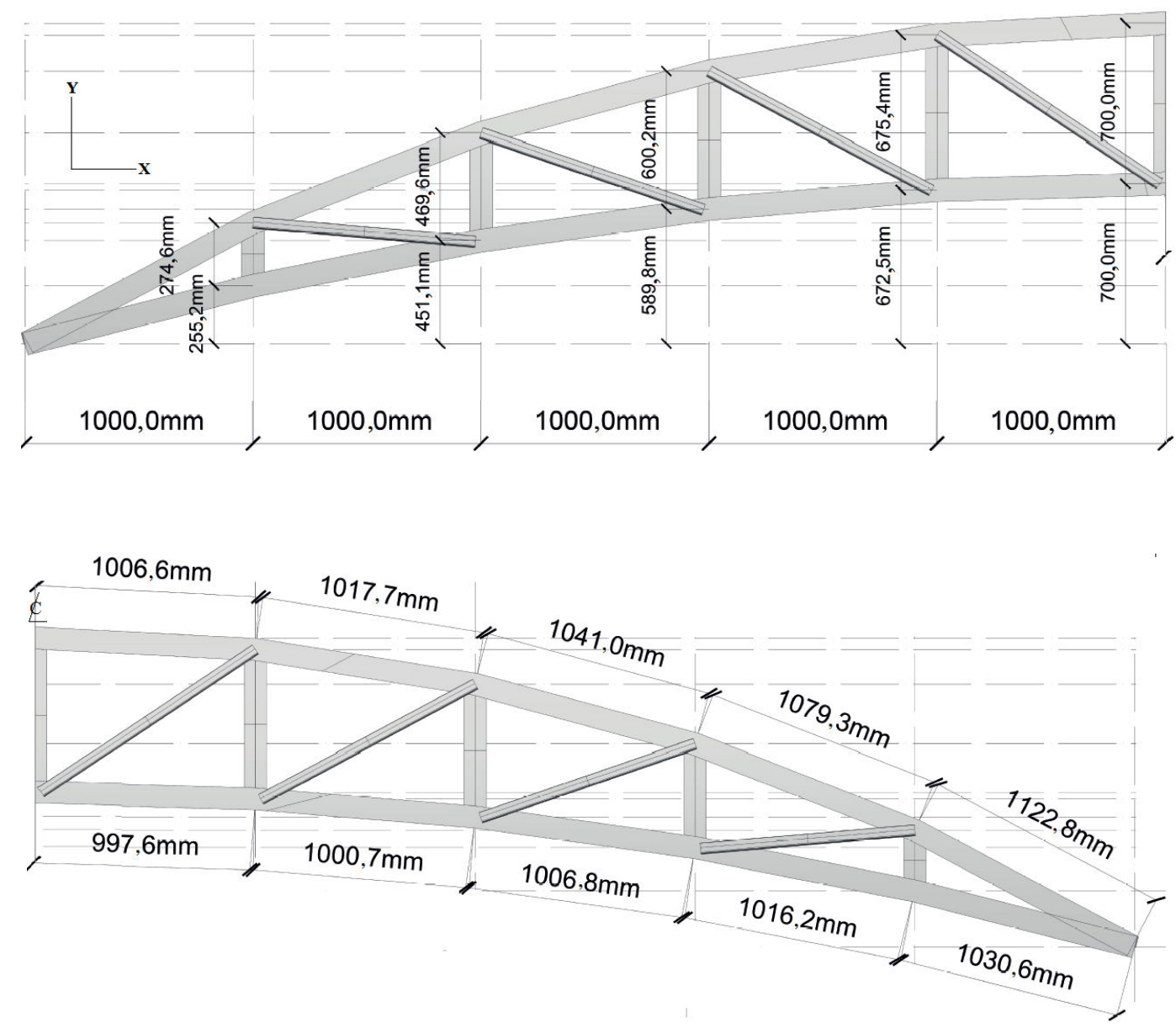

Figura 4.3 Identificação das posições dos nós do modelo de treliça de 10 m de vão.

Tabela 4.2 Coordenadas nós da simetria do modelo de treliças de 10 m de vão.

\begin{tabular}{|c|c|c|c|c|c|}
\hline \multicolumn{3}{|c|}{ Corda superior } & \multicolumn{3}{|c|}{ Corda inferior } \\
\hline $\mathrm{N}^{\circ}$ do nó & $\mathrm{X}(\mathrm{mm})$ & $\mathrm{Y}(\mathrm{mm})$ & $N^{\circ}$ do nó & $\mathrm{X}(\mathrm{mm})$ & $\mathrm{Y}(\mathrm{mm})$ \\
\hline 1 & 0 & 0 & 1 & 0 & 0 \\
\hline 2 & 1.000 & 529,818 & 7 & 1.000 & 255,178 \\
\hline 3 & 2.000 & 920,712 & 8 & 2.000 & 451,144 \\
\hline 4 & 3.000 & $1.189,995$ & 9 & 3.000 & 589,82 \\
\hline 5 & 4.000 & $1.347,93$ & 10 & 4.000 & 672,518 \\
\hline 6 & 5.000 & 1.400 & 11 & 5.000 & 700 \\
\hline
\end{tabular}




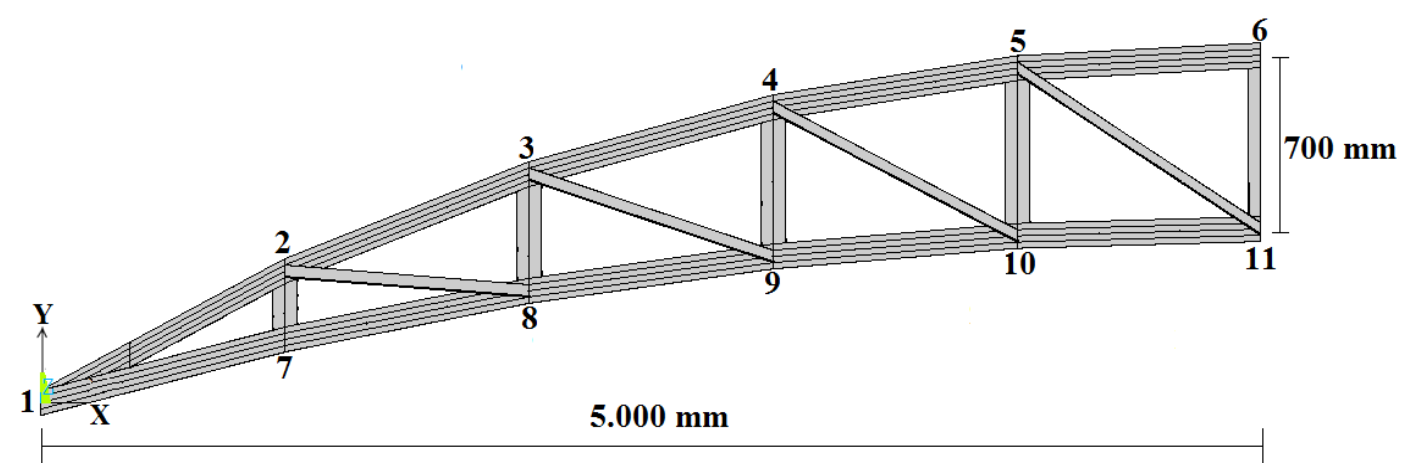

Figura 4.4 Identificações dos nós da simetria do modelo de treliça de $10 \mathrm{~m}$ de vão.

Tabela 4.3 Coordenadas nós da simetria do modelo de treliças de 20 m de vão.

\begin{tabular}{|c|c|c|c|c|c|}
\hline \multicolumn{3}{|c|}{ Corda superior } & \multicolumn{3}{|c|}{ Corda inferior } \\
\hline $\mathrm{N}^{\circ}$ do nó & $\mathrm{X}(\mathrm{mm})$ & $\mathrm{Y}(\mathrm{mm})$ & $\mathrm{N}^{\circ}$ do nó & $\mathrm{X}(\mathrm{mm})$ & $\mathrm{Y}(\mathrm{mm})$ \\
\hline 1 & 0 & 0 & 1 & 0 & 0 \\
\hline 2 & 2.000 & $1.143,691$ & 7 & 2.000 & 547,824 \\
\hline 3 & 4.000 & $1.980,572$ & 8 & 4.000 & 967,726 \\
\hline 4 & 6.000 & $2.554,162$ & 9 & 6.000 & $1.264,467$ \\
\hline 5 & 8.000 & $2.889,573$ & 10 & 8.000 & $1.441,27$ \\
\hline 6 & 10.000 & 3.000 & 11 & 10.000 & 1.500 \\
\hline
\end{tabular}

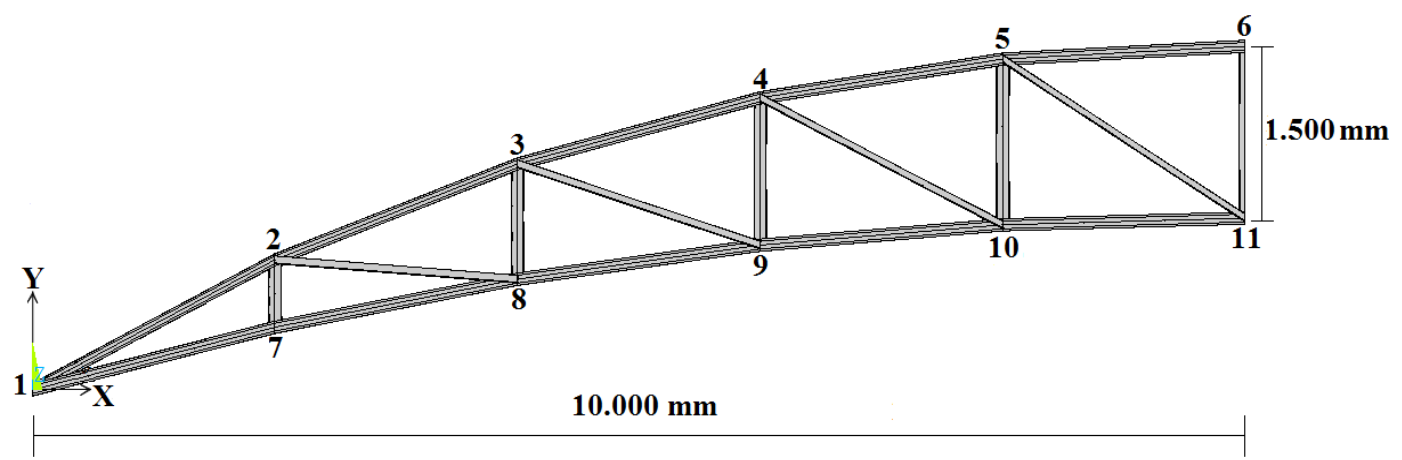

Figura 4.5 Identificações dos nós da simetria do modelo de treliça de 20 m de vão. 
Tabela 4.4 Coordenadas nós da simetria do modelo de treliças de $40 \mathrm{~m}$ de vão.

\begin{tabular}{|c|c|c|c|c|c|}
\hline \multicolumn{3}{|c|}{ Corda superior } & \multicolumn{3}{|c|}{ Corda inferior } \\
\hline $\mathrm{N}^{\circ}$ do nó & $\mathrm{X}(\mathrm{mm})$ & $\mathrm{Y}(\mathrm{mm})$ & $\mathrm{N}^{\circ}$ do nó & $\mathrm{X}(\mathrm{mm})$ & $\mathrm{Y}(\mathrm{mm})$ \\
\hline 1 & 0 & 0 & 1 & 0 & 0 \\
\hline 2 & 2.500 & $1.507,852$ & 10 & 2.500 & 715,383 \\
\hline 3 & 5.000 & $2.759,130$ & 11 & 5.000 & $1.329,156$ \\
\hline 4 & 7.500 & $3.782,075$ & 12 & 7.500 & $1.844,112$ \\
\hline 5 & 10.000 & $4.596,756$ & 13 & 10.000 & $2.262,514$ \\
\hline 6 & 12.500 & $5.217,491$ & 14 & 12.500 & $2.586,152$ \\
\hline 7 & 15.000 & $5.654,319$ & 15 & 15.000 & $2.816,379$ \\
\hline 8 & 17.500 & $5.913,889$ & 16 & 17.500 & $2.954,141$ \\
\hline 9 & 20.000 & 6.000 & 17 & 20.000 & 3.000 \\
\hline
\end{tabular}

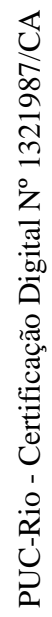

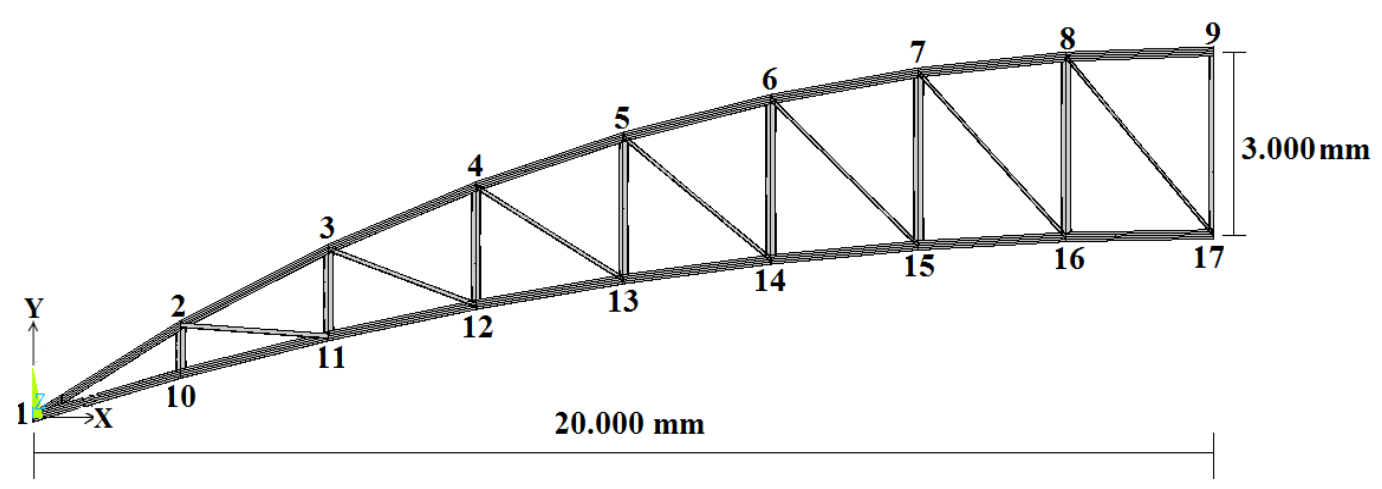

Figura 4.6 Identificações dos nós da simetria do modelo de treliça de 40 m de vão. 
Tabela 4.5 Coordenadas nós da simetria do modelo de treliças de $80 \mathrm{~m}$ de vão.

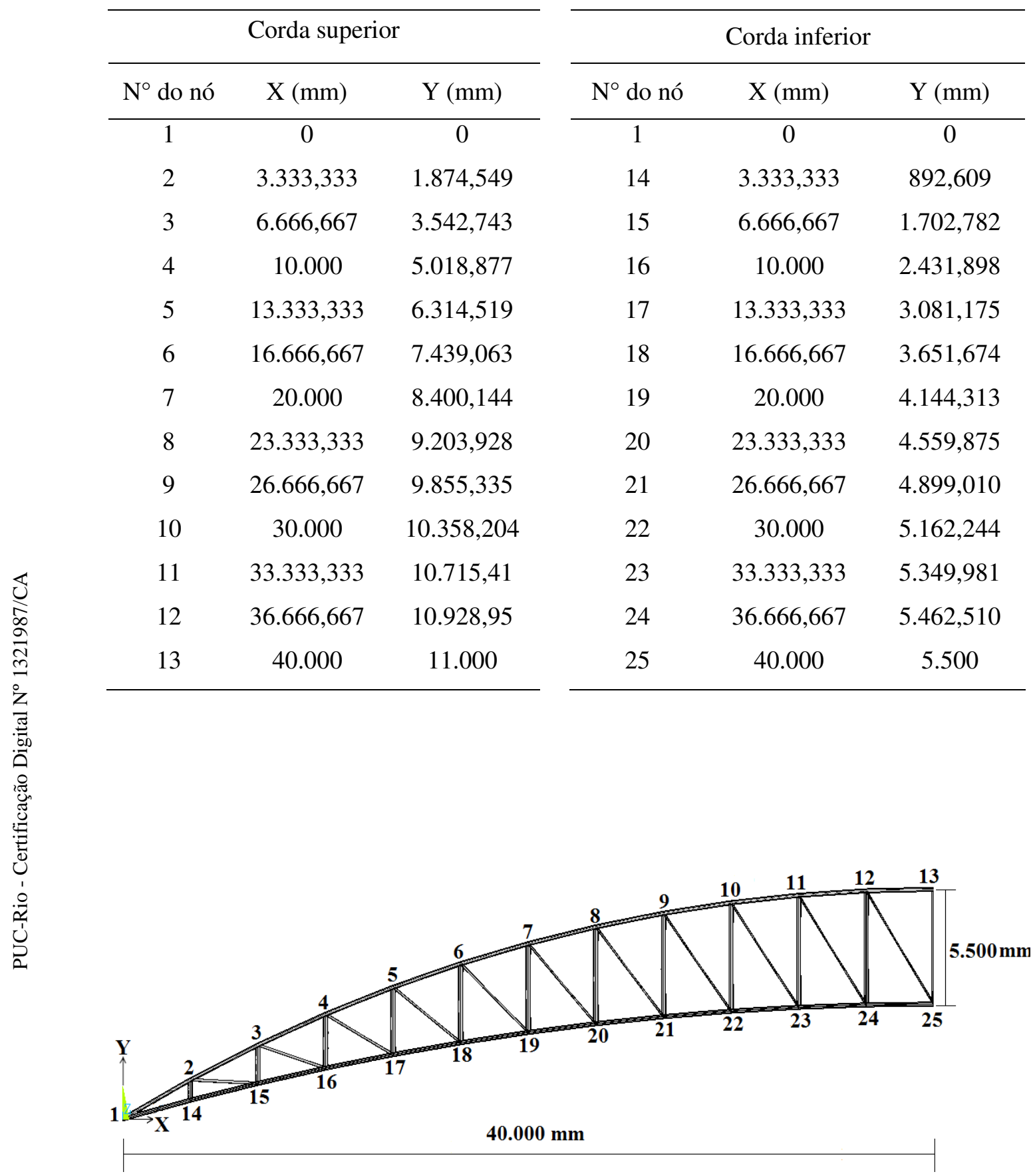

Figura 4.7 Identificações dos nós da simetria do modelo de treliça de $80 \mathrm{~m}$ de vão. 
Tabela 4.6 Coordenadas nós da simetria do modelo de treliças de 120 m de vão.

\begin{tabular}{|c|c|c|c|c|c|}
\hline \multicolumn{3}{|c|}{ Corda superior } & \multicolumn{3}{|c|}{ Corda inferior } \\
\hline $\mathrm{N}^{\circ}$ do nó & $\mathrm{X}(\mathrm{mm})$ & $\mathrm{Y}(\mathrm{mm})$ & $\mathrm{N}^{\circ}$ do nó & $\mathrm{X}(\mathrm{mm})$ & $\mathrm{Y}(\mathrm{mm})$ \\
\hline 1 & 0 & 0 & 1 & 0 & 0 \\
\hline 2 & 3750 & $1.698,701$ & 18 & 3.750 & 827,536 \\
\hline 3 & 7500 & $3.397,401$ & 19 & 7.500 & $1.655,072$ \\
\hline 4 & 11250 & $5.096,102$ & 20 & 11.250 & $2.482,608$ \\
\hline 5 & 15000 & $6.794,803$ & 21 & 15.000 & $3.310,144$ \\
\hline 6 & 18750 & $7.951,187$ & 22 & 18.750 & $3.894,308$ \\
\hline 7 & 22500 & $9.107,57$ & 23 & 22.500 & $4.478,473$ \\
\hline 8 & 26250 & $10.263,954$ & 24 & 26.250 & $5.062,637$ \\
\hline 9 & 30000 & $11.420,337$ & 25 & 30.000 & $5.646,801$ \\
\hline 10 & 33750 & $12.093,896$ & 26 & 33.750 & $5.994,607$ \\
\hline 11 & 37500 & $12.767,455$ & 27 & 37.500 & $6.342,413$ \\
\hline 12 & 41250 & $13.441,014$ & 28 & 41.250 & $6.690,218$ \\
\hline 13 & 45000 & $14.114,573$ & 29 & 45.000 & $7.038,024$ \\
\hline 14 & 48750 & $14.335,929$ & 30 & 48.750 & $7.153,518$ \\
\hline 15 & 52500 & $14.557,286$ & 31 & 52.500 & $7.269,012$ \\
\hline 16 & 56250 & $14.778,643$ & 32 & 56.250 & $7.384,506$ \\
\hline 17 & 60000 & 15.000 & 33 & 60.000 & 7.500 \\
\hline
\end{tabular}

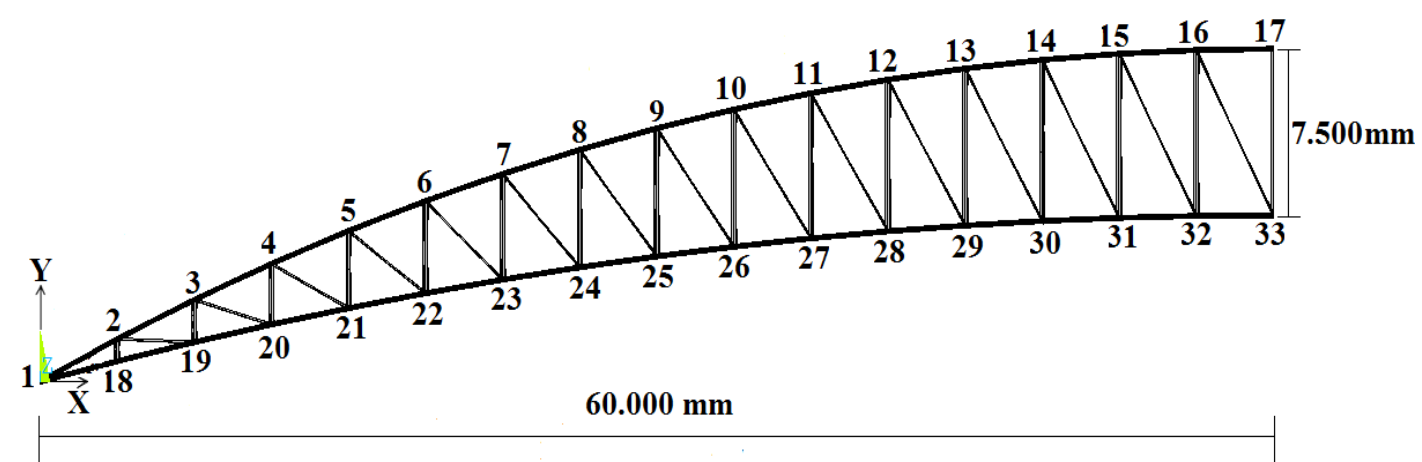

Figura 4.8 Identificações dos nós da simetria do modelo de treliça de 120 m de vão. 


\section{2.}

\section{Características físicas e geométricas das seções}

Neste item são apresentadas as principais características referentes aos modelos estruturais em análise, destacando-se as propriedades físicas e geométricas das seções, bem como os materiais empregados.

\subsection{1.}

\section{Características físicas dos materiais usados}

Para os modelos estruturais, no que diz respeito às características físicas o perfil de aço empregado foi o ASTM A572 grau 50 que tem módulo de elasticidade $E_{t}=200.000 \mathrm{MPa}$, tensão limite de escoamento $f_{t y}=345 \mathrm{MPa}$, coeficiente de Poisson $v=0,3$, massa especifica de $7.850 \mathrm{~kg} / \mathrm{m}^{3}$, coeficiente de dilatação térmica de $12 \cdot 10^{-6} /{ }^{\circ} \mathrm{C}$.

As características das tensões nas armaduras de protensão em concreto e aço protendido são limitadas a certos valores máximos (item 9.6.1.2.1 da norma NBR 6118: 2014), a fim de se reduzir o risco de ruptura dos cabos e também de evitar perdas exageradas por relaxação do aço. Os cabos de aço utilizados para os modelos estudados são cordoalhas de fios trefilados de alta resistência e de relaxação baixa (RB) de fabricação Belgo Mineira (capítulo 2, item 2.3).

Para os cabos de protensão utilizado nos modelos estruturais protendidos, no que tange às características físicas do cabo de aço empregado foi o ASTM A-421, que possui módulo de elasticidade longitudinal igual $E_{c}=195.000 \mathrm{MPa}$, valor característico da resistência à tração $f_{p t k}=1.900 \mathrm{MPa}$, tensão limite de escoamento $f_{p y k}=1.710 \mathrm{MPa}$. A tensão $\mathrm{f}_{\text {pyk }}$ é um valor convencional correspondente à deformação especifica permanente de $0,2 \%$, que é também considerada como a tensão correspondente a um alongamento unitário total de $1 \%$. As propriedades dos materiais utilizados também estão resumidas na Tabela 4.7. 
Tabela 4.7 Propriedades físicas dos perfiles e cabos utilizados na modelagem.

\begin{tabular}{ccccc}
\hline Elemento & $\mathrm{E}(\mathrm{MPa})$ & $\mathrm{f}_{\mathrm{y}}(\mathrm{MPa})$ & $\mathrm{f}_{\mathrm{u}}(\mathrm{MPa})$ & $v$ \\
\hline Perfil & 200.000 & 345 & 450 & 0,3 \\
Cordoalha de protensão & 195.000 & 1.710 & 1.900 & 0,3 \\
\hline
\end{tabular}

\subsection{2.}

\section{Características geométricas das seções.}

As treliças sem e com protensão em forma de arco deste estudo são constituídas por seção transversal do perfil tipo W nas cordas superior, inferior e montante. Nas diagonais têm-se cantoneiras duplas trabalhando como peça múltipla. Na Figura 4.9 é mostrada a geometria dos perfis utilizados.

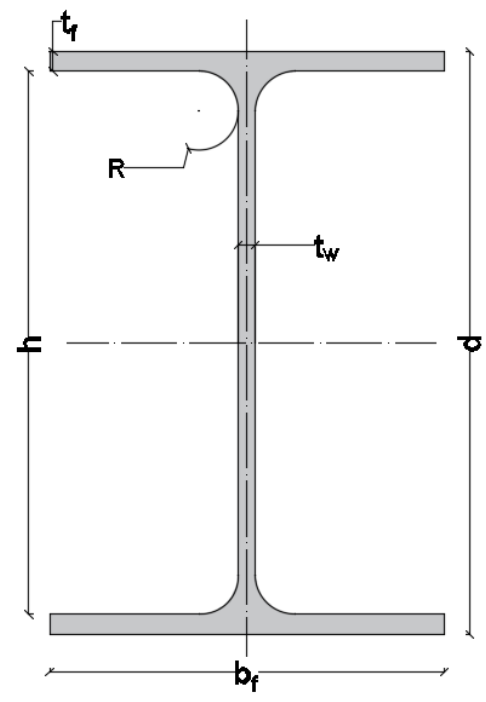

(a) Perfil tipo $\mathrm{W}$

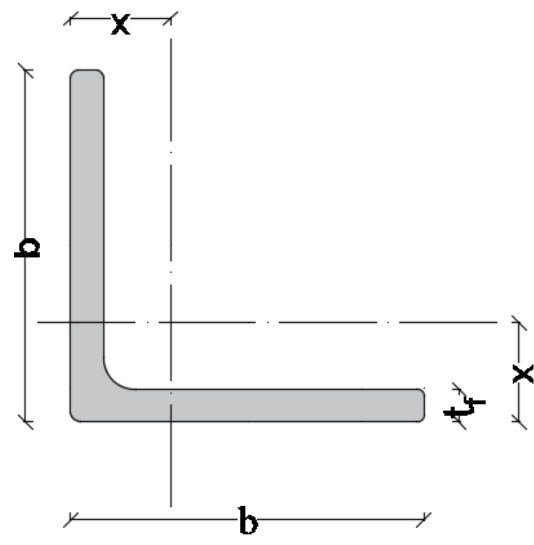

(b) Perfil tipo cantoneira de abas iguais

Figura 4.9 Perfis de aço utilizados.

Conforme ilustrado nas Figuras 4.10 e 4.11, são apresentadas várias perspectivas dos detalhes escolhidos das ligações com perfis W e cantoneira, adotadas para diferentes modelos estruturais estudados. Pode-se observar na Figura 4.10.a uma vista lateral do detalhe da ligação entre corda superior, o montante e a diagonais. Ressaltando-se que os ângulos nas ligações entre esses elementos são variáveis para cada um dos cinco modelos estruturais. A treliça tem duas cantoneiras soldadas nas duas abas e conectadas no centro da alma do perfil, como ilustra a Figura 4.10.b. 


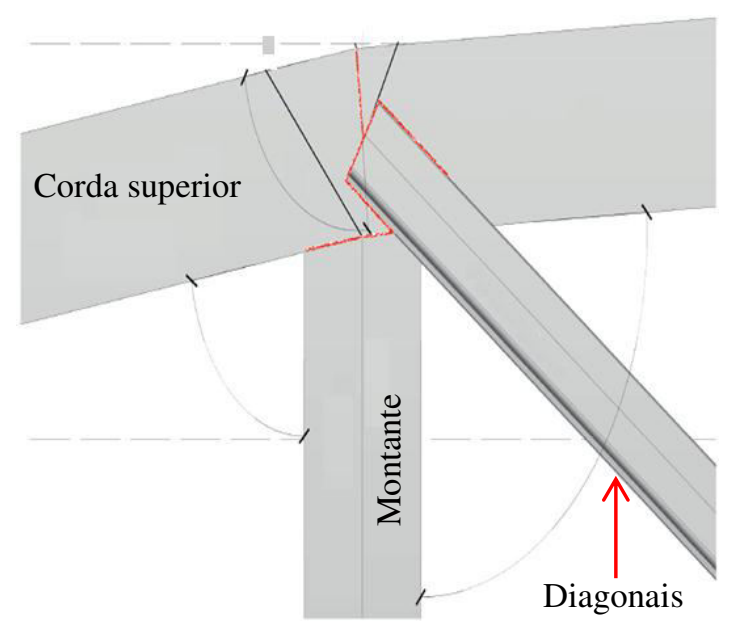

(a) Vista 2D

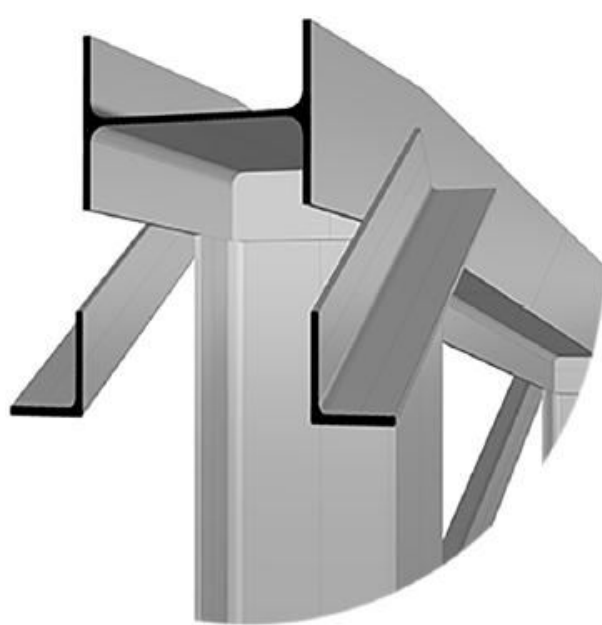

(b) Perspectiva

Figura 4.10 Detalhe da ligação da corda superior.

A Figura 4.11.a apresenta uma vista lateral do detalhe da ligação do centro da treliça na corda inferior, com o montante e duas cantoneiras. No centro da união as cantoneiras tem uma separação de $50 \mathrm{~mm}$. Os ângulos mostrados entre esses elementos são variáveis para cada modelo. Na Figura 4.11.b uma perspectiva do detalhe da ligação da corda inferior.

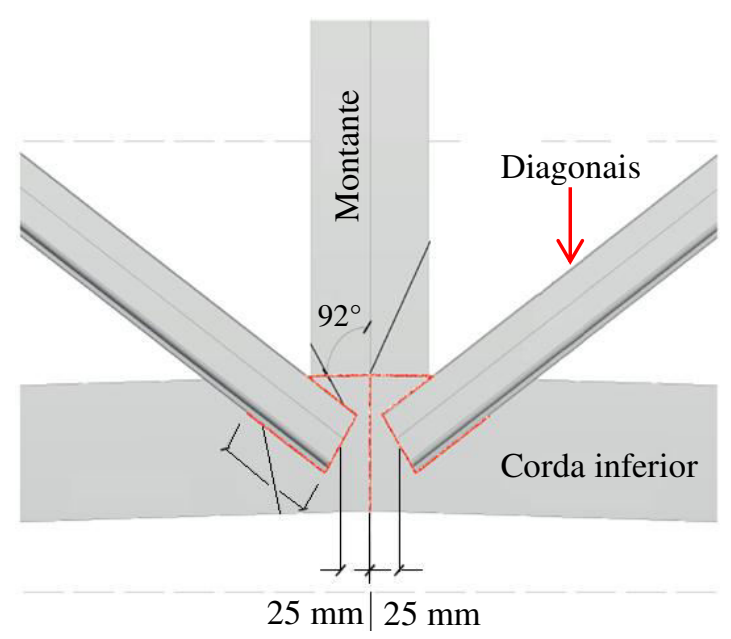

(a) Vista 2D

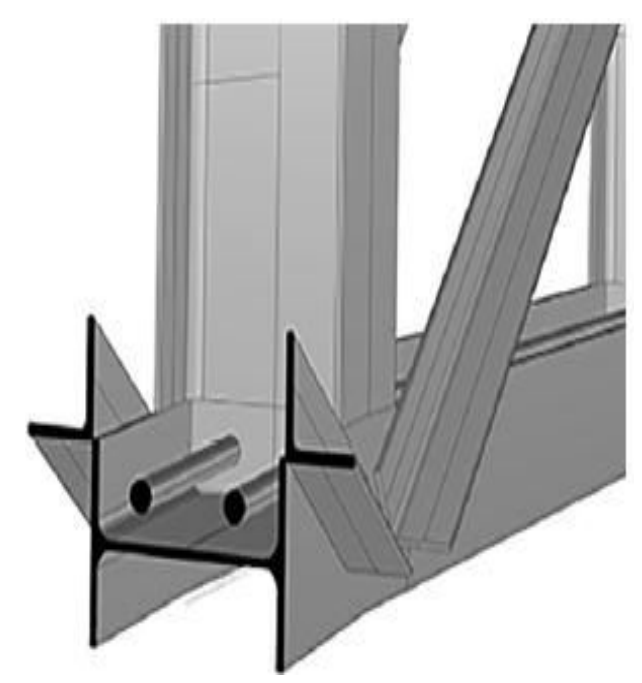

(b) Perspectiva.

Figura 4.11. Detalhe da ligação da corda inferior no centro da treliça.

A ancoragem do cabo constitui-se basicamente de uma chapa de aço nos apoios da treliça, com as seguintes espessuras: 9,3 mm (Para $A_{10}$ e $\left.B_{20}\right), 16 \mathrm{~mm}$ (C40), $19 \mathrm{~mm}\left(\mathrm{D}_{80}\right)$ e 22,4 mm $\left(\mathrm{E}_{120}\right)$. Na Figura 4.12 é mostrada a configuração da chapa de ancoragem dos cabos, onde sempre são usadas duas unidades. 


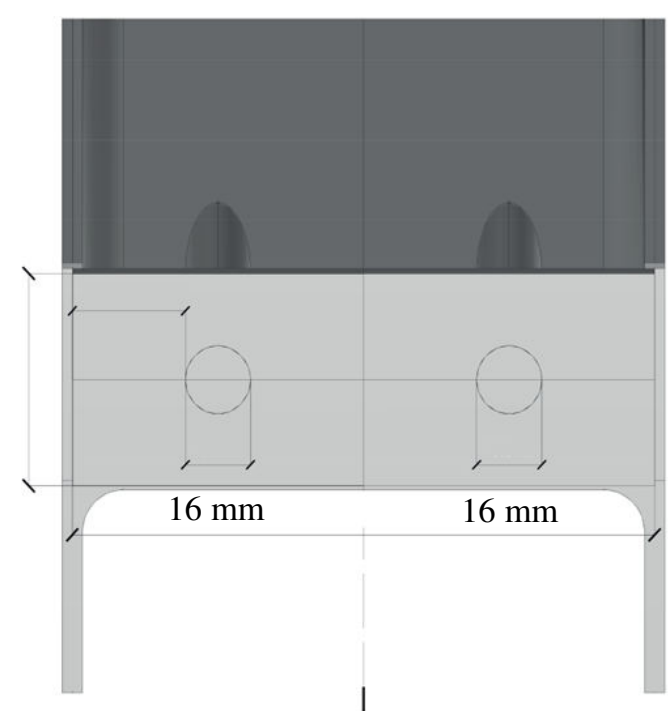

(a) Vista lateral

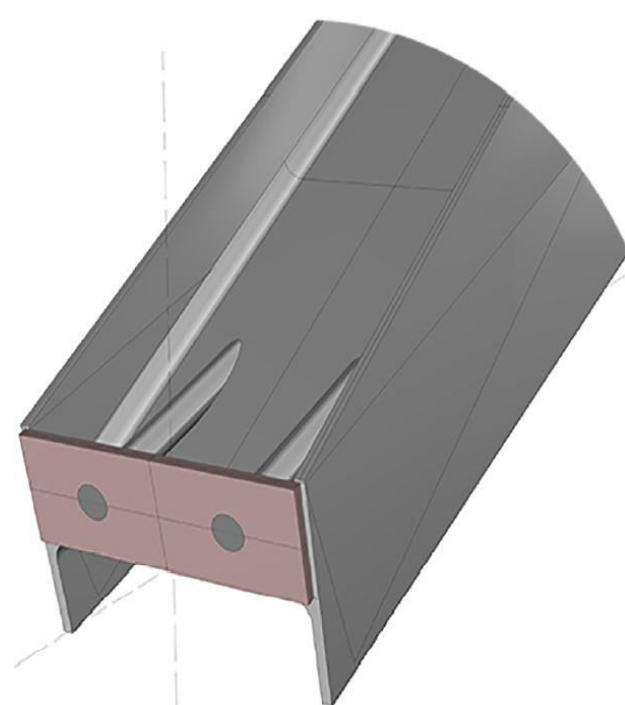

(b) Perspectiva

Figura 4.12 Perfis detalhe da chapa de ancoragem.

A geometria dos posicionamentos dos cabos de protensão foi poligonal, o traçado foi construído na corda inferior da treliça. Para construção de traçado utilizou-se desviadores constituídos por chapa de aço. Ressaltando-se que a configuração poligonal é mais complicada, pois exige maior número de desviadores, além de detalhes construtivos específicos. A Figura 4.13 ilustra o esquema do posicionamento do cabo e o desviador.

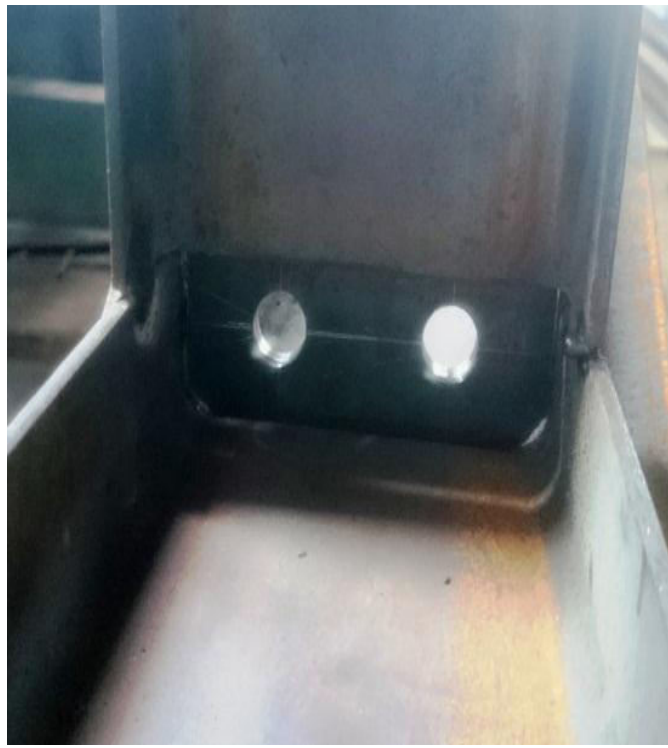

(a) Detalhe da chapa como desviador

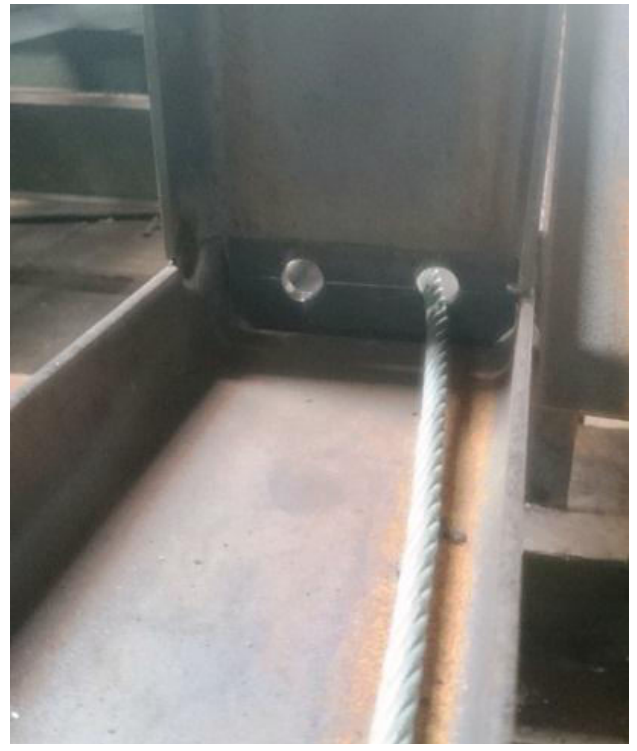

(b) Posicionamento do cabo

Figura 4.13 Esquema de desviador e cabo. 


\section{3.}

\section{Cargas atuantes sobre os modelos estruturais.}

Para o projeto das treliças protendidas são consideradas duas ações principais: 1) a ação gravitacional constituída pelos pesos próprios da estrutura, terças, telhas e acessórios; 2) a ação do vento. Neste item são apresentados os resultados das ações atuantes nos modelos, determinadas de acordo com as recomendações das ABNT NBR 8800:2008, ABNT NBR 6123:1988 e NBR: 6120:1980.

\subsection{1.}

\section{Calculo da ação do vento.}

Como foi apresentado no capitulo três desta tese, no presente item são considerados os fatores e parâmetros que foram usados para a determinação da pressão dinâmica do vento para os diferentes modelos.

$\mathrm{V}_{0}=35 \mathrm{~m} / \mathrm{s}$ valor assumido para o Rio de Janeiro, $\mathrm{S}_{1}=1$ (fator topográfico) e $S_{3}=0,95$ (fator estatístico), válidos para todos os modelos estudados.

No que diz respeito ao fator $\mathrm{S}_{2}$, ele é usado no cálculo da velocidade do vento em uma altura $\mathrm{z}$ acima do nível geral do terreno é obtido por uma expressão em função do fator de rajada (equação 3.5) e os parâmetros meteorológicos (categoria III e classe C) da NBR612. Foram adotados para os diferentes modelos estruturais os seguintes valores:

$$
\mathrm{S}_{2, \mathrm{~B}}=0,85, \mathrm{~S}_{2, \mathrm{~B}}=0,87, \mathrm{~S}_{2, \mathrm{C}}=0,91, \mathrm{~S}_{2, \mathrm{D}}=0,94 \text { e } \mathrm{S}_{2, \mathrm{E}}=0,96
$$

Para o calculo da Velocidade Característica do Vento $V_{k}$ obtidos para os diferentes modelos, os seguintes valores foram encontrados:

$$
\mathrm{V}_{\mathrm{k}, \mathrm{A}}=28,26 \mathrm{~m} / \mathrm{s}, \mathrm{V}_{\mathrm{k}, \mathrm{B}}=28,93 \mathrm{~m} / \mathrm{s}, \mathrm{V}_{\mathrm{k}, \mathrm{C}}=30,26 \mathrm{~m} / \mathrm{s}, \mathrm{V}_{\mathrm{k}, \mathrm{D}}=31,26 \mathrm{~m} / \mathrm{s} \text { e } \mathrm{V}_{\mathrm{k}, \mathrm{E}}=31,92 \mathrm{~m} / \mathrm{s}
$$

A pressão dinâmica (q) é determinada pela Equação 4.2 (ver capitulo 3 item 3.4) e para os diferentes modelos estudados e os seguintes valores foram obtidos:

$$
\mathrm{q}_{\mathrm{A}}=489,6 \mathrm{~N} / \mathrm{m}^{2}, \mathrm{q}_{\mathrm{B}}=513 \mathrm{~N} / \mathrm{m}^{2}, \mathrm{q}_{\mathrm{C}}=561,2 \mathrm{~N} / \mathrm{m}^{2}, \mathrm{q}_{\mathrm{D}}=598,8 \mathrm{~N} / \mathrm{m}^{2} \text { e } \mathrm{q}_{\mathrm{E}}=624,6 \mathrm{~N} / \mathrm{m}^{2} \text {. }
$$


Seguem-se os valores obtidos dos coeficientes aerodinâmicos empregados em coberturas curvas para pressão externa e interna.

\section{Coeficiente de pressão externa $C_{p e}$}

Os valores dos coeficientes de pressão externa foram determinados de acordo as Tabelas 24 a 29 do anexo E.1 da ABNT NBR 6123 (1988) para cobertura abóbadas cilíndricas de seção circular. Ressaltando-se que os dados obtidos foram os mais desfavoráveis e serão avaliados os seguintes eventos: vento perpendicular à geratriz da cobertura, vento paralelo à geratriz da cobertura e para vento obliquo à geratriz da cobertura. A Tabela 4.8 e Figura 4.14, mostram os valores mais desfavoráveis dos coeficientes pressão externos e a representação correspondente na cobertura.

Tabela 4.8 Coeficiente de pressão externa do vento a sucção para seção circular.

\begin{tabular}{ccccccccc}
\hline $\begin{array}{c}\text { Modelos } \\
\text { de }\end{array}$ & $\mathrm{f} / \mathrm{L}_{2}$ & $\mathrm{~h} / \mathrm{L}_{2}$ & \multicolumn{6}{c}{ Coeficientes de pressão externa $\mathrm{C}_{\mathrm{pe}}$ das seis partes } \\
\cline { 5 - 9 } Treliças & $\mathrm{C}_{1}$ & $\mathrm{C}_{2}$ & $\mathrm{C}_{3}$ & $\mathrm{C}_{4}$ & $\mathrm{C}_{5}$ & $\mathrm{C}_{6}$ \\
\hline $\mathrm{A}_{10}$ & $1 / 5$ & $1 / 2$ & $-1,2$ & $-0,7$ & $-0,9$ & $-0,8$ & $-0,3$ & $-0,2$ \\
$\mathrm{~B}_{20}$ & $1 / 5$ & $1 / 4$ & $-0,9$ & $-0,6$ & $-0,8$ & $-0,8$ & $-0,4$ & $-0,2$ \\
$\mathrm{C}_{40}$ & $1 / 5$ & $1 / 8$ & $-0,5$ & $-0,5$ & $-0,7$ & $-0,7$ & $-0,5$ & $-0,2$ \\
$\mathrm{D}_{80}$ & $1 / 5$ & $1 / 8$ & $-0,5$ & $-0,5$ & $-0,7$ & $-0,7$ & $-0,5$ & $-0,2$ \\
$\mathrm{E}_{120}$ & $1 / 10$ & $1 / 8$ & $-1,0$ & $-0,4$ & $-0,4$ & $-0,4$ & $-0,4$ & $-0,3$ \\
\hline
\end{tabular}

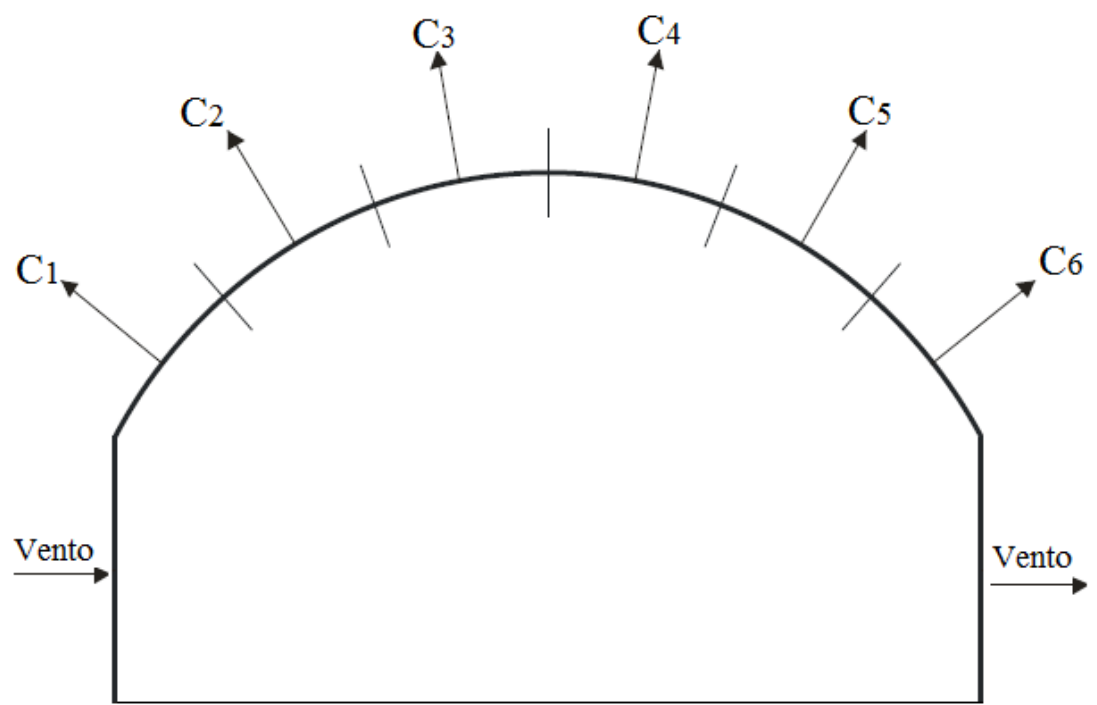

Figura 4.14 Representação da atuação dos coeficientes de pressão externa do vento perpendicular à geratriz da cobertura (vento $90^{\circ}$ ). 


\section{Coeficiente de pressão interna $C_{p i}$}

Segundo o item 6.2.5 da ABNT NBR6123 (1988) para edificações com paredes internas permeáveis a pressão interna pode ser considerada uniforme. Nesse caso devem ser adotados os seguintes valores para o coeficiente de pressão interna, admitindo-se que as estruturas possuem faces igualmente permeáveis: $\mathrm{C}_{\mathrm{pi}}=0$ ou $+0,3$ (considerar os valores mais críticos). Portanto, todos os modelos foram considerados o coeficiente de pressão interna, com caso mais desfavorável $\mathrm{C}_{\mathrm{pi}}=+0,3$ para esse tipo de cobertura submetida à efeitos de sucção.

Em resumo os coeficientes aerodinâmicos de pressão interna e externa na cobertura, mais desfavoráveis atuantes sobre os modelos das treliças ocorrem para o caso: $\mathrm{C}_{\mathrm{pe}}\left(90^{\circ}\right)-\mathrm{C}_{\mathrm{pi}}(+0,3)$. A Tabela 4.9 apresenta os resultados obtidos para o carregamento devido ao vento w, considerando-se a largura efetiva de influência $\left(\mathrm{L}_{\mathrm{e}}=10 \mathrm{~m}\right)$ entre terças.

Tabela 4.9 Composição dos valores das forças do vento mais desfavorável.

\begin{tabular}{ccccccc}
\hline \multirow{2}{*}{$\begin{array}{c}\text { Modelos } \\
\text { de } \\
\text { Treliças }\end{array}$} & \multicolumn{5}{c}{ Força do vento para as partes da curvatura (kN/mm) } \\
\cline { 2 - 7 } & $\mathrm{W}_{1}$ & $\mathrm{~W}_{2}$ & $\mathrm{~W}_{3}$ & $\mathrm{~W}_{4}$ & $\mathrm{~W}_{5}$ & $\mathrm{~W}_{6}$ \\
\hline $\mathrm{A}_{10}$ & $-7,34$ & $-4,90$ & $-5,88$ & $-5,39$ & $-2,94$ & $-2,45$ \\
$\mathrm{~B}_{20}$ & $-6,16$ & $-4,62$ & $-5,64$ & $-5,64$ & $-3,59$ & $-2,56$ \\
$\mathrm{C}_{40}$ & $-4,49$ & $-4,49$ & $-5,61$ & $-5,61$ & $-4,49$ & $-2,81$ \\
$\mathrm{D}_{80}$ & $-4,79$ & $-4,79$ & $-5,99$ & $-5,99$ & $-4,79$ & $-2,99$ \\
$\mathrm{E}_{120}$ & $-8,12$ & $-4,37$ & $-4,37$ & $-4,37$ & $-4,37$ & $-3,75$ \\
\hline
\end{tabular}

A Figura 4.15 mostra o esquema da ação do vento nas tipologias para as treliças $\mathrm{A}_{10}, \mathrm{~B}_{20}, \mathrm{C}_{4} 0, \mathrm{D}_{80}$ e $\mathrm{E}_{120}$ em função das variações paramétricas. $\mathrm{O}$ arco da treliça está dividido em seis partes iguais, sendo a carga distribuída consideradas constante em cada uma das seis partes. $\mathrm{O}$ valor da ação do vento $\mathrm{W}$ considerandose os resultados dos coeficientes $\left(\mathrm{C}_{\mathrm{pe}}-\mathrm{C}_{\mathrm{pi}}\right)$ e pressão dinâmica (Figura 4.16) é dado por: 


$$
\mathrm{W}=\mathrm{q}\left(\mathrm{C}_{\mathrm{pe}}-\mathrm{C}_{\mathrm{pi}}\right) \mathrm{L}_{\mathrm{e}}
$$

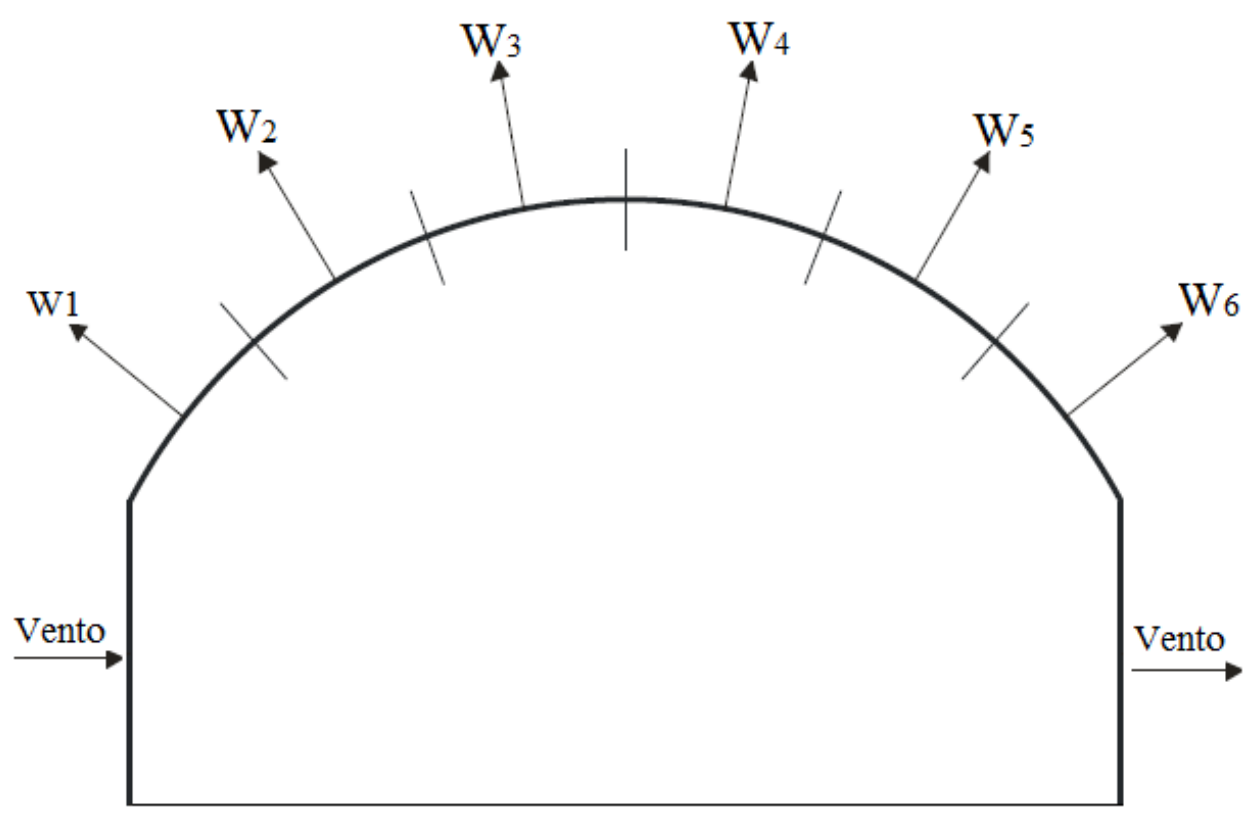

Figura 4.15 Representação paramétrica da atuação da carga distribuída do vento a sucção. 


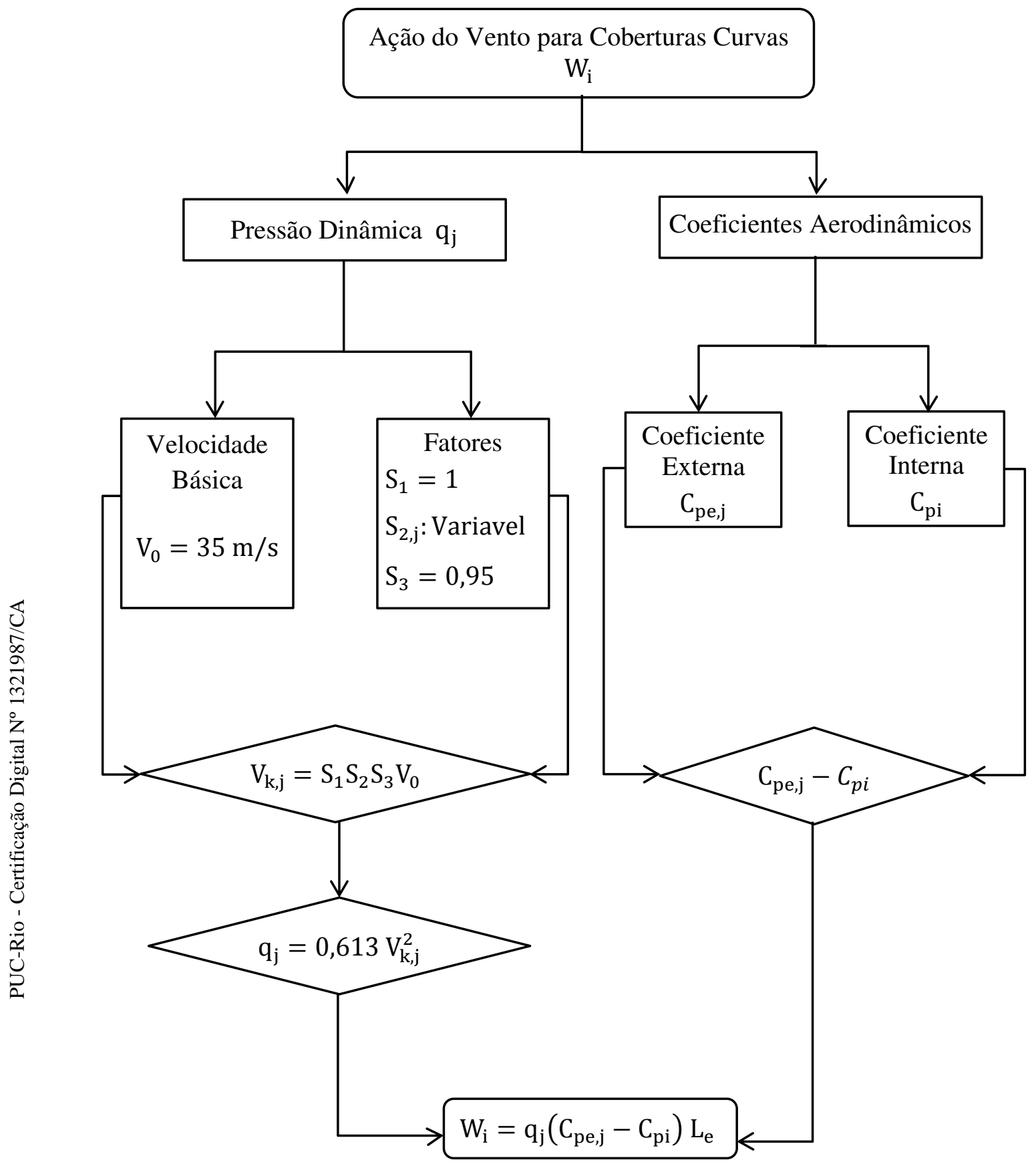

Figura 4.16 Fluxograma para o cálculo da ação do vento para cobertura curva. 


\subsection{2.}

\section{Cálculo das ações permanentes}

Para todos os modelos considerou-se uma ação permanente de $0,150 \mathrm{kN} / \mathrm{m}^{2}$, levando-se em conta o peso próprio das terças, telhas, tirantes, e demais elementos que permanecem fixos na cobertura. Ressaltando-se que o peso próprio das treliças é considerado automaticamente na modelagem. Na Tabela 4.10 são expostos os valores da ação permanente nas tipologias levando-se em consideração geometria de cada treliça.

Tabela 4.9 Ação permanente (G) nos modelos.

\begin{tabular}{ccc}
$\begin{array}{c}\text { Modelos de } \\
\text { Treliças }\end{array}$ & $\begin{array}{c}\text { Distância entre } \\
\text { Montante }(\mathrm{m})\end{array}$ & $\begin{array}{c}\mathrm{G} \\
(\mathrm{kN})\end{array}$ \\
\hline $\mathrm{A}_{10}$ & 1 & 1,5 \\
$\mathrm{~B}_{20}$ & 2 & 3 \\
$\mathrm{C}_{40}$ & 2,5 & 3,75 \\
$\mathrm{D}_{80}$ & 3,33 & 5,03 \\
$\mathrm{E}_{120}$ & 3,75 & 5,63 \\
\hline
\end{tabular}

\subsection{3.}

\section{Cálculo da força de protensão nas treliças protendidas}

A força de protensão ideal $\mathrm{P}_{\mathrm{opt}, \mathrm{c}}$ (ótima) foi obtida de acordo com a Equação 2.5 (ver capítulo 2 item 2.2). Ressalta-se que o nível de força de protensão ideal aplicado nas estruturas foi definido como aquele em que tanto os elementos da treliça como o cabo de protensão permaneçam no regime elástico, ou seja, a condição dada $\mathrm{f}_{\mathrm{cy}} \mathrm{E}_{\mathrm{t}}=\mathrm{f}_{\mathrm{ty}} \mathrm{E}_{\mathrm{c}}$. Além disso o cálculo da força equivalente $\mathrm{P}_{\text {equi, } x}$ foi executado com carregamento externo uniformemente distribuído por partes, ou seja, considerado carregamento por trecho, pois a força do vento distribuída na corda superior das treliças tem variação entre os trechos. 
Para simular a aplicação da força de protensão nas treliças será dada uma variação de deformação $\Delta_{c}$ nos cabos de protensão, fazendo com que esses elementos se deformem, e como consequência, será gerada uma força de tração na corda inferior da treliça. $O$ valor deformação unitária $\Delta_{c}$, diferença de deformação, a ser introduzida nos cabos deve ser tal que produza o esforço axial nos elementos de cabo igual ou próxima ao valor da força de protensão calculada. Sendo assim a tensão no cabo de protensão é:

$$
\sigma_{\mathrm{c}}=\Delta_{\mathrm{c}} \mathrm{E}_{\mathrm{c}}
$$

Então a força de protensão no cabo pode ser escrita da seguinte forma:

$$
F_{c}=\sigma_{c} A_{c}=\Delta_{c} E_{c} A_{c}
$$

sendo $F_{c}$ e $A_{c}$ e a força e área do cabo de protensão, respectivamente.

Então a variação de deformação unitária $\Delta_{c}$ do cabo é função da força, módulo de elasticidade e área do cabo de protensão, dai:

$$
\Delta_{c}=\frac{F_{c}}{E_{c} A_{c}}
$$




\section{4.}

\section{Combinação de ações}

Seguindo-se os critérios do item 4.7 da ABNT NBR 8800 (2008) foram adotadas as seguintes combinações de ações, para avaliação das solicitações mais desfavoráveis atuantes sobre as treliças e nos cabos. Todas as ações foram ponderadas para os estados limites de serviço.

Evento $1=1,25 \mathrm{G}_{\text {permanente }}+1,40 \mathrm{~W}_{\text {vento }}$ (Combinação normal);

Evento $2=1,15 \mathrm{P}_{\text {próprio }}+1,25 \mathrm{P}_{\mathrm{opt}, \mathrm{c}}($ Combinação da fase de construção);

Evento $3=1,25 \mathrm{G}_{\text {permanente }}+1,4 \mathrm{~W}_{\text {vento }}+1,25 \mathrm{P}_{\mathrm{opt}, \mathrm{c}}$ (Combinação normal).

onde

$\mathrm{P}_{\text {próprio: }}$ peso próprio da estrutura de aço;

$\mathrm{G}_{\text {permanente: }}$ carga permanente, devida ao peso-próprio das terças, telhas, tirantes, e demais elementos que permanecem fixos sobre a estrutura;

$\mathrm{W}_{\text {vento: }}$ ação devida ao vento.

Com as ações anteriores fez-se o pré-dimensionamento dos perfis e os cálculos das forças de protensão dos modelos estruturais estudados. Nas Tabelas 4.11 e 4.12 são apresentadas especificações dos perfis e os valores das forças de protensão equivalente $\mathrm{P}_{\text {equi, } \mathrm{x}}$ e ideal $\mathrm{P}_{\mathrm{opt}, \mathrm{c}}$ (ótima).

Considerando-se diferentes valores de área da seção transversal para todos os modelos de treliça, obtém-se diferentes valores para a força máxima de protensão. É importante notar que as características dos cabos de protensão empregados neste trabalho estão associadas a cordoalhas de três e sete fios de aço tipo 190 RB da Belgo Mineira. 
Tabela 4.10 Especificações dos perfis das treliças em cada modelo.

\begin{tabular}{ccccc}
\hline $\begin{array}{c}\text { Modelos } \\
\text { de } \\
\text { Treliças }\end{array}$ & \multicolumn{2}{c}{ Cordas: Superior, inferior e montante } & \multicolumn{2}{c}{ Corda: diagonais } \\
\cline { 2 - 5 } & Perfil W & $\begin{array}{c}\text { Área } \\
\left(\mathrm{mm}^{2}\right)\end{array}$ & $\begin{array}{c}\text { Cantoneiras duplas } \\
\left(\mathrm{mm}^{2}\right)\end{array}$ & $\begin{array}{c}\text { Área } \\
\left(\mathrm{mm}^{2}\right)\end{array}$ \\
\hline $\mathrm{A}_{10}$ & $150 \times 13$ & 1.660 & $50,8 \times 50,8 \times 4,76$ & 458 \\
$\mathrm{~B}_{20}$ & $150 \times 13$ & 1.660 & $63,5 \times 63,5 \times 9,52$ & 952 \\
$\mathrm{C}_{40}$ & $150 \times 29,8$ & 3.850 & $127 \times 127 \times 15,88$ & 2.696 \\
$\mathrm{D}_{80}$ & $200 \times 52$ & 6.690 & $152,4 \times 152,4 \times 19,05$ & 5.444 \\
$\mathrm{E}_{120}$ & $200 \times 86$ & 11.090 & $152,4 \times 152,4 \times 19,05$ & 5.444 \\
\hline
\end{tabular}

Tabela 4.11 Especificações dos cabos de protensão em cada modelo.

\begin{tabular}{ccccc}
\hline $\begin{array}{c}\text { Modelos } \\
\text { de } \\
\text { Treliças }\end{array}$ & Área de Cabo & Designação & $\mathrm{P}_{\text {opt,c }}$ & $\mathrm{P}_{\text {equi, } \mathrm{x}}$ \\
\cline { 2 - 5 } $\mathrm{A}_{10}$ & 60 & $2 \times \theta 3,5-3$ fios & 65,37 & 86,63 \\
$\mathrm{~B}_{20}$ & 120 & $4 \times 0$ 3,5-3 fios & 130,86 & 165,88 \\
$\mathrm{C}_{40}$ & 188 & $4 \times \theta 4,5-3$ fios & 205,27 & 247,5 \\
$\mathrm{D}_{80}$ & 404 & $4 \times \theta 12,7-7$ fios & 440,66 & 559,71 \\
$\mathrm{E}_{120}$ & 606 & $6 \times 012,7-7$ fios & 660,56 & 838,66 \\
\hline
\end{tabular}

Neste capítulo tem-se as geometrias, características físicas, ações atuantes e as combinações de ações nos modelos utilizadas no presente estudo. No capítulo a seguir são apresentados os modelos numérico-computacionais desenvolvidos. 
5

\section{Modelagem por elementos finitos}

\section{1.}

\section{Introdução}

Neste capítulo são apresentadas informações gerais sobre a modelagem computacional desenvolvida através do emprego do software ANSYS 15.0. Neste trabalho, além de detalhes sobre os tipos de elementos finitos utilizados, são abordados parâmetros de entrada da análise linear e não linear física, discretização dos diferentes tipos de treliças modeladas com elementos do tipo sólido, representação dos cabos de protensão com elemento de barra e detalhes das condições de contorno. A seguir são tratados os procedimentos de análise empregados.

\section{2.}

\section{Elementos finitos empregados na modelagem numérica}

A modelagem numérica foi realizada com base em formulações não lineares a partir do emprego do Método dos Elementos Finitos (MEF), avaliando-se o comportamento estrutural de modelos de treliças de aço em forma de arco até sua ruptura. Considerando-se a complexidade do comportamento das treliças em estudo, foram realizadas análises com inclusão dos efeitos da não linearidade física. Para as barras da treliça e para os cabos de protensão foram empregados os tipos de elementos a seguir descritos. 


\subsection{1.}

\section{Solid185}

As discretizações dos modelos numéricos foram elaboradas utilizando-se elementos sólidos SOLID185 presentes na biblioteca de elementos do software ANSYS 15.0 . O elemento SOLID185 é utilizado para modelagem tridimensional de sólidos. Tal elemento é definido por oito nós com três graus de liberdade em cada nó: translações nas direções $\boldsymbol{X}, \boldsymbol{Y}$ e $\boldsymbol{Z}$. Esse elemento possui propriedades de plasticidade, superplasticidade, rigidez à tração, enrijecimento devido ao estado de tensões, deformações devidas à fluência e grandes deformações e rotações. Também é dotado de uma formulação mista que torna capaz de simular deformações em materiais elastoplásticos semi-incompressíveis, além de materiais hiperplásticos incompressíveis. Esse elemento pode ter formato prismático, tetraédrico e piramidal. A geometria homogênea do sólido estrutural e as tensões indicadas nas direções globais do elemento são apresentadas nas Figuras 5.1 e 5.2.

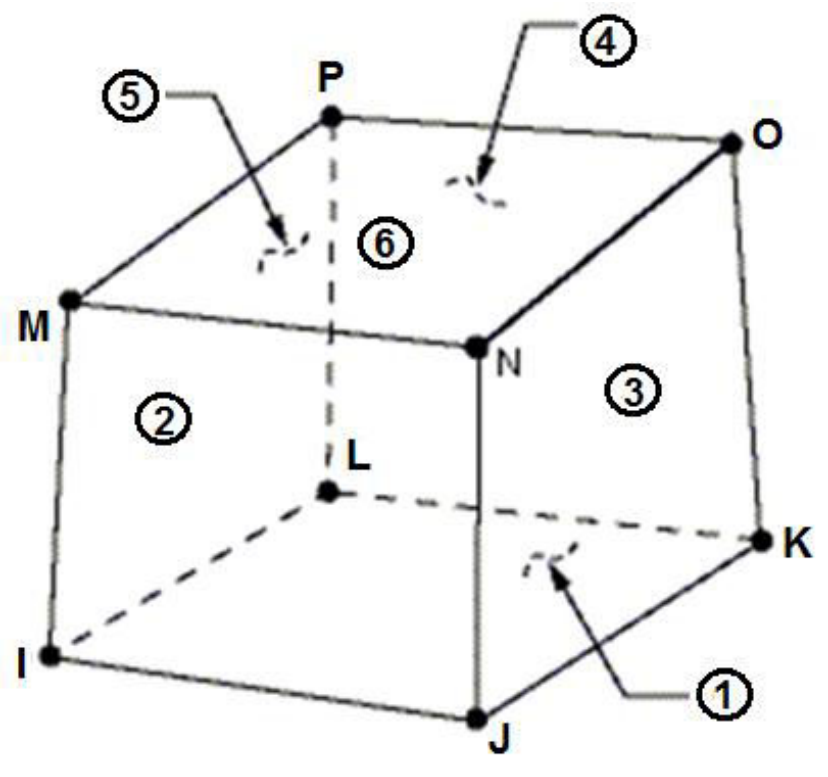

(a) Translação nas direções nodais

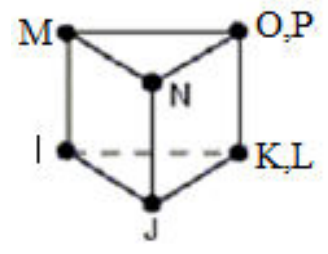

Opção Prismática

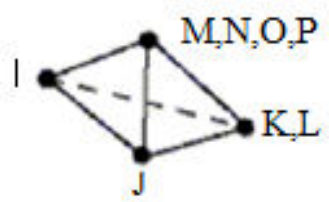

Opção Tetraédrica

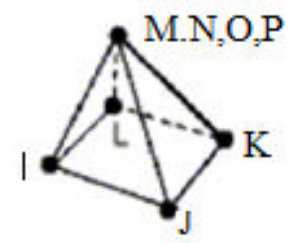

Opção Pirâmidal

(b) Opções de geometria do tipo de formato do sólido

Figura 5.1 Geometria do elemento finito SOLID185 implementado no programa ANSYS 15.0. 


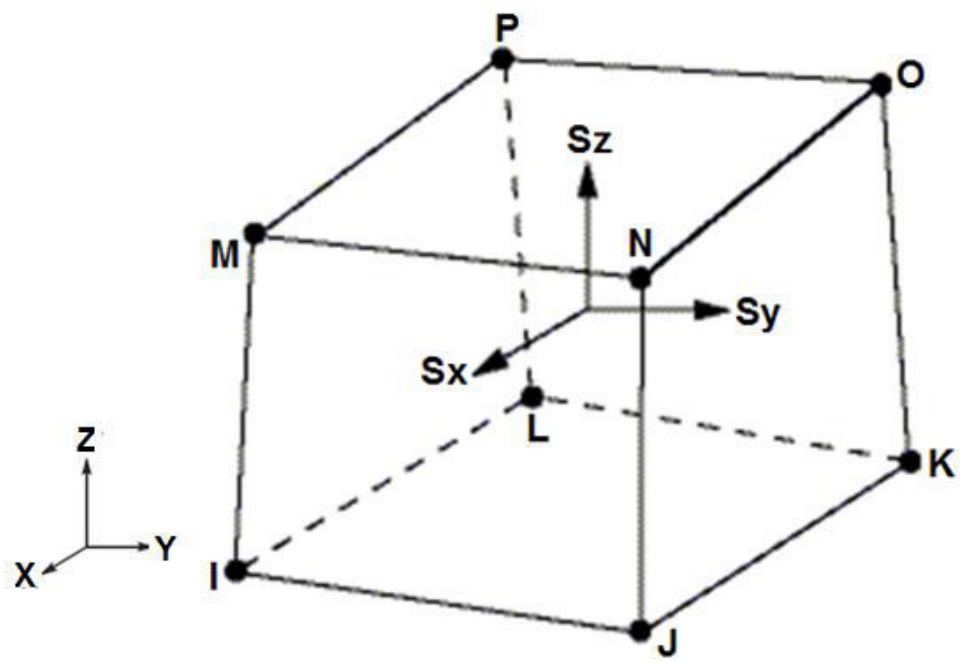

Figura 5.2 Elemento estrutural SOLID185: são indicadas as tensões para as direções globais ANSYS 15.0.

\subsection{2.}

\section{Link10}

O elemento linear "LINK10" é um elemento tridimensional do programa ANSYS 15.0 que apresenta características de rigidez bilinear resultando em um elemento com tensão uniaxial apenas de tração ou apenas de compressão. O uso do elemento "LINK10" no estado de compressão não é de interesse deste estudo. Com a opção de tensão uniaxial apenas para tração, esse elemento pode simular os cabos de protensão. Ao trabalhar somente à tração, a rigidez deste elemento é automaticamente removida da matriz de rigidez se o elemento entrar subitamente em compressão ou se cessar a ação de tração do cabo. A característica desse elemento de trabalhar apenas à tração, é útil para aplicações com cabos estáticos em estruturas protendidas, onde todo o cabo pode ser modelado com elementos finitos unidimensionais.

Também pode ser usada análise dinâmica e, portanto, serve para modelar a estrutura protendida quando da ruptura repentina do cabo de protensão. Esse elemento tem dois nós com três graus de liberdade por nós, que são as translações nodais nas direções $\boldsymbol{X}, \boldsymbol{Y}$ e $\boldsymbol{Z}$. Este elemento é definido pelos dois nós, pela área da seção transversal, por uma deformação inicial e pelas propriedades isotrópicas do material. Na Figura 5.3 tem-se o elemento LINK10, que será utilizado para a discretização dos cabos de proteção das treliças. 


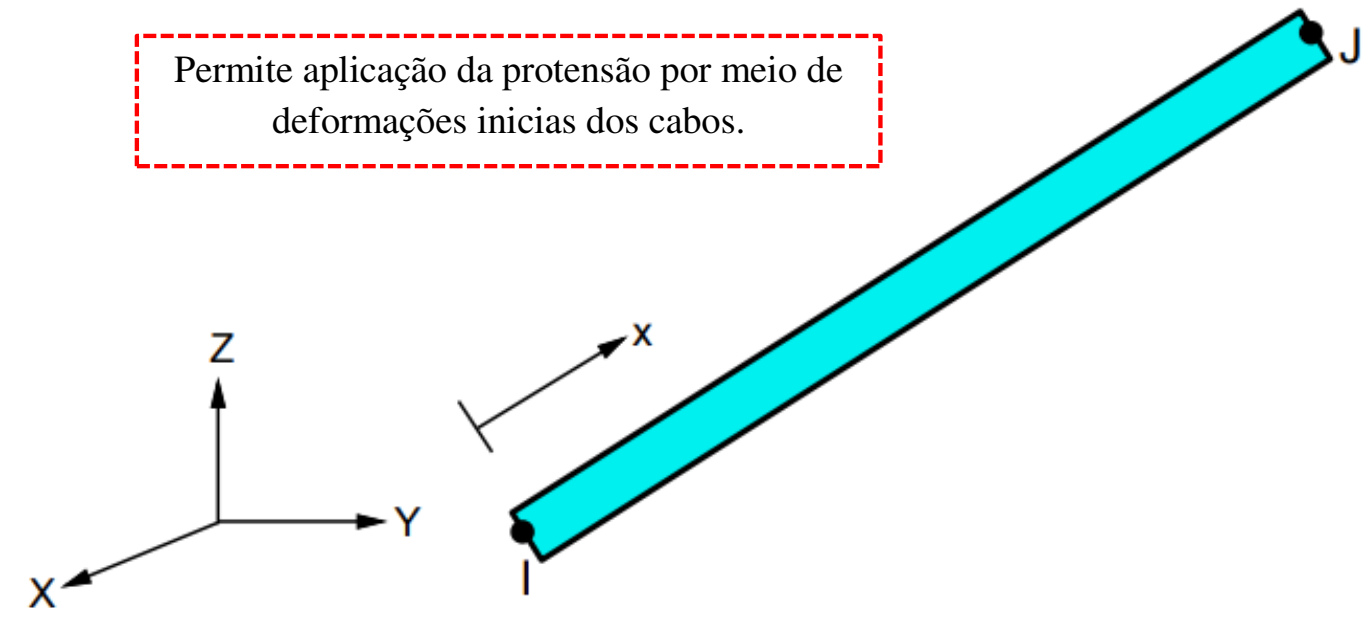

(a) Elemento LINK10 tridimensional

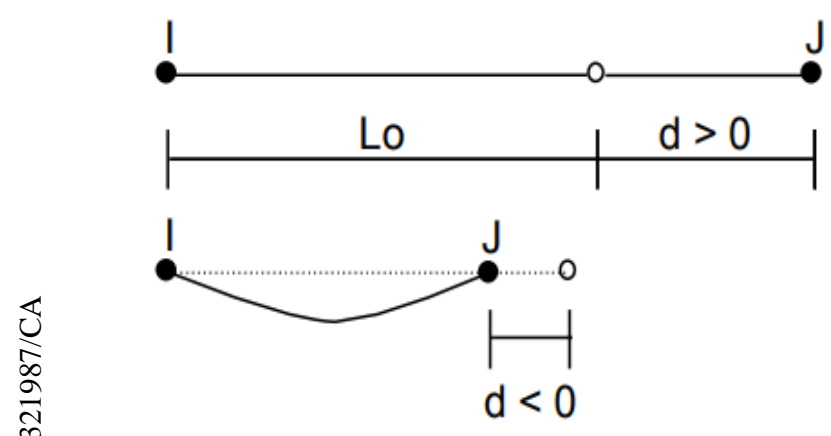

b) Opção somente tração
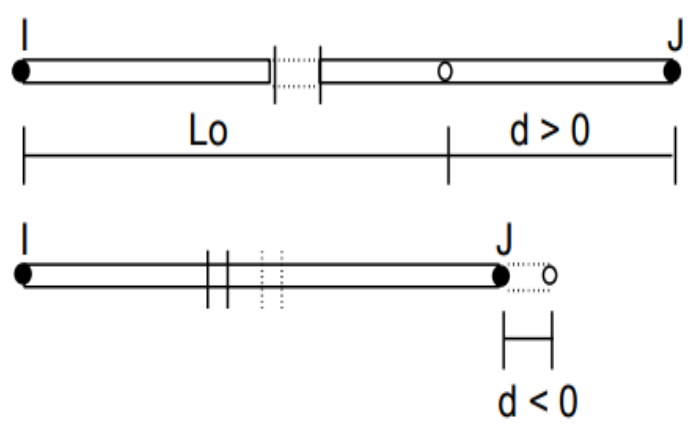

(c) Opção somente compressão

Figura 5.3 Elemento LINK10 ANSYS 15.0.

\section{3.}

\section{Testes de convergência das malhas}

Para definir o nível de refinamento da malha adotado para as análises foi realizado um estudo de sensibilidade dos resultados calculados, a fim de definir o tamanho do elemento a ser usado nos modelos estudados. Para ilustrar essa verificação foi utilizado o modelo de treliça com $10 \mathrm{~m}$ de vão, constituída por seção W150 x 13,0 para as cordas superior, inferior e montante. Nas diagonais foram empregadas cantoneiras duplas de $50,8 \mathrm{~mm}$ x $50,8 \mathrm{~mm}$ x 4,76 $\mathrm{mm}$ com suas condições de contorno. 
O estudo de sensibilidade foi realizado por meio da avaliação das tensões de von Mises e das reações de apoios para os diferentes níveis de discretização, assim encontrou-se o tamanho ideal do elemento para apresentar resultados precisos e buscando-se o menor custo computacional possível. Para a execução do estudo foram utilizados cinco tamanhos de malhas diferentes. A Figura 5.4 e as Tabelas 5.1 e 5.2 permitem visualizar os resultados de tensão máxima de von Mises e as reações de apoio da estrutura para os diferentes níveis de refinamentos da malha e, ainda, confrontá-los com os valores teóricos obtidos a partir da teoria da elasticidade.

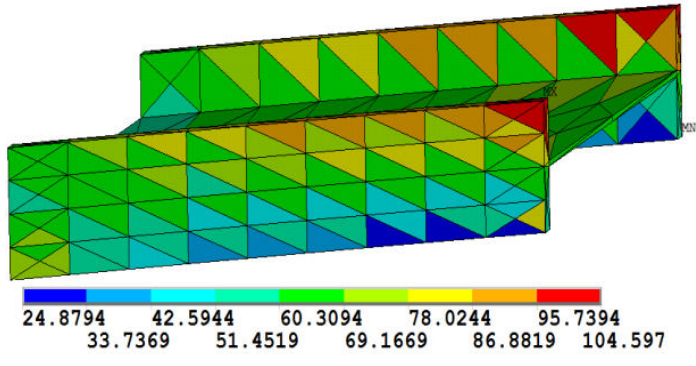

(a) Número de elemento 40.513 e com tensão de 104,6 MPa

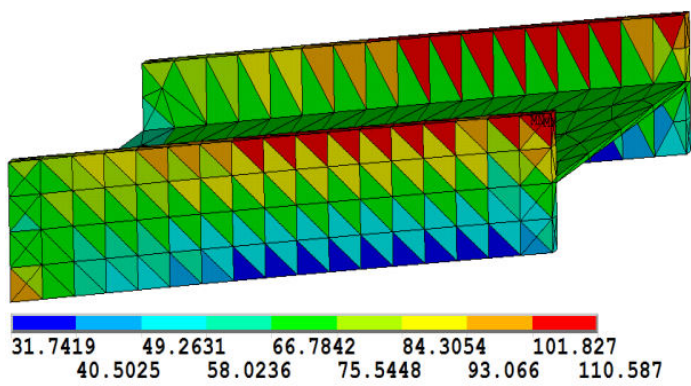

(c) Numero de elemento 58.602 e com tensão de $110,59 \mathrm{MPa}$

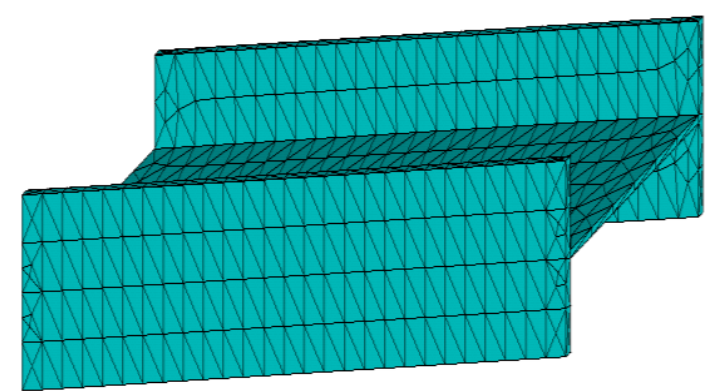

(e) Malhas otimizadas

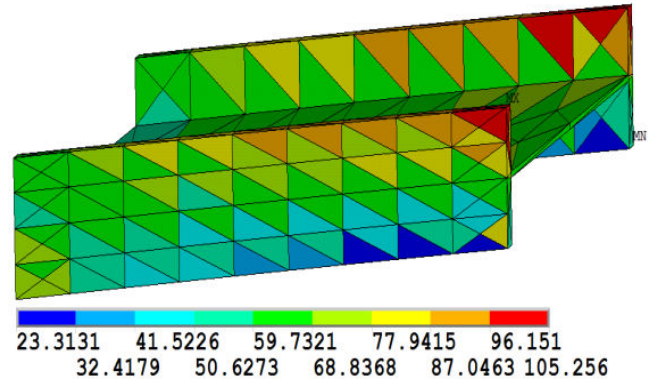

(b) Numero de elemento 42.980 e com tensão de $105,26 \mathrm{MPa}$

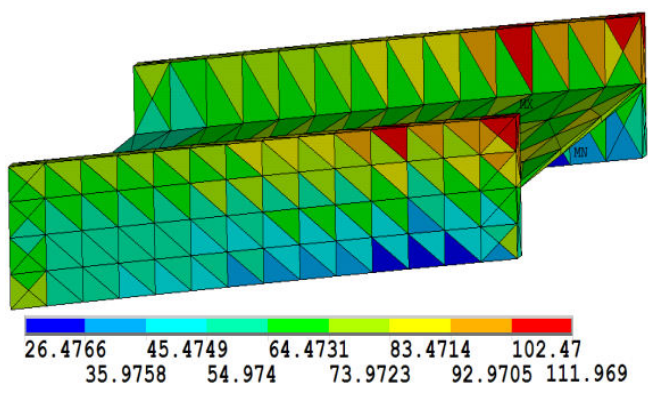

(d) Numero de elemento 85.856 e com tensão de $111,97 \mathrm{MPa}$

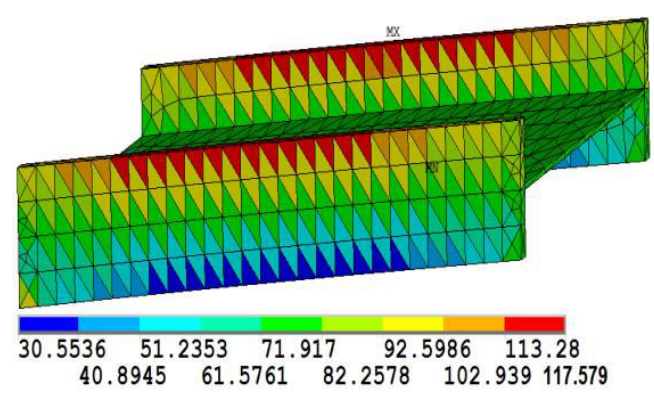

(d) Numero de elemento ótimo $144.778 \mathrm{e}$ com tensão ótima de $117,58 \mathrm{MPa}$

Figura 5.4 Detalhes dos níveis de discretização em função do número de elementos. 
Tabela 5.1 Resumo do estudo de tamanho de malhas.

\begin{tabular}{ccccccc}
\hline & Valor & \multicolumn{5}{c}{ Números de Elementos finitos } \\
\cline { 3 - 7 } Avaliação & Teórico & 40.513 & 42.980 & 58.602 & 85.856 & 144.778 \\
\hline $\begin{array}{c}\text { von Mises } \\
(\mathrm{MPa})\end{array}$ & 116,27 & 104,60 & 105,26 & 110,59 & 111,97 & 117,58 \\
$\begin{array}{c}\text { Reação X } \\
(\mathrm{KN})\end{array}$ & 5,75 & 5,74 & 5,74 & 5,74 & 5,88 & 5,74 \\
$\begin{array}{c}\text { Reação } Y_{1} \\
(\mathrm{KN})\end{array}$ & $-32,06$ & $-32,45$ & $-32,47$ & $-32,23$ & $-32,38$ & $-32,19$ \\
$\begin{array}{c}\text { ReaçãoY } \\
(\mathrm{KN})\end{array}$ & $-22,60$ & $-21,91$ & $-21,89$ & $-22,13$ & $-22,00$ & $-22,17$ \\
\hline
\end{tabular}

Tabela 5.2 Porcentual da diferença de tamanho de malhas.

\begin{tabular}{lccccc}
\hline & \multicolumn{5}{c}{ Números de Elementos finitos / Diferenças \% } \\
\cline { 2 - 6 } Avaliação & 40.513 & 42.980 & 58.602 & 85.856 & 144.778 \\
\hline von Mises & $10,04 \%$ & $9,47 \%$ & $4,89 \%$ & $3,70 \%$ & $1,12 \%$ \\
Reação $\mathrm{X}_{1}$ & $0,06 \%$ & $0,07 \%$ & $0,09 \%$ & $2,28 \%$ & $0,05 \%$ \\
Reação $\mathrm{Y}_{1}$ & $1,21 \%$ & $1,26 \%$ & $0,53 \%$ & $0,99 \%$ & $0,40 \%$ \\
ReaçãoY & $3,03 \%$ & $3,13 \%$ & $2,08 \%$ & $2,65 \%$ & $1,89 \%$ \\
\hline
\end{tabular}

A partir dos resultados mostrados nas Tabelas 5.1 e 5.2 mostra-se na Figura 5.5 o gráfico de convergência das malhas empregadas. $\mathrm{O}$ gráfico permite visualizar o número de elementos finitos vs tensões de von Mises para os resultados numéricos comparados com o valor teórico. 


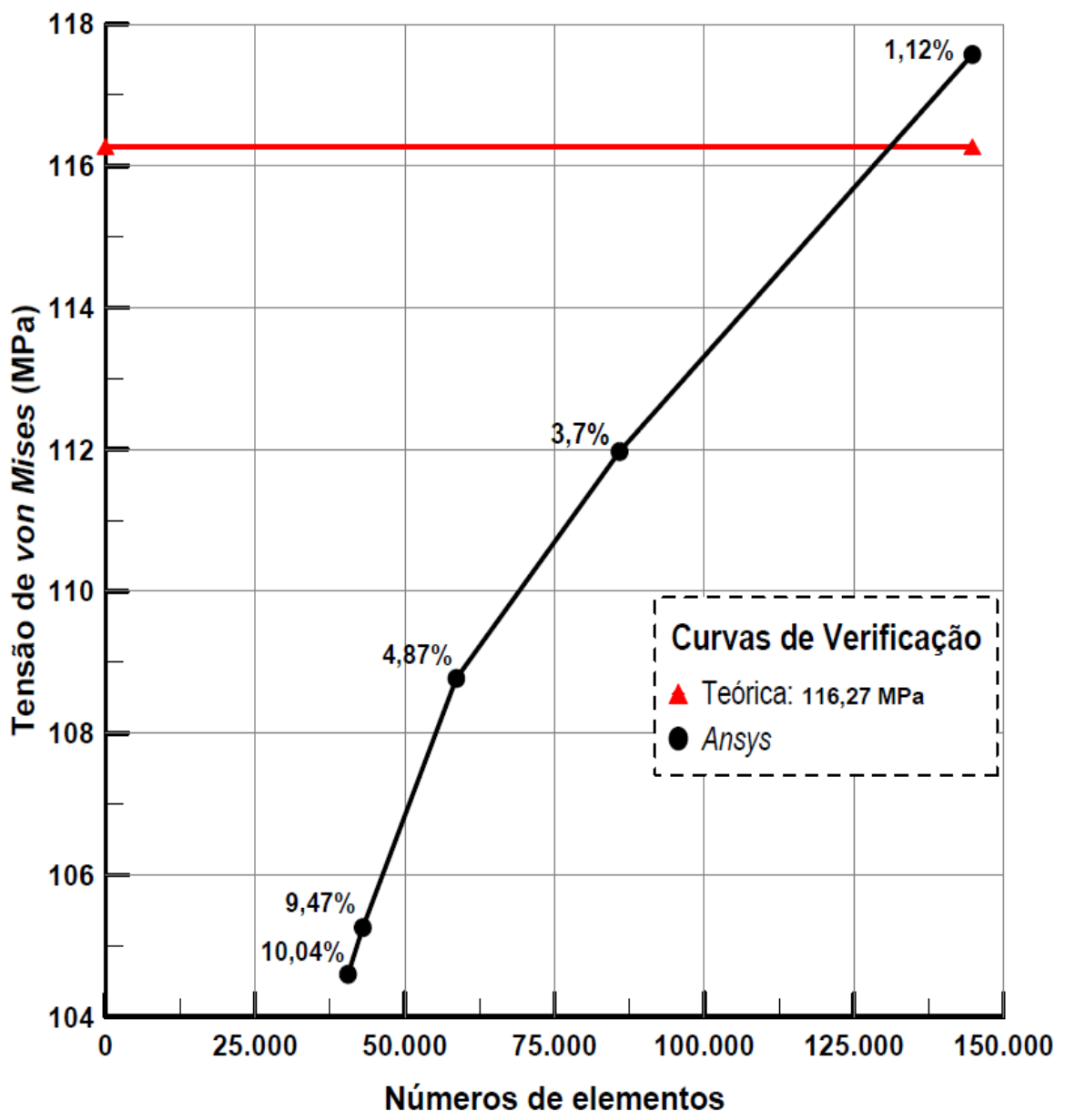

Figura 5.5 Gráfico de convergência entre os níveis de refinamento de malhas.

\section{4 .}

\section{Técnica MPC: Multi Point Constraint}

Para a realização de algumas análises desta tese foi utilizado um método denominado Multi Point Constraint (MPC). Essa metodologia consiste em vincular os deslocamentos prescritos aplicados sobre um nó da estrutura, denominado de "nó piloto" ou "nó mestre", com os deslocamentos dos nós de uma região da estrutura em análise, os quais são chamados de "nós escravos".

Assim, quando é atribuído um deslocamento ou uma força no "nó piloto" a força resultante, bem como os deslocamentos resultantes, são distribuídas aos nós "escravos" que compõem a região em estudo, gerando uma espécie de superfície rígida. A Figura 5.7 mostra um exemplo aplicado num modelo no qual foi usada essa técnica de modelagem. 


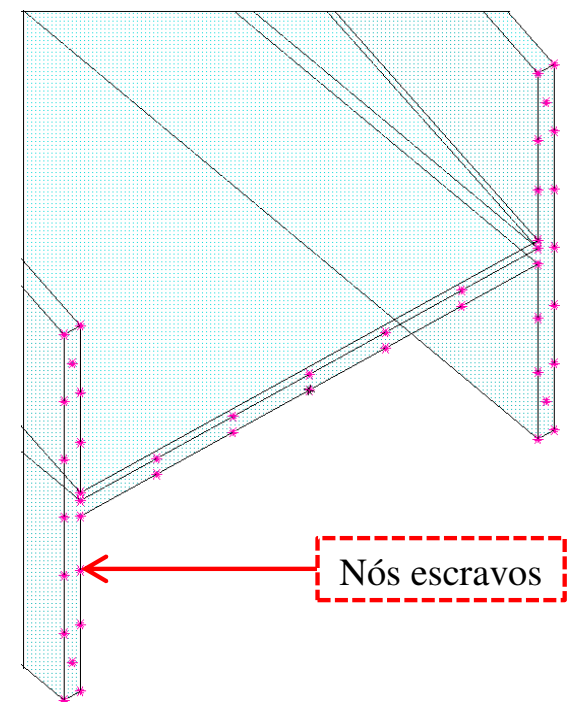

(a) Criação dos nos escravos

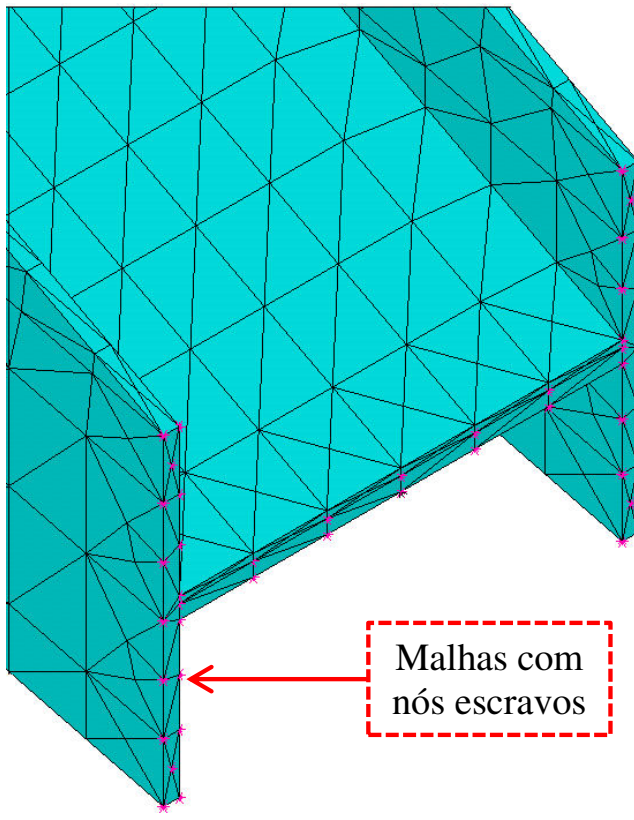

(c) Vista das malhas com nós escravos

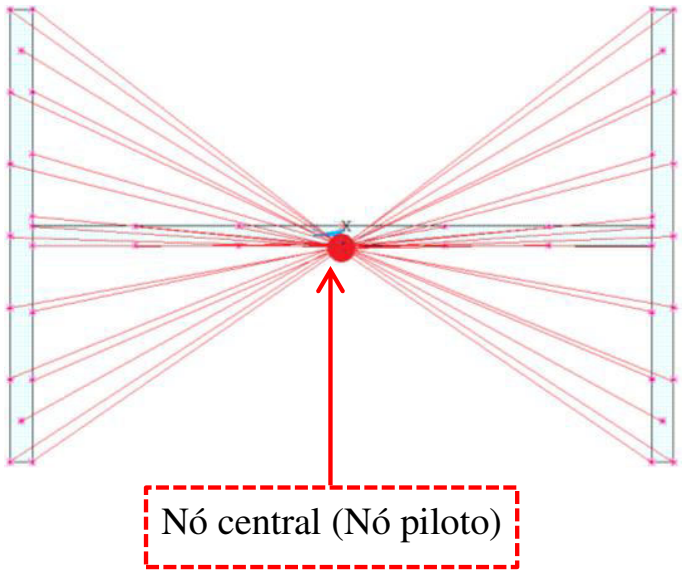

(b) Criação do nó piloto

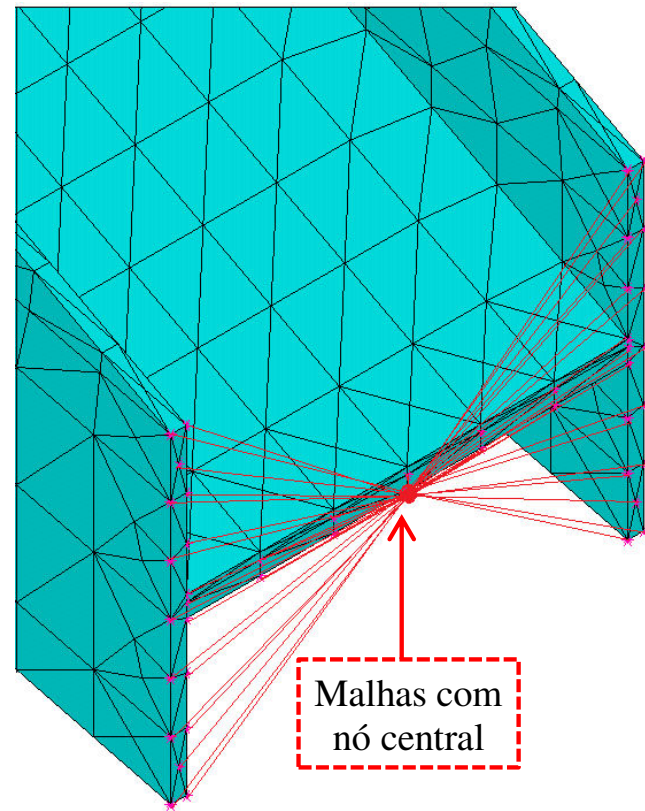

(d) Vista das malhas com nó piloto

Figura 5.6 Técnica MPC aplicada ao perfil na região do modelo.

Para a aplicação dessa técnica o ANSYS 15.0 tem disponível vários meios de criação dos nós pilotos, sendo cada um com suas particularidades. Para as condições realizadas neste trabalho, utilizou-se node to surface contact para designar os nós escravos. É usado para representar a vinculação das reações e aplicar-se o deslocamento. Para designar o nó piloto foi utilizado target segmento. A formulação e vários conceitos a respeito do tipo escravo e piloto podem ser pesquisados em Zienkiewicz (2000). 


\section{5 .}

\section{Análises numéricas realizadas}

Neste trabalho são realizados dois tipos de análises: análise estática linear e análise estática não linear física. Também são mostradas as considerações e objetivos da simulação para os dois tipos de análise.

\section{5 .1$.}

\section{Análise Estática Linear}

$\mathrm{Na}$ análise estática linear considera-se o aço das treliças como material de comportamento elástico, conforme o gráfico da Figura 5.7. Neste estudo o objetivo da análise estática linear foi determinar a resposta estrutural em termos de deslocamentos, das forças máximas e das tensões de von Mises para diferentes tipos de treliças em forma de arco sem e com protensão, com as combinações de serviços estudadas no capítulo quatro desta tese.

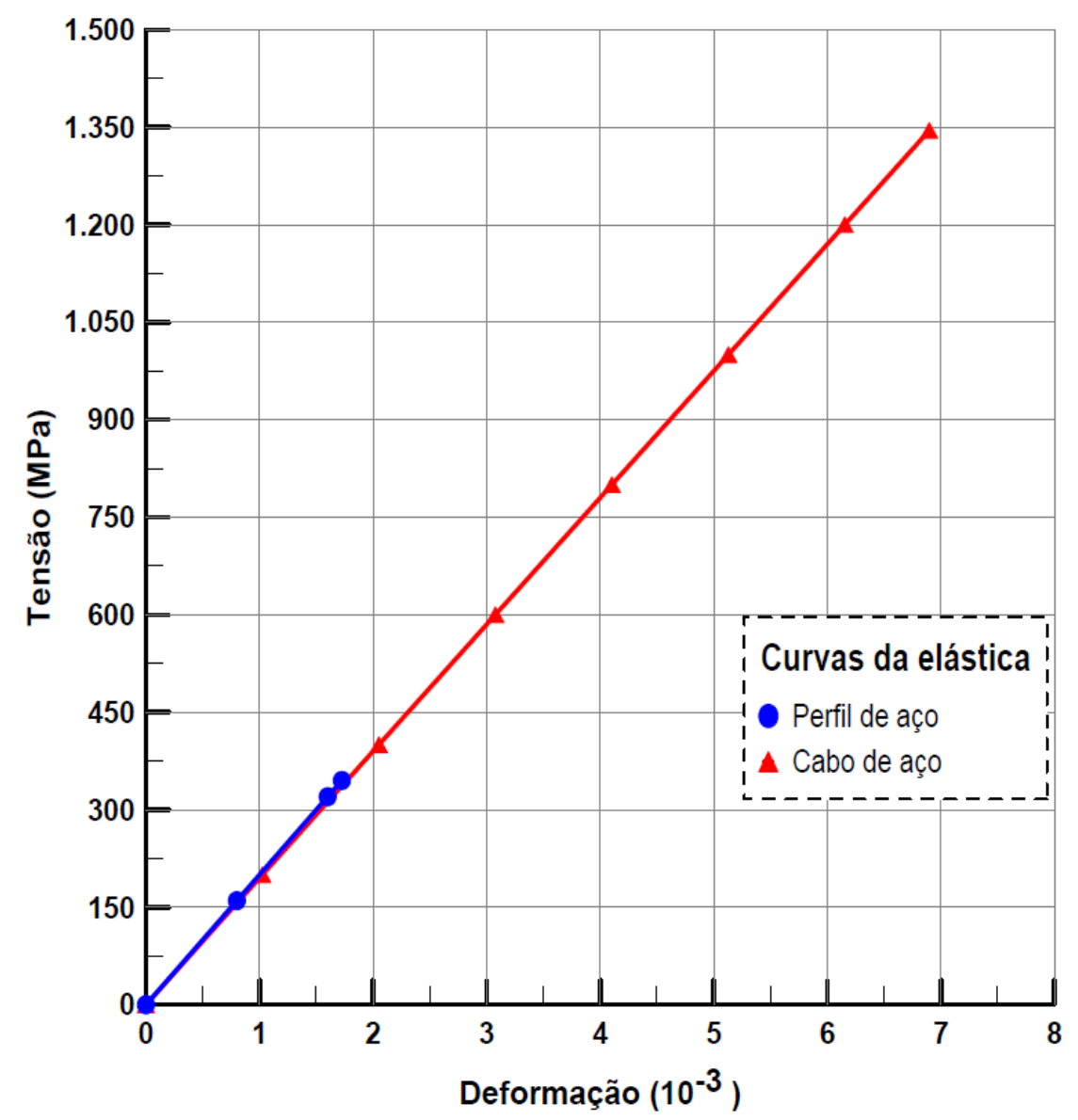

Figura 5.7 Tensão versus deformação específica da elástica do perfil e do cabo de protensão. 


\subsection{2.}

\section{Análise estática não linear física}

Para que as estruturas apresentem um bom desempenho é muito importante o conhecimento aprofundado das propriedades mecânicas de cada material. Utilizando-se os materiais de maneira racional, ou seja, aproveitando a boa resistência do perfil e do cabo aço à tração consegue-se obter estruturas que trabalhem de forma otimizada.

Os parâmetros de entrada para análise não linear das treliças, a opção utilizada para a análise elastoplástica no ANSYS 15.0 é modelo constitutivo bilinear, BISO (Bilinear Isotropic Hardening), utilizando-se um modelo de endurecimento bilinear isotrópico com a rigidez pós-limite de $20 \mathrm{MPa}$, representado na Figura 5.8, associado com o critério de escoamento de von Mises, por meio de uma lei constitutiva de tensão versus deformação. Essa pequena inclinação do digrama tensão/deformação específica foi adotada para serem evitadas as condições de Roundoff (erros de arredondamento).

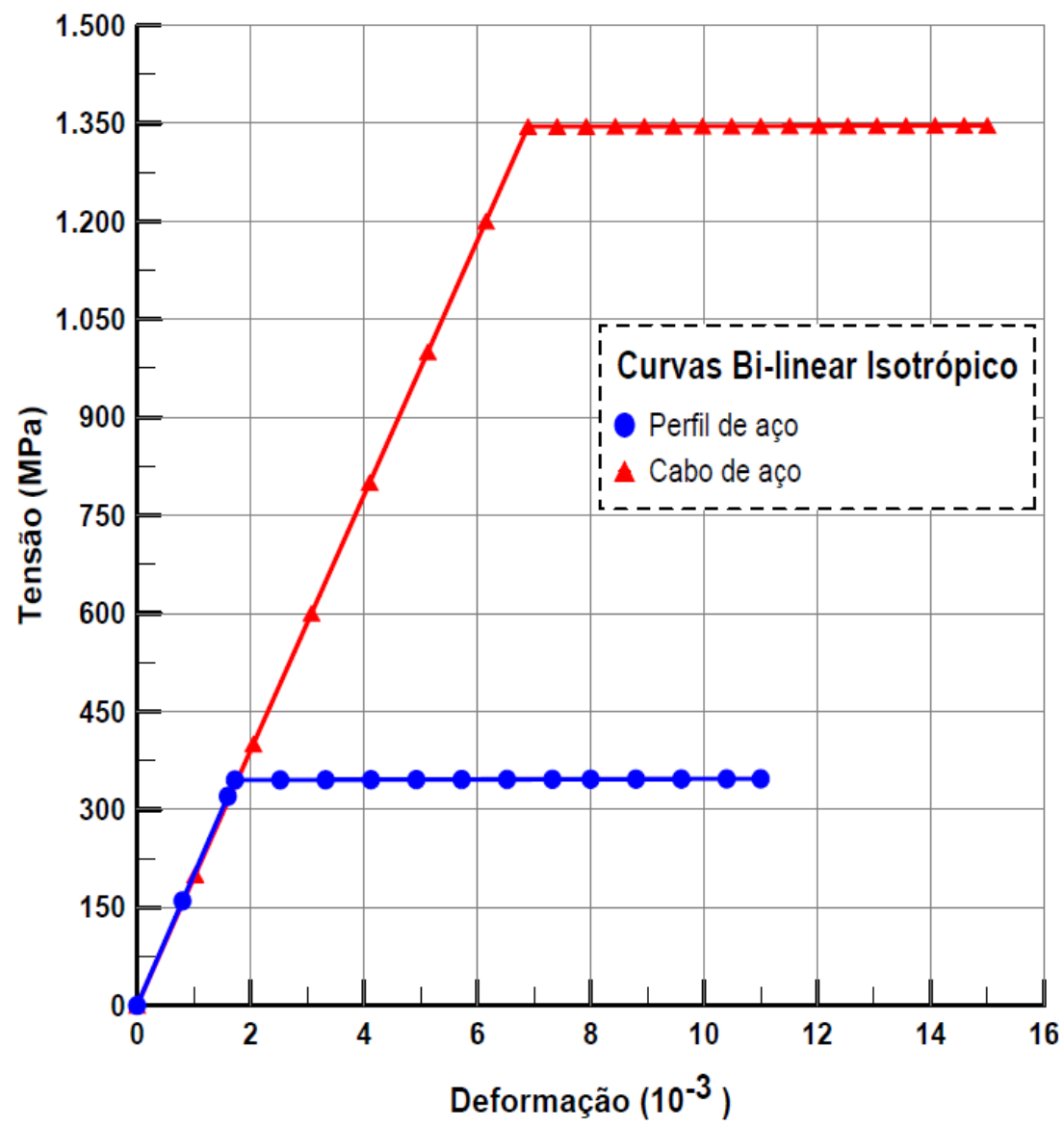

Figura 5.8 Tensão versus deformação bi-linear isotrópico com endurecimento linear. 


\section{6.}

\section{Modelos numéricos das treliças}

Dadas as inúmeras mudanças de geometria dos modelos estruturais investigados, optou-se por apresentar todas as figuras dos modelos em elementos finitos realizados neste estudo, garantindo, assim, o acompanhamento da evolução dos modelos à medida que os mesmos são apresentados.

\subsection{1.}

\section{Modelo de treliça com 10 m de Vão (Modelo $A_{10}$ )}

O modelo tipo " $\mathrm{A}_{10}$ " previsto para ser testado experimentalmente foi feito com vão de $10 \mathrm{~m}$ e altura de treliça no centro do vão de $700 \mathrm{~mm}$. Todas as treliças tem a flecha no centro do vão (distância entre a corda inferior e a linha horizontal entre apoios) de $700 \mathrm{~mm}$. A seção do perfil das cordas superior, inferior e montantes é W150 x 13,0, e nas diagonais foram empregadas cantoneiras duplas de 50,8 mm x 50,8 $\mathrm{mm}$ x 4,76 mm. A área da seção transversal do cabo é de $A c=60 \mathrm{~mm}^{2}$, com força de protensão adotada de $65,37 \mathrm{kN}$.

Foi utilizado o elemento SOLID185 de oito nós de um sólido para os elementos da treliça (modelo $\mathrm{A}_{10}$ ), sendo que o modelo resultou num total de 44.896 nós, 131.532 elementos finitos que resultaram em 269.376 graus de liberdade. As Figuras 5.9 a 5.12 ilustram criação dos elementos da treliça, refinamento da malha, os cabos de protensão, a distribuição do carregamento de sucção devido à ação do vento que atua sobre a estrutura e as condições de contorno utilizadas na modelagem.

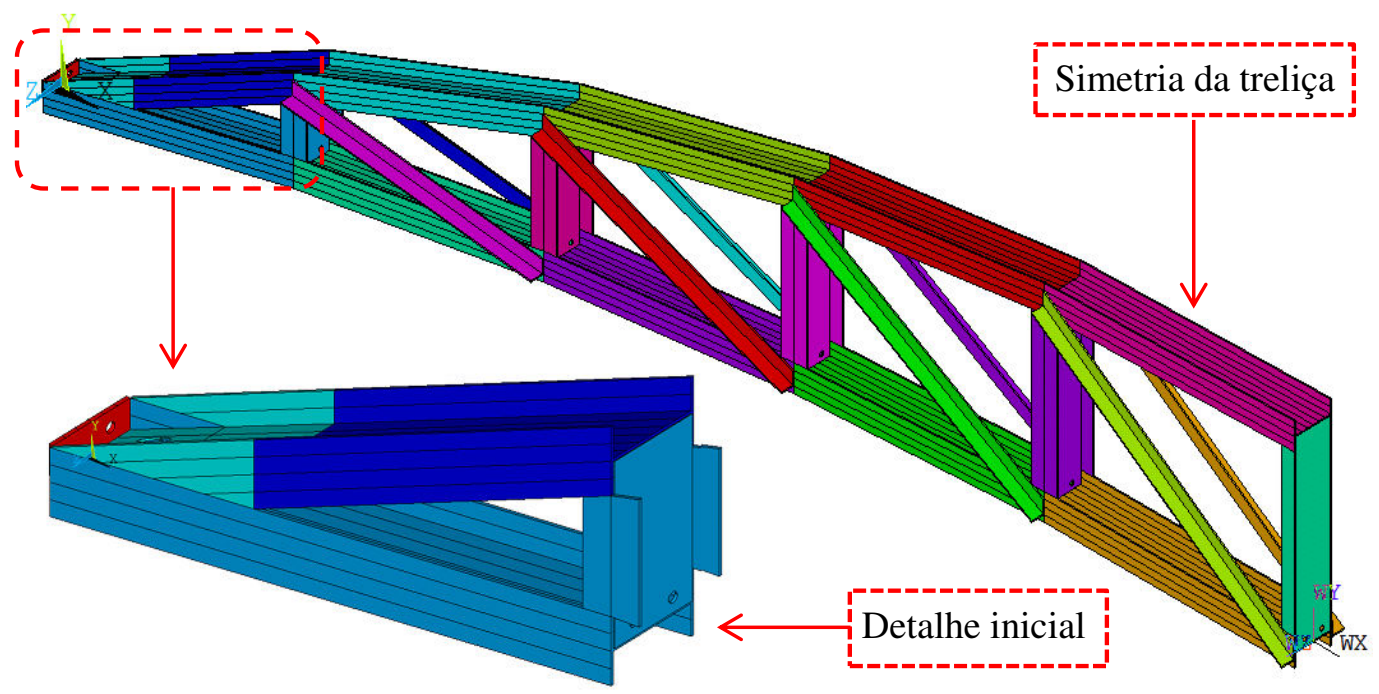

Figura 5.9 Perspectiva e simetria: criação dos elementos SOLID185 $\left(\mathrm{A}_{10}\right)$. 


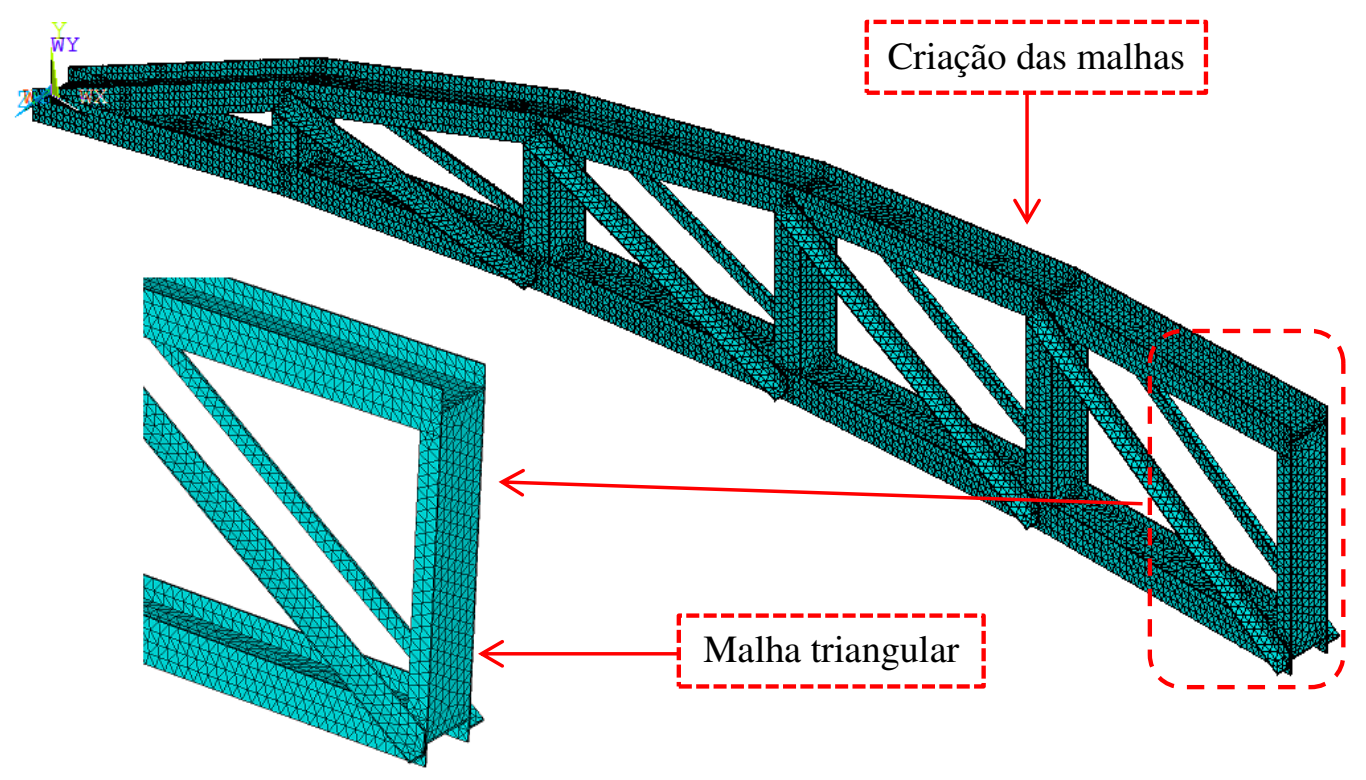

Figura 5.10 Perspectiva e simetria: criação da malha triangular $\left(\mathrm{A}_{10}\right)$.

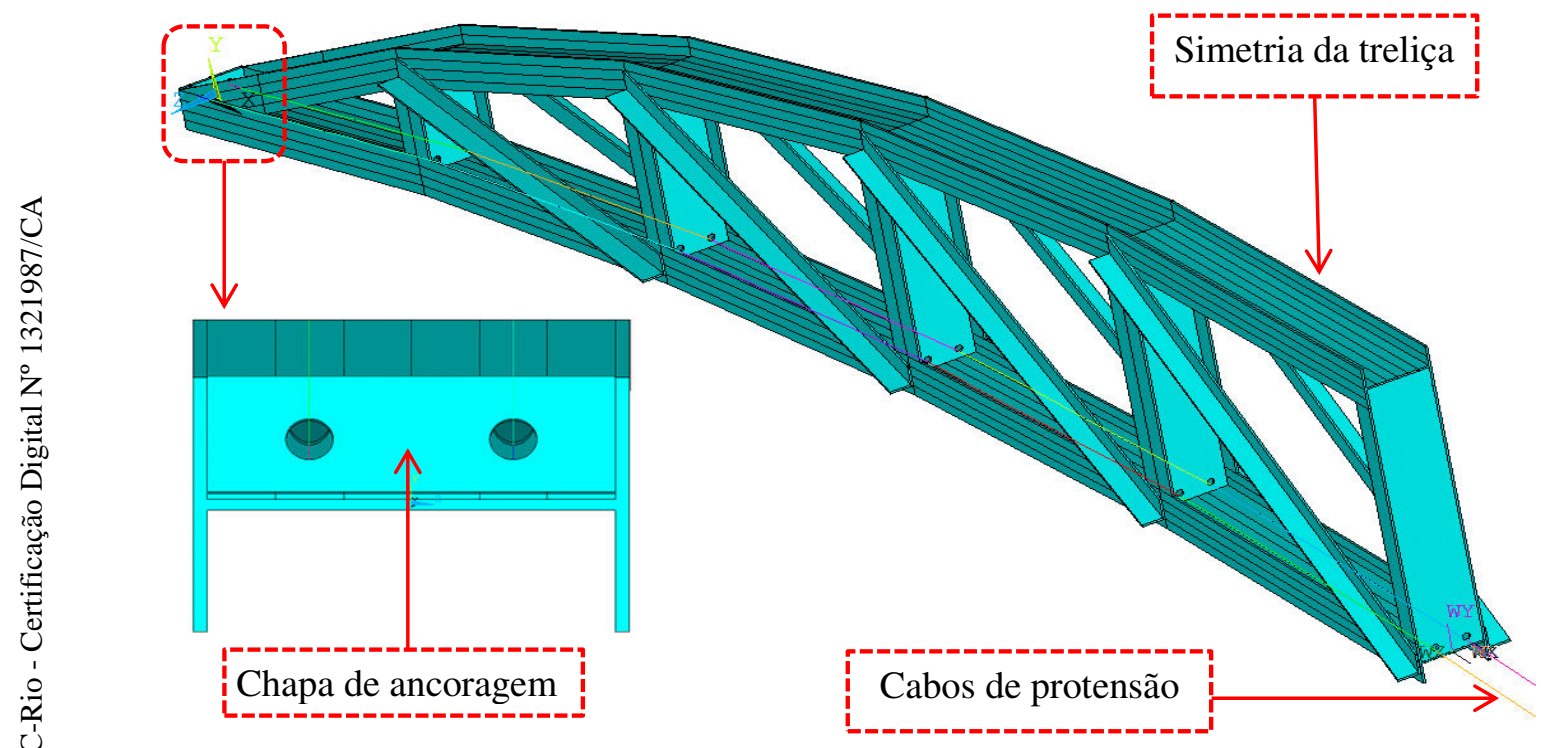

Figura 5.11 Perspectiva e simetria: elementos dos cabos de protensão $\left(\mathrm{A}_{10}\right)$.

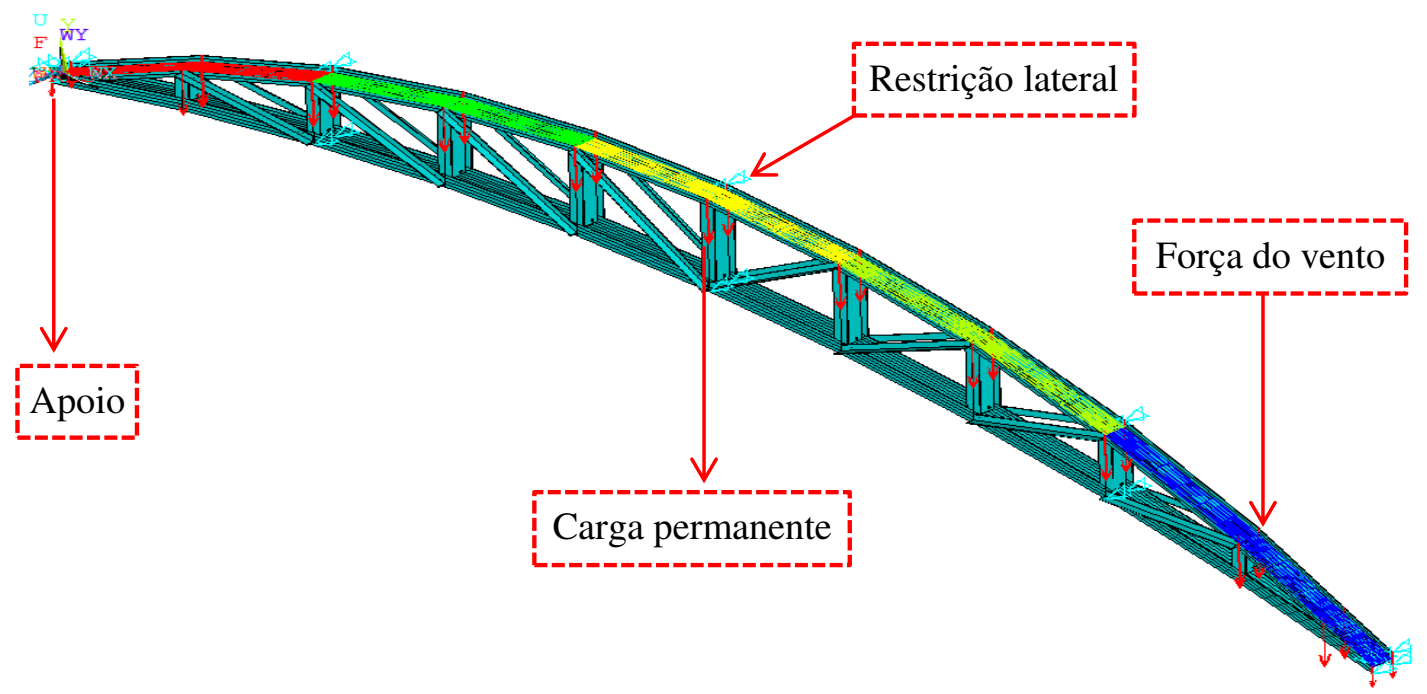

Figura 5.12 Perspectiva treliça protendida: sucção do vento e carga permanente $\left(\mathrm{A}_{10}\right)$ 


\subsection{2.}

\section{Modelo de treliça com 20 m de vão (Modelo B20)}

O modelo tipo " $\mathrm{B}_{20}$ " tem vão de $20 \mathrm{~m}$ e altura de treliça no centro do vão de $1500 \mathrm{~mm}$. As dimensões do perfil das cordas superior, inferior e montantes é $\mathrm{W} 150$ x 13,0 e nas diagonais foram empregadas cantoneiras duplas de 63,5 $\mathrm{mm}$ x $63,5 \mathrm{~mm}$ x 9,52 mm. A área da seção transversal do cabo é $\mathrm{A}_{\mathrm{c}}=120 \mathrm{~mm}^{2}$, com força de protensão adotada de 130,86 kN.

Foi utilizado o elemento SOLID185 de oito nós de um sólido para os elementos da treliça (modelo $\mathrm{B}_{20}$ ), sendo que o modelo resultou num total de 86.606 nós, 247.332 elementos finitos que resultaram em 519.636 graus de liberdade. As Figuras. 5.13 a 5.16 ilustram criação dos elementos da treliça, refinamento da malha, os cabos de protensão, a distribuição do carregamento de sucção devido à ação do vento que atua sobre a estrutura e as condições de contorno utilizadas na modelagem.

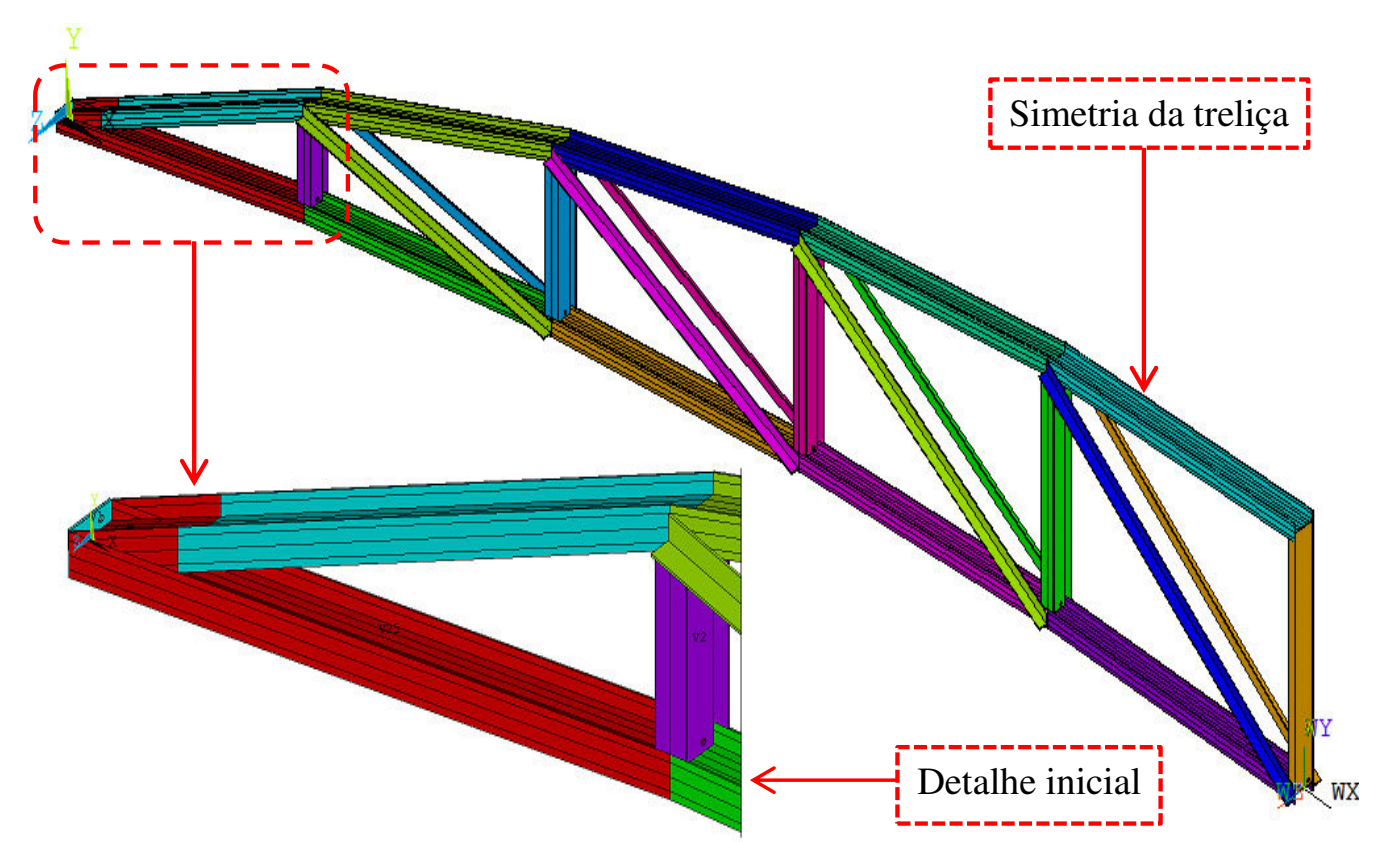

Figura 5.13 Perspectiva e simetria: criação dos elementos SOLID185 $\left(\mathrm{B}_{20}\right)$. 


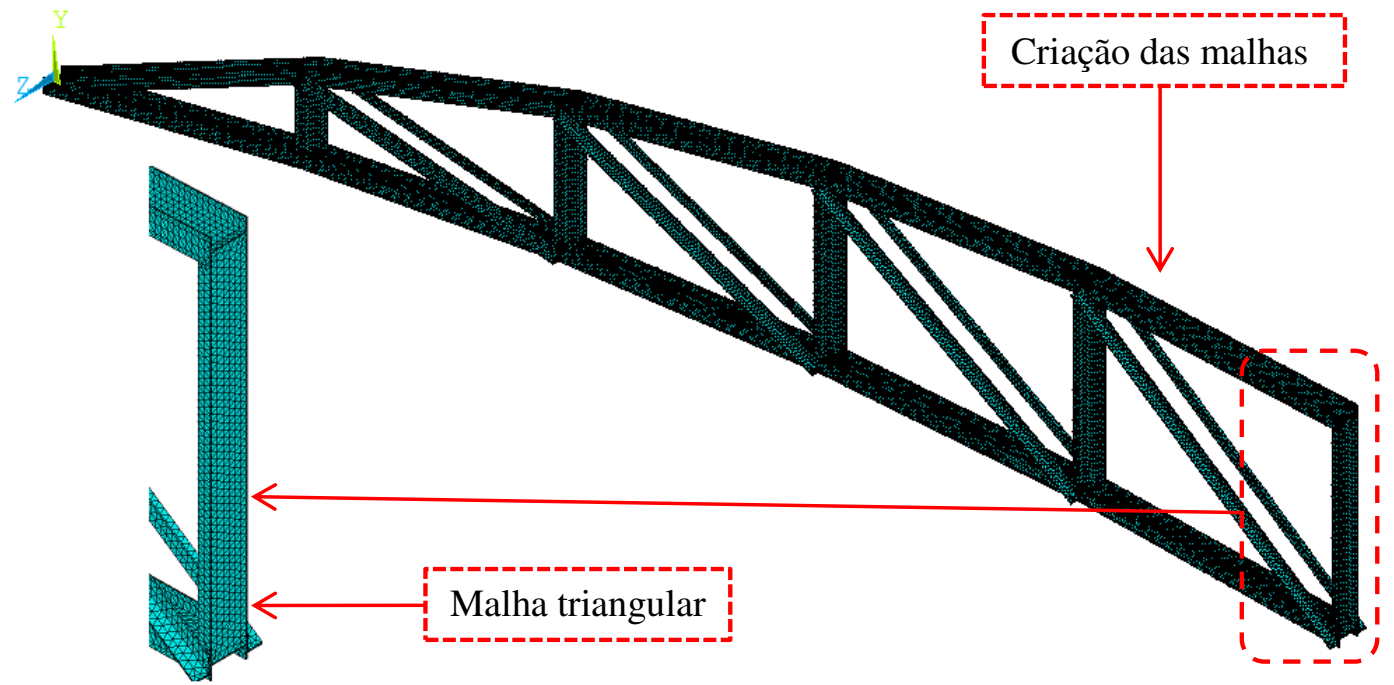

Figura 5.14 Perspectiva e simetria: criação da malha triangular $\left(\mathrm{B}_{20}\right)$.

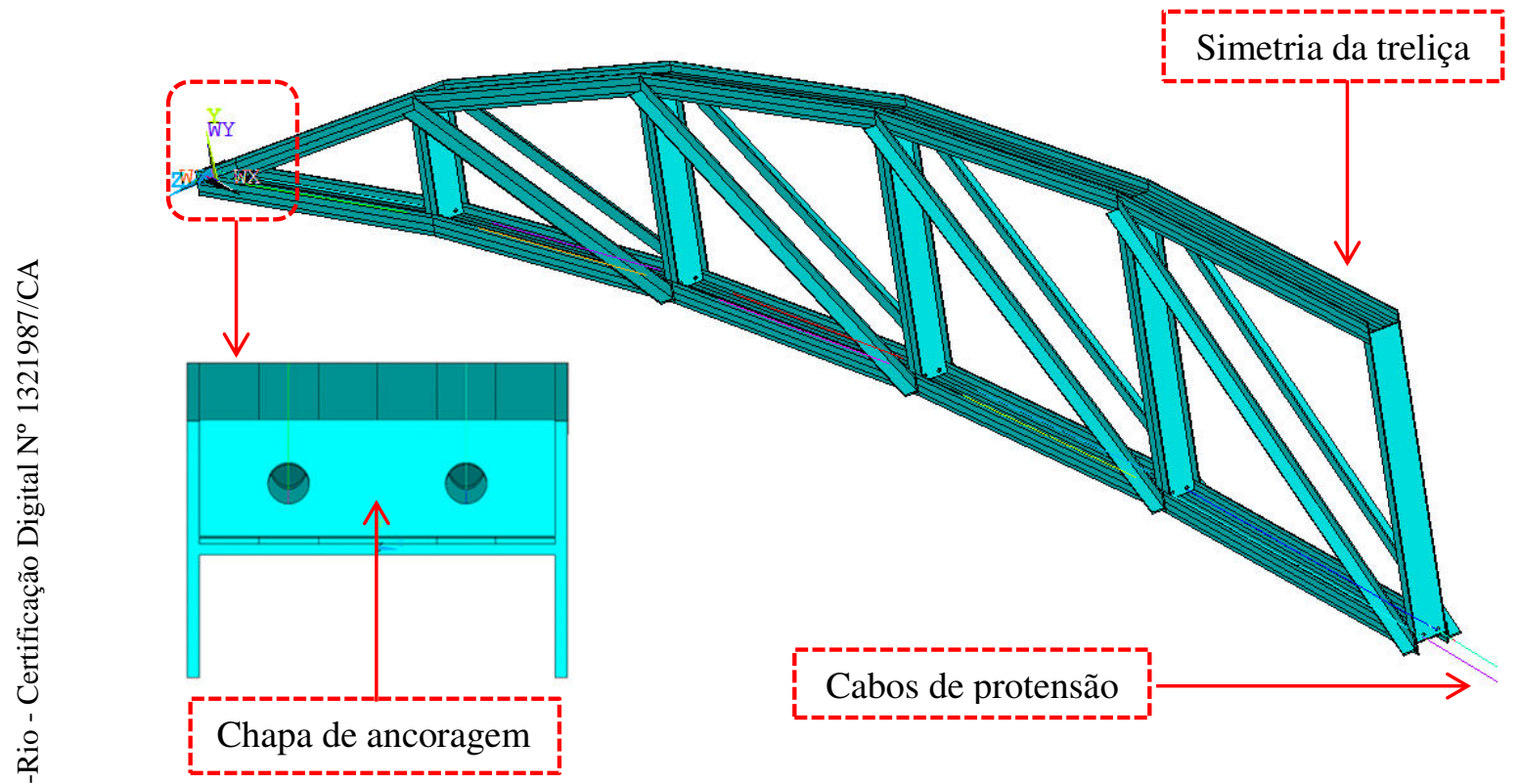

Figura 5.15 Perspectiva e simetria: elementos dos cabos de protensão $\left(\mathrm{B}_{20}\right)$.

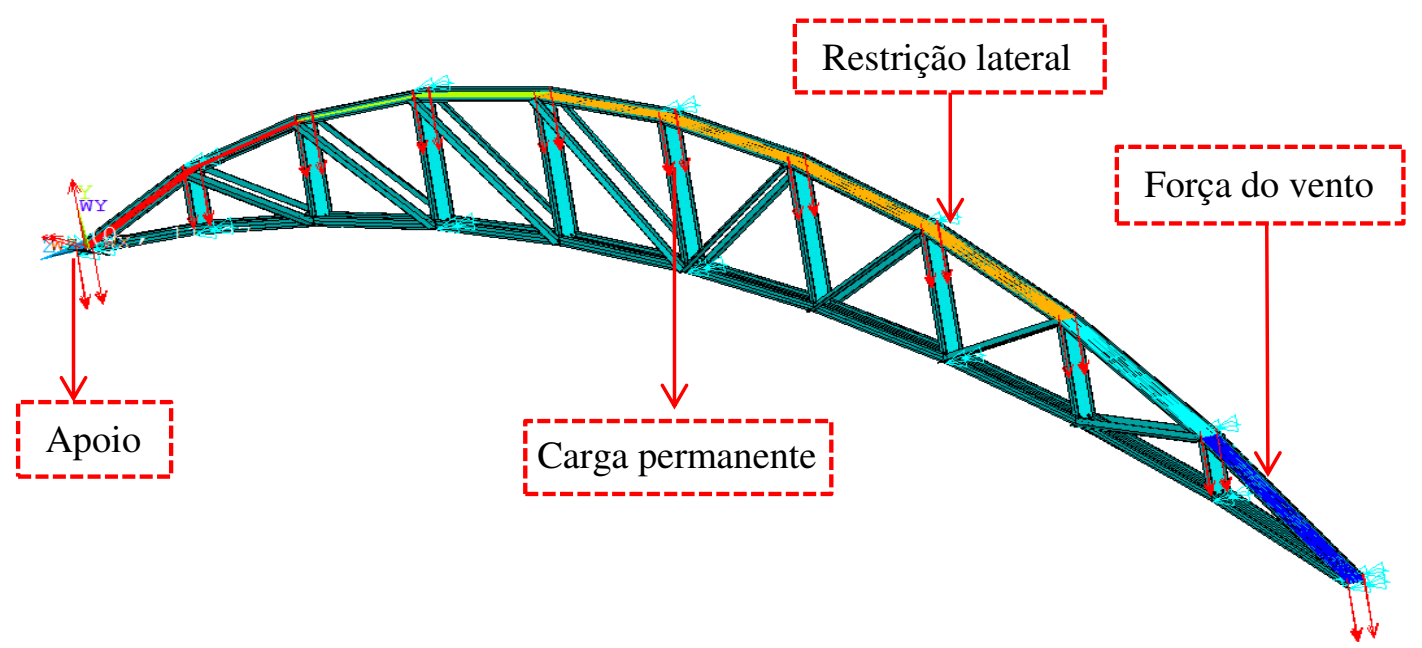

Figura 5.16 Perspectiva treliça protendida: sucção do vento e permanente $\left(B_{20}\right)$. 


\subsection{3.}

\section{Modelo de treliça com $\mathbf{4 0} \mathrm{m}$ de vão (Modelo $\mathrm{C}_{40}$ )}

O modelo tipo " $\mathrm{C}_{40}$ " apresenta um vão de $40 \mathrm{~m}$ e altura de treliça no centro do vão de $3000 \mathrm{~mm}$. As dimensões do perfil das cordas superior, inferior e montantes é W150 x 22.5 e nas diagonais foram empregadas cantoneiras duplas de $127 \mathrm{~mm}$ x $127 \mathrm{~mm}$ x 15,88 mm. A área da seção transversal do cabo é $\mathrm{A}_{\mathrm{c}}=188,0 \mathrm{~mm}^{2}$, com força de protensão adotada de $205,27 \mathrm{kN}$.

Foi utilizado o elemento SOLID185 de oito nós de um sólido para os elementos da treliça (modelo $\mathrm{C}_{40}$ ), sendo que o modelo resultou num total de 221.363 nós, 631.248 elementos finitos que resultaram em 1.328.178 graus de liberdade. As Figuras. 5.17 a 5.20 ilustram criação dos elementos da treliça, refinamento da malha, os cabos de protensão, a distribuição do carregamento de sucção devido à ação do vento que atua sobre a estrutura e as condições de contorno utilizadas na modelagem.

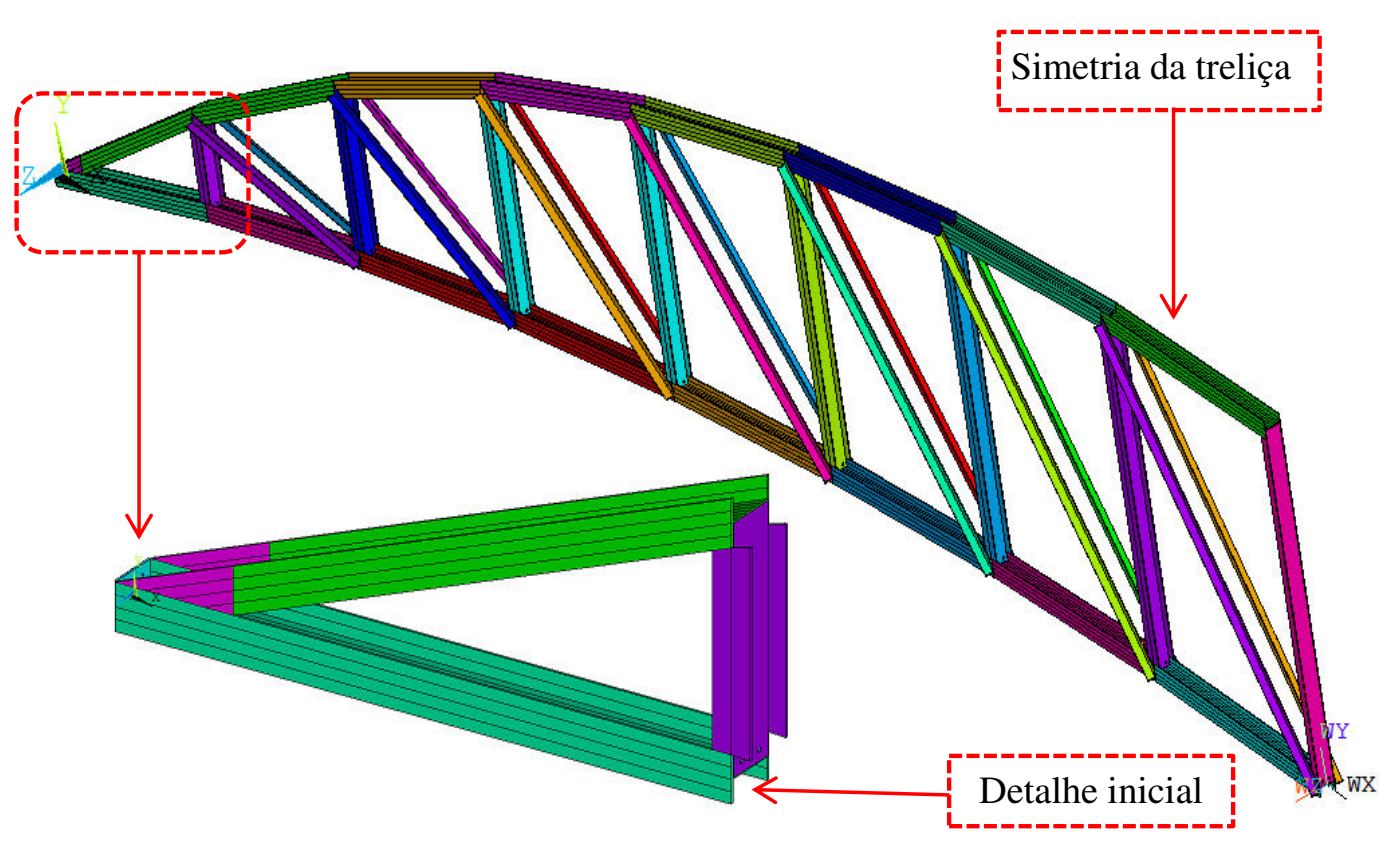

Figura 5.17 Perspectiva e simetria: criação dos elementos SOLID185 $\left(\mathrm{C}_{40}\right)$. 


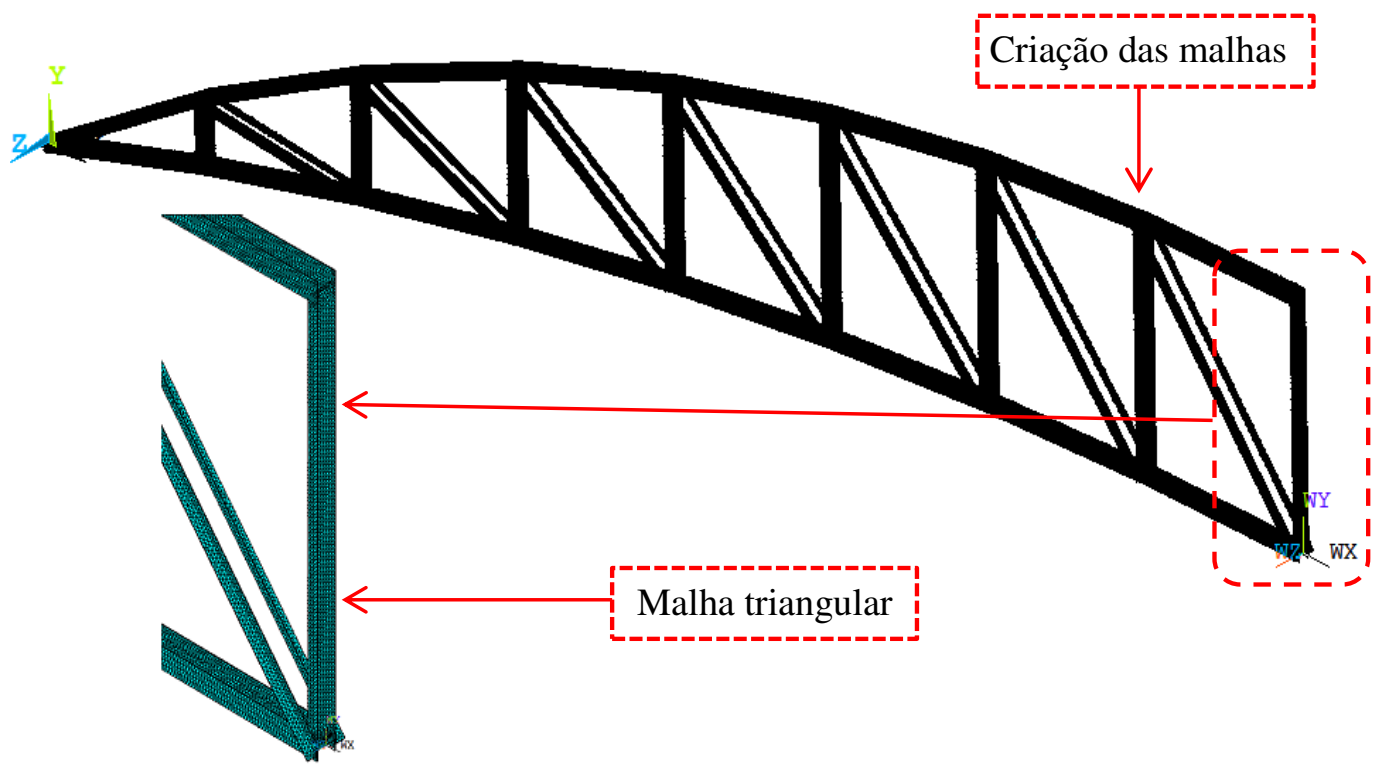

Figura 5.18 Perspectiva e simetria: criação da malha triangular $\left(\mathrm{C}_{40}\right)$.

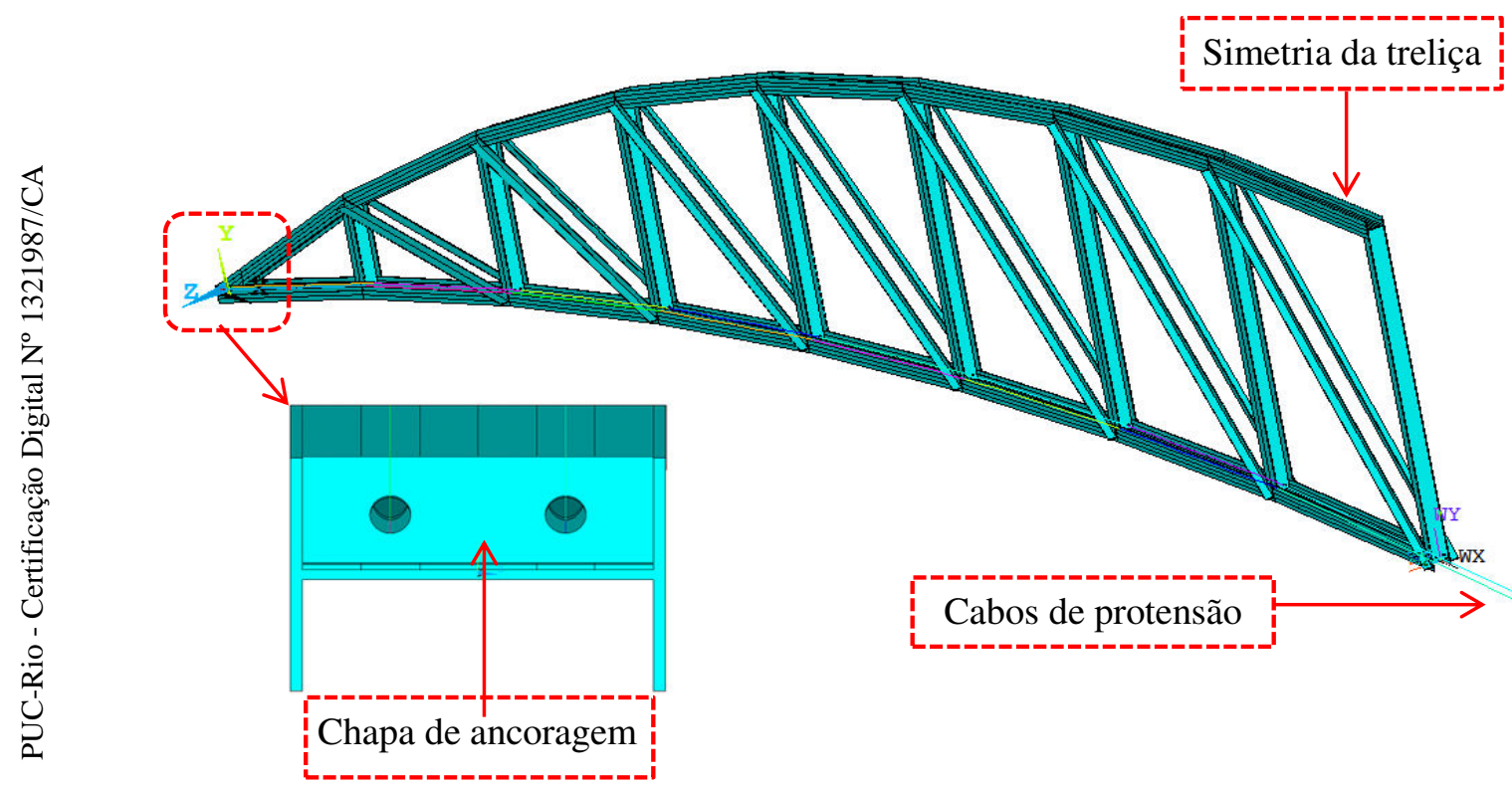

Figura 5.19 Perspectiva e simetria: elementos dos cabos de protensão $\left(\mathrm{C}_{40}\right)$.

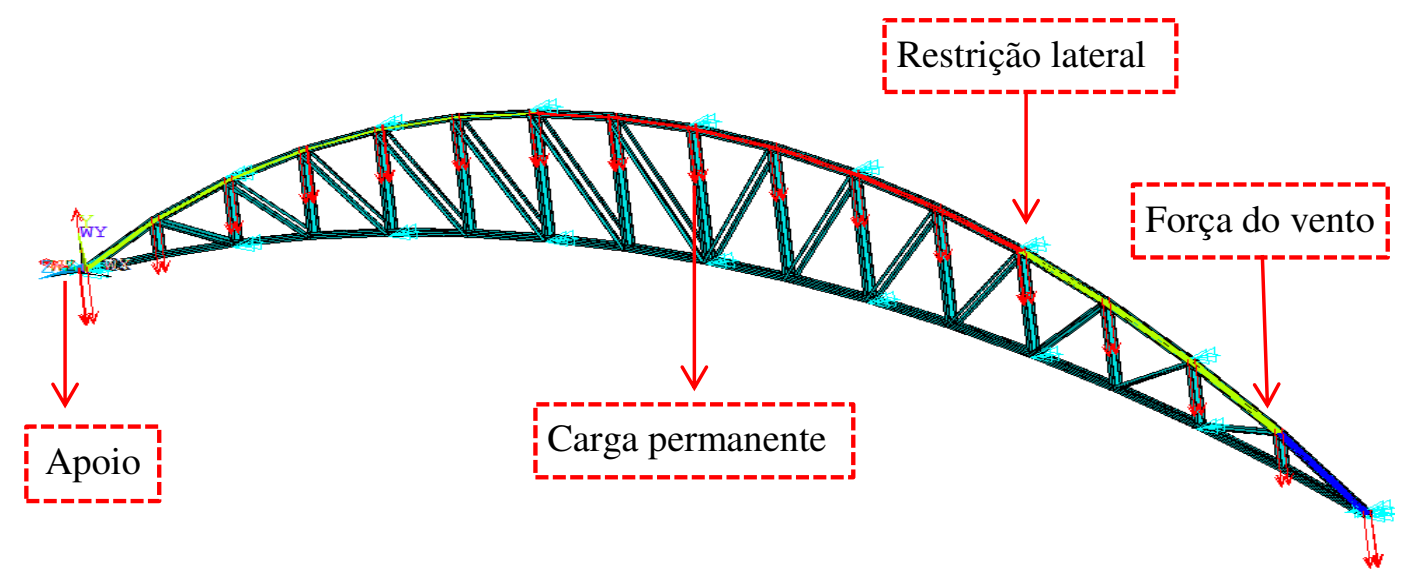

Figura 5.20 Perspectiva treliça protendida: sucção do vento e permanente $\left(\mathrm{C}_{40}\right)$. 


\subsection{4.}

\section{Modelo de treliça com 80 m de vão (Modelo $D_{80}$ )}

O modelo do tipo " $\mathrm{D}_{80}$ " com vão de $80 \mathrm{~m}$ e altura de treliça no centro do vão de $5500 \mathrm{~mm}$. As dimensões do perfil das cordas superior, inferior e montantes é W200 x 52 e nas diagonais foram empregadas cantoneiras duplas de 152,4 mm x 152,4 mm x 19,05 mm. A área da seção transversal do cabo é Ac $=404 \mathrm{~mm}^{2}$, com força de protensão adotada de 404,66 kN.

Foi utilizado o elemento SOLID185 de oito nós de um sólido para os elementos da treliça (modelo $\mathrm{D}_{80}$ ), sendo que o modelo resultou num total de 300.890 nós, 725.198 elementos finitos que resultaram em 1.805.340 graus de liberdade. As Figuras. 5.21 a 5.24 ilustram criação dos elementos da treliça, refinamento da malha, os cabos de protensão, a distribuição do carregamento de sucção devido à ação do vento que atua sobre a estrutura e as condições de contorno utilizadas na modelagem.

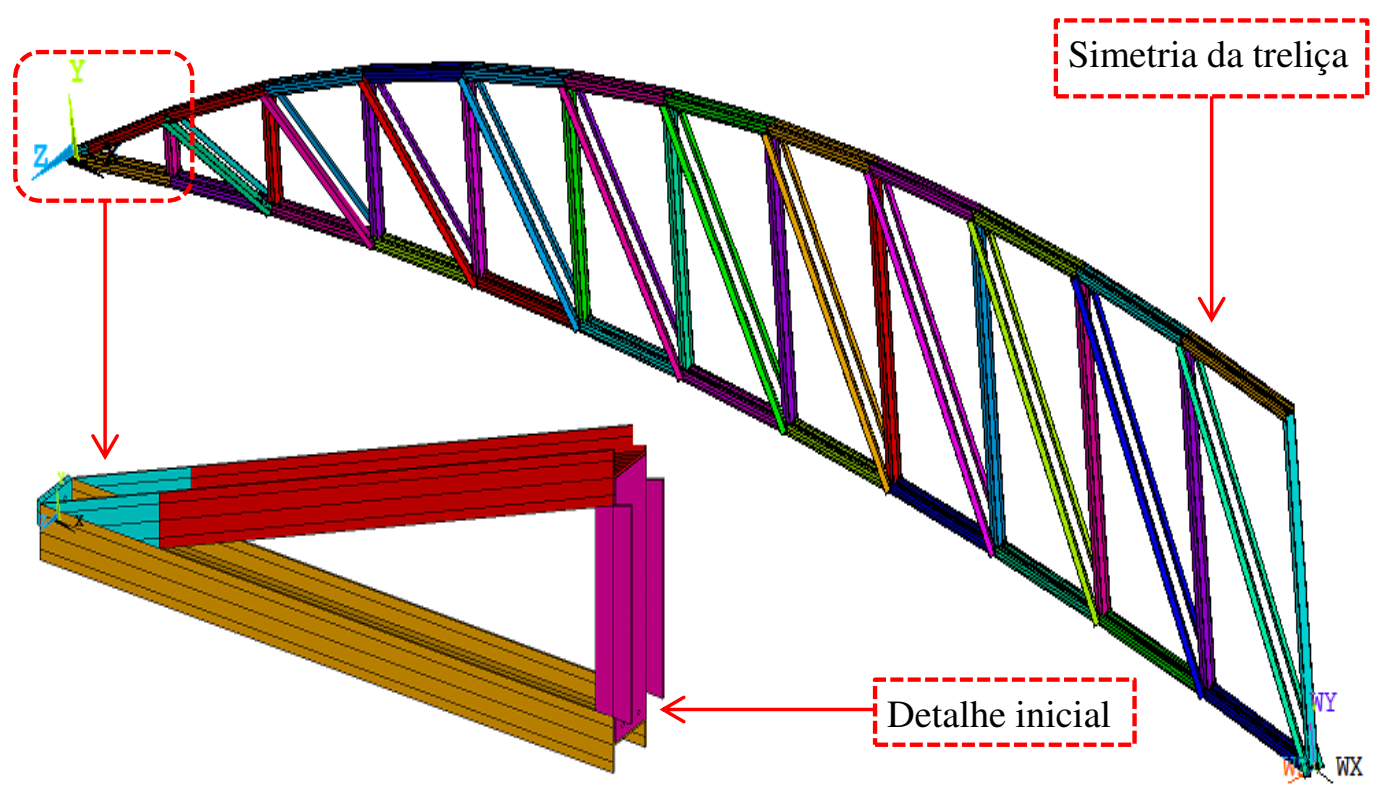

Figura 5.21 Perspectiva e simetria: criação dos elementos SOLID185 $\left(\mathrm{D}_{80}\right)$. 


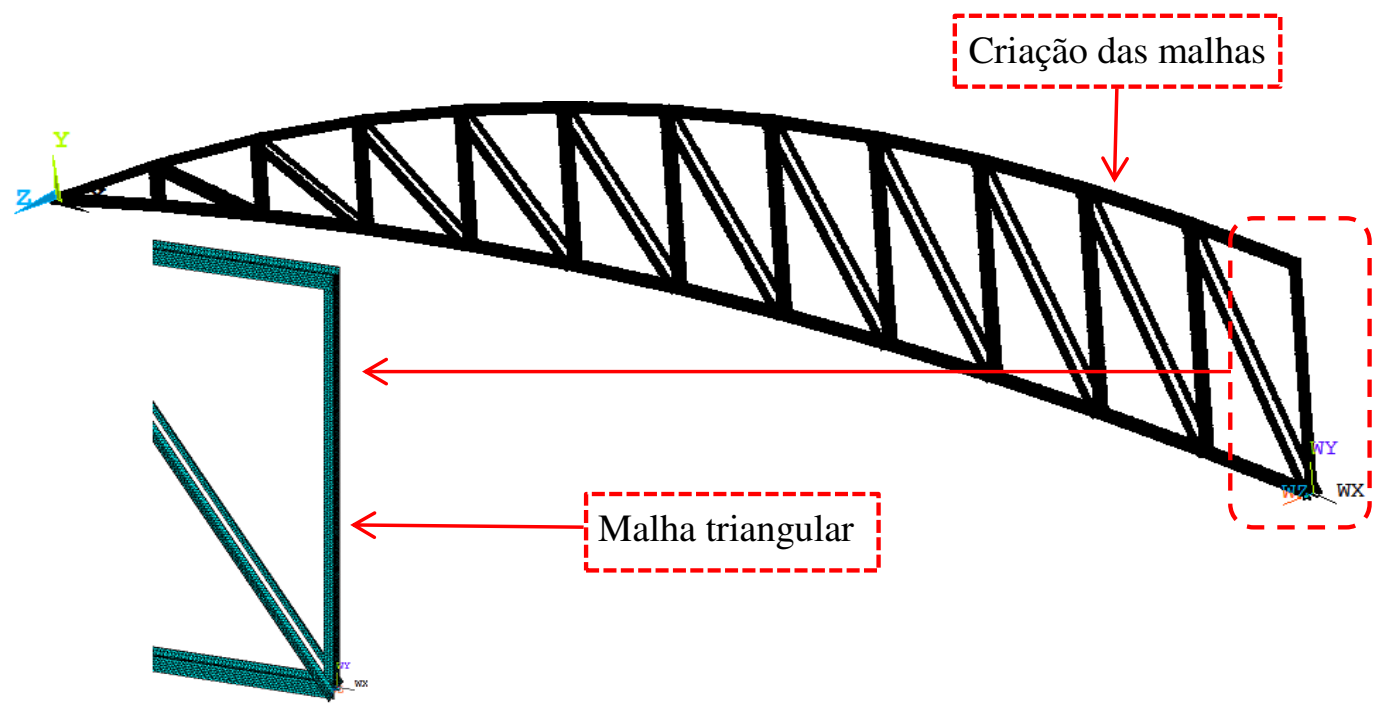

Figura 5.22 Perspectiva e simetria: criação da malha triangular $\left(\mathrm{D}_{80}\right)$.

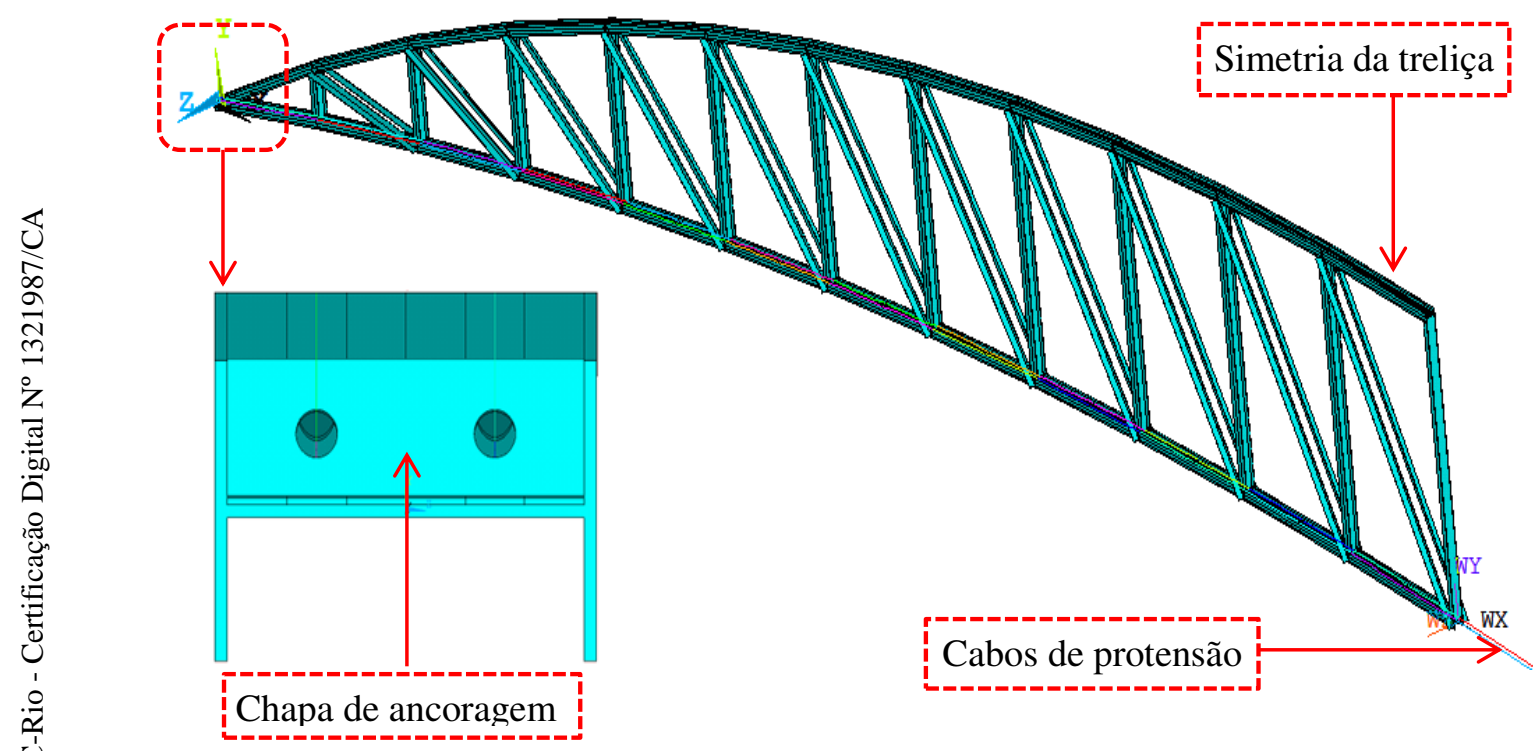

Figura 5.23 Perspectiva e simetria: elementos dos cabos de protensão $\left(\mathrm{D}_{80}\right)$.

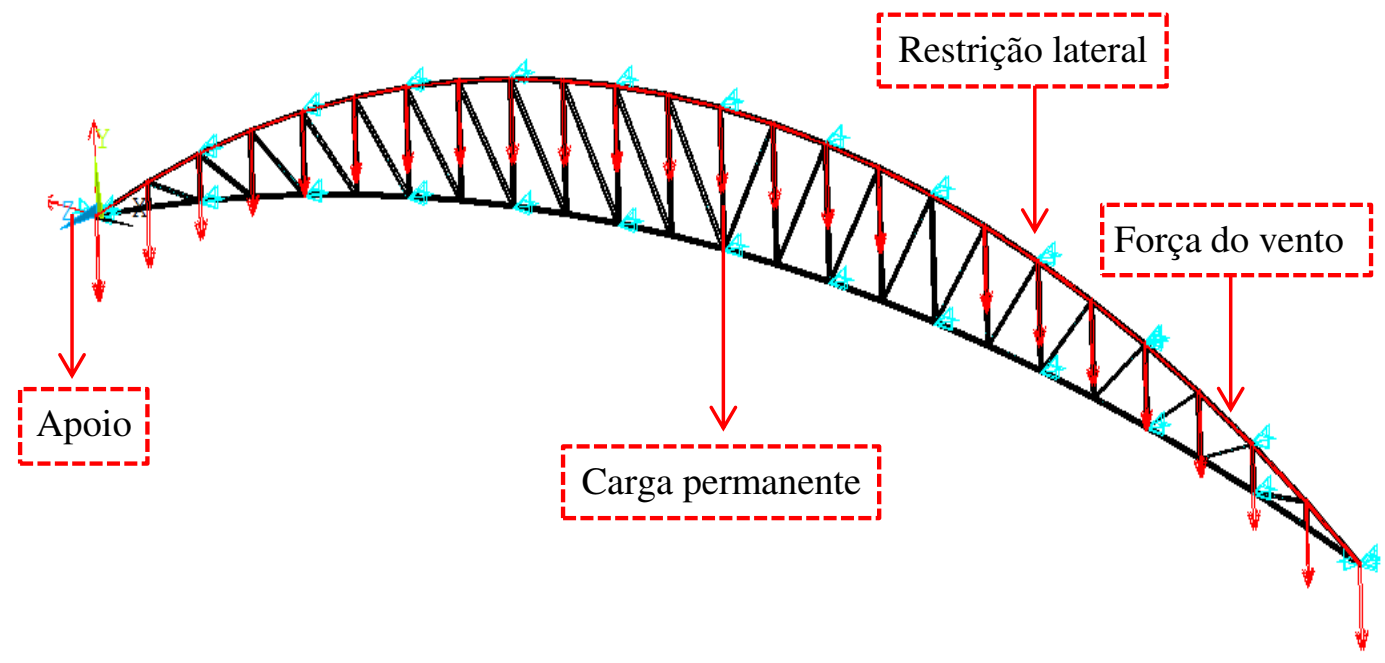

Figura 5.24 Perspectiva treliça protendida: sucção do vento e permanente $\left(D_{80}\right)$. 


\subsection{5.}

\section{Modelo de treliça com 120 m de vão (Modelo $E_{120}$ )}

O modelo tipo " $E_{120}$ " com vão de $120 \mathrm{~m}$ e altura de treliça no centro de vão de $7500 \mathrm{~mm}$. As dimensões do perfil das cordas superior, inferior e montantes é W200 x 86 e nas diagonais foram empregadas cantoneiras duplas de 152,4 mm x 152,4 mm x 19,05 mm. A área da seção transversal do cabo é Ac $=606,0 \mathrm{~mm}^{2}$, com força de protensão adotada de $660,56 \mathrm{kN}$.

Foi utilizado o elemento SOLID185 de oito nós de um sólido para os elementos da treliça (modelo $\mathrm{E}_{120}$ ), sendo que o modelo resultou num total de 336.953 nós, 951.376 elementos finitos que resultaram em 2.021.718 graus de liberdade. As Figuras. 5.25 a 5.28 ilustram criação dos elementos da treliça, refinamento da malha, os cabos de protensão, a distribuição do carregamento de sucção devido à ação do vento que atua sobre a estrutura e as condições de contorno utilizadas na modelagem.

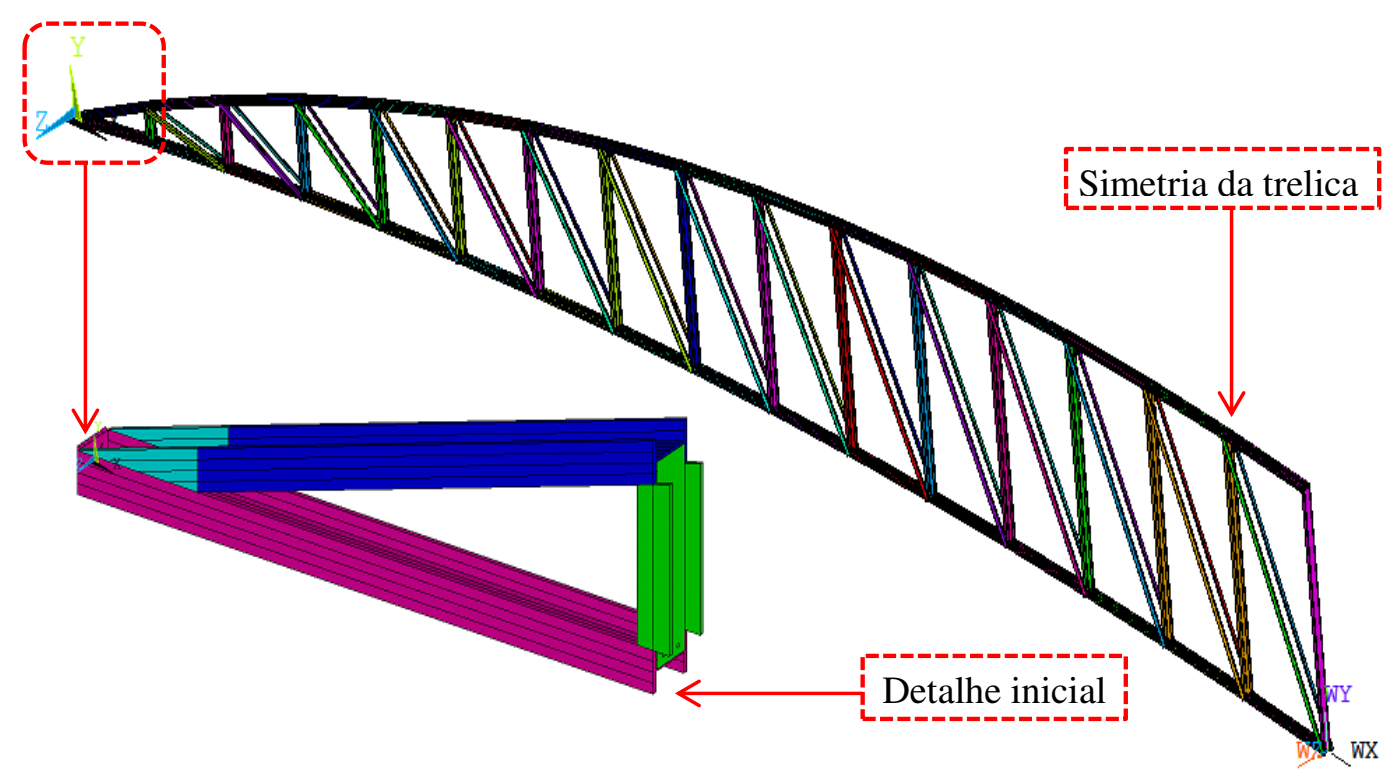

Figura 5.25 Perspectiva e simetria: criação dos elementos SOLID185 ( $\left.\mathrm{E}_{120}\right)$. 


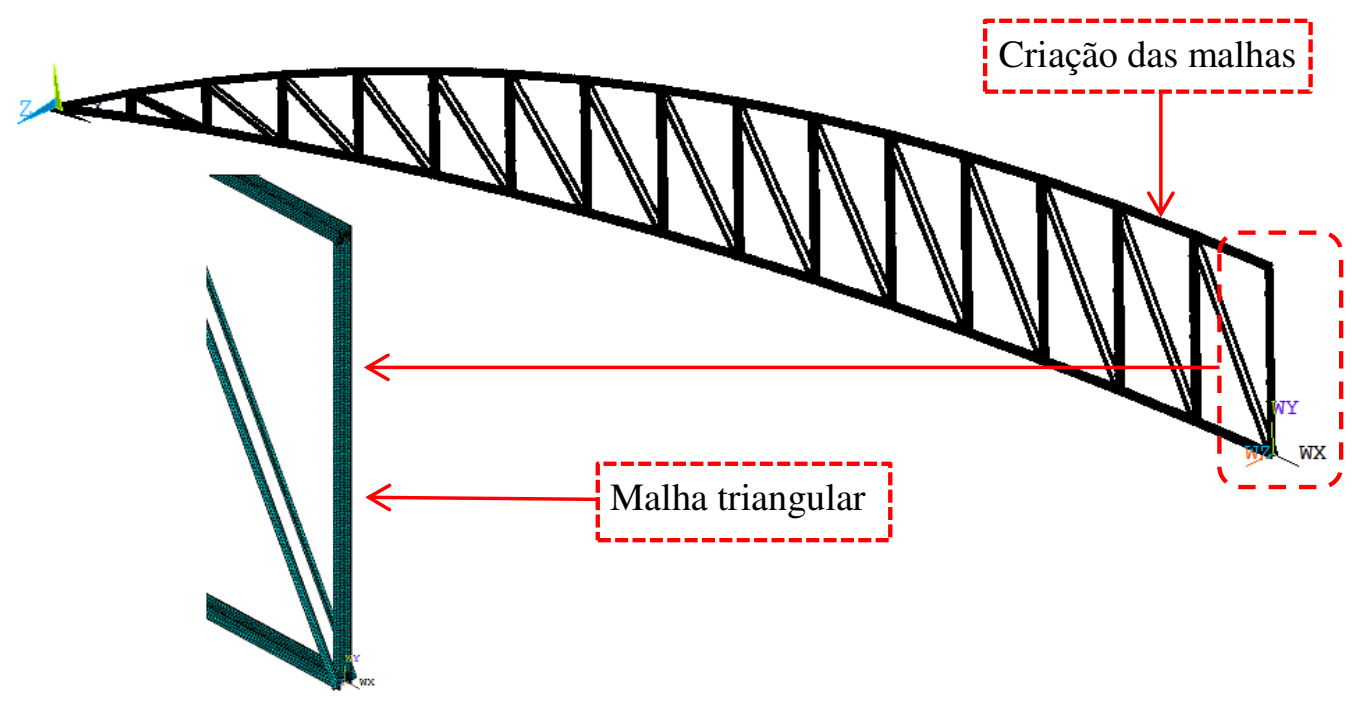

Figura 5.26 Perspectiva e simetria: criação da malha triangular $\left(\mathrm{E}_{120}\right)$.

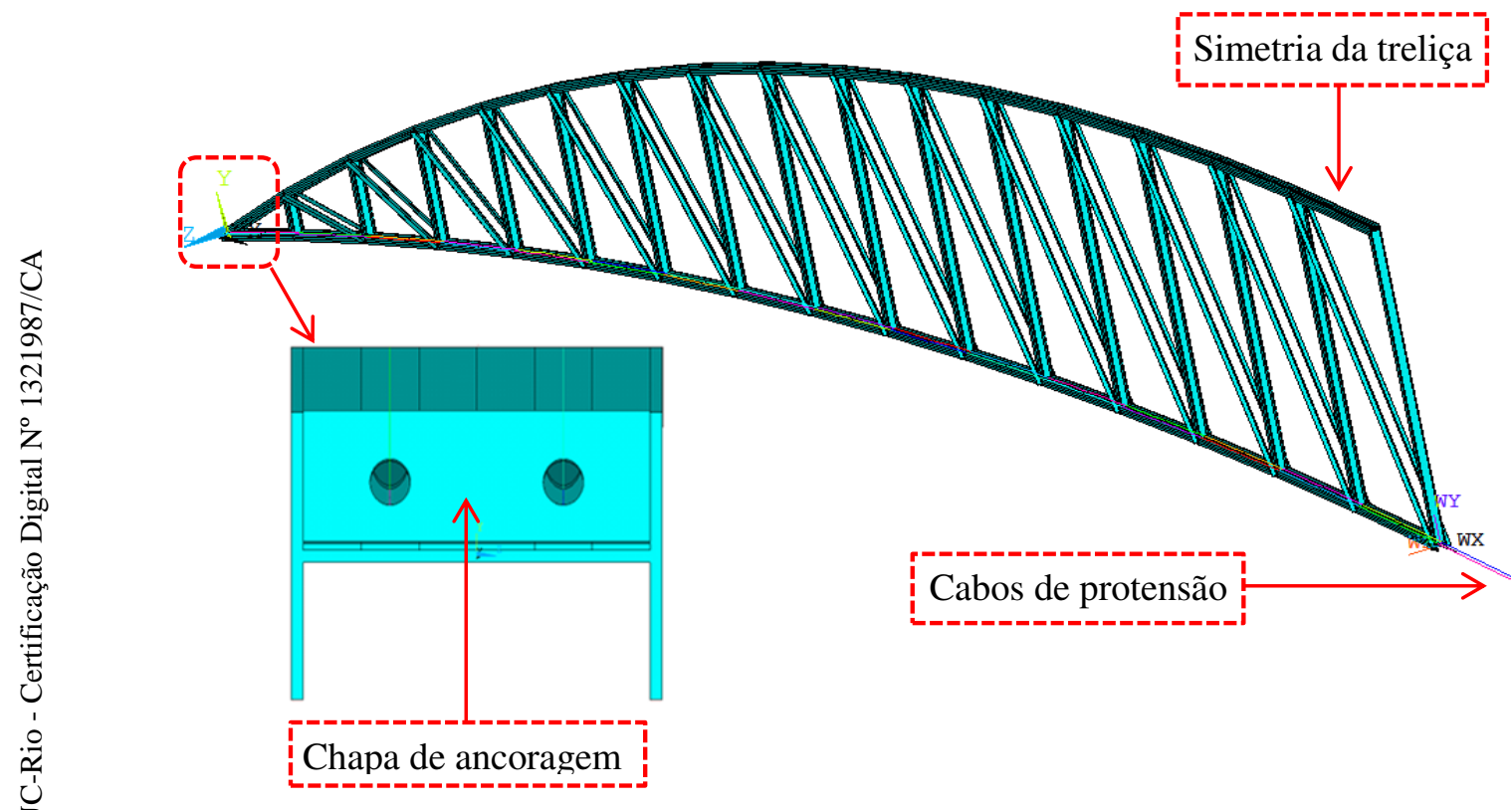

Figura 5.27 Perspectiva e simetria: elementos dos cabos de protensão $\left(\mathrm{E}_{120}\right)$.

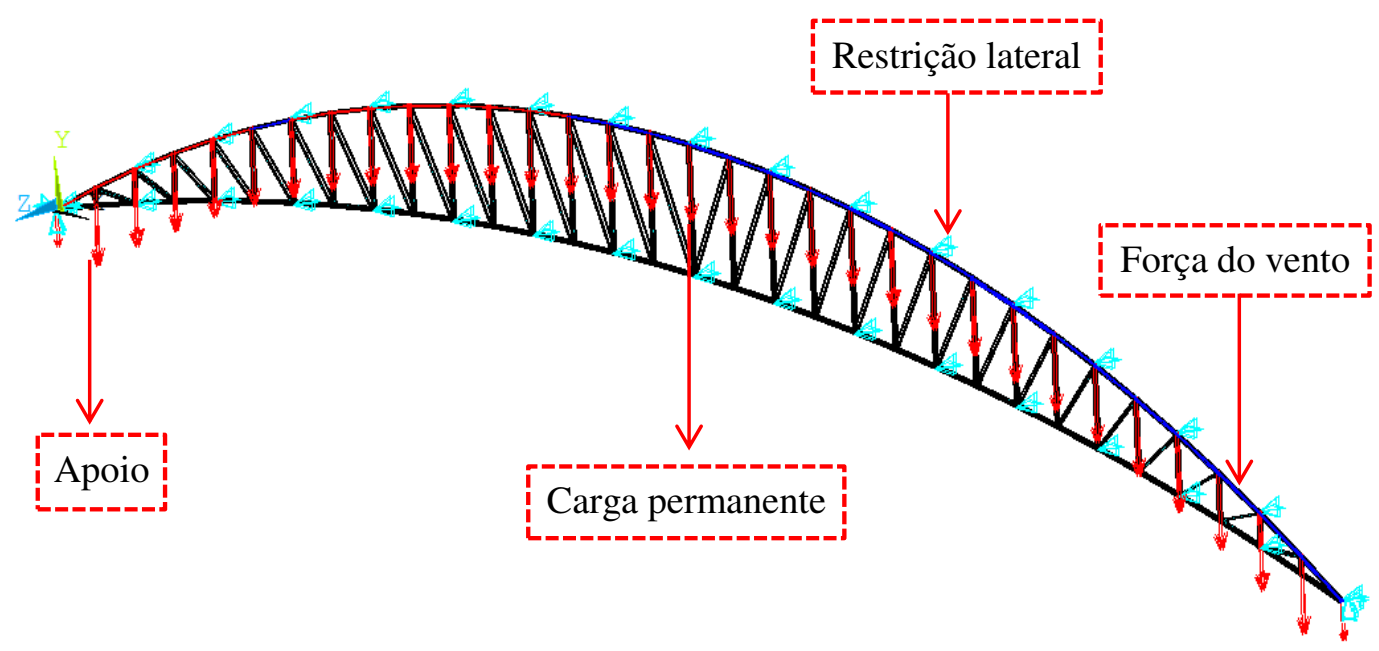

Figura 5.28 Perspectiva treliça protendida: sucção do vento e permanente $\left(\mathrm{E}_{120}\right)$. 
Nas figuras anteriores observa-se que, para a geração das malhas em elementos finitos para todos os modelos numéricos, foram aproveitadas as condições de simetria da treliça, que foram modeladas com a consideração de um plano de simetria paralelo ao plano Y-Z, para reduzir o tempo computacional para geração das malhas de cada simulação. Na Tabela 5.3 têm-se os números de nós, de elementos de malhas e de graus de liberdade de elementos finitos para os diferentes modelos estruturais em estudo.

Tabela 5.3 Resumos de números de elementos finitos para os diferentes modelos numéricos

\begin{tabular}{cccc}
\hline $\begin{array}{c}\text { Modelos } \\
\text { numéricos }\end{array}$ & Número de nós & $\begin{array}{c}\text { Números de } \\
\text { elementos }\end{array}$ & $\begin{array}{c}\text { Números de graus } \\
\text { de liberdades }\end{array}$ \\
\hline $\mathrm{A}_{10}$ & 44.896 & 131.532 & 269.376 \\
$\mathrm{~B}_{20}$ & 86.606 & 247.332 & 519.636 \\
$\mathrm{C}_{40}$ & 221.363 & 631.248 & 1.328 .178 \\
$\mathrm{D}_{80}$ & 300.890 & 725.198 & 1.805 .340 \\
$\mathrm{E}_{120}$ & 336.953 & 951.376 & 2.021 .718 \\
\hline
\end{tabular}




\section{Análise estática linear elástica das treliças}

Nesta seção são apresentados os resultados das análises estáticas dos modelos numérico-computacionais desenvolvidos usando-se o programa ANSYS APDL. Buscou-se, neste estudo, avaliar a resposta estrutural em termos de deslocamentos, forças das barras e tensões em certas partes críticas da estrutura, para diferentes tipos de treliças em forma de arco, com e sem protensão, analisadas para diferentes combinações de ações, apresentadas no capítulo quatro.

Os valores dos resultados de deslocamentos são comparados com os valores das flechas máximas permitidas (L/250), estabelecidas pela ABNT NBR 8800 (2008). Os valores de tensão são analisados conforme a tensão equivalente de von Mises, apresentada no capítulo dois.

\section{1.}

\section{Análise da treliça de $10 \mathrm{~m}$ de vão}

Com o objetivo de validar o ganho, em termos de comportamentos estruturais, do uso da protensão na treliça, foi realizada uma modelagem da estrutura sem e com protensão. Cabe ressaltar que, para análise sem protensão, foi investigado apenas o carregamento associado a evento 1, e para a análise com protensão, para os eventos 2 e 3 (ver capítulo 4, item 4.4). Nesta análise linear elástica da treliça protendida, para a fase de construção, foi realizado um estudo de sensibilidade da espessura da chapa de ancoragem, a fim de definir a espessura da chapa de espessura mínima para o modelo de treliça de $10 \mathrm{~m}$.

\subsection{1.}

\section{Treliça de $10 \mathrm{~m}$ sem protensão $\left(A_{10}\right)$}

As Figuras 6.1 e 6.2 apresentam a distribuição das tensões de von Mises (critério de plastificação) e os deslocamentos máximos, o que foi obtido na análise da treliça de $10 \mathrm{~m}$ de vão, sem protensão, provocada pela carga de serviço 
permanente e pela carga variável devido à ação do vento (evento1). Para melhor compressão do comportamento estrutural são também apresentadas na Figura 6.1 as forças internas atuantes nos principais elementos da treliça.

Nessa análise observa-se que a maior tensão de von Mises resultou em 345,139 MPa. Tal valor foi obtido junto à região apoio da treliça, como pode ser visto na Figura 6.1. Essa tensão é aproximada do valor de tensão limite de escoamento do material usado, ou seja, não há plastificação da estrutura.

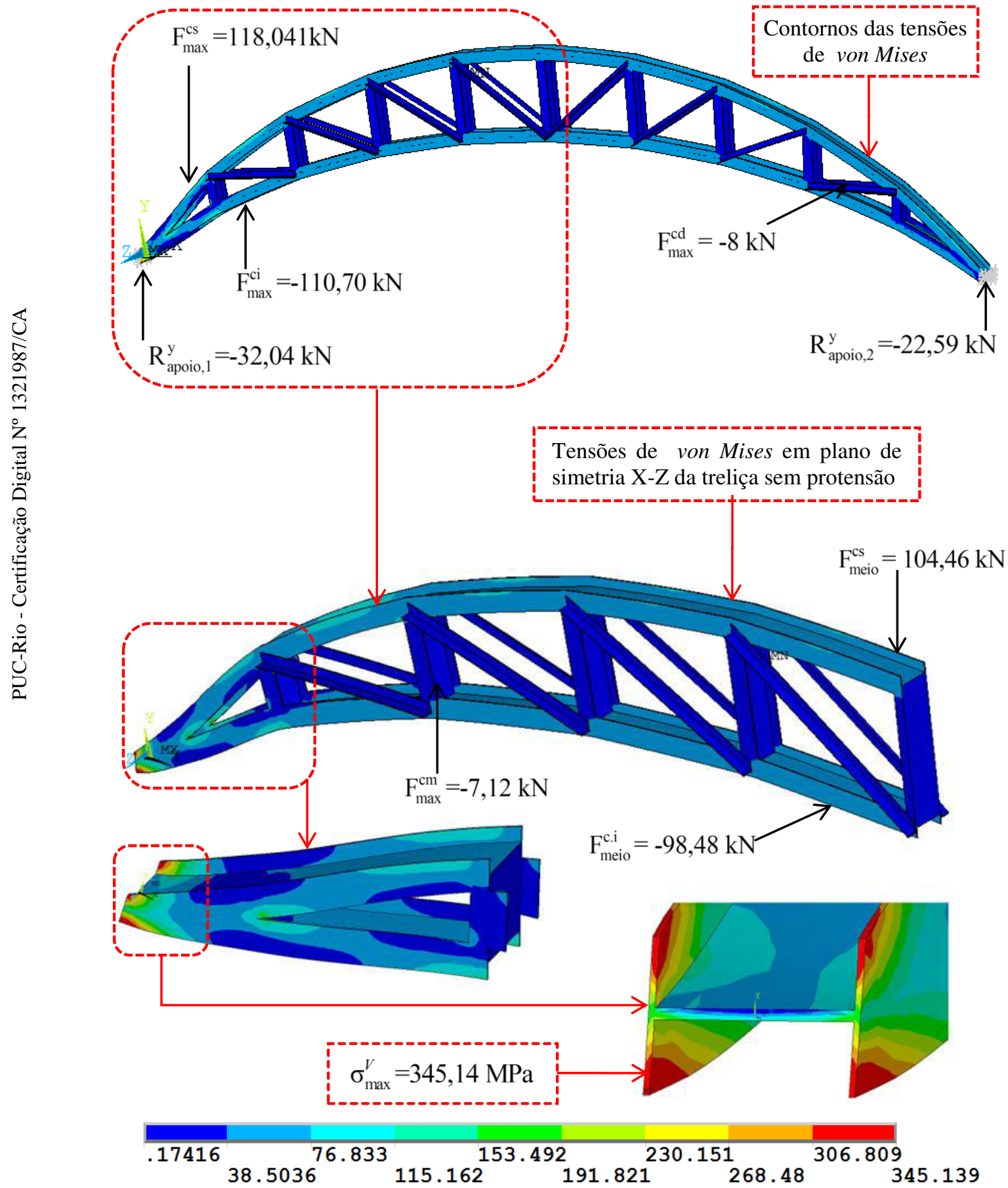

Figura 6.1 Distribuição das tensões de von Mises (em MPa) para o evento $1\left(\mathrm{~A}_{10}\right)$ 
Na Figura 6.2 apresenta-se o deslocamento máximo obtido no eixo vertical no centro da treliça com valor de $14,81 \mathrm{~mm}<\mathrm{L} / 250$. Convém notar que este valor é inferior ao deslocamento máximo da estrutura recomendado (NBR 8800).

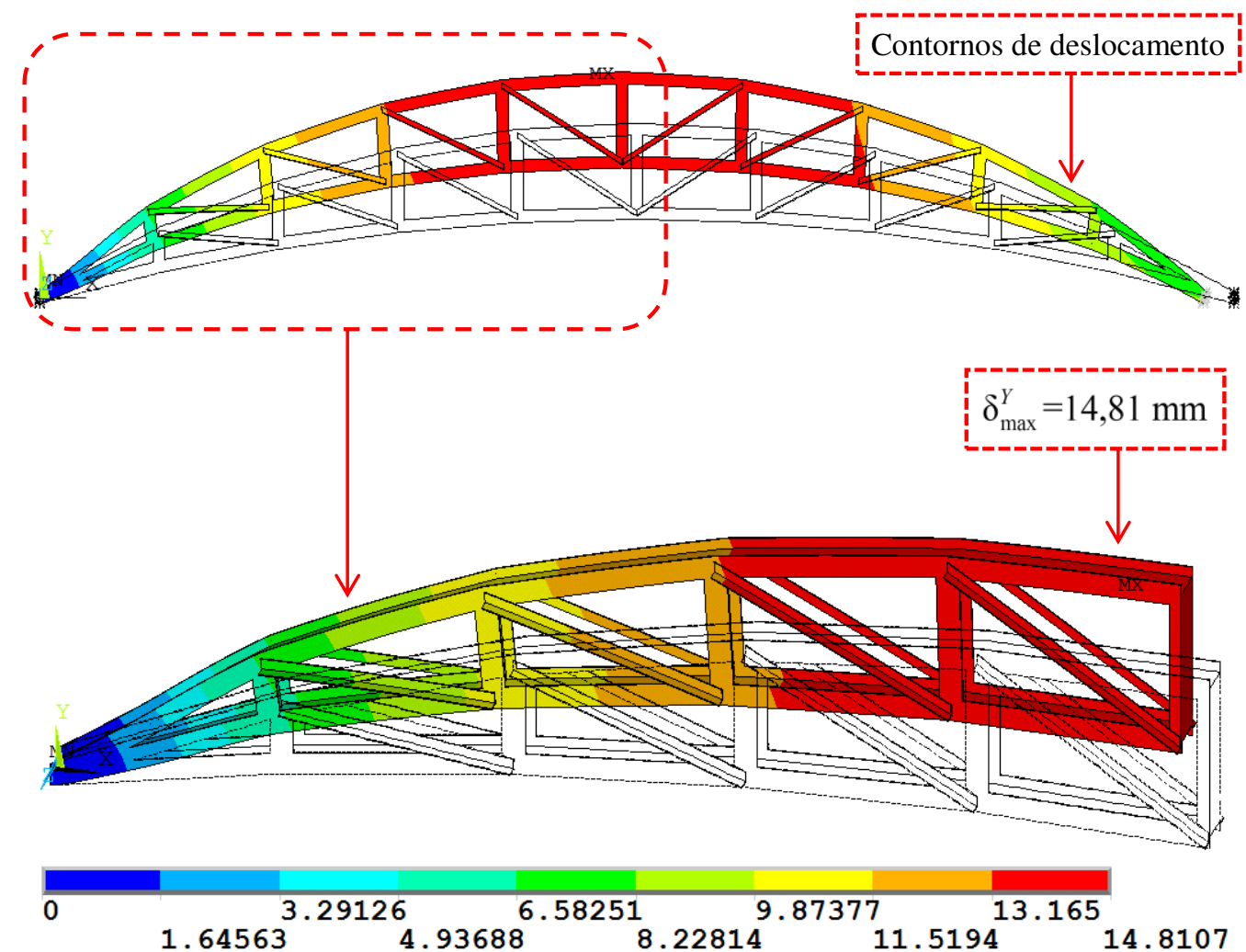

Figura 6.2 Vista lateral e perspectiva com plano de simetria X-Z: deslocamento Uy para o evento $1\left(\mathrm{~A}_{10}\right)$.

\subsection{2.}

\section{Treliça de $10 \mathrm{~m}$ protendida $\left(\mathrm{A}_{\mathrm{P} 10}\right)$}

Neste item são apresentadas as análises lineares que se referem às combinações das fases de construção (evento 2) e normal (evento 3). Os resultados obtidos são mostrados nesta seção.

\subsubsection{1.}

\section{Evento 2: Para combinação da fase de construção ( $\left.A_{P 10}\right)$}

Para a fase de construção, a treliça protendida com três espessuras de chapa de ancoragem foi modelada com a finalidade de analisar-se a interface da chapa e do cabo nas extremidades, com uma força de protensão aplicada de 65,37 kN. A seguir, são apresentados os resultados das análises das três espessuras da chapa de ancoragem: $2,45 \mathrm{~mm} ; 6,3 \mathrm{~mm}$ e $9,3 \mathrm{~mm}$ ancoragem. 


\section{Espessura da chapa de ancoragem: $2,45 \mathrm{~mm}$}

Nesta análise a estrutura modelada considerou uma espessura da chapa de ancoragem igual a 2,45 mm. Observou-se que a maior tensão de von Mises resultou em 365,02 $\mathrm{MPa}$. Isso foi obtido perto da região de ancoragem da treliça. Esta tensão excede o valor de tensão limite de escoamento do material usado, portanto a treliça plastifica nesta região da placa. A Figura 6.3 apresenta várias perspectivas da chapa de ancoragem, onde é mostrada a tensão máxima de von Mises localizada na abertura da chapa.

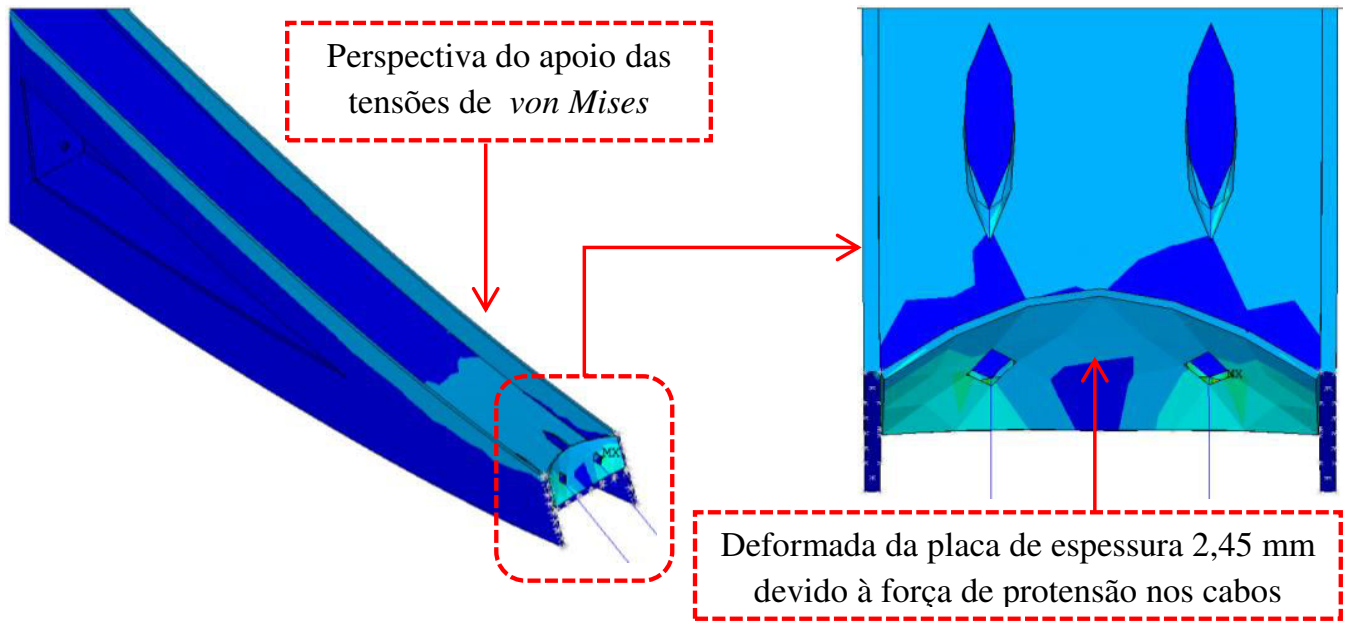

(a)

(b)
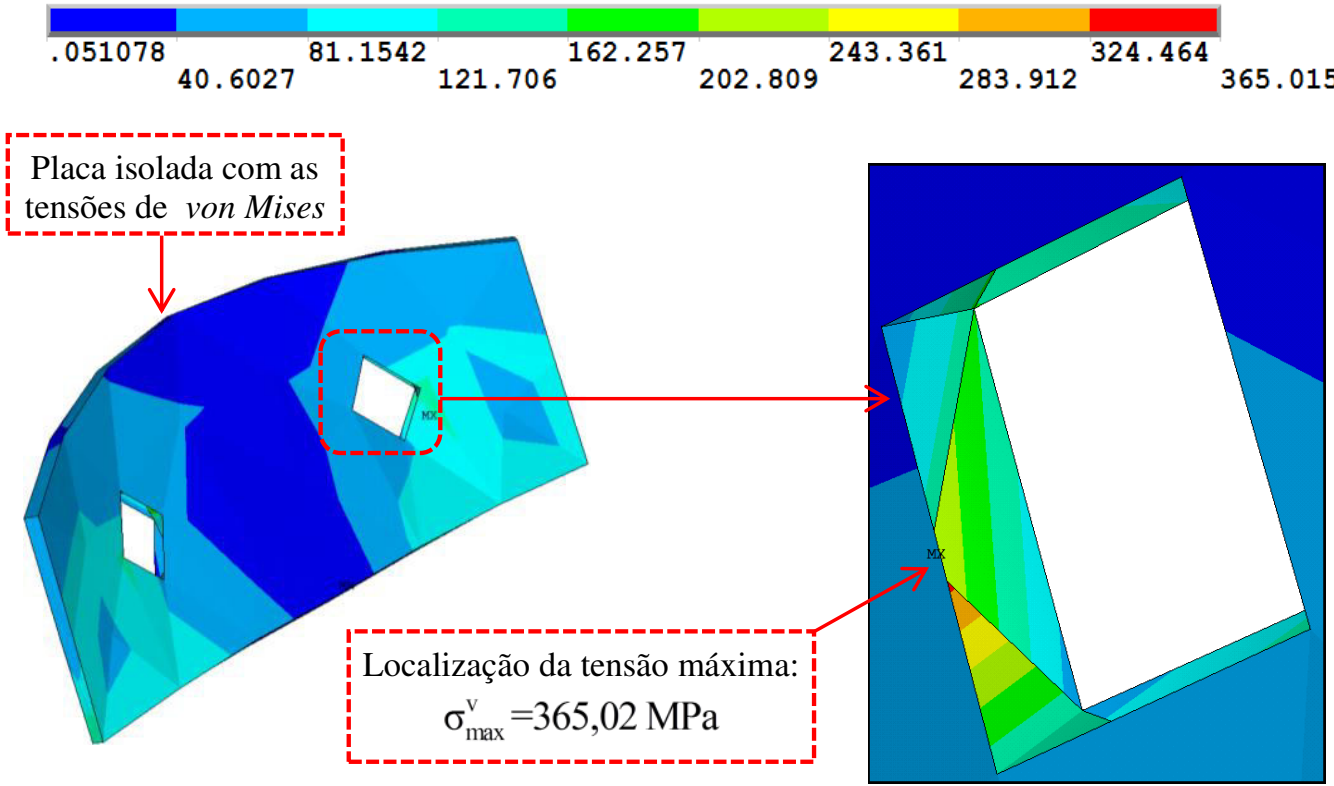

(c)

(d)

$15.483254 .3201^{93.157} 131.994^{170.831} 209.668^{248.505} 287.341^{326.178} 365.015^{3}$

Figura 6.3 Distribuição das tensões de von Mises (em MPa) correspondente na chapa com espessura de 2,45 $\mathrm{mm}$ para o evento 2 ( $\left.\mathrm{A}_{\mathrm{P} 10}\right)$. 


\section{Espessura da chapa de ancoragem: $6,3 \mathrm{~mm}$}

Observa-se que a maior tensão de von Mises resultou em 169,6 MPa. Tal valor encontrado também foi obtido na região de ancoragem da treliça. Este resultado não excede o valor da tensão limite de escoamento do material usado. Portanto, para esta nova espessura de chapa adotada, a treliça não plastifica nessa zona. Na Figura 6.4 são mostradas várias perspectivas da chapa de ancoragem sendo destacada na Figura 6.4.d, a tensão máxima de von Mises localizada na abertura da chapa.

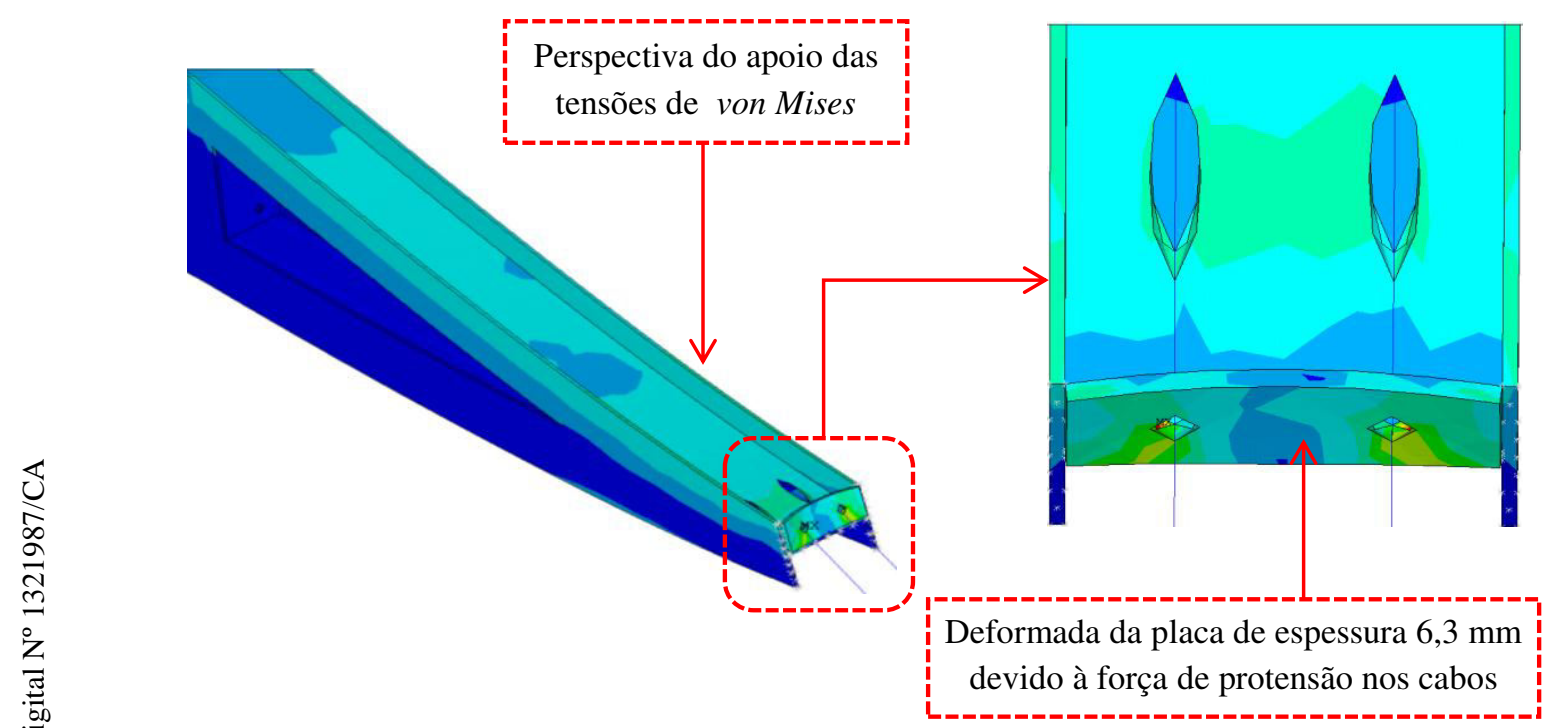

(a)

(b)

\begin{tabular}{|l|llllllll|}
\hline .051298 & & & & & & \\
\hline
\end{tabular}

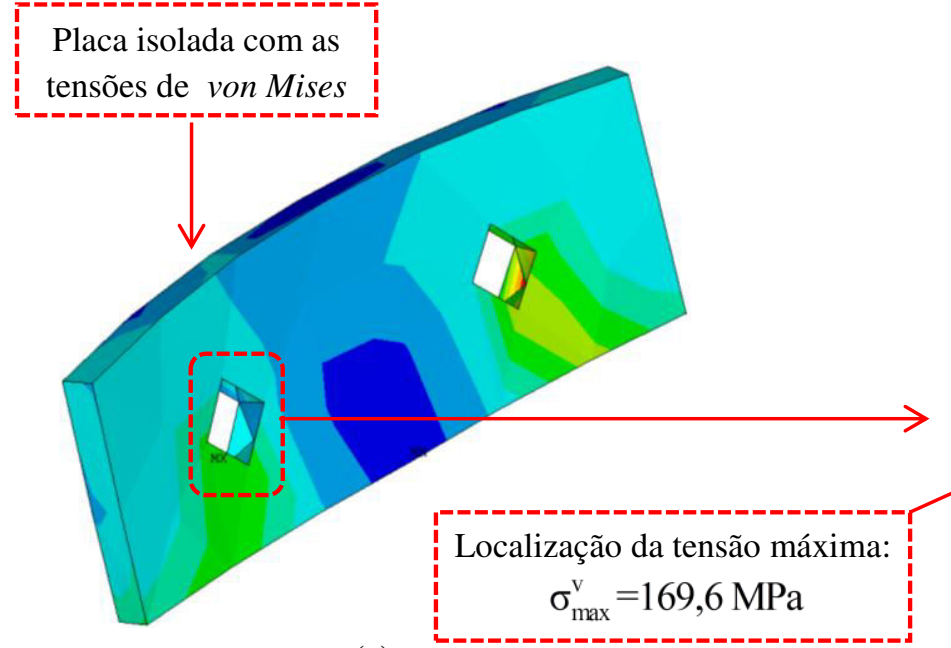

(c)

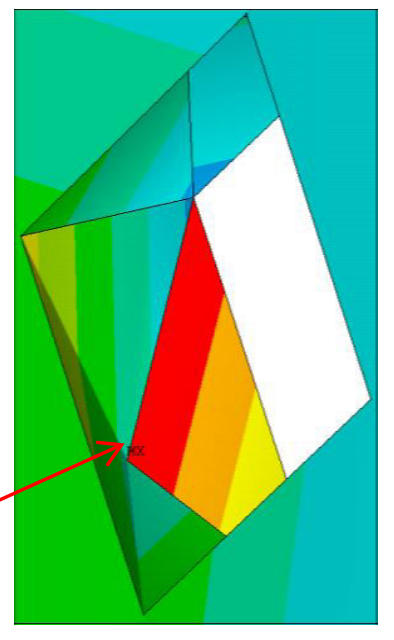

(d)

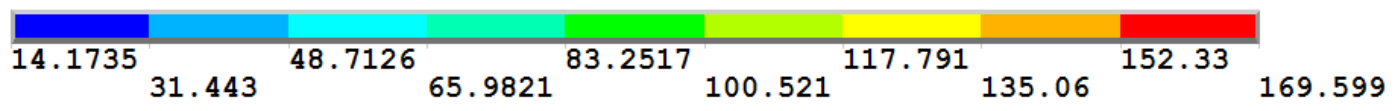

Figura 6.4 Distribuição das tensões de von Mises (em MPa) correspondente na chapa com espessura de $6,3 \mathrm{~mm}$ para o evento $2\left(\mathrm{~A}_{\mathrm{P} 10}\right)$. 


\section{Espessura da chapa de ancoragem: $9,3 \mathrm{~mm}$}

Observa-se que a maior tensão de von Mises resultou em 116,44 MPa. Tal valor encontrado também foi obtido na região de ancoragem da treliça. Esse resultado não excede o valor da tensão limite de escoamento do material usado. Portanto, para esta nova espessura de chapa adotada, a treliça não plastifica nessa zona. Ou seja, assim como na chapa de espessura $6,3 \mathrm{~mm}$, essa nova dimensão apresenta as mesmas características, porém as tensões distribuídas na estrutura são menores que nos dois casos anteriores. Daí conclui-se que essa espessura de 9,3 mm é a espessura ótima. Por isso, adota-se essa medida para as análises seguintes. Na Figura 6.5 são mostradas várias perspectivas da chapa de ancoragem, sendo destacada na Figura 6.5.d a tensão máxima localizada na abertura da chapa.

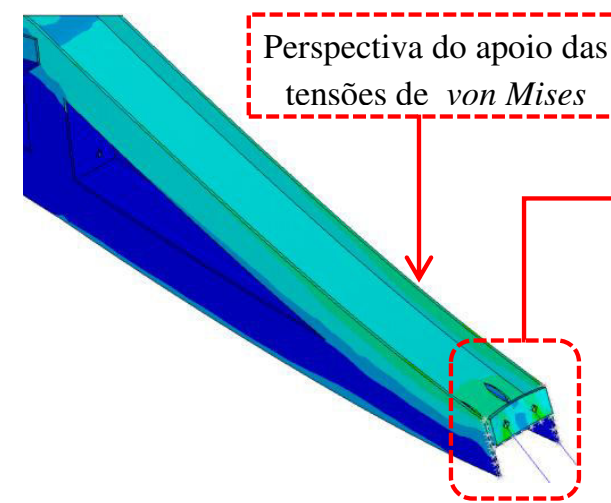

(a)

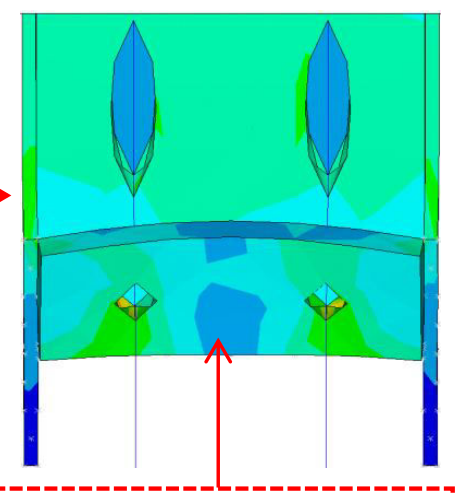

Deformada da placa de espessura $9,3 \mathrm{~mm}$ devido à força de protensão nos cabos

15.1181 26.3758 ${ }^{37.6334} 48.891^{60.1486} 71.4063^{82.6639} 93.9215^{105.179} 116.437^{8}$

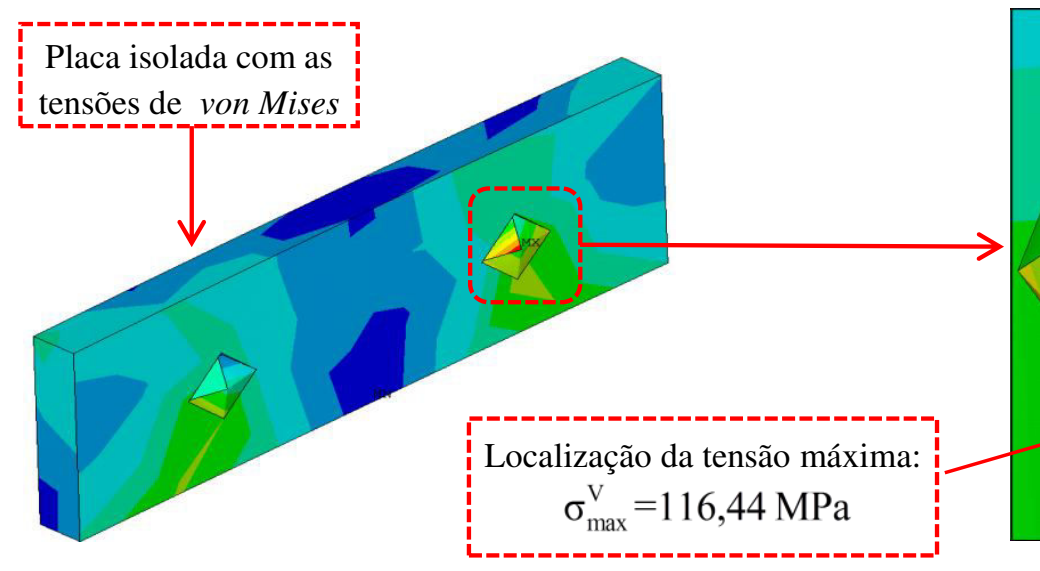

(c) (b)

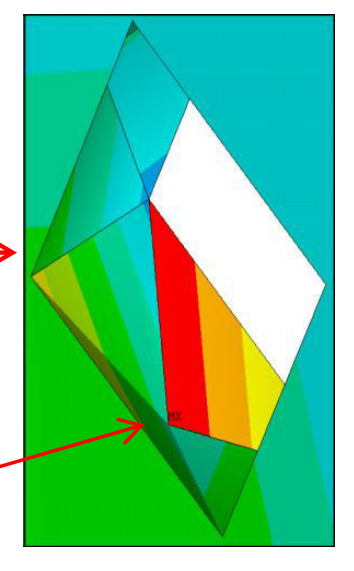

(d)

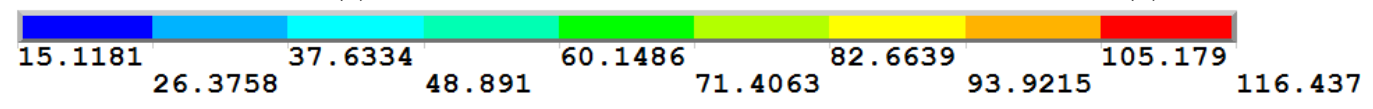

Figura 6.5 Distribuição das tensões de von Mises (em MPa) correspondente na chapa com espessura de 9,3 mm para o evento $2\left(\mathrm{~A}_{\mathrm{P} 10}\right)$. 
Com a chapa padronizada de $9,3 \mathrm{~mm}$ para treliça protendida, para o evento de construção (peso próprio e força de protensão ótima) verificou-se o deslocamento vertical. Na Figura 6.6 apresenta-se o deslocamento máximo obtido no eixo vertical no centro da treliça, com valor de $4,74 \mathrm{~mm}<\mathrm{L} / 250$, que é inferior ao deslocamento máximo da estrutura recomendado (NBR-8800).

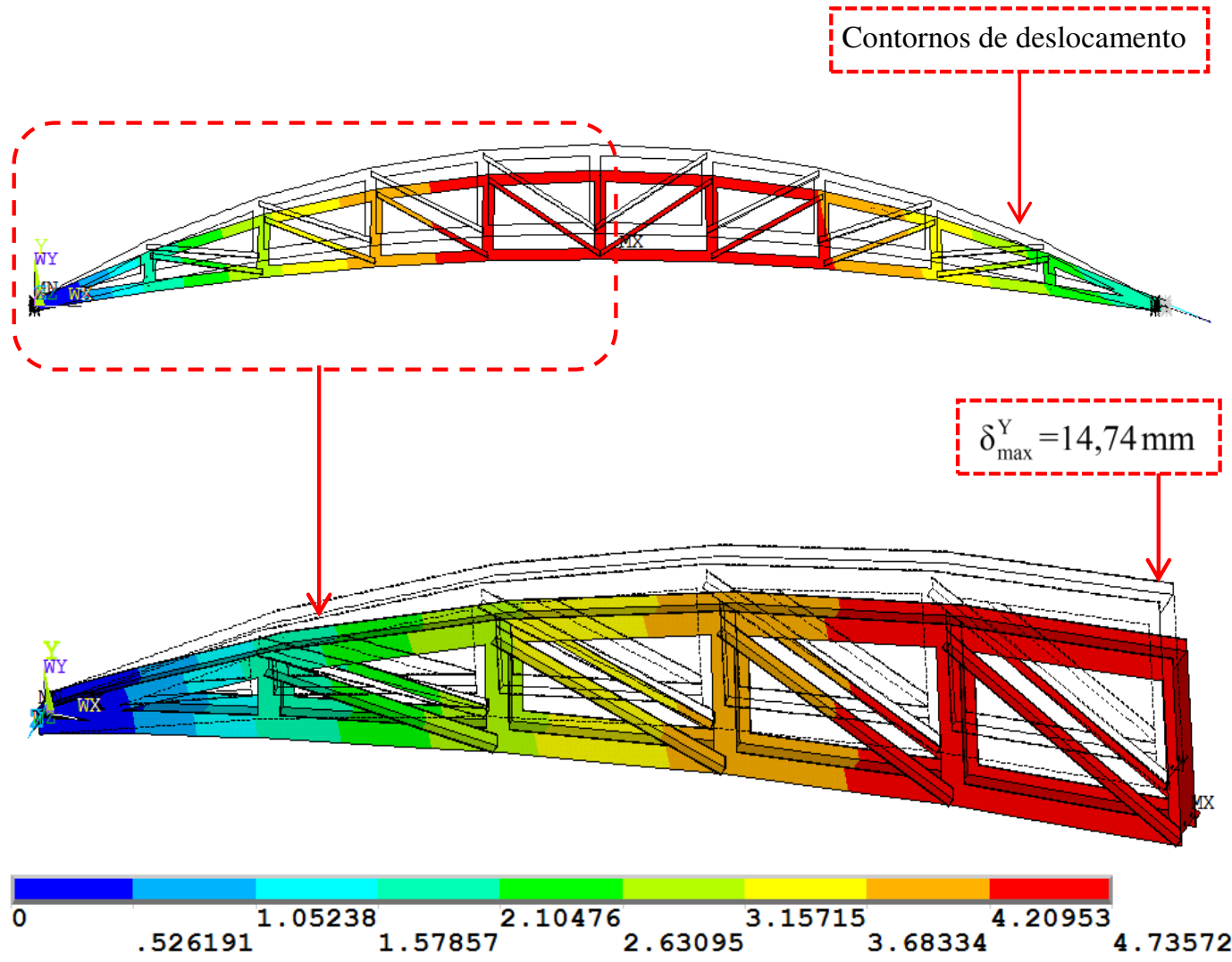

Figura 6.6 Vista lateral e perspectiva com plano de simetria X-Y: deslocamento Uy para o evento $2\left(\mathrm{~A}_{\mathrm{P} 10}\right)$.

\subsubsection{2.}

Evento 3 : Para combinação última normal $\left(A_{p 10}\right)$

Nesta análise foi realizada uma modelagem de uma treliça protendida de 10 m de vão com uma chapa de ancoragem padronizada de 9,3 mm. As Figuras 6.7 e 6.8 mostram as distribuições das tensões de von Mises e os deslocamentos máximos provocados pela carga permanente e pela carga variável devido à ação do vento e da força de protensão ótima (evento 3). Também são apresentadas na Figura 6.1 as forças internas atuantes nos principais elementos da treliça. 
Com base nos resultados obtidos, foi observado que a maior tensão de von Mises calculada foi igual a $166,26 \mathrm{MPa}$. Tal valor foi obtido junto ao apoio da treliça, como pode ser visto na Figura 6.7. Essa tensão é menor que o valor de tensão limite do escoamento do material usado, ou seja, não há plastificação da estrutura.

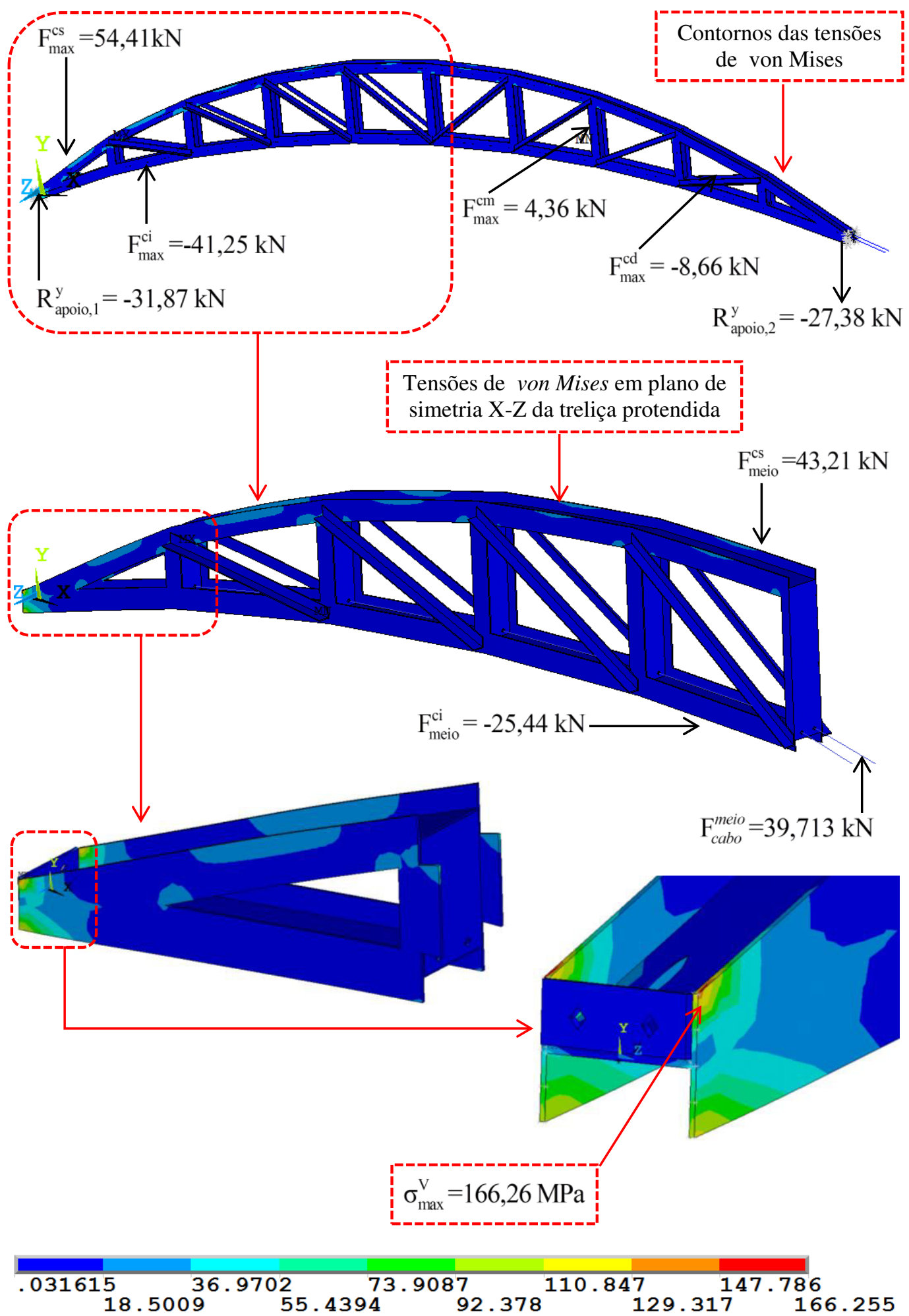

Figura 6.7 Distribuição das tensões de von Mises (em MPa) para o evento $3\left(\mathrm{~A}_{\mathrm{P} 10}\right)$ 
Com a chapa padronizada de 9,3 mm para treliça, para o evento 3 (carga permanente, ação do vento e força de protensão) verificou-se que o deslocamento vertical máximo foi igual a $1,63 \mathrm{~mm}<\mathrm{L} / 250$. O ponto onde isso ocorre está representado na Figura 6.8 com a nomenclatura MX. Convém notar que esse valor é inferior ao deslocamento máximo da estrutura recomendado (NBR 8800).

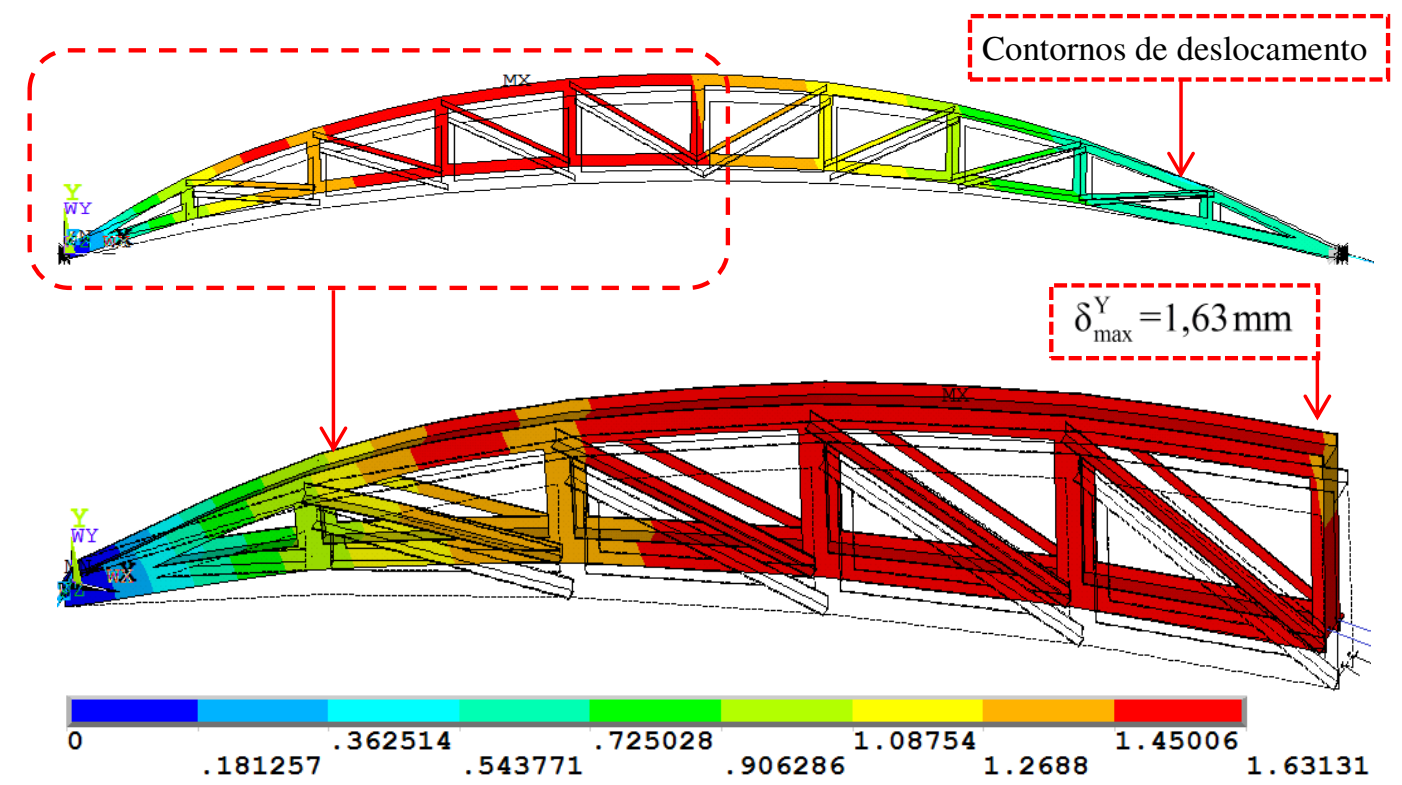

Figura 6.8 Vista lateral e perspectiva com plano de simetria X-Z: deslocamento Uy para o evento $3\left(\mathrm{~A}_{\mathrm{P} 10}\right)$.

\section{2.}

\section{Análise da treliça de $\mathbf{2 0} \mathrm{m}$ de vão}

Com o objetivo de mostrar a validação do uso da protensão na treliça de 20 m de vão, foi realizada uma modelagem da estrutura sem e com protensão. Cabe ressaltar que, para análise sem protensão, foi investigado apenas o carregamento associado ao evento 1, e, para a análise com força de protensão, para os eventos 2 e 3 (ver capítulo 4, item 4.4). Nesta modelagem, para treliça protendida, adotou-se uma chapa de ancoragem padronizada de 9,3 $\mathrm{mm}$ de espessura.

\subsection{1.}

\section{Treliça de $20 \mathrm{~m}$ sem protensão $\left(B_{20}\right)$}

As Figuras 6.9 e 6.10 apresentam a distribuição das tensões de von Mises e os deslocamentos máximos, o que foi obtido na análise da treliça de $20 \mathrm{~m}$ de vão, sem protensão, provocada pela carga de serviço permanente e pela carga variável devido à ação do vento (evento1). São, também apresentadas na Figura 6.9 as forças internas atuantes nos principais elementos da treliça. 
Nesta análise, observa-se que a maior tensão de von Mises resultou em 344,54 MPa. Tal valor foi obtido junto ao apoio e na ponta da abertura da treliça, como pode ser visto na Figura 6.9. Essa tensão é aproximada do valor de tensão limite de escoamento do material usado, ou seja, não há plastificação da estrutura. Além disso evidencia-se elevada distribuição das tensões de von Mises nas cordas superior e inferior da treliça.

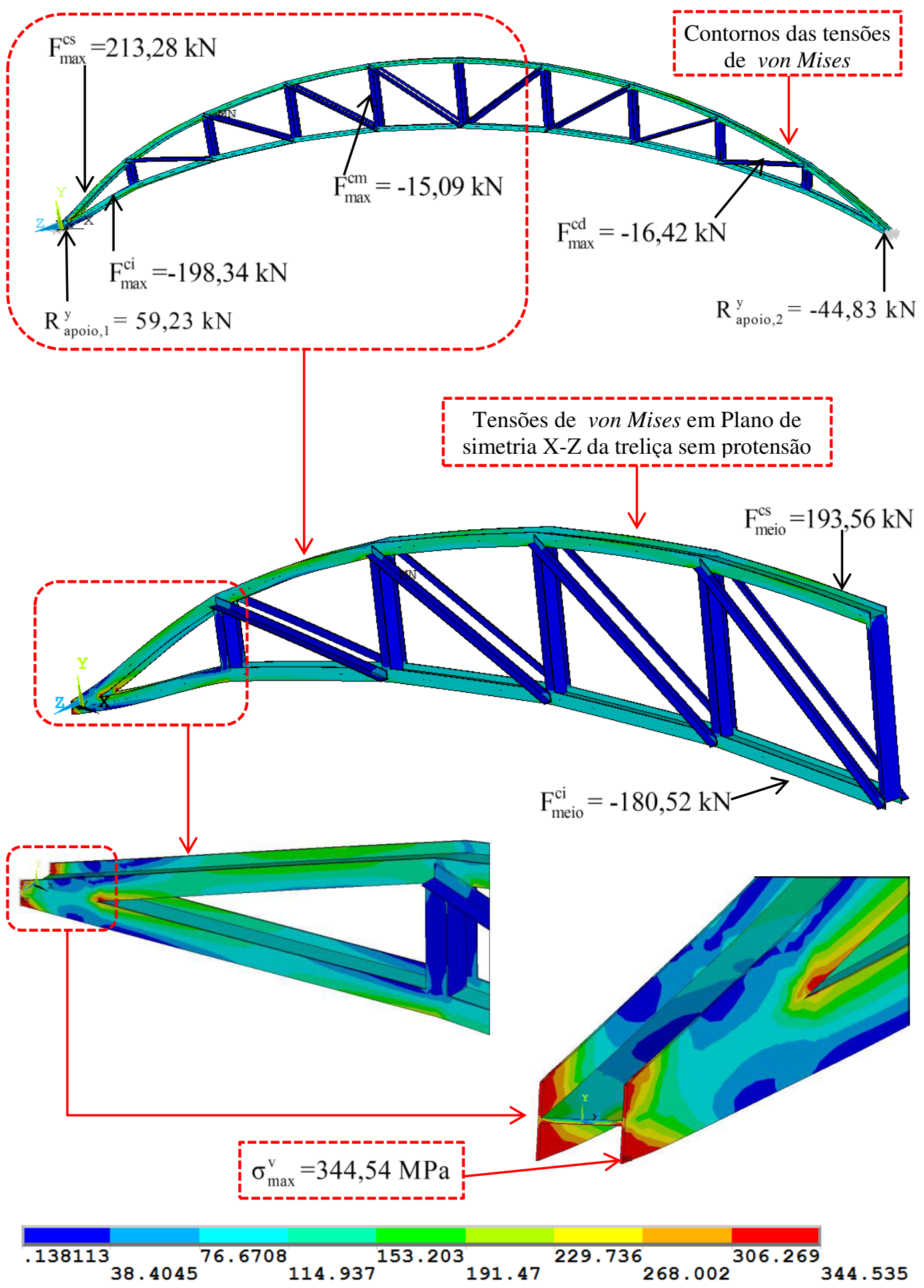

Figura 6.9 Distribuição das tensões de von Mises (em MPa) para o evento $1\left(\mathrm{~B}_{20}\right)$ 
São apresentados na Figura 6.10 à vista lateral e perspectiva com o plano de simetria X-Y do deslocamento vertical, assim como o seu valor máximo obtido no centro da treliça, provocado pela ação do vento, que resultou em um valor de deslocamento inferior ao permitido pela NBR-8800 (60,69 mm $>\mathrm{L} / 250)$.

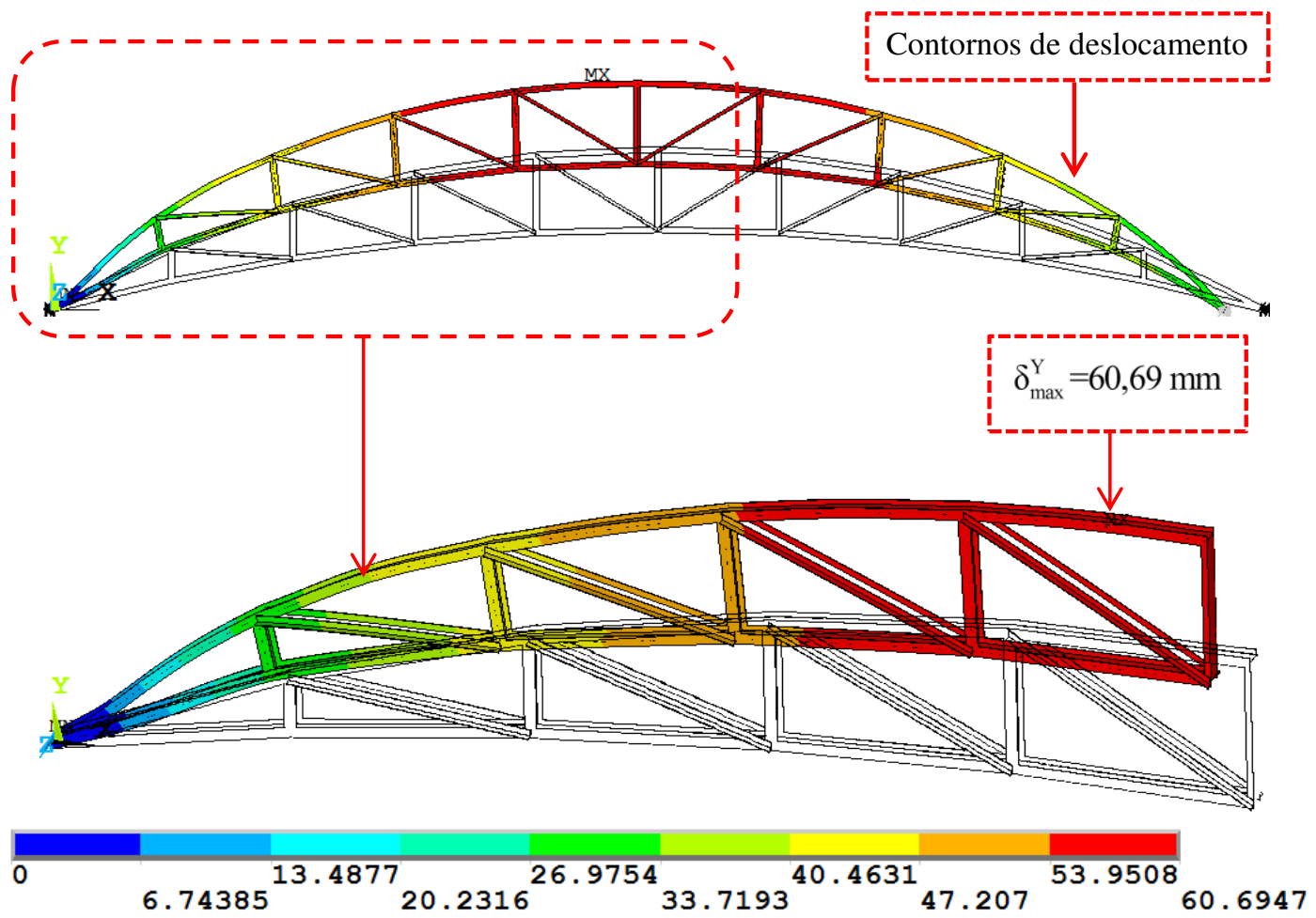

Figura 6.10 Vista lateral e perspectiva com plano de simetria X-Y: deslocamento Uy para o evento $1\left(\mathrm{~B}_{20}\right)$.

\subsection{2.}

\section{Treliça de $20 \mathrm{~m}$ protendida $\left(\mathrm{B}_{\mathrm{P} 20}\right)$}

Neste item, são apresentadas as análises lineares que se referem às combinações das fases de construção (evento 2) e normal (evento 3), ambas realizadas com a chapa de ancoragem padronizada de 9,3 $\mathrm{mm}$ para treliça protendida. Os resultados obtidos são mostrados nesta seção.

\subsubsection{1.}

\section{Evento 2: Para combinação da fase de construção $\left(B_{\mathrm{P} 20}\right)$}

Para a fase de construção, a treliça protendida com espessura 9,3 $\mathrm{mm}$ da chapa de ancoragem foi modelada com a finalidade de analisar a interface da chapa e do cabo nas extremidades, com uma força de protensão aplicada de 130,86 kN. A seguir são apresentados os resultados das tensões e deslocamentos da estrutura. 
Observa-se que a maior tensão de von Mises resultou em 269,87 MPa. Tal valor encontrado foi obtido na região de ancoragem da treliça. Esse resultado não excede o valor da tensão limite de escoamento do material usado. Portanto, para esta espessura de chapa adotada, a treliça não plastifica nesta zona. Daí, conclui-se que essa espessura de 9,3 mm é adequada. Na Figura 6.11 são apresentadas várias perspectivas da chapa de ancoragem sendo destacada a tensão máxima de von Mises localizada na abertura da chapa (Figura 6.11.d).

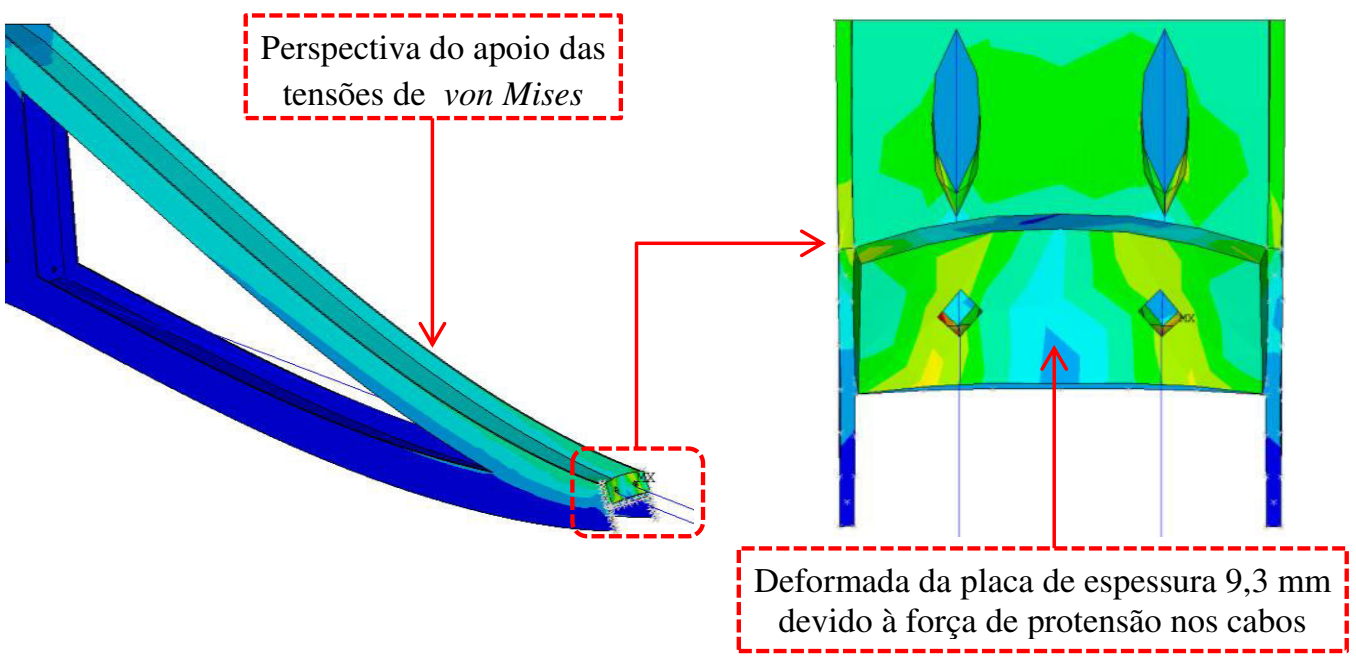

(a)

(b)
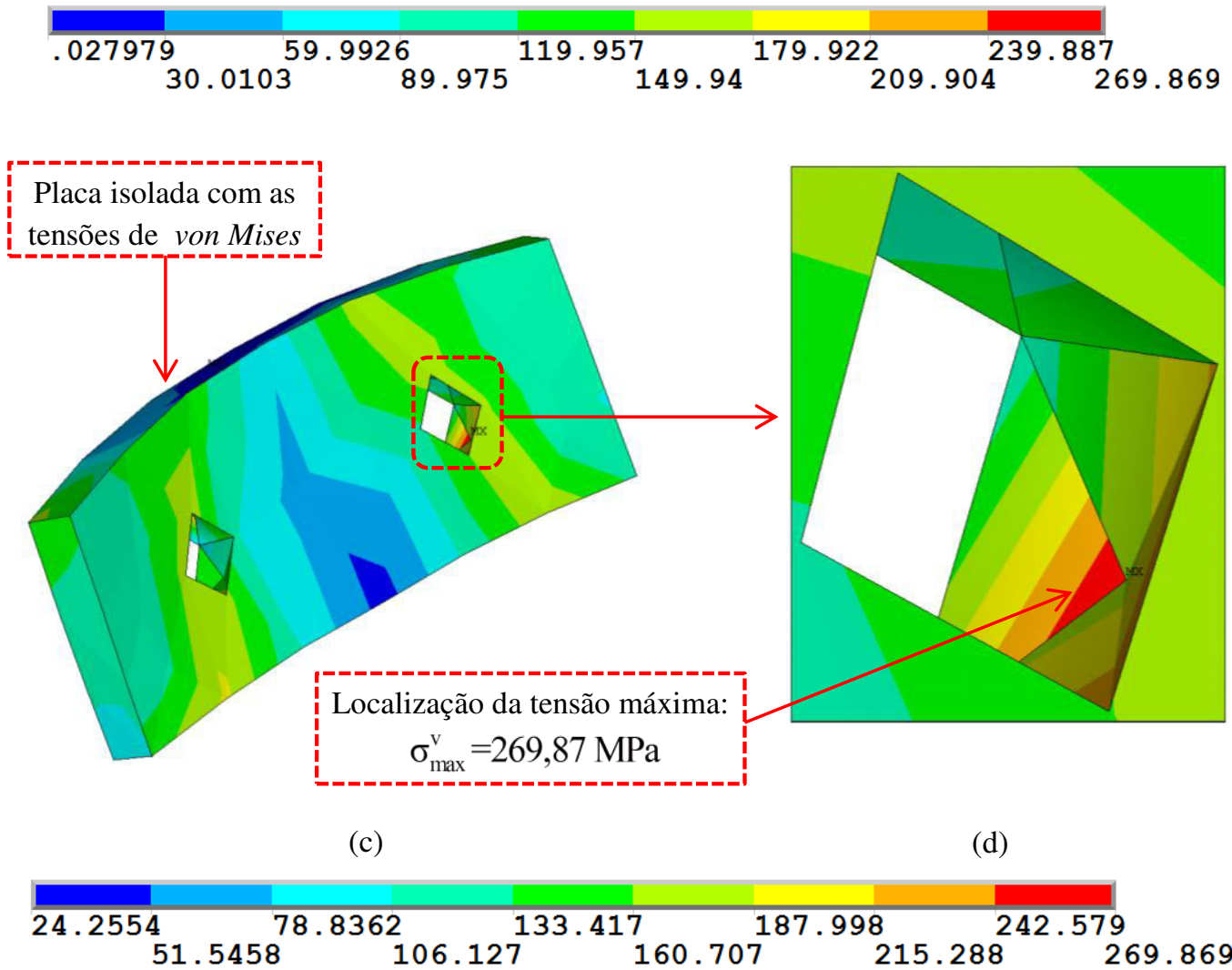

Figura 6.11 Distribuição das tensões de von Mises (em MPa) máxima para o evento $2\left(\mathrm{~B}_{\mathrm{P} 20}\right)$ 
Na Figura 6.12 apresenta-se o deslocamento máximo obtido no eixo vertical do centro da treliça, com valor de $14,10 \mathrm{~mm}<\mathrm{L} / 250$. Vale ressaltar que esse valor atende o limite de deslocamento máximo permitido na estrutura (NBR-8800). Também é ilustrada nessa figura a vista lateral e perspectiva do plano de simetria X-Y de deslocamento do modelo.

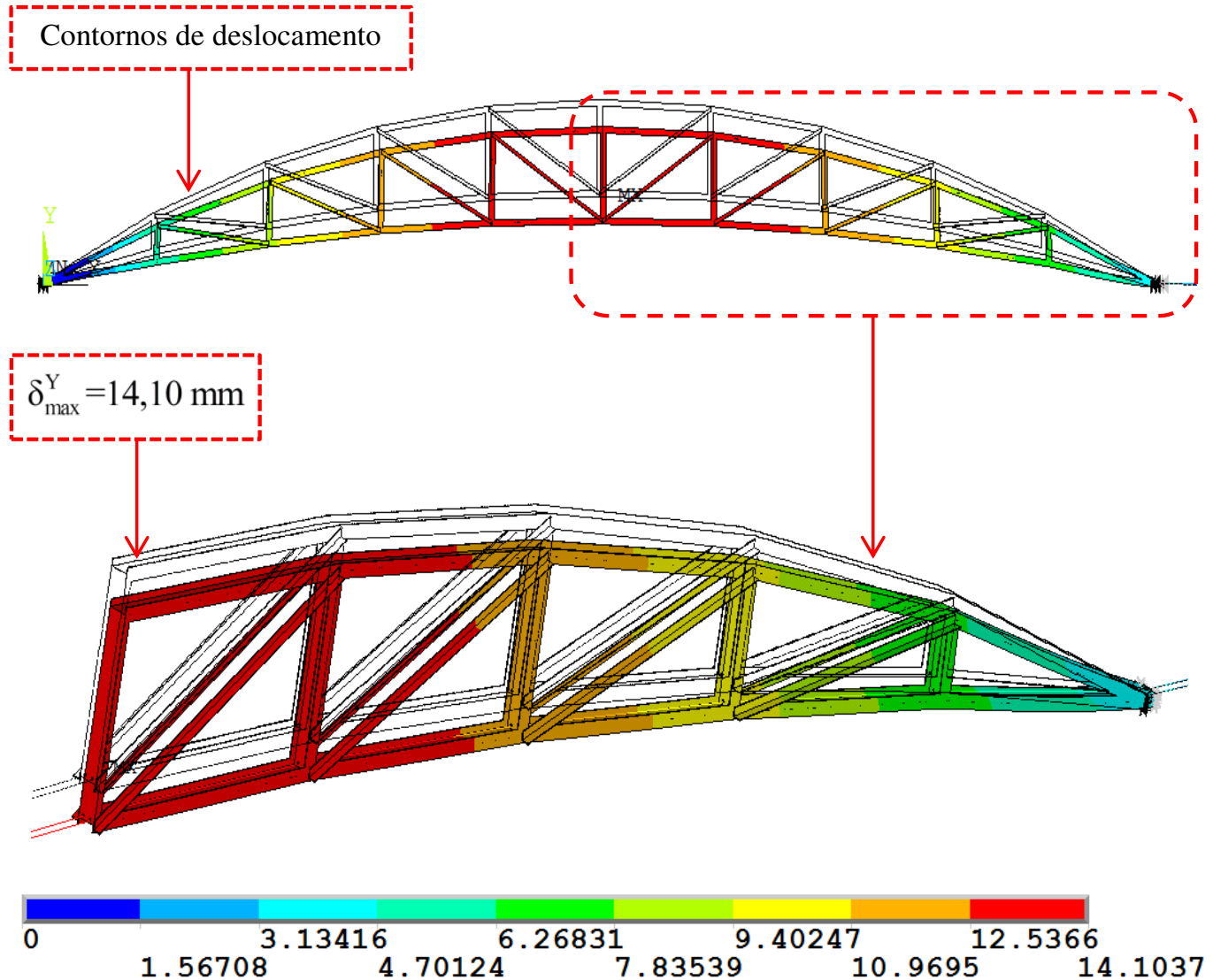

Figura 6.12 Vista lateral e perspectiva com plano de simetria X-Y: deslocamento Uy para o evento $2\left(\mathrm{~B}_{\mathrm{P} 20}\right)$.

\subsubsection{2.}

\section{Evento 3: Para combinação última normal $\left(B_{\mathrm{P} 20}\right)$}

Nesta análise foi realizada uma modelagem de uma treliça protendida de 20 m de vão com uma chapa de ancoragem padronizada de 9,3 mm. As Figuras 6.13 e 6.14 mostram as distribuições das tensões de von Mises, as forças internas e os deslocamentos máximos provocados pela carga de serviço permanente e pela carga variável devido à ação do vento e da força de protensão ótima (evento 3). 
Com base nos resultados obtidos, foi observado que a maior tensão de von Mises calculada foi igual a $272,31 \mathrm{MPa}$. Tal valor foi obtido junto ao apoio da treliça, como pode ser visto na Figura 6.13. Essa tensão é menor que o valor de tensão limite do escoamento do material usado, ou seja, não há plastificação da estrutura.
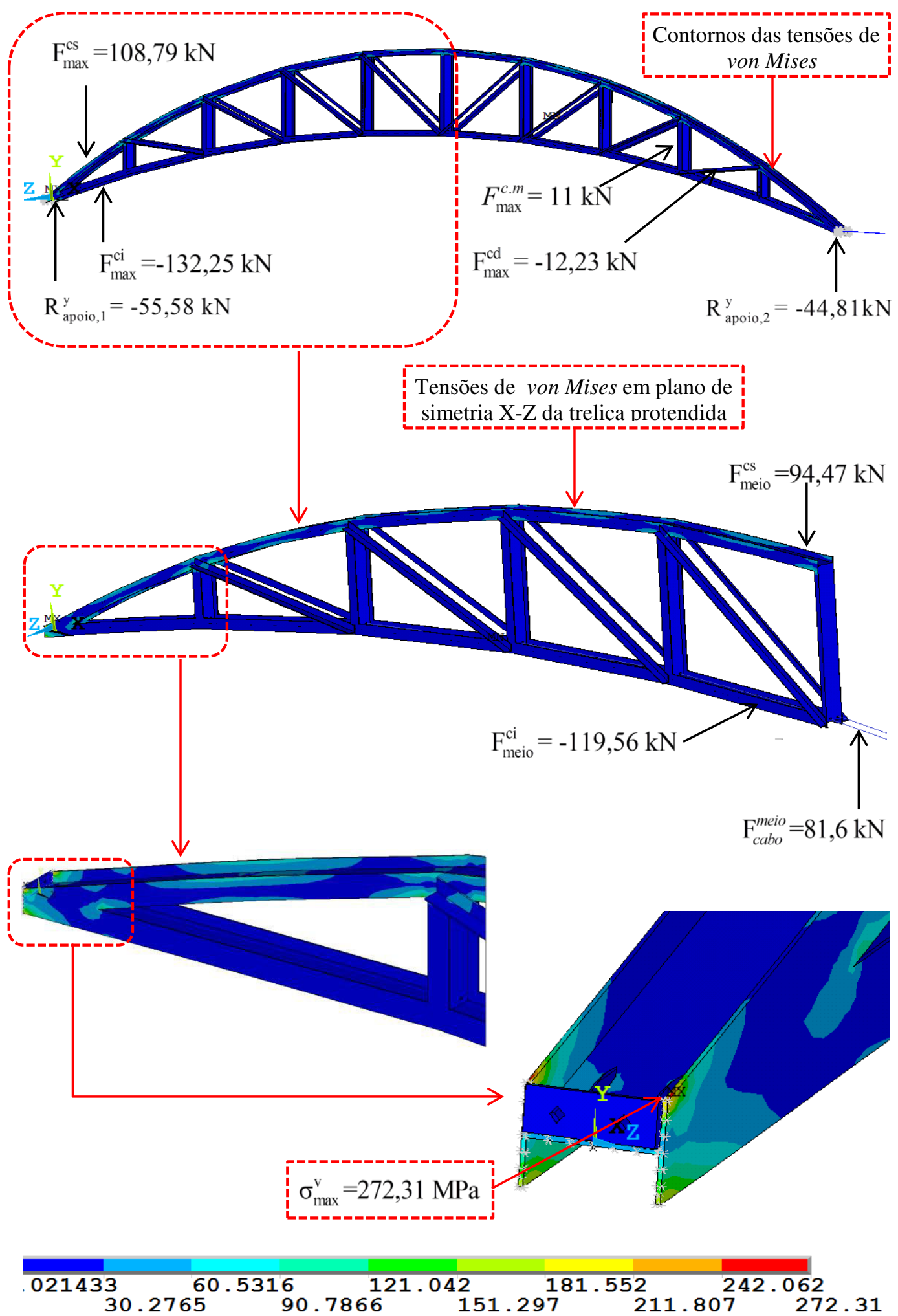

Figura 6.13 Distribuição das tensões de von Mises (em MPa) para o evento $3\left(\mathrm{~B}_{\mathrm{P} 20}\right)$. 
Com a chapa padronizada de 9,3 $\mathrm{mm}$ para treliça protendida, para o evento 3 (carga permanente, ação do vento e força de protensão) verificou-se que o deslocamento vertical máximo foi igual a $4,24 \mathrm{~mm}<\mathrm{L} / 250$. O ponto onde isto ocorre está representado na Figura 6.14 com a nomenclatura MX. Convém notar que esse valor é inferior ao deslocamento máximo da estrutura permitido.

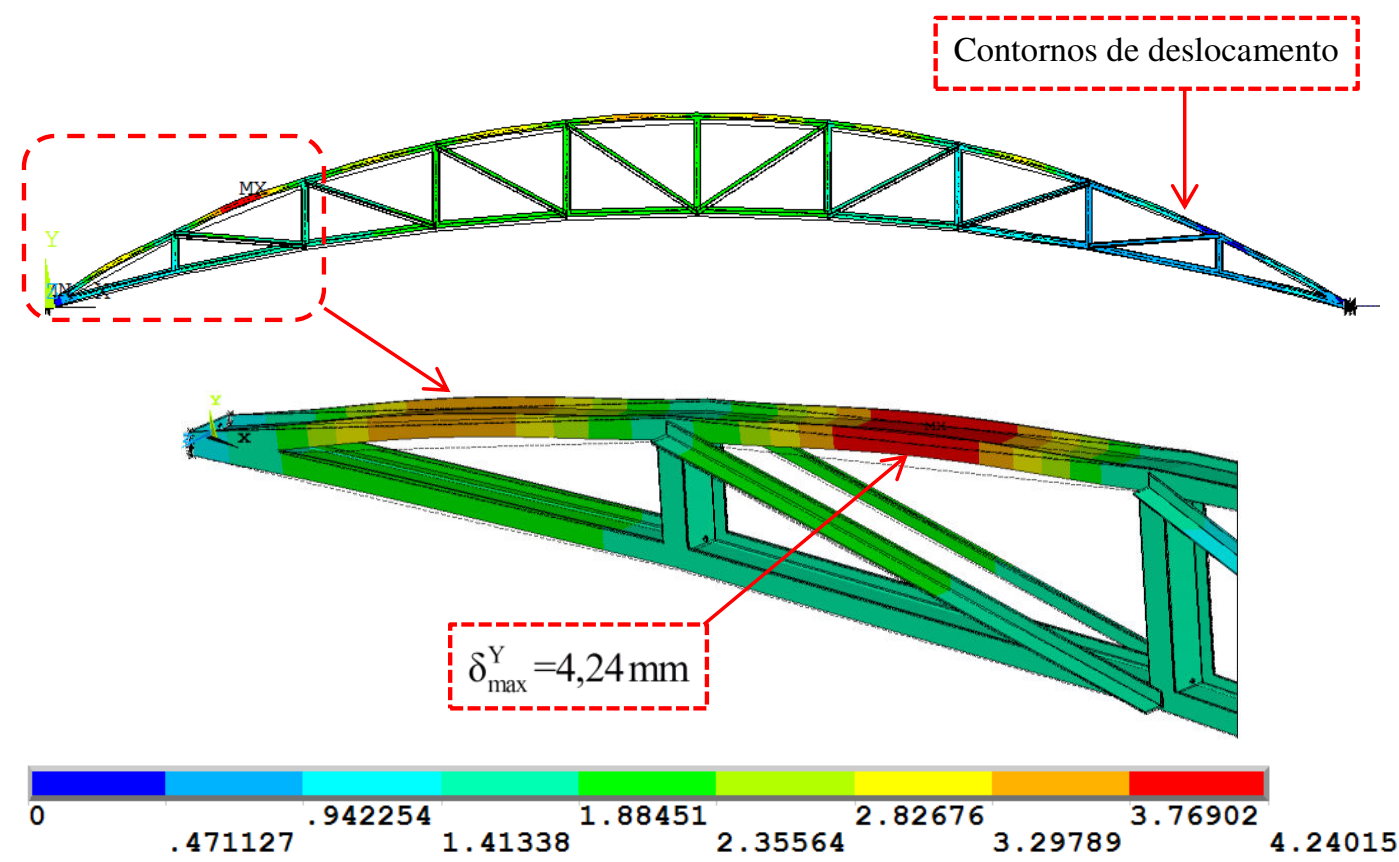

Figura 6.14 Vista lateral e perspectiva com plano de simetria X-Y: deslocamento Uy para o evento $3\left(\mathrm{~B}_{\mathrm{P} 20}\right)$.

\section{3.}

\section{Análise da treliça de $\mathbf{4 0} \mathrm{m}$ de vão}

Com o objetivo de mostrar a validação do uso da protensão na treliça de 40 m de vão, foi realizada uma modelagem da estrutura sem e com protensão. Nesta modelagem, para treliça protendida, adotou-se uma chapa ótima de ancoragem padronizada de $16 \mathrm{~mm}$ de espessura.

\subsection{1.}

\section{Treliça de $40 \mathrm{~m}$ sem protensão $\left(C_{40}\right)$}

As Figuras 6.15 e 6.16 apresentam a distribuição das tensões de von Mises, forças internas e os deslocamentos máximos, o que foi obtido na análise da treliça de $40 \mathrm{~m}$ de vão, sem protensão, provocada pela carga de serviço permanente e pela carga variável devido à ação do vento (evento1). São também apresentadas na Figura 6.15 as forças internas atuantes nos principais elementos da treliça. 
Nessa análise observa-se que a maior tensão de von Mises resultou em 345,26 MPa. Tal valor foi obtido junto ao apoio e na ponta da abertura da treliça, como pode ser visto na Figura 6.15. Essa tensão é aproximada do valor de tensão limite de escoamento do material usado, ou seja, não há plastificação da estrutura. Além disso evidencia-se elevada distribuição das tensões de von Mises nas cordas superior, inferior, e menor nas diagonais da treliça.

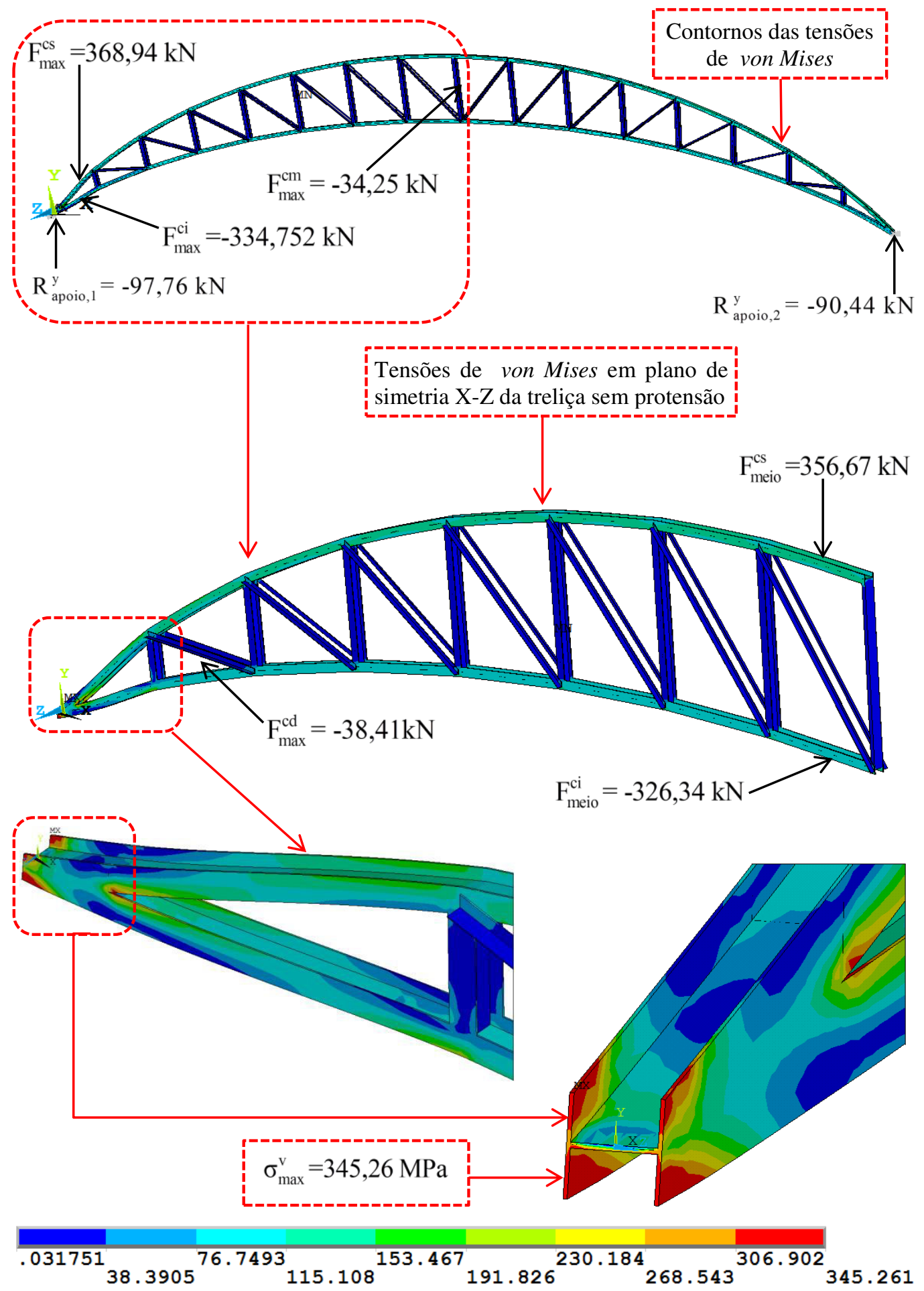

Figura 6.15 Distribuição das tensões de von Mises (em MPa) para o evento $1\left(\mathrm{C}_{40}\right)$. 
São apresentados na Figura 6.16 a vista lateral e perspectiva com o plano de simetria $\mathrm{X}-\mathrm{Z}$ do deslocamento vertical, assim como o seu valor máximo obtido no centro da treliça, provocado pela ação do vento, que resultou em um valor de deslocamento inferior ao permitido $(110,87 \mathrm{~mm}<\mathrm{L} / 250)$.

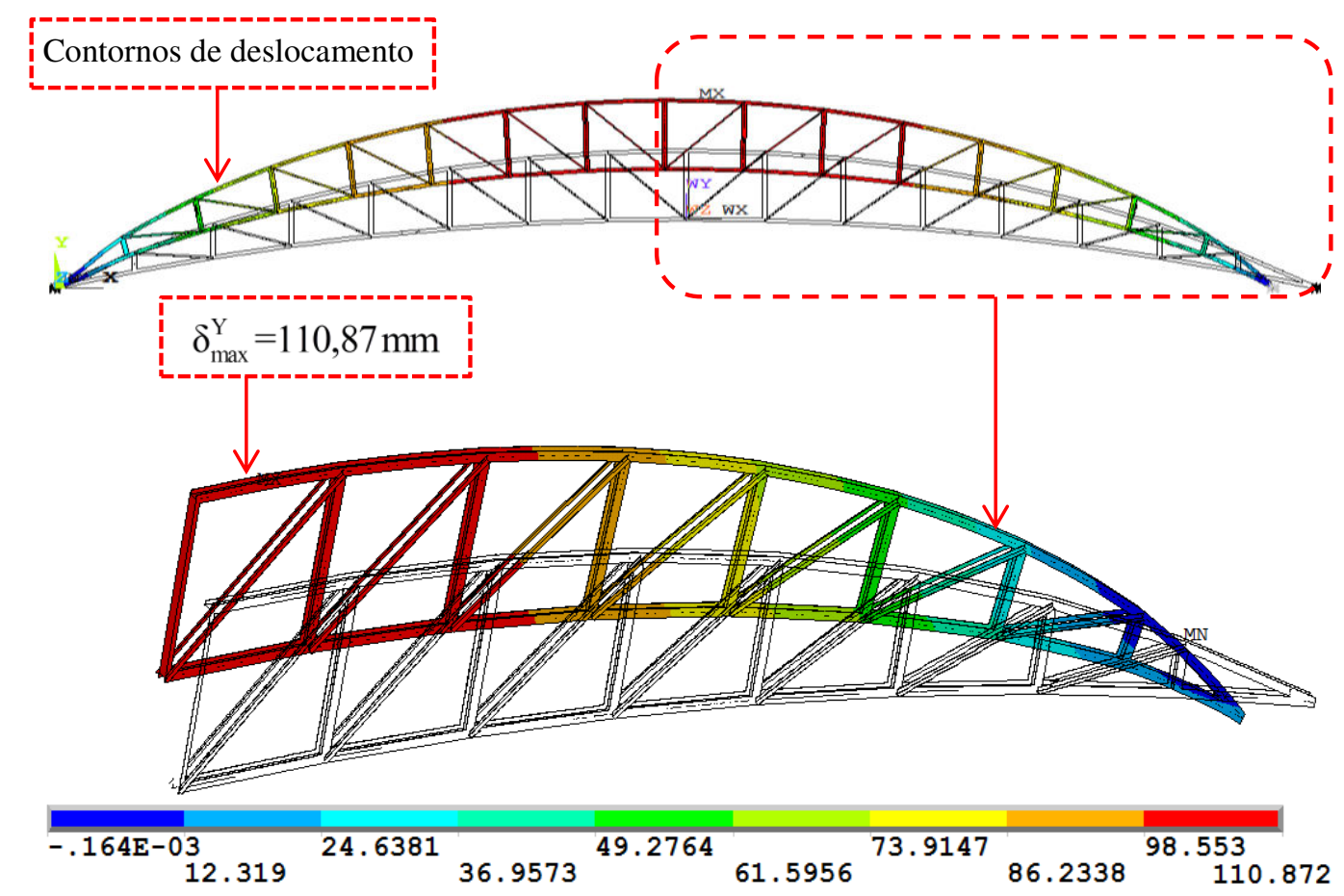

Figura 6.16 Vista lateral e perspectiva com plano de simetria X-Z: deslocamento Uy para o evento $1\left(\mathrm{C}_{40}\right)$.

\subsection{2.}

\section{Treliça de $\mathbf{4 0} \mathrm{m}$ protendida $\left(\mathrm{C}_{\mathrm{P} 40}\right)$}

Neste item, são apresentadas as análises lineares que se referem às combinações das fases de construção (evento 2) e normal (evento 3), ambas realizadas com a chapa de ancoragem padronizada de $16 \mathrm{~mm}$ para treliça protendida. Os resultados obtidos são mostrados nesta seção.

\subsubsection{1.}

\section{Evento 2: Para combinação da fase de construção $\left(\mathrm{C}_{\mathrm{P40}}\right)$}

Para a fase de construção a treliça protendida de 40 vão de vão, com espessura $16 \mathrm{~mm}$ da chapa de ancoragem foi modelada com a finalidade de analisar a interface da chapa e do cabo nas extremidades, com uma força de protensão aplicada de 205,27 kN. A seguir, são apresentados os resultados das tensões e deslocamentos da estrutura. 
Observa-se que a maior tensão de von Mises resultou em 335,11 MPa. Tal valor encontrado foi obtido na região de ancoragem da treliça. Este resultado não excede o valor da tensão limite de escoamento do material usado. Portanto, para esta espessura de chapa adotada, a treliça não plastifica nesta zona. Daí conclui-se que essa espessura de $16 \mathrm{~mm}$ é adequada. Na Figura 6.17 são apresentadas várias perspectivas da chapa de ancoragem sendo destacada a tensão máxima de von Mises localizada na abertura da chapa (Figura 6.17.d).

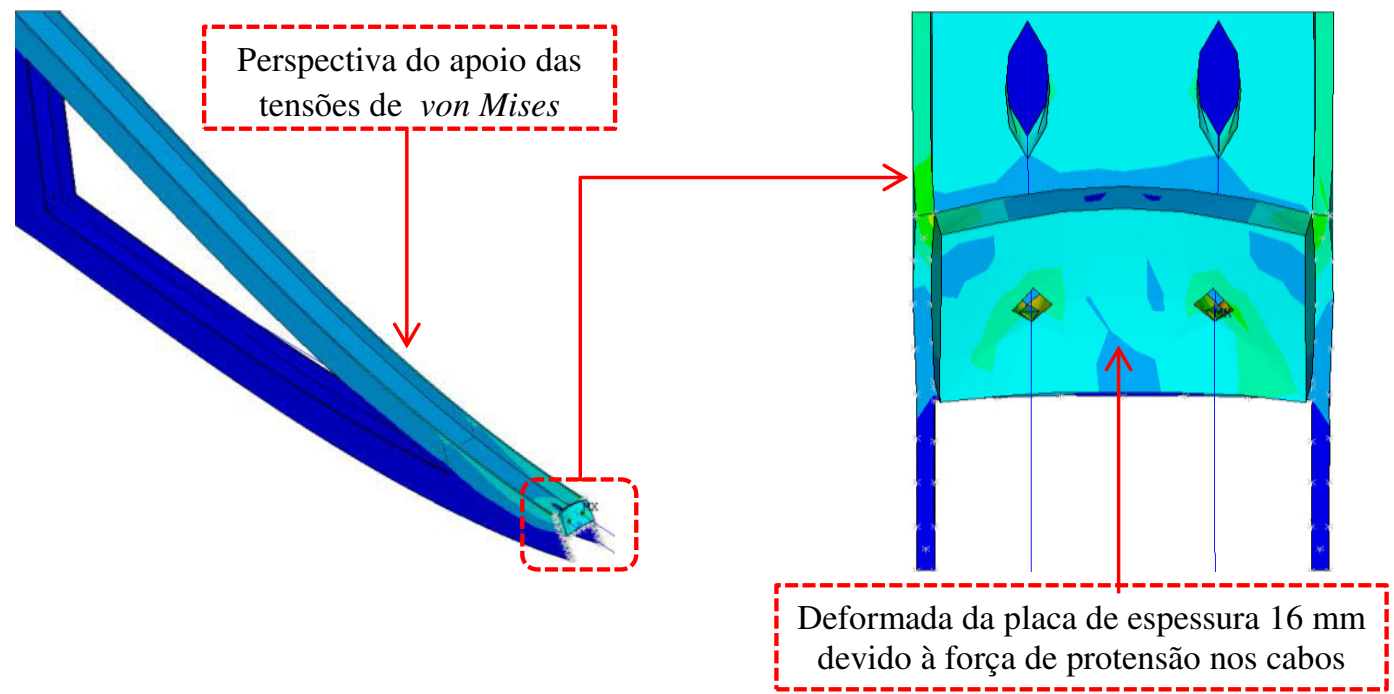

(a)

(b)

$.03390737 .2645^{74.495} 111.726^{148.956} 186.187^{223.417} 260.648^{297.878} 335.109$

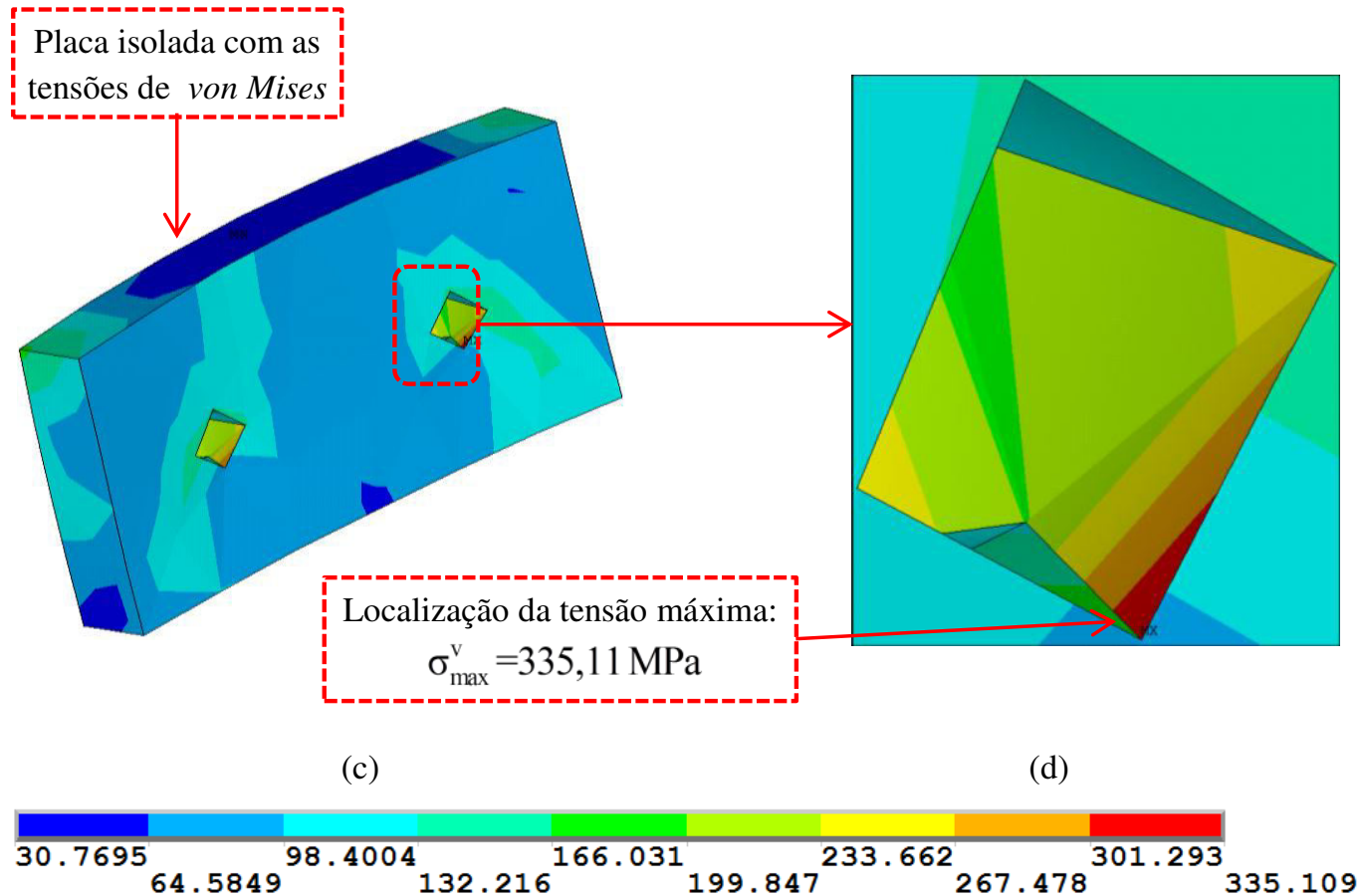

Figura 6.17 Distribuição das tensões de von Mises (em MPa) máxima para o evento $2\left(\mathrm{C}_{\mathrm{P} 40}\right)$. 
Na Figura 6.18 apresenta-se o deslocamento máximo obtido no eixo vertical do centro da treliça, com valor de $19,71 \mathrm{~mm}<\mathrm{L} / 250$. Vale ressaltar que este valor atende o limite de deslocamento máximo permitido na estrutura (NBR-8800). Também são ilustradas nessa figura a vista lateral e perspectiva do plano de simetria X-Z de deslocamento do modelo.

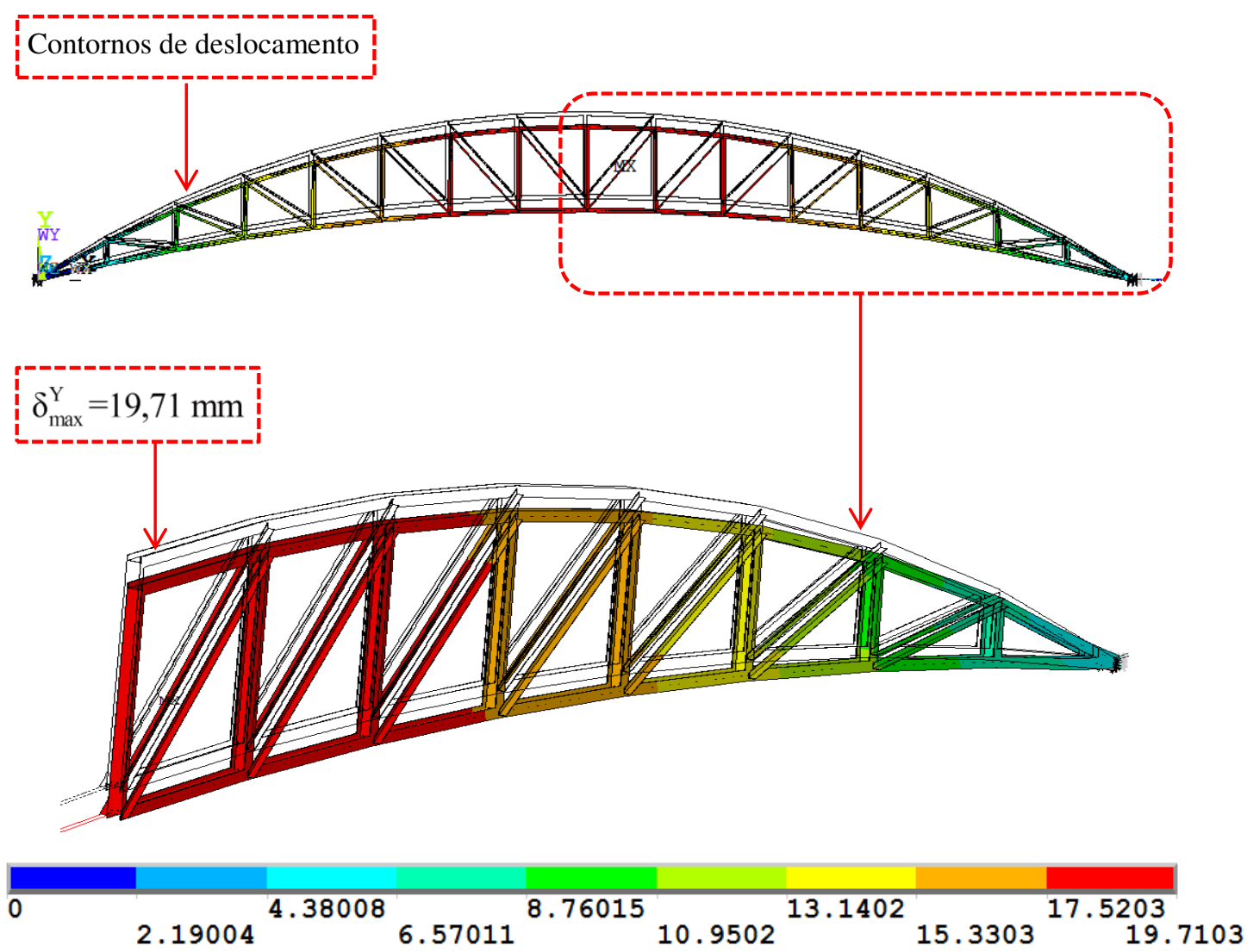

Figura 6.18 Vista lateral e perspectiva com plano de simetria X-Y: deslocamento Uy para o evento $2\left(\mathrm{C}_{\mathrm{P} 40}\right)$.

\subsubsection{2.}

\section{Evento 3: Carga combinação última normal $\left(\mathrm{C}_{\mathrm{P40}}\right)$}

Nesta análise foi realizada uma modelagem de uma treliça protendida de $40 \mathrm{~m}$ de vão com uma chapa de ancoragem padronizada de $16 \mathrm{~mm}$. As Figuras 6.23 até 6.25 mostram as distribuições das tensões de von Mises, forças internas e os deslocamentos máximos provocados pela carga de serviço permanente e pela carga variável devido à ação do vento e da força de protensão ótima (evento 3). 
Com base nos resultados obtidos observou-se que a maior tensão de von Mises calculada foi igual a 121,24 MPa. Esse valor foi obtido junto ao apoio da treliça, como pode ser visto na Figura 6.19. Essa tensão é menor que o valor de tensão limite do escoamento do material usado, ou seja, não há plastificação.

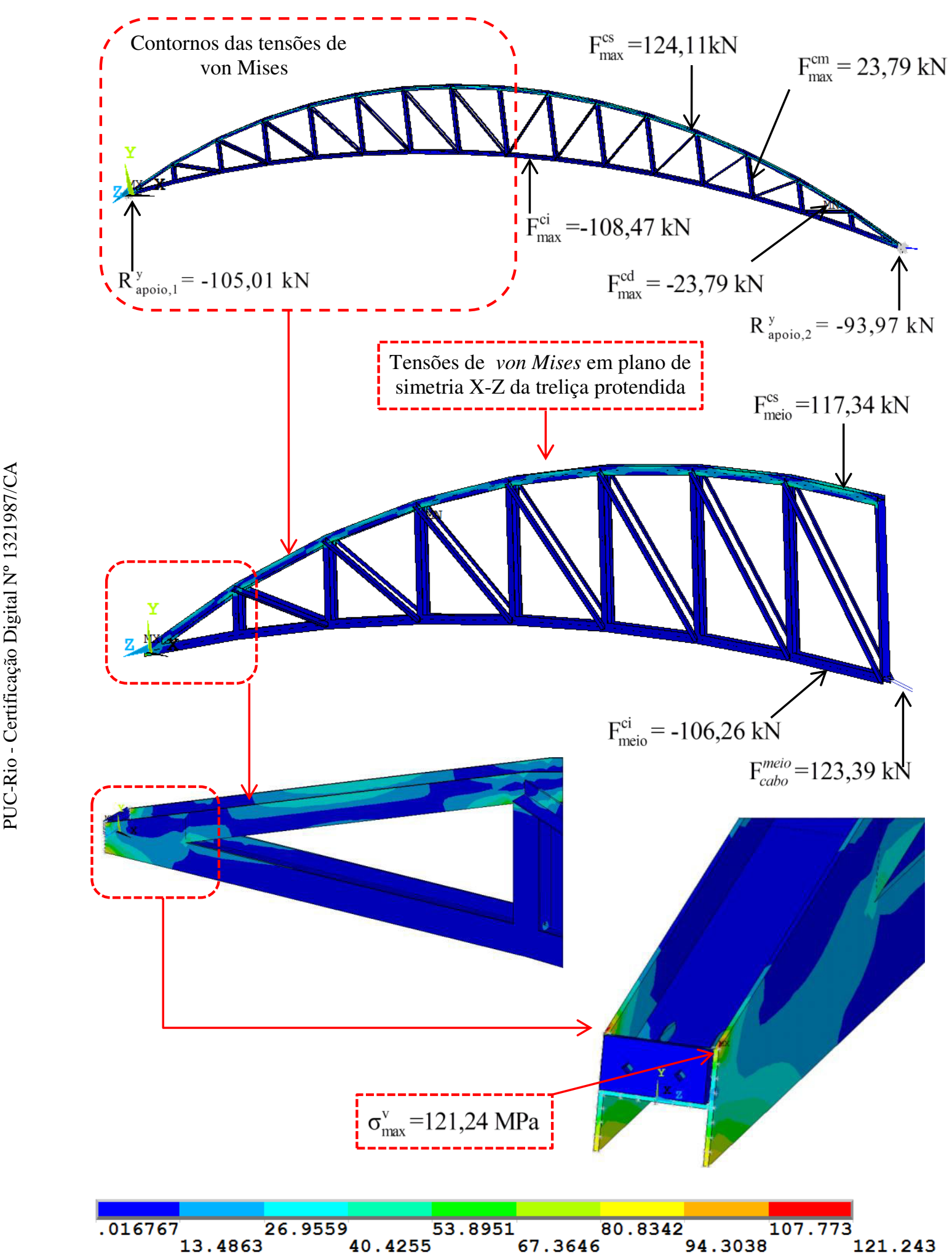

Figura 6.19 Distribuição das tensões de von Mises (em MPa) para o evento $3\left(\mathrm{C}_{\mathrm{P} 40}\right)$ 
$\mathrm{Na}$ Figura 6.20 tem-se a vista lateral e perspectiva com o plano de simetria $\mathrm{X}$-Y do deslocamento vertical, assim como o seu valor máximo obtido no centro da treliça, provocado pela ação do vento, que resultou em um valor de deslocamento inferior ao permitido pela NBR-8800 $(7,72 \mathrm{~mm}<\mathrm{L} / 250)$.

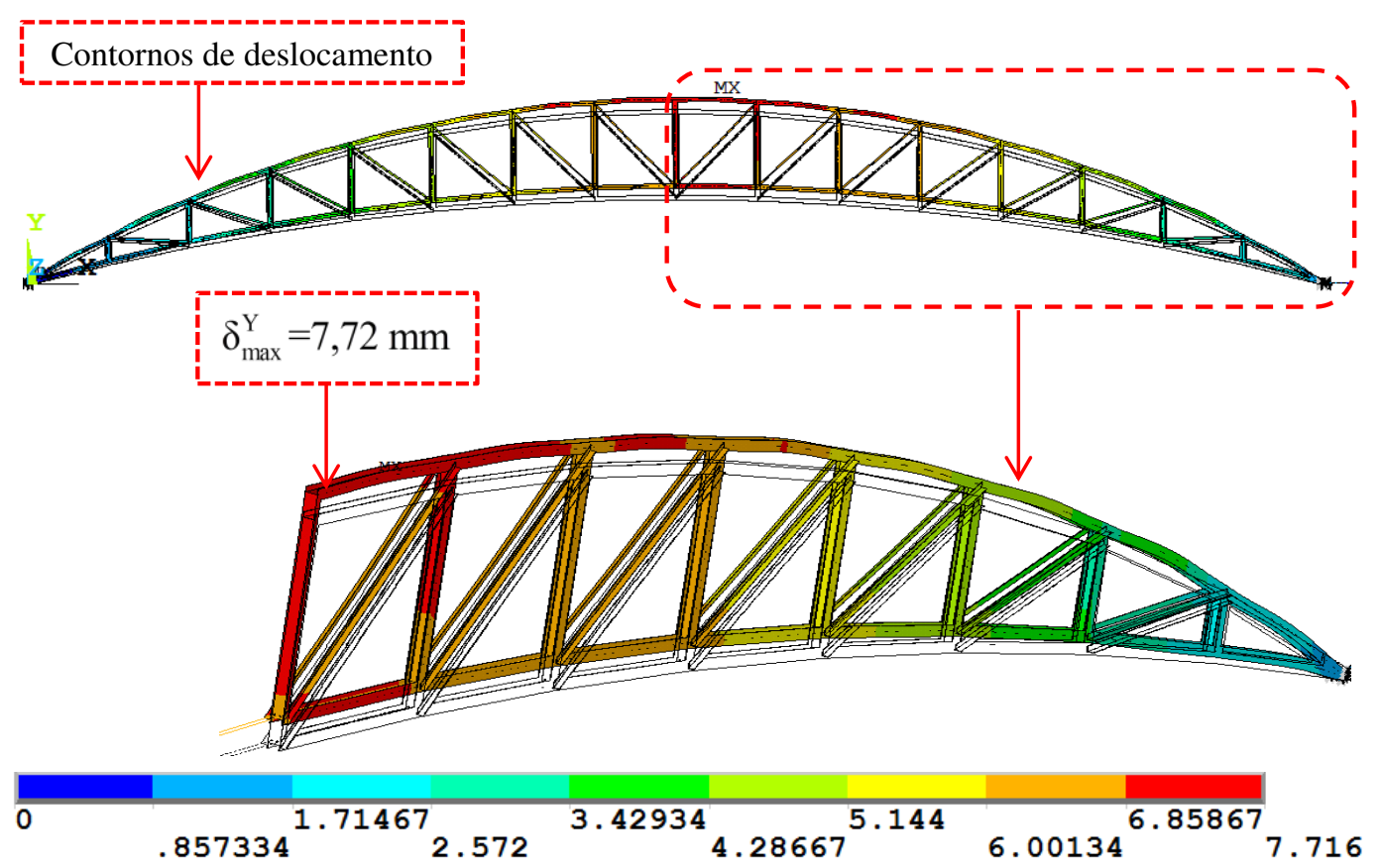

Figura 6.20 Vista lateral e perspectiva com plano de simetria X-Z: deslocamento Uy para o evento $3\left(\mathrm{C}_{\mathrm{P} 40}\right)$.

\section{4.}

\section{Análise da treliça de $80 \mathrm{~m}$ de vão}

Com o objetivo de mostrar a validação do uso da protensão na treliça de 80 m de vão, foi realizada uma modelagem da estrutura sem e com protensão. Cabe ressaltar que, para análise sem protensão, foi investigado apenas o carregamento associado ao evento 1, e, para a análise com força de protensão, para os eventos 2 e 3 (ver capítulo 4, item 4.2). Nessa modelagem, para treliça protendida, adotou-se uma chapa ótima de ancoragem padronizada de $19 \mathrm{~mm}$ de espessura.

\subsection{1.}

\section{Treliça de $80 \mathrm{~m}$ sem protensão $\left(D_{80}\right)$}

As Figuras 6.21 e 6.22 apresentam a distribuição das tensões de von Mises, Forças Internas e os deslocamentos máximos, o que foi obtido na análise da treliça de $80 \mathrm{~m}$ de vão, sem protensão, provocada pela carga de serviço permanente e pela carga variável devida à ação do vento (evento1). São também apresentadas na Figura 6.21 as forças internas atuantes nos principais elementos da treliça. 
Nessa análise observa-se que a maior tensão de von Mises resultou em 348,1 MPa. Tal valor foi obtido junto ao apoio e na ponta da abertura da treliça, como pode ser visto na Figura 6.21.Essa tensão é maior do valor de tensão limite de escoamento do material usado, ou seja, a estrutura plastifica nesta zona do apoio. Além, disso, evidencia-se elevada distribuição das tensões de von Mises nas cordas superior e inferior, e menor nas diagonais da treliça.

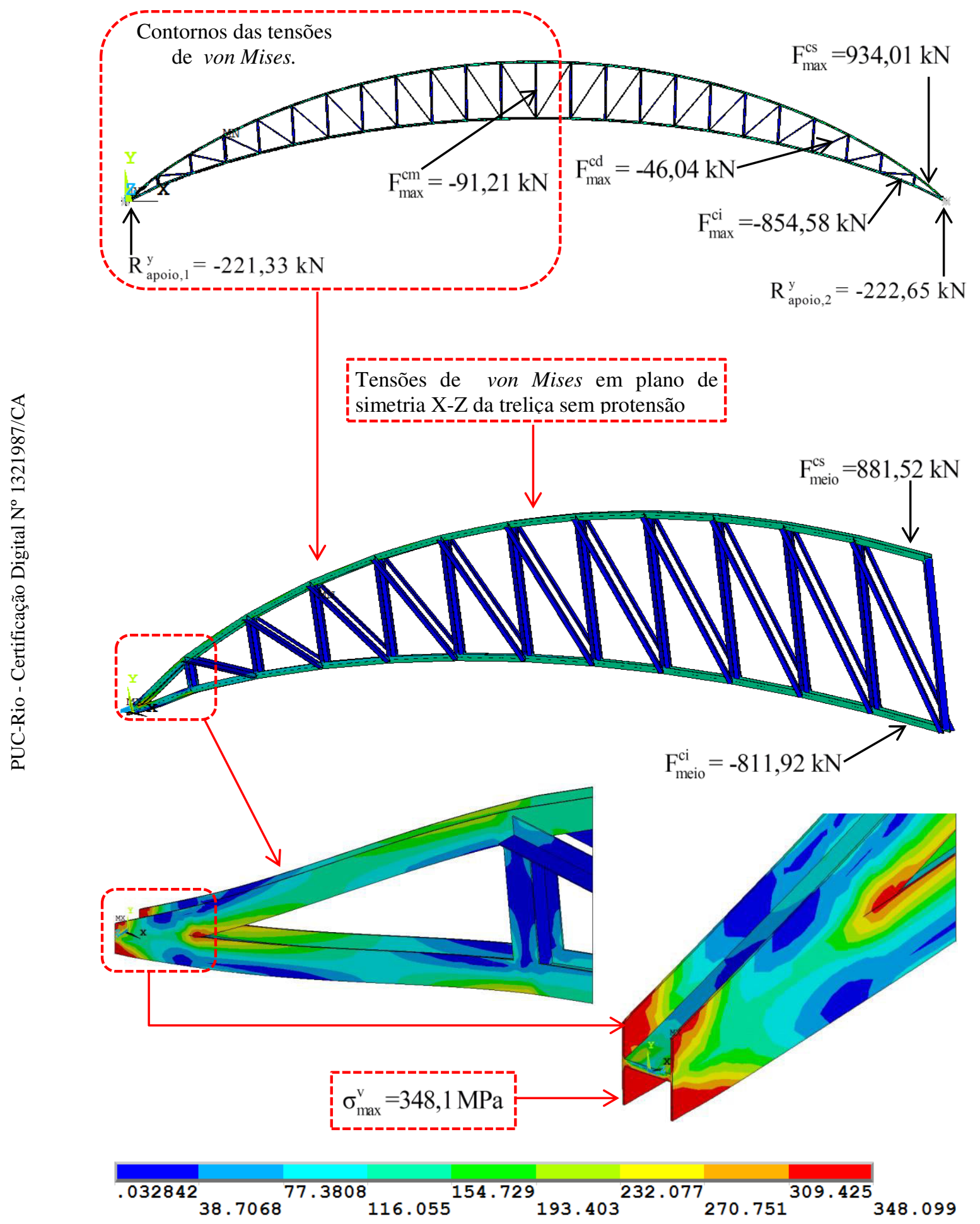

Figura 6.21 Distribuição das tensões de von Mises (em MPa) para o evento $1\left(\mathrm{D}_{80}\right)$. 
São apresentados na Figura 6.22 a vista lateral e perspectiva com o plano de simetria $\mathrm{X}-\mathrm{Z}$ do deslocamento vertical, assim como o seu valor máximo obtido no centro da treliça, provocado pela ação do vento, que resultou em um valor de deslocamento superior ao permitido pela NBR-8800 ( 276,3 $\mathrm{mm}<\mathrm{L} / 250)$.

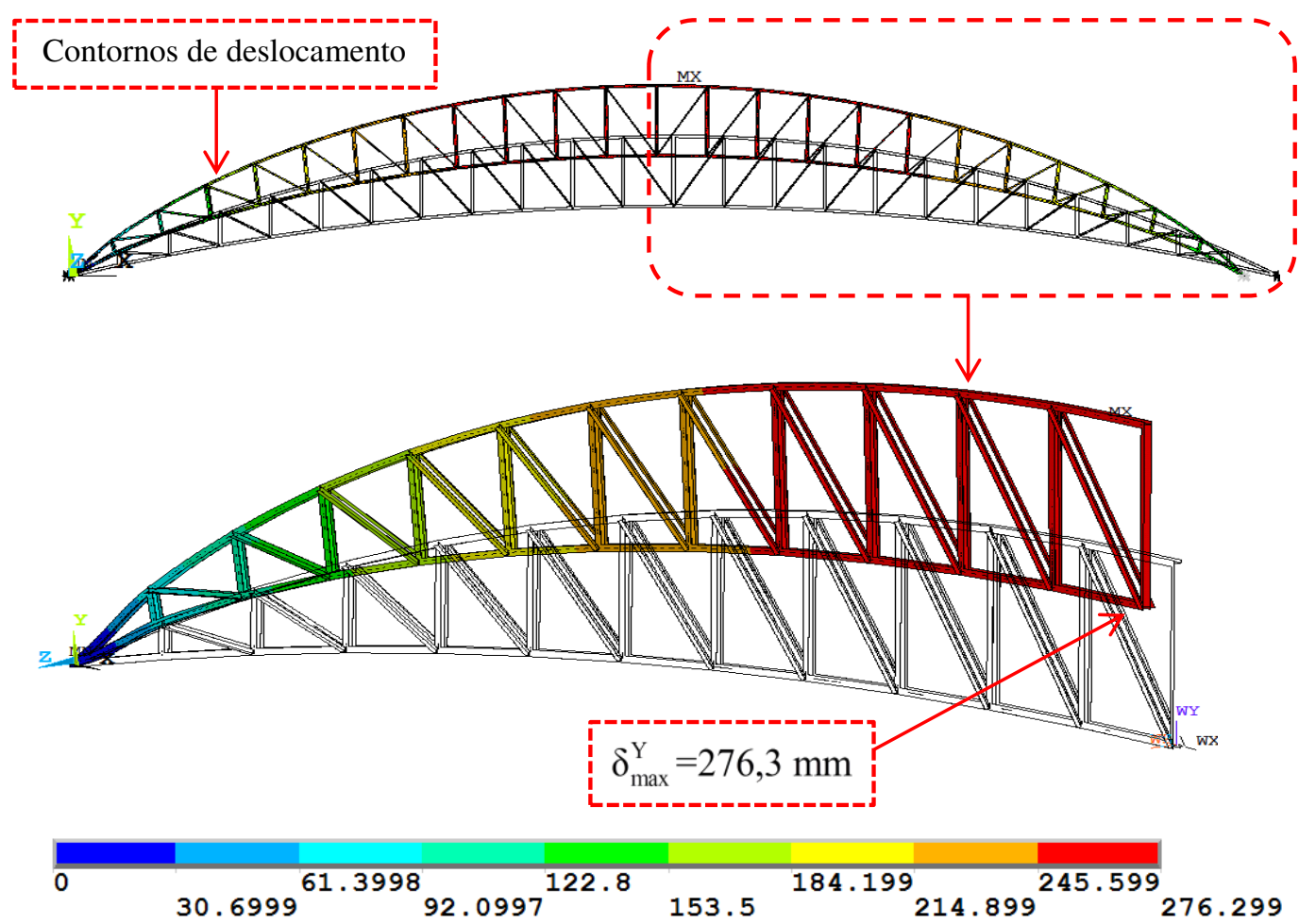

Figura 6.22 Vista lateral e perspectiva com plano de simetria X-Y: deslocamento Uy para o evento $1\left(\mathrm{D}_{80}\right)$.

\subsection{2.}

\section{Treliça de $80 \mathrm{~m}$ protendida $\left(\mathrm{D}_{\mathrm{P} 80}\right)$}

Neste item, são apresentadas as análises lineares que se referem às combinações das fases de construção (evento 2) e normal (evento 3), ambas realizadas com a chapa de ancoragem padronizada de $19 \mathrm{~mm}$ para treliça protendida. Os resultados obtidos são mostrados nesta seção.

\subsubsection{1.}

\section{Evento 2: Para combinação da fase de construção ( $\left.D_{\mathrm{P} 80}\right)$}

Para a fase de construção, a treliça protendida de 80 vão de vão, com espessura $19 \mathrm{~mm}$ da chapa de ancoragem foi modelada com a finalidade de analisar a interface da chapa e do cabo nas extremidades, com uma força de protensão aplicada de 440,66 kN. A seguir são apresentados os resultados das tensões e deslocamentos da estrutura. 
Observa-se que a maior tensão de von Mises resultou em 337,39 MPa. Tal valor encontrado foi obtido na região de ancoragem da treliça. Este resultado não excede o valor da tensão limite de escoamento do material usado. Portanto, para esta espessura de chapa adotada, a treliça não plastifica nesta zona. Daí conclui-se que essa espessura de $16 \mathrm{~mm}$ é adequada. Na Figura 6.23 são apresentadas várias perspectivas da chapa de ancoragem sendo destacada a tensão máxima de von Mises localizada na abertura da chapa (Figura 6.23.d).

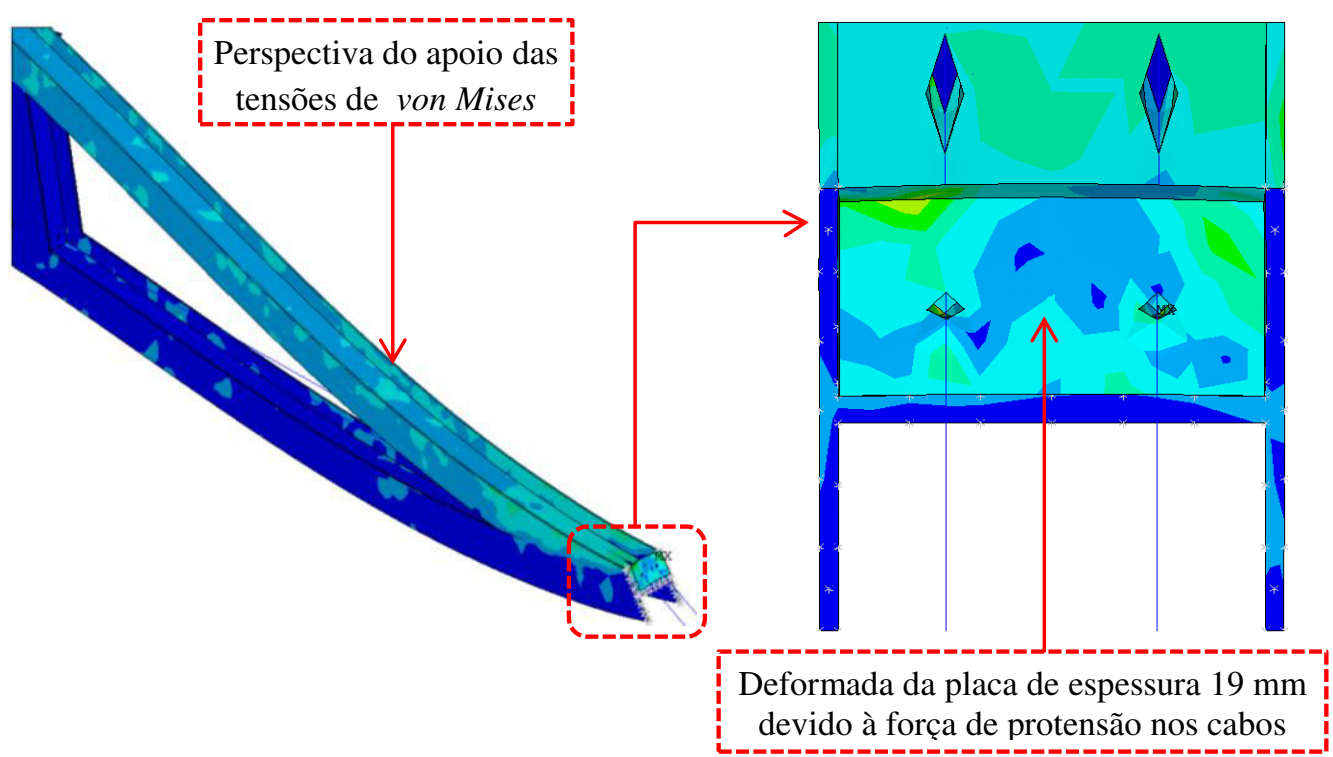

(a)

(b)
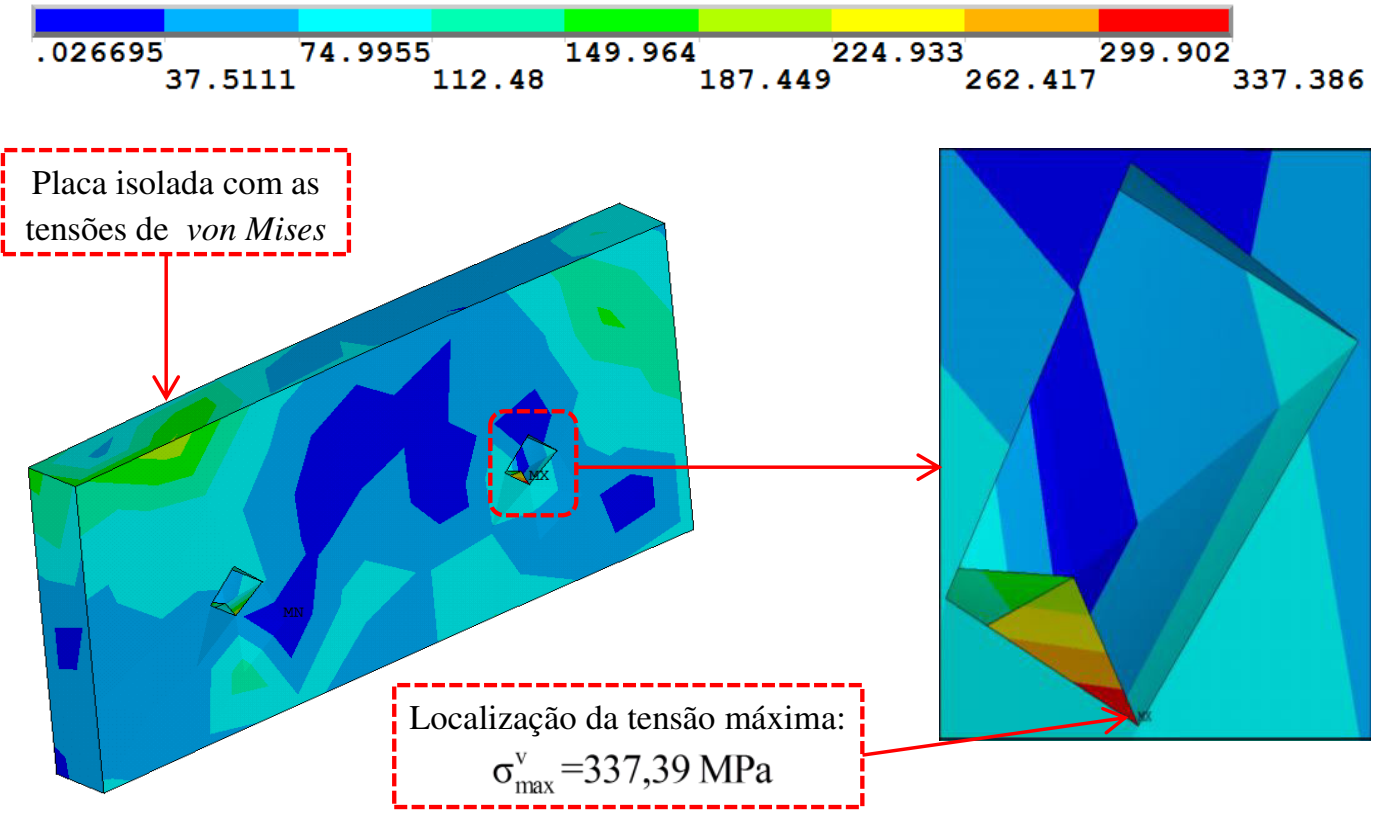

(c)

(d)

$22.226457 .2442^{92.2619} 127.28^{162.297} 197.315^{232.333} 267.351^{302.368} 337.386$

Figura 6.23 Distribuição das tensões de von Mises (em MPa) máxima para o evento $2\left(\mathrm{D}_{\mathrm{P} 80}\right)$. 
Na Figura 6.24 apresenta-se o deslocamento máximo obtido no eixo vertical do centro da treliça, com valor de $51,667 \mathrm{~mm}<\mathrm{L} / 250$. Vale ressaltar que este valor atende o limite de deslocamento máximo permitido na estrutura (NBR 8800). Também é ilustrada nessa figura a vista lateral e perspectiva do plano de simetria X-Z de deslocamento do modelo.

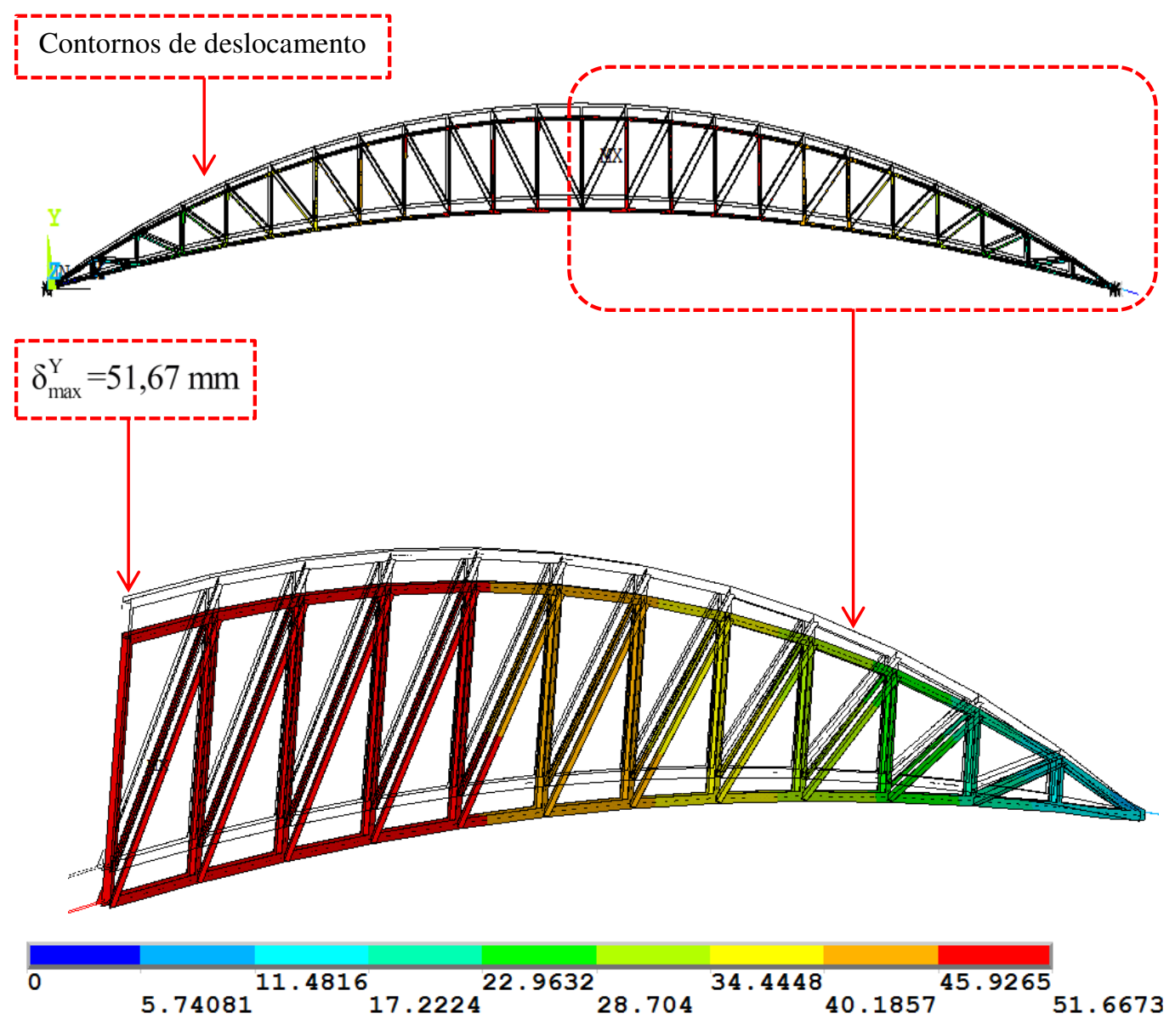

Figura 6.24 Vista lateral e perspectiva com plano de simetria X-Y: deslocamento Uy para o evento $2\left(\mathrm{C}_{\mathrm{P} 80}\right)$.

\subsubsection{2.}

\section{Evento 3: Carga combinação última normal $\left(D_{\mathrm{P} 80}\right)$}

Nessa análise foi realizada uma modelagem de uma treliça protendida de $80 \mathrm{~m}$ de vão com uma chapa de ancoragem padronizada de $19 \mathrm{~mm}$. As Figuras 6.25 e 6.26 mostram as distribuições das tensões de von Mises e os deslocamentos máximos provocados pela carga de serviço permanente e pela carga variável devido à ação do vento e da força de protensão ótima (evento 3). 
Nessa análise observa-se que a maior tensão de von Mises resultou em 335,2 MPa. Tal valor foi obtido na chapa de ancoragem. Ressaltando-se que a tensão obtida junto ou mais próxima ao apoio da treliça protendida é de 123,39 MPa. Essa tensão é menor do valor de tensão limite de escoamento do material usado, ou seja, não há plastificação da estrutura. Também de forma a evidenciar a elevada distribuição das tensões de von Mises nas cordas superior e inferior, e menor nas diagonais da treliça, como pode ser visto na Figura 6.25.

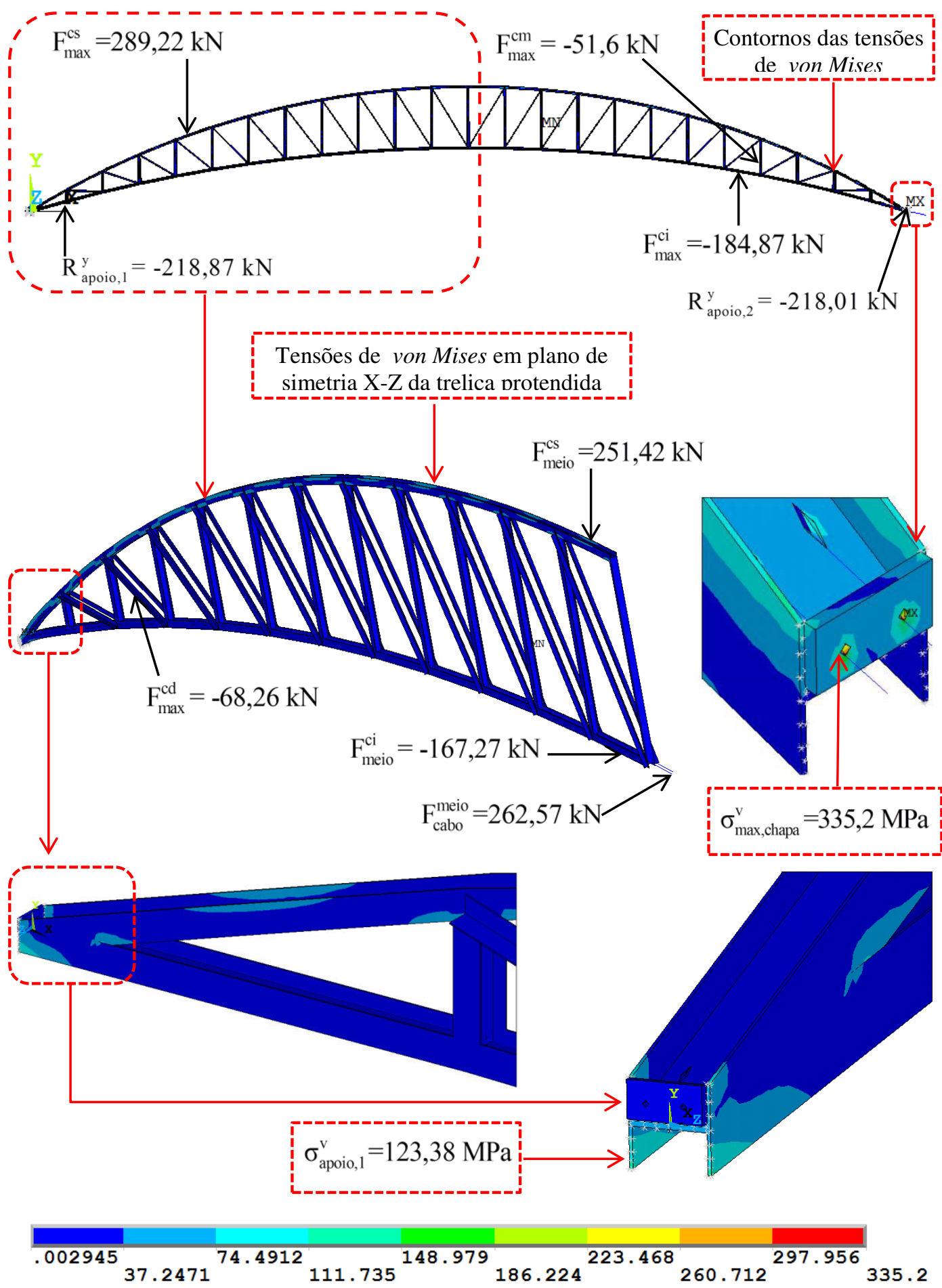

Figura 6.25 Distribuição das tensões de von Mises (em MPa) para o evento $3\left(\mathrm{C}_{\mathrm{P} 80}\right)$. 
Com a chapa padronizada de $19 \mathrm{~mm}$, o deslocamento vertical máximo foi igual a 23,93 mm $<\mathrm{L} / 250$. O ponto onde isso ocorre está representado na Figura $6.26 \mathrm{com}$ a nomenclatura MX. Convém notar que esse valor é inferior ao deslocamento máximo da estrutura permitido (NBR 8800).

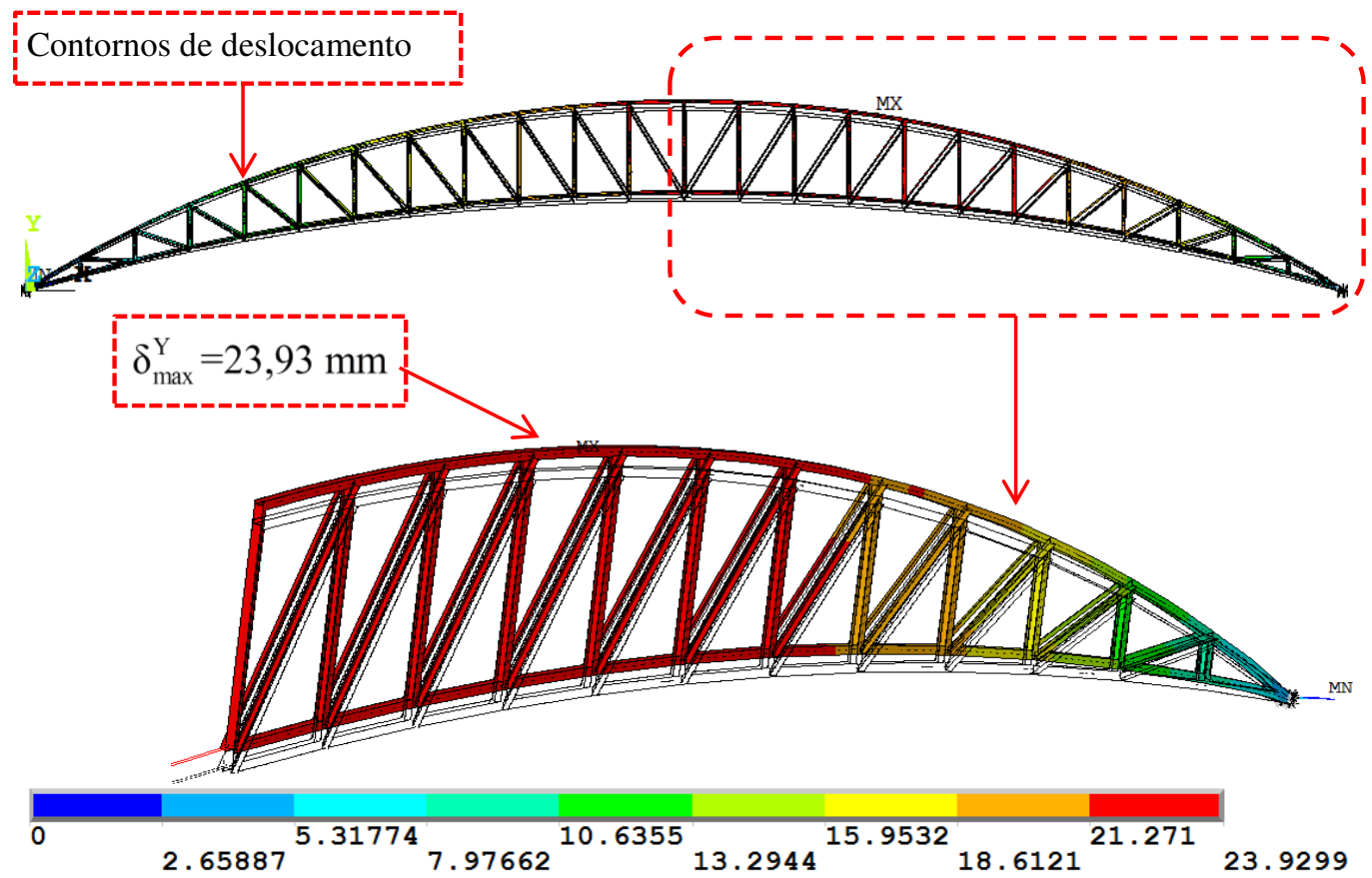

Figura 6.26 Vista lateral e perspectiva com plano de simetria X-Y: Deslocamento Uy para o evento $3\left(\mathrm{C}_{\mathrm{P} 80}\right)$.

\section{5.}

\section{Análise da treliça de 120 m de vão}

Com o objetivo de mostrar a validação do uso da protensão na treliça, foi realizada uma modelagem da estrutura sem e com protensão. Nessa modelagem, para treliça protendida, adotou uma chapa ótima de ancoragem padronizada de $22,4 \mathrm{~mm}$ de espessura.

\subsection{1.}

Treliça de $120 \mathrm{~m}$ sem protensão $\left(E_{120}\right)$

As Figuras 6.27 e 6.28 apresentam a distribuição das tensões de von Mises (Critério de plastificação) e os deslocamentos máximos, o que foi obtido na análise da treliça de $120 \mathrm{~m}$ de vão, sem protensão, provocada pela carga de serviço permanente e pela carga variável devido à ação do vento (evento1). São também apresentadas na Figura 6.27 as forças internas atuantes nos principais elementos da treliça. 
Nessa análise observa-se que a maior tensão de von Mises resultou em 351,78 MPa. Tal valor foi obtido junto ao apoio e na ponta da abertura da treliça, como pode ser visto na Figura 6.27. Essa tensão é maior do que o valor de tensão limite de escoamento do material usado, ou seja, a estrutura plastifica nessa zona do apoio e abertura. Além disso evidencia-se elevada distribuição das tensões de von Mises nas cordas superior e inferior da treliça.
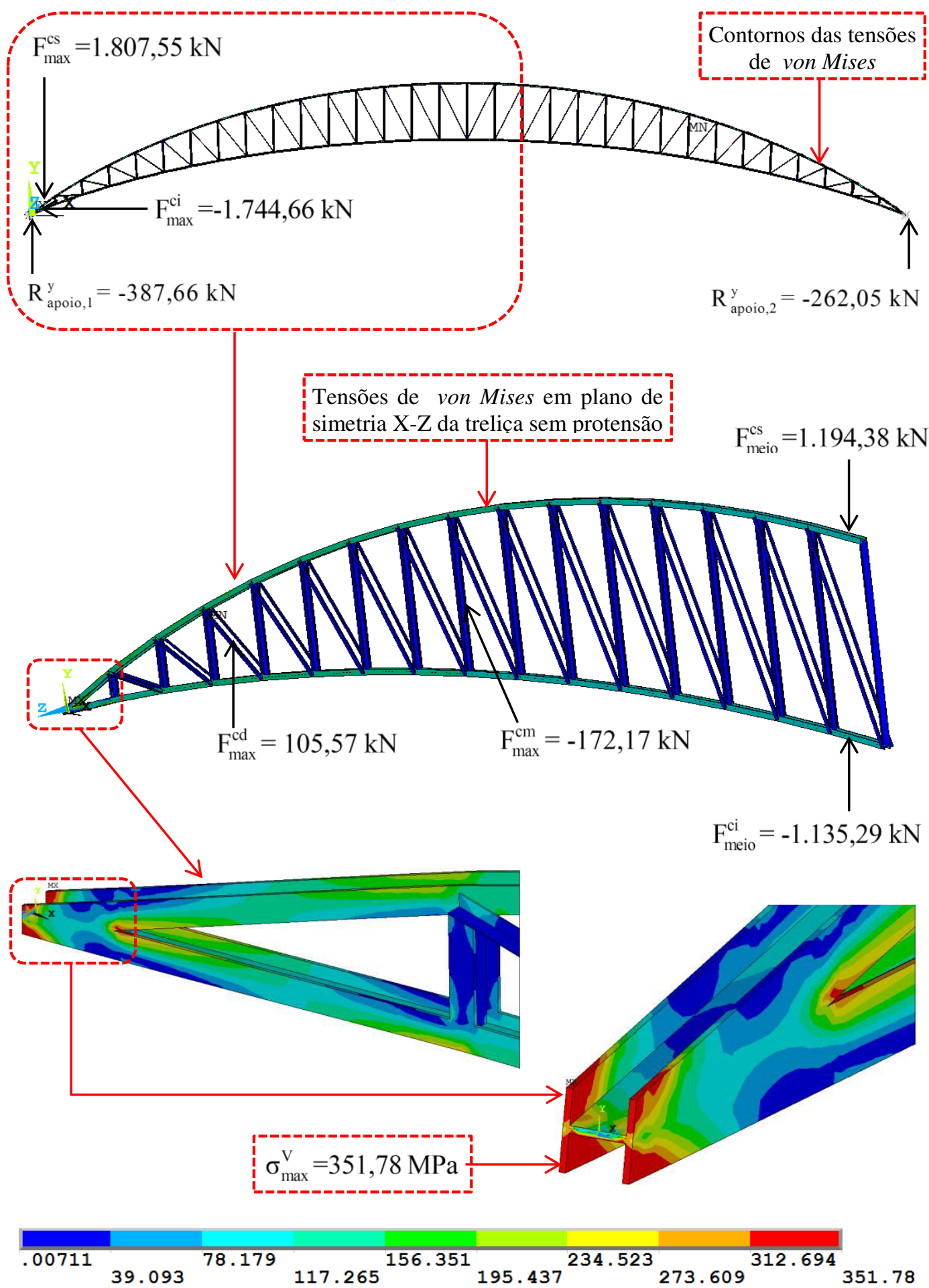

Figura 6.27 Distribuição das tensões de von Mises (em MPa) para o evento $1\left(\mathrm{E}_{120}\right)$. 
São apresentados na Figura 6.28 à vista lateral e perspectiva com o plano de simetria $\mathrm{X}-\mathrm{Z}$ do deslocamento vertical, assim como o seu valor máximo obtido no centro da treliça, provocado pela ação do vento, que resultou em um valor de deslocamento superior ao permitido pela NBR-8800 (379,03 mm > L/250).

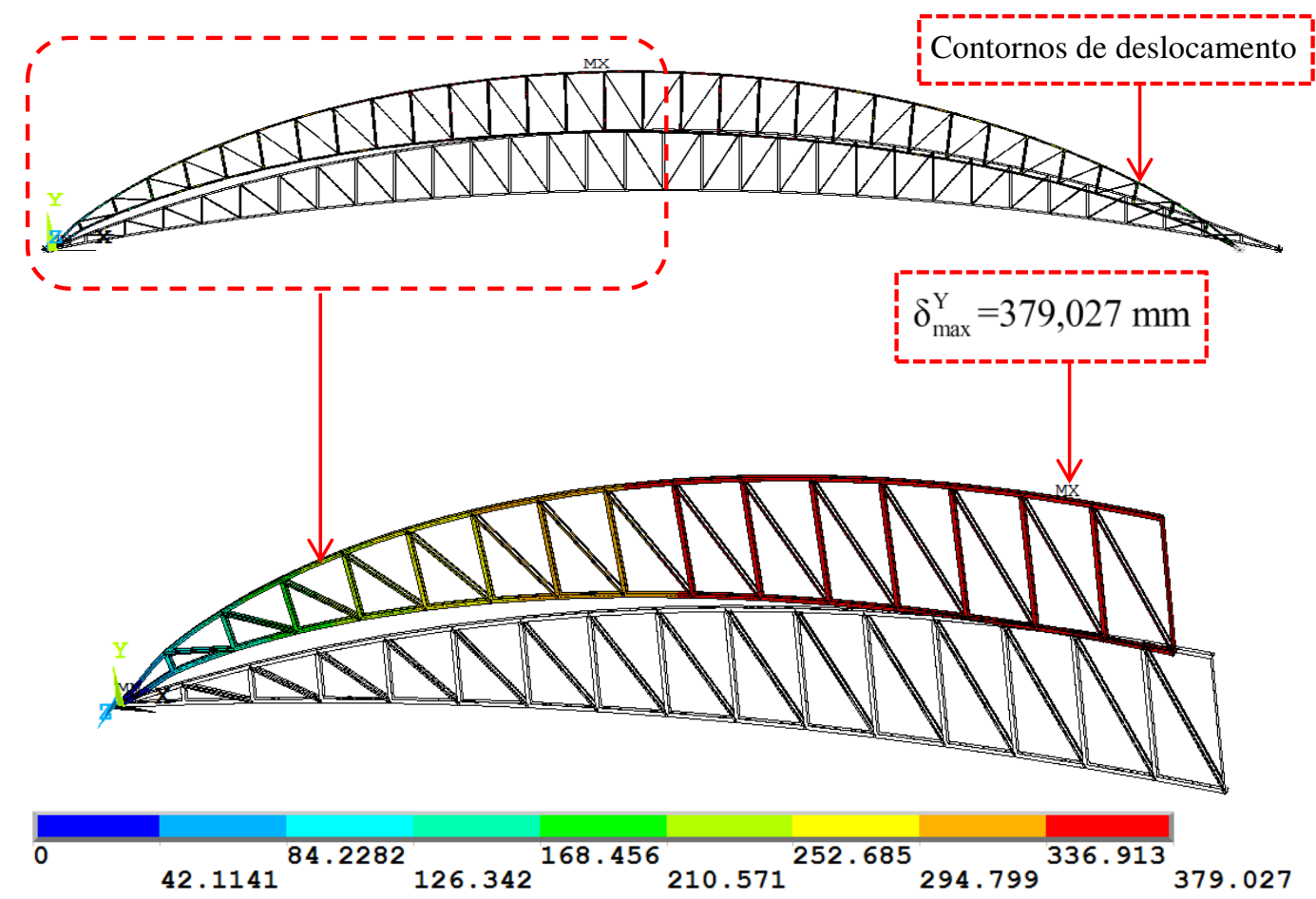

Figura 6.28 Vista lateral e perspectiva com plano de simetria X-Z: deslocamento Uy para o evento $1\left(\mathrm{D}_{120}\right)$.

\subsection{2.}

\section{Treliça de $120 \mathrm{~m}$ protendida $\left(\mathrm{E}_{\mathrm{P} 120}\right)$}

Neste item são apresentadas as análise lineares que se referem às combinações das fases de construção (evento 2) e normal (evento 3), ambas realizadas com a chapa de ancoragem padronizada de $22,4 \mathrm{~mm}$ para treliça protendida. Os resultados obtidos são mostrados nesta seção.

\subsubsection{1.}

\section{Evento 2: Para combinação da fase de construção $\left(E_{P 120}\right)$}

Para a fase de construção, a treliça protendida de 120 vão de vão, com espessura 22,4 $\mathrm{mm}$ da chapa de ancoragem foi modelada com a finalidade de analisar a interface da chapa e do cabo nas extremidades, com uma força de protensão aplicada de $660,56 \mathrm{kN}$. A seguir são apresentados os resultados das tensões e deslocamentos da estrutura. 
Observa-se que a maior tensão de von Mises resultou em 339,85 MPa. O valor encontrado foi obtido na região de ancoragem da treliça. Esse resultado não excede o valor da tensão limite de escoamento do material usado. Portanto, para esta espessura de chapa adotada, a treliça não plastifica nesta zona. Daí conclui-se que essa espessura de $22,4 \mathrm{~mm}$ é adequada. Na Figura 6.29 são apresentadas várias perspectivas da chapa de ancoragem sendo destacada a tensão máxima de von Mises localizada na abertura da chapa (Figura 6.29.d).

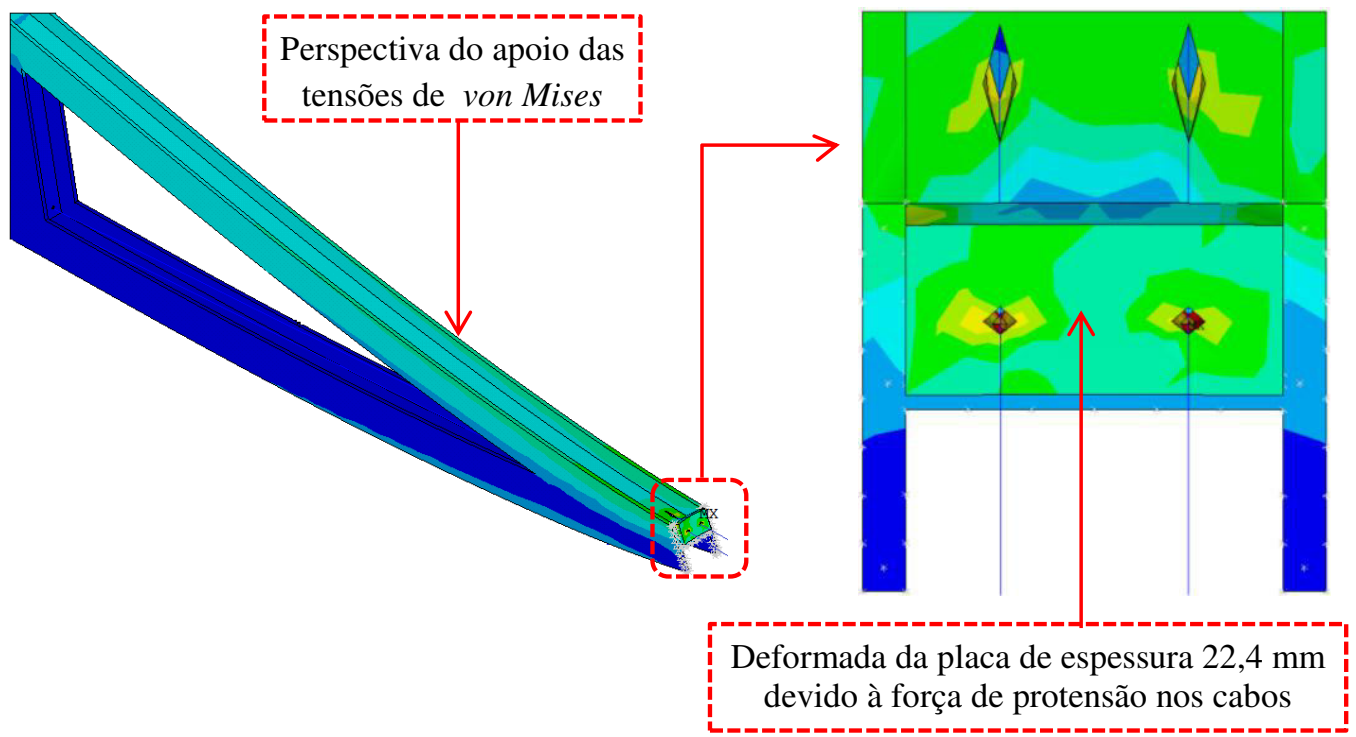

(a)

(b)

$.01727937 .7764^{75.5356} 113.295^{151.054} 188.813^{226.572} 264.331^{302.09} 339.85$

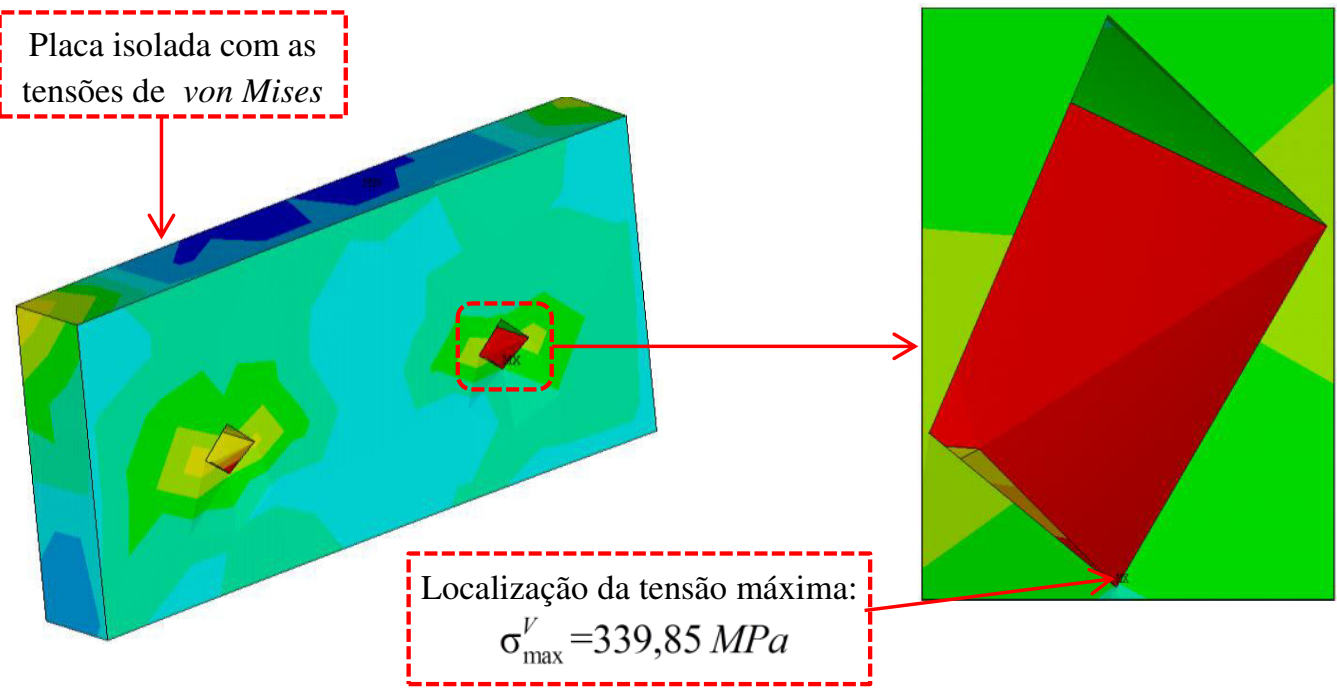

(c)

(d)

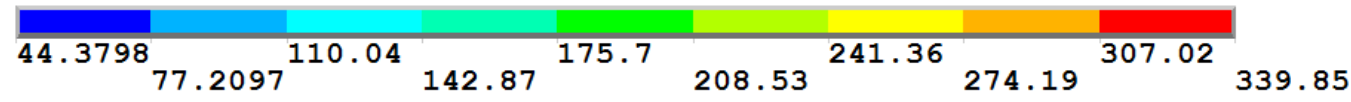

Figura 6.29 Distribuição das tensões de von Mises (em MPa) máxima para o evento $2\left(\mathrm{E}_{\mathrm{p} 120}\right)$. 
Na Figura 6.30 apresenta-se o deslocamento máximo obtido no eixo vertical do centro da treliça, com valor de $187,05 \mathrm{~mm}<\mathrm{L} / 250$. Vale ressaltar que esse valor atende o limite de deslocamento máximo permitido na estrutura (NBR-8800). Também é ilustrada nessa figura a vista lateral e perspectiva do plano de simetria X-Z de deslocamento do modelo.

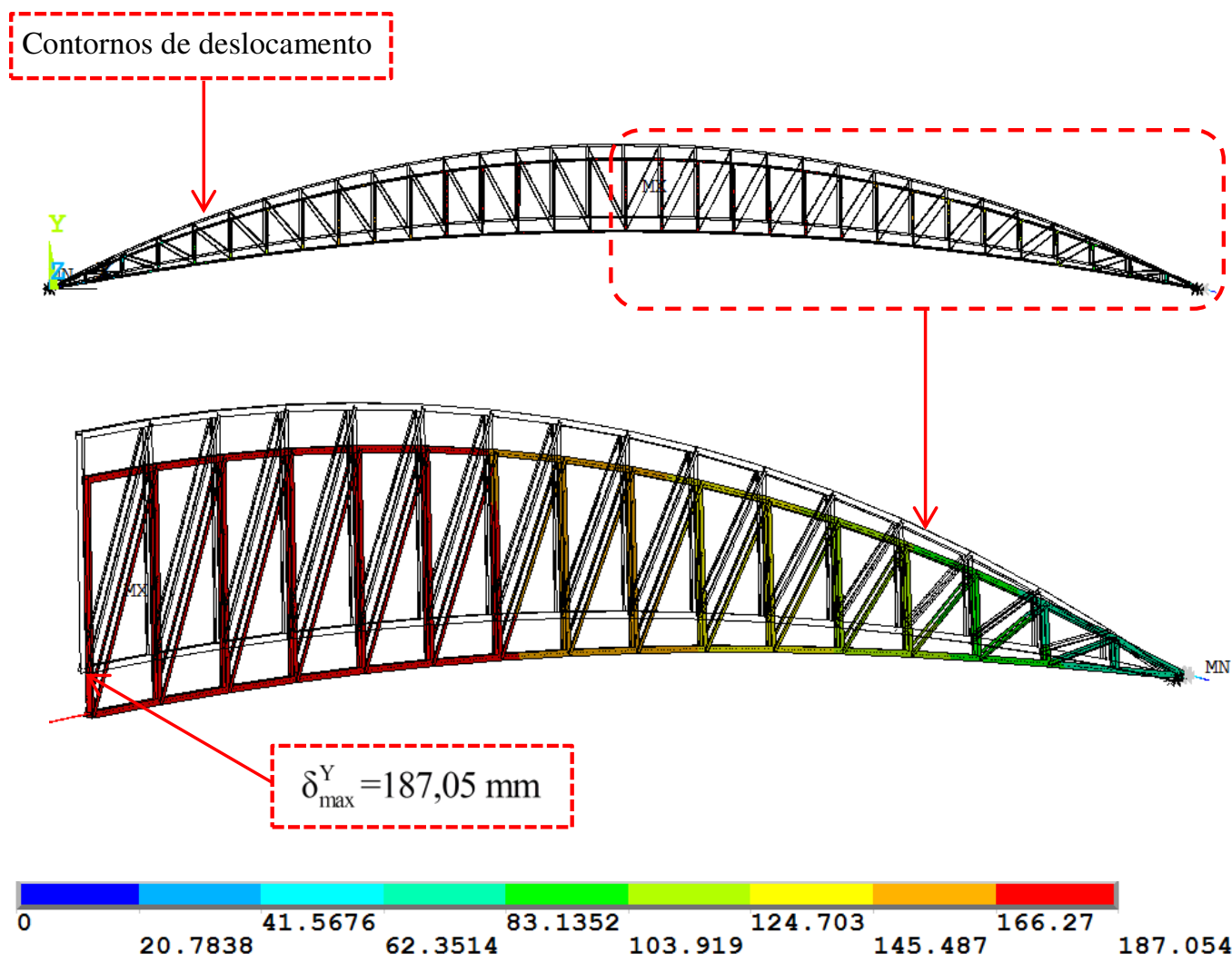

Figura 6.30 Vista lateral e perspectiva com plano de simetria X-Y: deslocamento Uy para o evento $2\left(\mathrm{C}_{\mathrm{P} 120}\right)$.

\subsubsection{2.}

\section{Evento 3: Carga combinação última normal $\left(E_{\mathrm{P} 120}\right)$}

Nesta análise foi realizada uma modelagem de uma treliça protendida de $120 \mathrm{~m}$ de vão com uma chapa de ancoragem padronizada de $22,4 \mathrm{~mm}$. As Figuras 6.31 e 6.32 mostram as distribuições das tensões de von Mises e os deslocamentos máximos provocados pela carga de serviço permanente e pela carga variável devido à ação do vento e da força de protensão ótima (evento 3). 
Nessa análise (Figura 6.31) observa-se que a maior tensão de von Mises (335,01 MPa) foi obtida na chapa de apoio de ancoragem à direita da treliça, ressaltando-se que a tensão obtida junto, ou mais próxima ao apoio da treliça protendida é de 111,68 MPa. Essa tensão é menor do que o valor de tensão limite de escoamento do material usado, ou seja, não há plastificação da estrutura. Além, disso, evidencia-se elevada distribuição das tensões de nas cordas superior e inferior, e menor nas diagonais da treliça, como pode ser visto na Figura 6.31.

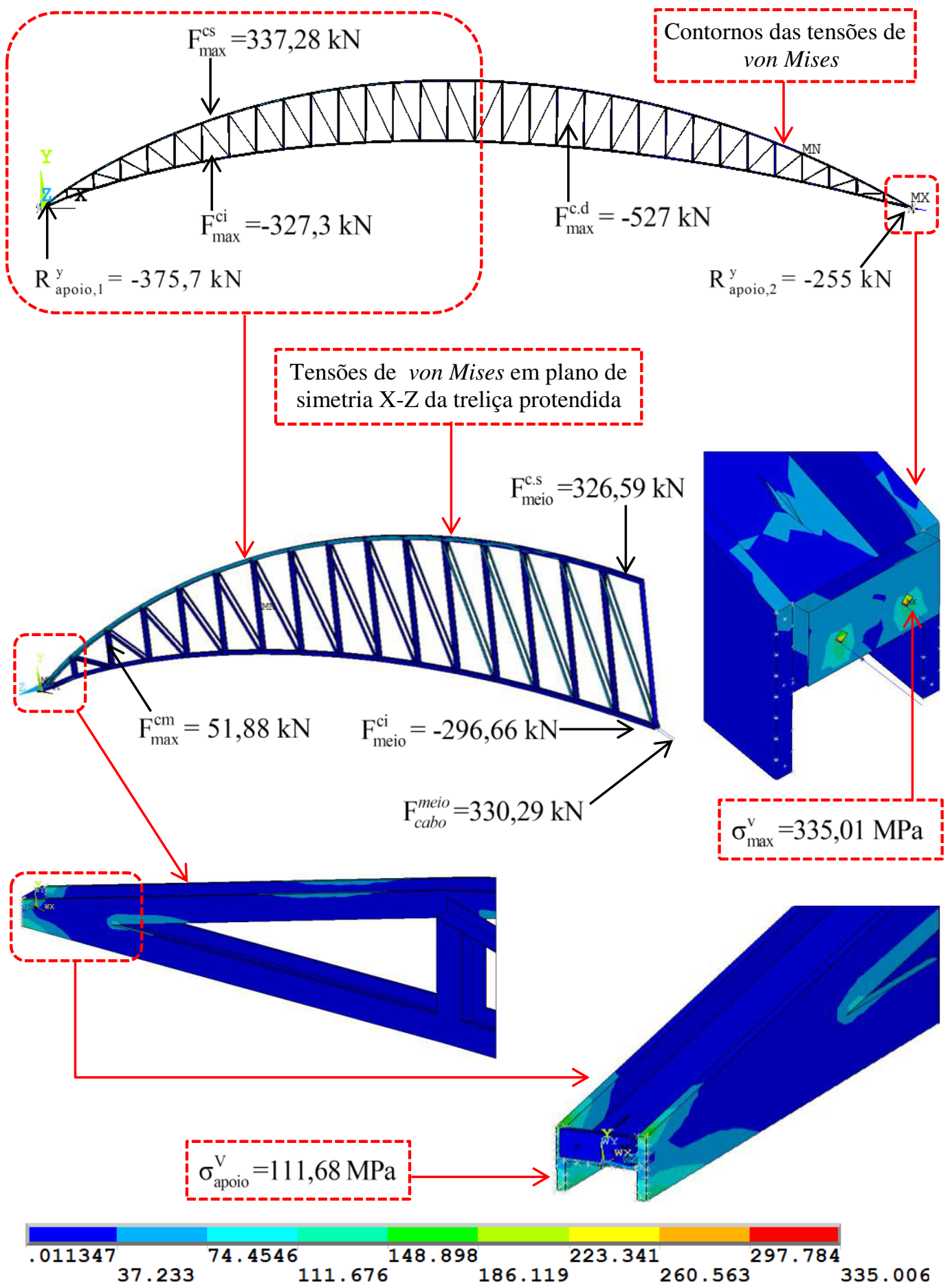

Figura 6.31 Distribuição das tensões de von Mises (em MPa) para o evento $3\left(\mathrm{E}_{\mathrm{P} 120}\right)$ 
Com a chapa padronizada de $22,4 \mathrm{~mm}$ para treliça protendida, para o evento 3 (carga permanente, ação do vento e força de protensão ótima) verificou-se que o deslocamento vertical máximo foi igual a $64,28 \mathrm{~mm}<\mathrm{L} / 250$. O ponto onde isso ocorre está representado na Figura $6.32 \mathrm{com}$ a nomenclatura MX. Convém notar que esse valor é inferior ao deslocamento máximo da estrutura recomendado (NBR-8800).

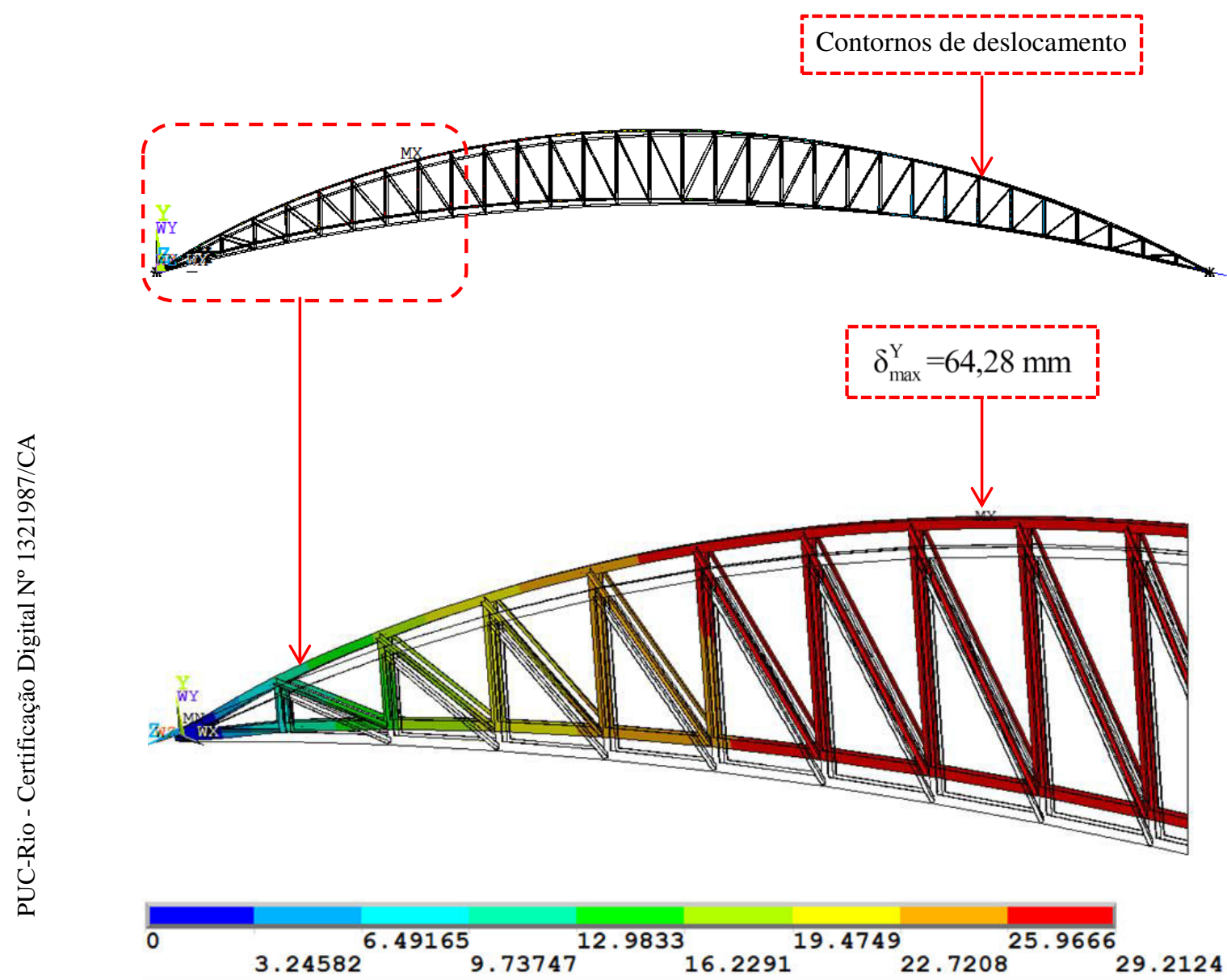

Figura 6.32 Vista lateral e perspectiva com plano de simetria X-Y: deslocamento Uy para o evento $3\left(\mathrm{C}_{\mathrm{P} 120}\right)$. 


\section{6.}

\section{Avalição das forças nas cordas superior e inferior ao longo do vão obtidos na análise estática linear das treliças}

Nas seguintes seções são apresentados os resultados dos esforços das cordas superior e inferior, em cada distância ao longo do vão para combinação de ações última normal, obtidos a partir de uma análise linear dos cinco modelos de treliças, sem e com força de protensão, já apresentados no capítulo 5. Para a determinação da solicitação foi utilizado o programa ANSYS APDL de análise por elementos finitos. As Figuras 6.34 a 6.38 apresentam resultados obtidos na modelagem numérica desenvolvida neste estudo, destacando-se os resultados das solicitações fatoradas nas cordas superior e inferior $\left(F_{d}\right)$ normalizadas pelos valores de nível de protensão ótima $\left(\mathrm{F}_{\mathrm{d}} / \mathrm{P}_{\mathrm{opttc}}\right)$ e a redução dos valores da mesma com a presença da protensão.

Os valores apresentados estão desenhados na posição da seção central do respetivo trecho da corda e representados nos gráficos na mesma vertical (Figura 6.33). Também para facilidade de leitura dos gráficos são apresentados na Figura 6.34 dois exemplos de visualização dos resultados: um resultado da corda superior $(X=3,5 \mathrm{~m})$ e outro da corda inferior $(X=7,5 \mathrm{~m})$.

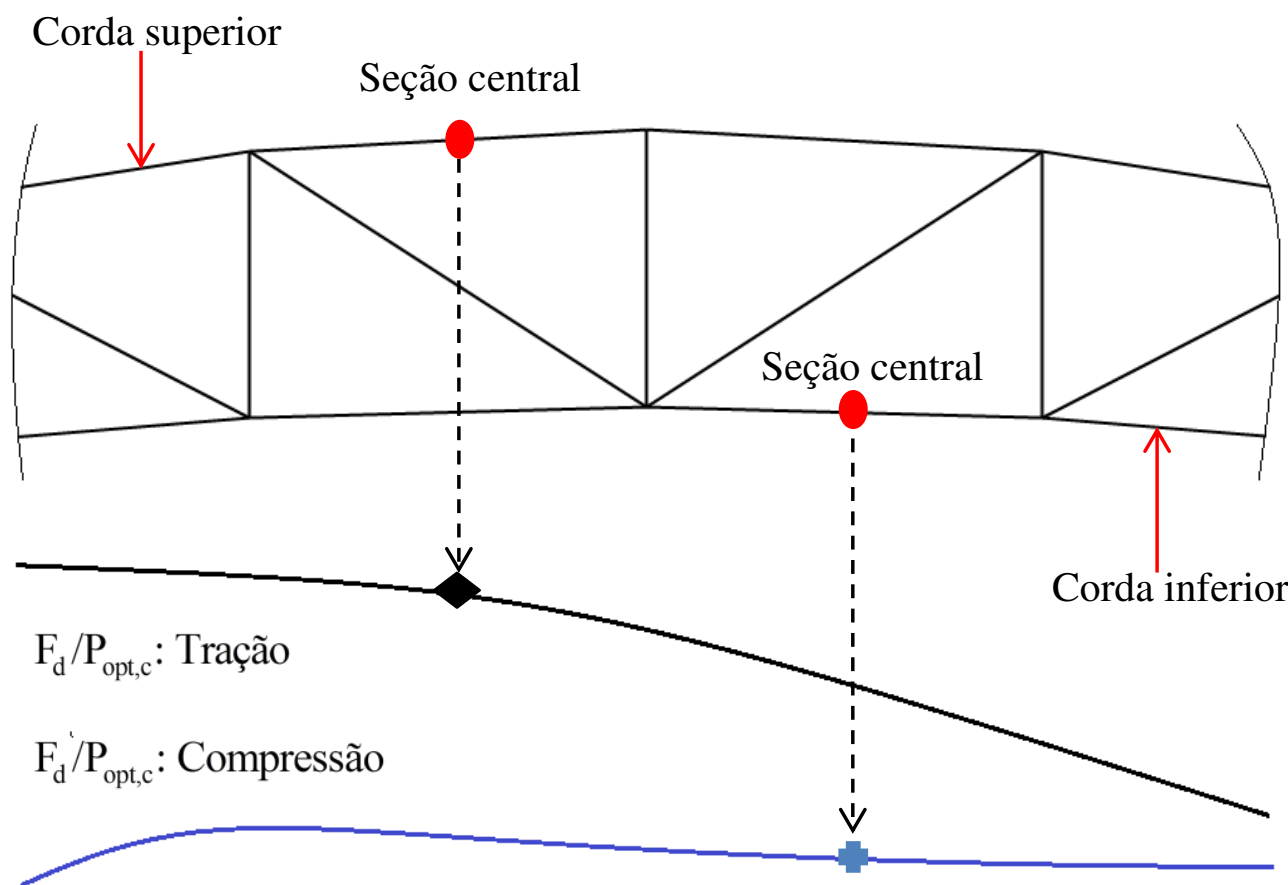

Figura 6.33 Corte da seção dos trechos das cordas superior e inferior para visualização dos resultados. 
A Figura 6.4 apresenta os resultados para a treliça de $10 \mathrm{~m}$ com força de protensão de 65,37 kN. Para os valores para corda superior (traço) há uma redução de força normalizada de 1,81 a 0,83 , ou seja, uma diferença de $54,15 \%$. Para corda inferior (compressão) ocorre uma redução de 1,74 a 0,64 , com uma diferença de $63,22 \%$.

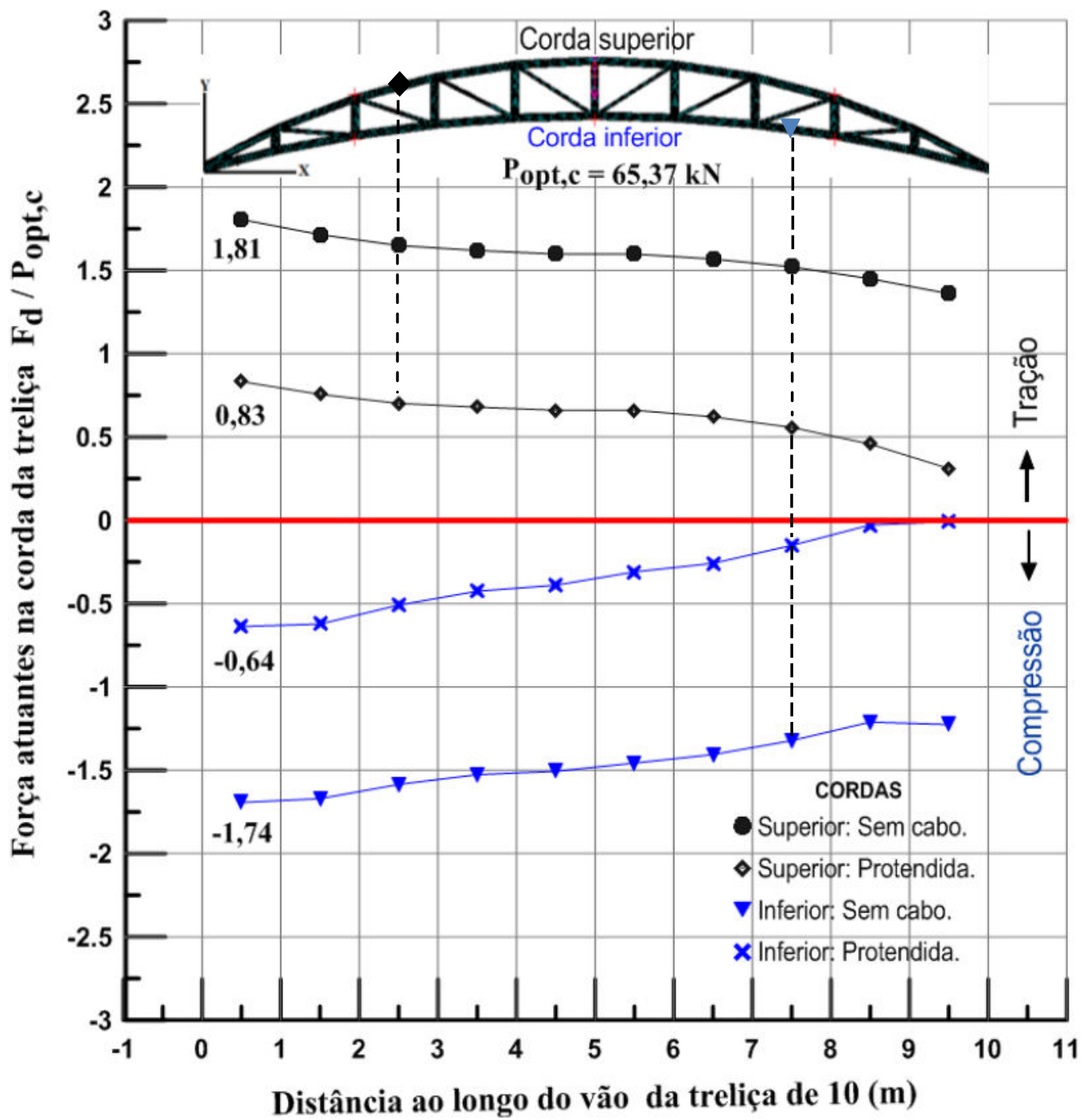

Figura 6.34 Forças fatoradas normalizadas atuantes nas cordas da treliça de $10 \mathrm{~m}$ de vão para as combinações de ações dos eventos 1 e 3. 
A Figura 6.35 apresenta os resultados para a treliça de $20 \mathrm{~m}$ com força de protensão de 130,86 kN. Para os valores para corda superior (traço) há uma redução da força normalizada de 1,63 a 0,83 , ou seja, uma diferença de $49,08 \%$. Para corda inferior (compressão) ocorre uma redução de 1,52 a 1,01, com uma diferença de $33,55 \%$.

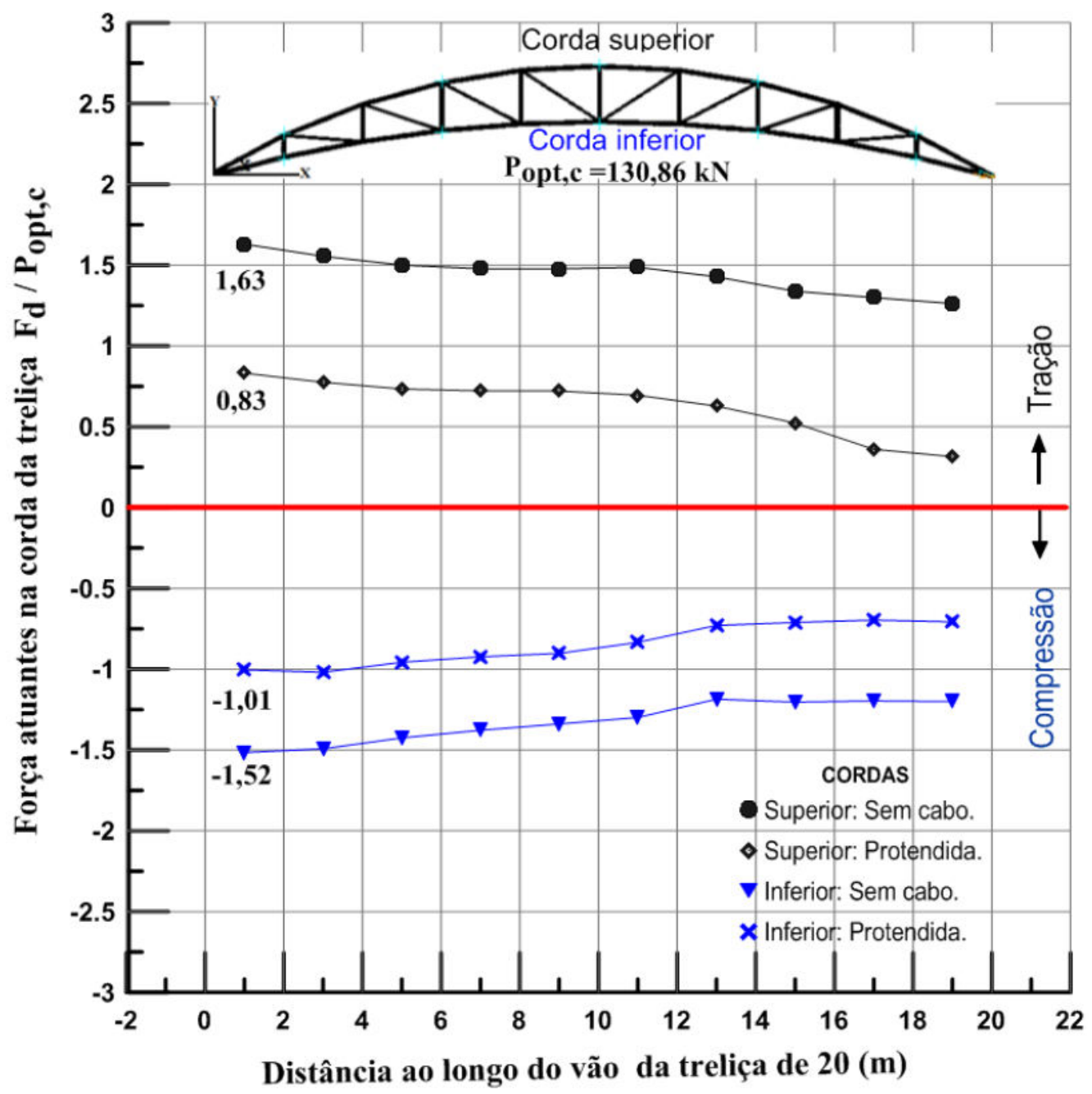

Figura 6.35 Forças fatoradas normalizadas atuantes nas cordas da treliça de $20 \mathrm{~m}$ de vão para as combinações de ações dos eventos 1 e 3 . 
A Figura 6.36 apresenta os resultados para a treliça de $40 \mathrm{~m}$ com força de protensão de 205,27 kN. Para os valores para corda superior (traço) há uma redução da força normalizada de 1,8 a 0,6 , ou seja, uma diferença de $66,67 \%$. Para corda inferior (compressão) ocorre uma redução de 1,63 a 0,53, com uma diferença de $67,5 \%$.

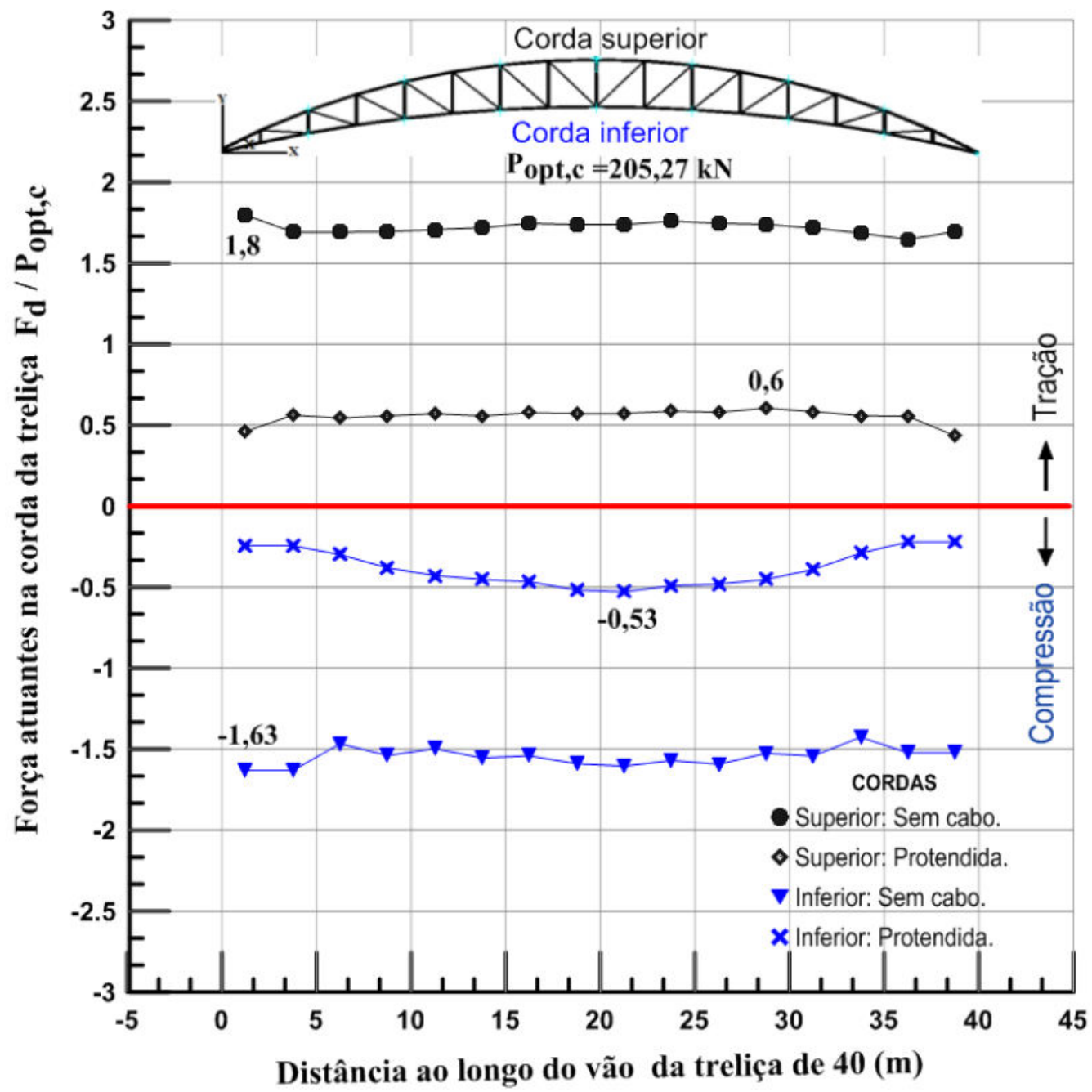

Figura 6.36 Forças fatoradas normalizadas atuantes nas cordas da treliça de $40 \mathrm{~m}$ de vão para as combinações de ações dos eventos 1 e 3. 
A Figura 6.37 apresenta os resultados para a treliça de $80 \mathrm{~m}$ com força de protensão de 440,66 kN. Para os valores para corda superior (traço) há uma redução da força normalizada de 2,12 a 0,66, ou seja, uma diferença de 68,89\%. Para corda inferior (compressão) ocorre uma redução de 1,94 a 0,42, com uma diferença de $78,35 \%$.

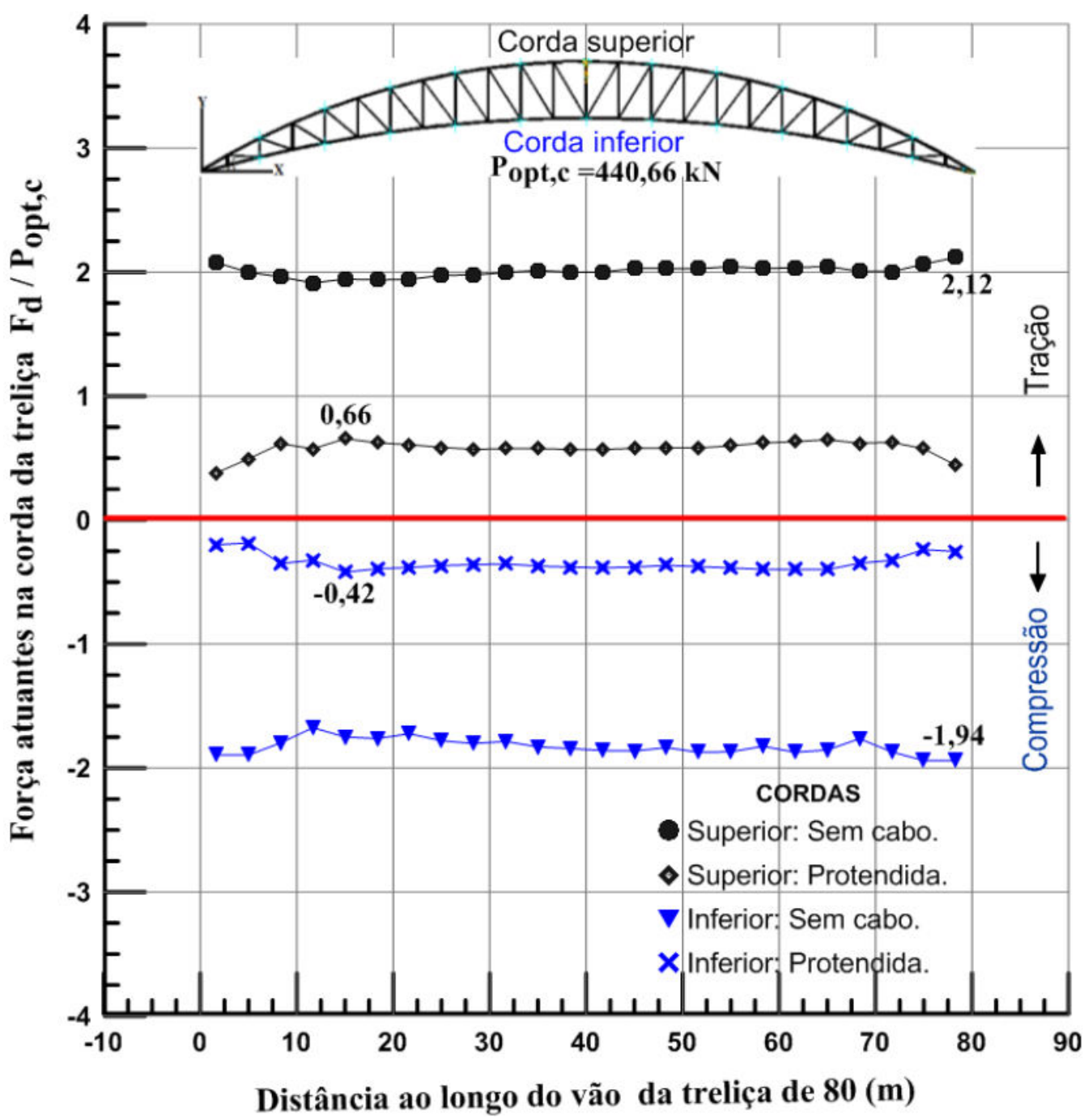

Figura 6.37 Forças fatoradas normalizadas atuantes nas cordas da treliça de $80 \mathrm{~m}$ de vão para as combinações de ações dos eventos 1 e 3 . 
A Figura 6.38 apresenta os resultados para a treliça de $120 \mathrm{~m}$ com força de protensão de 660,56 kN. Para os valores para corda superior (traço) há uma redução da força normalizada de 2,74 a 0,51 , ou seja, uma diferença de $81,4 \%$. Para corda inferior (compressão) ocorre uma redução de 2,64 a 0,19, com uma diferença de $92,8 \%$.

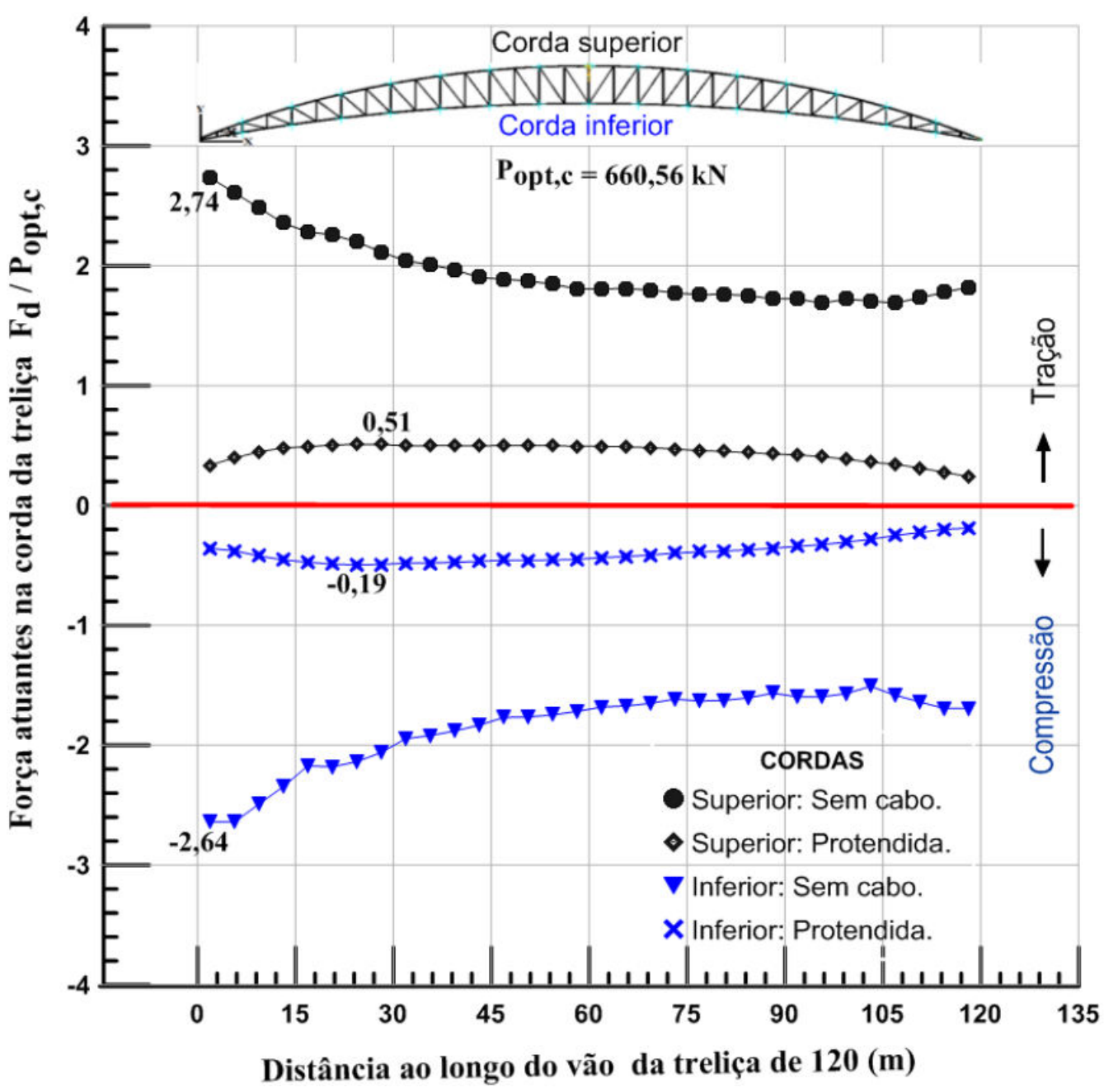

Figura 6.38 Forças fatoradas normalizadas atuantes nas cordas da treliça de $120 \mathrm{~m}$ de vão para as combinações de ações dos eventos 1 e 3.

As Tabelas 6.1 a 6.2 apresentam os resultados das forças normalizadas $\left(\mathrm{F}_{\mathrm{d}} / \mathrm{P}_{\mathrm{opttc}}\right)$ atuantes máximas nas cordas superior (tração) e inferior (compressão) para os diferentes modelos estruturais das treliças (sem e com o efeito da protensão). 
Tabela 6.1 Força máxima normalizada atuante na corda superior.

\begin{tabular}{ccccc}
\hline Modelo & $\begin{array}{c}\text { Forças de } \\
\text { Protensão }\end{array}$ & $\begin{array}{c}\text { Treliça sem } \\
\text { cabo }\end{array}$ & $\begin{array}{c}\text { Treliça } \\
\text { Protendida }\end{array}$ & $\begin{array}{c}\text { \% Razão } \\
\text { de força }\end{array}$ \\
\cline { 2 - 4 }$(\mathrm{kN})$ & $\mathrm{F}_{\mathrm{d}} / \mathrm{P}_{\mathrm{opt,c}}$ & $\mathrm{F}_{\mathrm{d}} / \mathrm{P}_{\mathrm{opt}, \mathrm{c}}$ & \\
\hline $\mathrm{A}_{10}$ & 65,37 & 1,81 & 0,83 & 54,14 \\
$\mathrm{~B}_{20}$ & 130,86 & 1,63 & 0,83 & 49,08 \\
$\mathrm{C}_{40}$ & 205,27 & 1,80 & 0,60 & 66,67 \\
$\mathrm{D}_{80}$ & 440,66 & 2,12 & 0,66 & 68,87 \\
$\mathrm{E}_{120}$ & 660,56 & 2,74 & 0,51 & 81,39 \\
\hline
\end{tabular}

Tabela 6.2 Força máxima normalizada atuante na corda inferior.

\begin{tabular}{ccccc}
\hline Modelo & $\begin{array}{c}\text { Forças de } \\
\text { Protensão }\end{array}$ & $\begin{array}{c}\text { Treliça sem } \\
\text { cabo }\end{array}$ & $\begin{array}{c}\text { Treliça } \\
\text { Protendida }\end{array}$ & $\begin{array}{c}\text { \% Razão } \\
\text { de força }\end{array}$ \\
\cline { 2 - 4 }$(\mathrm{kN})$ & $\mathrm{F}_{\mathrm{d}} / \mathrm{P}_{\mathrm{opt,c}}$ & $\mathrm{F}_{\mathrm{d}} / \mathrm{P}_{\mathrm{opt}, \mathrm{c}}$ & \\
\hline $\mathrm{A}_{10}$ & 65,37 & 1,74 & 0,64 & 63,22 \\
$\mathrm{~B}_{20}$ & 130,86 & 1,52 & 1,01 & 33,55 \\
$\mathrm{C}_{40}$ & 205,27 & 1,63 & 0,53 & 67,48 \\
$\mathrm{D}_{80}$ & 440,66 & 1,94 & 0,42 & 78,35 \\
$\mathrm{E}_{120}$ & 660,56 & 2,64 & 0,19 & 92,80 \\
\hline
\end{tabular}

Nas Tabelas 6.1 e 6.2 são informados os valores das variações das forças máximas normalizadas em relação a forças de protensão ótima nas cordas superior e inferior das treliças, para os carregamentos associados aos eventos 1 e 3 ( ver capitulo 4, item 4.4). Percebe-se a redução nas forças normalizadas para os modelos de treliças protendidas e, além disso, nota-se, à medida que o vão aumenta, maior ganho de forças normalizadas. Também se observa que os resultados da corda inferior apresentam maior relação de força que na corda superior, devido ao posicionamento dos cabos de protensão, que estão presentes na corda inferior. Vale ressaltar que, para treliça de $20 \mathrm{~m}$ mostra menor valor de redução de força, pois os perfis utilizados na modelagem são os mesmos que foram empregados na treliça de $10 \mathrm{~m}$ de vão. Tais perfis são as menores bitolas comerciais existentes no Brasil. 


\section{7.}

\section{Análise dos resultados das solicitações máximas obtidos na análise linear das treliças investigada}

Nas seguintes seções são apresentados os resultados das solicitações e deslocamentos obtidos a partir de uma análise linear dos cinco modelos de treliças já apresentados no capítulo $5\left(\mathrm{~A}_{10}, \mathrm{~B}_{20}, \mathrm{C}_{40}, \mathrm{D}_{80}\right.$ e $\left.\mathrm{E}_{120}\right)$. Para a determinação das tensões, forças e deslocamentos foi utilizado o programa ANSYS APDL de elementos finitos.

\subsection{1.}

\section{Análise dos valores das forças}

A Figura 6.39 apresenta as variações das forças de tração solicitantes máximas nas barras da corda superior para diferentes modelos estruturais da treliça protendida e da treliça sem protensão. Observa-se a diminuição significativa das forças com base no emprego da protensão, como ilustrado na Figura 6.33. A partir dos resultados obtidos na modelagem numérica desenvolvida neste estudo destacam-se:

a) o modelo estrutural $\mathrm{A}_{10}$ apresenta uma redução de força que passa de 118,04 kN a $54,41 \mathrm{kN}$, ou seja, uma diferença de 53,9\% ( Figura 6.39);

b) no modelo estrutural $\mathrm{B}_{20}$ apresenta uma redução de força de $213,28 \mathrm{kN}$ para $108,79 \mathrm{kN}$, ou seja, uma diferença de 49\% (Figura 6.39);

c) no modelo estrutural $\mathrm{C}_{40}$ apresenta uma redução de força $368,94 \mathrm{kN}$ para $124,61 \mathrm{kN}$, ou seja, uma diferença de 66,2\% (Figura 6.39);

d) no modelo estrutural $\mathrm{D}_{80}$ apresenta uma redução de força de $934,01 \mathrm{kN}$ para 289,21 kN, ou seja, uma diferença de 69\% (Figura 6.39);

e) no modelo estrutural $\mathrm{E}_{120}$ apresenta uma redução de força de $1.807,55 \mathrm{kN}$ a $337,38 \mathrm{kN}$, ou seja, uma diferença de 81,3\% (Figura 6.39). 


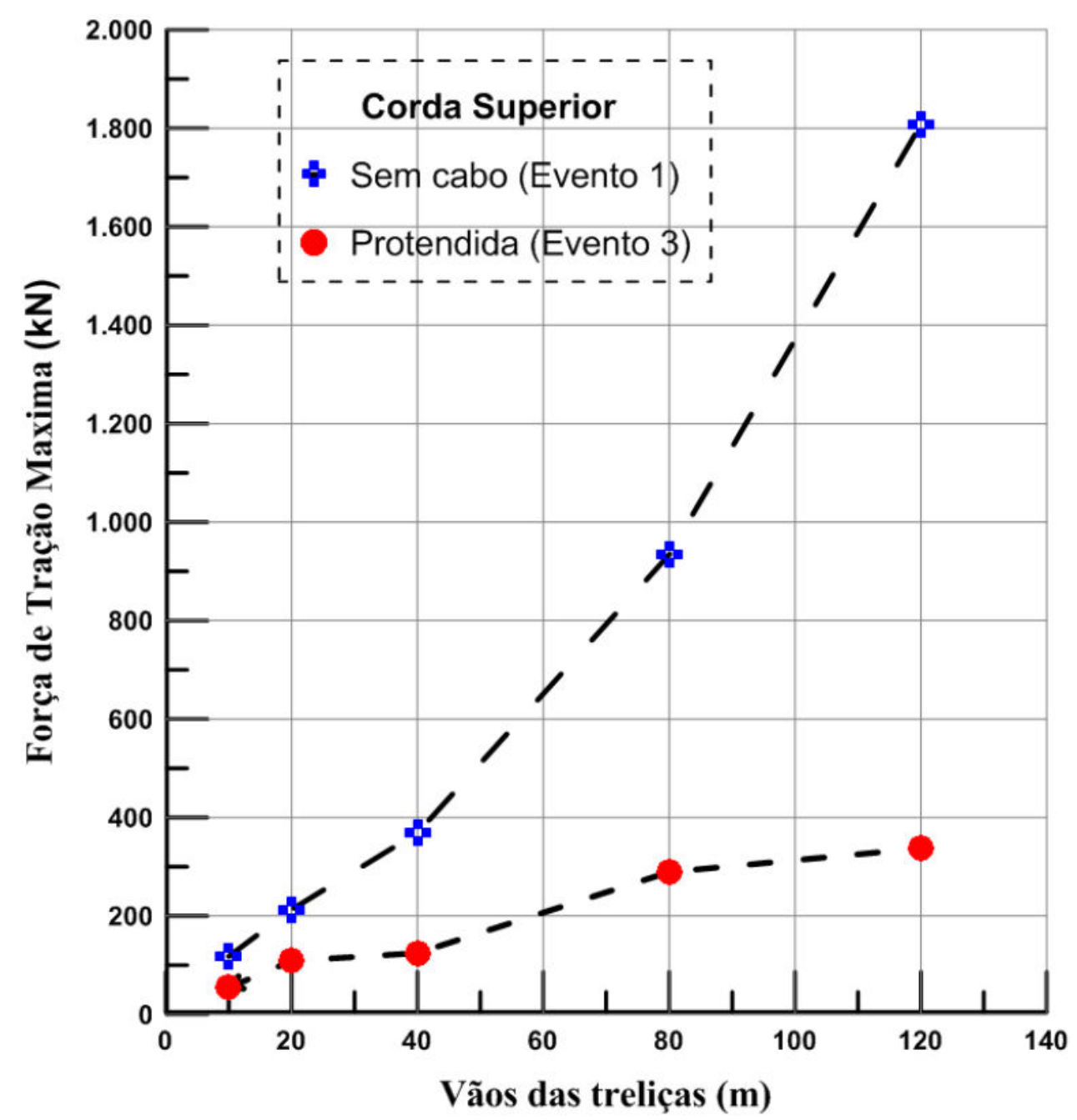

Figura 6.39 Forças de tração máximas solicitantes da corda superior para diferentes modelos.

Em seguida a Figura 6.40 apresenta as variações das forças de compressão solicitantes máximas nas barras da corda inferior para diferentes modelos estruturais da treliça protendida e da treliça sem protensão. Verifica-se a diminuição das forças com uso da protensão, como apresentado na Figura 6.34. A partir dos resultados obtidos na modelagem numérica destaca-se:

a) para o modelo estrutural $\mathrm{A}_{10}$ ocorre uma redução de força que passa de 110,7 $\mathrm{kN}$ para $41,25 \mathrm{kN}$, ou seja, uma diferença de 62,7\% (Figura 6.40);

b) o modelo estrutural $\mathrm{B}_{20}$ ocorre uma redução de força de $198,34 \mathrm{kN}$ a 132,25 $\mathrm{kN}$, ou seja, uma diferença de 33,3\% (Figura 6.40); 
c) o modelo estrutural $\mathrm{C}_{40}$ apresenta uma redução de força de $334,75 \mathrm{kN}$ a 108,5 $\mathrm{kN}$, ou seja, uma diferença de 68,6\% (Figura 6.40);

d) o modelo estrutural $\mathrm{D}_{80}$ ocorre uma redução de força de $854,58 \mathrm{kN}$ a 184,83 $\mathrm{kN}$, ou seja, uma diferença de 78,4\% (Figura 6.40);

e) o modelo estrutural $E_{120}$ ocorre uma redução de força de $1.744,66 \mathrm{kN}$ a 327,3 kN, ou seja, uma diferença de 81,2\% (Figura 6.40).

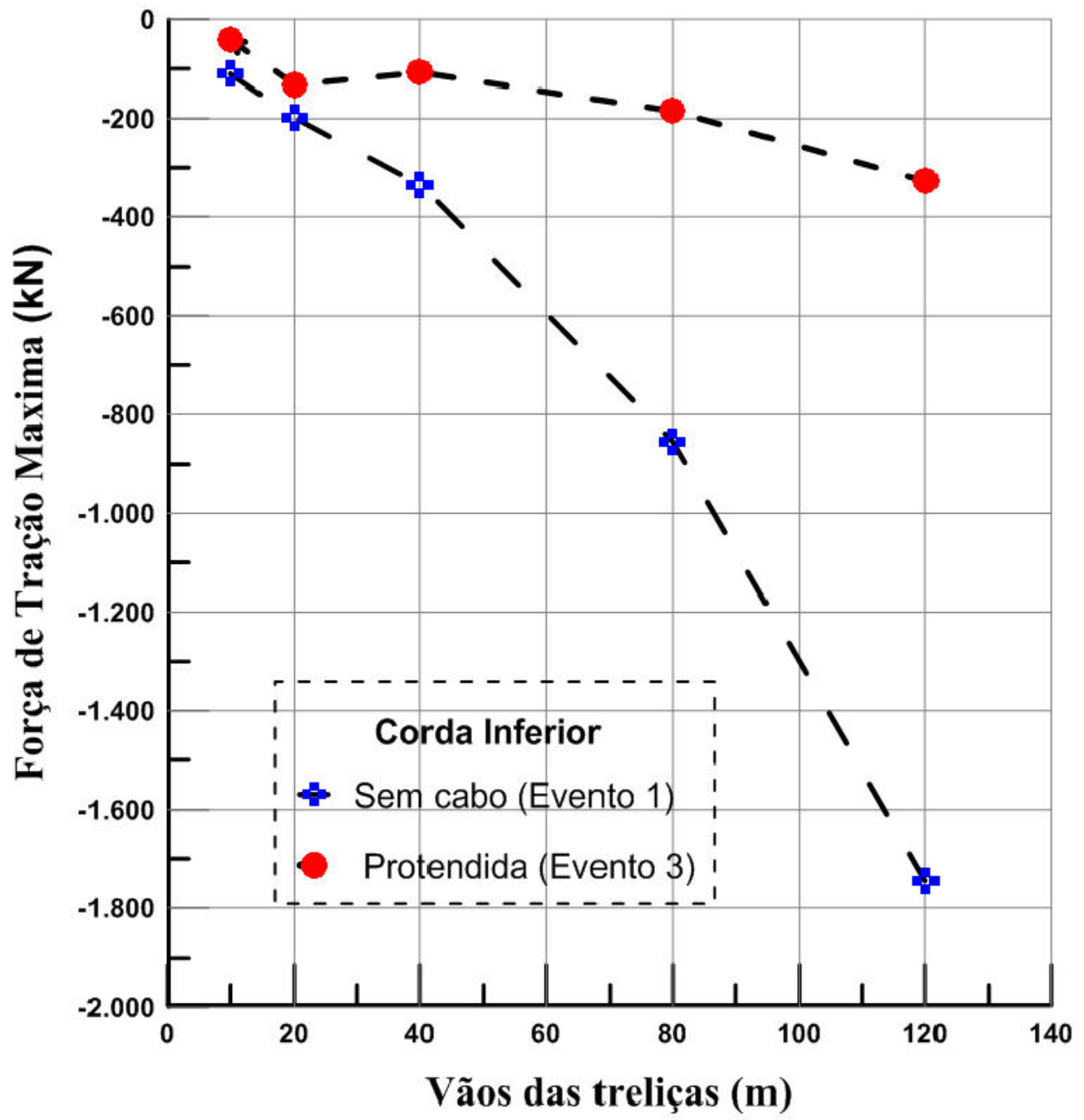

Figura 6.40 Forças de compressão máximas solicitantes da corda inferior para diferentes modelos.

As Tabelas 6.3 a 6.4 apresentam os resultados obtidos com o emprego do programa ANSYS APDL, no que diz respeito às forças máximas nas cordas superior e inferior e os deslocamentos no centro do vão para os diferentes modelos estruturais de treliça (sem e com o efeito da protensão). Ressalta-se que efeito da protensão influenciou de uma maneira significativa as forças da estrutura. 
Tabela 6.3 Força máxima atuante na corda superior.

\begin{tabular}{cccc}
\hline \multirow{2}{*}{ Modelo } & Treliça sem cabo & Treliça Protendida & \multirow{2}{*}{$\begin{array}{c}\text { R Razão } \\
\text { de força }\end{array}$} \\
\cline { 2 - 3 } $\mathrm{A}_{10}$ & 118,04 & 54,41 & 53,9 \\
$\mathrm{~B}_{20}$ & 213,28 & 108,79 & 48,99 \\
$\mathrm{C}_{40}$ & 368,94 & 124,61 & 66,22 \\
$\mathrm{D}_{80}$ & 934,01 & 289,21 & 69,04 \\
$\mathrm{E}_{120}$ & $1.807,55$ & 337,28 & 81,33 \\
\hline
\end{tabular}

Tabela 6.4 Força máxima e deslocamento atuante na corda inferior.

\begin{tabular}{|c|c|c|c|c|c|}
\hline \multirow{2}{*}{ Modelo } & \multicolumn{2}{|c|}{$\begin{array}{l}\text { Treliça sem cabo } \\
\text { (Evento 1) }\end{array}$} & \multicolumn{2}{|c|}{$\begin{array}{l}\text { Treliça Protendida } \\
\text { (Evento 3) }\end{array}$} & \multirow{2}{*}{$\begin{array}{l}\text { \% Razão } \\
\text { de força }\end{array}$} \\
\hline & $\begin{array}{c}\text { Força } \\
(\mathrm{kN})\end{array}$ & $\begin{array}{l}\text { Deslocamento } \\
(\mathrm{mm})\end{array}$ & $\begin{array}{c}\text { Força } \\
(\mathrm{kN})\end{array}$ & $\begin{array}{l}\text { Deslocamento } \\
(\mathrm{mm})\end{array}$ & \\
\hline $\mathrm{A}_{10}$ & $-110,7$ & 14,81 & $-41,25$ & 1,63 & 62,74 \\
\hline $\mathrm{B}_{20}$ & $-198,34$ & 60,69 & $-132,25$ & 3,96 & 33,32 \\
\hline $\mathrm{C}_{40}$ & $-334,75$ & 110,87 & $-108,05$ & 7,72 & 68,62 \\
\hline $\mathrm{D}_{80}$ & $-854,58$ & 276,3 & $-184,87$ & 23,93 & 78,37 \\
\hline $\mathrm{E}_{120}$ & $-1.744,66$ & 379,03 & $-327,28$ & 64,28 & 81,24 \\
\hline
\end{tabular}

\section{8.}

\section{Análise dos valores de tensões}

Com base nas simulações numéricas realizadas, a Tabela 6.5 mostra o resumo dos resultados obtidos no que diz respeito às tensões máximas de von Mises, para os diferentes modelos estruturais de treliça (sem e com o efeito da protensão). Ressalta-se que o efeito da protensão influenciou de maneira significativa nas tensões das estruturas. A partir dos resultados obtidos na modelagem numérica desenvolvida neste estudo são destacados os itens a seguir descritos. 
a) para o modelo estrutural $A_{10}$ tem uma redução de tensão que passa de 345,14 MPa para 166,26 MPa, ou seja, uma diferença de 51,83\% (Tabela 6.5);

b) o modelo estrutural $\mathrm{B}_{20}$ tem uma redução de tensão que passa de $345,53 \mathrm{MPa}$ para 181,55 MPa, ou seja, uma diferença de 47,31\% (Tabela 6.5);

c) o modelo estrutural $\mathrm{C}_{40}$ tem uma redução de tensão que passa de $345,26 \mathrm{MPa}$ para 121,24 MPa, ou seja, uma diferença de 64,88\% (Tabela 6.5);

d) o modelo estrutural $\mathrm{D}_{80}$ tem uma redução de tensão que passa de $348,1 \mathrm{MPa}$ para 111,74 MPa, ou seja, uma diferença de 67,9\% (Tabela 6.5);

e) o modelo estrutural $E_{120}$ tem uma redução de tensão que passa de $351,78 \mathrm{MPa}$ para 111,68 MPa, ou seja, uma diferença de 68,25\% (Tabela 6.5);

Tabela 6.5 Tensão máxima de von Mises.

\begin{tabular}{cccc}
\hline \multirow{2}{*}{ Modelo } & Treliça sem cabo & Treliça Protendida & $\begin{array}{c}\text { Relação de } \\
\text { Tensão }\end{array}$ \\
\cline { 2 - 4 } & (Evento 1) $(\mathrm{MPa})$ & $($ Evento 3) $(\mathrm{MPa})$ & $(\%)$ \\
$\mathrm{A}_{10}$ & 345,14 & 166,26 & 51,83 \\
$\mathrm{~B}_{20}$ & 345,53 & 181,55 & 47,31 \\
$\mathrm{C}_{40}$ & 345,26 & 121,24 & 64,88 \\
$\mathrm{D}_{80}$ & 348,1 & 111,74 & 67,9 \\
$\mathrm{E}_{120}$ & 351,78 & 111,68 & 68,25 \\
\hline
\end{tabular}

Os resultados apresentados nas Tabelas 6.3 até 6.5 mostram as variações de esforços máximos nas cordas superior (tração) e inferior (compressão) da treliça. Observa-se que o efeito de protensão tende a proporcionar uma grande redução de esforço solicitante nas barras da treliça. Esses resultados confirmam as conclusões de Belenya (1997) e de Troitsky (1990) de que os sistemas de treliças protendidas são eficientes para grandes vãos e resultam em estruturas mais leves e econômicas e o uso de protensão também oferece grande redução de deslocamentos verticais da estrutura. 


\section{Análise estática não linear das treliças}

Conforme citado no capítulo cinco deste trabalho, esta seção apresenta os resultados obtidos na análise não linear das treliças sem e com protensão. O objetivo, é avaliar o comportamento estrutural dos modelos até a ruptura.

Para esta análise não linear o programa ANSYS 15.0 [11] utiliza o método de Newton-Raphson para resolução do sistema de equações não lineares. Esse método se baseia na divisão de deslocamento em uma série de incrementos, sendo aplicados em vários passos de deslocamento. Em cada etapa de aplicação de deslocamento, uma configuração de equilíbrio é gerada e um novo incremento é aplicado até se concluir o número total de incrementos.

Para se obter a curva carga versus deslocamento vertical foi aplicado um controle direto de deslocamento prescrito na corda superior no meio do vão da treliça biapoiada. Um esquema do deslocamento imposto é apresentado na Figura 7.1, onde a carga de vento de elevação na treliça de arcos induz forças de compressão adicionais na corda inferior de protensão, que está fixa de um lado e apoiada em rolos do outro. Para todos os modelos de treliças foram aplicados deslocamentos e etapas de cargas diferentes. Como resposta foram obtidas forças correspondentes tanto na fase elástica quanto na fase não elástica.

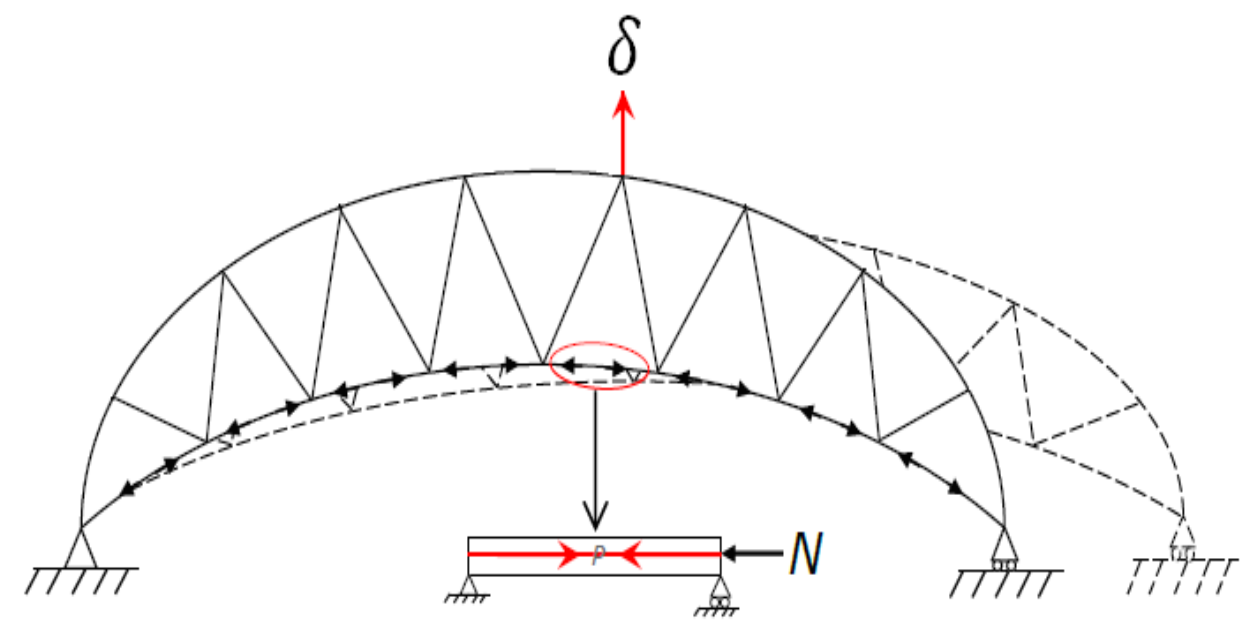

Figura 7.1 Esquema de controles de deslocamento vertical (Fida, 2015). 
Conforme a análise a seguir são verificadas as diferenças do deslocamento vertical e das forças máximas dos modelos apresentados neste trabalho, aumentando-se a intensidade da força de protensão desde o valor mínimo até o valor ótimo.

\section{1.}

\section{Análise não linear da treliça de $10 \mathrm{~m}$ de vão}

A análise não linear para a treliça de $10 \mathrm{~m}$ de vão sem e com protensão foi executada a partir da aplicação de deslocamento no centro da treliça, na direção do eixo x de nó piloto, onde se está simulando-se a ação do vento nessa direção. Na Figura 7.2 são mostrados um modelo de treliça, as condições de contorno e aplicação do deslocamento. Também é mostrada uma ampliação da estrutura na parte em que está aplicando o deslocamento. Observa-se que há simetria do modelo em relação ao eixo paralelo a $z$ no meio do vão.

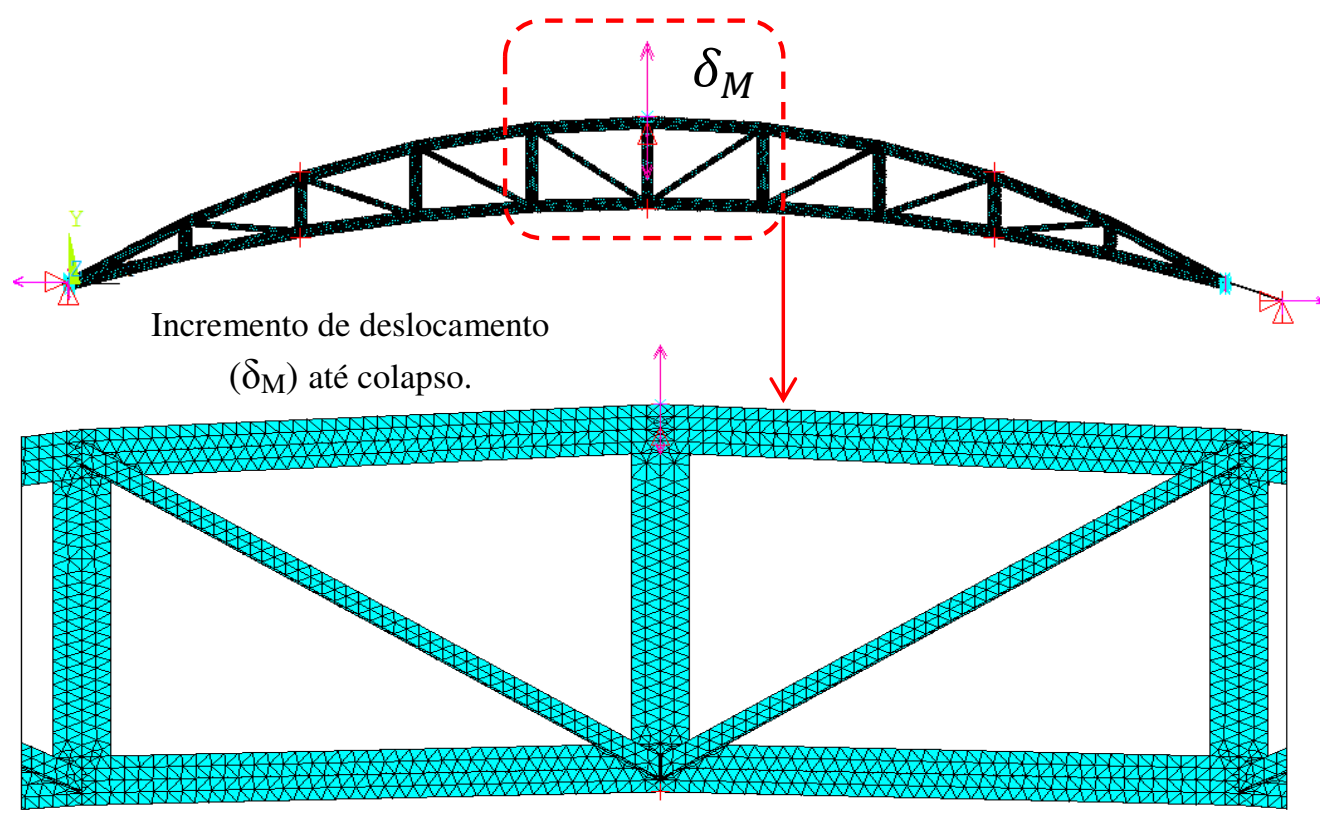

Figura 7.2 Deslocamento vertical aplicado no centro da treliça $\mathrm{A}_{10}$.

A Figura 7.3 apresenta as curvas carga versus deslocamento da treliça de 10m em forma de arco sem o uso da força de protensão (ver capítulo 4, item 4.2) e com protensão na corda inferior, onde o carregamento foi aplicado por meio de incremento de deslocamento vertical até atingir a rupturas da treliça utilizando-se como critério de convergência a norma de deslocamentos. É possível observar que as curvas com protensão são muito similares, além de terem cargas máximas superiores à curva da treliça sem protensão. 


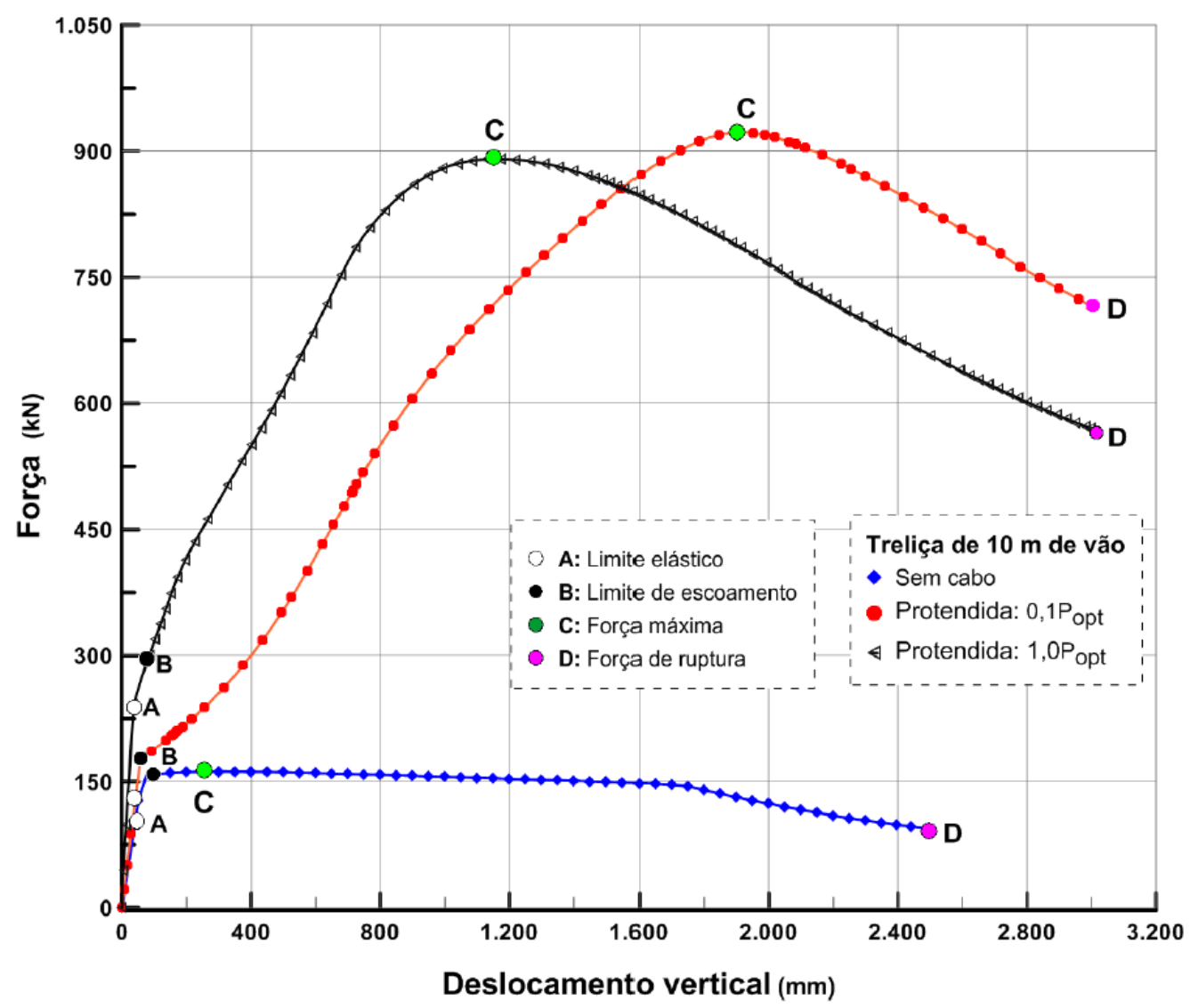

Figura 7.3 Força versus deslocamento vertical do meio do vão de $\mathrm{A}_{10}$ sem e com protensão.

$\mathrm{Na}$ Figura 7.3, referente às curvas, são traçados os pontos A (limite elasticidade), B (limite de escoamento), C (força máxima) e D (força de ruptura) são mostradas as forças e deslocamentos em trecho linear e não linear nas treliças sem e com protensão de $10 \mathrm{~m}$. Na sequência do estudo das Figuras 7.4 até 7.12 mostram os resultados das tensões correspondentes às forças e deslocamentos dos pontos das curvas.

\subsection{1.}

\section{Treliça de $10 \mathrm{~m}$ sem protensão $\left(\mathrm{A}_{10}\right)$}

Nas Figuras 7.4 até 7.7 são apresentados os resultados das distribuições das tensões de von Mises (Critério de plastificação) para diversos pontos da curva força versus deslocamento vertical aplicado, obtidas a partir da análise não linear física para a treliça de $10 \mathrm{~m}$ de vão sem protensão, provocada pelo deslocamento aplicado no centro da treliça. Os resultados dos pontos característicos importantes das curvas da Figura 7.3, são analisados nesta seção. 
1. Ponto A: com base nos resultados obtidos a Figura 7.4 ilustra a distribuição das tensões de von Mises referente ao ponto do limite de elasticidade da Figura 7.3, onde se observa que o valor da tensão calculada foi igual a $323,58 \mathrm{MPa}$ (correspondente a um carregamento aplicado de $157,68 \mathrm{kN}$ ) na região onde foi aplicado o deslocamento vertical $\partial_{M, A}$ de $75 \mathrm{~mm}$. Essa tensão é menor que o valor de tensão limite do escoamento do material usado. Também se nota que o apoio da treliça sem protensão apresenta grandes concentrações de tensões, no qual a maior tensão de von Mises resultou em 348,72 MPa. Esse valor excede o valor limite de escoamento e, portanto, a treliça começa a plastificar nesta área.

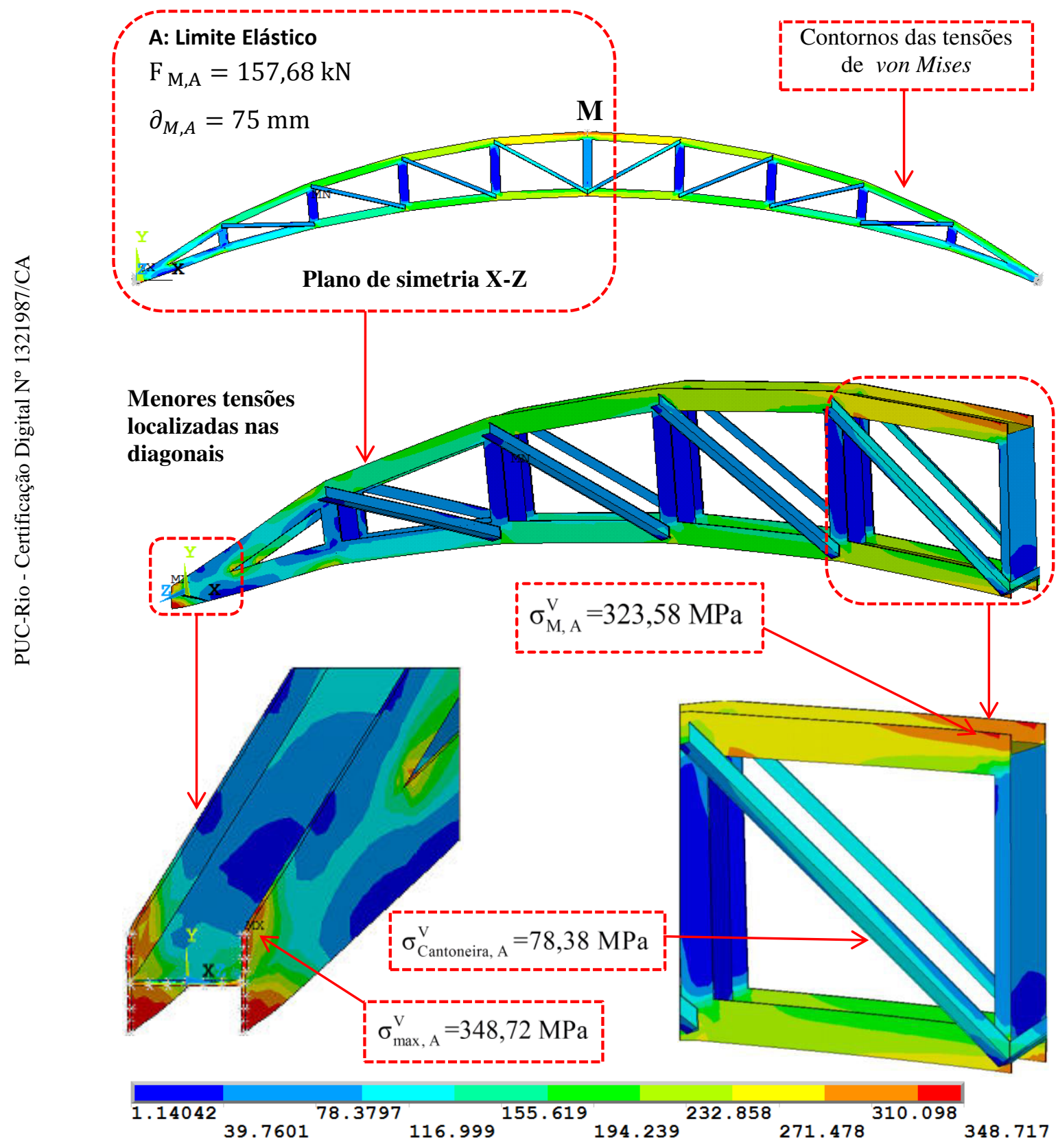

Figura 7.4 Distribuição de tensões de von Mises (MPa) correspondente ao ponto A $\left(\mathrm{A}_{10}\right)$. 
2. Ponto B: na Figura 7.5 verifica-se que há um aumento da distribuição das tensões de von Mises no que se refere ao ponto de limite de escoamento (Figura 7.3). Na região do centro da treliça $\partial_{M}$, foi observado que o valor da tensão calculada resultou em 338,24 MPa (correspondente a um carregamento aplicado de 158,92 kN) para um deslocamento vertical de $100 \mathrm{~mm}$. Essa tensão é menor que o valor da tensão limite de escoamento, ou seja, não há plastificação da estrutura. Vale ressaltar que, na região do apoio, identifica-se a elevada distribuição de $351,75 \mathrm{MPa}$, que, por sua vez, excede o valor limite de escoamento, fazendo com que a estrutura continue plastificando nesta zona.

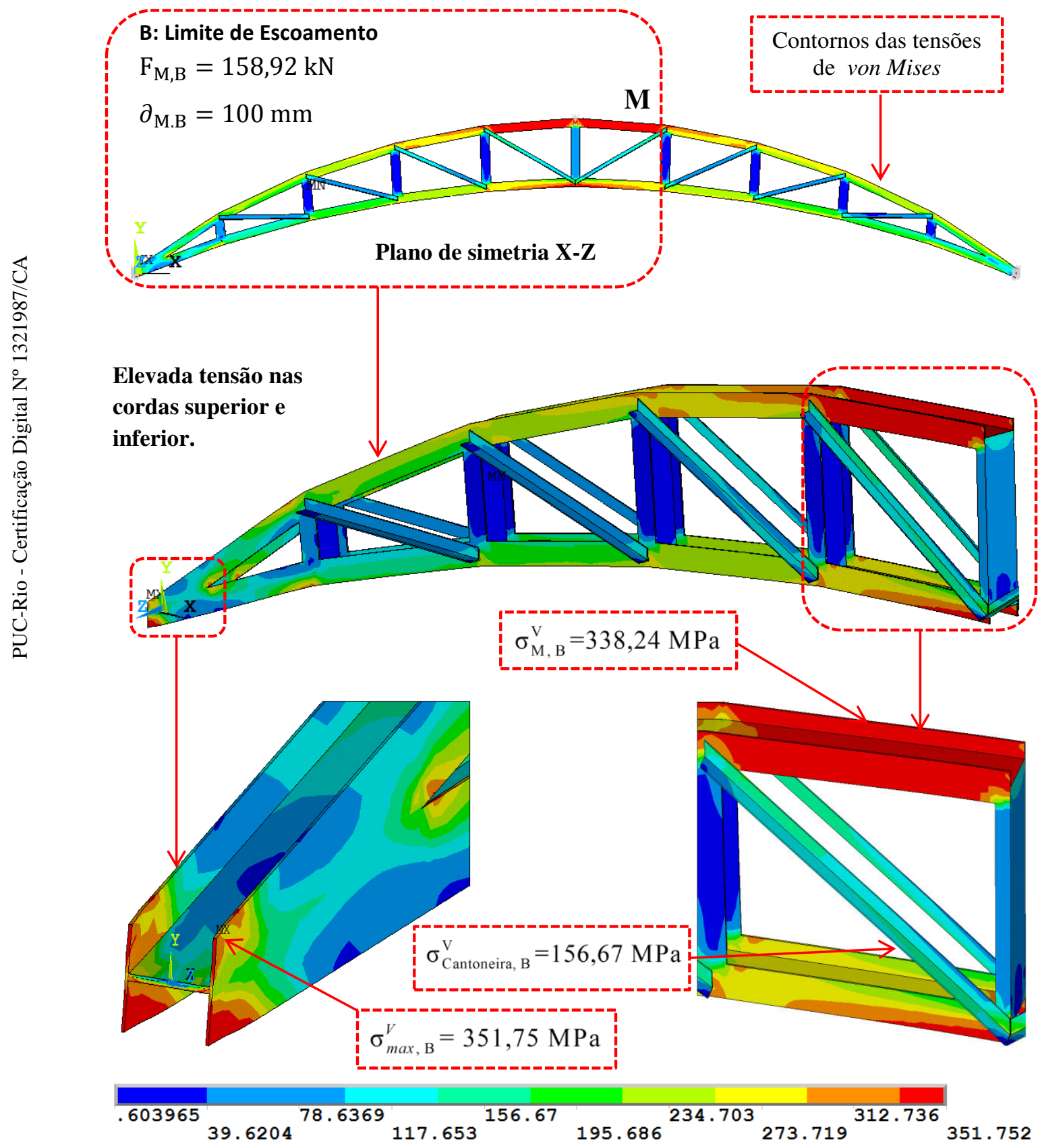

Figura 7.5 Distribuição de tensões de von Mises (MPa) correspondente ao ponto $\mathrm{B}\left(\mathrm{A}_{10}\right)$. 
3. Ponto C: observando-se a distribuição das tensões de von Mises da Figura 7.6 referente ao ponto de força máxima da Figura 7.3, constata-se que o valor da tensão calculada foi igual a 353,95 MPa. Tal valor foi obtido na região do centro da treliça, para um deslocamento vertical $\partial_{M}$ de $325 \mathrm{~mm}$, correspondendo a um carregamento aplicado de 161,83 kN. Esta tensão é maior do que o valor de tensão limite de escoamento, ou seja, a estrutura plastifica. Vale ressaltar que, na região do apoio, observa-se a máxima distribuição de 365,18 MPa e, consequentemente, a estrutura continua plastificando nesta zona de apoio. Também foi verificada uma elevada distribuição de tensões nas cordas superior e inferior da treliça.

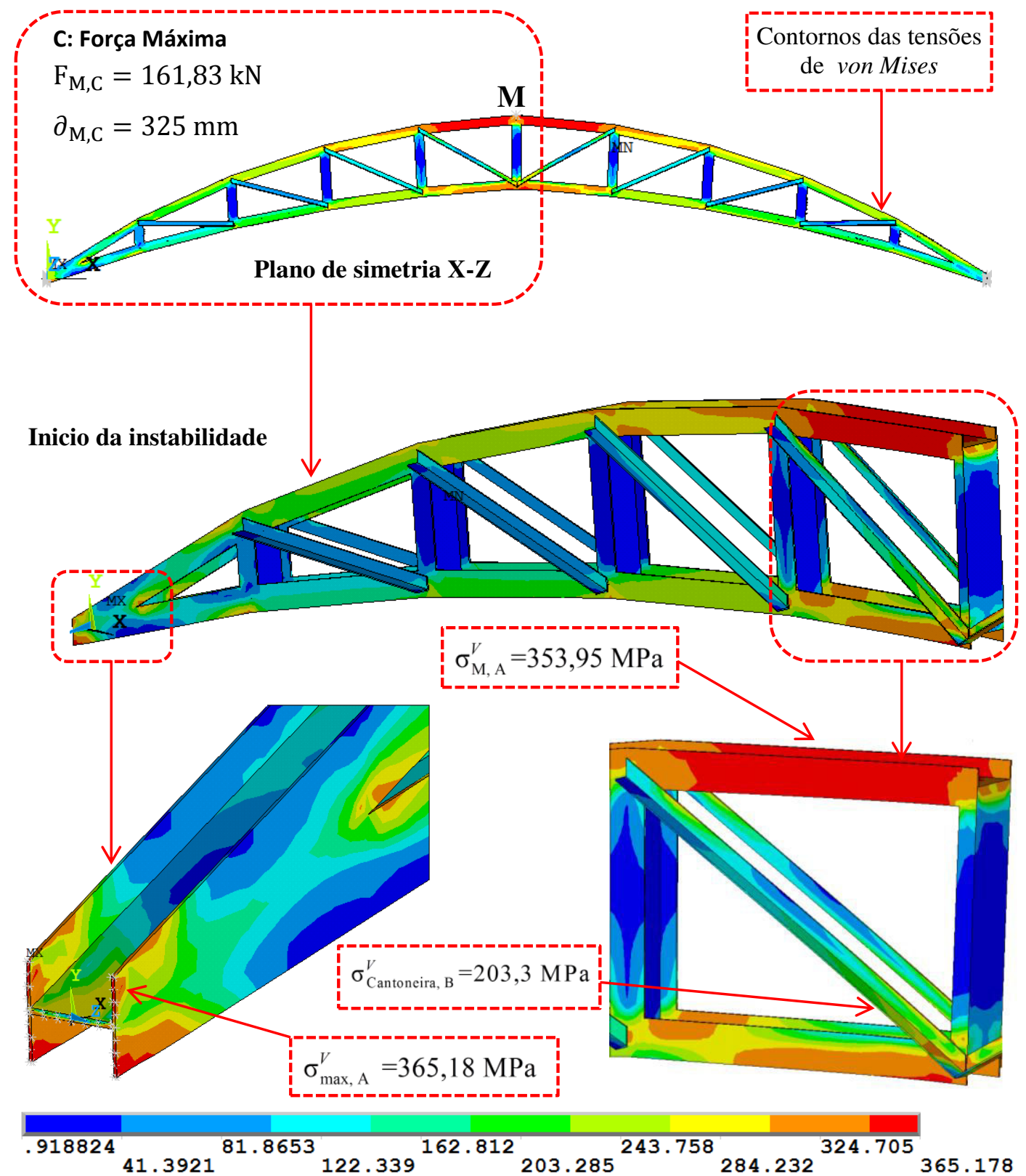

Figura 7.6 Distribuição de tensões de von Mises $(\mathrm{MPa})$ correspondente ao ponto $\mathrm{C}\left(\mathrm{A}_{10}\right)$. 
4. Ponto D: avaliando-se a distribuição das tensões de von Mises da Figura 7.7, referente ao ponto de ruptura mostrado na Figura 7.3, pode-se verificar que o valor da tensão apresentada resultou em 464,54 MPa. Tal valor foi obtido na região do centro da treliça, para um grande deslocamento vertical $\partial_{M}$, de $2.462,4 \mathrm{~mm}$, correspondente a uma força de ruptura igual a 95,47 $\mathrm{kN}$. Essa região apresenta deformações elevadas e os perfis das cordas superior, inferior, montantes e diagonais apresentam estrangulamento e redução da seção. Ressaltando-se que a tensão máxima obtida é de 493,736 MPa, o ponto onde isto ocorre está representado (Figura 7.7) com a nomenclatura MX.

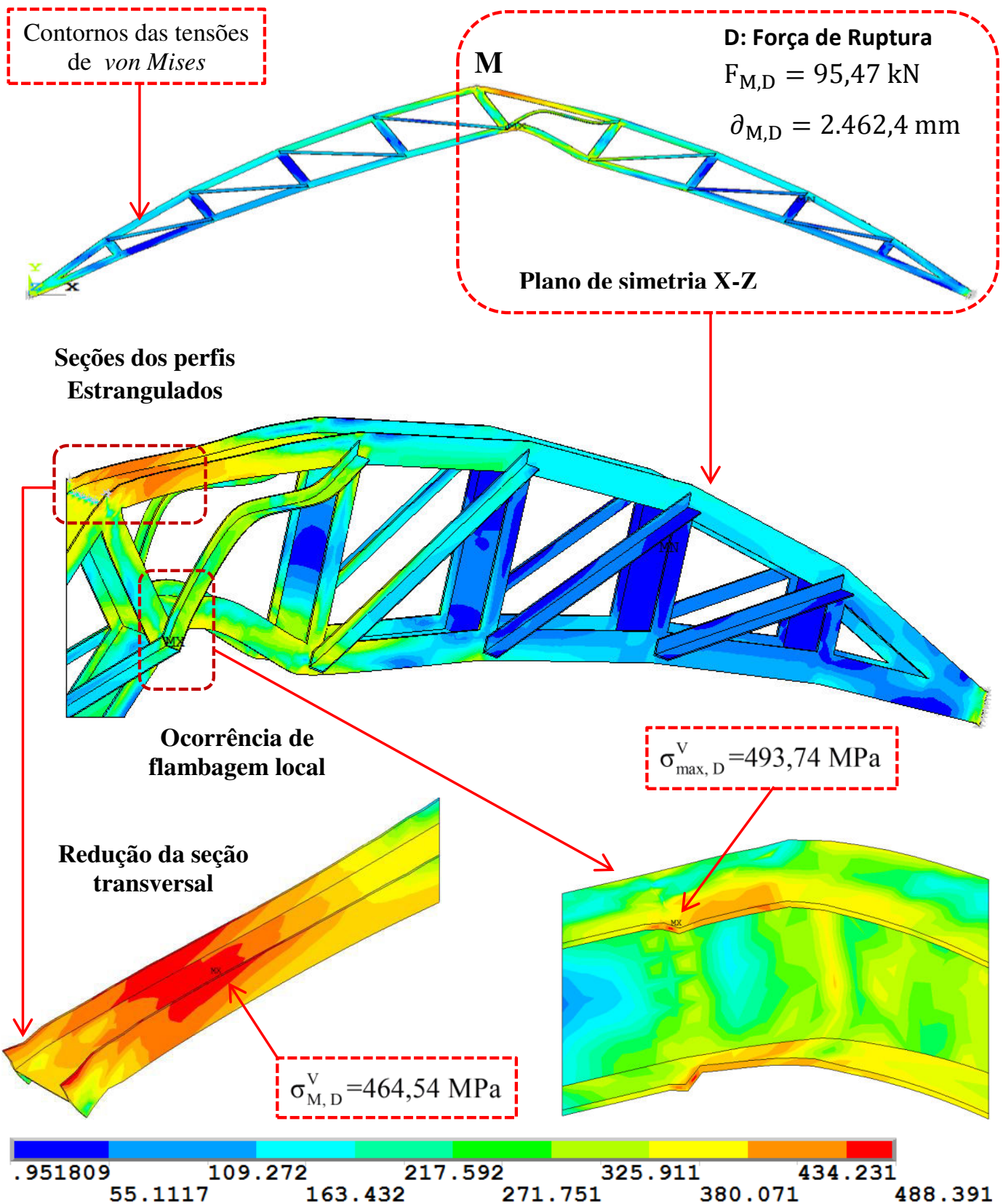

Figura 7.7 Distribuição de tensões de von Mises $(\mathrm{MPa})$ correspondente ao ponto $\mathrm{D}\left(\mathrm{A}_{10}\right)$. 


\subsection{2.}

\section{Treliça de $10 \mathrm{~m}$ protendida $\left(\mathrm{A}_{\mathrm{P} 10}\right)$}

Neste item são apresentados os resultados da análise não linear física para treliça protendida de $10 \mathrm{~m}$ de vão, para vários níveis de força de protensão (Figura 7.8). Os resultados da análise com protensão ótima $(65,37 \mathrm{kN})$ são indicados nas Figuras 7.8 a 7.11. Estas Figuras apresentam as distribuições das tensões de von Mises para cada ponto da curva da força versus deslocamento vertical, em decorrência do deslocamento aplicado no centro (ponto $\mathrm{M}$ ) da treliça.

\subsubsection{1.}

\section{Análise dos níveis de força de protensão para o modelo $A_{P 10}$}

Fazendo uso de cinco variações de forças de protensão $\left(0,1 \mathrm{P}_{\mathrm{opt}} ; 0,25 \mathrm{P}_{\mathrm{opt}}\right.$; $0,50 \mathrm{P}_{\text {opt }} ; 0,75 \mathrm{P}_{\text {opt }}$ e $\left.\mathrm{P}_{\text {opt }}\right)$, a treliça protendida foi modelada com a finalidade de analisar o comportamento da estrutura à medida que o nível da força aumenta, até a sua ruptura para cada nível de protensão. Os resultados são apresentados na Figura 7.8, onde são confrontados os deslocamentos e as forças.

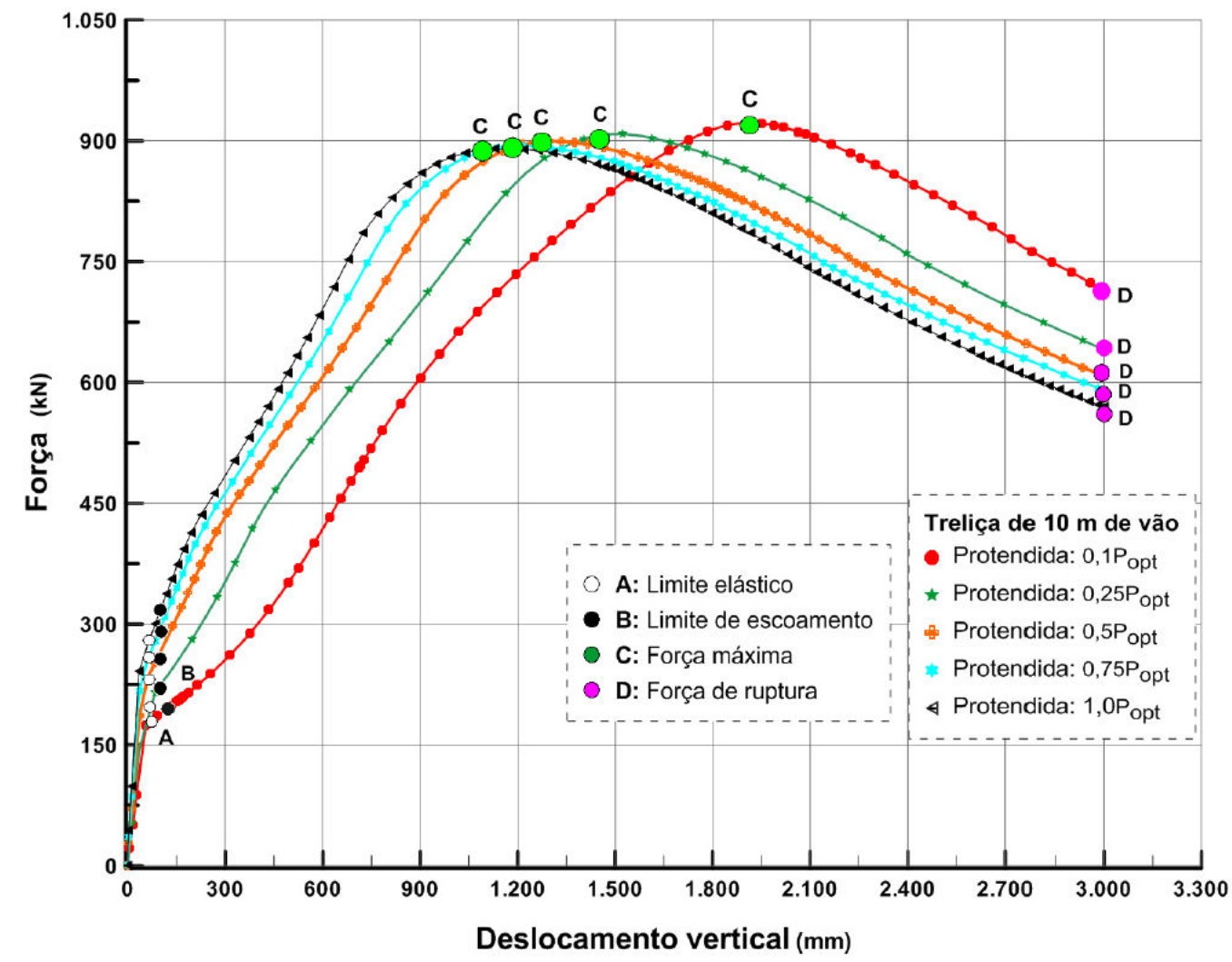

Figura 7.8 Força versus deslocamento vertical do meio do vão da $A_{P 10}$ para vários níveis de protensão. 
A Figura 7.8 apresenta gráficos de forças versus deslocamentos para diferentes níveis de força de protensão obtidas a partir de uma análise não linear física, onde os pontos característicos das curvas são analisados. As principais informações obtidas nestes gráficos são destacadas a seguir:

\section{Ponto A correspondente ao limite elástico}

Para uma variação de forças de protensão de $\mathbf{0 , 1} \mathbf{P}_{\mathbf{o p t}}$ para $\mathbf{0 , 2 5} \mathbf{P}_{\mathbf{o p t}}$, as forças aumentam de 181,19 $\mathrm{kN}$ (com deslocamento 72,64 mm) a 202,4 kN (com deslocamento de $60 \mathrm{~mm}$ ), ou seja, um acréscimo de 11,7\%.

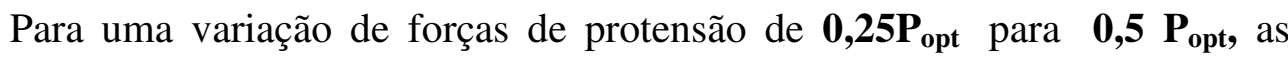
forças aumentam de 202,4 $\mathrm{kN}$ (com deslocamento $60 \mathrm{~mm}$ ) a 232,8 $\mathrm{kN}$ (com deslocamento de $60 \mathrm{~mm}$ ), ou seja, um acréscimo de 15,02\%.

Para uma variação de forças de protensão de $\mathbf{0 , 5} \mathbf{P}_{\mathbf{o p t}}$ para $\mathbf{0 , 7 5} \mathbf{P}_{\mathbf{o p t}}$, as forças aumentam de 232,8 $\mathrm{kN}$ (com deslocamento $60 \mathrm{~mm}$ ) a 255,3 kN (com deslocamento de $60 \mathrm{~mm}$ ), ou seja, um acréscimo de 9,67\%.

Para uma variação de forças de protensão de $\mathbf{0 , 7 5} \mathbf{P}_{\mathbf{o p t}}$ para $\mathbf{P}_{\mathbf{o p t}}$, as forças aumentam de 255,3 $\mathrm{kN}$ (com deslocamento $60 \mathrm{~mm}$ ) a 273,265 kN (com deslocamento de $60 \mathrm{~mm}$ ), ou seja, um acréscimo de 7,04\%.

\section{Ponto B correspondente ao limite de escoamento}

Para uma variação de forças de protensão de $\mathbf{0 , 1} \mathbf{P}_{\mathbf{o p t}}$ para $\mathbf{0 , 2 5} \mathbf{P}_{\mathbf{o p t}}$, as forças aumentam de 185,95 $\mathrm{kN}$ (com deslocamento 89,47 mm) a 215,15 kN (com deslocamento de $84 \mathrm{~mm}$ ), ou seja, um acréscimo de 15,71\%.

Para uma variação de forças de protensão de $\mathbf{0 , 2 5} \mathbf{P}_{\mathbf{o p t}}$ para $\mathbf{0 , 5} \mathbf{P}_{\mathbf{o p t}}$, as forças aumentam de 215,15 kN (com deslocamento $84 \mathrm{~mm}$ ) a 252,11 kN (com deslocamento de $84 \mathrm{~mm}$ ), ou seja, um acréscimo de 17,18\%. 
Para uma variação de forças de protensão de $\mathbf{0 , 5} \mathbf{P}_{\mathbf{o p t}}$ para $\mathbf{0 , 7 5} \mathbf{P}_{\mathbf{o p t}}$, as forças aumentam de 252,11 kN (com deslocamento $84 \mathrm{~mm}$ ) a 279,14 kN (com deslocamento de $84 \mathrm{~mm}$ ), ou seja, um acréscimo de 10,72\%.

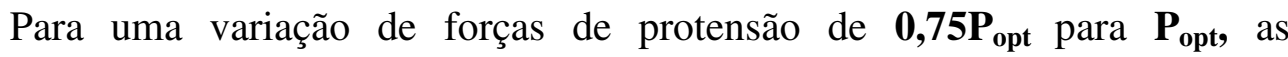
forças aumentam de 279,14 $\mathrm{kN}$ (com deslocamento $84 \mathrm{~mm}$ ) a $300,12 \mathrm{kN}$ (com deslocamento de $84 \mathrm{~mm}$ ), ou seja, um acréscimo de 7,51\%.

\section{Ponto $\mathrm{C}$ correspondente à força máxima (Inicia da instabilidade)}

Para uma variação de forças de protensão de $\mathbf{0 , 1} \mathbf{P}_{\text {opt }}$ para $\mathbf{0 , 2 5} \mathbf{P}_{\mathbf{o p t}}$, as forças diminuem de 922,32 $\mathrm{kN}$ (com deslocamento 1.905,39 mm) para 908,75 kN (com deslocamento de 1.492,93 mm), ou seja, uma redução de 1,47\%.

Para uma variação de forças de protensão de $\mathbf{0 , 2 5} \mathbf{P}_{\mathbf{o p t}}$ para $\mathbf{0 , 5} \mathbf{P}_{\mathbf{~ o p t}}$, as forças diminuem de $908,75 \mathrm{kN}$ (com deslocamento $1.492,93 \mathrm{~mm}$ ) a $899,44 \mathrm{kN}$ (com deslocamento de 1.295,2 mm), ou seja, uma redução de 1,02\%.

Para uma variação de forças de protensão de $\mathbf{0 , 5} \mathbf{P}_{\mathbf{o p t}}$ para $\mathbf{0 , 7 5} \mathbf{P}_{\mathbf{o p t}}$, as forças diminuem de $899,44 \mathrm{kN}$ (com deslocamento $1.295,2 \mathrm{~mm}$ ) a $893,71 \mathrm{kN}$ (com deslocamento de 1.217,09 mm), ou seja, uma redução de 0,64\%.

Para uma variação de forças de protensão de $\mathbf{0 , 7 5} \mathbf{P}_{\mathbf{o p t}}$ para $\mathbf{P}_{\mathbf{o p t}}$, as forças diminuem de $893,71 \mathrm{kN}$ (com deslocamento $1.217,09 \mathrm{~mm}$ ) a 890,51 kN (com deslocamento de 1.151,63 mm), ou seja, uma redução de 0,36\%. 


\section{Ponto $D$ correspondente à força de ruptura final:}

Para uma variação de forças de protensão de $\mathbf{0 , 1} \mathbf{P}_{\mathbf{o p t}}$ para $\mathbf{0 , 2 5} \mathbf{P}_{\mathbf{o p t}}$, as forças diminuem de 715,34 $\mathrm{kN}$ (com deslocamento $3.000 \mathrm{~mm}$ ) para 640,88 $\mathrm{kN}$ (com deslocamento de $3.000 \mathrm{~mm}$ ), ou seja, uma redução de 10,41\%.

Para uma variação de forças de protensão de $\mathbf{0 , 2 5} \mathbf{P}_{\mathbf{o p t}}$ para $\mathbf{0 , 5} \mathbf{P}_{\mathbf{o p t}}$, as forças diminuem de 640,88 $\mathrm{kN}$ (com deslocamento $3.000 \mathrm{~mm}$ ) a 608,03 $\mathrm{kN}$ (com deslocamento de $3.000 \mathrm{~mm}$ ), ou seja, uma redução de 5,13\%.

Para uma variação de forças de protensão de $\mathbf{0 , 5} \mathbf{P}_{\mathbf{o p t}}$ para $\mathbf{0 , 7 5} \mathbf{P}_{\mathbf{~ o p t}}$, as forças diminuem de $608,03 \mathrm{kN}$ (com deslocamento $3.000 \mathrm{~mm}$ ) a 590,35 kN (com deslocamento de $3.000 \mathrm{~mm}$ ), ou seja, uma redução de $2,91 \%$.

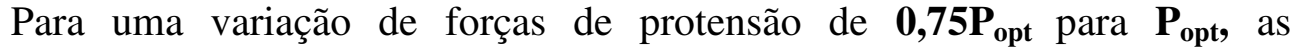
forças diminuem de 590,35 $\mathrm{kN}$ (com deslocamento $3.000 \mathrm{~mm}$ ) a $569,79 \mathrm{kN}$ (com deslocamento de $3.000 \mathrm{~mm}$ ), ou seja, uma redução de 3,48\%.

A Tabela 7.1 apresenta um resumo dos resultados obtidos a partir dos níveis de protensão para a treliça de $10 \mathrm{~m}$, no que diz respeito às forças protendidas nos pontos de limite elástico, de escoamento, de força máxima e de ruptura da análise não linear física. Ressalta-se que o efeito da protensão influenciou significativamente as forças da estrutura.

Tabela 7.1 Níveis de força de protensão da treliça $\mathrm{A}_{10}$.

\begin{tabular}{cccccc}
\hline \multirow{2}{*}{$\begin{array}{c}\text { Pontos das } \\
\text { curvas }\end{array}$} & $0,1 \mathrm{P}_{\mathrm{opt}}$ & $0,25 \mathrm{P}_{\mathrm{opt}}$ & $0,50 \mathrm{Popt}$ & $0,75 \mathrm{P}_{\mathrm{opt}}$ & $1,0 \mathrm{P}_{\mathrm{opt}}$ \\
\cline { 2 - 6 } & $(\mathrm{kN})$ & $(\mathrm{kN})$ & $(\mathrm{kN})$ & $(\mathrm{kN})$ & $(\mathrm{kN})$ \\
\hline A & 181,19 & 202,4 & 232,8 & 255,3 & 273,27 \\
B & 185,95 & 215,15 & 252,11 & 279,14 & 300,12 \\
C & 922,32 & 908,75 & 899,44 & 893,71 & 890,51 \\
D & 715,34 & 640,88 & 608,03 & 590,35 & 569,79 \\
\hline
\end{tabular}


Em conclusão, os resultados apresentados na Tabela 7.1 mostram as variações de forças de ganho devido ao efeito dos níveis de forças de protensão solicitadas na estrutura. A partir dos resultados obtidos nesta análise, destacam-se:

No limite de elasticidade há ganho de força à medida que se aumenta a força de protensão até ótima. Ressaltando-se que, comparando $10 \%$ da força de protensão com ótima, a força aumenta de $181,19 \mathrm{kN}$ a $273,27 \mathrm{kN}$, ou seja, uma diferença de força de $50,81 \%$.

Para limite de escoamento, ganho de força à medida que um aumenta a força de protensão até ótima. Ressaltando-se que comparando $10 \%$ da força de protensão com ótima, a força aumenta de $185,95 \mathrm{kN}$ a $300,12 \mathrm{kN}$, ou seja, uma diferença de força $61,4 \%$.

Com referência à força máxima e de ruptura, nesses pontos apresenta-se uma redução de força leve aproximadamente de 3,5\%, à medida que um aumenta a força de protensão até ótima. Observa-se que a estrutura rompe com o mesmo deslocamento $(3.000 \mathrm{~mm})$ com forças diferentes de rupturas.

7.1.2.2.

Treliça de $10 \mathrm{~m}$ com protensão ótima $\left(\mathrm{A}_{\mathrm{P} 10}\right)$

As Figuras 7.4 até 7.7 apresentam as distribuições das tensões de von Mises para todos os pontos da curva força $v s$ deslocamento, obtidas na análise não linear física da treliça protendida $\left(\mathrm{P}_{\mathrm{opt}}\right)$ de $10 \mathrm{~m}$ de vão. Tais resultados foram provocados pelo deslocamento aplicado no centro da treliça e pela força de protensão ótima (ver capítulo 4, item 4.2). Nesta seção é realizada uma análise com respeito aos pontos característicos da curva segundo a Figura 7.3. 
1. Ponto A: com base nos resultados obtidos, a Figura 7.9 ilustra a distribuição das tensões de von Mises, referente ao ponto do limite de elasticidade da Figura 7.3 , onde se observa que o valor da tensão calculada foi igual a $344,75 \mathrm{MPa}$ (correspondente a um carregamento aplicado de $273,27 \mathrm{kN}$ ) na região onde foi aplicado o deslocamento vertical $\partial_{\mathrm{M}}$ de $60 \mathrm{~mm}$. Ess tensão é menor que o valor de tensão limite do escoamento, ou seja, não há plastificação da estrutura nesta área. Observa-se que, na chapa de ancoragem da treliça protendida, apresenta grandes concentrações de tensões, onde se tem maior tensão de $346,49 \mathrm{MPa}$. O ponto onde isso ocorre está representado na Figura 7.9 com a nomenclatura MX.

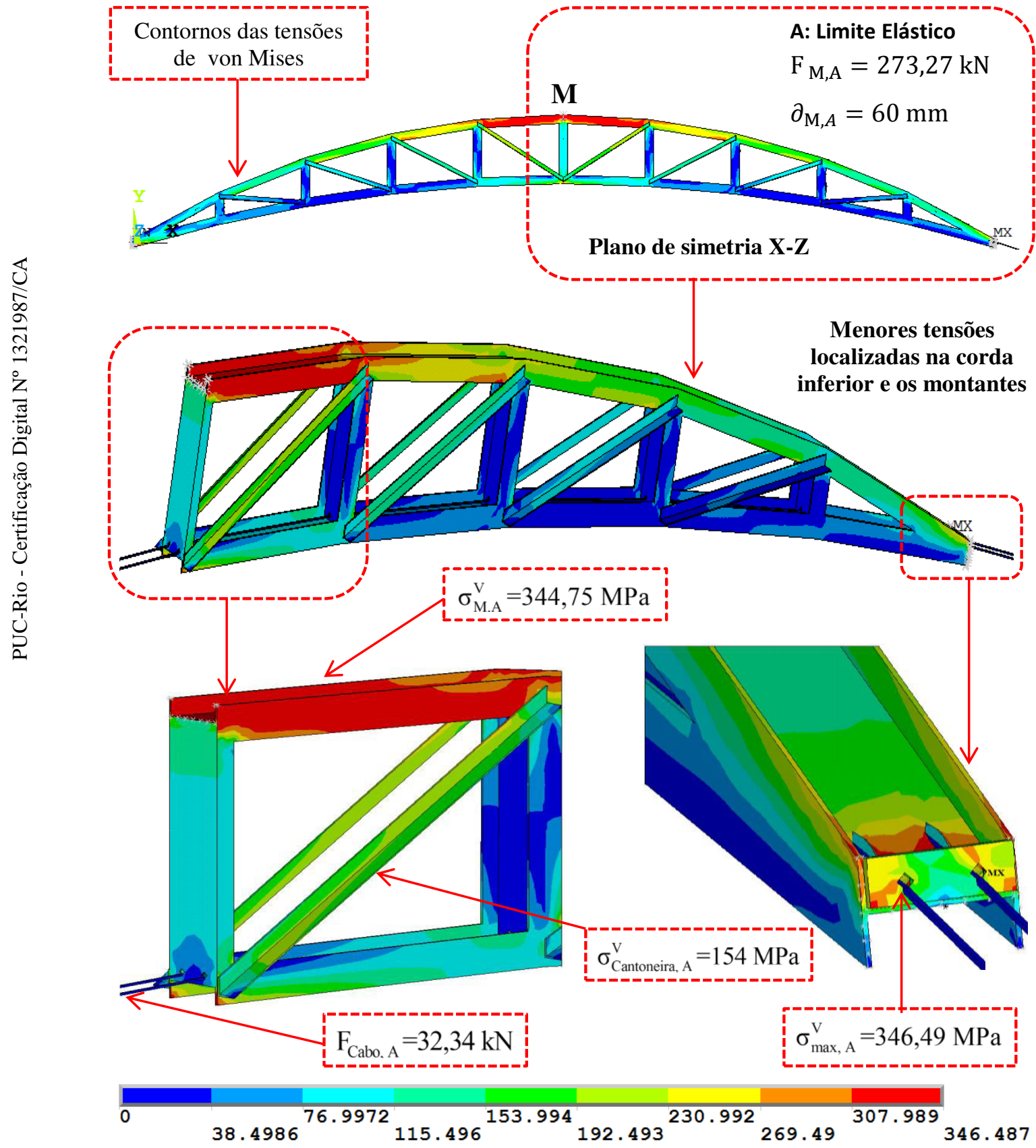

Figura 7.9 Distribuição de tensões de von Mises $(\mathrm{MPa})$ correspondente ao ponto $\mathrm{A}\left(\mathrm{A}_{\mathrm{P} 10}\right)$. 
2. Ponto B: na Figura 7.10 percebe-se que há um aumento da distribuição das tensões de von Mises no que se refere ao ponto de limite de escoamento (Figura 7.3). Na região do centro da treliça $\partial_{M}$, foi observado que o valor da tensão calculada resultou em 345,51MPa (a um carregamento aplicado de 300,12 $\mathrm{kN}$ ) para um deslocamento vertical de $84 \mathrm{~mm}$. Essa tensão é próxima do valor da tensão limite de escoamento, ou seja, não há plastificação da estrutura. Vale ressaltar que na região da chapa de ancoragem, identifica-se a elevada distribuição de 356,85 MPa (ponto MX) que, por sua vez, excede o valor limite de escoamento, fazendo com que a estrutura continue plastificando nesta zona.

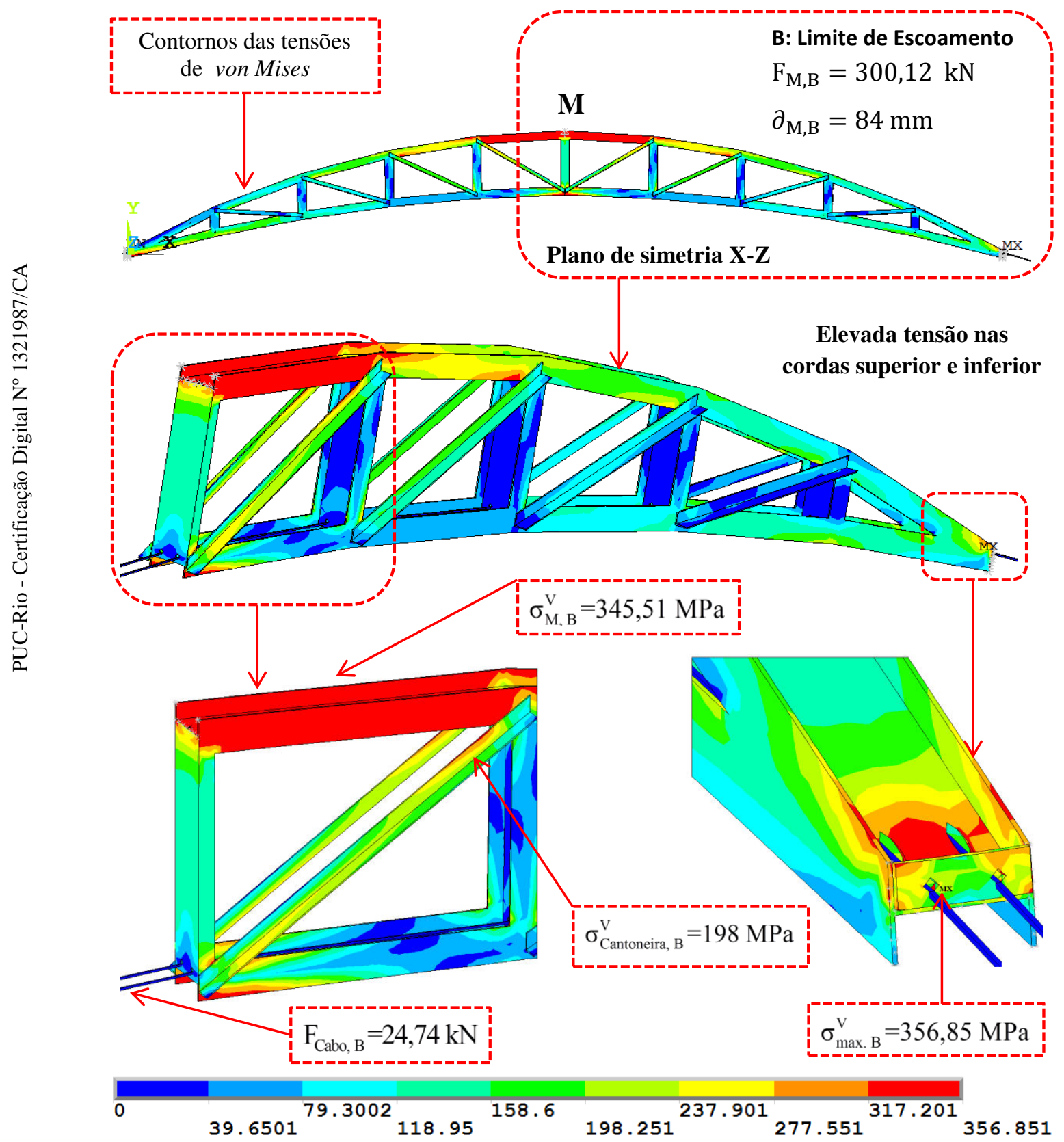

Figura 7.10 Distribuição de tensões de von Mises $(\mathrm{MPa})$ correspondente ao ponto $\mathrm{B}\left(\mathrm{A}_{\mathrm{P} 10}\right)$. 
3. Ponto C: observando-se a distribuição das tensões de von Mises da Figura 7.11 referente ao ponto de força máxima da Figura 7.3, constata-se que o valor da tensão calculada foi igual a 522,84 MPa. Tal valor foi obtido na região do centro da treliça $\partial_{M}$ para um deslocamento vertical de 1.151,63 mm, correspondendo a um carregamento aplicado de 890,51 kN. Essa tensão é maior do que o valor de tensão limite de escoamento, fazendo com que a estrutura plastifique. Vale ressaltar que, na região da chapa da treliça, observa-se a máxima distribuição 941,23 MPa e, consequentemente, a estrutura continua plastificando nesta zona da chapa. O ponto onde isto ocorre está representado com a nomenclatura MX.

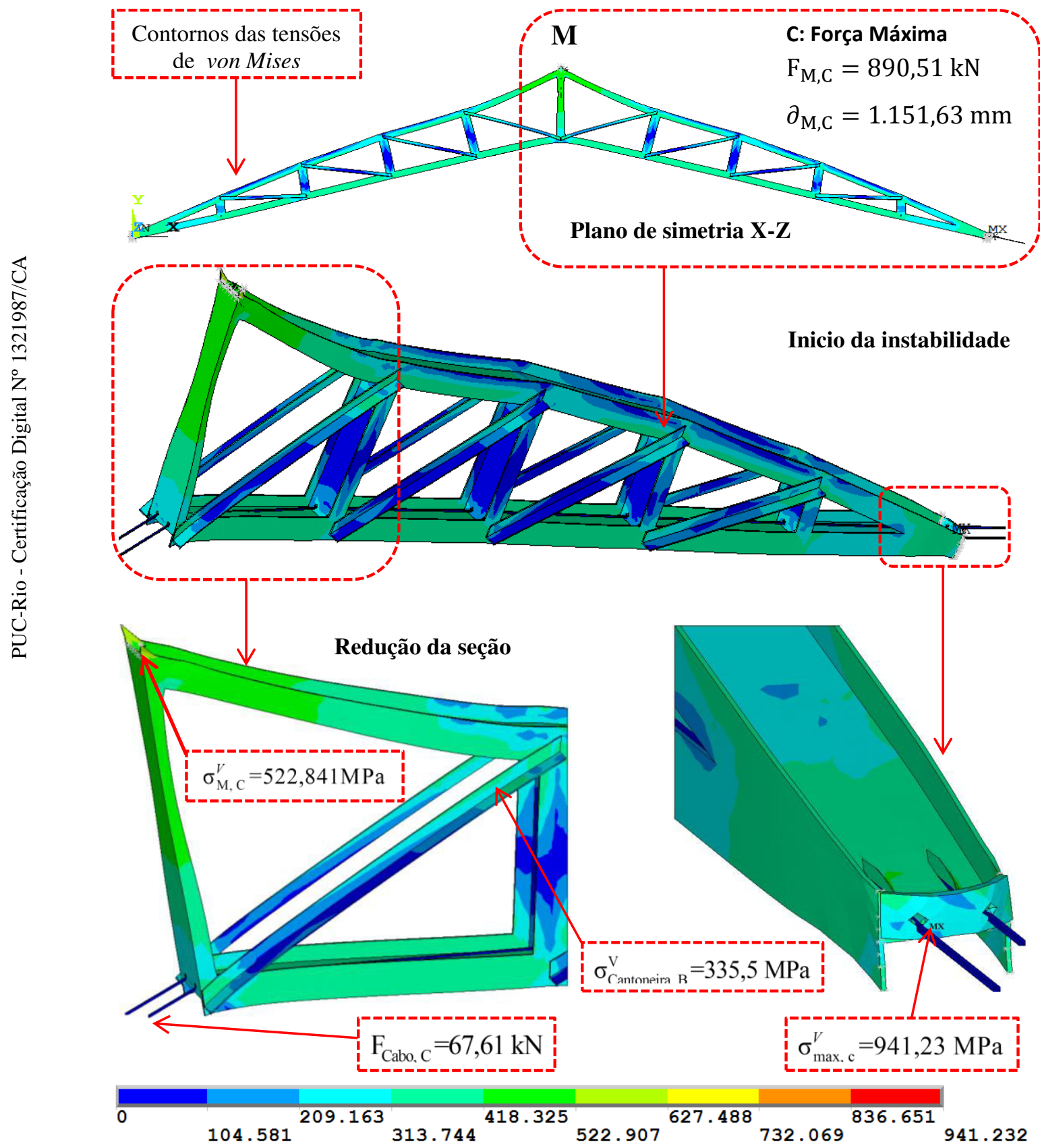

Figura 7.11 Distribuição de tensões de von Mises $(\mathrm{MPa})$ correspondente ao ponto $\mathrm{C}\left(\mathrm{A}_{\mathrm{P} 10}\right)$. 
4. Ponto D: avaliando-se a distribuição das tensões de von Mises da Figura 7.12 referente ao ponto de ruptura mostrado na Figura 7.3, pode-se verificar que o valor da tensão apresentada resultou em 960,8 MPa. Tal valor foi obtido na região do centro da treliça, para um grande deslocamento vertical de $3.000 \mathrm{~mm}$, correspondente a uma força de ruptura igual a 769,79 kN. Essa região apresenta deformações elevadas e os perfis das cordas superior, inferior, montantes e diagonais mostram estrangulamento e redução da seção. Ressalta-se que a tensão máxima onde ocorre está representada com a nomenclatura MX.

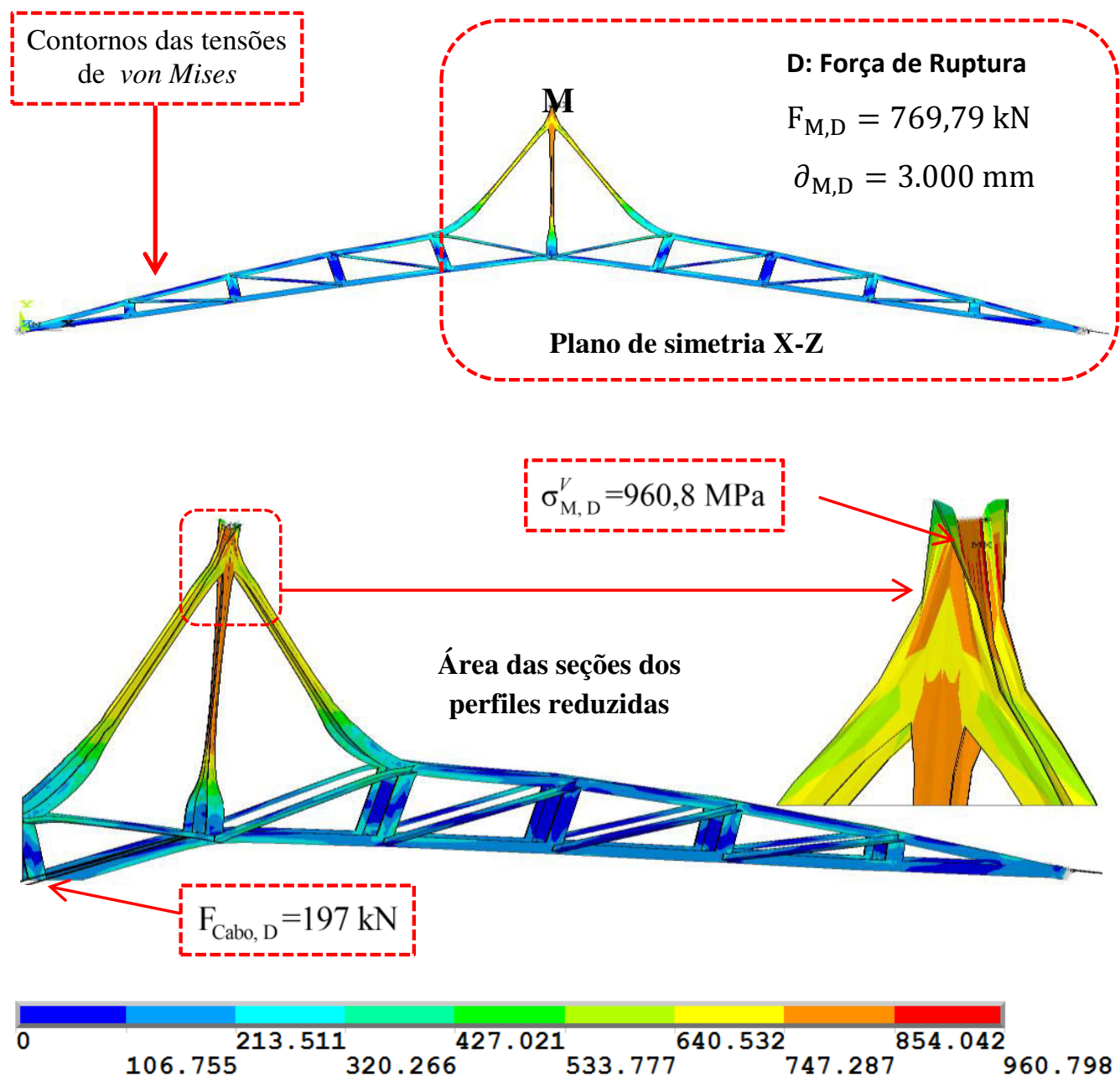

Figura 7.12 Distribuição de tensões de von Mises $(\mathrm{MPa})$ correspondente ao ponto $\mathrm{D}\left(\mathrm{A}_{\mathrm{P} 10}\right)$.

Com base na sequência das simulações numéricas realizadas, a Tabela 7.2 apresenta um resumo dos resultados obtidos no que se refere a forças e deslocamentos nos pontos de limite elástico, escoamento, força máxima e ruptura no centro do vão para a treliça de 10 m, sem e com protensão. 
Tabela 7.2 Resumo dos resultados das forças e deslocamentos da treliça $10 \mathrm{~m}$ sem e com protensão nos pontos das curvas (Figura 7.3).

\begin{tabular}{|c|c|c|c|c|c|}
\hline \multirow{2}{*}{$\begin{array}{c}\text { Pontos das } \\
\text { curvas }\end{array}$} & \multicolumn{2}{|c|}{ Treliça sem Protensão } & \multicolumn{2}{|c|}{ Treliça com Protensão } & \multirow{2}{*}{$\begin{array}{l}\text { \% Razão } \\
\text { de força }\end{array}$} \\
\hline & $\begin{array}{l}\text { Força } \\
(\mathrm{KN})\end{array}$ & $\begin{array}{c}\text { Deslocamento } \\
(\mathrm{mm})\end{array}$ & $\begin{array}{l}\text { Força } \\
(\mathrm{KN})\end{array}$ & $\begin{array}{l}\text { Deslocamento } \\
(\mathrm{mm})\end{array}$ & \\
\hline $\begin{array}{c}\text { A: } \\
\text { (Limite elástico) }\end{array}$ & 157,68 & 75 & 273,27 & 60 & 73,3 \\
\hline $\begin{array}{l}\text { B: } \\
\text { (Limite escoamento }\end{array}$ & 158,92 & 100 & 300,12 & 84 & 88,9 \\
\hline $\begin{array}{c}\text { C: } \\
\text { (Força máxima) }\end{array}$ & 161,83 & 325 & 890,51 & 1.152 & 450,3 \\
\hline $\begin{array}{c}\text { D: } \\
\text { (Força ruptura) }\end{array}$ & 95,47 & 2.462 & 769,79 & 3.000 & 706,3 \\
\hline
\end{tabular}

Os resultados das Tabelas 7.1 e 7.2 apresentam um resumo das forças e deslocamentos para diferentes pontos da curva carga versus deslocamento nos trechos elástico e plástico para o modelo da treliça de $10 \mathrm{~m}$ sem e com protensão (com variação da força de protensão até o nível ótimo). Cabe notar o benefício fornecido para a treliça de aço pela incorporação de cabos de protensão.

Observa-se que a Tabela 7.1 mostra os resultados das variações de força de protensão: à medida que há aumento dos níveis de esforço de protensão, há um ganho na capacidade de carga que contribui para um aumento significativo da rigidez na estrutura. Este resultado confirma as conclusões do Projeto HILONG "HSS trusses to be tested at Imperial College" (Gkantou et al., 2015).

Analisando-se a Tabela 7.2 verifica-se que, com força máxima referente ao trecho linear, a carga aumenta significativamente, com valor médio de $81,1 \%$ para treliça sem e com protensão $\mathrm{P}_{\text {opt }}$. Ressalta-se para todos os casos, que os deslocamentos na treliça no meio do vão na carga final diminuem significativamente quando a força de protensão é atribuída na presença dos cabos na corda inferior. Estes resultados confirmam as conclusões de Belenya (1997) e de Troitsky (1990) de que os sistemas de treliças protendidas oferecem grande redução de deslocamentos verticais da estrutura. 


\section{2.}

\section{Análise não linear da treliça de $\mathbf{2 0}$ m de vão}

A análise não linear para a treliça de $20 \mathrm{~m}$ de vão sem e com protensão foi executada a partir da aplicação de deslocamento no centro da treliça. $\mathrm{Na}$ Figura 7.13 são mostrados um modelo de treliça, as condições de contorno e a aplicação do deslocamento. Também é mostrada uma ampliação da estrutura na parte em que está se aplicando o deslocamento.

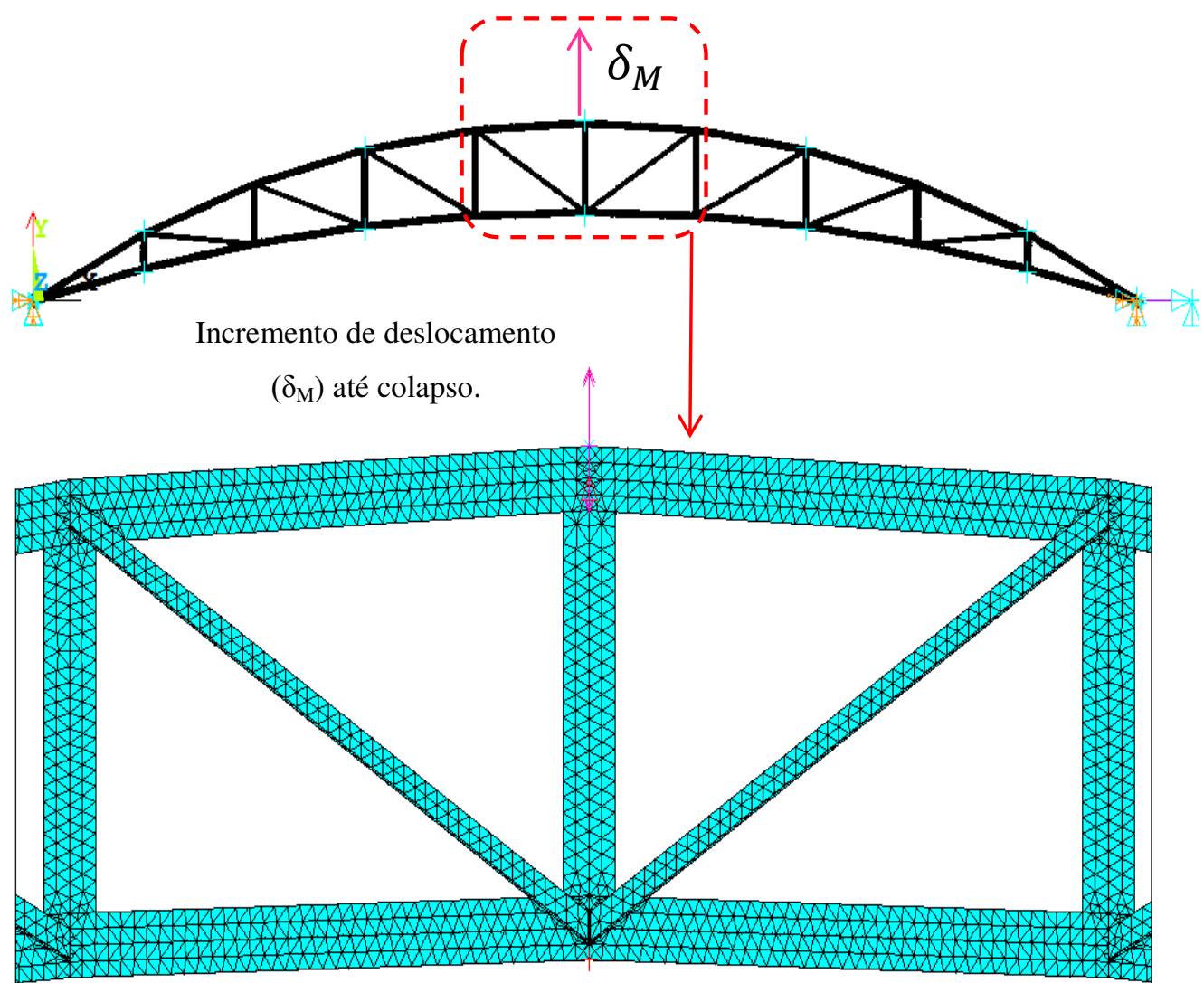

Figura 7.13 Deslocamento vertical aplicado no centro da treliça $\mathrm{B}_{20}$.

A Figura 7.14 apresenta as curvas carga versus deslocamento da treliça de 20 m de vão, sem e com protensão na corda inferior, onde o carregamento foi aplicado através de incremento de deslocamento vertical até atingir a ruptura da treliça, utilizando-se como critério de convergência a norma de deslocamentos. É terem cargas máximas superiores à curva da treliça sem protensão. 


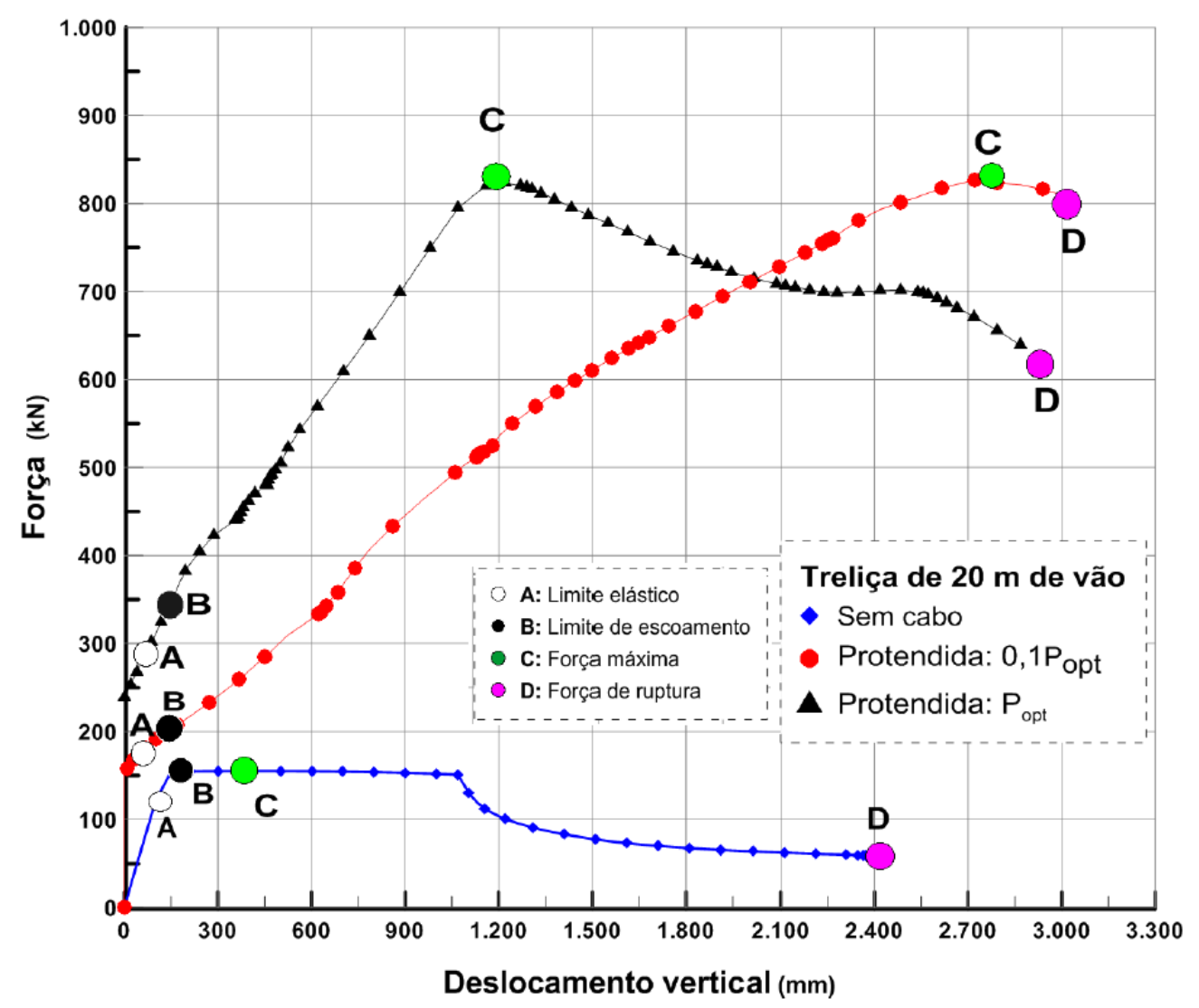

Figura 7.14 Força versus deslocamento vertical do meio do vão de $\mathrm{B}_{20}$ sem e com protensão.

$\mathrm{Na}$ Figura 7.14, referente às curvas, nos pontos traçados $\mathbf{A}$ (limite elasticidade), $\mathbf{B}$ (limite de escoamento), $\mathbf{C}$ (força máxima) e $\mathbf{D}$ (força de ruptura) são mostradas as forças e deslocamentos em trecho linear e não linear nas treliças sem e com protensão de $20 \mathrm{~m}$. Na sequência do estudo, as Figuras 7.15 até 7.22 mostram os resultados das tensões correspondentes às forças e deslocamentos dos pontos das curvas.

\subsection{1.}

\section{Treliça de $20 \mathrm{~m}$ sem protensão $\left(B_{20}\right)$}

Nas Figuras 7.15 até 7.18 são apresentados os resultados das distribuições das tensões de von Mises para diversos pontos da curva força versus deslocamento vertical aplicado no centro para a treliça de $20 \mathrm{~m}$ de vão sem protensão. Os resultados dos pontos característicos importantes das curvas da Figura 7.14 são analisados nesta seção. 
1. Ponto A: com base nos resultados obtidos, a Figura 7.15 ilustra a distribuição das tensões de von Mises referente ao ponto do limite de elasticidade da Figura 7.14 , onde se observa que o valor da tensão calculada foi igual a 338,24 MPa (correspondente a um carregamento aplicado de $127,5 \mathrm{kN}$ ) na região onde foi aplicado o deslocamento vertical de 50,07 mm. Essa tensão é menor que ao valor de tensão limite do escoamento do material usado. Também se nota que o apoio da treliça sem protensão apresenta grandes concentrações de tensões, no qual a maior tensão resultou em 348,72 MPa. Esse valor excede o valor limite de escoamento e, portanto, a treliça começa a se plastificar nesta área.

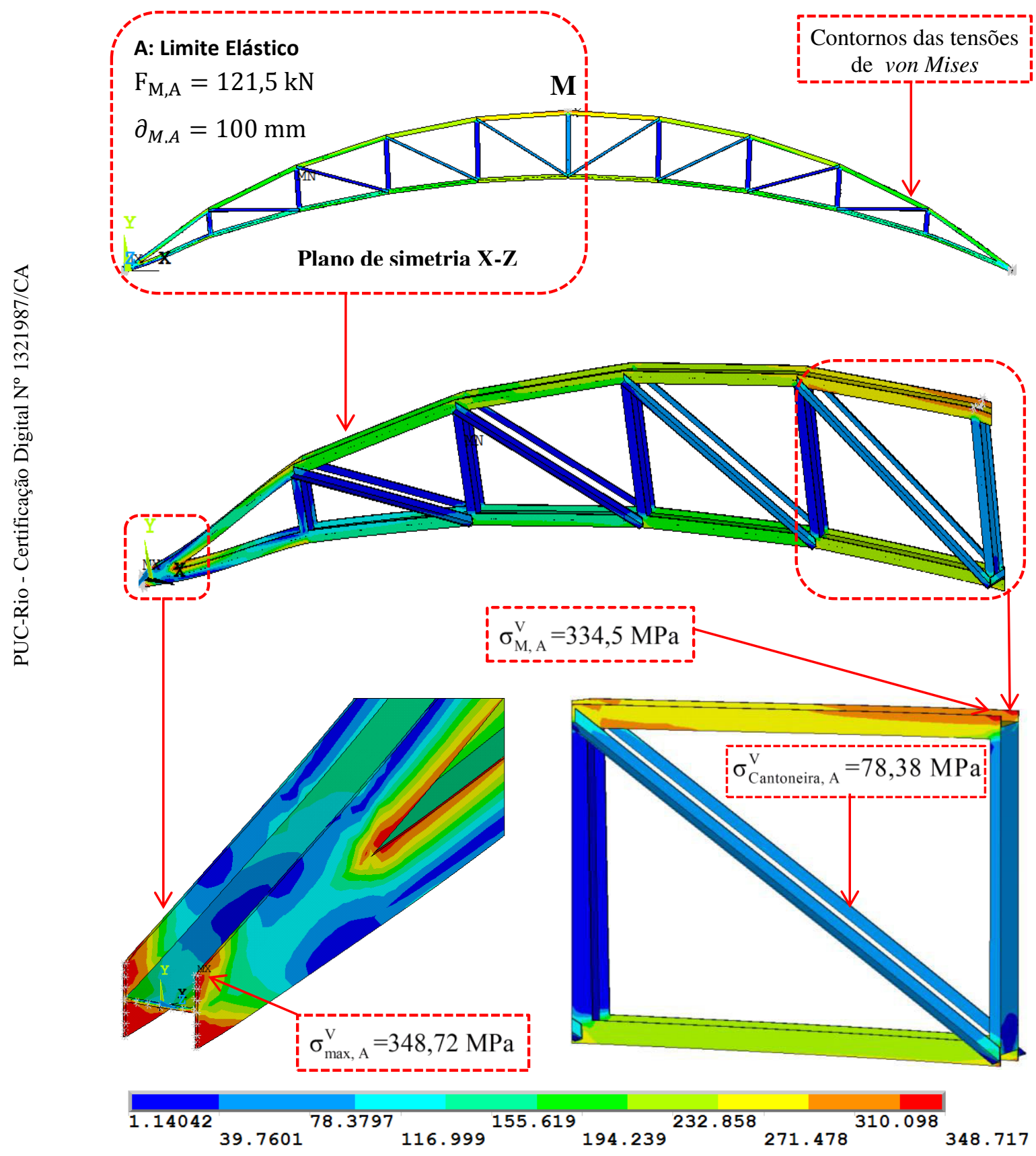

Figura 7.15 Distribuição de tensões de von Mises (MPa) correspondente ao ponto $\mathrm{A}\left(\mathrm{B}_{20}\right)$. 
2. Ponto B: na Figura 7.16 percebe-se que há um aumento da distribuição das tensões de von Mises no que se refere ao ponto de limite de escoamento (Figura 7.14). Na região do centro da treliça $\partial_{M}$, foi observado que o valor da tensão calculada resultou em $345,11 \mathrm{MPa}$ (correspondente a um carregamento aplicado de 154,3 kN) para um deslocamento vertical de $150 \mathrm{~mm}$. Essa tensão é próxima do valor da tensão limite de escoamento, ou seja, não há plastificação da estrutura. Vale ressaltar que na região do apoio identifica-se a elevada distribuição de 350,21 MPa, que, por sua vez excede o valor limite de escoamento, fazendo com que a estrutura continue plastificando-se nessa zona.
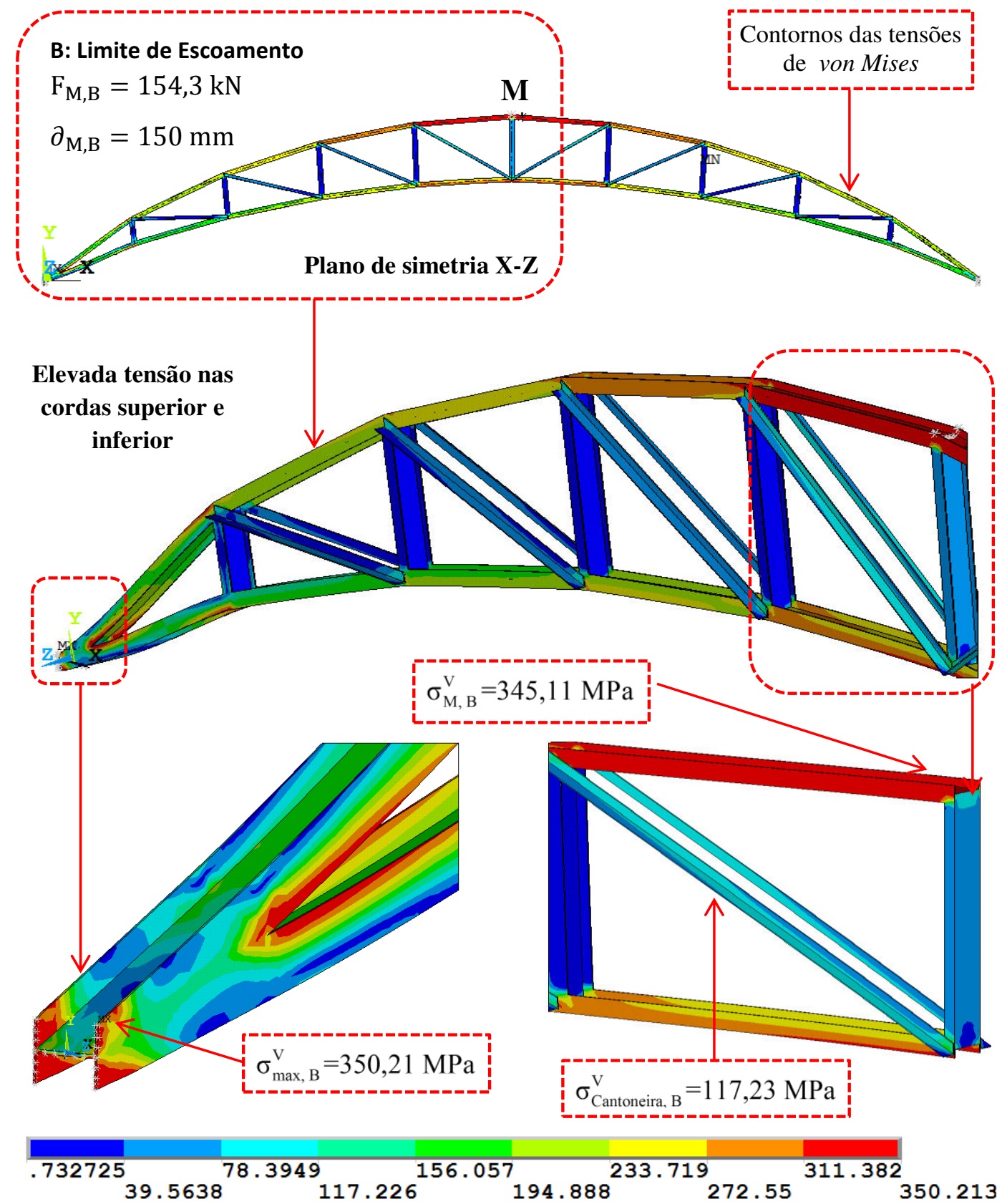

Figura 7.16 Distribuição de tensões de von Mises $(\mathrm{MPa})$ correspondente ao ponto $\mathrm{B}\left(\mathrm{B}_{20}\right)$. 
3. Ponto C: observando-se a distribuição das tensões de von Mises da Figura 7.17 referente ao ponto de força máxima da Figura 7.14, constata-se que o valor da tensão calculada foi igual a 354,26 MPa. Tal valor foi obtido na região do centro da treliça, para um deslocamento vertical $\partial_{M}$ de 400,63 mm, correspondendo a um carregamento aplicado de $155,23 \mathrm{kN}$. Essa tensão é maior do que o valor de tensão limite de escoamento, ou seja, a estrutura começa a plastificar. Vale ressaltar que, na região do apoio, observa-se a máxima distribuição de 358,17 MPa (nomenclatura MX) e, consequentemente, a estrutura continua plastificando nessa zona de apoio. Também foi verificada uma elevada distribuição de tensões nas cordas superior e inferior da treliça. Ressaltando-se que nas diagonais se apresentam menores tensões.

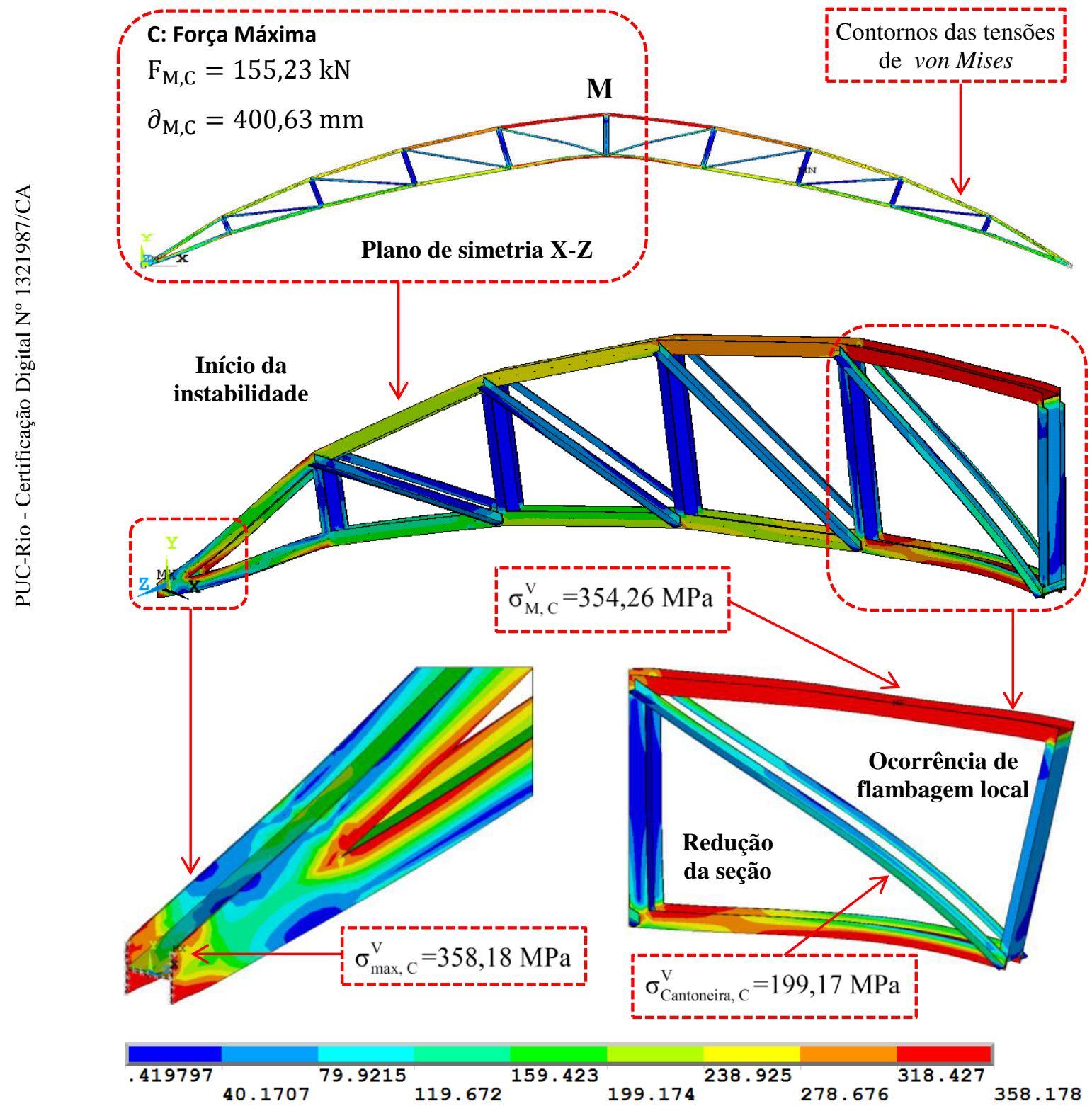

Figura 7.17 Distribuição de tensões de von Mises (MPa) correspondente ao ponto $\mathrm{C}$ ( $\mathrm{B}_{20}$ ). 
4. Ponto D: avaliando-se a distribuição das tensões de von Mises da Figura 7.18 referente ao ponto de ruptura mostrado na Figura 7.14, pode-se verificar que o valor da tensão apresentada resultou em 381,21 MPa. Tal valor foi obtido na região do centro da treliça, para um grande deslocamento vertical de 2.462,4 mm, correspondente a uma força de ruptura igual a 95,47 kN. Essa região apresenta deformações elevadas e os perfis das cordas superior, inferior, montantes e diagonais apresentam estrangulamento e redução da seção. Ressaltando-se que a tensão máxima de distribuição de 443,73 MPa está representado com a nomenclatura MX.

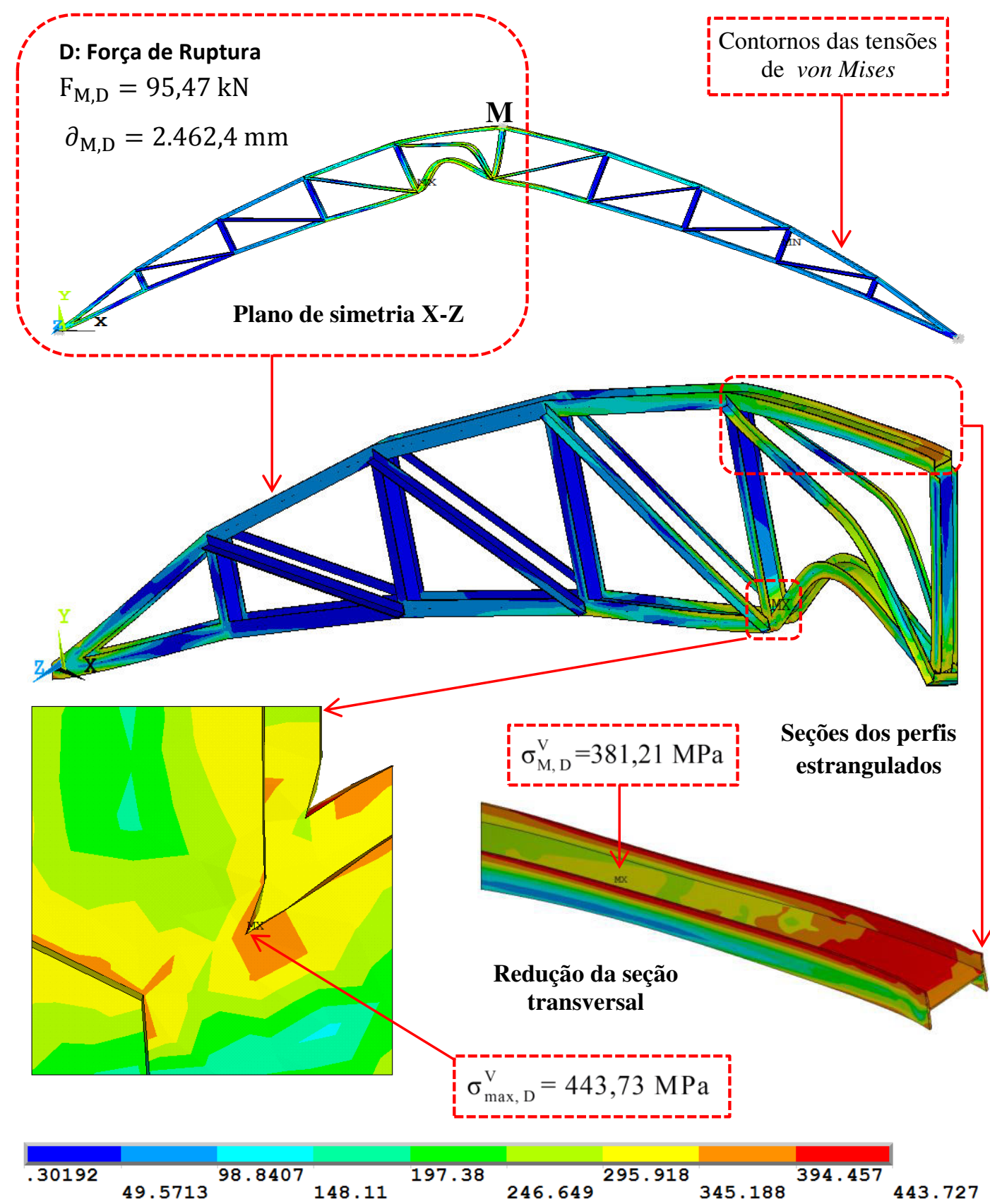

Figura 7.18 Distribuição de tensões de von Mises $(\mathrm{MPa})$ correspondente ao ponto $\mathrm{D}\left(\mathrm{B}_{20}\right)$. 


\subsection{2.}

\section{Treliça de $20 \mathrm{~m}$ protendida $\left(\mathrm{B}_{\mathrm{P} 20}\right)$}

Neste item, são apresentados os resultados da análise não linear física para treliça protendida de $20 \mathrm{~m}$ de vão, para dois níveis de força de protensão (Figura 7.14). Os resultados da análise com protensão ótima $(130,86 \mathrm{kN})$ são indicados nas Figuras 7.19 a 7.22. Essa figuras apresentam as distribuições das tensões de von Mises para cada ponto da curva da força versus deslocamento vertical (ponto $\mathrm{M}$ ) da treliça.

\subsubsection{1.}

\section{Analise dos níveis de força de protensão para de $B_{\mathrm{P} 20}$}

A Figura 7.14 apresenta gráficos de forças versus deslocamentos para os dois diferentes níveis de força de protensão $\left(0,1 \mathrm{P}_{\mathrm{opt}}\right.$ e $\left.\mathrm{P}_{\mathrm{opt}}\right)$, obtidas a partir de uma análise não linear física, onde os pontos característicos das curvas são analisados. As principais informações obtidas nestes gráficos são destacadas a seguir:

\section{Ponto A correspondente ao limite elástico}

Para uma variação de forças de protensão de $\mathbf{0 , 1} \mathbf{P}_{\mathbf{o p t}}$ para $\mathbf{P}_{\mathbf{o p t}}$ as forças aumentam de 191,24 kN (com deslocamento $100 \mathrm{~mm}$ ) a 324,28 kN (com deslocamento de 118,13 mm), ou seja, ocorre um acréscimo de 69,57\%.

\section{Ponto B correspondente ao limite de escoamento}

Para uma variação de forças de protensão de $\mathbf{0 , 1} \mathbf{P}_{\mathbf{o p t}}$ para $\mathbf{P}_{\mathbf{o p t}}$ as forças aumentam de 195,34 kN (com deslocamento112,25 mm) a 346,471 kN (com deslocamento de 148,75 mm), ou seja, um acréscimo de 77,37 \%.

\section{Ponto $\mathrm{C}$ correspondente à força máxima (Inicia da instabilidade):}

Para uma variação de forças de protensão de $\mathbf{0 , 1} \mathbf{P}_{\mathbf{o p t}}$ para $\mathbf{P}_{\mathbf{o p t}}$ as forças diminuem de $827,7 \mathrm{kN}$ (com deslocamento 2.769,6mm) para 823,2 kN (com deslocamento de $1.222,1 \mathrm{~mm}$ ), ou seja, uma redução de $0,55 \%$, ressaltando-se que a estruturas tem aproximadamente mesma força máxima, com diferente deslocamento. 


\section{Ponto $\mathrm{D}$ correspondente à força de ruptura final}

Para uma variação de forças de protensão de $\mathbf{0 , 1} \mathbf{P}_{\mathbf{o p t}}$ para $\mathbf{P}_{\mathbf{o p t}}$ as forças diminuem de 804,7 KN (com deslocamento 3.020,07 mm) a 639,25 kN (com deslocamento de 2.867,32 mm), ou seja, uma redução de 205,56 \%. Observa-se que a estrutura com protensão ótima rompe com menor força de ruptura.

Com base na sequência das simulações numéricas realizadas a Tabela 7.3 apresenta um resumo dos resultados obtidos no que se refere a forças e deslocamentos nos pontos de limite elástico, escoamento, força máxima e ruptura no centro do vão para a treliça de $20 \mathrm{~m}$. Em conclusão, os resultados mostram as variações de forças de ganho devido ao efeito dos níveis de forças de protensão solicitadas na estrutura.

Tabela 7.3 Níveis de força de protensão da treliça $\mathrm{B}_{20}$.

\begin{tabular}{cccc}
\hline $\begin{array}{c}\text { Pontos das } \\
\text { curvas }\end{array}$ & $0,1 \mathrm{P}_{\mathrm{opt}}$ & $\mathrm{P}_{\mathrm{opt}}$ & $\begin{array}{r}\text { \% Razão } \\
\text { de força }\end{array}$ \\
\cline { 2 - 3 } A & $(\mathrm{kN})$ & $(\mathrm{kN})$ & 69,57 \\
B & 191,24 & 324,28 & 77,37 \\
C & 827,7 & 823,28 & 0,55 \\
D & 804,7 & 639,25 & 20,56 \\
\hline
\end{tabular}

\subsubsection{2.}

\section{Treliça de $20 \mathrm{~m}$ com protensão ótima $\left(\mathrm{B}_{\mathrm{P} 20}\right)$}

Nas Figuras 7.19 até 7.23 são apresentados os resultados das distribuições das tensões de von Mises para diversos pontos da curva força versus deslocamento vertical aplicado no centro, para a treliça de $20 \mathrm{~m}$ de vão sem protensão. Os resultados dos pontos característicos importantes das curvas da Figura 7.14 são analisados nesta seção. 
1. Ponto A: com base nos resultados obtidos, a Figura 7.19 ilustra a distribuição das tensões de von Mises referente ao ponto do limite de elasticidade da Figura 7.14 , onde se observa que o valor da tensão calculada foi igual a 344,27 MPa (correspondente a um carregamento aplicado de $324,28 \mathrm{kN}$ ) na região onde foi aplicado o deslocamento vertical $\partial_{\mathrm{M}}$ de $118,25 \mathrm{~mm}$. Essa tensão é aproximadamente do valor de tensão limite do escoamento, ou seja, não há plastificação da estrutura nesta área. Observa-se, que na chapa de ancoragem da treliça protendida, apresenta grandes concentrações de tensões, onde se tem maior tensão de 346,63 MPa. O ponto onde isto ocorre está representado na Figura 7.9 com a nomenclatura MX.

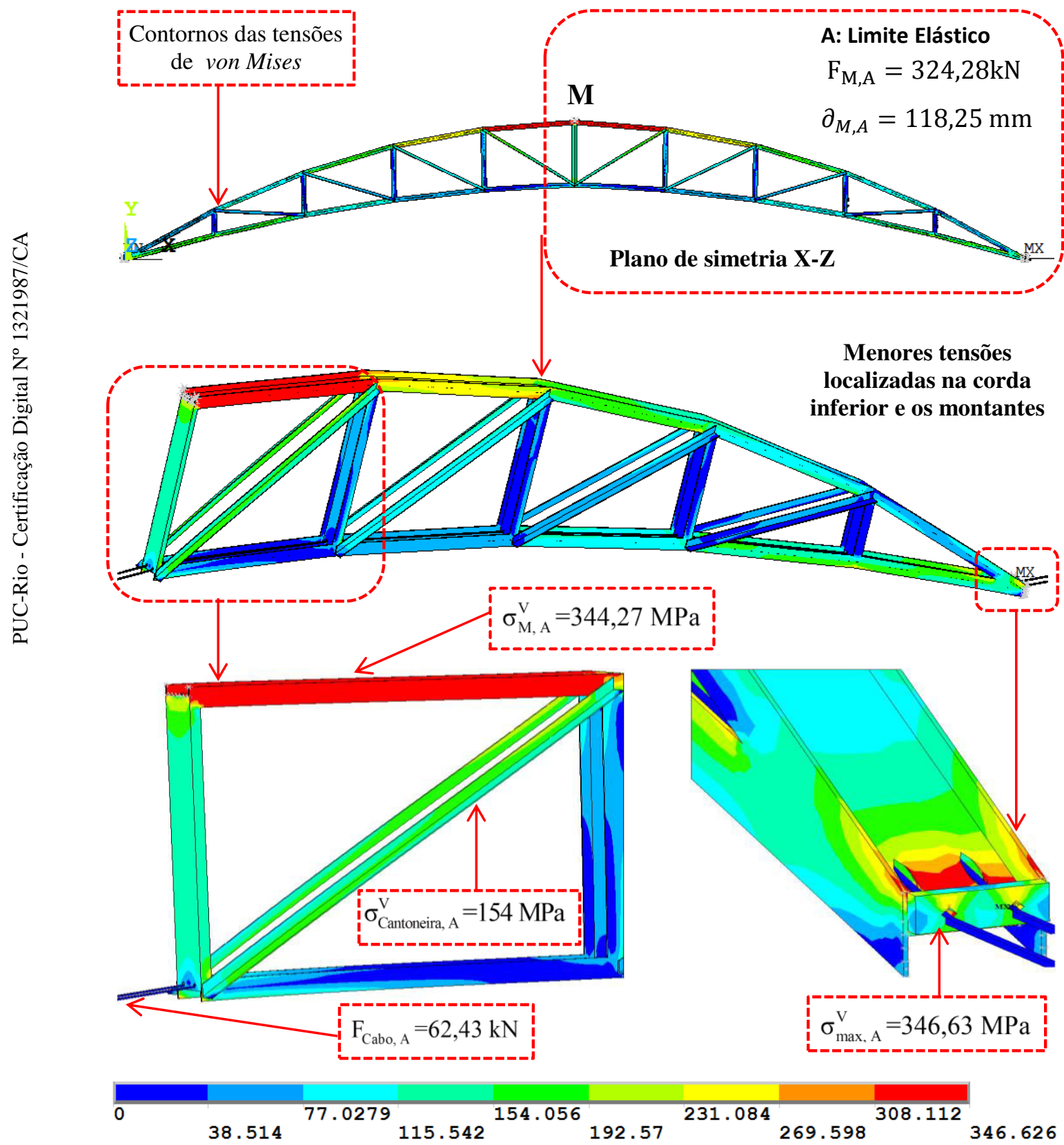

Figura 7.19 Distribuição de tensões de von Mises $(\mathrm{MPa})$ correspondente ao ponto A ( $\left.\mathrm{B}_{\mathrm{P} 20}\right)$. 
2. Ponto B: na Figura 7.20 percebe-se que há um aumento da distribuição das tensões de von Mises no que se refere ao ponto de limite de escoamento (Figura 7.14). Na região do centro da treliça $\partial_{M}$, foi observado que o valor da tensão calculada resultou em 345,94 MPa (a um carregamento aplicado de $346,28 \mathrm{kN}$ ) para um deslocamento vertical de 148,75 mm. Essa tensão é aproximadamente do valor de tensão limite do escoamento, ou seja, não há plastificação da estrutura nesta área. Vale ressaltar que na região da chapa de ancoragem, identifica-se a elevada distribuição de 347,78 MPa (ponto MX) que, por sua vez, excede o valor limite de escoamento fazendo com que a estrutura continue plastificando nessa zona.
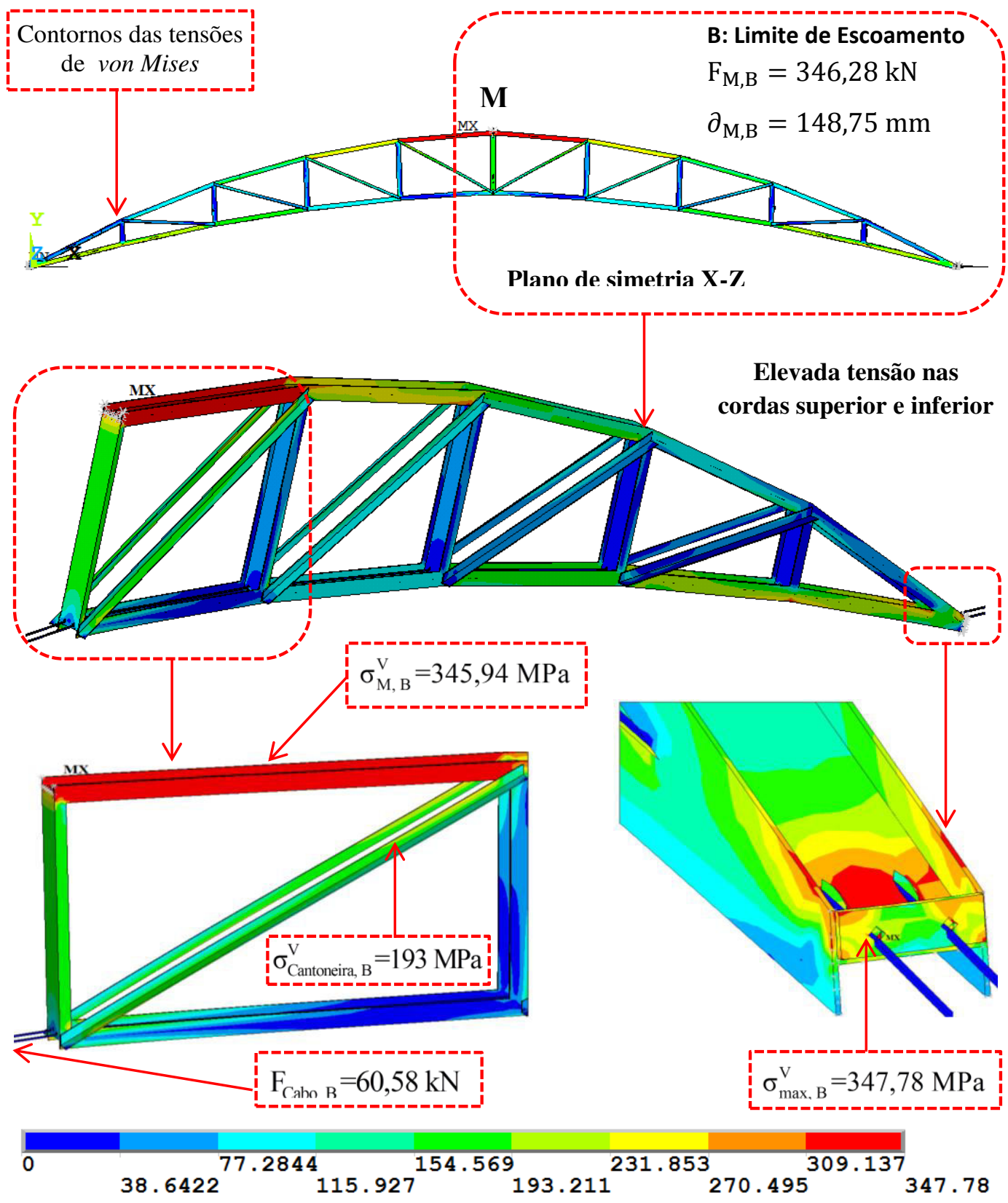

Figura 7.20 Distribuição de tensões de von Mises $(\mathrm{MPa})$ correspondente ao ponto $\mathrm{B}\left(\mathrm{B}_{\mathrm{P} 20}\right)$. 
3. Ponto C: observando-se a distribuição das tensões de von Mises da Figura 7.21 referente ao ponto de força máxima da Figura 7.14, constata-se que o valor da tensão calculada foi igual a 469,88 MPa. Tal valor foi obtido na região do centro da treliça $\partial_{M}$ para um deslocamento vertical de $1.222,1 \mathrm{~mm}$, correspondendo a um carregamento aplicado de $823,28 \mathrm{kN}$. Essa tensão é maior do que o valor de tensão limite de escoamento fazendo com que a estrutura plastifique. Vale ressaltar que na região da chapa de ancoragem, observa-se a máxima distribuição $515,72 \mathrm{MPa}$, e, a estrutura continua plastificando nesta zona da chapa. O ponto onde isto ocorre está representado com a nomenclatura MX.

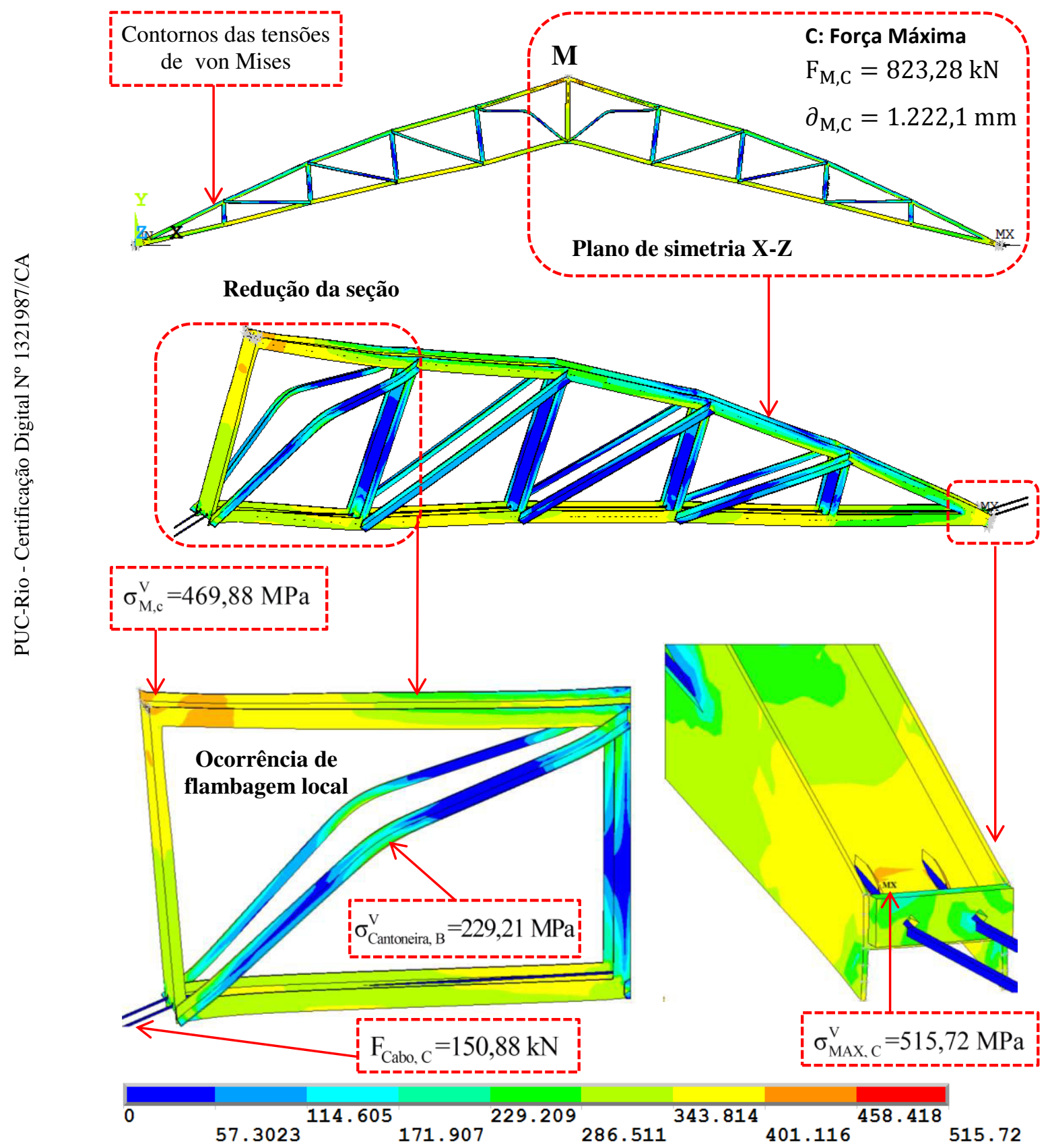

Figura 7.21 Distribuição de tensões de von Mises $(\mathrm{MPa})$ correspondente ao ponto $\mathrm{C}\left(\mathrm{B}_{\mathrm{P} 20}\right)$. 
4. Ponto D: avaliando-se a distribuição das tensões de von Mises da Figura 7.22 referente ao ponto de ruptura mostrado na Figura 7.14, pode-se verificar que o valor da tensão máxima apresentada resultou em 1.616,05 MPa, onde ocorre está representado com a nomenclatura MX. Tal valor foi obtido na região do centro da treliça, para um grande deslocamento vertical de 2.940,07 mm, correspondente a uma força de ruptura igual a 639,25 kN. Esta região apresenta deformações elevadas e os perfis das cordas superior, inferior, montantes e diagonais mostram estrangulamento e redução da seção.
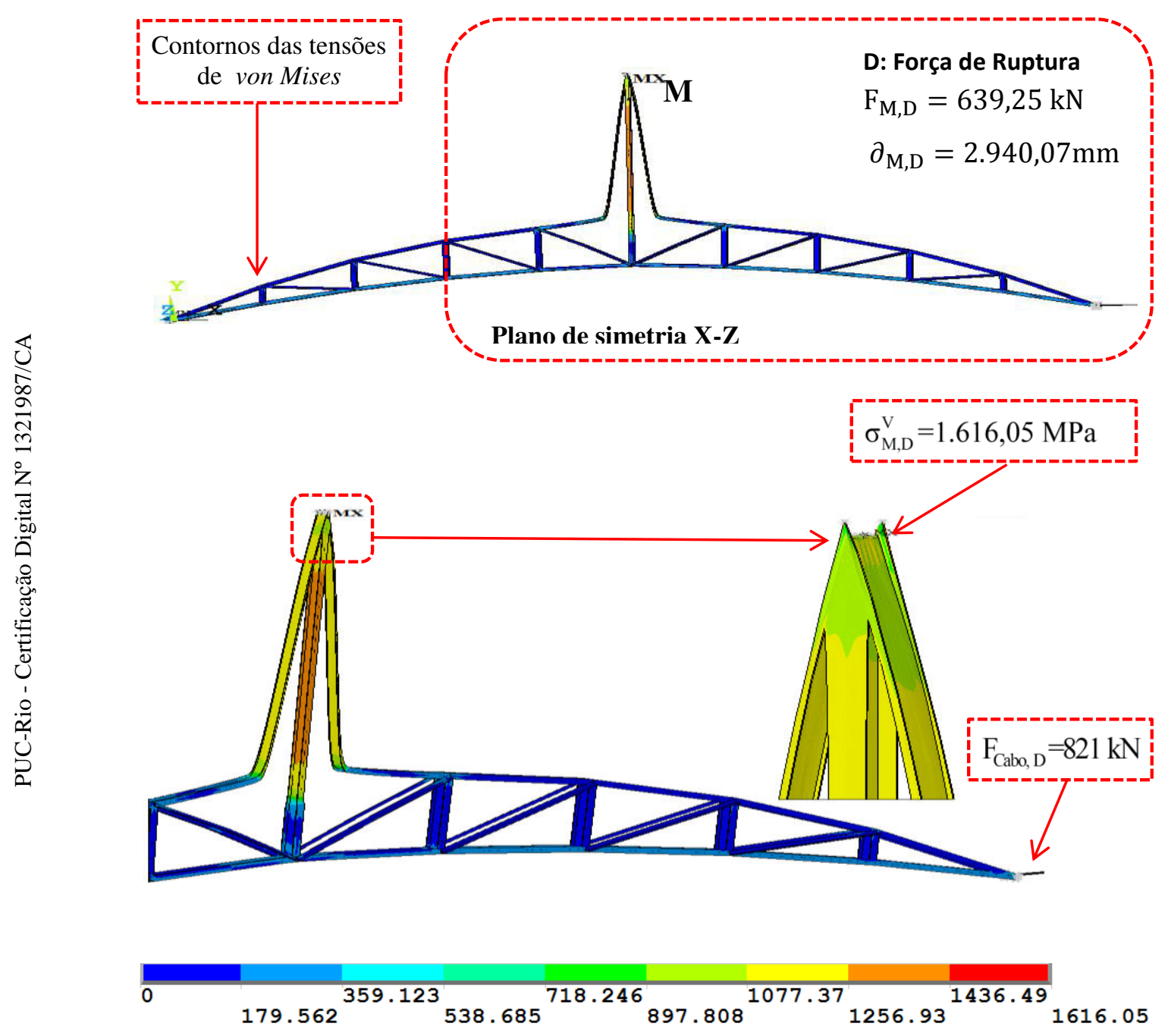

Figura 7.22 Distribuição de tensões de von Mises $(\mathrm{MPa})$ correspondente ao ponto $\mathrm{D}\left(\mathrm{B}_{\mathrm{P} 20}\right)$.

Com base na sequência da modelagem numérica realizada, a Tabela 7.4 apresenta um resumo dos resultados obtidos no que se refere a forças e deslocamentos nos pontos de limite elástico, escoamento, força máxima e ruptura no centro do vão para a treliça de $20 \mathrm{~m}$, sem e com protensão. 
Tabela 7.4 Resumo dos resultados das forças e deslocamentos da treliça $20 \mathrm{~m}$ sem e com protensão nos pontos das curvas (Figura 7.14).

\begin{tabular}{cccccc}
\hline & \multicolumn{2}{c}{ Treliça sem Protensão } & \multicolumn{2}{c}{ Treliça com Protensão } \\
Pontos das curvas & \% Razão \\
\cline { 2 - 5 } & $\begin{array}{c}\text { Força } \\
(\mathrm{kN})\end{array}$ & $\begin{array}{c}\text { Deslocamento } \\
(\mathrm{mm})\end{array}$ & $\begin{array}{c}\text { Força } \\
(\mathrm{kN})\end{array}$ & $\begin{array}{c}\text { Deslocamento } \\
(\mathrm{mm})\end{array}$ & de força \\
\hline $\begin{array}{c}\text { A: } \\
\text { (Limite elástico) }\end{array}$ & 121,5 & 100 & 324,28 & 118 & 166,9 \\
$\begin{array}{c}\text { B: } \\
\text { (Limite escoamento) } \\
\text { C: }\end{array}$ & 154,3 & 150 & 346,47 & 149 & 124,5 \\
$\begin{array}{c}\text { (Força máxima) } \\
\text { D: }\end{array}$ & 155,23 & 401 & 823,28 & 1.222 & 430,4 \\
\begin{tabular}{c} 
(Força ruptura) \\
\hline
\end{tabular} & 95,47 & 2.462 & 639,25 & 2.867 & 569,6 \\
\hline
\end{tabular}

Com base nos resultados da Tabela 7.4 apresentam um resumo das forças e deslocamentos para diferentes pontos da curva carga versus deslocamento nos trechos elástico e plástico para o modelo da treliça de $20 \mathrm{~m}$ sem e com protensão. Esse resultados confirmam o resultados obtidos na modelagem da treliça de $10 \mathrm{~m}$, e as conclusões do Projeto, HILONG "HSS trusses to be tested at Imperial College" (Gkantou et al., 2015) e as conclusões de Belenya (1997) e de Troitsky (1990). 


\section{3.}

\section{Análise não linear da treliça de $\mathbf{4 0}$ m de vão}

A análise não linear para a treliça de $40 \mathrm{~m}$ de vão sem e com protensão foi executada a partir da aplicação de deslocamento no centro da treliça. $\mathrm{Na}$ Figura 7.23 são mostrados um modelo de treliça, as condições de contorno e a aplicação do deslocamento. Também é mostrada uma ampliação da estrutura na parte em que está aplicando o deslocamento.

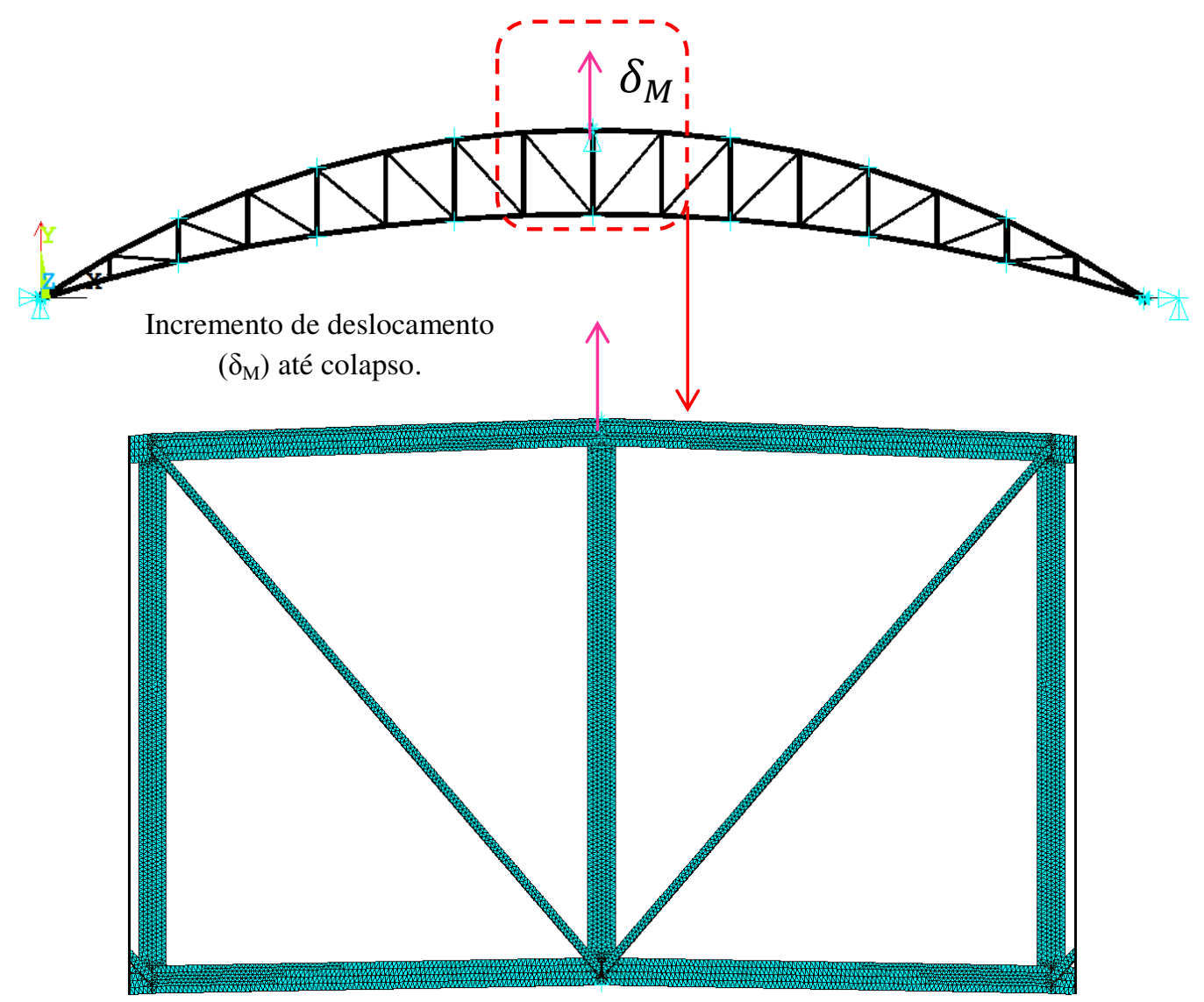

Figura 7.23 Deslocamento vertical aplicado no centro da treliça C40.

A Figura 7.24 apresenta as curvas carga versus deslocamento da treliça de $40 \mathrm{~m}$ de vão sem e com protensão na corda inferior, onde o carregamento foi aplicado por meio de incremento de deslocamento vertical até atingir a ruptura da treliça, utilizando-se como critério de convergência a norma de deslocamentos. É possível observar que as curvas com protensão são muito similares, além de possuírem cargas máximas superiores à curva da treliça sem protensão. 


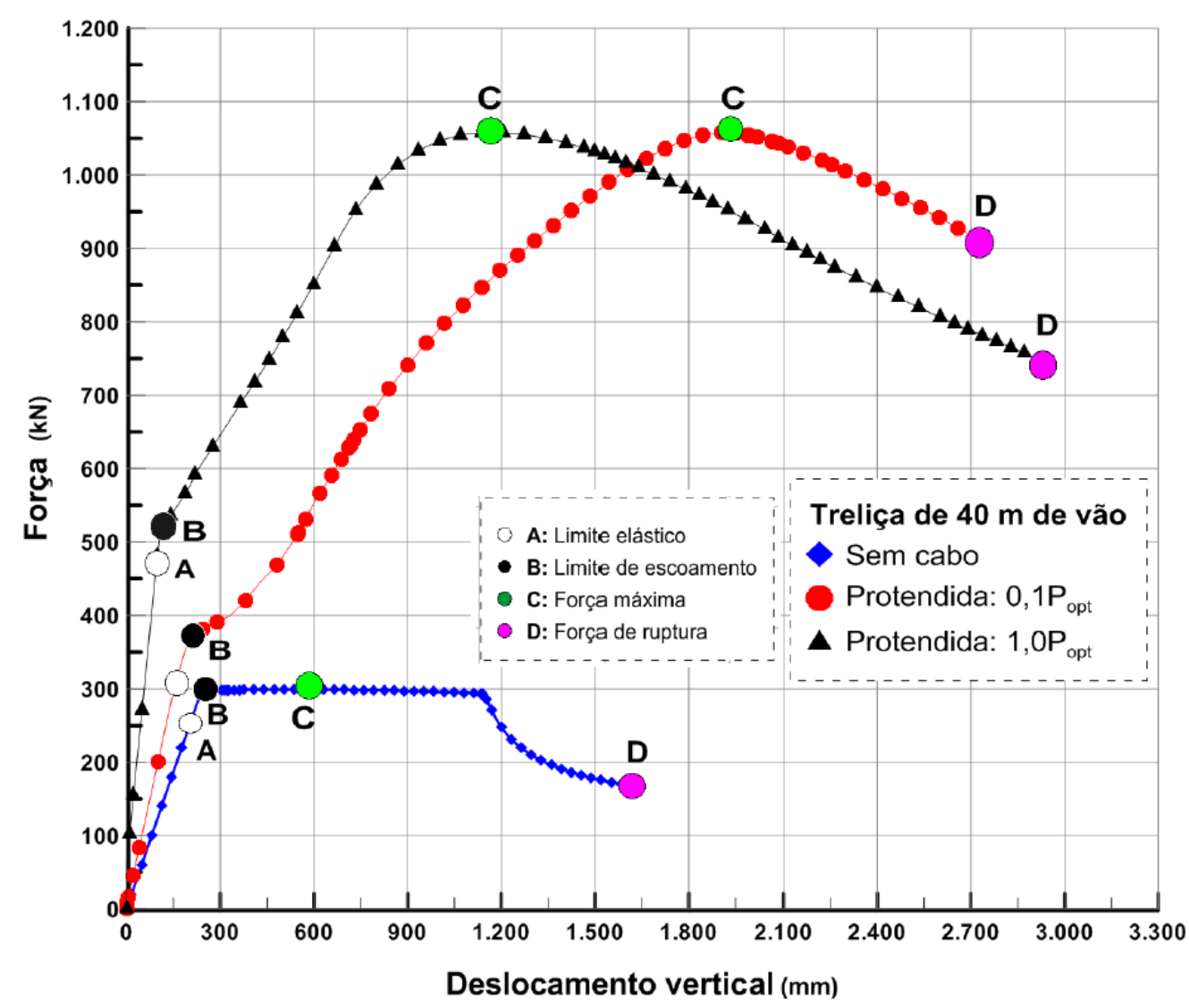

Figura 7.24 Força versus deslocamento vertical do meio do vão de $\mathrm{C}_{40}$ sem e com protensão.

$\mathrm{Na}$ Figura 7.24 referente às curvas nos pontos traçados $\mathbf{A}$ (limite elasticidade), B (Limite de escoamento), C (força máxima) e D (força de ruptura), são mostradas as forças e deslocamentos em trecho linear e não linear na treliça de 40 de vão, sem e com protensão. Na sequência do estudo as Figuras 7.25 até 7.32 mostram os resultados das tensões correspondentes às forças e deslocamentos dos pontos das curvas.

\subsection{1.}

\section{Treliça de $40 \mathrm{~m}$ sem protensão $\left(\mathrm{C}_{40}\right)$}

Nas Figuras 7.25 até 7.28 são apresentados os resultados das distribuições das tensões de von Mises para diversos pontos da curva força versus deslocamento vertical aplicado no centro para a treliça de $40 \mathrm{~m}$ de vão sem protensão. Os resultados dos pontos característicos importantes das curvas da Figura 7.24, são analisados nesta seção. 
1. Ponto A: com base nos resultados obtidos, a Figura 7.25 ilustra a distribuição das tensões de von Mises referente ao ponto do limite de elasticidade da Figura 7.24 , onde se observa que o valor da tensão calculada foi igual a 345,03 $\mathrm{MPa}$ (correspondente a um carregamento aplicado de 157,68 kN) na região onde foi aplicado o deslocamento vertical de $75 \mathrm{~mm}$. Essa tensão é igual ao valor de tensão limite do escoamento do material usado. Também se nota que o apoio da treliça sem protensão apresenta grandes concentrações de tensões, no qual a maior tensão resultou em 348,29 $\mathrm{MPa}$. Esse valor excede o valor limite de escoamento e, portanto, a treliça começa a plastificar nesta área.

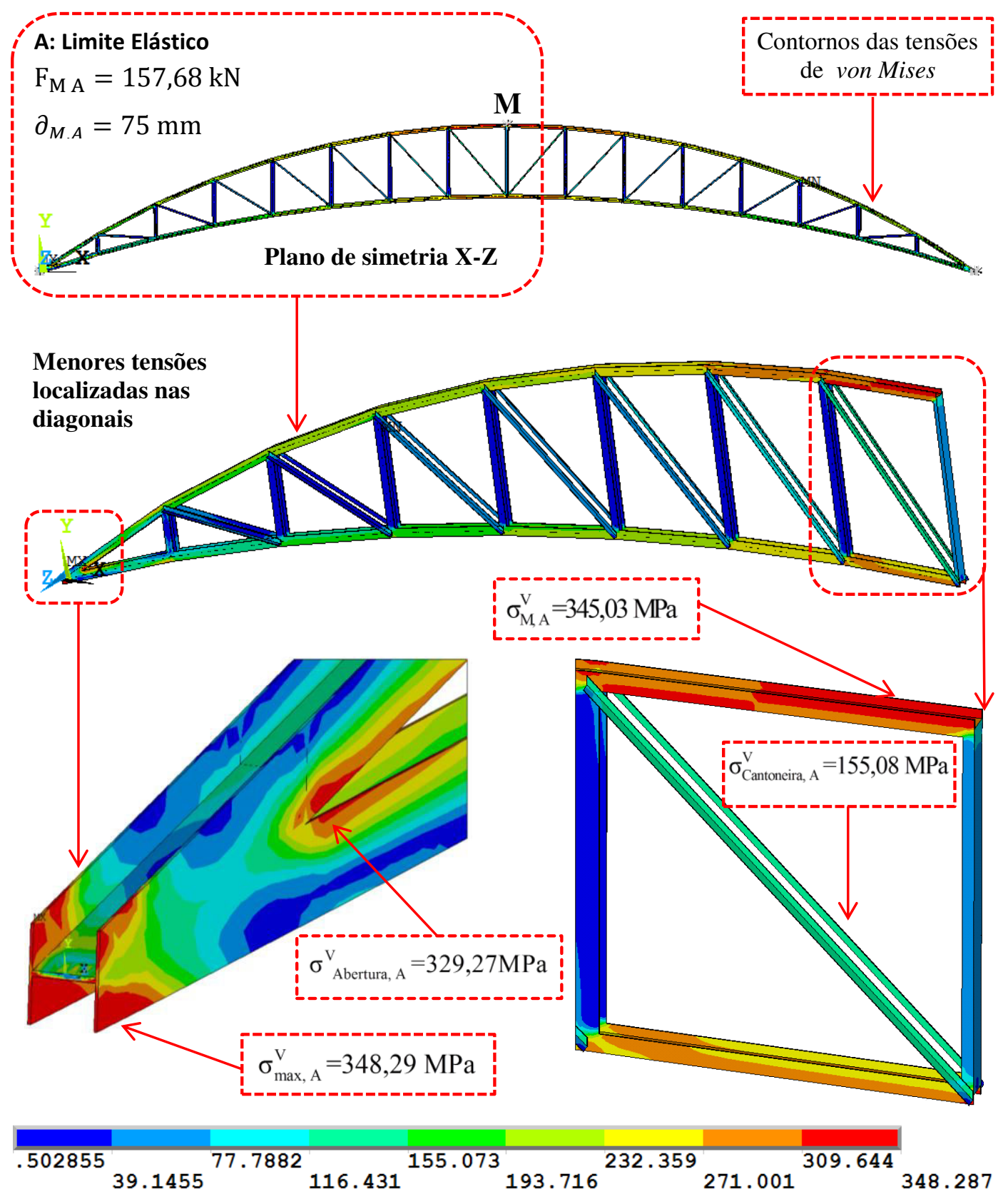

Figura 7.25 Distribuição de tensões de von Mises $(\mathrm{MPa})$ correspondente ao ponto $\mathrm{A}\left(\mathrm{C}_{40}\right)$. 
2. Ponto B: na Figura 7.26 percebe-se que há um aumento da distribuição das tensões de von Mises no que se refere ao ponto de limite de escoamento (Figura 7.24). Na região do centro da treliça $\partial_{M}$, foi observado que o valor da tensão calculada resultou em 345,08 $\mathrm{MPa}$ (correspondente a um carregamento aplicado de $296 \mathrm{kN}$ ) para um deslocamento vertical de $240 \mathrm{~mm}$. Essa tensão é próxima do valor da tensão limite, ou seja, não há plastificação da estrutura. Vale ressaltar que na região do apoio identifica-se a elevada distribuição de 348,81 MPa que, por sua vez, excede o valor limite de escoamento fazendo com que a estrutura continue plastificando na zona do apoio.

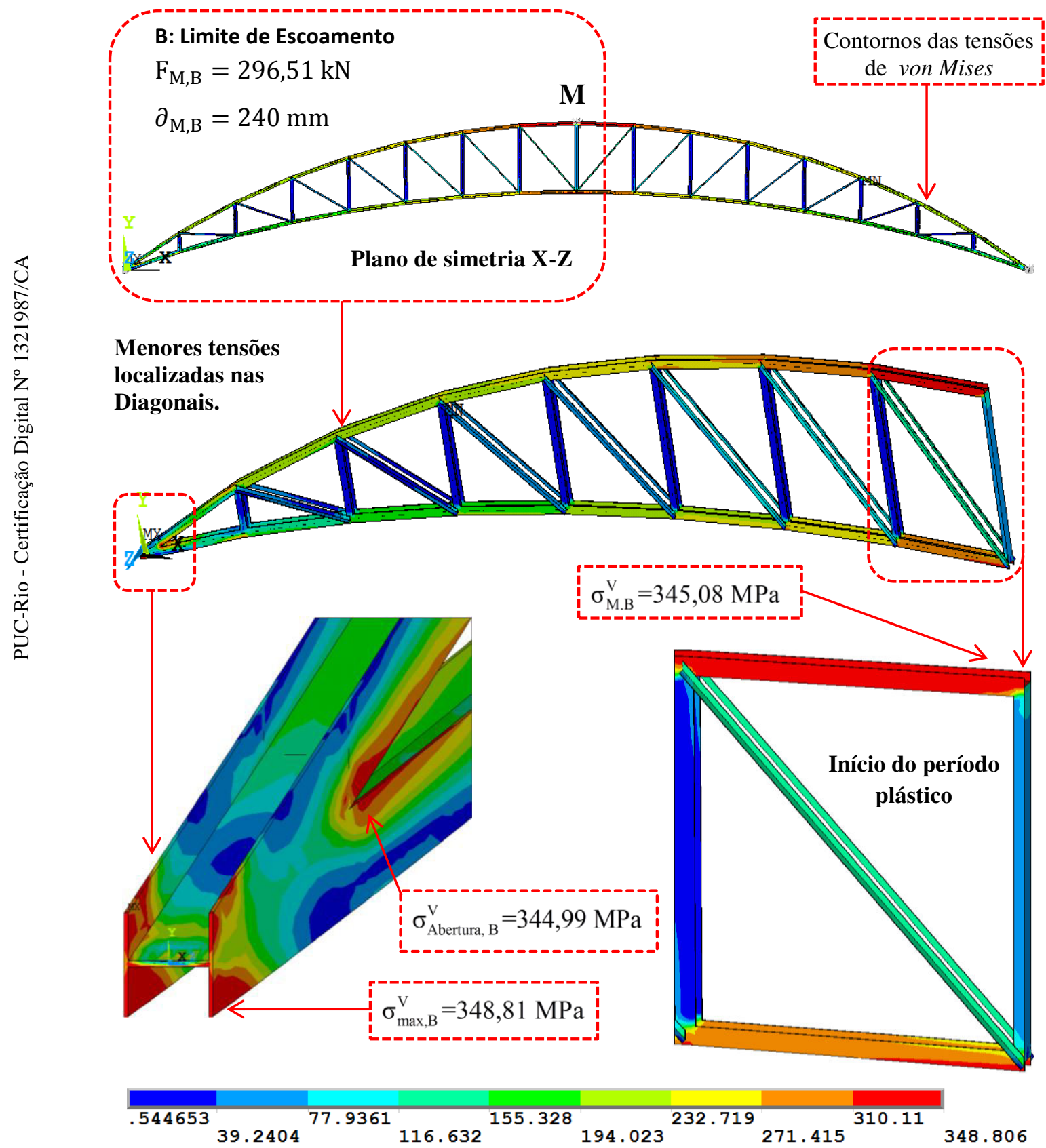

Figura 7.26 Distribuição de tensões de von Mises (MPa) correspondente ponto B $\left(\mathrm{C}_{40}\right)$. 
3. Ponto C: observando-se a distribuição das tensões de von Mises da Figura 7.27 referente ao ponto de força máxima da Figura 7.24, constata-se que o valor da tensão calculada foi igual a $365,18 \mathrm{MPa}$. Tal valor foi obtido na região do centro da treliça, para um deslocamento vertical $\partial_{M}$ de $325 \mathrm{~mm}$, correspondendo a um carregamento aplicado de 299,01 kN. Essa tensão é maior do que o valor de tensão limite de escoamento, ou seja, a estrutura começa a plastificar. Também foi verificada uma elevada distribuição de tensões nas cordas superior e inferior da treliça, ressaltando-se que nas diagonais se apresentam menores tensões.

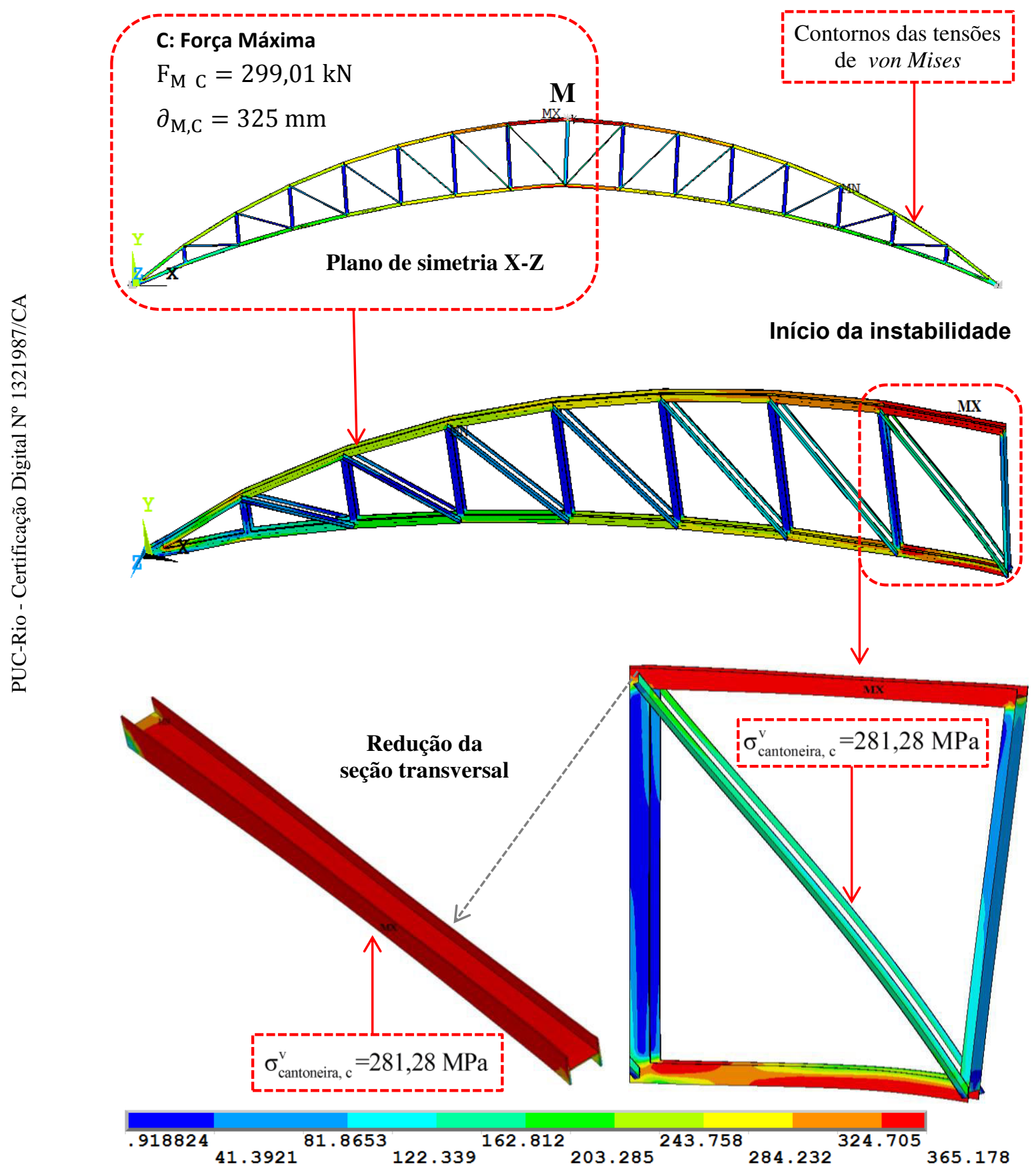

Figura 7.27 Distribuição de tensões de von Mises (MPa) correspondente ao ponto $\mathrm{C}\left(\mathrm{C}_{40}\right)$. 
4. Ponto D: avaliando-se a distribuição das tensões de von Mises da Figura 7.28 referente ao ponto de ruptura mostrado na Figura 7.24, pode-se verificar que o valor da tensão apresentada resultou em $370 \mathrm{MPa}$. Tal valor foi obtido na região do centro da treliça, para um grande deslocamento vertical de $1.600 \mathrm{~mm}$, correspondente a uma força de ruptura igual a 168,45 kN. Essa região apresenta deformações elevadas e os perfis das cordas superior, inferior, montantes e diagonais apresentam estrangulamento e redução da seção, ressaltando-se que a tensão máxima distribuição de 443,73 MPa está representada com a nomenclatura MX.

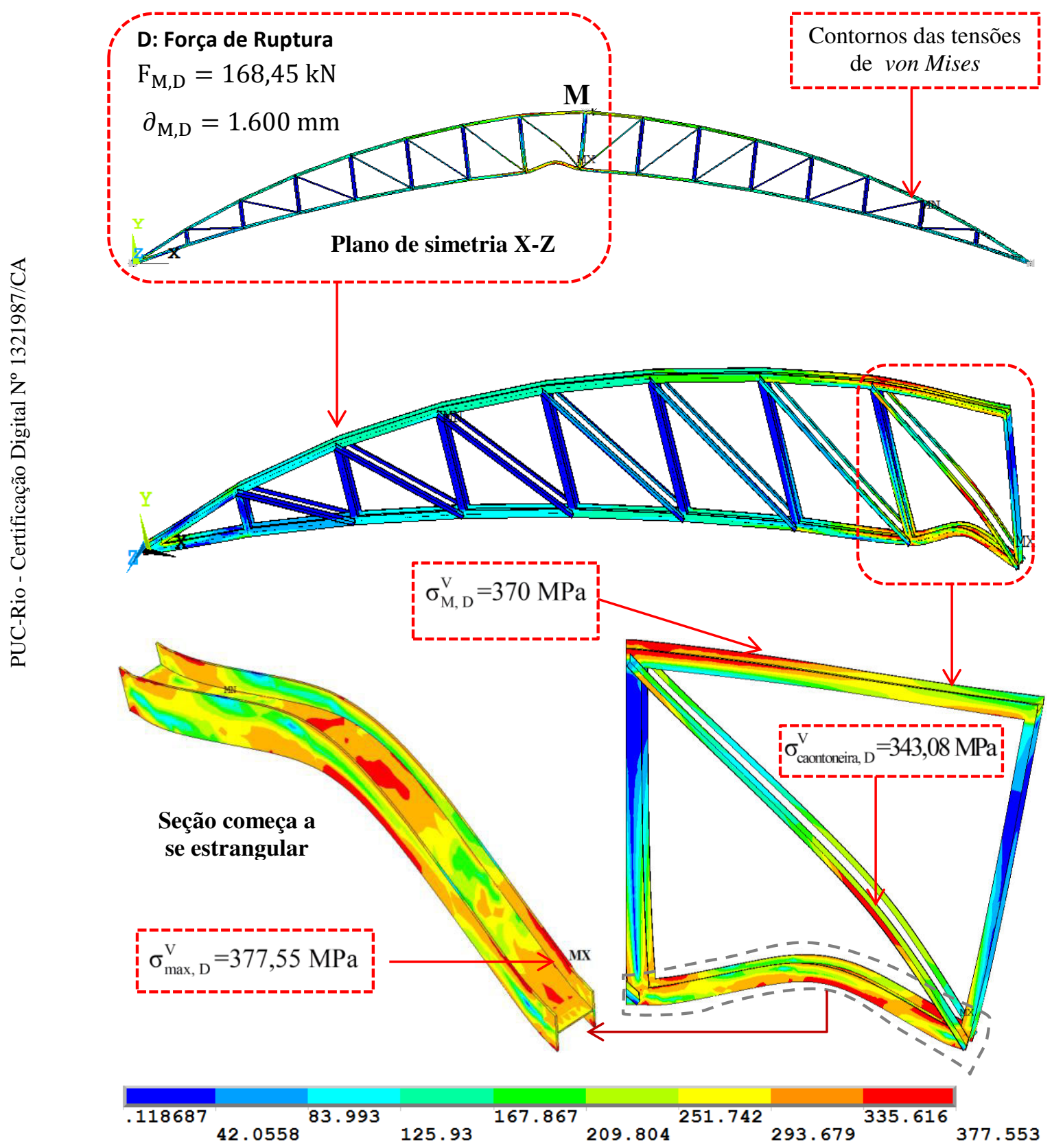

Figura 7.28 Distribuição de tensões de von Mises $(\mathrm{MPa})$ correspondente ao ponto $\mathrm{D}\left(\mathrm{C}_{40}\right)$. 


\subsection{2.}

\section{Treliça de $40 \mathrm{~m}$ protendida $\left(\mathrm{C}_{\mathrm{P} 40}\right)$}

Neste item são apresentados os resultados da análise não linear física para treliça protendida de $40 \mathrm{~m}$ de vão, para dois níveis de força de protensão (Figura 7.24). Os resultados da análise com protensão ótima $(205,27 \mathrm{kN})$ são indicados nas Figuras 7.29 até 7.32. Essa figuras apresentam as distribuições das tensões de von Mises para cada ponto da curva da força versus deslocamento vertical (ponto $\mathrm{M}$ ) da treliça.

\subsubsection{1.}

\section{Analise dos níveis de força de protensão para de $\mathbf{C}_{\mathrm{P} 40}$}

A Figura 7.24 apresenta gráficos de forças versus deslocamentos para os dois diferentes níveis de força de protensão $\left(0,1 \mathrm{P}_{\mathrm{opt}}\right.$ e $\left.\mathrm{P}_{\mathrm{opt}}\right)$, obtidas a partir de uma análise não linear física, onde os pontos característicos das curvas são analisados. As principais informações obtidas nestes gráficos são destacadas a seguir:

\section{Ponto A correspondente ao limite elástico}

Para uma variação de forças de protensão de $\mathbf{0 , 1} \mathbf{P}_{\mathbf{o p t}}$ para $\mathbf{P}_{\mathbf{o p t}}$ as forças aumentam de 297,6 $\mathrm{kN}$ (com deslocamento $150 \mathrm{~mm}$ ) a 481,1 $\mathrm{kN}$ (com deslocamento de $98 \mathrm{~mm}$ ), ou seja, um acréscimo de 61,62\%.

\section{Ponto B correspondente ao limite de escoamento}

Para uma variação de forças de protensão de $\mathbf{0 , 1} \mathbf{P}_{\mathbf{o p t}}$ para $\mathbf{P}_{\mathbf{o p t}}$ as forças aumentam de 372,28 $\mathrm{kN}$ (com deslocamento $200 \mathrm{~mm}$ ) a 506,43 kN (com deslocamento de 105,04 mm), ou seja, um acréscimo de 36,04\%.

\section{Ponto $\mathrm{C}$ correspondente à força máxima (Inicia da instabilidade)}

Para uma variação de forças de protensão de $\mathbf{0 , 1} \mathbf{P}_{\mathbf{o p t}}$ para $\mathbf{P}_{\mathbf{o p t}}$, as forças aumentam de $1.057,18 \mathrm{kN}$ (com deslocamento $1.905,39 \mathrm{~mm}$ ) para $1.057,51 \mathrm{kN}$ (com deslocamento de 1.160,21 $\mathrm{mm}$ ), ou seja, uma acréscimo de 0,03\%, ressaltando-se que a estruturas tem aproximadamente mesma força máxima, com diferente deslocamento. 


\section{Ponto $D$ correspondente à força de ruptura final}

Para uma variação de forças de protensão de $\mathbf{0 , 1} \mathbf{P}_{\mathbf{o p t}}$ para $\mathbf{P}_{\mathbf{o p t}}$ as forças diminuem de 920,57 $\mathrm{KN}$ (com deslocamento 2.689,14 mm) a 755,72 $\mathrm{kN}$ (com deslocamento de 2.886,33 mm), ou seja, uma redução de 17,07\%. Observa-se que a estrutura com protensão ótima rompe com menor força de ruptura.

Com base na sequência das simulações numéricas realizadas, a Tabela 7.5 apresenta um resumo dos resultados obtidos no que se refere a forças e deslocamentos nos pontos de limite elástico, escoamento, força máxima e ruptura no centro do vão para a treliça de $40 \mathrm{~m}$. Em conclusão, os resultados mostram as variações de forças de ganho devido ao efeito dos níveis de forças de protensão solicitadas na estrutura.

Tabela 7.5 Níveis de força de protensão da treliça $\mathrm{C}_{40}$

\begin{tabular}{cccc}
\hline $\begin{array}{c}\text { Pontos das } \\
\text { curvas }\end{array}$ & $0,1 \mathrm{P}_{\mathrm{opt}}$ & $\mathrm{P}_{\mathrm{opt}}$ & $\begin{array}{c}\text { \% Razão } \\
\text { de força }\end{array}$ \\
\cline { 2 - 4 } $\mathrm{A}$ & $(\mathrm{kN})$ & $(\mathrm{kN})$ & 61,66 \\
$\mathrm{~B}$ & 372,28 & 506,43 & 36,04 \\
$\mathrm{C}$ & $1.057,2$ & $1.057,51$ & 0,03 \\
$\mathrm{D}$ & 920,57 & 755,72 & 17,91 \\
\hline
\end{tabular}

\subsubsection{2.}

\section{Treliça de $40 \mathrm{~m}$ com protensão ótima $\left(\mathrm{C}_{\mathrm{P40}}\right)$}

Nas Figuras 7.29 até 7.32 são apresentados os resultados das distribuições das tensões de von Mises para diversos pontos da curva força versus deslocamento vertical aplicado no centro para a treliça de $40 \mathrm{~m}$ de vão sem protensão. Os resultados dos pontos característicos importantes das curvas da Figura 7.24, são analisados nesta seção. 
1. Ponto A: com base nos resultados obtidos, a Figura 7.29 ilustra a distribuição das tensões de von Mises referente ao ponto do limite de elasticidade da Figura 7.24 , onde se observa que o valor da tensão calculada foi igual a 344,27 MPa (correspondente a um carregamento aplicado de $481,1 \mathrm{kN}$ ) na região onde foi aplicado o deslocamento vertical $\partial_{\mathrm{M}}$ de $98 \mathrm{~mm}$. Essa tensão é aproximadamente do valor de tensão limite do escoamento, ou seja, não há plastificação da estrutura nesta área. Observa-se, que na chapa de ancoragem da treliça protendida, apresenta grandes concentrações de tensões, onde se tem maior tensão de 344,99 MPa. O ponto onde isto ocorre está representado na Figura 7.29 com a nomenclatura MX.

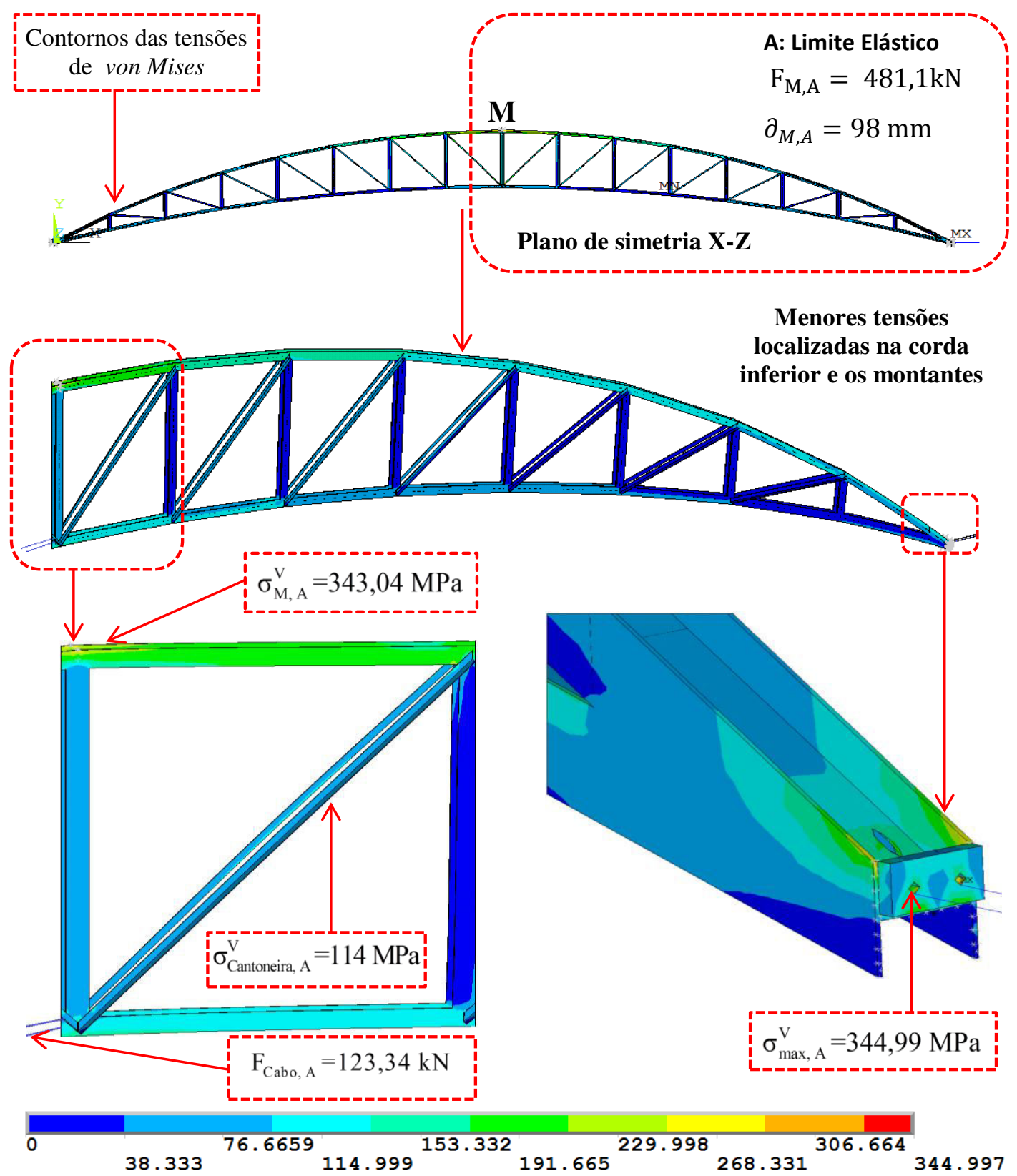

Figura 7.29. Distribuição de tensões de von Mises $(\mathrm{MPa})$ correspondente ao ponto $\mathrm{A}\left(\mathrm{C}_{\mathrm{P} 40}\right)$. 
2. Ponto B: na Figura 7.30 percebe-se que há um aumento da distribuição das tensões de von Mises no que se refere ao ponto de limite de escoamento (Figura 7.24). Na região do centro da treliça $\partial_{M}$, foi observado que o valor da tensão calculada resultou em 345,04 MPa (a um carregamento aplicado de $506,43 \mathrm{kN}$ ) para um deslocamento vertical de 105,04 mm. Essa tensão é aproximadamente do valor de tensão limite do escoamento, ou seja, não há plastificação da estrutura nesta área. Vale ressaltar que na região da chapa de ancoragem, identifica-se a elevada distribuição de 345,28 MPa (ponto MX) que, por sua vez, é aproximadamente o valor limite de escoamento.

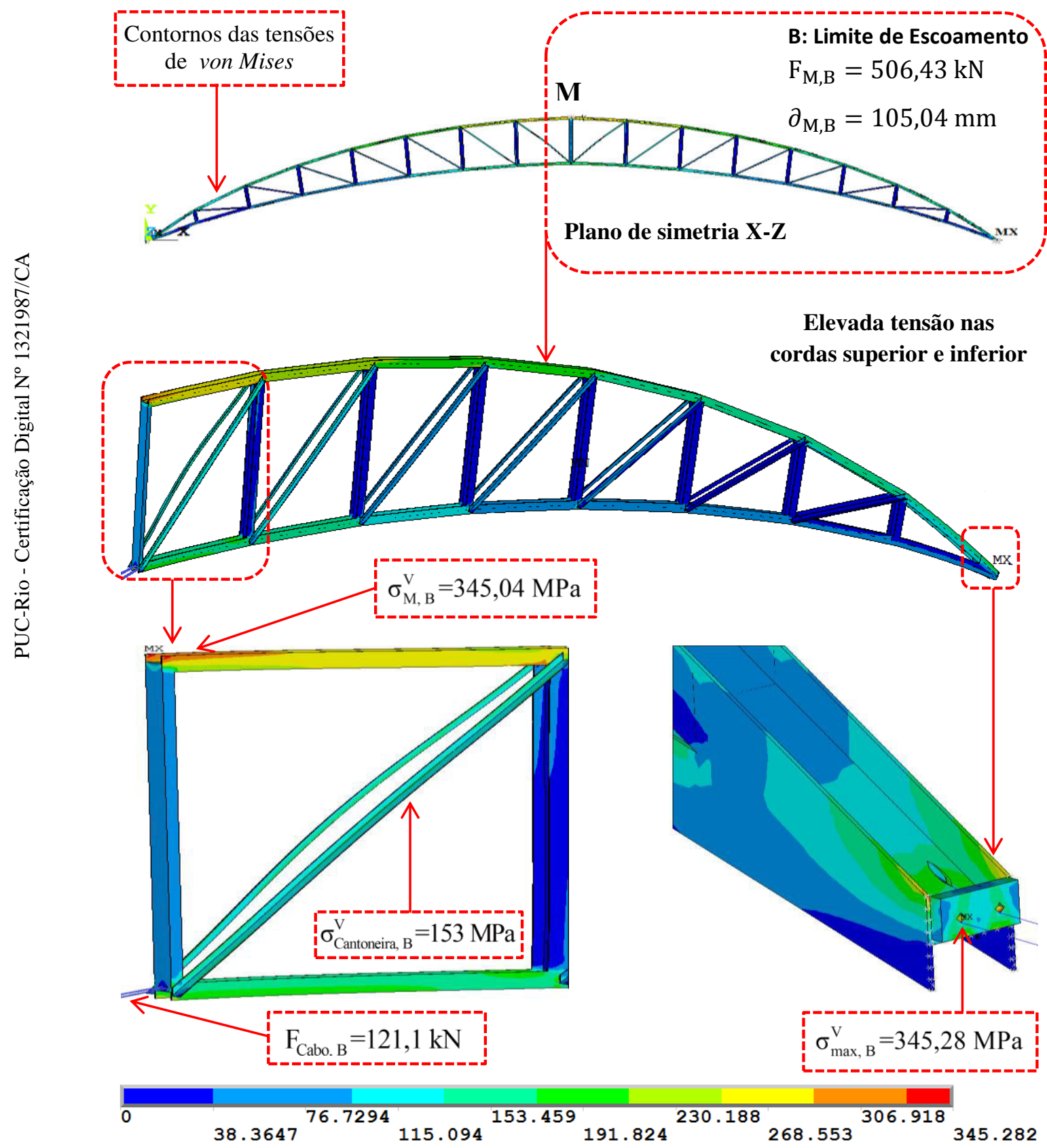

Figura 7.30 Distribuição de tensões de von Mises $(\mathrm{MPa})$ correspondente ao ponto $\mathrm{B}\left(\mathrm{C}_{\mathrm{P} 40}\right)$. 
3. Ponto C: observando-se a distribuição das tensões de von Mises da Figura 7.31 referente ao ponto de força máxima da Figura 7.24, constata-se que o valor da tensão calculada foi igual a 365,3 MPa. Tal valor foi obtido na região do centro da treliça $\partial_{M}$ para um deslocamento vertical de $1.160,22 \mathrm{~mm}$, correspondendo a um carregamento aplicado de 1.057,51 kN. Essa tensão é maior do que o valor de tensão limite de escoamento fazendo com que a estrutura plastifique. Vale ressaltar que nas diagonais, observa-se a ocorrência de flambagem local, com valor da tensão de distribuição de $344,567 \mathrm{MPa}$.

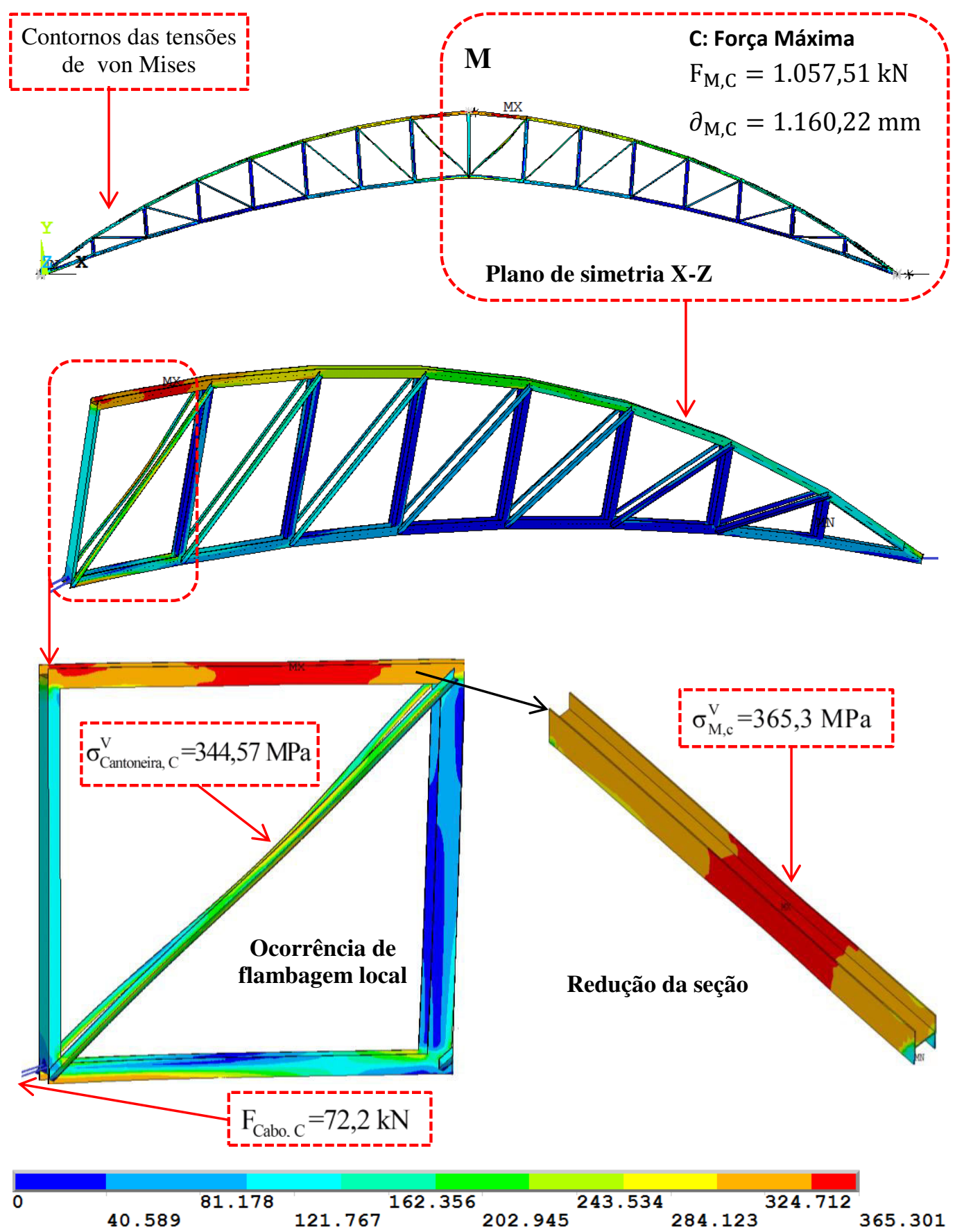

Figura 7.31 Distribuição de tensões de von Mises $(\mathrm{MPa})$ correspondente ponto $\mathrm{C}\left(\mathrm{C}_{\mathrm{P} 40}\right)$. 
4. Ponto D: avaliando-se a distribuição das tensões de von Mises da Figura 7.32 referente ao ponto de ruptura mostrado na Figura 7.24, pode-se verificar que o valor da tensão apresentada resultou em $366,73 \mathrm{MPa}$. Tal valor foi obtido na região do centro da treliça, para um grande deslocamento vertical de $2.886,33 \mathrm{~mm}$, correspondente a uma força de ruptura igual a 755,72 kN. Essa região apresenta deformações elevadas e os perfis das cordas superior, inferior, montantes e diagonais mostram estrangulamento e redução da seção. Ressaltandose que a tensão máxima onde ocorre está representada com a nomenclatura MX.

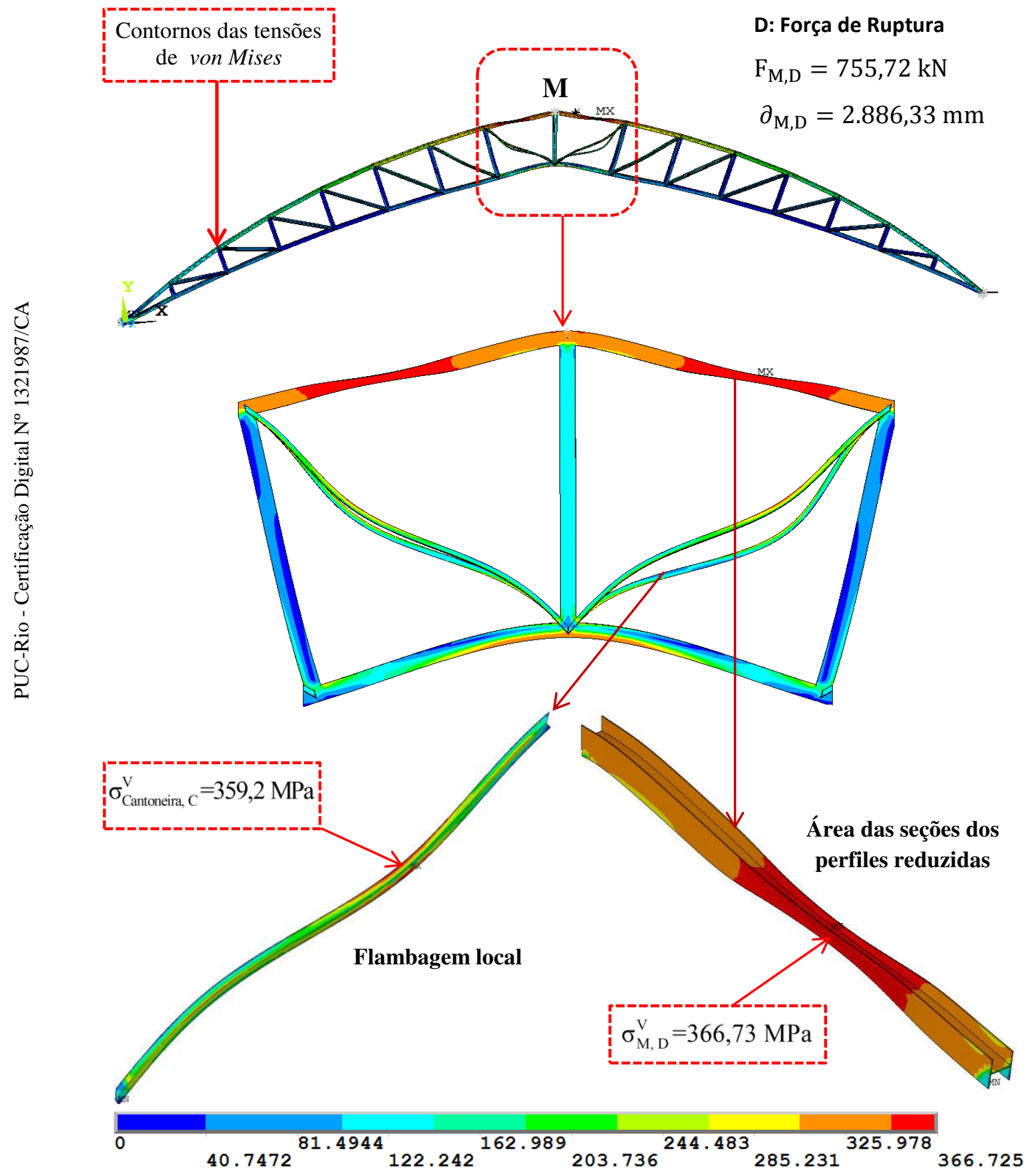

Figura 7.32 Distribuição de tensões de von Mises $(\mathrm{MPa})$ correspondente ao ponto $\mathrm{D}\left(\mathrm{C}_{\mathrm{P} 40}\right)$. 
Com base na sequência da modelagem numérica realizada, a Tabela 7.6 apresenta um resumo dos resultados obtidos no que se refere a forças e deslocamentos nos pontos de limite elástico, escoamento, força máxima e ruptura no centro do vão para a treliça de $40 \mathrm{~m}$, sem e com protensão.

Tabela 7.6 Resumo dos resultados das forças e deslocamentos da treliça $40 \mathrm{~m}$ sem e com protensão nos pontos das curvas (Figura 7.24).

\begin{tabular}{cccccc}
\hline & \multicolumn{3}{c}{ Treliça sem Protensão } & \multicolumn{3}{c}{ Treliça com Protensão } & \% Razão \\
\cline { 2 - 5 } Pontos das curvas & $\begin{array}{c}\text { Força } \\
(\mathrm{KN})\end{array}$ & $\begin{array}{c}\text { Deslocamento } \\
(\mathrm{mm})\end{array}$ & $\begin{array}{c}\text { Força } \\
(\mathrm{KN})\end{array}$ & $\begin{array}{c}\text { Deslocamento } \\
(\mathrm{mm})\end{array}$ & de Força \\
\hline $\begin{array}{c}\text { A: } \\
\text { (Limite elástico) }\end{array}$ & 278,6 & 224 & 481,1 & 98 & 205,1 \\
$\begin{array}{c}\text { B: } \\
\text { (Limite escoamento) }\end{array}$ & 296,51 & 240 & 506,43 & 105 & 70,8 \\
C: & 299,01 & 325 & $1.057,51$ & 1.160 & 253,7 \\
$\begin{array}{c}\text { (Força máxima) } \\
\text { D: }\end{array}$ & 168,45 & 1.600 & 755,72 & $2.886,32$ & 348,6 \\
(Força ruptura) & & & & & \\
\hline
\end{tabular}

Com base nos resultados da Tabela 7.6 aprsentam um resumo das forças e deslocamentos para diferentes pontos da curva carga versus deslocamento nos trechos elástico e plástico para o modelo da treliça de $40 \mathrm{~m}$. Essa resultados confirmam o resultados obtidos na modelagem das treliças de $10 \mathrm{~m}$ e $20 \mathrm{~m}$, e as conclusões do Projeto, HILONG "HSS trusses to be tested at Imperial College" (Gkantou et al., 2015) e as conclusões de Belenya (1997) e de Troitsky (1990). 


\section{4.}

\section{Análise não linear da treliça de $80 \mathrm{~m}$ de vão}

A análise não linear para a treliça de $80 \mathrm{~m}$ de vão sem e com protensão foi executada a partir da aplicação de deslocamento no centro da treliça. $\mathrm{Na}$ Figura 7.33, são mostrados um modelo de treliça, as condições de contorno e a aplicação do deslocamento. Também é mostrada uma ampliação da estrutura na parte em que está aplicando o deslocamento.

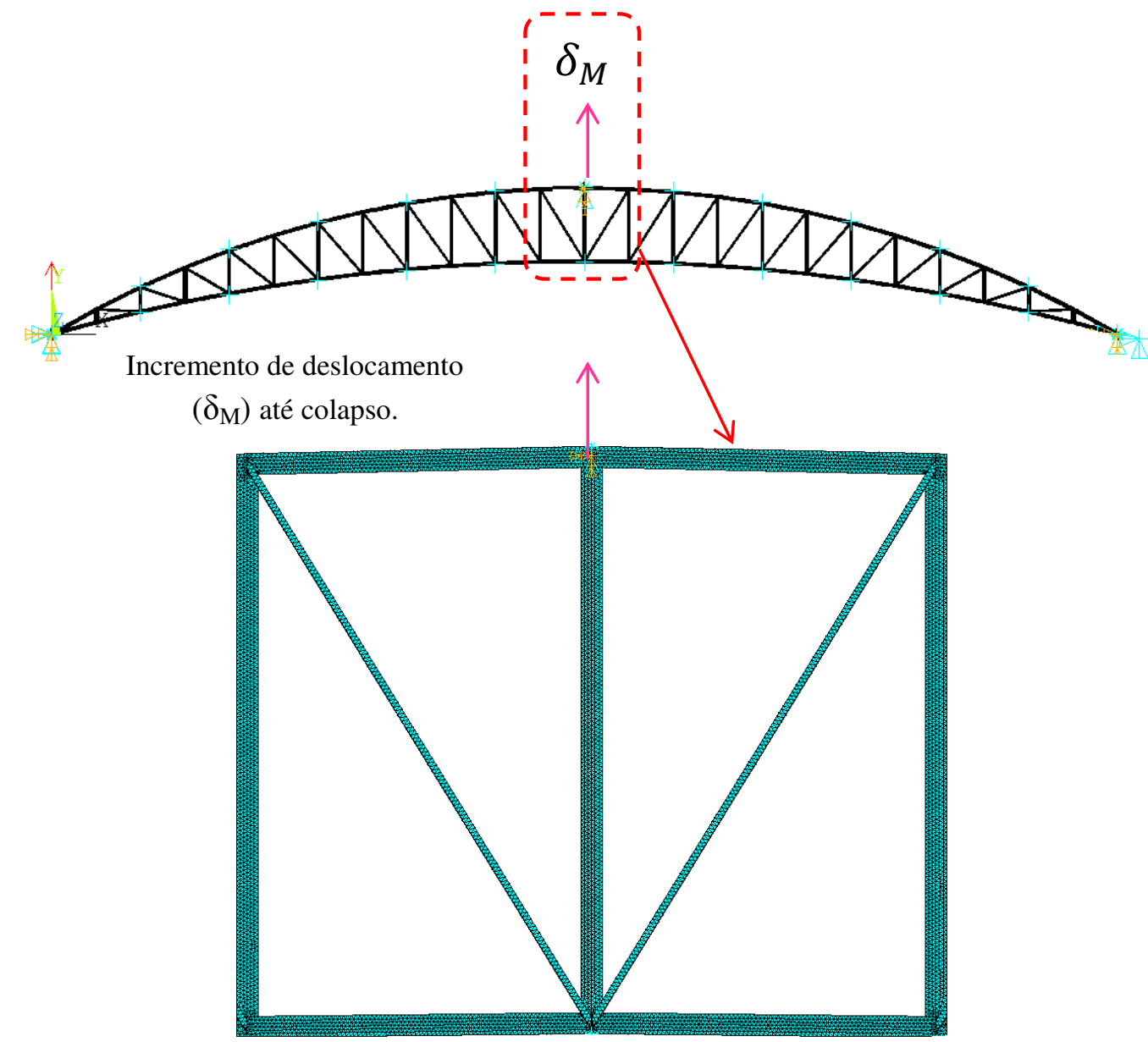

Figura 7.33 Deslocamento vertical aplicado no centro da treliça $\mathrm{D}_{80}$.

A Figura 7.34 apresenta as curvas carga versus deslocamento da treliça de $80 \mathrm{~m}$ de vão sem e com protensão na corda inferior, onde o carregamento foi aplicado através de incremento de deslocamento vertical até atingir a ruptura da treliça, utilizando-se como critério de convergência a norma de deslocamentos. É possível observar que as curvas com protensão são muito similares, além de terem cargas máximas superiores à curva da treliça sem protensão. 


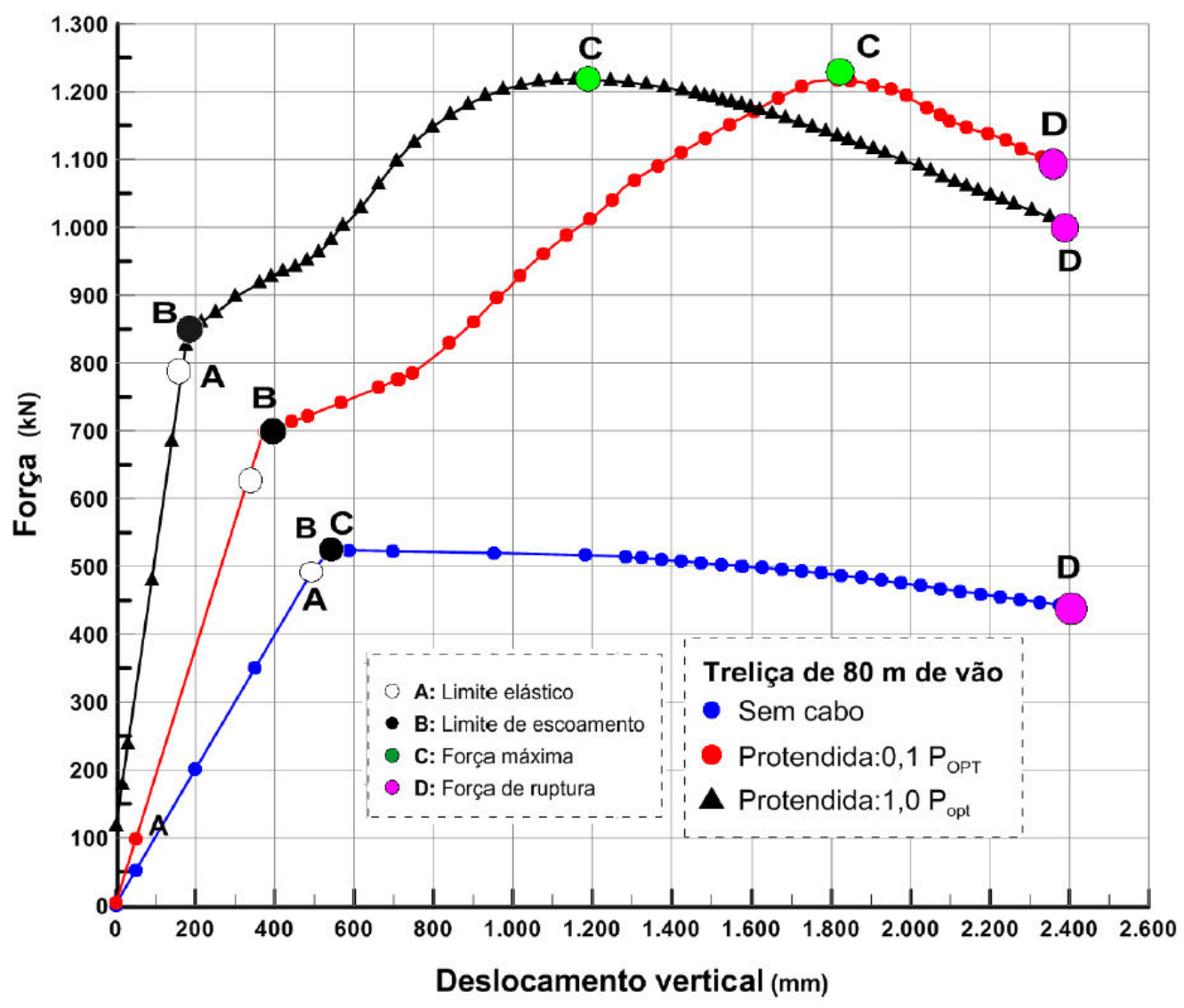

Figura 7.34 Força versus deslocamento vertical do meio do vão de $\mathrm{D}_{80}$ sem e com protensão.

Na Figura 7.34 referente às curvas nos pontos traçados $\mathbf{A}$ (limite elasticidade), B (limite de escoamento), C (força máxima) e $\mathbf{D}$ (força de ruptura) são mostradas as forças e deslocamentos em trecho linear e não linear nas treliças sem e com protensão de $80 \mathrm{~m}$. Na sequência do estudo as Figuras 7.35 até 7.43 mostram os resultados das tensões correspondentes às forças e deslocamentos dos pontos das curvas.

\subsection{1.}

\section{Treliça de $80 \mathrm{~m}$ sem protensão $\left(D_{80}\right)$}

Nas Figuras 7.25 até 7.28 são apresentados os resultados das distribuições das tensões de von Mises para diversos pontos da curva força versus deslocamento vertical aplicado no centro para a treliça de $80 \mathrm{~m}$ de vão sem protensão. Os resultados dos pontos característicos importantes das curvas da Figura 7.34 são analisados nesta seção. 
1. Ponto A: com base nos resultados obtidos, a Figura 7.35 ilustra a distribuição das tensões de von Mises referente ao ponto do limite de elasticidade da Figura 7.34 , onde se observa que o valor da tensão calculada foi igual a $318,74 \mathrm{MPa}$ (correspondente a um carregamento aplicado de $479,4 \mathrm{kN}$ ) na região onde foi aplicado o deslocamento vertical de 437,5 mm. Essa tensão é menor que ao valor de tensão limite do escoamento do material usado. Também se nota que o apoio da treliça sem protensão apresenta grandes concentrações de tensões, no qual a maior tensão resultou em 345,68 MPa. Esse valor é aproximado à tensão limite de escoamento, não há plastificação da estrutura nessa área.

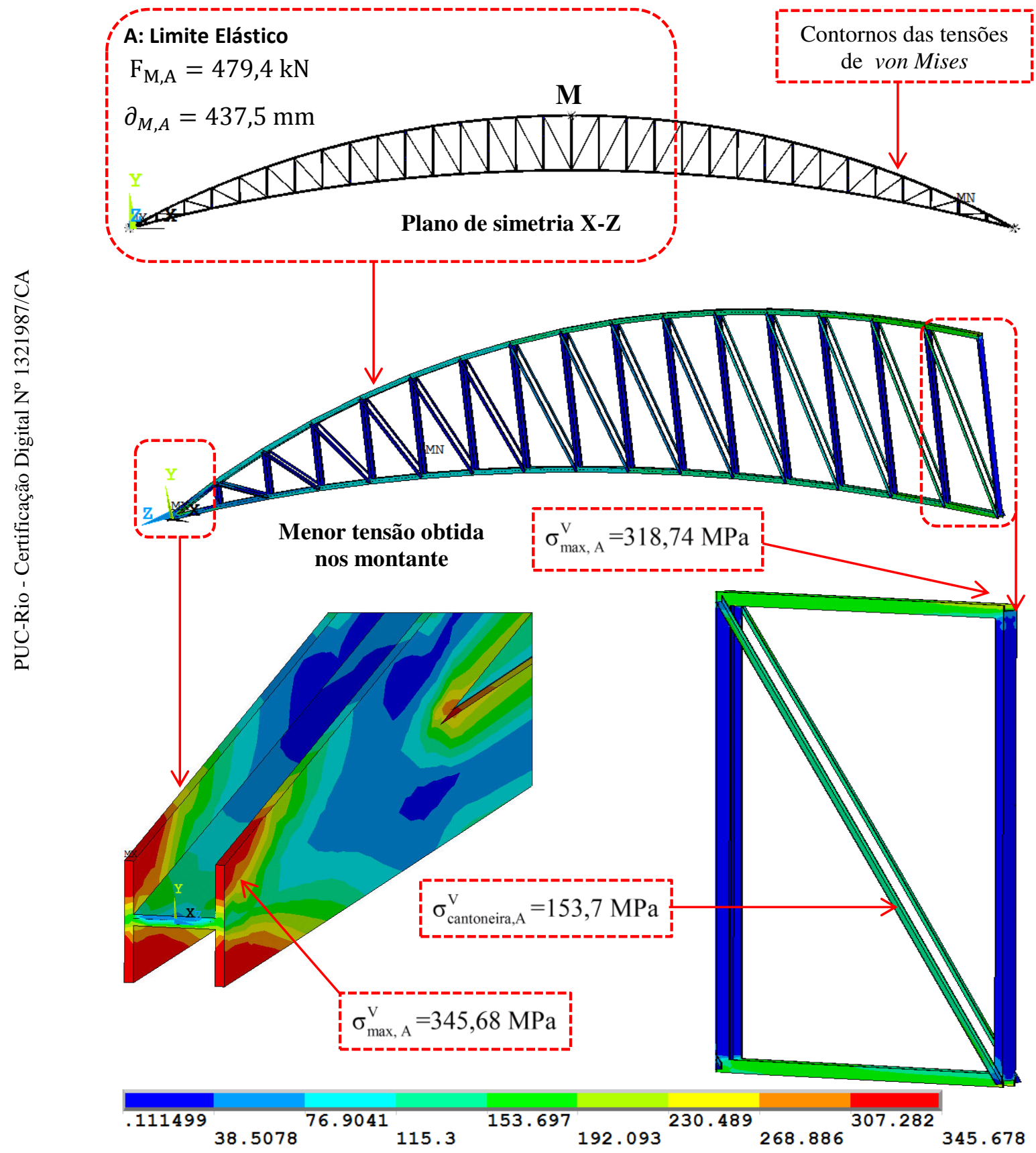

Figura 7.35 Distribuição de tensões de von Mises $(\mathrm{MPa})$ correspondente ao ponto $\mathrm{A}\left(\mathrm{D}_{80}\right)$ 
2. Ponto B: na Figura 7.36 percebe-se que há um aumento da distribuição das tensões de von Mises no que se refere ao ponto de limite de escoamento (Figura 7.34). Na região do centro da treliça $\partial_{M}$, foi observado que o valor da tensão calculada resultou em $322,041 \mathrm{MPa}$ (correspondente a um carregamento aplicado de 494,79 kN) para um deslocamento vertical de 496,13 mm. Essa tensão é menor que o valor de tensão limite do escoamento, ou seja, não há plastificação nesta região. Vale ressaltar que na região do apoio identifica-se a elevada distribuição de 346,25 MPa que, por sua vez, excede o valor limite de escoamento fazendo com que a estrutura comece a plastificar na zona do apoio. Também de forma a evidenciar na corda superior e inferior, nesta region. apresenta aproximadamente uma elevada tensão.

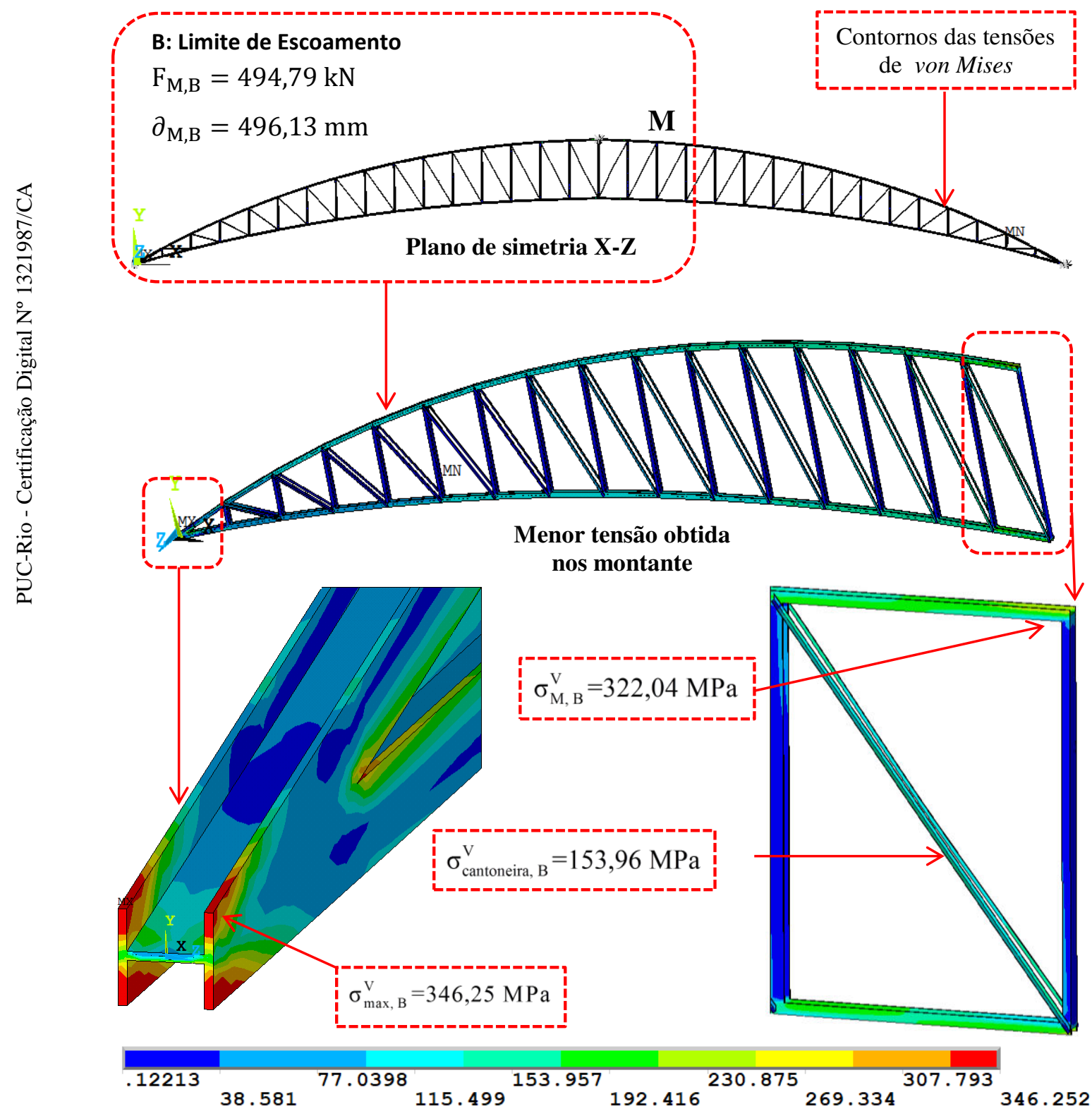

Figura 7.36 Distribuição de tensões de von Mises (MPa) correspondente ao ponto B $\left(\mathrm{D}_{80}\right)$. 
3. Ponto C: observando-se a distribuição das tensões de von Mises da Figura 7.37 referente ao ponto de força máxima da Figura 7.35, constata-se que o valor da tensão calculada foi igual a $344,96 \mathrm{MPa}$. Tal valor foi obtido na região do centro da treliça, para um deslocamento vertical $\partial_{M}$ de $541,14 \mathrm{~mm}$, correspondendo a um carregamento aplicado de 524,05 kN. Essa tensão é aproximadamente o valor de tensão limite de escoamento, ou seja, a estrutura não plastifica. Vale ressaltar que na região do apoio, observa-se a máxima distribuição de $349,53 \mathrm{MPa}$ (nomenclatura MX) e, a estrutura continua plastificando nesta zona de apoio. Também observado que nas diagonais ocorrência de estrangulação das cantoneiras para uma tensão de 283,49 MPa.

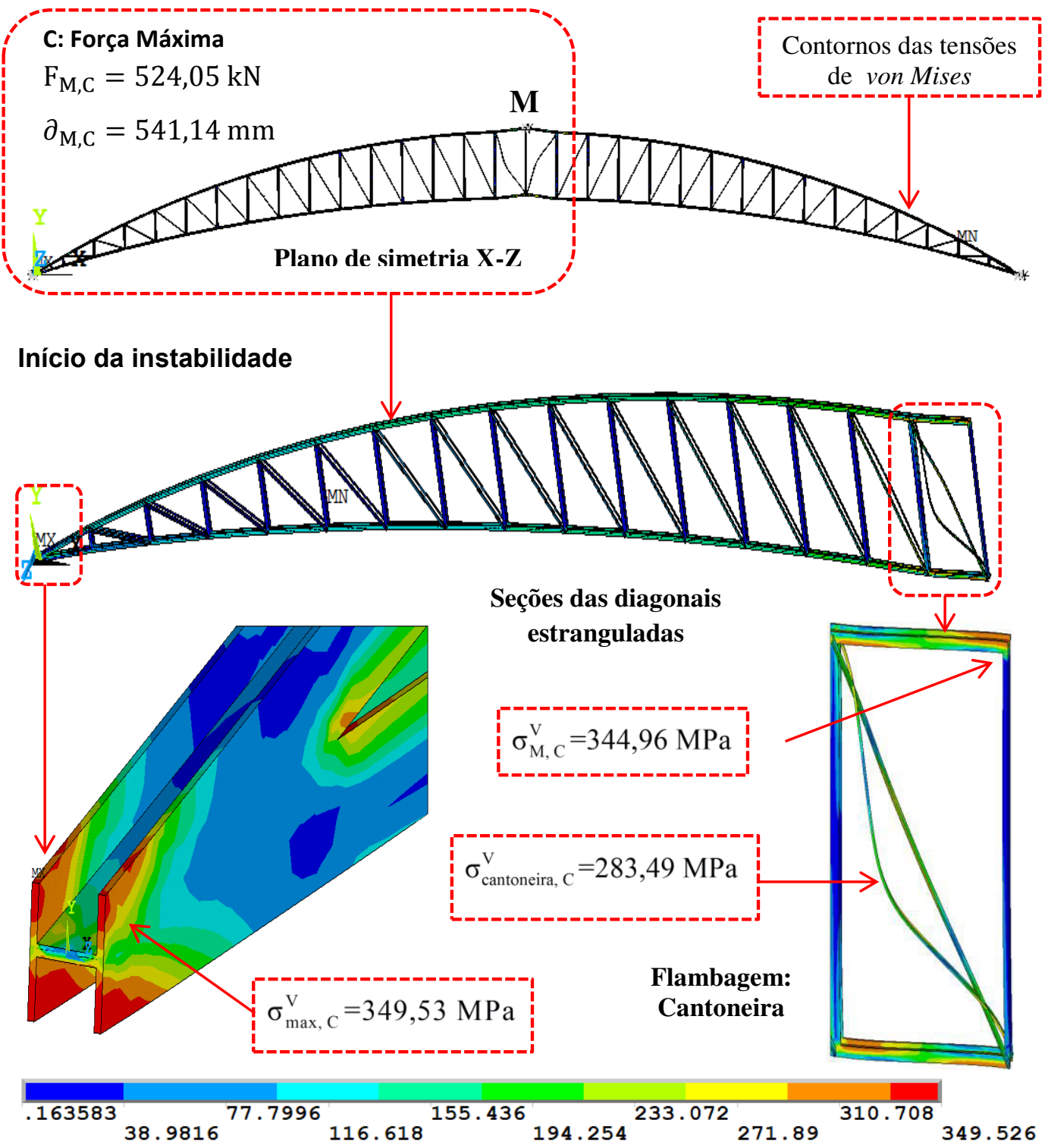

Figura 7.37 Distribuição de tensões de von Mises (MPa) correspondente ponto $C\left(D_{80}\right)$. 
4. Ponto D: avaliando-se a distribuição das tensões de von Mises da Figura 7.38 referente ao ponto de ruptura mostrado na Figura 7.35, pode-se verificar que o valor da tensão apresentada resultou em $363,58 \mathrm{MPa}$. Tal valor foi obtido na região do centro da treliça $\partial_{M}$, para um grande deslocamento vertical de 2.395,98 mm, correspondente a uma força de ruptura igual a 441,43 kN. Essa região apresenta deformações elevadas e os perfis das cordas superior, inferior, montantes e diagonais apresentam estrangulamento e redução da seção.

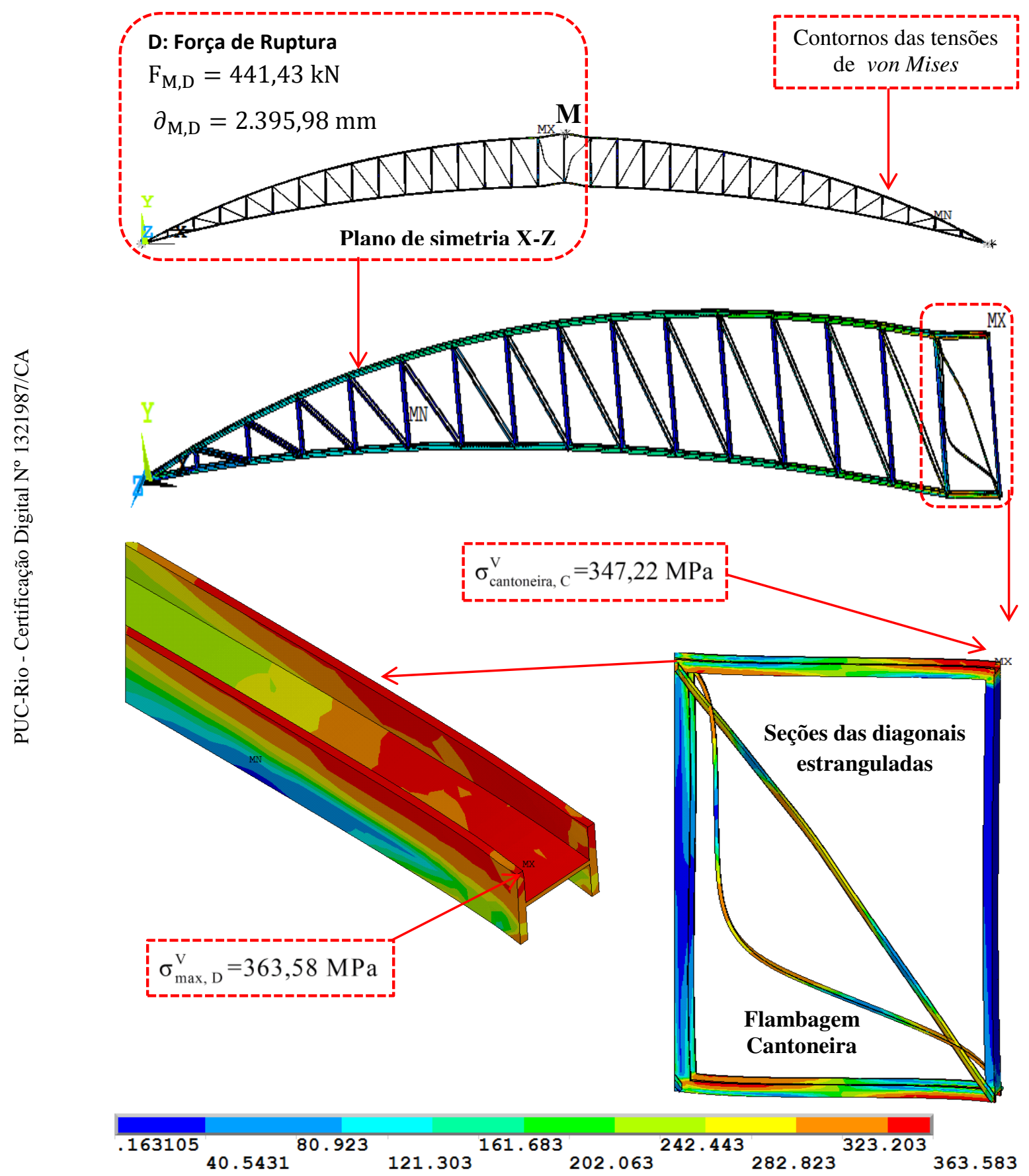

Figura 7.38 Distribuição de tensões de von Mises (MPa) correspondente ao ponto $\mathrm{D}\left(\mathrm{D}_{80}\right)$. 


\subsection{2.}

\section{Treliça de $80 \mathrm{~m}$ protendida $\left(\mathrm{D}_{\mathrm{P} 80}\right)$}

Neste item são apresentados os resultados da análise não linear física para treliça protendida de $80 \mathrm{~m}$ de vão, para dois níveis de força de protensão (Figura 7.34). Os resultados da análise com protensão ótima $(440,66 \mathrm{kN})$ são indicados nas Figuras 7.39 até 7.42. Estas Figuras apresentam as distribuições das tensões de von Mises para cada ponto da curva da força versus deslocamento vertical (ponto $\mathrm{M}$ ) da treliça.

\subsubsection{1.}

\section{Analise dos níveis de força de protensão para de $D_{\mathrm{P} 80}$}

A Figura 7.24 apresenta gráficos de forças versus deslocamentos para os dois diferentes níveis de força de protensão $\left(0,1 \mathrm{P}_{\text {opt }}\right.$ e $\left.\mathrm{P}_{\mathrm{opt}}\right)$, obtidas a partir de uma análise não linear física, onde os pontos característicos das curvas são analisados. As principais informações obtidas nestes gráficos são destacadas a seguir.

\section{Ponto A correspondente ao limite elástico}

Para uma variação de forças de protensão de $\mathbf{0 , 1} \mathbf{P}_{\mathbf{o p t}}$ para $\mathbf{P}_{\mathbf{o p t}}$ as forças aumentam de $627,01 \mathrm{kN}$ (com deslocamento $332,25 \mathrm{~mm}$ ) a $842,13 \mathrm{kN}$ (com deslocamento de 180,18 mm), ou seja, um acréscimo de 34,31\%.

\section{Ponto B correspondente ao limite de escoamento}

Para uma variação de forças de protensão de $\mathbf{0 , 1} \mathbf{P}_{\mathbf{o p t}}$ para $\mathbf{P}_{\mathbf{o p t}}$ as forças aumentam de 690,81 kN (com deslocamento 367,5 mm) a 845,153 kN (com deslocamento de 180,93 mm), ou seja, um acréscimo de 22,34\%.

\section{Ponto $\mathrm{C}$ correspondente à força máxima (Inicia da instabilidade)}

Para uma variação de forças de protensão de $\mathbf{0 , 1} \mathbf{P}_{\mathbf{o p t}}$ para $\mathbf{P}_{\mathbf{o p t}}$ as forças aumentam de $1.217,8 \mathrm{kN}$ (com deslocamento 1.815,39 mm) para 1.217,505 kN (com deslocamento de 1.156,22 mm), ou seja, uma redução de 0,02\%, ressaltando-se que a estruturas tem aproximadamente mesma força máxima, com deslocamentos diferentes. 


\section{Ponto $D$ correspondente à força de ruptura final:}

Para uma variação de forças de protensão de $\mathbf{0 , 1} \mathbf{P}_{\mathbf{o p t}}$ para $\mathbf{P}_{\mathbf{o p t}}$ as forças diminuem de $1.098,52 \mathrm{KN}$ (com deslocamento $2.359,14 \mathrm{~mm}$ ) a $1.006,48 \mathrm{kN}$ (com deslocamento de 2.394,83 mm), ou seja, uma redução de 8,38\% Observa-se que a estrutura com protensão ótima rompe com menor força de ruptura.

Com base na sequência das simulações numéricas realizadas, a Tabela 7.7 apresenta um resumo dos resultados obtidos no que se refere a forças e deslocamentos nos pontos de limite elástico, escoamento, força máxima e ruptura no centro do vão para a treliça de $80 \mathrm{~m}$. Em conclusão, os resultados mostram as variações de forças de ganho devido ao efeito dos níveis de forças de protensão solicitadas na estrutura.

Tabela 7.7 Níveis de força de protensão da treliça $\mathrm{D}_{80}$.

\begin{tabular}{cccc}
\hline \multirow{2}{*}{$\begin{array}{c}\text { Pontos das } \\
\text { curvas }\end{array}$} & $0,1 \mathrm{P}_{\mathrm{opt}}$ & $\mathrm{P}_{\mathrm{opt}}$ & $\begin{array}{c}\text { \% Razão } \\
\text { de força }\end{array}$ \\
\cline { 2 - 4 } & $(\mathrm{kN})$ & $(\mathrm{kN})$ & 34,31 \\
$\mathrm{~A}$ & 627,01 & 842,13 & 22,34 \\
$\mathrm{~B}$ & 690,81 & 845,15 & 0,02 \\
$\mathrm{C}$ & $1.217,8$ & $1.217,51$ & 8,38 \\
$\mathrm{D}$ & $1.098,52$ & $1.006,49$ & \\
\hline
\end{tabular}

\subsubsection{2.}

\section{Treliça de $80 \mathrm{~m}$ com protensão ótima $\left(\mathrm{D}_{\mathrm{P} 80}\right)$}

Nas Figuras 7.39 até 7.42 são apresentados os resultados das distribuições das tensões de von Mises para diversos pontos da curva força versus deslocamento vertical aplicado no centro para a treliça de $80 \mathrm{~m}$ de vão sem protensão. Os resultados dos pontos característicos importantes das curvas da Figura 7.34 são analisados nesta seção. 
1. Ponto A: com base nos resultados obtidos, a Figura 7.39 ilustra a distribuição das tensões de von Mises referente ao ponto do limite de elasticidade da Figura 7.34 , onde se observa que o valor da tensão calculada foi igual a 309,54 MPa (correspondente a um carregamento aplicado de $824,48 \mathrm{kN}$ ) onde foi aplicado o deslocamento vertical $\partial_{\mathrm{M}}$ de $175,78 \mathrm{~mm}$. Essa tensão é menor que valor de tensão limite do escoamento, ou seja, não há plastificação da estrutura nesta área. Observa-se, que na chapa de ancoragem da treliça protendida, apresenta grandes concentrações de tensões, onde se tem maior tensão de 346,07 MPa.

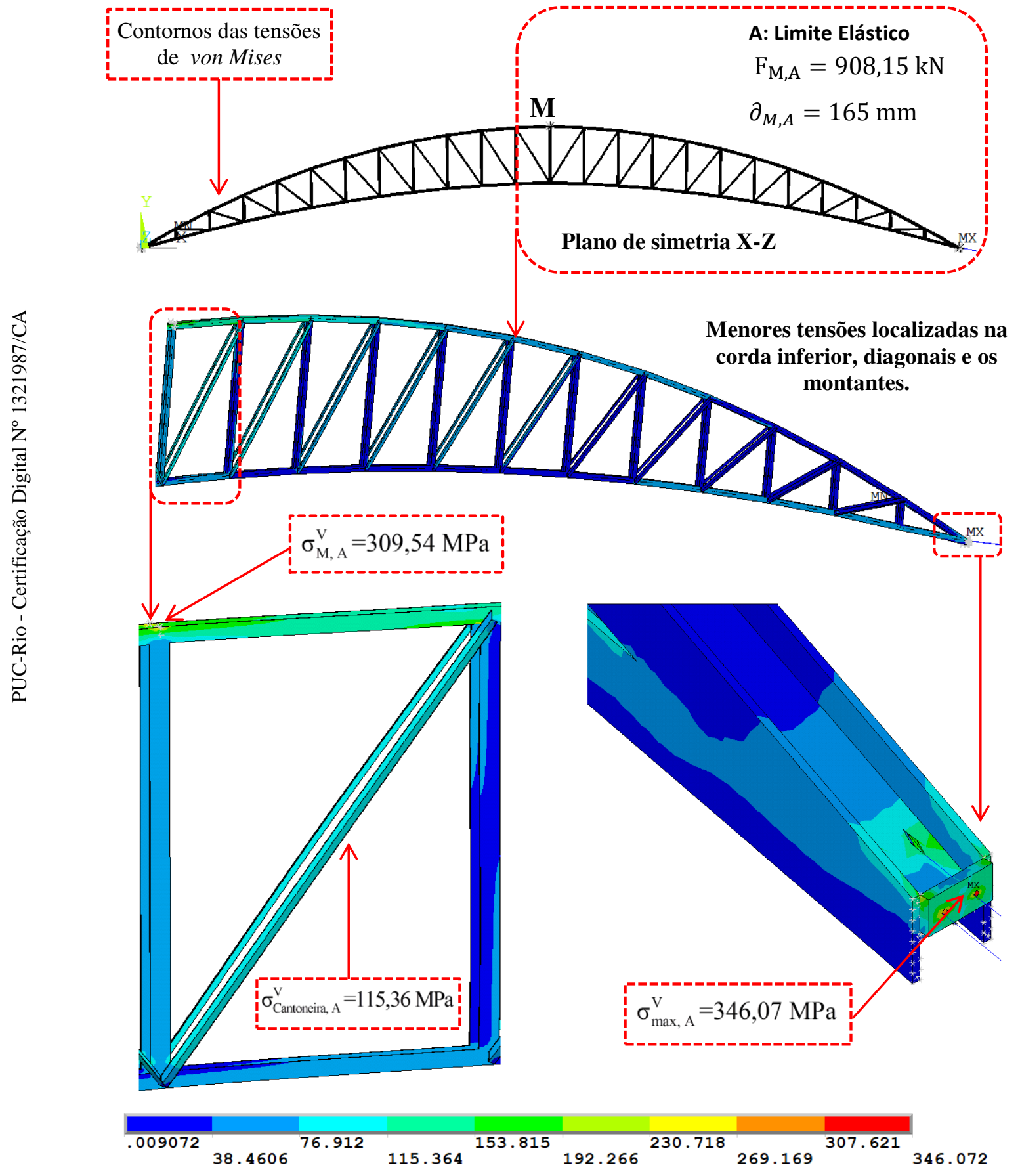

Figura 7.39. Distribuição de tensões de von Mises $(\mathrm{MPa})$ correspondente ao ponto $\mathrm{A}\left(\mathrm{D}_{\mathrm{P} 80}\right)$. 
2. Ponto B: na Figura 7.40 percebe-se que há um aumento da distribuição das tensões de von Mises no que se refere ao ponto de limite de escoamento (Figura 7.34). Na região do centro da treliça $\partial_{M}$, foi observado que o valor da tensão calculada resultou em 344,63 MPa (a um carregamento aplicado de $840,99 \mathrm{kN}$ ) para um deslocamento vertical de 180,18 mm. Essa tensão é aproximadamente do valor de tensão limite do escoamento, ou seja, não há plastificação da estrutura nesta área. Vale ressaltar que na região da chapa de ancoragem, identifica-se a elevada distribuição de 350,01 MPa (ponto MX) nas diagonais.

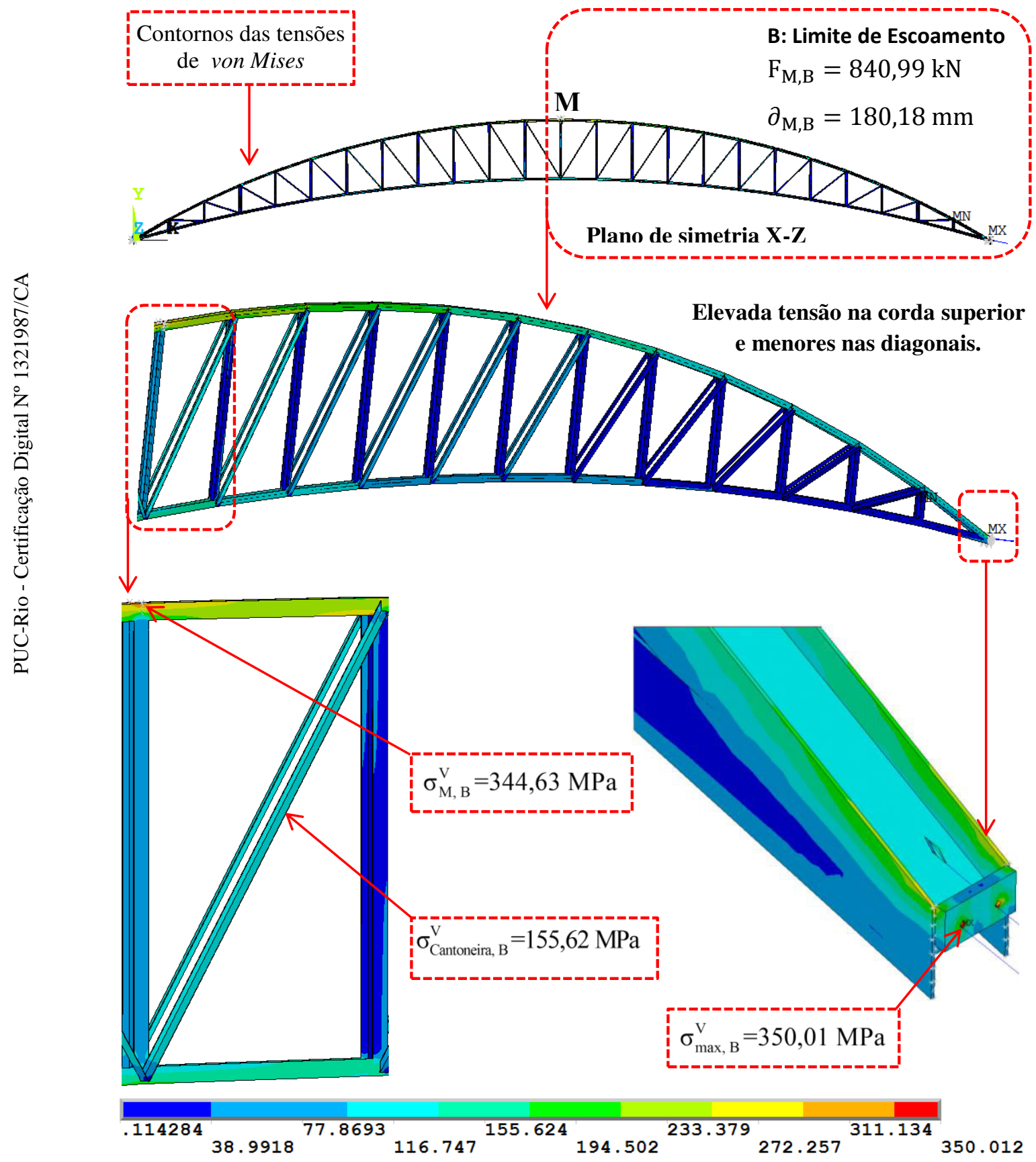

Figura 7.40 Distribuição de tensões de von Mises $(\mathrm{MPa})$ correspondente ao ponto $\mathrm{B}\left(\mathrm{D}_{\mathrm{P} 80}\right)$. 
3. Ponto C: observando-se a distribuição das tensões de von Mises da Figura 7.41 referente ao ponto de força máxima da Figura 7.34, constata-se que o valor da tensão calculada foi igual a 351,45 MPa. Tal valor foi obtido na região do centro da treliça $\partial_{M}$ para um deslocamento vertical de 1.156,22 $\mathrm{mm}$, correspondendo a um carregamento aplicado de 1.217,06 kN. Essa tensão é maior do que o valor de tensão limite de escoamento. Vale ressaltar que na região da chapa da treliça, observa-se a máxima distribuição $360,72 \mathrm{MPa}$ e, a estrutura continua plastificando-se nessa zona da chapa. Nas diagonais observa-se a ocorrência de flambagem local, com valor da tensão de 260,53 MPa.

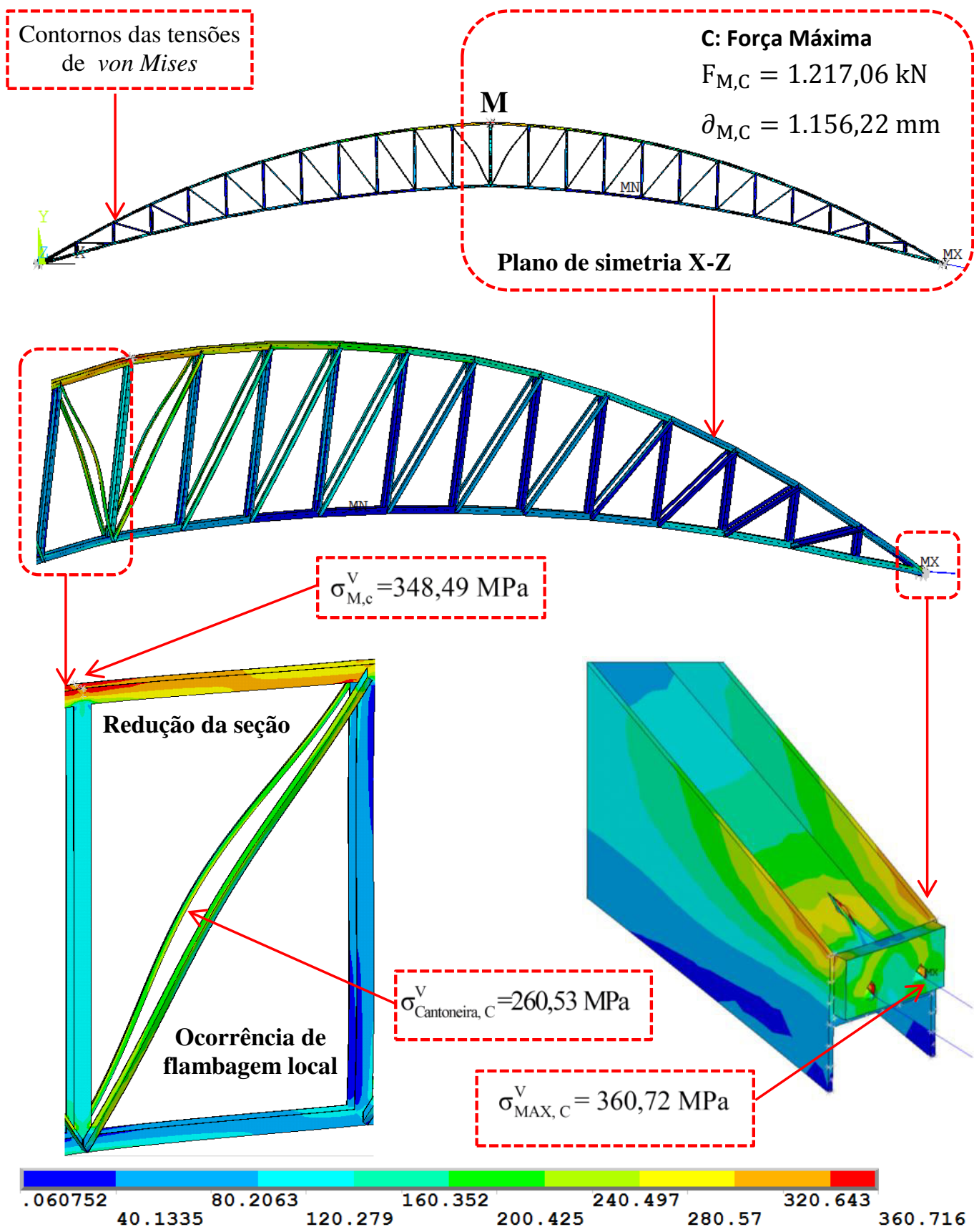

Figura 7.41 Distribuição de tensões de von Mises $(\mathrm{MPa})$ correspondente ponto $\mathrm{C}\left(\mathrm{D}_{\mathrm{P} 80}\right)$. 
4. Ponto D: avaliando-se a distribuição das tensões de von Mises da Figura 7.42 referente ao ponto de ruptura mostrado na Figura 7.34, pode-se verificar que o valor da tensão máxima apresentada resultou em 365,12 MPa, onde ocorre está representado com a nomenclatura MX. Tal valor foi obtido na região do centro da treliça, para um grande deslocamento vertical de $2.394,83 \mathrm{~mm}$, correspondente a uma força de ruptura igual a 1.006,49 kN. Essa região apresenta deformações elevadas e os perfis das cordas superior, inferior, montantes e diagonais mostram flambagem.

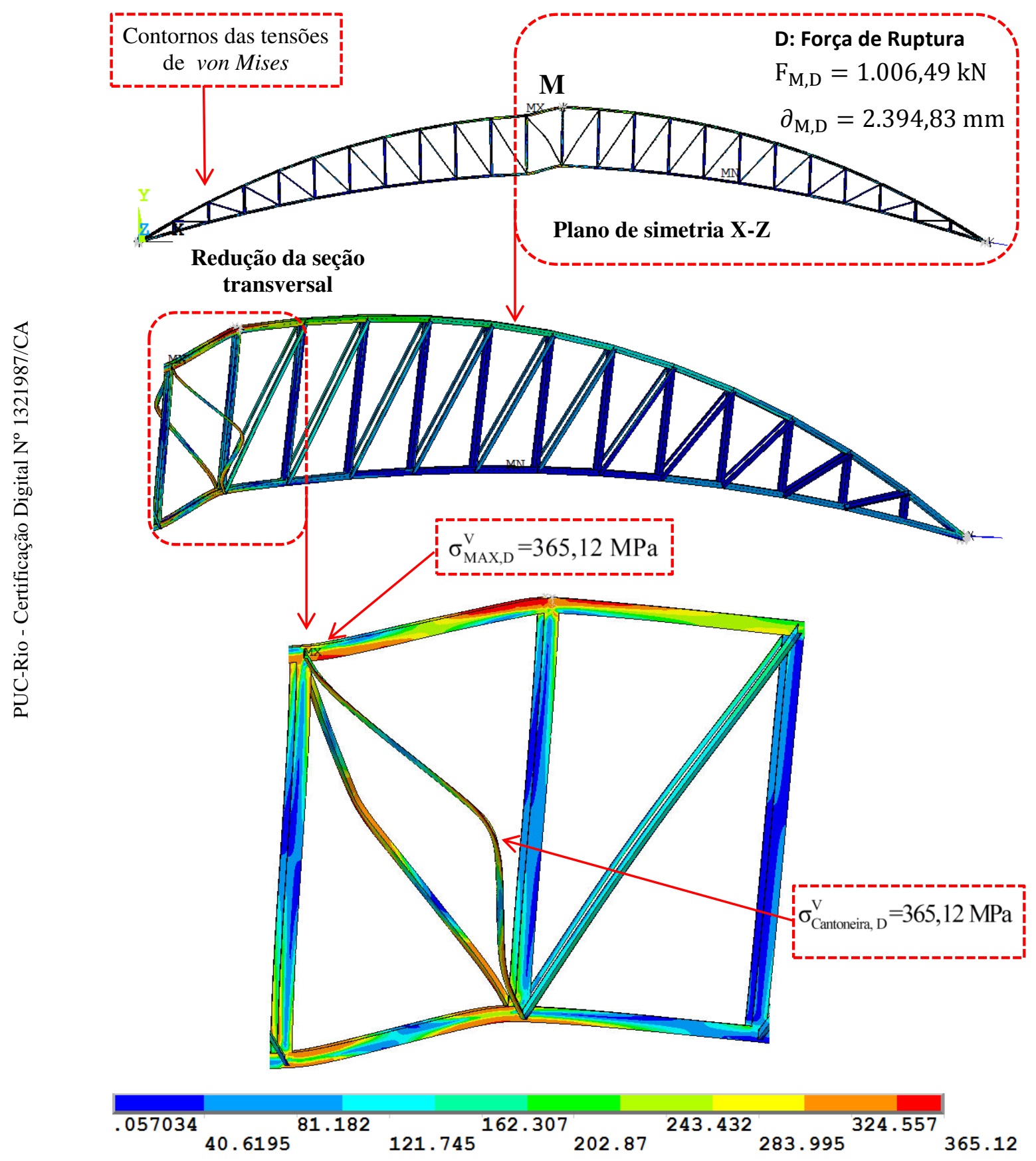

Figura 7.42. Distribuição de tensões de von Mises $(\mathrm{MPa})$ correspondente ao ponto $\mathrm{D}\left(\mathrm{D}_{80}\right)$ 
Com base na sequência da modelagem numérica realizada a Tabela 7.8 apresenta um resumo dos resultados obtidos no que se refere a forças e deslocamentos nos pontos de limite elástico, escoamento, força máxima e ruptura no centro do vão para a treliça de $80 \mathrm{~m}$, sem e com protensão.

Tabela 7.8 Resumo dos resultados das forças e deslocamentos da treliça $80 \mathrm{~m}$ sem e com protensão nos pontos das curvas (Figura 7.34).

\begin{tabular}{cccccc}
\hline & \multicolumn{2}{c}{ Treliça sem protensão } & \multicolumn{2}{c}{ Treliça com protensão } & \% Razão \\
\cline { 2 - 5 } Pontos das curvas & $\begin{array}{c}\text { Força } \\
(\mathrm{kN})\end{array}$ & $\begin{array}{c}\text { Deslocamento } \\
(\mathrm{mm})\end{array}$ & $\begin{array}{c}\text { Força } \\
(\mathrm{kN})\end{array}$ & $\begin{array}{c}\text { Deslocamento } \\
(\mathrm{mm})\end{array}$ & de Força \\
\hline $\begin{array}{c}\text { A: } \\
\text { (Limite elástico) }\end{array}$ & 479,4 & 437,5 & 824,48 & 175,78 & 72 \\
$\begin{array}{c}\text { B: } \\
\begin{array}{c}\text { (Limite escoamento) } \\
\text { C: }\end{array}\end{array}$ & 494,79 & 496,13 & 840,99 & 180,18 & 70 \\
$\begin{array}{c}\text { (Força máxima) } \\
\text { D: }\end{array}$ & 524,05 & 541,14 & $1.217,06$ & $1.156,22$ & 132,24 \\
(Força ruptura) & 441,43 & $2.395,98$ & $1.006,49$ & $2.394,83$ & 128 \\
\hline
\end{tabular}

Com base nos resultados da Tabela 7.8 apresentam um resumo das forças e deslocamentos para diferentes pontos da curva carga versus deslocamento nos trechos elástico e plástico para o modelo da treliça de $80 \mathrm{~m}$. Esse resultados confirma o obtidos na modelagem das treliças de $10 \mathrm{~m}, 20 \mathrm{~m}$ e $40 \mathrm{~m}$, as conclusões do Projeto, HILONG "HSS trusses to be tested at Imperial College" (Gkantou et al., 2015) e as conclusões de Belenya (1997) e de Troitsky (1990). 


\section{5.}

\section{Análise não linear da treliça de 120 m de vão}

A análise não linear para a treliça de $120 \mathrm{~m}$ de vão sem e com protensão foi executada a partir da aplicação de deslocamento no centro da treliça. $\mathrm{Na}$ Figura 7.43, são mostrados um modelo de treliça, as condições de contorno e a aplicação do deslocamento. Também é mostrada uma ampliação da estrutura na parte em que está aplicando o deslocamento.

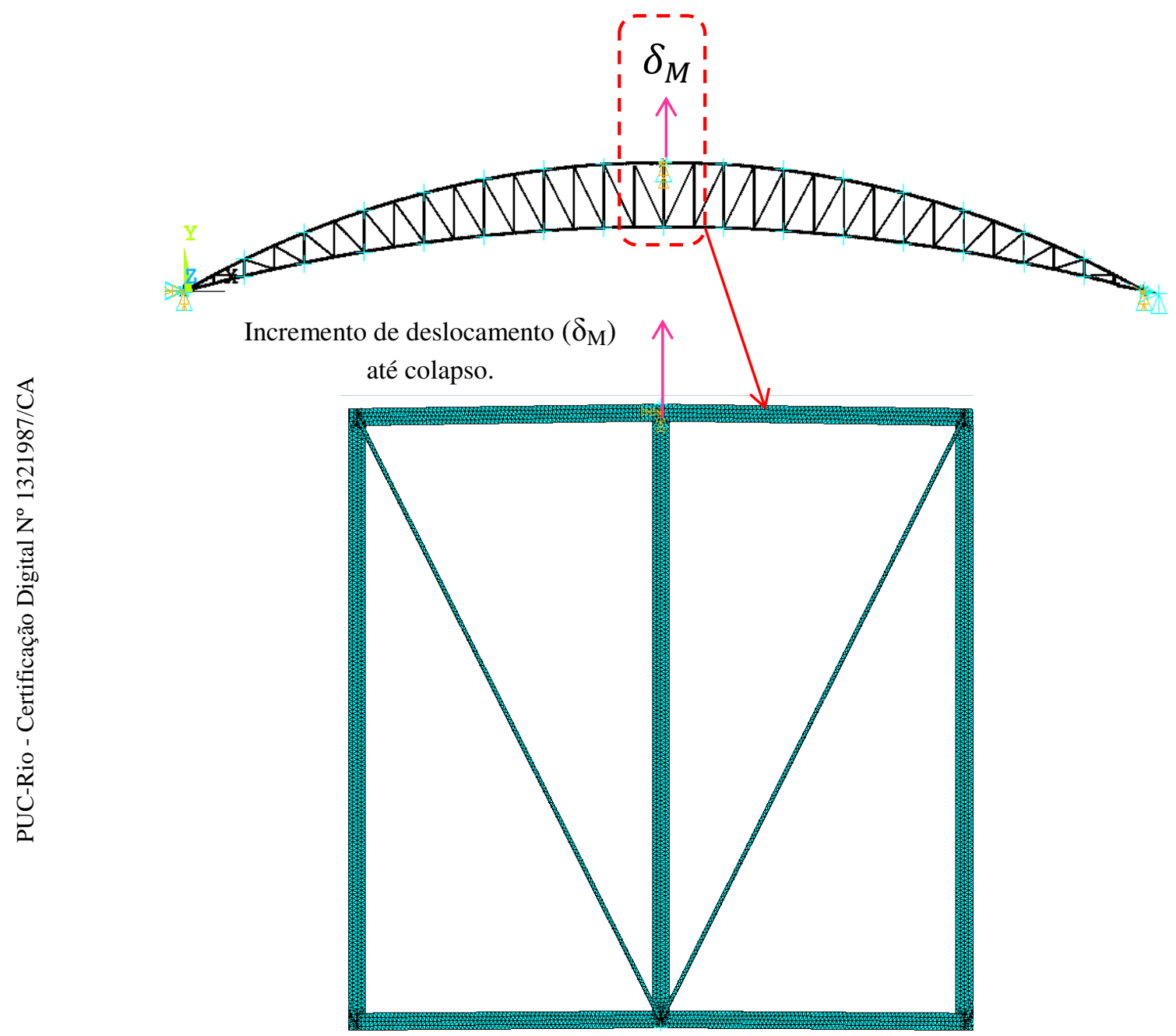

Figura 7.43 Deslocamento vertical aplicado no centro da treliça $\mathrm{E}_{120}$.

A Figura 7.44 apresenta as curvas carga versus deslocamento da treliça de 120 m de vão sem e com protensão na corda inferior, onde o carregamento foi aplicado por meio de incremento de deslocamento vertical. Observa-se que as curvas com protensão são muito similares, além de terem cargas máximas superiores à da treliça sem protensão. 


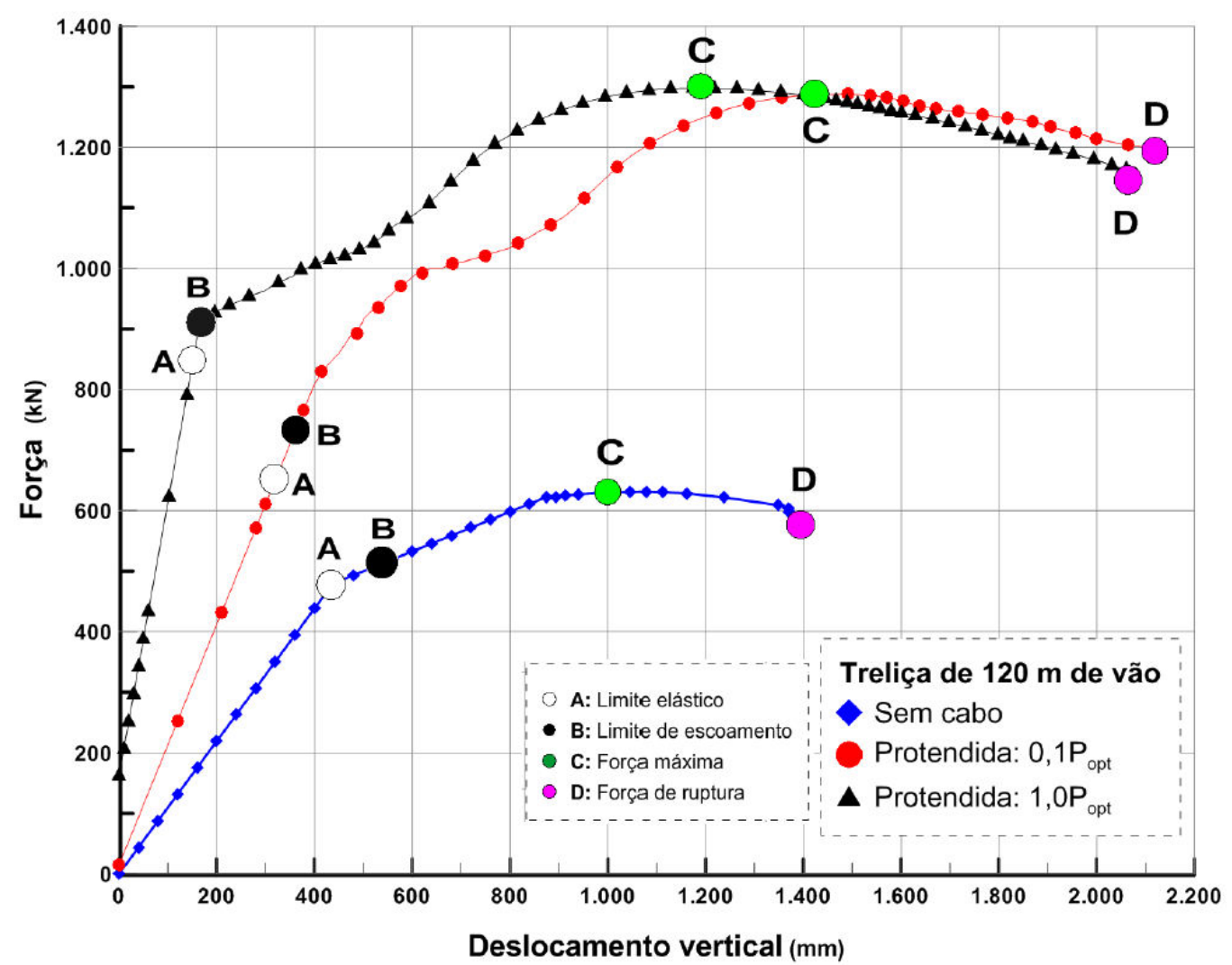

Figura 7.44 Força versus deslocamento vertical do meio do vão de $\mathrm{E}_{120}$ sem cabo e com protensão.

$\mathrm{Na}$ Figura 7.44 referente às curvas nos pontos traçados A (limite elasticidade), B (limite de escoamento), C (força máxima) e D (força de ruptura) são mostradas as forças e deslocamentos em trecho linear e não linear nas treliças sem e com protensão de $120 \mathrm{~m}$. Na sequência do estudo, as Figuras 7.41até 7.48 mostram os resultados das tensões correspondentes às forças e deslocamentos dos pontos das curvas.

\subsection{1.}

\section{Treliça de $120 \mathrm{~m}$ sem protensão $\left(E_{120}\right)$}

Nas Figuras 7.45 até 7.48 são apresentados os resultados das distribuições das tensões de von Mises para diversos pontos da curva força versus deslocamento vertical aplicado no centro para a treliça de $120 \mathrm{~m}$ de vão sem protensão. Os resultados dos pontos característicos importantes das curvas da Figura 7.44 são analisados nesta seção. 
1. Ponto A: com base nos resultados obtidos, a Figura 7.45 ilustra a distribuição das tensões de von Mises referente ao ponto do limite de elasticidade da Figura 7.44 , onde se observa que o valor da tensão calculada foi igual a 318,74 MPa (correspondente a um carregamento aplicado de $480 \mathrm{kN}$ ) na região onde foi aplicado o deslocamento vertical $\partial_{\mathrm{M}}$ de 493,3 $\mathrm{mm}$. Essa tensão é aproximadamente do valor de tensão limite do escoamento, ou seja, não há plastificação da estrutura nesta área. Observa-se que na chapa de ancoragem da treliça protendida, apresenta grandes concentrações de tensões, onde se tem maior tensão de 345,68 MPa está representada com a nomenclatura MX.

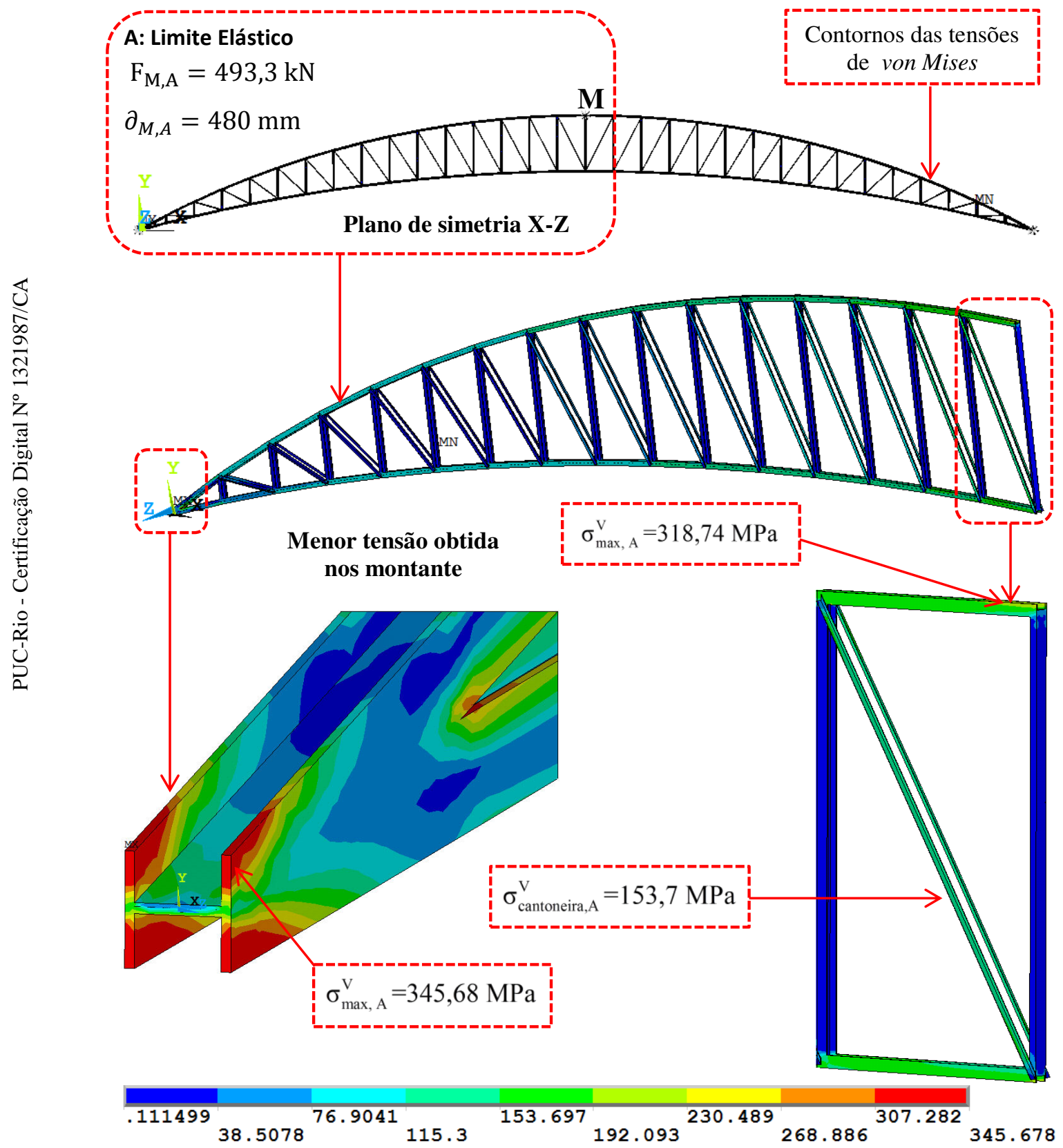

Figura 7.45 Distribuição de tensões de von Mises $(\mathrm{MPa})$ correspondente ao ponto A $\left(\mathrm{D}_{120}\right)$. 
2. Ponto B: na Figura 7.46 percebe-se que há um aumento da distribuição das tensões de von Mises no que se refere ao ponto de limite de escoamento (Figura 7.44). Na região do centro da treliça $\partial_{M}$, foi observado que o valor da tensão calculada resultou em 322,04 MPa (correspondente a um carregamento aplicado de506,39 kN) para um deslocamento vertical de $520 \mathrm{~mm}$. Essa tensão é menor que o valor de tensão limite do escoamento, ou seja, não há plastificação nesta região. Vale ressaltar que na região do apoio identifica-se a elevada distribuição de 346,25 MPa que, por sua vez, excede o valor limite de escoamento fazendo com que a estrutura comece a plastificar na zona do apoio. Também de forma a evidenciar a corda superior e inferior, nessa região apresenta aproximadamente uma elevada tensão.

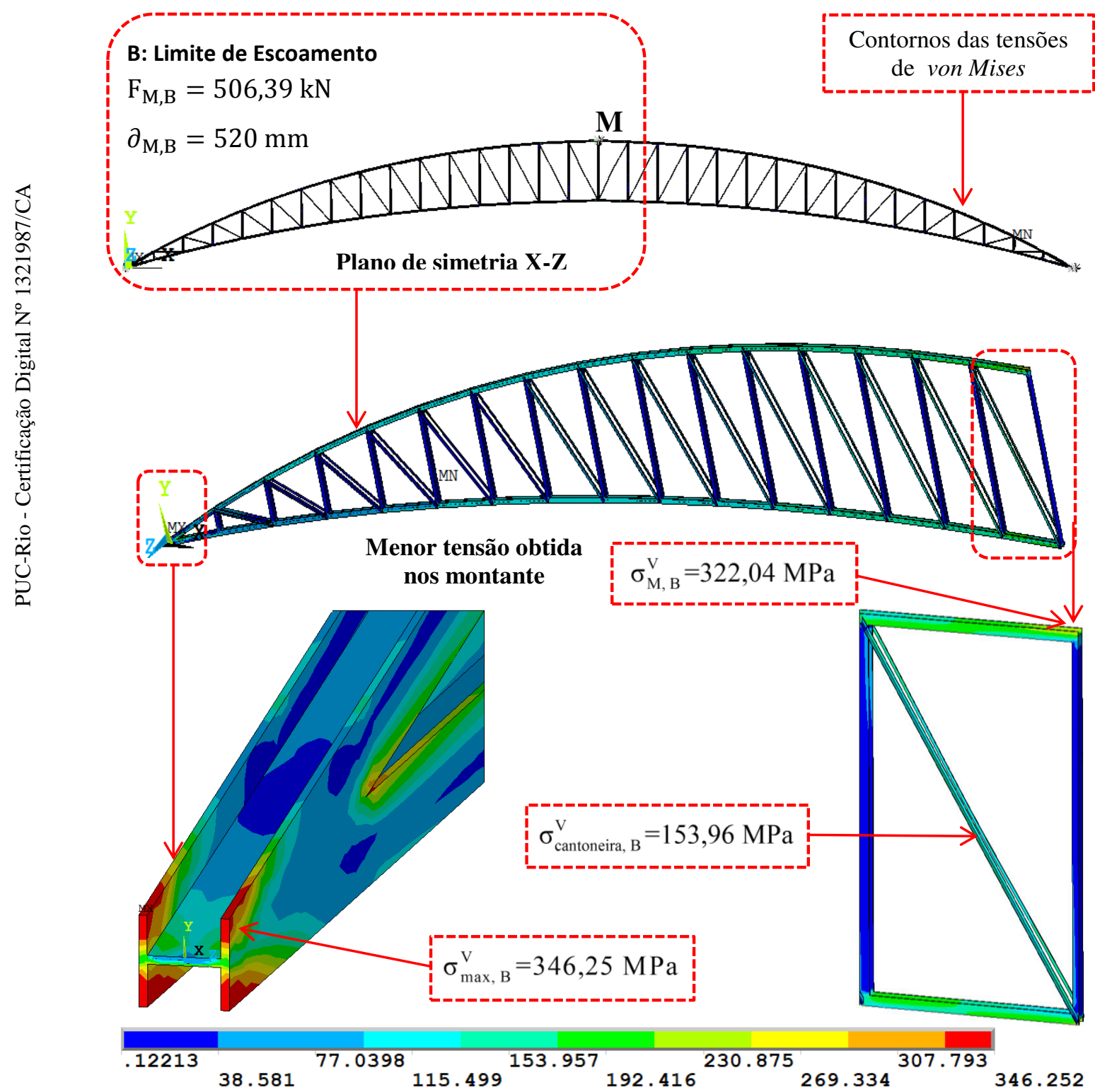

Figura 7.46. Distribuição de tensões de von Mises $(\mathrm{MPa})$ correspondente ao ponto $\mathrm{B}\left(\mathrm{E}_{120}\right)$. 
3. Ponto C: observando-se a distribuição das tensões de von Mises da Figura 7.47 referente ao ponto de força máxima da Figura 7.35, constata-se que o valor da tensão calculada foi igual a 344,96 MPa. Tal valor foi obtido na região do centro da treliça, para um deslocamento vertical $\partial_{M}$ de $1.079,4 \mathrm{~mm}$, correspondendo a um carregamento aplicado de 631,43 kN. Esta tensão é aproximadamente o valor de tensão limite de escoamento, ou seja, a estrutura não plastifica. Vale ressaltar que na região do apoio, observa-se a máxima distribuição de 349,526 $\mathrm{MPa}$ (nomenclatura MX) e, a estrutura continua plastificando nesta zona de apoio. Também observado que nas diagonais ocorrência de estrangulação das cantoneiras, para uma tensão de 283,58 MPa.
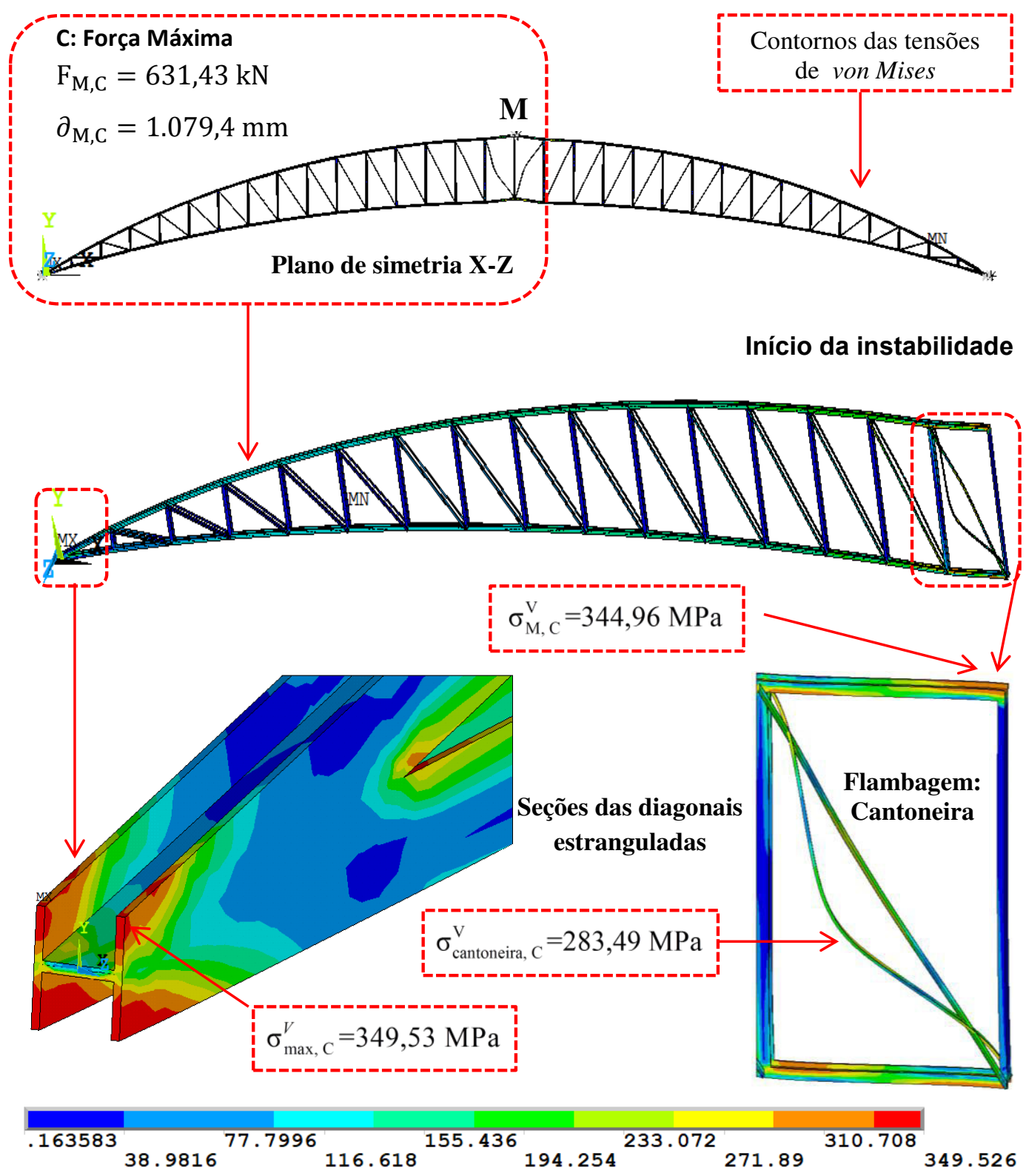

Figura 7.47. Distribuição de tensões de von Mises $(\mathrm{MPa})$ correspondente ao ponto $\mathrm{C}\left(\mathrm{E}_{120}\right)$. 
4. Ponto D: avaliando-se a distribuição das tensões de von Mises da Figura 7.48 referente ao ponto de ruptura mostrado na Figura 7.44, pode-se verificar que o valor da tensão apresentada resultou em 363,58 MPa. Tal valor foi obtido na região do centro da treliça $\partial_{M}$, para um grande deslocamento vertical de $1.371,43 \mathrm{~mm}$, correspondente a uma força de ruptura igual a $595,95 \mathrm{kN}$. Essa região apresenta deformações elevadas e os perfis das cordas superior, inferior, montantes e diagonais apresentam estrangulamento e redução da seção.

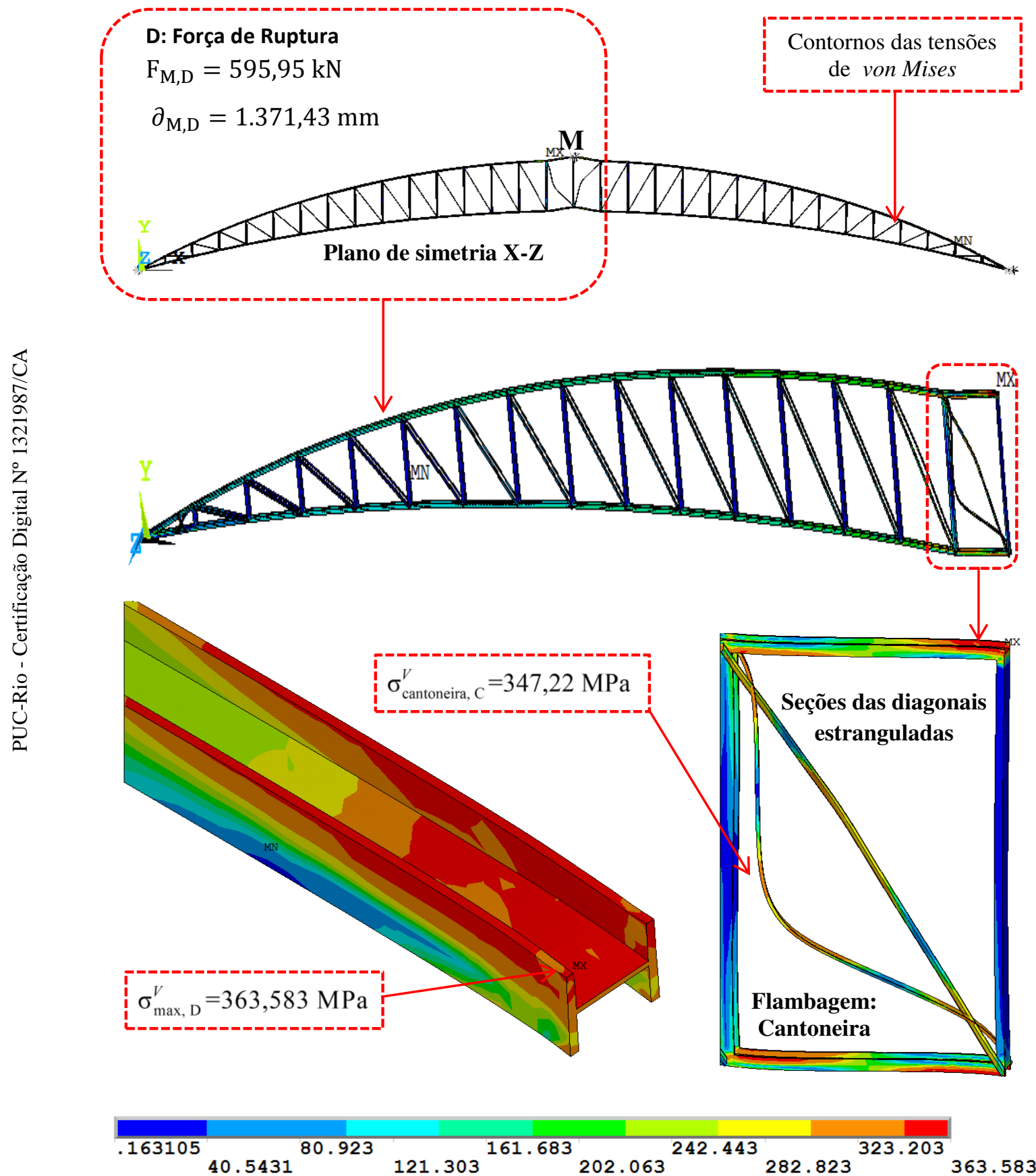

Figura 7.48. Distribuição de tensões de von Mises $(\mathrm{MPa})$ correspondente ponto $\mathrm{D}\left(\mathrm{E}_{120}\right)$. 


\subsection{2.}

\section{Treliça de $120 \mathrm{~m}$ protendida $\left(\mathrm{E}_{\mathrm{P} 120}\right)$}

Neste item são apresentados os resultados da análise não linear física para treliça protendida de $120 \mathrm{~m}$ de vão, para dois níveis de força de protensão (Figura 7.44). Os resultados da análise com protensão ótima $(860,56 \mathrm{kN})$ são indicados nas Figuras 7.49 até 7.52. Estas figuras apresentam as distribuições das tensões de von Mises para cada ponto da curva da força versus deslocamento vertical (ponto $\mathrm{M}$ ) da treliça.

\subsubsection{1.}

\section{Analise dos níveis de força de protensão para de $E_{\mathrm{P} 120}$}

A Figura 7.24 apresenta gráficos de forças versus deslocamentos para os dois diferentes níveis de força de protensão $\left(0,1 \mathrm{P}_{\mathrm{opt}}\right.$ e $\left.\mathrm{P}_{\mathrm{opt}}\right)$, obtidas a partir de uma análise não linear física, onde os pontos característicos das curvas são analisados. As principais informações obtidas nestes gráficos são destacadas a seguir:

\section{Ponto A correspondente ao limite elástico}

Para uma variação de forças de protensão de $\mathbf{0 , 1} \mathbf{P}_{\mathbf{o p t}}$ para $\mathbf{P}_{\mathbf{o p t}}$ as forças aumentam de 640,39 $\mathrm{kN}$ (com deslocamento $310 \mathrm{~mm}$ ) a 908,15 kN (com deslocamento de $165 \mathrm{~mm}$ ), ou seja, um acréscimo de 41,81\%.

\section{Ponto B correspondente ao limite de escoamento}

Para uma variação de forças de protensão de $\mathbf{0 , 1} \mathbf{P}_{\mathbf{o p t}}$ para $\mathbf{P}_{\mathbf{o p t}}$ as forças aumentam de 685,13 kN (com deslocamento $330 \mathrm{~mm}$ ) a 927,08 kN (com deslocamento de 195,16 mm), ou seja, um acréscimo de 35,32\%.

\section{Ponto $\mathrm{C}$ correspondente à força máxima (Inicia da instabilidade)}

Para uma variação de forças de protensão de $\mathbf{0 , 1} \mathbf{P}_{\mathbf{o p t}}$ para $\mathbf{P}_{\mathbf{o p t}}$ as forças aumentam de $1.287,51 \mathrm{kN}$ (com deslocamento $1.469,13 \mathrm{~mm}$ ) para $1.057,51 \mathrm{kN}$ (com deslocamento de 1.174,13 mm), ou seja, uma acréscimo de 0,77\%, ressaltando-se que a estruturas tem aproximadamente mesma força máxima, com diferente deslocamento. 


\section{Ponto $D$ correspondente à força de ruptura}

Para uma variação de forças de protensão de $\mathbf{0 , 1} \mathbf{P}_{\mathbf{o p t}}$ para $\mathbf{P}_{\mathbf{o p t}}$ as forças diminuem de 1.196,50 KN (com deslocamento 2.115,24 mm) a 1.162,51 kN (com deslocamento de 2.060,24 mm), ou seja, uma redução de 2,84 \%. Observase que a estrutura com protensão ótima rompe com menor força de ruptura.

Na sequência das simulações numéricas realizadas a Tabela 7.9 apresenta um resumo dos resultados obtidos no que se refere a forças e deslocamentos nos pontos de limite elástico, escoamento, força máxima e ruptura no centro do vão para a treliça de $120 \mathrm{~m}$. Em conclusão, os resultados mostram as variações de forças de ganho devido ao efeito dos níveis de forças de protensão solicitadas na estrutura.

Tabela 7.9 Níveis de força de protensão da treliça $\mathrm{E}_{120}$

\begin{tabular}{cccc}
\hline \multirow{2}{*}{$\begin{array}{c}\text { Pontos das } \\
\text { curvas }\end{array}$} & $0,1 \mathrm{P}_{\mathrm{opt}}$ & $\mathrm{P}_{\mathrm{opt}}$ & $\begin{array}{c}\text { \% Razão } \\
\text { De força }\end{array}$ \\
\cline { 2 - 3 } & $(\mathrm{KN})$ & $(\mathrm{KN})$ & \\
\cline { 2 - 4 } $\mathrm{A}$ & 640,39 & 908,15 & 41,81 \\
B & 685,13 & 927,08 & 35,32 \\
C & $1.287,51$ & $1.297,51$ & 0,78 \\
D & $1.196,5$ & $1.162,51$ & 2,84 \\
\hline
\end{tabular}

\subsection{3.}

\section{Treliça de 120 com Protensão Ótima $\left(E_{\mathrm{P} 120}\right)$}

Nas Figuras 7.49 até 7.52 são apresentados os resultados das distribuições das tensões de von Mises para diversos pontos da curva força versus deslocamento vertical aplicado no centro para a treliça de $40 \mathrm{~m}$ de vão sem protensão. Os resultados dos pontos característicos importantes das curvas da Figura 7.24, são analisados nesta seção. 
Ponto A: com base nos resultados obtidos, a Figura 7.49 ilustra a distribuição das tensões de von Mises referente ao ponto do limite de elasticidade da Figura 7.44, onde se observa que o valor da tensão calculada foi igual a 333,24 MPa (correspondente a um carregamento aplicado de $908,15 \mathrm{kN}$ ) na região onde foi aplicado o deslocamento vertical $\partial_{\mathrm{M}}$ de $165 \mathrm{~mm}$. Essa tensão é menor que valor de tensão limite do escoamento, ou seja, não há plastificação da estrutura nesta área. Observa-se, que na chapa de ancoragem da treliça protendida, apresenta grandes concentrações de tensões, onde se tem maior tensão de 342,2 MPa.

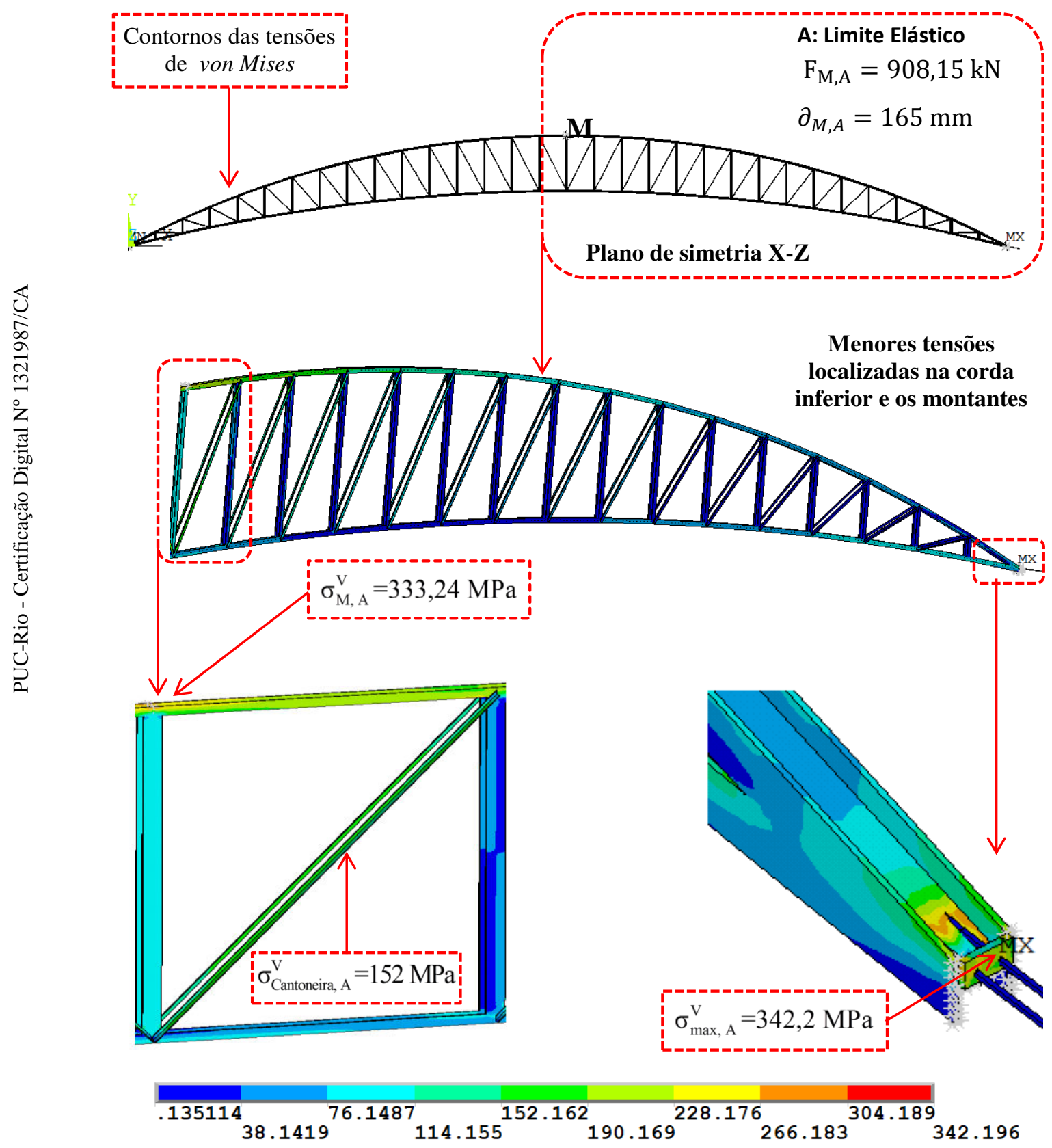

Figura 7.49. Distribuição de tensões de von Mises (MPa) correspondente ao ponto A ( $\left.\mathrm{E}_{\mathrm{P} 120}\right)$. 
2. Ponto B: na Figura 7.50 verifique-se que há um aumento da distribuição das tensões de von Mises no que se refere ao ponto de limite de escoamento (Figura 7.44). Na região do centro da treliça $\partial_{M}$, foi observado que o valor da tensão calculada resultou em 342,55 MPa (a um carregamento aplicado de 927,08 kN) para um deslocamento vertical de $195 \mathrm{~mm}$. Essa tensão é aproximadamente do valor de tensão limite do escoamento, ou seja, não há plastificação da estrutura nesta área. Vale ressaltar que na região da chapa de ancoragem, identifica-se a elevada distribuição de 346,07 MPa (ponto MX) nas diagonais.

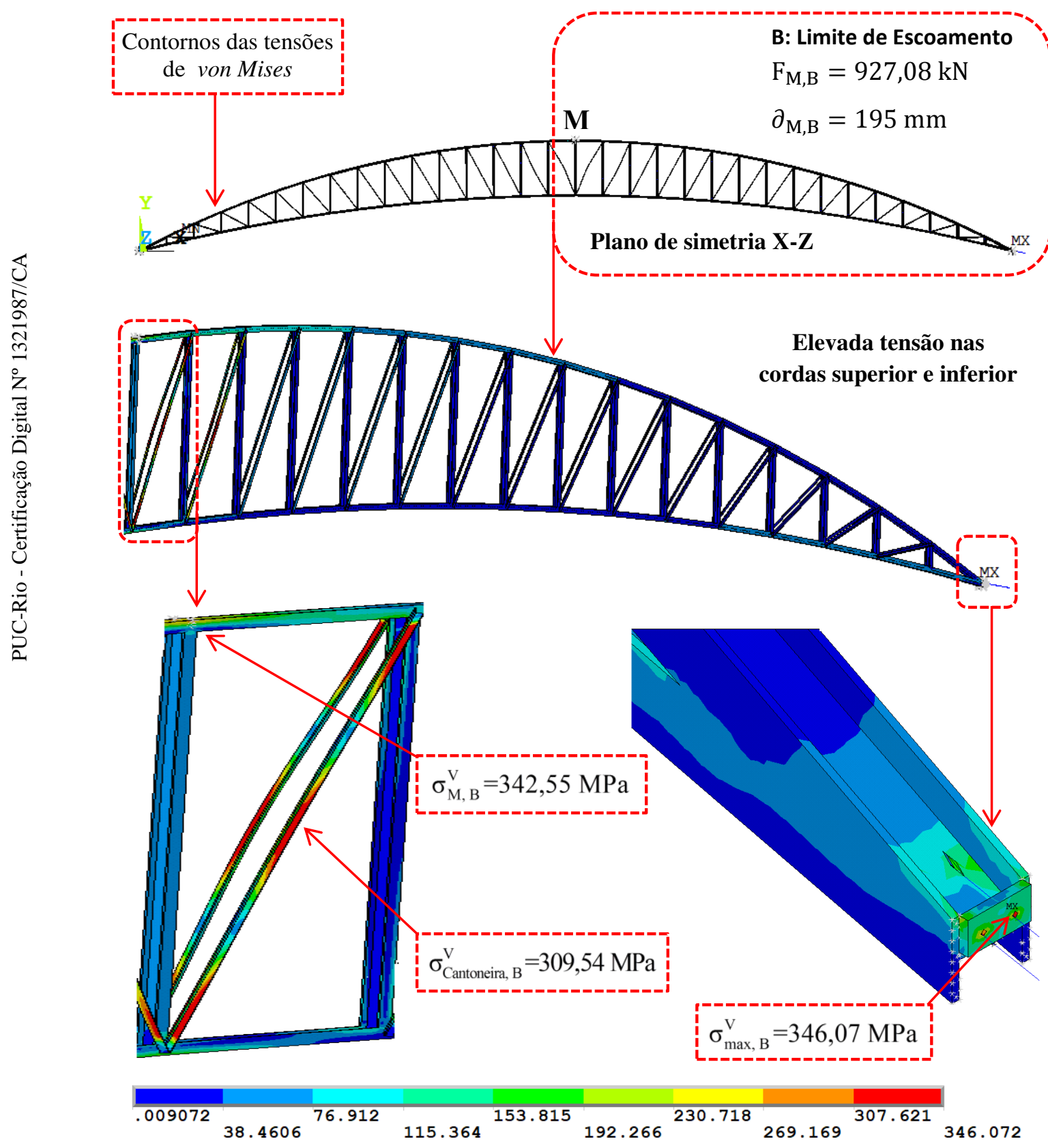

Figura 7.50 Distribuição de tensões de von Mises $(\mathrm{MPa})$ correspondente ao ponto $\mathrm{B}\left(\mathrm{E}_{\mathrm{P} 120}\right)$. 
3. Ponto C: observando-se a distribuição das tensões de von Mises da Figura 7.51 referente ao ponto de força máxima da Figura 7.44, constata-se que o valor da tensão calculada foi igual a 348,49 $\mathrm{MPa}$. Tal valor foi obtido na região do centro da treliça $\partial_{M}$ para um deslocamento vertical de $1.174 \mathrm{~mm}$, correspondendo a um carregamento aplicado de 1.297,51 kN. Essa tensão é maior do que o valor de tensão limite de escoamento fazendo com que a estrutura plastifique. Vale ressaltar que na região da chapa da treliça, observa-se a máxima distribuição 364,8 MPa e, consequentemente, a estrutura continua plastificando nesta zona da chapa. Também nas diagonais, observa-se a ocorrência de flambagem local, com valor da tensão de distribuição de $315,27 \mathrm{MPa}$.

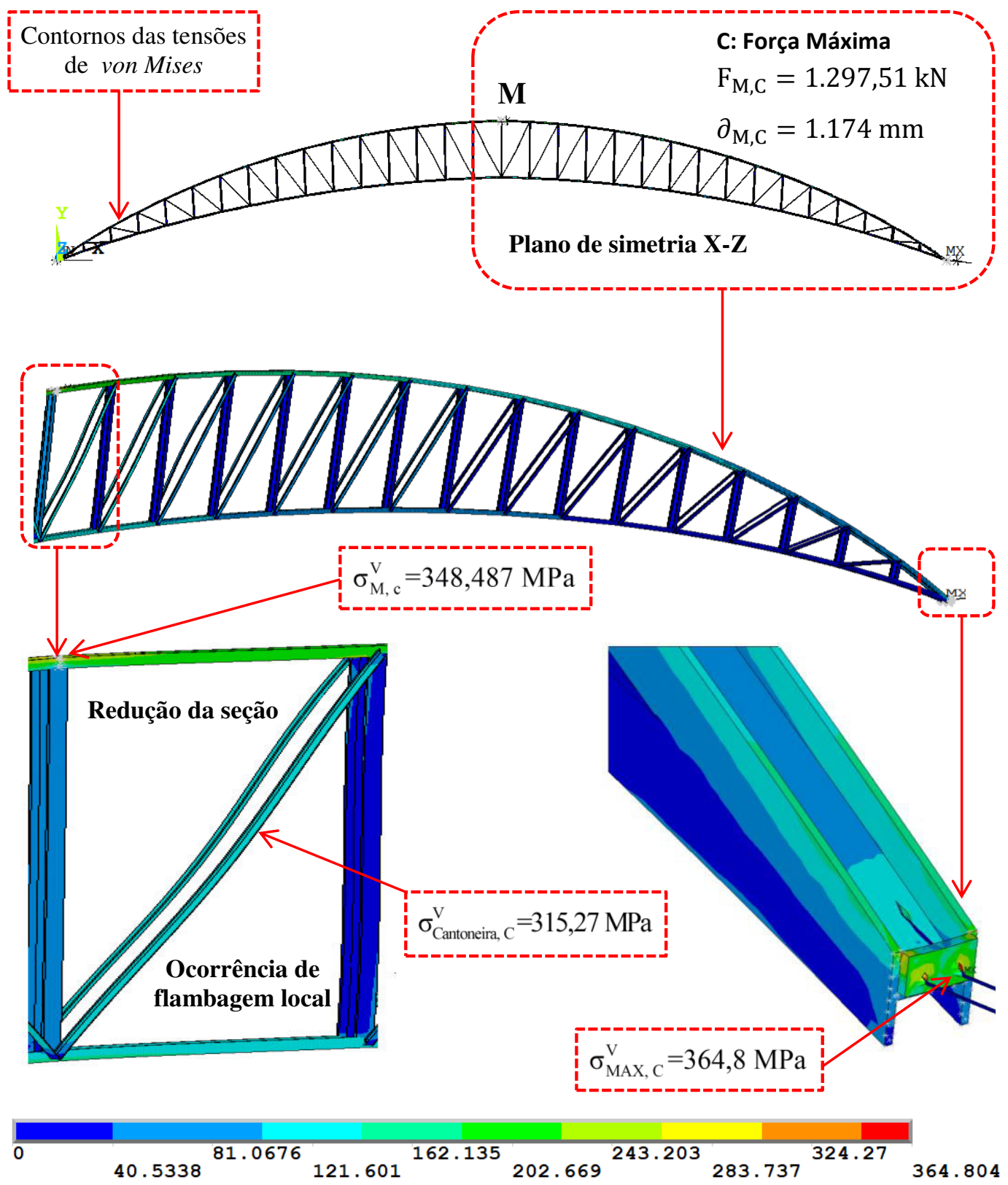

Figura 7.51 Distribuição de tensões de von Mises $(\mathrm{MPa})$ correspondente ponto $\mathrm{C}\left(\mathrm{E}_{\mathrm{P} 120}\right)$. 
4. Ponto D: avaliando-se a distribuição das tensões de von Mises da Figura 7.22 referente ao ponto de ruptura mostrado na Figura 7.14, pode-se verificar que o valor da tensão máxima apresentada resultou em 371,05 MPa, onde ocorre está representado com a nomenclatura MX. Tal valor foi obtido na região do centro da treliça, para um grande deslocamento vertical de 2.060,24 mm, correspondente a uma força de ruptura igual a 981,36 kN. Essa região apresenta deformações elevadas e os perfis das cordas superior, inferior, montantes e diagonais mostram estrangulamento e redução da seção.

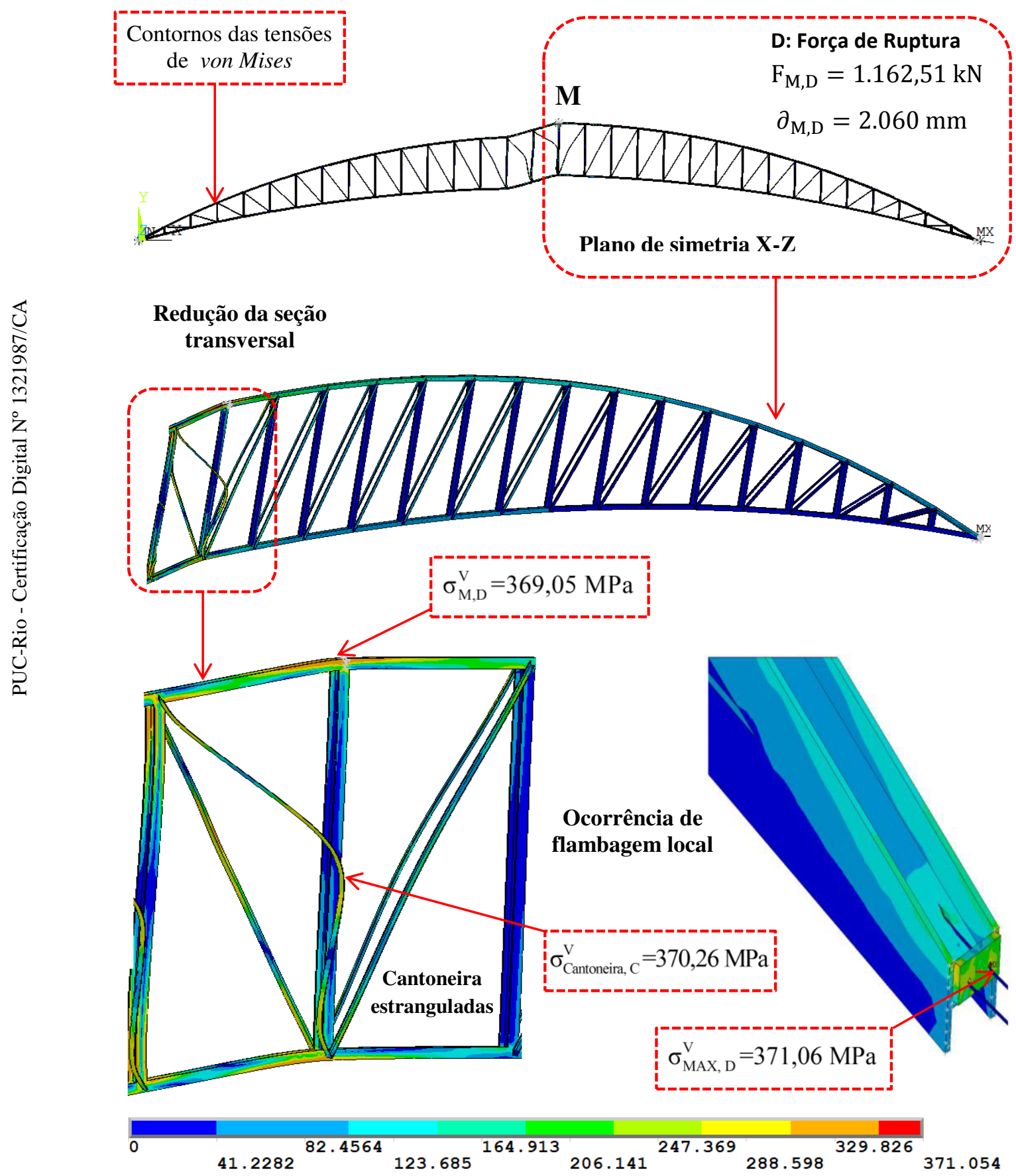

Figura 7.52. Distribuição de tensões de von Mises $(\mathrm{MPa})$ correspondente ao ponto D ( $\left.\mathrm{E}_{\mathrm{P} 120}\right)$ 
Com base na sequência da modelagem numérica realizada, a Tabela 7.10 apresenta um resumo dos resultados obtidos no que se refere a forças e deslocamentos nos pontos de limite elástico, escoamento, força máxima e ruptura no centro do vão para a treliça de 120 m, sem e com protensão.

Tabela 7.10 Resumo dos resultados das forças e deslocamentos da treliça $120 \mathrm{~m}$ sem e com protensão nos pontos das curvas (Figura 7.44).

\begin{tabular}{|c|c|c|c|c|c|}
\hline \multirow{2}{*}{ Pontos das curvas } & \multicolumn{2}{|c|}{ Treliça sem Protensão } & \multicolumn{2}{|c|}{ Treliça com Protensão } & \multirow{2}{*}{$\begin{array}{l}\text { \% Razão } \\
\text { de Força }\end{array}$} \\
\hline & $\begin{array}{l}\text { Força } \\
(\mathrm{kN})\end{array}$ & $\begin{array}{l}\text { Deslocamento } \\
(\mathrm{mm})\end{array}$ & $\begin{array}{l}\text { Força } \\
(\mathrm{kN})\end{array}$ & $\begin{array}{l}\text { Deslocamento } \\
(\mathrm{mm})\end{array}$ & \\
\hline $\begin{array}{c}\text { A: } \\
\text { (Limite elástico) }\end{array}$ & 493,3 & 480 & 908,15 & 165 & 84,1 \\
\hline $\begin{array}{c}\text { B: } \\
\text { (Limite escoamento) }\end{array}$ & 506,39 & 520 & 927,08 & 195 & 83,1 \\
\hline $\begin{array}{c}\text { C: } \\
\text { (Força máxima) }\end{array}$ & 631,43 & $1.079,4$ & $1.297,51$ & 1.174 & 105,5 \\
\hline $\begin{array}{c}\text { D: } \\
\text { (Força ruptura) }\end{array}$ & 595,95 & $1.371,43$ & $1.162,51$ & 2.060 & 95,1 \\
\hline
\end{tabular}

Com base nos resultados da Tabela 7.10 apresentam um resumo das forças e deslocamentos para diferentes pontos da curva carga versus deslocamento nos trecho elástico e plástico para o modelo da treliça de $80 \mathrm{~m}$. Estes resultados confirmam os resultados obtidos nas modelagens das treliças de $10 \mathrm{~m}, 20 \mathrm{~m}, 40$ m, $80 \mathrm{~m}$, as conclusões do Projeto HILONG "HSS trusses to be tested at Imperial College" (Gkantou et al., 2015) e as conclusões de Belenya (1997) e de Troitsky (1990). 


\section{8}

\section{Considerações finais}

Neste capítulo são relatadas às conclusões finais, as contribuições e sugestões para trabalhos futuros, com base nos resultados da investigação do comportamento estrutural de treliças de aço em forma de arco utilizadas no projeto de coberturas.

Este estudo compreendeu quatro fases distintas. Na primeira foi realizada uma descrição dos modelos estruturais. Na segunda etapa foi demonstrada a eficiência da modelagem numérica das treliças, desenvolvida com base no método dos elementos finitos (MEF). A etapa seguinte apresentou os desenvolvimentos da análise estática linear das treliças. A última etapa abordou uma análise estática não linear física das treliças.

\section{1.}

\section{Conclusões}

Neste estudo foram consideradas treliças em forma de arco com 10, 20, 40, 80 e 120 m de vão. Por meio de modelagem computacional comprovou-se a eficiência do sistema estrutural, dado que ao se introduzirem forças de protensão nos cabos conseguiu-se atingir uma redução de solicitações de no mínimo 50\%, comparada com as estruturas sem essa protensão. Com o aumento dos vãos, os benefícios da protensão, proporcionam que as solicitações nas treliças diminuam substancialmente chegando a uma redução de até $90 \%$.

Com base nos resultados obtidos com as análises estática linear e não linear, sem e com efeito da protensão, para as diferentes modelagens numéricas, seguem diversas conclusões especificas. 


\section{Conclusões sobre a treliça de $\mathbf{4 0}$ m de vão}

$\mathrm{Na}$ análise estática linear com nível de protensão ótima de 205,27 kN atingiu-se uma capacidade de reduções de tensões, de forças e de deslocamentos em todos os elementos da estrutura protendida. Com respeito à tensão máxima de von Mises, obtida junto à região de apoio da treliça protendida, foi igual a 121,24 $\mathrm{MPa}$, enquanto a treliça sem protensão esse valor foi igual a 345,26 MPa. Sendo assim, aquele apresentou melhor comportamento estrutural teve uma redução de aproximadamente de $64,88 \%$ na tensão máxima.

Verificou-se também uma redução de forças nas cordas superior e inferior ao longo do vão com força de protensão (Figura 6.36). A corda superior atingiu uma capacidade de força máxima de $368,94 \mathrm{kN}$ a $124,61 \mathrm{kN}$ e uma redução de $66,22 \%$, enquanto na corda inferior ocorreu uma redução de $334,752 \mathrm{kN}$ para 108,05 kN, significando uma redução de 68,62 \%. Esse modelo apresenta, ainda, uma redução de deslocamento, no centro do vão da treliça, que variou de $110,87 \mathrm{~mm}$ a $7,72 \mathrm{~mm}$.

$\mathrm{Na}$ análise estática não linear comparando-se os resultados da estrutura $\mathrm{C}_{40}$ sem e com protensão ótima referentes aos pontos traçados da Figura 7.24, observa-se que o ponto elástico, A, com protensão, atingiu uma capacidade máxima de carga de 481,102 kN para um deslocamento de $98 \mathrm{~mm}$, enquanto que a treliça sem protensão alcançou uma carga de $278,6 \mathrm{kN}$ para um deslocamento de $224 \mathrm{~mm}$. Sendo assim, houve um aumento de força de 72,7 \% e uma redução de deslocamento de $56,25 \%$.

Para o ponto elástico, B, a influência da protensão apresentou um ganho com uma capacidade de carga de 296,51 kN, para um deslocamento de $105 \mathrm{~mm}$, enquanto que, sem protensão, alcançou uma carga de 506,433 kN para um deslocamento de 105,04 mm, ou seja, uma razão de força de 56,2 \%.

No ponto da força máxima, C, a carga passa de $299,01 \mathrm{kN}$ a $1.057,51 \mathrm{kN}$, representando um aumento de $253,7 \%$ da força de flambagem. Para o ponto de ruptura, D, a treliça sem protensão rompe-se com $168,45 \mathrm{kN}$, enquanto a treliça com protensão rompe-se com $755,72 \mathrm{KN}$ com um aumento de $348,6 \%$. 
É importante notar que não só as cargas foram expressivamente maiores, mas, também, a capacidade de absorver energia, melhorando a rigidez da estrutura. Ressalta-se, para todos os pontos analisados, que a protensão reduz as tensões de von Mises nos elementos da estrutura (ver Item 7.3).

\section{Conclusões sobre a treliça de 80 m de vão}

$\mathrm{Na}$ análise estática linear com nível de protensão ótima de 440,66 kN, atingiu-se uma capacidade de reduções de tensões, de forças e de deslocamentos em todos os elementos da estrutura protendida. Com respeito à tensão máxima de von Mises, obtida junto à região de apoio da treliça protendida, apresentou-se uma tensão de 111,74 MPa, enquanto a treliça sem protensão atingiu o valor de 348,1 MPa. Sendo assim, aquele apresentou melhor comportamento estrutural em relação a este, com uma redução de aproximadamente de $64,88 \%$ na tensão máxima.

Verificou-se também uma redução de forças nas cordas superior e inferior ao longo do vão com força de protensão (Figura 6.37). A corda superior atingiu uma capacidade de força máxima de tração de $934,01 \mathrm{kN}$ a $289,21 \mathrm{kN}$ e uma redução de 69,04\%, enquanto na corda inferior ocorreu uma redução de força máxima de compressão de $854,58 \mathrm{kN}$ para $184,866 \mathrm{kN}$, significando uma redução de $78,37 \%$. Este modelo apresenta, ainda, uma redução de deslocamento, no centro do vão da treliça, que passa de $276,3 \mathrm{~mm}$ a $23,93 \mathrm{~mm}$.

$\mathrm{Na}$ análise estática não linear comparando-se os resultados da estrutura $\mathrm{D}_{80}$ sem e com protensão ótima referentes aos pontos traçados da Figura 7.34, observa-se que o ponto elástico, A, com protensão, atingiu uma capacidade máxima de carga de $824,48 \mathrm{kN}$ para um deslocamento de $175,81 \mathrm{~mm}$, enquanto que a treliça sem protensão alcançou uma carga de 479,4 kN para um deslocamento de 437,5 mm. Sendo assim, houve um aumento de força de $72 \%$ e uma redução de deslocamento de 59,82\%.

Para o ponto elástico, B, a influência da protensão apresentou um ganho com uma capacidade de carga de $840,989 \mathrm{kN}$, para um deslocamento de 180,18 mm, enquanto que, sem protensão, alcançou uma carga de 494,79 kN para um deslocamento de 496,13 mm, ou seja, uma relação de força de $70 \%$. 
No ponto da força máxima, C, a carga passa de $524,05 \mathrm{kN}$ a $1.217,06 \mathrm{kN}$, representando um aumento de 132,24 \% da carga de flambagem. Para o ponto de ruptura, D, a treliça sem protensão rompe-se com $441,43 \mathrm{kN}$, enquanto a treliça com protensão rompe-se com 1.006,49 $\mathrm{kN}$ com um aumento de $128 \%$. Ressalta-se, para todos os pontos analisados, que a protensão reduz as tensões de von Mises nos elementos da estrutura (ver Item 7.4).

\section{Conclusões sobre a treliça de 120 m de vão}

$\mathrm{Na}$ análise estática linear com nível de protensão ótima de 660,56 kN, atingiu-se uma capacidade de reduções de tensões, de forças e de deslocamentos em todos os elementos da estrutura protendida. Com respeito à tensão máxima de von Mises, obtida junto à região de apoio da treliça protendida, apresentou-se uma tensão de 111,68 MPa, enquanto a treliça sem protensão atingiu o valor de 351,78 MPa. Sendo assim, aquele apresentou melhor comportamento estrutural em relação a este, com uma redução de aproximadamente de 68,25 \% na tensão máxima.

Verificou-se também uma redução de forças nas cordas superior e inferior ao longo do vão com força de protensão (Figura 6.38). A corda superior atingiu uma capacidade de força máxima de tração de $1.807,55 \mathrm{kN}$ a $337,28 \mathrm{kN}$ e uma redução de $81,33 \%$, enquanto na corda inferior ocorreu uma redução de força máxima de compressão de $1.744,66$ kN para 327,28 kN, significando uma redução de 81,24 \%. Este modelo apresenta, ainda, uma redução de deslocamento, no centro do vão da treliça, que passa de $379,03 \mathrm{~mm}$ a $64,28 \mathrm{~mm}$.

$\mathrm{Na}$ análise estática não linear comparando-se os resultados da estrutura $\mathrm{E}_{120}$ sem e com protensão ótima referentes aos pontos traçados da Figura 7.44, observa-se que o ponto elástico, A, com protensão, atingiu uma capacidade máxima de carga de 908,15 KN para um deslocamento de $165 \mathrm{~mm}$, enquanto que a treliça sem protensão alcançou uma carga de 493,3 kN para um deslocamento de $480 \mathrm{~mm}$. Sendo assim, houve um aumento de força de $84,1 \%$ e uma redução de deslocamento de $65,63 \%$.

Para o ponto elástico, B, a influência da protensão apresentou um ganho com uma capacidade de carga de 927,08 kN, para um deslocamento de $195 \mathrm{~mm}$, enquanto que, sem protensão, alcançou uma carga de $506,39 \mathrm{kN}$ para um deslocamento de $520 \mathrm{~mm}$, ou seja, uma relação de força de 83,1\%. 
No ponto da força máxima, C, a força variou de $631,43 \mathrm{kN}$ a $1.297,51 \mathrm{kN}$, representado um aumento de 105,5 \% da força de flambagem. Para o ponto de ruptura, D, a treliça sem protensão rompeu-se com 595,95 kN, enquanto a treliça com protensão rompeu-se com 1.162,51 kN um aumento de 95,1\%. Ressalta-se que para todos os pontos analisados, com a protensão as tensões de von Mises nos elementos da estrutura foram reduzidas (Item 7.4).

\section{Conclusões finais}

Para combinação da fase de construção para modelo $\mathrm{A}_{10}$, foram consideradas três espessuras de chapas de ancoragem, onde se observou que a chapa de 2,45 mm apresentou uma tensão de von mises de plastificação de 365,02 MPa. A chapa de 6,3 mm resultou numa tensão de 169,599 MPa, enquanto a chapa de 9,3 mm atingiu um valor de 116,44 MPa. Portanto, Essa última foi adotada para evitar grande plastificação na região.

$\mathrm{Na}$ análise estática não linear da treliça de $10 \mathrm{~m}$ de vão foi verificada a estrutura para cinco magnitudes de forças de protensão (Figura 7.8). A análise mostrou grande acréscimo de forças e deslocamento no trecho elástico na estrutura à medida que aumentou-se a força de protensão, levando a uma estrutura mais rígida (Tabela 7.1). Observa-se que o trecho plástico revela um rendimento de redução de deslocamento, ressaltando-se como a adição do cabo aumenta a resistência do elemento, mesmo quando é aplicada uma força de protensão mínima.

Com base nos resultados obtidos ao longo deste estudo para todos os casos analisados, conclui-se que a grande vantagem da utilização da protensão se deve à redução do peso do aço em até aproximadamente $90 \%$. Foi demonstrado que a introdução da protensão para a parte inferior da corda aumenta a capacidade de carga e diminui significativamente a flecha correspondente. Tal benefício é particularmente interessante para esse tipo de geometria (treliça em forma de arco), uma vez que pode facilitar a concepção de estruturas especiais cobrindo grandes vãos. 
As áreas de seção transversal dos cabos e forças de protensão ótima $\mathrm{P}_{\mathrm{opt}, \mathrm{c}}$ (Tabela 4.13 do capítulo 4) tiveram variação dependendo dos diferentes vãos. Também foi observado que adicionando-se o cabo, tanto a resistência quanto a rigidez da treliça têm aumento, ainda que não tenha sido aplicada a força de protensão. Cabe ressaltar que o principal benefício da protensão é o aumento das forças de tração nas barras da corda inferior, com a diminuição das forças de compressão da mesma e atenuação das forças na corda superior. Conclui-se que as soluções estruturais com protensão mostram vantagens econômicas que compensam o seu custo da protensão.

Constata-se que os resultados confirmam as conclusões de Belenya (1997) e de Troitsky (1990) de que os sistemas de treliças protendidas são eficientes para grandes vãos e resultam em estruturas mais leves e econômicas. O uso de protensão oferece grande redução de deslocamentos verticais da estrutura, confirmando também as conclusões do Projeto HILONG “HSS trusses to be tested at Imperial College” (Gkantou et al., 2015). 


\section{2.}

\section{Principais contribuições}

De forma resumida as principais contribuições desta tese são descritas a seguir:

A implementação paramétrica e otimização para as diferentes variações de geometria e de vão nos modelos de treliças de aço em forma de arco, executada com o método dos elementos finitos utilizando-se linguagem $A P D L$ do programa ANSYS.

A execução de modelagem tridimensional com a utilização de perfil com seção tipo $\mathrm{W}$, para construção dos elementos das treliças em forma de arco, com grandes vãos para cobertura de hangares, com o emprego do método dos elementos finitos.

Uma outra contribuição é o emprego de cabos de protensão na análise paramétrica aplicado para diferentes tipos de treliças em forma de arco para grandes vãos, com a utilização de perfil tipo W, avaliando-se o comportamento estrutural, na análise estática linear e não linear física, levando-se as estruturas sem e com protensão até a fase de ruptura.

Destaca-se, que esta implementação computacional da modelagem das espessuras de chapas de ancoragem adequadas para os diferentes modelos das treliças protendidas, com a finalidade de analisar-se a interface entre a chapa e o cabo nas extremidades com a força de protensão.

Ressaltam-se os resultados obtidos nos modelos das treliças, variando-se as magnitudes das forças de protensão em função da protensão ótima, com a finalidade de se analisar o comportamento da estrutura à medida que a força aumenta, nos trechos elástico e inelástico, até que se atinja a ruptura.

Concluiu-se, que esta pesquisa é relevante no que diz respeito às análises linear e não linear, apor meio do método dos elementos finitos MEF (ANSYS, com implementação da linguagem APDL) para a análise uso de treliça de aço protendida em forma de arco, com uso de perfis de seção tipo $\mathrm{W}$, para diferentes geometrias e grandes vãos (chegando-se a 120 m). 
Vale lembrar que foi avaliada a eficiência do referido sistema estrutural com cabos de protensão, tendo-se mostrado satisfatória no que tange ao acréscimo de forças tanto na fase elástica quanto na inelástica.

\section{3.}

\section{Sugestões para trabalhos futuros}

Este trabalho de modelagem de treliças em aço protendidas para coberturas, desenvolvido na Pontifícia Universidade Católica do Rio de Janeiro faz parte de uma linha de pesquisa em soluções estruturais para coberturas de grandes vãos, e restam ainda diversos aspectos sobre o tema a serem analisados de maneira numérica e experimental. A seguir relacionam-se algumas propostas para a continuidade e desenvolvimento de futuros trabalhos sobre o tema.

A principal sugestão seria realizar o programa experimental na treliça de $10 \mathrm{~m}$, sem e com protensão, para que seja possível comparar todos os pontos da curva de comportamento estrutural, obtidos nos trechos linear elástico e inelástico desta modelagem, e com isso, corroborar os resultados numéricos obtidos para esse tipo de projeto de coberturas protendidas, além de comparar as diferentes magnitudes de forças de protensão obtidas numericamente;

Sugere-se a realização de estudo de modelagem incluindo-se a análise de outros tipos de perfis de aço, como, por exemplo, tubos de aço, seções compostas, entre outros, podendo-se variar as seções transversais nos elementos da treliça, possibilitando assim um melhor aproveitamento dos perfis.

Caberia também avaliar alguns aspectos de treliças de aço, sem e com protensão, referentes ao comportamento dinâmico na parte de análise modal, além de realizar análises estáticas não lineares geométricas.

Recomenda-se desenvolver na modelagem numérica a utilização de elemento tridimensional tipo sólido para os cabos de protensão. 


\section{9}

\section{Referências bibliográficas}

ABNT NBR 6123. Forças Devidas ao Vento em Edificações. Associação Brasileira de Normas Técnicas. Rio de Janeiro, Brasil, 1988.

ABNT NBR 8800. Projeto de Estruturas de Aço e de Estruturas Mista de Aço e Concreto de Edifícios. Associação Brasileira de normas técnicas. Rio de Janeiro, Brasil, 2008.

ABNT NBR 6120. Cargas para o Cálculo de Estruturas de Edificações. Associação Brasileira de normas técnicas. Rio de Janeiro, Brasil. 1978.

ABNT NBR 6118. Projeto de Estruturas de Concreto Procedimento. Associação Brasileira de normas técnicas. Rio de Janeiro. Brasil, 2014.

ABNT NBR 7197. Projeto de Estruturas de Concreto Protendido. Associação Brasileira de normas técnicas. Rio de Janeiro. Brasil, 2011.

ABNT NBR 6327. Cabos de Aço para Geral- Requisitos Mínimos. Associação Brasileira de normas técnicas. Rio de Janeiro, Brasil. 2006.

Andrade, S.; Vellasco, P.; Silva, J. Concepção e projeto estrutural do palco principal do Rock in Rio III, Construção Magazine, Porto, Portugal. Vol 7; pp 30-55, (2003).

ANSYS R15. Mechanical APDL Advanced Analysis. Guide. Release 15.0. ANSYS Inc; 2015.

AS/NZS 1170.2. Structural Design Actions, Part 2: Wind Actions, Standards Australia \& Standards New Zealand, 2005. 
Ayyub, B. M.; Ibrahim, A.; Schelling, D. Posttensioned truss: analysis and design, Journal of Structural Engineering, 116, 14911506; 1990.

Belenya, E.; Prestressed load-bearing metal structures. 1a ed. Moscow: MIR Publishers, 463 p; 1977.

BELGO. Disponível: < https://www.belgo.com.br/> Acesso em: 4 de jul. 2015.

Belletti, B.; Gasperi, A. Behavior of prestressed steel beams. Journal of Structural Engineering, [S.I.], v. 136, no. 9, p. 1131-1139, Sept. 2010.

Bhargavi. E.; Rama. G. Comparative Parametric Study of Steel Bridge Trusses by Applying External Prestressing, International Journal of Engineering Technology, Management and applied Sciences; July, 2015.

Bradford, M. Buckling of prestressed steel girders, Engineering Journal, American Institute of Steel Constructions, [S.I.], v. 34, p. 98-101, 1991.

Coff, L. American engineer studies: prestressing of structural steel. Civil Engineering, 20(11), pp.64-65; 1950.

Daly, A. F.; Witarnawan, W. Method for increasing the capacity of short and medium span Bridges. Indonesia, p. 11; 2000.

Darnell, V. C. The Pioneering Iron Trusses of Nathaniel Rider. Construction History, 69-81; 1991.

Dischinger, F.; Prestressed Structural Steel, Technical University of Berlin, Germany; pp. 60-73; 1979.

Ellen, P. E. Post-tensioned steel structure. Google Patents. US Patent 4,676,045; June 1987.

Ellen, M.; Gosaye, J.; Gardner, L.; Wadee, M. Design and construction of longspan post-tensioned tubular steel structures. Pages 687-693 of: Gardner, L. (ed), Tubular structures XIV; 2012. 
Eurocode1: Actions on structures, Part 1-4: General actions - Wind actions. 1991.

Ferreira, C. Vigas metálicas protendidas: análise estática, modal e de ruptura do cabo de protensão e aplicativo computacional para projetos. $276 \mathrm{f}$. Dissertação, Faculdade de Tecnologia da Universidade de Brasília, Brasília, 2007.

Gkantou. M.; Theofanous. M.; Baniotopoulos. C. Optimisation of High Strength Steel Prestressed Trusses. Congress on Computational Mechanics; 12 July; 2015 .

Gonçalves, R. Alguns aspectos relativos à inspeção e recuperação de pontes de aço: ênfase em pontes ferroviárias. 1992. 309 f. Tese (Doutorado em Engenharia de Estruturas) - Escola de Engenharia de São Carlos da Universidade de São Paulo, São Carlos, 1992.

Granter, E. Prestressed steel structures, discussion on professor Magnel's paper. The Structural Engineer, 28(11), 285, 1950.

Griggs, F. E.; DeLuzio, A. J. Stephen h. long and squire whipple: The first American structural engineers. Journal of Structural Engineering, ASCE, 121(9), 1352-1361; 1995.

Han, Kyoung-Bong.;Park, Sun-Kyu. Parametric study of truss bridges by the posttensioning method, Canadian Journal of Civil Engineering, 32, 420-429; 2005 .

He, Y; Wang, J; Zhou, X; Zhang, X. Stability of a pretensioned latticed threedimensional arch structure with cross cable-strut arrangement. Journal of Constructional Steel Research, 147, 43-52; 2018.

Impacto: Ancoragem; Disponível: http://impactoprotensao.com.br> acesso em 4 de jul.2014.

Magnel, G, Prestressed Concrete, Third Edition, London; 1954. 
Mohamed, G; Mahmoud, N; Badr, A; Salem, F. Numerical Analysis for Strengthening Steel Trusses using Post Tensioned Cables. Global Journal of Research In Engineering; 2017.

Naillon, Jacob D. Prestressed girder, U.S. Patent 3,010,257, issued November $28 ; 1961$.

Nunziata, V. Prestressed steel structures. Structture in acciaio precompresso. In. Congresso C.T.A, XVII,.Napoli. Proceedings. Napoli: [s.n.], 1999. p. 6; 1999.

Nunziata, V. Strutture in acciaio precompresso, 2.ed. Palermo: Dario Flaccovio, 229 p; 2004.

Nunziata, Prestressed steel structures design: a new frontier for structural engineering. In: ISCE-02 Second International tructural Engineering and Construction Conference, 2nd, 2003. Roma. Proceedings. Roma: [s.n.]. Disponível:<http://www.studionunziata.com> Acesso em: 01 mar. 2014.

Osofero, AI; Wadee, MA; Gardner, L. Experimental study of critical and postbuckling behaviour of prestressed stayed columns. Journal of Constructional Steel Research; Dec, 2012.

PTIA. Post-Tensioning Institute of Australia Limited, 2007. Disponível: www.s-squared.com.au >. Acesso em: 20 de jul.2014.

Ravindra, P.; Nagaraja, P. An Analytical Investigation on Deflections of Pratt Pattern Bridge Truss Posttensioned with External Tendons. Int. J. of Inventive Eng. and Sci. 2: 23-28; 2013.

Reagan, R. S.; Krahl, N. W. Behavior of prestressed composite beams. Journal of the Structural Division, ASCE, 93(6), 87-108; 1967.

Reis, J. C. Influência do nível da protensão na deformação de estruturas executadas com protensão externa. 118p. Dissertação, Universidade Federal do Rio de Janeiro/ COPPE, 2003.

Rezende, C. R. Análise estrutural de vigas metálicas protendidas. $119 \mathrm{f}$. Dissertação, Universidade Federal do Espírito Santo, Espírito Santo, 2007. 
Ronghe, G. N.; Gupta, L. M. Parametric Study of tendon profiles in prestressed steel plate girder. Advances in Structural Engineering, [S.I.], v. 5, n. 2, p 75-85, Apr. 2002.

Sampaio, C. Dimensionamento econômico de vigas protendidas de aço. 1976. 133 f. Dissertação (Mestre em Engenharia de Estruturas) Escola de Engenharia de São Carlos da Universidade de São Paulo, São Carlos, 1976.

SAP2000-V17. Computers and Structures. Finite Element Analysis-User's Manual. 2015.

Seward, AFrick. Chemistry Laboratory, The Architecture Newspaper, New York, USA,; (2012). (http://archpaper.com/news/ articles.asp?id=5303) Squire Whipple Bridge at UnionCollege, 1980. Disponível: http://www.hmdb.org. Acesso em: 28 de jul.2014.

Szilard, R. Design of prestressed composite steel structures. Journal of the Structural Division 85, no. 9: 97-124; 1959.

Troitsky, M. S. Prestressed Steel Bridges, Theory and Design, Professor of Engineering Concordia University, Montreal Van Nostrand Reinhold Company, New York; 1990.

Troitsky, M. Prestressed steel bridges: theory and design. 16th ed. New York:Van Nostrand Reinhold, 1990. 386 p; 1990.

ZIENKIEWICZ, O. C.; TAYLOR, R. L. The finite element method. Oxford: Butterworth-Heinemann, 2000. 


\section{Apêndice A}

Neste apêndice é apresentada a descrição do modelo da treliça de $10 \mathrm{~m}$ projetada como sugestão para trabalhos futuros num programa experimental.

\section{Planta da treliça de $10 \mathrm{~m}$}

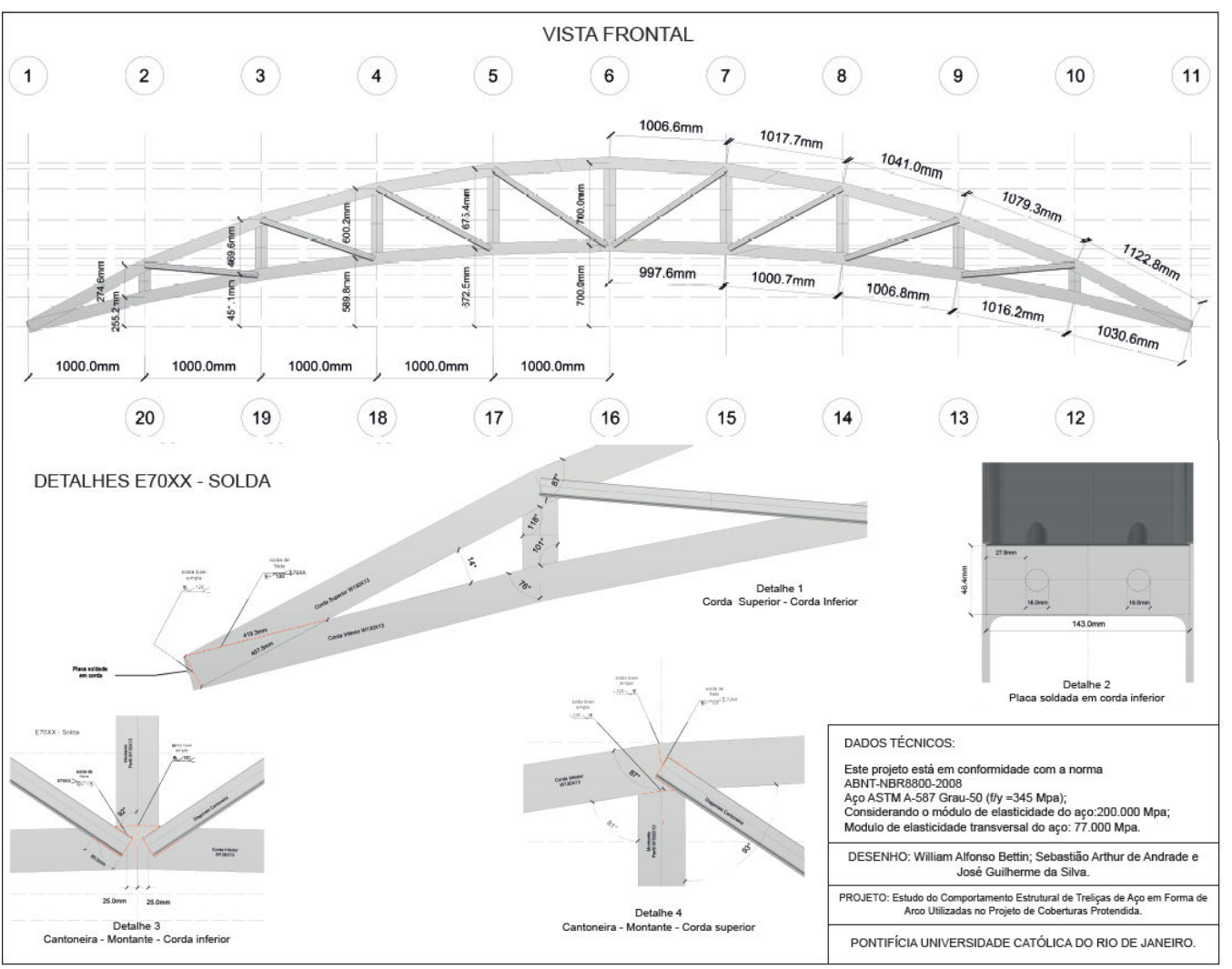

Figura A.1 Vista lateral e detalhe do modelo $\mathrm{A}_{10}$, para pesquisa experimental. 


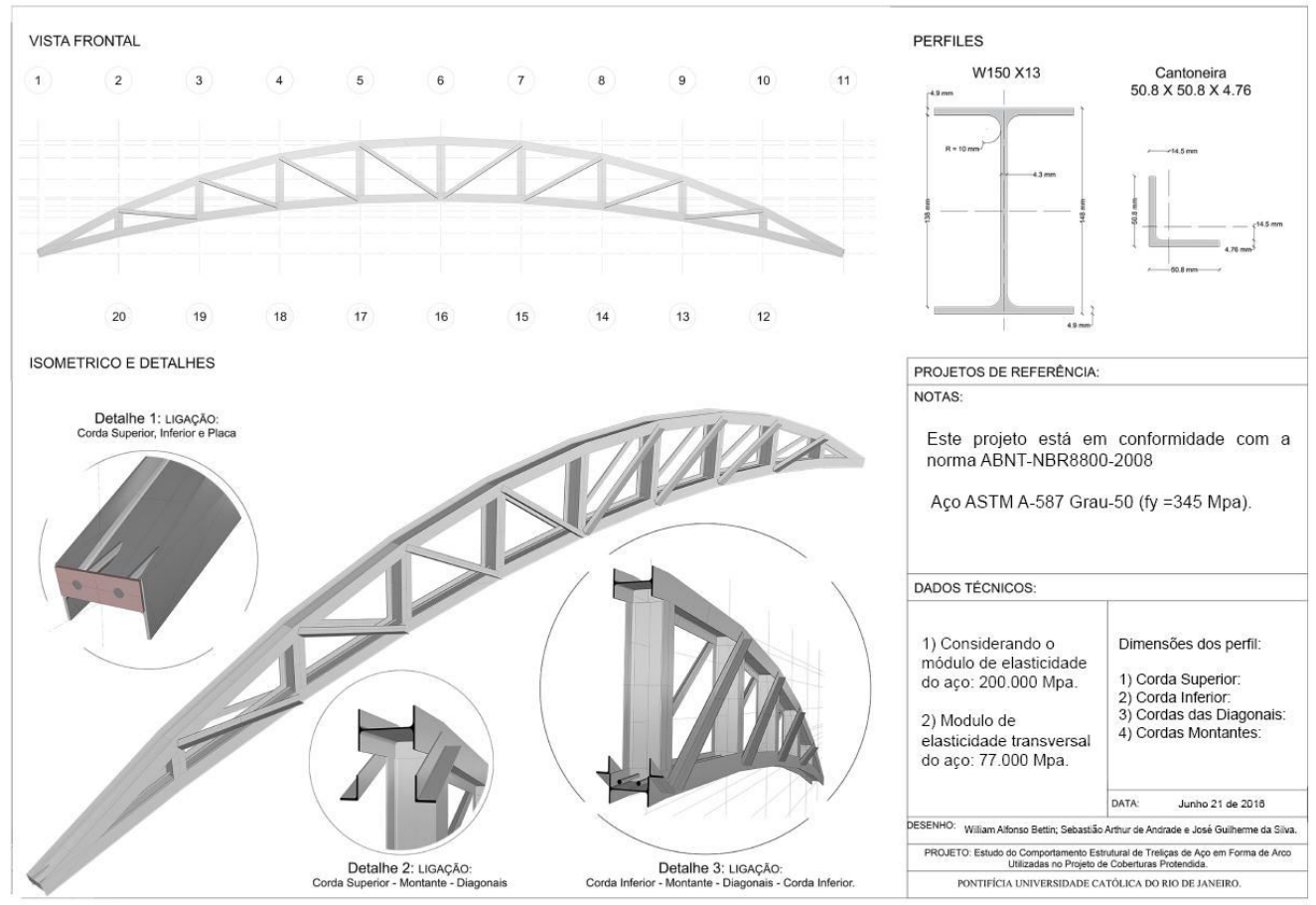

Figura A.2 Perspectiva e detalhe do modelo $\mathrm{A}_{10}$, para pesquisa experimental futura.

\section{Fabricação da treliça de $10 \mathrm{~m}$ em madeira em escada 1:10}

Foi construído o modelo da treliça de $10 \mathrm{~m}$, em madeira de palitos de picolé, em escala 1:10 (Figura A.3), como objetivo de alcançar uma precisão adequada nas modelagens numéricas dos modelos estudados, incluindo-se, dentre outros aspectos, uma melhor identificação da geometria das seções, que são modeladas por coordenadas nodais. Além disso cumpre identificar os detalhes das ligações entre os perfis e as cantoneiras das diagonais.

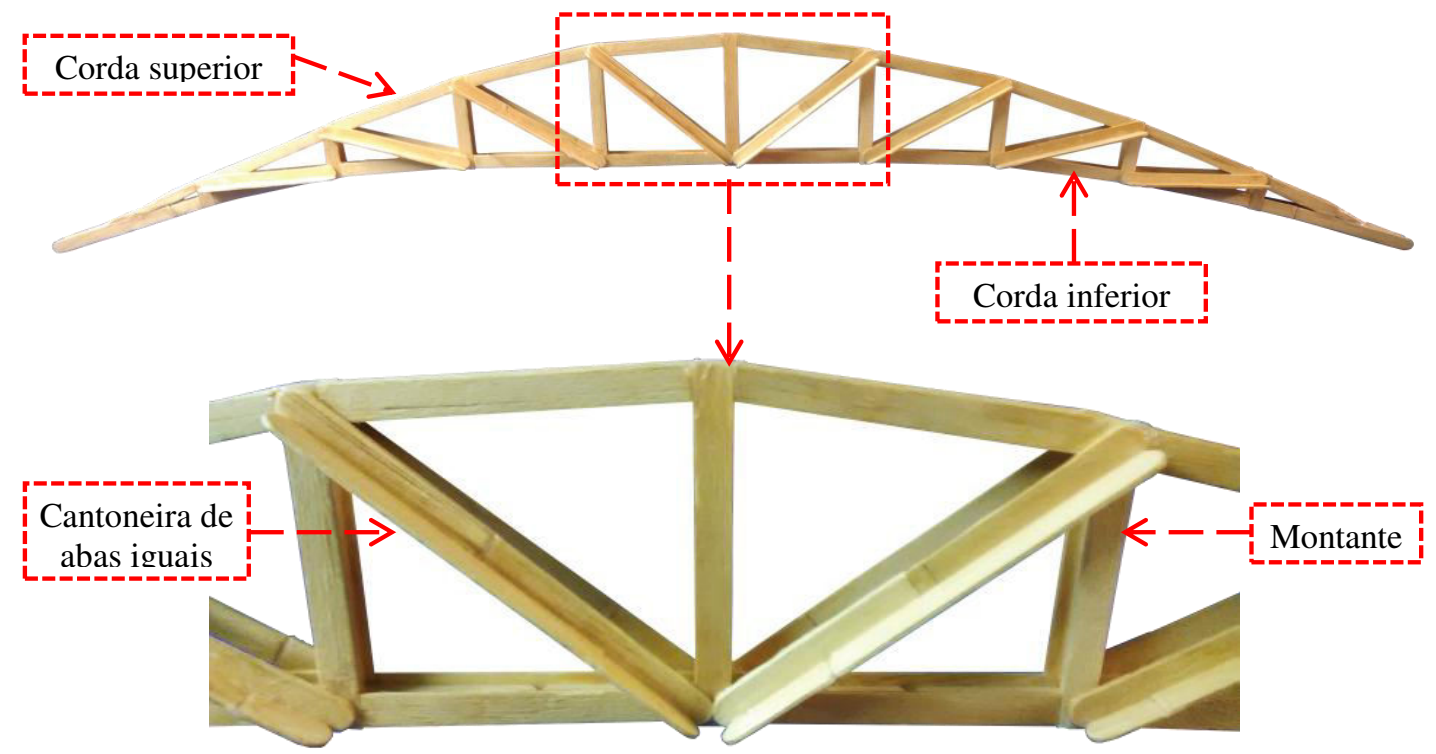

Figura A.3 Modelo da treliça a $10 \mathrm{~m}$ de vão fabricado em madeira. 


\section{Fabricação da treliça de 10 m em escada real}

Para o modelo da treliça de $10 \mathrm{~m}$ foram fabricadas quatro estruturas em escala real, com as especificações da planta do Anexo A1.

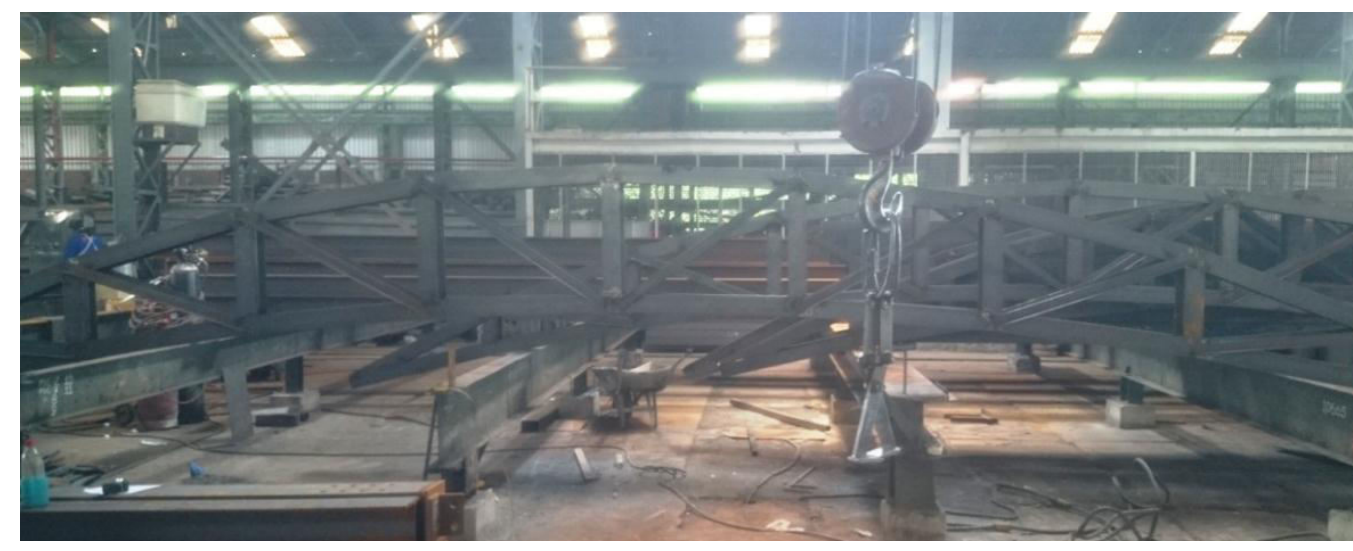

Figura A.4 Vista lateral da fabricação do modelo $\mathrm{A}_{10}$.

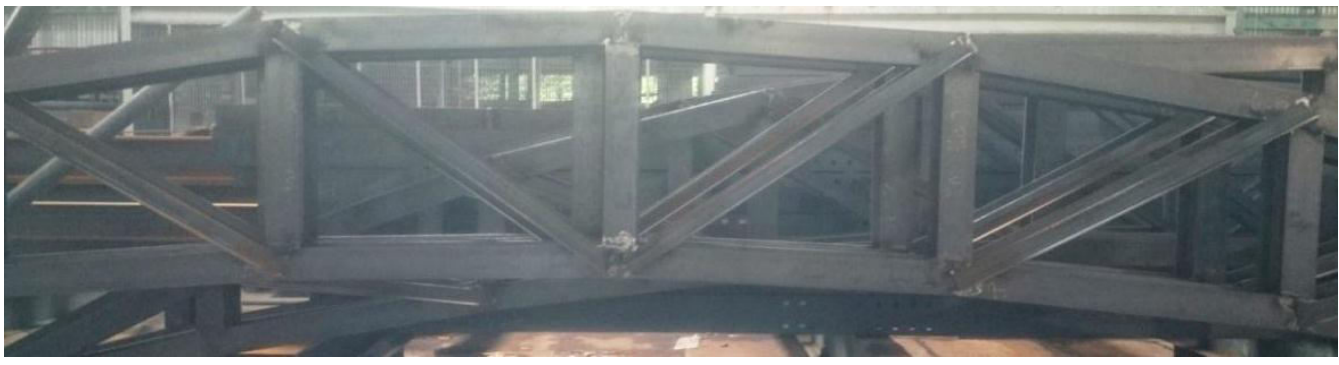

Figura A.5 Corte do centro da fabricação do modelo $\mathrm{A}_{10}$.

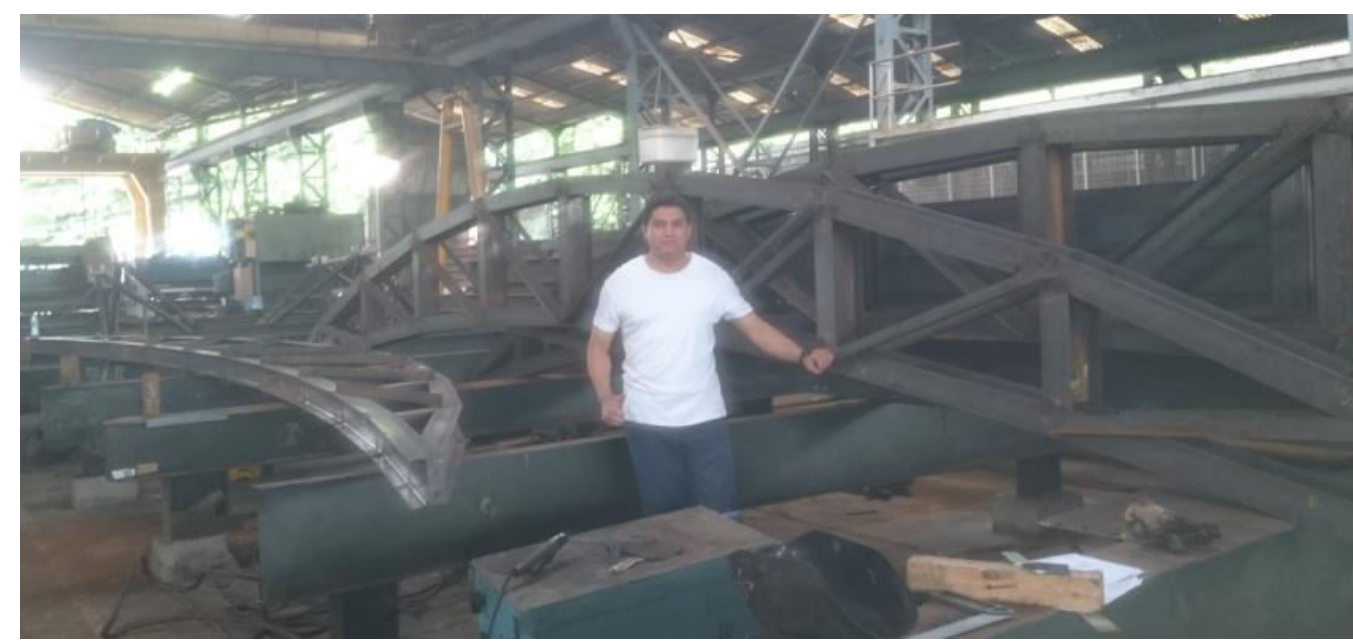

Figura A.6 Visita técnica para verificação das dimensões da estrutura. 


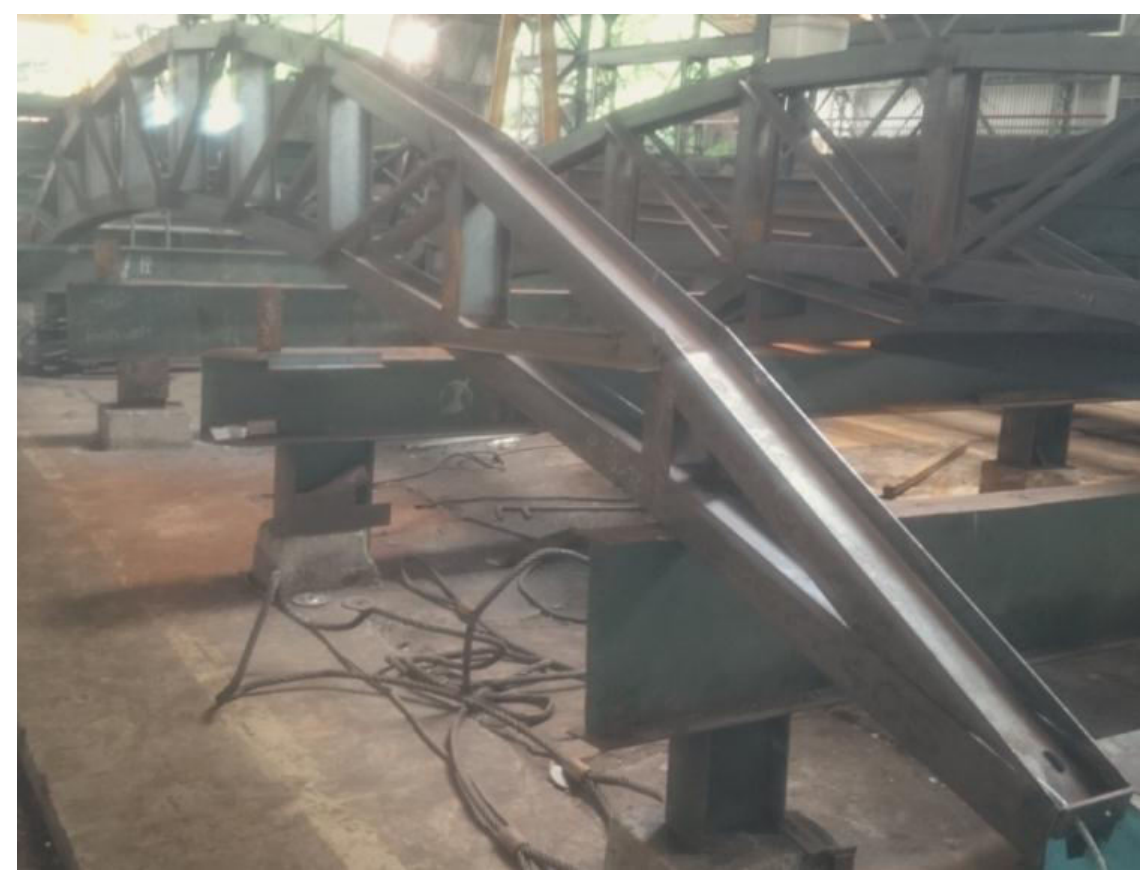

Figura A.7 Perspectiva do modelo $\mathrm{A}_{10}$,

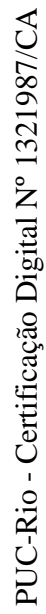
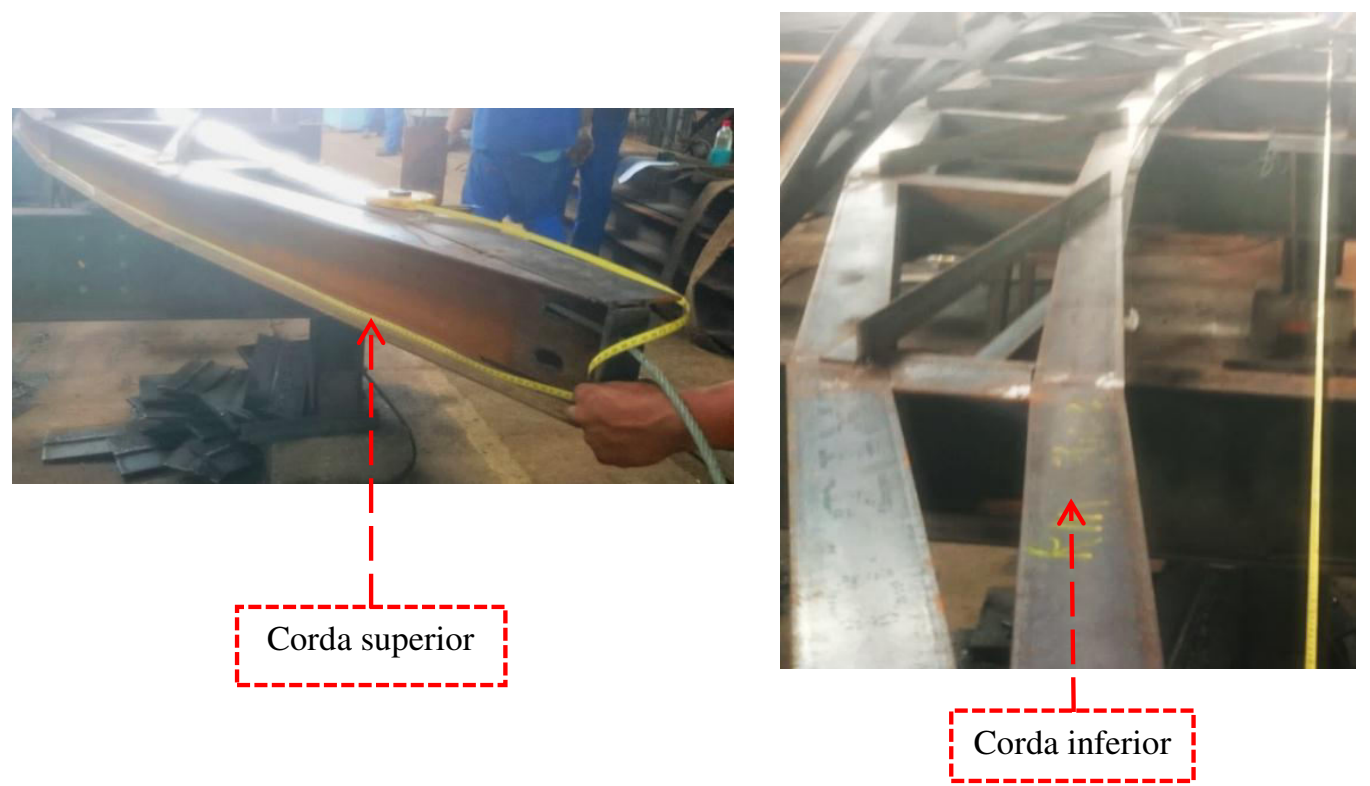

Figura A.8 Verificação das medidas da corda inferior e vão. 


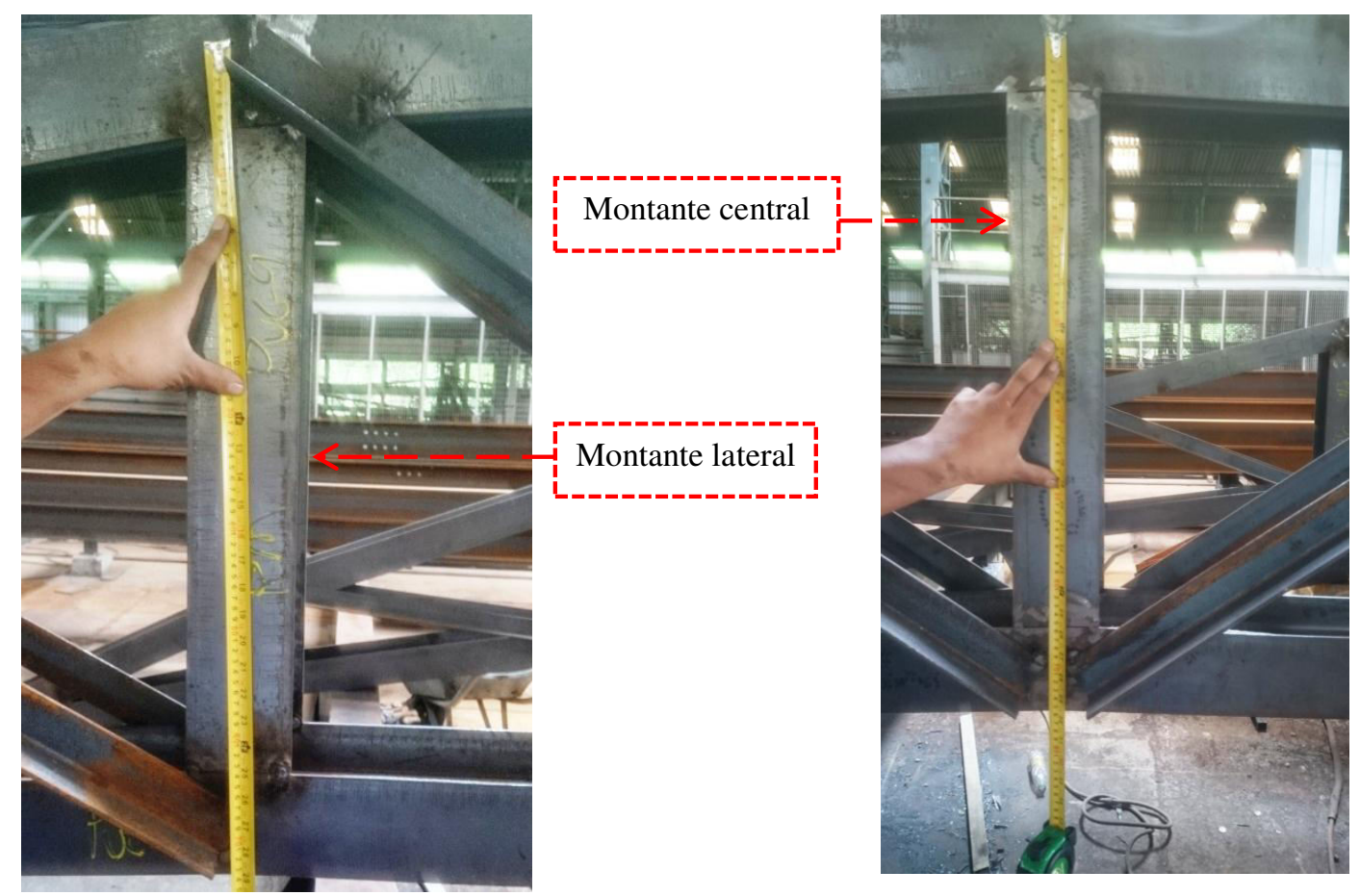

Figura A.9 Verificação das medidas dos montantes.

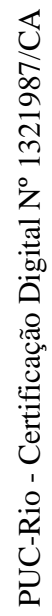
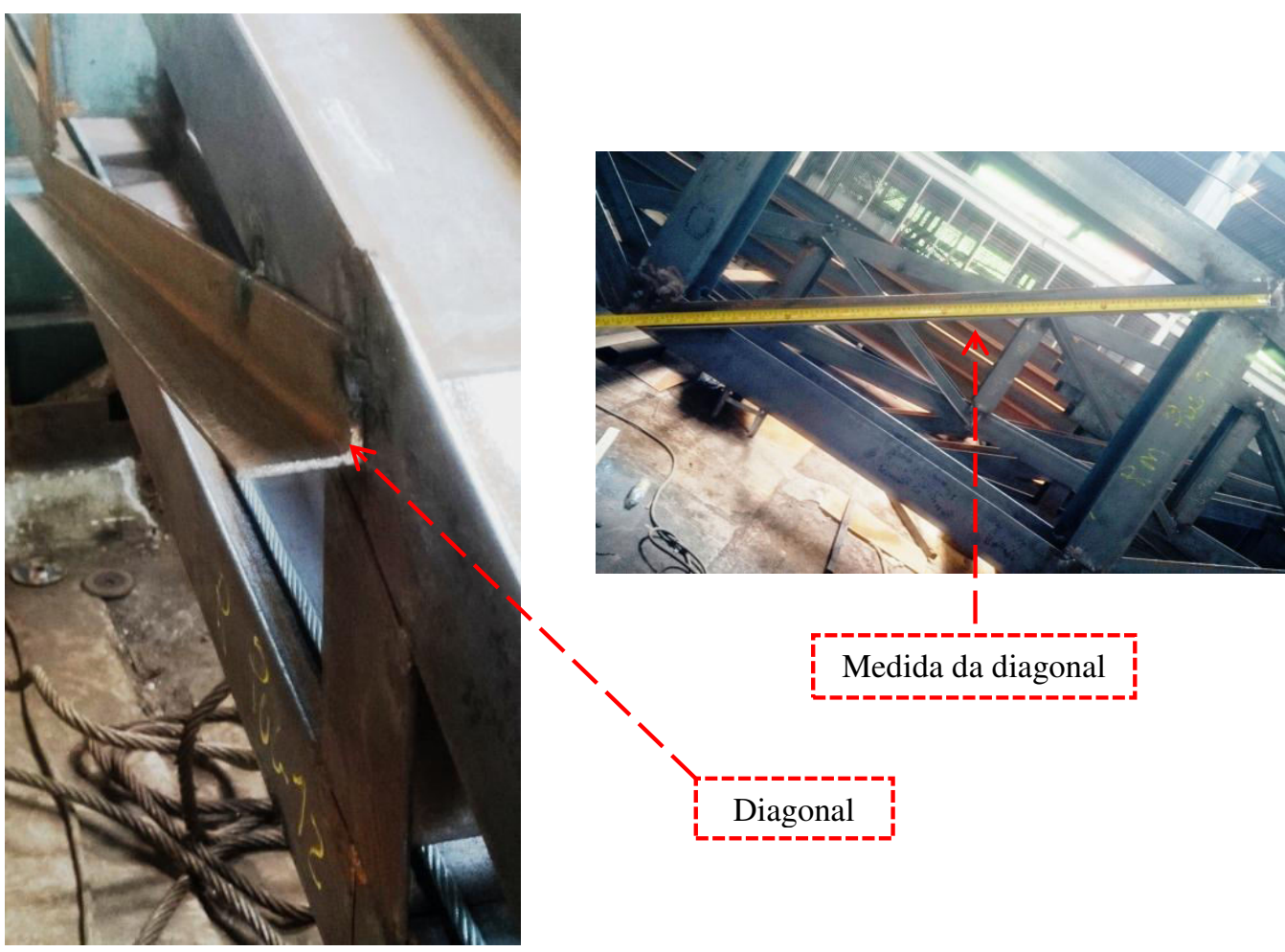

Figura A.10 Verificação das medidas das diagonais da treliça de $10 \mathrm{~m}$. 


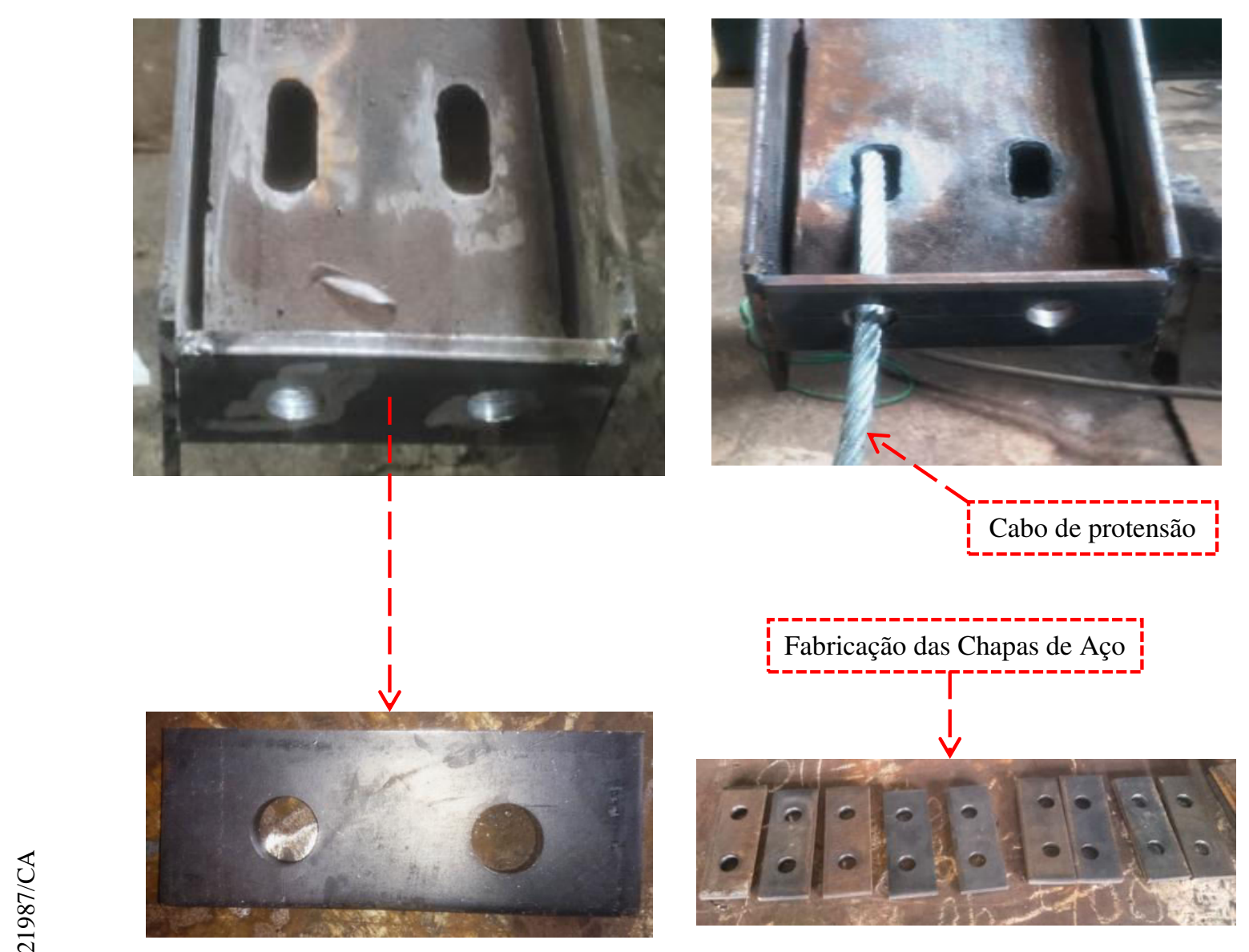

Figura A.11 Verificação das chapas e cabo na treliça. 